\title{
PROPOSTA DE UM SISTEMA DE BANCO DE DADOS PARA TOMOGRAFIA POR RESSONÂNCIA MAGNÉTICA NUCLEAR
}

Henrique Jota de Paula Freire

Dissertação apresentada ao Instituto de Física de São Carlos, da Universidade de São Paulo, para a obtenção do título de Mestre em Ciências: Física aplicada.

Orientador: Prof. Dr. Horácio Carlos Panepucci

São Carlos

1997 

Freire, Henrique Jota de Paula

Proposta de um sistema de banco de dados para tomografia por ressonância magnética nuclear/Henrique Jota de Paula Freire.--São Carlos, 1997. $412 \mathrm{p}$.

Dissertação (Mestrado)--Instituto de Física de São Carlos, 1997.

Orientador: Prof. Dr. Horácio Carlos Panepucci

1. Banco de dados. 2. Ressonância magnética. I. Título. 
Aos meus queridos pais, Tarcísio e Elizabeth. 


\section{AGRADECIMENTOS}

Ao Prof. Panepucci, pela a oportunidade de realização deste trabalho, e aos demais participantes do projeto do ToRM-05 Alberto, Edson, Jan, Kleber, Mateus e Rodrigo - pelas discussões e ajuda.

Aos demais membros do Grupo de Ressonância - alunos, professores e funcionários - pelo companheirismo sempre presente.

Às minhas queridas amigas e aos meus amigos, que me acompanharam durante todos estes anos, me incentivaram, se divertiram, riram e choraram comigo.

Às minhas irmãs, Tatiana e Gabriela, pela amizade e paciência.

Aos demais colegas do Instituto de Física de São Carlos e da cidade de São Carlos, pela companhia de tantos anos.

Ao CNPq, pelas bolsas de mestrado e do programa RHAE concedidas para a realização deste trabalho. 


\section{SUMÁRIO}

LISTA DE FIGURAS

LISTA DE TABELAS

LISTA DE ABREVIATURAS

RESUMO

ABSTRACT

1 INTRODUÇÃO

1.1 Motivação e objetivo 2

$\begin{array}{ll}1.2 \text { Síntese da metodologia e dos resultados } & 6\end{array}$

$\begin{array}{ll}1.3 \text { Organização do documento } & 8\end{array}$

2 REVISÃO DA LITERATURA

$\begin{array}{ll}2.1 \text { PACS } & 13\end{array}$

2.2 Sistemas de imagens por RMN $\quad 33$

2.3 Padrão DICOM 3.0 41

2.4 Sistema de banco de dados $\quad 54$

2.5 Formação de imagens por RMN 96

$\begin{array}{lr}2.6 \text { Engenharia de programação } & 118\end{array}$

3 METODOLOGIA E RESULTADO

$\begin{array}{ll}3.1 \text { Introdução } & 124\end{array}$

$\begin{array}{ll}\text { 3.2 Levantamento do contexto do problema } & 127\end{array}$

$\begin{array}{ll}3.3 \text { Proposta para o sistema de banco de dados } & 143\end{array}$

$\begin{array}{ll}3.4 \text { Implementação do DataTORM } & 177\end{array}$

4 DISCUSSÃO $\quad 188$

$\begin{array}{lr}\text { 4.1 PACS } & 189\end{array}$

$\begin{array}{ll}\text { 4.2 DICOM 3.0 } & 191\end{array}$

$\begin{array}{ll}4.3 \text { Dados não-convencionais } & 193\end{array}$

$\begin{array}{ll}\text { 4.4 Comunicação } & 195\end{array}$

$\begin{array}{ll}\text { 4.5 Metodologia utilizada } & 197\end{array}$

4.6 Utilização do MS Access 2.0 201

4.7 Considerações sobre a instalação do ToRM-05 204

5 CONCLUSÃO 206

6 REFERÊNCIAS BIBLIOGRÁFICAS 209 
APÊNDICE I - Especificações técnicas do ToRM-005

APÊNDICE II - DICOM 3.0

APÊNDICE III - Descrição formal da codificação espacial com gradientes de campo

APÊNDICE IV - Microsoft Access Versão 2.0

APÊNDICE V - Documentos do LAL do sistema ToRM-005

APÊNDICE VI - Modelo EER completo do DataTORM

APÊNDICE VII - Dicionário de dados

APÊNDICE VIII - Formulários do SGBD DataTORM 


\section{LISTA DE FIGURAS}

Figura 1 - Representação esquemática de PACS.

Figura 2 - Diagrama de blocos com os principais módulos de um sistema de tomografia computadorizada genérico.

Figura 3 - Diagrama de blocos de um sistema de MRI genérico. 36

Figura 4 - Diagrama de blocos do sistema ToRM-005. 38

Figura 5 - Modelo ER do mundo real usado pelo DICOM 3.0. 43

Figura 6 - Estruturas principais do modelo de informações do DICOM. 45

Figura 7 - Partes correntes do padrão DICOM e partes propostas para extensão do padrão.

Figura 8 - Modelo ER composto para a modalidade ressonância magnética.

Figura 9 - Modelos ER das classes SOP da classe de serviço Query/Retrieve Service Class.

Figura 10 - Esquema básico da estrutura de um SBD.

Figura 11 - Fases do projeto de um banco de dados.

Figura 12 - Exemplo de relacionamento entre entidades.

Figura 13 - Exemplo de relacionamento recursivo.

Figura 14 - Momento de dipolo sob ação de um campo magnético.

Figura 15 - Magnetização devido a presença de um campo magnético na direção $z$.

Figura 16 - Esquema de um gerador de RF produzindo um campo $B_{l}(t)$ perpendicular a $B_{0}$.

Figura 17 - Decomposição do campo de RF em dois campos circularmente polarizados.

Figura 18 - Aplicação de pulsos com ângulos de flip $\theta, \pi / 2$ e $\pi$.

102

Figura 19 - Esquema do sistema de recepção (a) e o sinal do FID (b). $\quad 104$

Figura 20 - Formação de um eco de spin.

Figura 21 - Formação do eco de spin, com destaque à magnetização no plano transversal.

Figura 22 - Exemplo de codificação espacial em usando três tubinhos com água.

Figura 23 - Esquema das codificações em fase e freqüência em um plano.

Figura 24 - Seqüência de aquisição Spin-echo.

Figura 25 - Seqüências Saturation-recovery (a), steady-state free precession (b), inversion recovery ( c), Carr-Purcell spin-echo (d).

Figura 26 - Ciclo de vida clássico da engenharia de programação. $\quad 120$

Figura 27 - Modelo espiral da engenharia de programação. 121

Figura 28 - Diagrama de contexto do ToRM-005. 129

Figura 29 - Janela principal do programa Lex. 132

Figura 30 - Janela principal do aplicativo PosProc. 136

Figura 31 - Configuração dos computadores que compõem o ToRM-05. 139

Figura 32 - Diagrama dos módulos de programa do sistema ToRM-05. 140

Figura 33 - Proposta de diagrama de contexto para o sistema ToRM-05. 144

Figura 34 - Modelo EER do SIA. $\quad 148$

Figura 35 - Modelo EER do SIRMN. 
Figura 36 - Visão geral do modelo de implementação relacional. 155

Figura 37 - Parte 1 do modelo de implementação relacional: SIA. 156

Figura 38 - Parte 2 do modelo de implementação relacional: Estudo e Série.

Figura 39 - Parte 3 do modelo de implementação relacional: Dados. 158

Figura 40 - Parte 4 do modelo de implementação relacional: Aquisição. 159

Figura 41 - Especificação da arquitetura de arquivos do DataTORM. 166

Figura 42 - Tipos de dados não-convencionais. 170

Figura 43 - Requisitos de comunicação de dados entre o DataTORM e demais módulos do ToRM-05.

Figura 44 - Arquitetura de arquivos do DataTORM implementada.

Figura 45 - Formulário de opções de integridade referencial do MS Access 2.0.

Figura 46 - Grupos de serviços disponíveis no formulário da barra de serviços do SGBD DataTORM. 


\section{LISTA DE TABELAS}

Tabela 1 - Volume anual de imagens para um grande hospital de 600 leitos 14

Tabela 2 - Hierarquia de armazenamento

Tabela 3 - Resumo das partes do padrão DICOM 3.0

Tabela 4 - Lista dos objetos de informação do DICOM

Tabela 5 - Query/Retrieve Service Class

Tabela 6 - Resumo da notação gráfica dos diagramas ER

Tabela 7 - Resumo da notação gráfica dos diagramas EER

Tabela 8 - Comparação entre os conceitos do MRD e uma representação de dados em tabela

Tabela 9 - Exemplos de especificações de domínios

Tabela 10 - Resumo das operações da álgebra relacional

Tabela 11 - Resumo da sintaxe da linguagem SQL

Tabela 12 - Regras de mapeamento do modelo ER para o modelo relacional

Tabela 13 - Regras de mapeamento do modelo EER para o modelo relacional

Tabela 14 - Tempos de relaxação $T_{1}$ e $T_{2}$ de prótons em biópsias de doenças em seio humano.

Tabela 15 - Descrição dos fluxos de informações e interfaces com o sistema do diagrama de contexto do ToRM-005

Tabela 16 - Equipamentos de MRI visitados

Tabela 17 - Especificações do sistema ToRM-05

Tabela 18 - Descrição de FI e IS da proposta de diagrama de contexto geral

Tabela 19 - Tabela com os tipos de dados do Access

Tabela 20 - Equivalência entre tipos de dados do DICOM 3.0 e do MS Access 2.0

Tabela 21 - Atributos da tabela de documentação de objetos do MS Access 2.0

Tabela 22 - Grupos de usuários e restrições de acesso

Tabela 23 - Resumo dos itens implementados no DataTORM com o MS Access 2.0

Tabela 24 - Lista dos formulários do DataTORM

Tabela 25 - Lista dos relatórios padrões implementados no DataTORM

Tabela 26 - Resumo dos resultados do trabalho 


\section{LISTA DE ABREVIATURAS}

API - Application Programming Interface

ACR - American College of Radiology

ATM - Asynchronous Transfer Mode

BD - banco de dados

CASE - computer-aided software engineering

CE - Contexto Externo

CR - Computed Radiography

CT - Computerized Tomography

DAO - Data Access Objects

DDE - Dynamic Data Exchange

DDL - Data Definition Language

DF - dependência funcional

DFI - Direct Fourier Imaging

DICOM - Digital Imaging and Communications in Medicine

DIMSE - DICOM message service elements

DLL - Dynamic Link Library

DML - Data Manipulation Language

EER - Enhanced Entity-relationship

ER - Entity-relationship

FDDI - Fiber Distributed Data Interface

FID - Free Induction Decay

GR - Grupo de Ressonância

HIS - Hospital Information System

IO - information object

IOD - information object definition

LAL - Léxico Ampliado da Linguagem

LUT - Lookup Table

MRD - Modelo Relacional de Dados

MRI - Magnetic Resonance Imaging

MS Access 2.0 - Microsoft ${ }^{\circledR}$ Access ${ }^{\circledR}$, versão 2.0

MS Visual Basic 3.0 - Microsoft ${ }^{\circledR}$ Visual Basic ${ }^{\circledR}$, versão 3.0

NEMA - National Electrical Manufacturers Association

ODBC - Open Database Connectivity

OLE - Object Linking and Embedding

PACS - Picture Archiving and Communication Systems

PSF - Point Spread Function

RF - radiofreqüência

RI - regra de inferência

RIS - Radiology Information System

RMN - Ressonância Magnética Nuclear

ROI - Region of Interest

SBD - sistema de banco de dados

SCP - service class provider

SCU - service class user

SDL - Storage Definition Language 
SGBD - sistema de gerenciamento de banco de dados SIA - Sistema de Informação Administrativo

SIRMN - Sistema de Informação para RMN

SOP - service object pair

ST - Sala de Tomografia

TE - tempo ao eco

TR - tempo de repetição

VDL - View Definition Language

WORM - write once, read many 


\section{RESUMO}

Este trabalho é uma proposta e uma implementação de um sistema de banco de dados para ser utilizado no armazenamento e gerenciamento dos dados resultantes da operação de tomógrafos de ressonância magnética nuclear. O objetivo é obter tecnologia na área de sistemas de arquivamento e comunicação de imagens médicas. O trabalho insere-se em um esforço maior do grupo de ressonância do IFSC/USP-São Carlos na pesquisa e desenvolvimento de tecnologias na área de imagens por ressonância magnética. A motivação para a utilização de sistemas digitais de bancos de dados para o armazenamento e gerenciamento de imagens médicas é o crescente aumento do volume gerado deste tipo de imagem nas instalações médicas. Quando comparado com o sistema de armazenamento tradicional, baseado em filmes, os sistemas digitais prometem ser mais seguros, eficientes e eficazes, além de proporcionar novas possibilidades na área de diagnóstico médico. Os principais resultados do trabalho são um modelo de dados conceitual elaborado com o modelo Entidade-relacionamento Estendido; um modelo de implementação relacional; e um sistema de banco de dados desenvolvido para uma plataforma computacional baseada em microcomputador e sistema operacional da família Windows. A metodologia utilizada no desenvolvimento do trabalho é baseada em conceitos básicos da disciplina de engenharia de programação. O sistema de banco de dados foi desenvolvido utilizando um sistema de gerenciamento de banco de dados comercial, o Microsoft ${ }^{\circledR}$ Access® Versão 2.0. O trabalho também apresenta o padrão industrial DICOM 3.0 e destaca as partes que são específicas para a modalidade de imagens médicas por ressonância magnética e que foram implementadas neste trabalho. 


\begin{abstract}
This work is a proposal and an implementation of a database system for archiving and management of data related to the operation of magnetic resonance imaging systems. The objective is to acquire technology in the area of medical image archiving and communication systems. This work is part of a broader effort of the IFSC/USP-São Carlos magnetic resonance group in the research and development of technologies in the area of magnetic resonance imaging. The reason for using digital database systems to archive and manage medical images is the growing volume of this kind of images in medical institutions. When compared to the traditional film based archiving systems, digital systems claim to be more secure, efficient and effective, besides giving place to new possibilities in medical diagnoses. The main results of this work are: a conceptual data model built with the Enhanced Entity-relationship model; a relational implementation model; and a database system to run in a PC-Windows computational platform and operational system. The methodology used throughout the development of this work is based on some basic concepts of the software engineering discipline. The database system was developed using a commercial database management system, the Microsoft ${ }^{\circledR}$ Access ${ }^{\circledR}$ Version 2.0. This work also presents the industrial standard DICOM 3.0 and highlights those parts that are specific for the magnetic resonance imaging modality and were implemented in this work.
\end{abstract}



1 INTRODUÇÃO 


\subsection{Motivação e objetivo}

Sistemas de imagens médicas estão entre as mais modernas tecnologias desenvolvidas para área diagnóstico médico, tendo, portanto, um expressivo impacto na área de saúde pública. O volume de imagens médicas geradas por estes sistemas tem crescido enormemente devido ao aumento, tanto do número de exames executados, quanto na quantidade de modalidades disponíveis deste tipo de sistema. Conseqüentemente, o armazenamento e a distribuição de imagens e respectivos dados de pacientes é um dos principais problemas no campo da saúde moderna.

Sistemas de armazenamento e comunicação de imagens (PACS - Picture Archiving and Communication Systems) representam uma forma alternativa à metodologia tradicional de interpretação, distribuição e gerenciamento de imagens médicas baseada em filmes e papel, para imagens e registros médicos respectivamente. PACS são baseados no conceito de manipulação de imagens na forma digital, utilizando os mais modernos avanços na tecnologia de computadores. O principal objetivo desta abordagem é fornecer meios eficientes e econômicos de examinar, armazenar e restaurar imagens de diagnóstico médico. Estes sistemas baseiam-se na integração de tecnologias de formação de imagem, processamento de imagem, projeto de estações de trabalho, engenharia de banco de dados, engenharia de comunicações e engenharia de programação. $O$ resultado da integração destas tecnologias são sistemas de aquisição, armazenamento, transmissão e visualização de imagens. ${ }^{1}$

Atualmente, as mais modernas e equipadas instalações médicas em todo o mundo não apenas utilizam equipamentos de imagens médicas de última geração, mas também utilizam PACS para armazenar e distribuir, de maneira integrada e automática, imagens médicas no formato digital. Estes sistemas representam o estado 
da arte neste campo do conhecimento, mas o domínio destas tecnologias passa por um processo gradual de esforço concentrado em pesquisa e desenvolvimento abrangendo várias disciplinas. Sem uma integração apropriada dos diversos aspectos, as potencialidades de sistemas do tipo PACS podem não passar de promessas devido a grande complexidade inerente a este tipo de sistema.

Neste contexto, o Grupo de Ressonância do Instituto de Física de São Carlos vem, desde 1983, pesquisando e desenvolvendo tecnologias para sistemas de imagens médicas na modalidade de imagens por ressonância magnética (MRI - Magnetic Resonance Imaging). ${ }^{2}$ Os princípios físicos da ressonância magnética nuclear envolvidos nesta modalidade de diagnóstico médico são conhecidos há quatro décadas e são de domínio público, mas apenas um grupo relativamente pequeno de empresas e universidades estrangeiras detêm o domínio completo da tecnologia. Desta forma, o objetivo do grupo é a obtenção do domínio tecnológico para a construção e operação de sistemas de MRI. Para isso, um processo gradual de pesquisa e desenvolvimento vem sendo executado, inicialmente abordando as áreas mais básicas e essenciais desta tecnologia e, recentemente, aprimorando os avanços já conquistados e incorporando novas áreas de conhecimento, estas necessárias para que o domínio tecnológico na área de sistemas de imagens médicas por ressonância magnética fique cada vez mais próximo do que existe de mais moderno e atual.

O Grupo de Ressonância desenvolveu e opera, para uso clínico e acadêmico, um sistema de MRI de 0,05 Tesla batizado de ToRM-005. Atualmente está sendo construído um novo sistema, o ToRM-05, de 0,5 Tesla, que será instalado no hospital Santa Casa de São Carlos. A utilização clínica do sistema ToRM-005, à partir de meados de 1992, foi o marco que representou o domínio tecnológico básico na área de sistemas de MRI. Já o início da construção do novo sistema, por um lado correspondeu a um processo engenharia de produto da tecnologia já desenvolvida, mas por outro lado, salientou a necessidade de pesquisa e desenvolvimento em outras áreas. Em particular, devido ao grande volume de dados e imagens envolvido na operação clínica de sistemas de MRI, surgiu a necessidade de pesquisa e desenvolvimento na área de sistemas de banco de dados, com o objetivo de 
gradualmente obter o domínio da tecnologia de armazenamento e gerenciamento de imagens médicas.

Desta forma, o objetivo deste trabalho é realizar estudos que contribuam para a obtenção gradual do domínio da tecnologia de armazenamento e gerenciamento de dados obtidos por sistemas de MRI tendo em vista a posterior utilização destes dados pelos usuários finais. Este objetivo é atingido com elaboração de uma proposta de um modelo de banco de dados para MRI e pela implementação inicial de um aplicativo de banco de dados baseado neste modelo. Como resultado deste primeiro passo na área de sistemas banco de dados para imagens médicas, que é uma subárea dos modernos PACS, cria-se condições de prosseguir no processo de obtenção e desenvolvimento de tecnologia na área de gerenciamento e armazenamento de imagens médicas.

A proposta de um modelo de banco de dados para MRI e a implementação inicial de um aplicativo de banco de dados baseado neste modelo são voltadas para as necessidades locais do projeto de construção do sistema ToRM-05. O DataTORM, o nome dado tanto para o modelo de dados quanto para o aplicativo, é um subsistema do ToRM-05, e a sua importância surgiu à partir da necessidade de armazenamento e gerenciamento de uma grande diversidade e volume de dados relacionados com a futura utilização do ToRM-05. O seu papel dentro do sistema é:

- armazenar os resultados da operação de sistemas de MRI, em especial do ToRM05, e os respectivos dados que os contextualizam;

- gerenciar as transações de manipulação de dados: inserção, atualização e eliminação;

- gerenciar as transações de consulta aos dados;

- dar suporte à exportação e importação de dados;

- automatizar o arquivamento e backup dos dados, gerenciando automaticamente a utilização dos meios físicos de armazenamento, como discos rígidos e removíveis;

- servir como um aplicativo de consulta de resultados para usuários remotos;

- comunicar diretamente com os outros módulos de programa do ToRM-05 para entrada e saída de dados. 
Como o DataTORM é parte de um projeto maior, ele deve obedecer às diretrizes gerais estabelecidas para os módulos de programação, que são:

- automatizar a operação do sistema de tomografia;

- proporcionar um sistema de operação adequado para treinar pessoas que irão eventualmente trabalhar com sistemas comerciais;

- satisfazer as necessidades do ambiente de operação local que, sendo uma instituição de pesquisa e desenvolvimento, possui particularidades e necessidades que os sistemas comerciais existentes não costumam atender. 


\subsection{Síntese da metodologia e dos resultados}

O processo de obtenção de tecnologia na área de gerenciamento e armazenamento de imagens médicas envolve um estudo amplo desta área e uma série de atividades paralelas de pesquisa, desenvolvimento e implementação de sistemas. Estes últimos devem ser voltados para as necessidades locais, mas tendo em vista o rumo que o estado da arte da tecnologia tem tomado. A crescente importância de PACS e seus subsistemas fez com que muitos grupos de pesquisa, tanto acadêmicos quanto da iniciativa privada, dedicassem esforços em pesquisa e desenvolvimento nesta área. Assim, existe uma extensa literatura, abordando, principalmente, os requisitos de sistemas do tipo PACS e estudos de caso de implementações. ${ }^{1,3-6}$

De uma forma geral, existe consenso entre os especialistas de que o gerenciamento de imagens radiológicas pode ser melhorado com a utilização de sistemas digitais baseados em computadores, mas as opiniões variam sobre quais tipos são melhores e mais adequados. As possíveis soluções dependem de fatores como a natureza do serviço radiológico, os tipos de imagens e a demanda clínica. ${ }^{6}$ Assim, vários sistemas já foram implementados em instalações médicas em todo o mundo, e, em cada um dos casos, metodologias e tecnologias diferentes foram utilizadas.

A metodologia geral utilizada neste trabalho é baseada nos conceitos da engenharia de programação. $O$ trabalho seguiu um ciclo de vida tradicional de desenvolvimento de programas, iniciando com uma fase de análise de requisitos, seguido da especificação, implementação e testes. Devido a interdisciplinaridade da área, e por ser esta a primeira experiência do grupo com este tipo de tecnologia, optou-se por utilizar tecnologias conhecidas e bem estabelecidas para cada fase do desenvolvimento. 
$\mathrm{Na}$ etapa de análise foram feitas entrevistas estruturadas e análise de léxico. Um modelo do ambiente de operação foi elaborado utilizando diagrama de contexto. Em seguida, foi utilizado o tradicional modelo de dados Entidade-relacionamento Estendido para a modelagem de alto nível do banco de dados e o Modelo Relacional de Dados para o modelo conceitual de implementação. A implementação foi de um banco de dados relacional utilizando um sistema de gerenciamento de banco de dados comercial, o Microsoft Access® versão 2.0.*

O presente trabalho teve como principais resultados:

- modelo de dados conceitual para o DataTORM, elaborado com o modelo Entidade-relacionamento Estendido;

- modelo de implementação relacional; e

- o DataTORM, que é um sistema de banco de dados para ser utilizado em microcomputadores com sistema operacional da família Windows, implementado com o aplicativo MS Access 2.0.

O processo de desenvolvimento usado para obter os resultados acima gerou outros resultados igualmente importantes, como:

- estudo e discussão sobre PACS e sobre o padrão Digital Imaging and Communications in Medicine (DICOM);

- análise crítica da aplicação das metodologias e tecnologias da engenharia de programação para o desenvolvimento de sistemas deste tipo;

- proposta de um modelo de comunicação entre os diversos módulos de programa do ToRM-05 utilizando a tecnologia Object Linking and Embedding (OLE);

- proposta de modelo do sistema de informação local elaborada usando diagrama de contexto;

- programa para auxiliar o estudo do léxico de um domínio de informação;

- programa de pós-processamento de imagens que atualmente é utilizado pelo sistema ToRM-005.

\footnotetext{
* Microsoft Access é marca registrada da Microsoft Corporation. A versão 2.0 deste produto será indicada como MS Access 2.0 no restante deste documento.
} 


\subsection{Organização do documento}

O corpo desta dissertação é constituído em cinco capítulos principais: 1) introdução, 2) revisão da literatura, 3) metodologia e resultado, 4) discussão e 5) conclusão. Cada um destes capítulos contêm as seguintes seções:

\section{Introdução:}

A introdução apresenta o trabalho, descrevendo as motivações e declarando os objetivos. Também são resumidas as metodologias utilizadas durante o desenvolvimento e são apresentados os principais resultados obtidos.

\section{Revisão da literatura:}

2.1 PACS: apresenta as motivações para a utilização de PACS e descreve os vários aspectos envolvidos nesta tecnologia. Objetivando fornecer uma visão geral dos diversos aspectos envolvidos com manipulação e gerenciamento de imagens médicas, ênfase é dada na arquitetura básica deste tipo de sistema e os requisitos mínimos para uma implementação de sucesso. Ainda nesta seção são detalhados os principais requisitos e tipos de arquiteturas de bancos de dados em PACS, pois esta é a área de concentração deste trabalho.

2.2 Sistemas de imagens por RMN: das várias modalidades de imagens médicas existentes, esta é a desenvolvida pelo grupo de ressonância do Instituto de Física de São Carlos, e o presente estudo sobre armazenamento e gerenciamento de imagens médicas é voltada para esta modalidade. Esta seção descreve sistemas imagens que utilizam RMN de uma forma geral e, como exemplo, apresenta o sistema ToRM-005 construído e em operação no Instituto de Física de São Carlos. 
2.3 Padrão DICOM 3.0: O padrão DICOM 3.0 foi uma das principais fontes de informação para o desenvolvimento do modelo de banco de dados deste trabalho. Nesta seção, o padrão é apresentado resumidamente, destacando-se os aspectos utilizados no desenvolvimento deste trabalho e também os aspectos específicos para a modalidade de MRI.

Como este é uma trabalho interdisciplinar, várias áreas básicas do conhecimento são abordadas, sendo que as principais são: banco de dados, ressonância magnética nuclear e engenharia de programação. Especialistas que atuam em cada uma destas áreas podem não conhecer os vários aspectos existentes de outra área, destacando-se neste caso a distância entre as duas disciplinas da área de computação e a disciplina da área de física. Assim sendo, como esta é uma dissertação multidisciplinar, a revisão da literatura apresenta mais três seções destinadas à apresentação dos principais aspectos de cada área que foram utilizados no trabalho.

2.4 Sistema de Banco de Dados: nesta seção são introduzidos os principais conceitos de banco de dados e detalhados os tópicos utilizados no trabalho, como modelagem de dados usando EER e o modelo relacional de dados.

2.5 Princípios físicos da formação de imagens por RMN: são apresentados os princípios físicos utilizados por sistemas de MRI para a obtenção de imagens, incluindo desde os conceitos básicos de spin nuclear até a técnica de aquisição de imagens bidimensionais. Esta seção destina-se principalmente à apresentação dos vários conceitos da técnica de MRI que devem fazer parte de uma banco de dados voltado para esta técnica.

2.6 Engenharia de programação: uma definição geral da engenharia de programação é apresentada nesta seção, juntamente com uma rápida descrição de dois paradigmas da engenharia de programação: o ciclo de vida clássico e o modelo espiral. Detalhes sobre métodos, ferramentas e procedimentos não são abordados nesta seção, mas sim na parte seguinte do texto.

Em seguida é apresentada a metodologia de desenvolvimento do trabalho e os resultados obtidos. A apresentação segue a ordem em que o trabalho foi executado, começando com a fase de levantamento de requisitos e modelagem da proposta de 
modelo de dados, seguindo para a fase de especificação do sistema baseando-se no modelo elaborado na fase de requisitos e, finalmente, na implementação de um aplicativo de banco de dados. A descrição da metodologia é feita utilizando os conceitos e informações apresentados na revisão da literatura e que são, nesta parte do texto, reunidos para formar o modelo proposto e a aplicação implementada. Descrições completas dos resultados foram inseridas em apêndices para não sobrecarregar o texto.

\section{Metodologia e resultado:}

3.2 Levantamento do contexto do problema: esta seção aborda as fases iniciais da análise de requisitos onde foi feito um estudo do sistema de MRI ToRM-005 e de sistemas comercias. Também é apresentado o projeto do novo sistema de MRI, o ToRM-05, destacando os aspectos relevantes para o desenvolvimento deste trabalho.

3.3 Proposta para o sistema de banco de dados: nesta seção são propostos modelos de dados conceituais e de implementação para um sistema de banco de dados para MRI. Também são descritas a arquitetura de distribuição dos arquivos de dados, a extensão para dados não convencionais, a comunicação com outros módulos de programa, e os critérios de segurança e restrições de acesso.

3.4 Implementação do DataTORM: são apresentadas as partes das propostas da seção anterior que foram implementadas no DataTORM.

\section{Discussão:}

Nesta parte da dissertação, os diversos aspectos abordados no trabalho são discutidos. É feita uma avaliação crítica sobre a metodologia utilizada no desenvolvimento do trabalho. São destacados os aspectos mais críticos encontrados, que são os dados não-convencionais e a comunicação entre os módulos de programa do sistema.

\section{Conclusão:}

$\mathrm{Na}$ conclusão do trabalho, os objetivos propostos são confrontados com os resultados alcançados. Também são indicadas algumas das possíveis continuações, 
principalmente aquelas que são importantes para a operação do DataTORM no sistema ToRM-05.

Esta dissertação contêm oito apêndices com informações ilustrativas e de referência. Os apêndices I, III, V, VI, VII e VIII possuem subprodutos resultantes deste trabalho. Já os apêndices II e IV são apenas informativos, com a intenção apenas de facilitar a consulta, com informações extraídas do padrão DICOM 3.0 e do manual do MS Access 2.0, respectivamente. 
2 REVISÃO DA LITERATURA 


\subsection{PACS}

\subsubsection{Introdução}

Em um hospital existem muitas atividades de gerenciamento de informações redundantes e semiautomatizadas que atendem as necessidades mais imediatas das várias unidades funcionais. As funções de um sistema de informação hospitalar podem ser agrupadas em seis grupos principais: ${ }^{6}$ registros médicos, sistema financeiro, sistema administrativo, sistema de informação sobre pacientes, serviço de imagens radiológicas e rede de pesquisa educacional. Algumas destas funções se sobrepõe e outras possuem mecanismos de comunicação entre si bastante complicados. Todos que interagem com este ambiente confuso possuem uma visão limitada de todo o contexto do atendimento ao paciente e das funções de gerenciamento do hospital, e, em uma escala global, os custos para comunicação e coordenação correspondem normalmente a 25 porcento do total dos gastos operacionais de um hospital.

Sistemas de armazenamento e comunicação de imagens, amplamente conhecidos pela abreviatura do nome original em inglês (PACS - Picture Archiving and Communication Systems), representam uma possível resposta a um dos grandes e atuais desafios da informática médica: o crescente volume de imagens médicas provenientes, principalmente, de sistemas de imagens médicas para diagnóstico. Apesar do tradicional exame de raio $\mathrm{x}$ ainda ser a modalidade mais comum de diagnóstico médico por de imagem, várias outras técnicas estão atualmente disponíveis e com utilização cada vez maior. Entre as principais modalidades atualmente disponíveis destacam-se a tomografia computadorizada por raio x (CT - 
Computerized Tomography), imagens por ressonância magnética, ultra-som e medicina nuclear.

Enquanto um exame de raio $\mathrm{x}$ inclui de duas a quatro imagens do corpo, exames típicos de CT e MRI geram de 20 a 100 imagens, organizadas em séries de seções do volume de interesse no paciente. ${ }^{1}$ Aproximadamente 70 porcento dos pacientes que chegam a um hospital necessitam de algum tipo de exame diagnóstico, dos quais aproximadamente 30 porcento do volume de imagens geradas são digitais, enquanto os restantes 70 porcento são imagens de raios x convencional. ${ }^{6}$ A Tabela 1 mostra uma estimativa anual do volume de imagens geradas em um grande hospital típico de 600 leitos nos Estados Unidos da América. ${ }^{1} \mathrm{O}$ volume de imagens total anual é de mais de um milhão, o que corresponde a uma necessidade de capacidade de armazenamento de quase dois Tbytes $\left(2 \times 10^{12}\right.$ bytes $)$. A tendência destes números é crescer à medida que: exames de CT e MRI estão sendo cada vez mais comuns e gerando mais imagens por estudo; mais equipamentos de imagens médicas, como ultra-som, são instalados e utilizados em hospitais; e novas modalidades de imagens médicas estão sendo clinicamente aceitas e difundidas, como a tomografia por emissão de pósitrons e imagens biomagnéticas.

Tabela 1 - Volume anual de imagens para um grande hospital de 600 leitos

\begin{tabular}{|l|l|l|l|}
\hline \hline Modalidade & \multicolumn{1}{|c|}{$\begin{array}{c}\text { Número de } \\
\text { imagens }\end{array}$} & \multicolumn{1}{|c|}{$\begin{array}{c}\text { Número de } \\
\text { bits/imagem }\end{array}$} & \multicolumn{1}{|c|}{$\begin{array}{c}\text { Número de } \\
\text { Gbytes }\end{array}$} \\
\hline \hline Raio $\mathrm{x}$ & 250.000 & $2048 \times 2048 \times 12$ & 1.573 \\
\hline CT & 425.000 & $512 \times 512 \times 12$ & 167 \\
\hline MRI & 225.000 & $512 \times 512 \times 12$ & 88 \\
\hline Ultra-som & 150.000 & $512 \times 512 \times 8$ & 39 \\
\hline $\begin{array}{l}\text { Medicina } \\
\text { nuclear }\end{array}$ & 100.000 & $256 \times 256 \times 8$ & 7 \\
\hline Total & 1.150 .000 & - & 1.874 \\
\hline \hline
\end{tabular}

Tamanho estimado das imagens é dado pelo número de pixels (altura e largura) vezes o número de bits/pixel. Um byte é igual a oito bits; um gigabyte (Gbyte) é igual a $10^{9}$ bytes.

Fonte: traduzido de LEOTTA, D.F.; KIM, Y., IEEE Engineering in Medicine and Biology, mar. 1993, p.63.

Este grande volume de dados representa um grande desafio para sistemas de aquisição, gerenciamento, distribuição e armazenamento. A proposta dos PACS para lidar com este problema é a manipulação das imagens na forma digital, usando as 
modernas tecnologias de computadores existentes. Com relação ao sistema tradicional em que as imagens são manipuladas em filmes, os PACS oferecem diversas vantagens:

- a aquisição digital elimina a necessidade de processamento de filmes, economizando tempo e material;

- sistemas tradicionais estão sujeitos a atrasos devido a manipulação e roteamento manual dos filmes, o que também possibilita trocas e perdas. A tecnologia digital de armazenamento é mais eficiente que os arquivos de filmes, tanto em termos de espaço de armazenamento quanto velocidade de acesso. Imagens arquivadas podem ser consultadas eletronicamente, eliminando a possibilidade de perda de filmes;

- em PACS, grandes grupos de imagens relacionadas podem ser organizadas em arquivos eletrônicos de pacientes, facilitando o gerenciamento dos dados;

- a utilização de redes de comunicação pode possibilitar o acesso simultâneo de vários usuários, sejam eles locais ou remotos;

- através da utilização de programas de processamento e análise pode-se manipular e melhorar as imagens.

Desta forma, o impacto da utilização de PACS no ambiente clínico é enorme. A capacidade de comunicação por redes e de visualização disponibiliza os dados simultaneamente para, por exemplo, o especialista responsável pelo laudo e para o médico que requisitou o exame, podendo eles estarem em locais completamente diferentes. A possibilidade de fácil obtenção de exames e relatórios passados juntamente com o exame atual possibilita ao usuário uma visão mais integrada e global do histórico médico do paciente. Consultas instantâneas entre os departamentos de radiologia e de emergência podem ser decisivas em casos que requerem atenção imediata. Programas dedicados podem ajudar no processo de diagnóstico através de processamento de imagens, como, por exemplo, detecção de bordas para o diagnóstico de tumores e utilização de parâmetros de visualização prédefinidos para melhor visualização de determinadas patologias.

Os benefícios potenciais de PACS são reconhecidos a muitos anos, mas, se por um lado o uso de CT e MRI, que são modalidades inerentemente digitais, estimulou a manipulação digital de imagens, por outro lado, o grande volume de imagens ainda é 
proveniente de exames de raio x. Apesar da possibilidade de se utilizar digitalizadores para incorporar os resultados do tradicional exame de raio x em PACS, este processo requer uma intensa mão de obra, pois dados devem ser digitados pelo operador, e é sujeito a ocorrência de muitos erros, tornando a relação custo benefício desfavorável. Com o advento recente da radiografia computadorizada (CR - Computed Radiography), que fornece um resultado digital do exame de raio $\mathrm{x}$, a utilização de PACS recebeu um grande impulso pois, com a conexão adequada de sistemas de CR com PACS, esta modalidade de sistema de diagnóstico pode se tornar a maior fonte de dados para PACS e seus usuários. ${ }^{1}$

\subsubsection{Arquitetura básica}

\subsubsection{Introdução}

Sistemas de arquivamento e comunicação de imagens envolvem a integração de tecnologias de formação de imagem, processamento de imagem, projeto de estações de trabalho, engenharia de banco de dados, engenharia de comunicações e engenharia de programação. O resultado final da integração destes componentes são sistemas capazes de adquirir, armazenar, transmitir e visualizar imagens.

A Figura 1 mostra a estrutura genérica de um PACS. De um lado estão os equipamentos de imagens médicas e as respectivas conexões para a transferência de dados para o PACS. Os resultados destes sistemas de imagens podem ser digitais ou podem ser convertidos para o formato digital através de digitalizadores. Estando os dados na forma digital, eles podem ser incorporados ao PACS. Este processo de aquisição envolve a conexão entre os equipamentos de imagens, um banco de dados central e um sistema de armazenamento. $\mathrm{O}$ banco de dados é o sistema de arquivos no computador que gerencia o arquivamento e as consultas às imagens e aos dados médicos relacionados. Já o sistema de armazenamento, que é usado como repositório de dados para o banco de dados, é o análogo eletrônico dos arquivos filmes usados nos departamentos de radiologia tradicionais. 


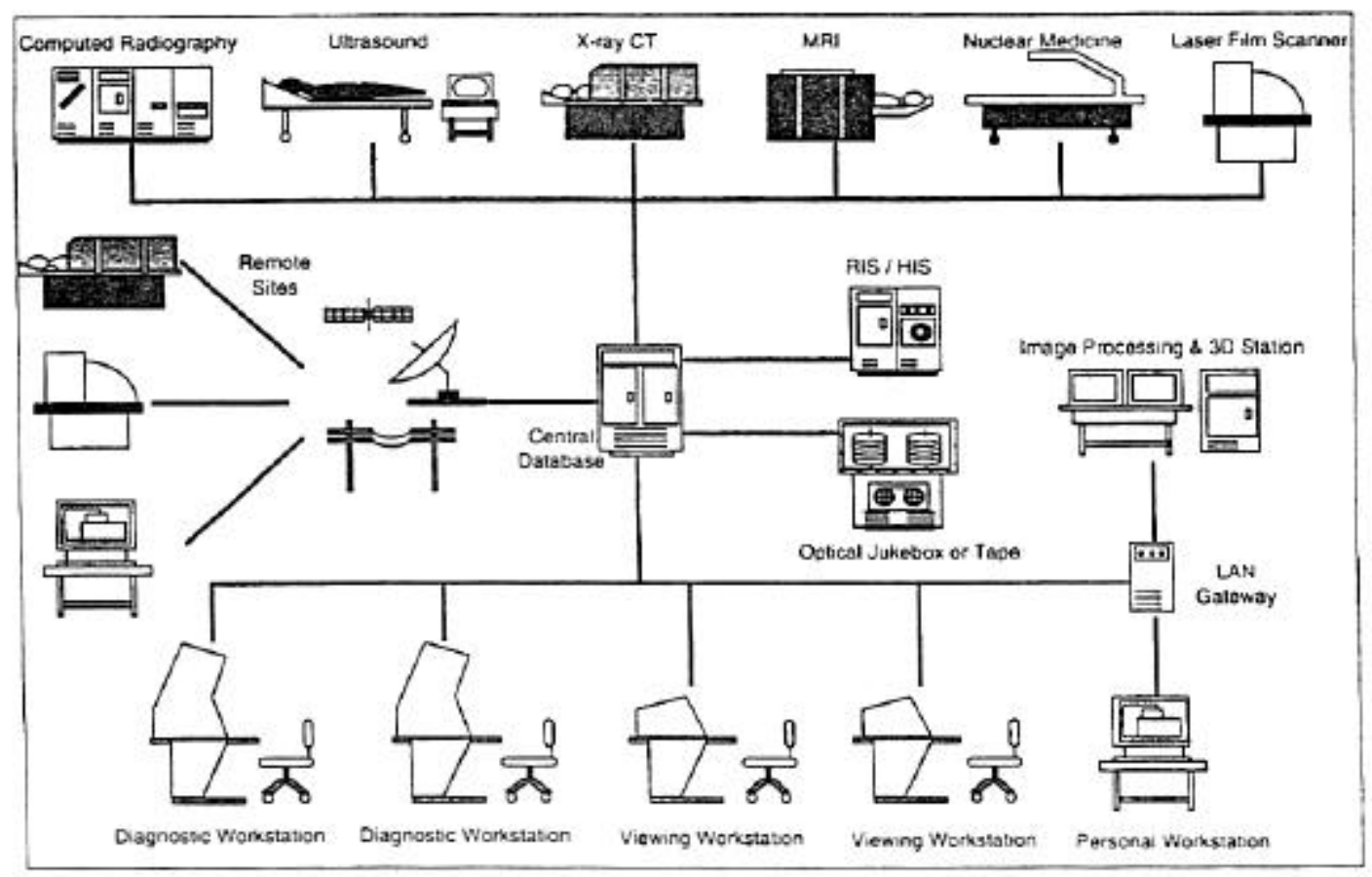

Figura 1 - Representação esquemática de PACS.*

Uma vez adquiridas e armazenadas, as imagens são colocadas à disposição dos usuários através de um sistema de rede. Dependendo do escopo do sistema, os dados podem ser transmitidos para dentro ou fora das instalações médicas, sendo possível o acesso remoto através de linhas de telefone, ligações de microondas e satélites. As imagens são apresentadas ao usuário através de monitores de alta resolução conectados a estações de trabalho específicas para PACS, que possibilitam vários graus de manipulação e processamento de imagens, dependendo da necessidade e aplicação.

Como os PACS consistem da integração de vários componentes complexos, a implementação de um sistema clinicamente útil é uma tarefa difícil. Para atender ao objetivo de ser uma alternativa ao sistema tradicional baseado em filmes, cada um dos principais componentes dos PACS e o sistema como um todo devem satisfazer requisitos específicos, descritos em detalhes nas seções subsequentes.

\subsubsection{Aquisição de dados}

Vários tipos de dispositivos de aquisição já produzem resultados digitais $(\mathrm{CR}, \mathrm{CT}$, MRI, PET) e por isso são inerentemente adequados para serem integrados a PACS. 
Já as imagens de raio $\mathrm{x}$ convencionais devem ser digitalizadas para serem incorporadas a este tipo de sistema. Imagens de ultra-som podem ser digitalizadas a partir de filmes, de vídeos, ou podem ser obtidas diretamente no formato digital dependendo do equipamento.

O tamanho das imagens (número de pixels e número de bits/pixel) varia de acordo com a modalidade e com as implementações específicas de fabricantes. O formato das imagens e o conjunto de informações relacionadas tanto com as imagens quanto com os pacientes foram sujeitos a uma proposta de padronização formulada pelo American College of Radiology e National Electrical Manufacturers Association (ACR/NEMA). Este padrão, que será descrito em mais detalhes na seção 2.3, "Padrão DICOM 3.0", também inclui especificações para a conexão dos equipamentos de aquisição de imagens com uma rede de dados. Apesar deste padrão não ser universalmente aceito pelos fabricantes, ele provavelmente passará a ser implementado em novos equipamentos para que estes possam ser integrados a PACS.

O componente de aquisição de dados deve ser implementado de maneira a possibilitar uma aquisição fácil e confiável de imagens, rápida revisão dos exames, e capacidade de impressão dos resultados para o caso de falha do PACS.

\subsubsection{Sistema de armazenamento e banco de dados}

O banco de dados organiza as informações sobre os exames de pacientes e gerencia o fluxo de imagens entre o sistema de armazenamento e as estações de trabalho do PACS.

Para um armazenamento e recuperação eficiente das imagens, é recomendado a utilização de uma estrutura de arquivamento de três níveis: ${ }^{1}$ 1) armazenamento de imagens em estações de trabalho individuais, 2) armazenamento central de curtoprazo para estudos correntes e imagens relacionadas para comparação, e 3) armazenamento de longo prazo, de alta capacidade e acesso lento, para imagens sem previsão de interesse imediato.

\footnotetext{
* LEOTTA, D.F.; KIM, Y., IEEE Engineering in Medicine and Biology, mar.1993, p.64 - Figura 1.
} 
Imagens e informações relacionadas que devem estar preferencialmente nos dispositivos de armazenamento de curto prazo são: ${ }^{6}$

- exames efetuados nas últimas 48 horas;

- exames aguardando a interpretação primária;

- exames efetuados em um período inferior ou igual ao tempo médio de permanência de um paciente interno;

- exames históricos selecionados para serem usados em atividades clínicas;

- exames históricos de pacientes que fizeram novas imagens.

O armazenamento de longo prazo deve ser capaz de armazenar dados para possíveis consultas futuras, podendo o período de retenção variar em função de diversos parâmetros:

- as imagens do ano atual e de mais quatro anos, ou pelo período mínimo definido pela legislação ou pela própria instalação médica;

- imagens de crianças até que elas atinjam 21 anos de idade;

- alguns exames de mamografia devem ser armazenados por toda a vida do paciente.

O computador do banco de dados pode incorporar um conjunto de regras para a distribuição das imagens. Por exemplo, garantir que, na maioria dos casos, as imagens de cérebro sejam encaminhadas para o departamento de neurocirurgia, enquanto as radiografias de ossos devem ir para a ortopedia.

Para assegurar a disponibilidade de todas as imagens necessárias, o banco de dados pode antecipar estudos passados que provavelmente serão necessários em cada estação de trabalho. ${ }^{1}$ Estes possíveis estudos podem ser selecionados baseado na parte do corpo que está sendo examinada, no tipo de modalidade de imagem médica que está sendo utilizada, no departamento de origem do exame e na data do exame. Por exemplo, uma requisição de um estudo de CT abdominal pode automaticamente recuperar imagens fluoroscópicas armazenadas com os dados do paciente. Estas imagens seriam automaticamente encaminhadas às estações de trabalho do radiologista responsável e do médico requisitante. Esta capacidade é desejável pois o armazenamento de longo prazo (terceiro nível) é geralmente lento. A capacidade de armazenamento de segundo nível depende da velocidade de seleção e recuperação de 
imagens no terceiro nível. Armazenamento de imagens dos últimos 15 dias é recomendável para o segundo nível.

As imagens médicas devem ser armazenadas por um período mínimo determinado pela legislação. Assumindo um período de sete anos para um hospital como o da Tabela 1, a capacidade de armazenamento necessária é de aproximadamente 7 Tbytes. Esta estimativa assume a utilização de compressão de dados reversível capaz de reduzir o volume por um fator de dois. A exigência legal de armazenamento de tal volume de dados estimula a utilização de técnicas de compressão de dados poderosas. Para obter altas taxas de compressão existem algoritmos de compressão com perdas, mas a aceitação destas técnicas para serem usadas em imagens de diagnóstico ainda é um problema aberto, apesar existirem estudos que mostram a equivalência da capacidade diagnóstica de imagens de certas patologias com compressão de 10:1 e sem compressão (CHEN apud LEOTTA).

Muitos hospitais administram as informações sobre pacientes através de sistemas de informação hospitalar (HIS - Hospital Information System) computadorizados. Um sistema de informação radiológico (RIS - Radiology Information System), que pode ser módulo de um HIS ou ser independente, é usado para gerenciar exames radiológicos, relatórios e contas. Estes sistemas são baseados em texto, enquanto PACS são orientados a imagens. Se no passado estes sistemas foram implementados separadamente, dificultando a integração entre eles, novas implementações devem permitir a comunicação entre HIS/RIS e PACS. Assim, além dos processamentos relativos às imagens, um PACS deve incluir funções de entrada e utilização de dados demográficos de pacientes, entrada de pedidos e elaboração de relatórios de resultados, todas funções tradicionalmente desempenhadas por RIS. Os dados de pacientes existentes no RIS devem estar disponíveis para os usuários do PACS, e uma interface adequada de PACS com RIS evita que ocorram entradas manuais redundantes de elementos de dados comuns. Comunicação PACS/PACS também deve ser possível para facilitar a troca de informações entre diferentes unidades médicas para os casos de transferência de paciente, emergência ou consulta.

\footnotetext{
* CHEN, J. et al. Observer detection of image degradation caused by irreversible data compression processes. Medical Imaging V: Image Capture, Formatting, and Dsiplay, Y Kim (ed), Proc SPIE 1444:256-264. 1991.
} 


\subsubsection{Distribuição das imagens}

Sistemas de comunicação em rede para a transferência de imagens de PACS podem ser divididos em três segmentos principais: ${ }^{1}$ 1) rede de alto desempenho para o departamento de radiologia; 2) rede de menor capacidade para outros setores hospital; e 3) acesso externo, tipicamente através de linhas telefônicas. A rede de alto desempenho, que pode ser, por exemplo, de fibra ótica com protocolo FDDI, ou tecnologias mais modernas como ATM ou Fast Ethernet, deve ser restrita para a transmissão de imagens dentro da radiologia e para outros departamentos com reconhecida alta demanda por imagens. Ela deve ser isolada de outras redes de menor capacidade como, por exemplo, uma rede Ethernet que pode ser usada para conectar setores do hospital com pequena demanda por imagens. Esta separação reduz a sobrecarga na rede ocasionada pelo grande tráfego de dados.

A compressão de dados é aqui, também, um aspecto importante. Ela pode ser usada para melhorar o desempenho da rede, mas os tempos de compressão e descompressão devem ser levados em consideração para se avaliar os benefícios de utilização de compressão.

As redes de comunicação para PACS devem ser seguras para proteger dados confidenciais sobre pacientes, e devem ser confiáveis para suportar um grande volume de imagens. Flexibilidade deve ser uma de suas principais características, já que um dos principais benefícios de sistemas do tipo PACS é a habilidade de expansão e de incorporação de novas tecnologias à medida que elas ficam disponíveis. Expansões, reconfigurações e manutenções de rotina devem ser simples e não devem comprometer o funcionamento de todo o sistema.

\subsubsection{Visualização}

Um projeto adequado para estações de trabalho para PACS é um fator determinante na aceitação deste tipo de sistema pela comunidade médica. Radiologistas e clínicos sem muita experiência com computadores devem se sentir confortáveis com a capacidade de visualização e com a interface com o usuário destes sistemas. $\mathrm{O}$ processamento de imagens radiológicas é normalmente realizado em três níveis: ${ }^{6}$ no sistema de imagens, pelo operador que produz a cópia das imagens em filmes e pelo 
radiologista, no momento que analisa as imagens. Pelo menos três tipos de estações de trabalho são necessárias: para elaboração de laudos diagnósticos, para revisão e para aplicações especiais.

Os requisitos físicos de uma estação de trabalho indicados na literatura como sendo aceitos para radiologia e para diagnóstico primário incluem vários monitores de 19”, resolução de aproximadamente 2048 x 2048 pixels, 256 tons de cinza e brilho de 60 footlamberts $^{*} .^{1} \mathrm{O}$ processamento para visualização deve preservar toda a faixa dinâmica dos dados das imagens. A capacidade de armazenamento dos discos locais deve comportar pelo menos uma sessão inteira de diagnóstico se o acesso aos arquivos de segundo nível for lento.

A interface com o usuário deve ser eficiente e fácil de usar. A seleção de funções específicas deve ser fácil e deve poder ser feita rapidamente. Deve existir uma padronização para a apresentação de exames com várias imagens, com uma opção para ver uma versão minimizada de todo o conjunto de imagens. A apresentação da interface com o usuário deve ser configurável para as preferências de usuários individuais. Estudos de uma lista de trabalho e imagens individuais do arquivo eletrônico de pacientes devem ser selecionáveis à partir de listas disponíveis na tela. Deve ser possível trocar rapidamente de casos, já que os radiologistas são freqüentemente chamados para atender a casos de emergência. O sistema deve fornecer ajuda na forma de manuais e tutoriais. Devem haver mensagens claras a respeito do funcionamento do sistema e do andamento das operações, como, por exemplo, uma indicação de que a transferência de um conjunto de imagens foi bem sucedida.

As característica de processamento de imagens podem ser divididas em dois grupos: um conjunto mínimo necessário e características desejáveis adicionais. ${ }^{1}$ As funções básicas incluem:

\footnotetext{
*Footlambert é uma unidade de medida de brilho fotométrico. Um footlambert (candela/ $\pi p e^{2}$ ) é igual a 3,426259 candela/metro ${ }^{2}$, onde candela é uma unidade de intensidade luminosa. O brilho fotométrico é definido pela equação $L=d^{2} \Phi / d w d(A \cos \theta)=d I / d(A \cos \theta)$, onde $\Phi$ é o fluxo radiante (energia radiante por unidade de tempo), $w$ é o ângulo sólido relativo a fonte de radição onde o fluxo é considerado, $A$ é a área da superfície considerada, $\theta$ é o ângulo entre a linha de visão e a normal da superfície e $I$ é a intesidade luminosa. ${ }^{8}$
} 
- ajuste de contraste e brilho através de window/level (W/L);

- maximizar e minimizar;

- reorientação;

- inversão de vídeo;

- navegação;

- medidas quantitativas (distância, área, estatística, etc.);

- anotação na imagem.

As características avançadas desejáveis são:

- funções de processamento de imagens adicionais (equalização adaptativa por histograma, filtros, medida de textura, etc.);

- visualização tridimensional;

- registro espacial de diferentes estudos;

- elaboração de arquivos didáticos.

A visualização de imagens em três dimensões não possui alta prioridade no diagnóstico radiológico, mas é um tópico de grande interesse nas áreas de terapia por radiação, planejamento cirúrgico e outras áreas com aplicações especiais. ${ }^{6}$

Fora do departamento de radiologia, os requisitos para a visualização de imagens são basicamente os mesmos citados acima, mas menos exigentes e extensos. ${ }^{1}$ Os médicos que pedem os exames, em nome de seus pacientes, são os usuários primários do serviço radiológico e, para eles, a disponibilidade dos resultados diagnósticos é muitas vezes mais importante que as imagens propriamente ditas. Relatórios perdidos ou sem assinaturas e relatórios separados de suas imagens são um dos maiores problemas atualmente. $\mathrm{O}$ número de monitores em cada estação de trabalho pode ser menor, e com menor resolução (1024 x 1024 pixels). A possibilidade de distribuir imagens para fora do departamento de radiologia é uma característica atrativa de PACS, pois, sem o risco de perder cópias originais de imagens durante o transporte pelo hospital, as imagens ficam disponíveis para os médicos rapidamente, em qualquer lugar e hora do dia, sem a necessidade de requisições formais. 


\subsubsection{Requisitos de sistema}

Segurança e confiabilidade são características essenciais para PACS devido a própria natureza do tipo de dados com que este tipo de sistema lida. Ao mesmo tempo que o sistema deve proteger os dados que ele acabou de adquirir, ele deve ser capaz de suportar um fluxo constante de dados novos. Redundâncias e cópias de segurança devem ser implementadas no sistema para prevenir atrasos e falhas que possam afetar negativamente o tratamento de pacientes. O sistema deve ser flexível para acomodar atualizações e adições de novos componentes. A manutenção deve ser automatizada ao máximo para diminuir a necessidade de intervenção humana e, conseqüentemente, diminuir os custos. Neste sentido, devem haver funções automáticas de controle de qualidade e de acompanhamento do funcionamento dos diversos componentes que formam o sistema.

\subsubsection{Sistemas de banco de dados em PACS}

\subsubsection{Introdução}

Em um departamento de radiologia manual, os filmes de imagens são armazenados em bibliotecas manuais de filmes. As imagens adquiridas por diferentes modalidades são separadas e armazenadas em pastas classificadas por paciente. Quando o radiologista está pronto para analisar um conjunto de imagens, ele faz uma requisição à biblioteca de filmes, marca um horário para a seção de diagnóstico, vê as imagens do exame corrente e, se necessário, imagens anteriores, discute o caso com o médico que pediu o exame e, finalmente, escreve o relatório do exame. O relatório é colocado com os filmes na pasta do paciente e esta é arquivada novamente.

Todo este processo acarreta muito desperdício de tempo e de recursos. Muitas imagens são perdidas ou arquivadas erroneamente, e, conseqüentemente, elas devem ser feitas novamente. Como o trabalho na biblioteca de filmes é manual, na melhor das hipóteses o tempo de recuperação de filmes é da ordem de alguns minutos. A freqüente insuficiência de estações para visualização de filmes dificulta o agendamento para os exames das imagens, o que acarreta uma demora para que o médico que requisitou o exame receba os resultados. Em geral, é difícil obter uma 
cópia do filme e, quando necessário, este é digitalizado para depois ser impresso em filme novamente. Informações adicionais sobre o paciente normalmente não se encontram disponíveis em um mesmo lugar, sendo necessário ter acesso a outros sistemas de informação da instalação médica para obté-las.

Os sistemas do tipo PACS, ao integrar e automatizar as diversas funções de um departamento de radiologia manual, utilizam sistemas de banco de dados para armazenar e gerenciar as diversas informações relacionadas com os pacientes e as suas imagens. Em geral, os dados são do tipo texto, imagem e voz. Este último tipo de dado é utilizado em alguns tipos de PACS para armazenar a versão oral do relatório do exame. ${ }^{4}$

O exame radiológico é a entidade primária de PACS e, conseqüentemente, de sistemas de banco de dados para PACS. Os principais requisitos para este tipo de sistema são: ${ }^{4}$

- incluir dados do tipo texto, imagem e, possivelmente, som, que devem ser utilizados em conjunto para formar os exames;

- proporcionar consultas eficientes, limitando o tempo de espera a, no máximo, dois segundos;

- manter um desempenho aceitável utilizando compressão de dados para minimizar o tempo de transferência pela rede e o espaço de armazenamento necessário;

- ao utilizar compressão de dados, garantir que a qualidade das imagens não diminua a ponto de prejudicar os diagnósticos;

- proporcionar a possibilidade de se recuperar exames passados antes ou durante a avaliação do exame corrente, podendo estes exames serem selecionados através de chaves primárias ou conteúdo das imagens;

- apenas apagar as imagens no caso de falecimento do paciente ou se a imagem ultrapassar o período mínimo de armazenamento estabelecido;

- como as operações mais comuns são de adicionar e consultar dados, o sistema deve otimizar estas operações;

\footnotetext{
* Allen;Frieder ${ }^{4}$ afirmam que o tempo de resposta do sistema deve ser no máximo de dois segundos e que por isso o projeto do BD deve proporcionar recuperação de dados eficiente. Eles indicam Sheng et al. ${ }^{3}$ como sendo a fonte desta informação. Mas este autor apenas diz que o tempo de resposta deve ser inferior ou tempo necessário para se retirar manualmente um filme de uma pasta de arquivo.
} 
- a transmissão de imagens deve ser confiável e o sistema deve ser seguro no que se refere a proteção da integridade e sigilo dos dados;

- todas as imagens e exames devem ser passíveis de serem impressas;

- deve ser possível o acesso múltiplo e concorrente aos dados;

- o sistema deve continuar funcionando mesmo se um ou mais equipamentos ou computadores na rede PACS parar de funcionar ou se um novo equipamento for adicionado;

- deve ser possível incorporar, através de digitalização, exames e imagens que antes eram manualmente arquivados;

- o sistema deve ser flexível para poder estabelecer comunicação com RIS e HIS.

Para satisfazer estes requisitos, vários aspectos devem ser abordados, destacando-se: a localização física dos dados; o tipo de projeto de banco de dados (relacional ou orientado a objetos e centralizado ou distribuído) e técnicas de consulta. A seguir estes pontos são apresentados com mais detalhes.

\subsubsection{Armazenamento físico}

O tamanho das imagens radiológicas requer que o meio de armazenamento físico seja capaz de lidar com volumes muito grandes de dados. Associado com o fato de que as imagens também devem ser armazenadas por períodos longos de tempo, levando em consideração as atuais modalidades de diagnóstico e tecnologias de armazenamento, são indicados quatro níveis de armazenamento físico, resumidos na tabela a seguir. ${ }^{4}$

Tabela 2 - Hierarquia de armazenamento

\begin{tabular}{c|l|l|l}
\hline \hline Nível & \multicolumn{1}{|c|}{$\begin{array}{c}\text { Período de } \\
\text { retenção }\end{array}$} & \multicolumn{1}{c}{$\begin{array}{c}\text { Meio de } \\
\text { armazenamento }\end{array}$} & Capacidade aproximada \\
\hline 1 & 1 a 7 dias & disco magnético & 21 Gbytes \\
\hline 2 & 8 a 31 dias & $\begin{array}{l}\text { torre de discos óticos } \\
\text { com seleção automática }\end{array}$ & 31 Gbytes \\
\hline 3 & 31 dias até 3 anos & $\begin{array}{l}\text { torre de discos óticos } \\
\text { com seleção manual }\end{array}$ & 3,2 Tbytes \\
\hline 4 & 3 anos até 18 anos & fitas óticas & 1 Tbyte por rolo de 12 pol. \\
\hline \hline
\end{tabular}

Fonte: Adaptado de ALLEN,L.; FRIEDER,O., IEEE Engineering in Medicine and Biology, mar. 1992, p.43.

A tabela da referência original não possui o nível quatro, mas este nível adicional é indicado no texto do artigo. 
Neste sistema de armazenamento hierarquizado, as imagens mais requisitas ou com maior probabilidade de serem consultadas devem ficar no meio físico de mais rápido acesso. À medida que a idade dos dados, ou o período desde o último acesso, ultrapassa os limites de cada nível, eles são movidos para níveis inferiores, até o quarto e último nível, liberando espaço para novos dados nos níveis de acesso rápido. Como nem todas as requisições são de dados obtidos nos últimos sete dias, um movimento contrário de dados para meios de acesso mais rápidos também é necessário, e, neste caso, o marcador de tempo dos dados é reinicializado.

Para dados no primeiro nível são utilizados discos rígidos fixos ou removíveis. Este meio de armazenamento proporciona a maior velocidade de acesso, mas estão limitados no volume máximo de dados possível. Para os segundo e terceiro nível são usados discos óticos, sendo o tipo de uma gravação e várias leituras (WORM - write once, read many) o mais comum, pois a maioria dos acessos são para adicionar e consultar dados. Estes discos têm capacidade de armazenar de 600 Mbytes até dois Gbytes. Para o quarto nível são usadas fitas óticas, que são capazes de armazenar um volume muito maior que meios magnéticos e, por isso, são necessárias poucas fitas para armazenar dados antigos.

O período mínimo de armazenamento dos dados varia para cada país ou até mesmo para cada instalação médica. O período de retenção mínimo de 18 anos da Tabela 2 é específico do exemplo apresentado por ALLEN;FRIEDER. ${ }^{4}$ No Brasil ainda não existe uma legislação específica para registros médicos eletrônicos, ${ }^{7}$ mas algumas leis relacionadas servem como parâmetro para se estabelecer o período mínimo de retenção de dados e imagens médicas:

“... Segundo Wilson Andreoni '(ANDREONI apud MELO)"' existe apenas um Decreto do Estado de São Paulo n. 12.479 de 18/10/78 que no seu artigo 45 item $B$, determina que o arquivo de resultados técnico de estabelecimentos médicos devem ser mantidos durante 5 (cinco) anos

O Conselho Federal de Medicina (Resolução 1.331/89) afirma que $o$ Prontuário Médico é de manutenção permanente pelos estabelecimentos de saúde (Art. 1o.) e que após prazo não inferior

\footnotetext{
* ANDREONI, W. R. Prontuário Médico: Aspectos Éticos-Legais. Boletim do Corpo Clínico do HCFMUSP, n.52, p.5-8, 1992.
} 
a 10 (dez) anos do último registro, o prontuário pode ser substituído por métodos de registro capazes de assegurar a restauração plena das informações (Art. 2o.).

Do ponto de vista do direito do paciente e do médico, o Art. 177 do Código Civil diz que as ações pessoais prescrevem ordinariamente em vinte anos...'...." MELO;FERREIRA. ${ }^{7}$

\subsubsection{Projeto do banco de dados}

O projeto de banco de dados para PACS é uma tarefa complexa devido a diversidade dos dados em questão. Os dados relativos a cada exame devem incluir nome do paciente, identificação, data de nascimento, nome para contato, identificação dada pelo hospital, dia e hora do exame, modalidade, tipo de exame e localização, as imagens, o nome do médico que solicitou o exame e do que acompanhou o exame. $\mathrm{O}$ relatório final deve conter a interpretação dos resultados do exame e o texto com o pedido original de exame.

No sistema manual de arquivamento, quando o radiologista recebe a pasta de um paciente, ele tem acesso a todas as informações relativas a exames passados. Como normalmente apenas os dados de um paciente são requisitados por vez, sistemas de banco de dados para PACS também utilizam o conceito de pasta do paciente, tentando automatizar o acesso a todos os dados correntes e passados do paciente. Como os dados ficam distribuídos em vários níveis de armazenamento físico, são utilizados algoritmos especiais para determinar quais dados são mais prováveis de serem requisitados e, assim, colocá-los disponíveis antecipadamente no primeiro nível de armazenamento.

Vários tipos de modelos de banco de dados podem ser utilizados para definir e implementar bancos de dados para PACS. O modelo relacional de dados, apresentado em detalhes na Seção 2.4 desta dissertação, é um destes modelos devido a sua grande popularidade em bancos de dados tradicionais, mas extensões a este modelo devem ser utilizadas para que este tipo de banco de dados suporte imagens, que é um tipo de dado não convencional. Outro tipo de bancos de dados são os orientados a objetos, que são utilizados para resolver uma das principais restrições dos modelos relacionais, que é a consulta à imagem baseada em seu conteúdo. Nesta abordagem, a imagem 
não é um dado final, mas ela é segmentada em partes de interesse que formam diferentes tipos de objetos.

Os bancos de dados para PACS podem ser centralizados ou distribuídos. A primeira opção utiliza um banco de dados central que recebe todas as imagens geradas e as envia para as estações de trabalho mediante solicitações. Esta abordagem tem como vantagens a consistência e integridade dos dados, mas também possui vários problemas. Em grandes PACS, a consulta a um banco de dados central é cara, pois o tempo para o sistema receber uma requisição, processá-la e enviar o resultado pode variar de alguns segundos até vários minutos. Assim, em um sistema muito utilizado, o desempenho fica a desejar e a aceitação do sistema por parte dos usuários é prejudicada. Como há apenas um banco de dados, qualquer falha em um dos componentes pode interromper todas as consultas a dados radiológicos, e o sistema pode ser necessariamente paralisado para se efetuar atividades de manutenção e atualização de equipamentos.

A opção por bancos de dados distribuídos divide o banco de dados em fragmentos que são colocados em locais onde há uma maior probabilidade dos dados serem utilizados localmente. Desta forma, a estratégia para a distribuição dos dados é o principal fator de sucesso desta abordagem. Cada subsistema que possui uma parte do banco de dados possui um diretório com a localização de todos os dados, que é mantido atualizado automaticamente. Assim, quando uma imagem não está armazenada localmente, a estação de trabalho faz uma requisição a outra estação, que envia a imagem para ser consultada. Nesta abordagem, apesar de serem resolvidos alguns problemas existentes em sistemas centralizados, outros problemas surgem, como a segurança nas transmissões em rede, duplicação de dados e uma maior dificuldade de manter a integridade do banco de dados como um todo.

Comparando as duas opções descritas acima, a abordagem distribuída é adequada para grandes sistemas que possuem diversas partes fisicamente separadas. Já a opção por um sistema centralizado é adequado para sistemas radiológicos menores. 


\subsubsection{Técnicas de consulta}

Os bancos de dados relacionais, introduzidos na seção anterior, recuperam as imagens baseando-se apenas nos dados textuais que as acompanham, como o nome do paciente ou a data. Já na abordagem de orientação a objetos, as imagens podem ser selecionadas com regras que pesquisam características internas das imagens, como partes do corpo, curvas, etc. Estas regras definem, basicamente, sistemas especialistas, que também podem ser incorporados em sistemas relacionais para selecionar imagens pelo seu conteúdo.

Para otimizar o trabalho dos radiologistas, funções de busca antecipada (prefetching) providenciam para que imagens sejam carregadas na estação de trabalho antes de serem requisitadas pelo radiologista. Para executar estas funções, são utilizados sistemas baseados em regras e mecanismos de aprendizado automático.

As regras são definidas de acordo com as características de utilização em cada setor da instalação hospitalar (radiologia, pediatria, emergência, etc.) e em função de características pessoais dos usuários. Como exemplo, em um estudo feito por Cheng et. al., ${ }^{3}$ percebeu-se que radiologistas com menos experiência (1 a 5 anos) em uma especialidade, tinham a tendência de requisitar todas as informações possíveis sobre o paciente. Já os radiologistas com mais experiência (5 a 25 anos) aparentemente sabiam qual informação específica era necessária. Os radiologistas com muita experiência (mais de 25 anos) sabiam quais informações eram necessárias mas também requisitavam todas as informações possíveis sobre o paciente. Estes padrões de comportamento podem ser implementados na forma de regras que são automaticamente executadas de acordo com o usuário e a requisição corrente.

Mecanismos de aprendizado podem ser incorporados nestes sistemas para detectar padrões de comportamento novos ou outros não programados e, então, alterar as regras já existentes ou criar novas regras.

\subsubsection{Conclusões}

De uma forma geral, existe o consenso de que o gerenciamento de imagens radiológicas pode ser melhorado com a utilização de sistemas baseados em 
computadores, mas as opiniões variam sobre qual tipo de sistema é melhor e é mais adequado. Os possíveis sistemas dependem de fatores como a natureza do serviço radiológico, os tipos de imagens e a demanda clínica. Várias instituições já incorporaram a utilização de PACS no dia-a-dia clínico. Destas experiências, algumas conclusões já podem ser extraídas e devem ser levadas em consideração em novas implementações.

A principal característica que afeta a aceitação de PACS na comunidade clínica é a confiabilidade. ${ }^{1}$ Por exemplo, se o sistema fica constantemente fora do ar, a confiança dos usuários na acessibilidade do sistema cai consideravelmente, dificultando a sua aceitação na rotina da instalação médica. Um outro exemplo, que afeta a confiança do usuário no desempenho do sistema, é a constatação que as instalações iniciais destes sistemas sofrem freqüentemente de problemas e incompatibilidades nas redes e interfaces, e modificações subsequentes são muitas vezes necessárias para se alcançar velocidades aceitáveis de transmissão e visualização das imagens. Outro ponto observado é a importância das estações de trabalho como interface entre o PACS e o usuário: é extremamente importante que os usuários estejam confortáveis com a utilização destas estações e que confiem na capacidade delas de apresentar imagens com qualidade equivalente aos filmes que eles estão acostumados.

Entre os benefícios observados estão uma maior eficiência na comunicação entre radiologistas e clínicos, e uma maior velocidade de acesso às imagens arquivadas. A possibilidade de se utilizar sistemas de teleradiologia, que possibilita aos radiologistas terem acesso a exames e imagens de suas próprias casas, é sempre recebida com muito entusiasmo.

Os PACS atuais possuem limitações que indicam alguns dos futuros passos necessários na área. Um dos principais aspectos que necessitam de melhoras é a velocidade dos sistemas como um todo. O tempo de resposta dos bancos de dados é uma das principais limitações. Outro fator importante é o congestionamento da rede de comunicação, que pode gerar tempos de resposta muito longos e até mesmo imprevisíveis. 
Outra área de intenso debate é a resolução das imagens e a questão da aceitação do diagnóstico baseado em imagens digitais no lugar dos tradicionais filmes. Sabe-se que existem casos em que são necessárias imagens com resolução de até 4096 x 4096 pixels para se ter certeza de que informações diagnósticas não são perdidas. Este é o caso, por exemplo, da mamografia, que requer alta resolução e contraste. ${ }^{1}$ Sistemas de CR com resolução de 2048 x 2048 pixels são considerados inadequados para este tipo de exame.

No que se refere a integração de PACS, a atual falta de um padrão universal de interfaces complica a integração de equipamentos de diferentes fabricantes. Este mesmo problema afeta as futuras expansões e atualizações do sistema.

No passado, várias pessoas entenderam que PACS seria uma forma de mover imagens rapidamente, mas à medida que as capacidades de processamento de imagens desenvolveram e ficaram mais rápidas e menos caras, percebeu-se estes sistemas podiam servir mais do que para gerenciamento de imagens. O sistema de comunicação de imagens pode proporcionar capacidades adicionais que podem melhorar a qualidade dos diagnósticos. Este objetivo pode ser atingido com a integração do diagnóstico auxiliado por computador, caracterização de tecidos, visualização de imagens em 3D e apresentação de dados utilizando multimídia. 


\subsection{Sistemas de imagens por RMN}

\subsubsection{Introdução}

Uma importante modalidade de diagnóstico médico é a tomografia computadorizada por ressonância magnética nuclear, normalmente chamada de Imagem por Ressonância Magnética (MRI - Magnetic Resonance Imaging). Esta técnica consiste da obtenção de imagens que representam a distribuição espacial do sinal de Ressonância Magnética Nuclear (RMN), ou um outro parâmetro de RMN, em uma amostra heterogênea. Quando aplicada em sistemas biológicos, inclusive em seres vivos, as imagens obtidas retratam a constituição ou a fisiologia de estruturas internas. Em comparação com outras modalidades de diagnóstico, ela se destaca por não ser invasiva, não utilizar radiação ionizante como na tomografia computadorizada por raios $\mathrm{x}$, por permitir a obtenção de contraste entre tecidos sem a utilização de substâncias marcadoras ou de contraste, por permitir a obtenção de cortes em direções arbitrárias, e por possibilitar o diagnóstico de patologias que não são observadas por outras modalidades de tomografia, como, por exemplo, a esclerose múltipla, que não aparece na tomografia por raios x convencional. ${ }^{2,9}$

A tecnologia que envolve a técnica de MRI é bastante interdisciplinar, pois envolve desde aspectos físicos do fenômeno da ressonância magnética nuclear, vários equipamentos para aquisição, processamento e visualização dos dados, até aspectos dos sistemas de informação dos locais onde equipamentos de MRI estão instalados.

Particularmente para este trabalho, destacam-se o grande volume e a diversidade de informações que estão inerentemente ligados à aplicação da técnica de MRI. Estas informações compreendem, além das imagens resultantes, os parâmetros 
da técnica utilizada, a configuração do sistema de MRI, a identificação e organização dos resultados, entre outras. O conhecimento destas informações é imprescindível para o processo de diagnóstico baseado em resultados de MRI

Desta forma, esta seção faz uma descrição geral de sistemas de MRI, com o objetivo de apresentar alguns aspectos básicos, dentre os quais alguns devem ser retratados no banco de dados para contextualizar as imagens resultantes da operação deste tipo de sistema. Inicialmente é feita uma descrição geral dos componentes de sistemas de MRI, abrangendo principalmente os equipamentos que constituem o sistema. Em seguida, como exemplo de sistema de MRI, é descrito o sistema ToRM005 em operação no Instituto de Física de São Carlos. Detalhes sobre os princípios físicos envolvidos na formação de imagens através da técnica de MRI são apresentados na seção 2.5, Formação de imagens por RMN, devido a extensão e complexidade do assunto.

\subsubsection{Configuração básica de sistemas de MRI}

As várias modalidades de tomografia computadorizada diferem basicamente nos princípios físicos do fenômeno envolvido, na banda de energia associada e no tipo de algoritmo de reconstrução utilizado, mas estes sistemas possuem uma estrutura básica comum composta de três partes principais: aquisição de dados, processamento e visualização. ${ }^{10}$

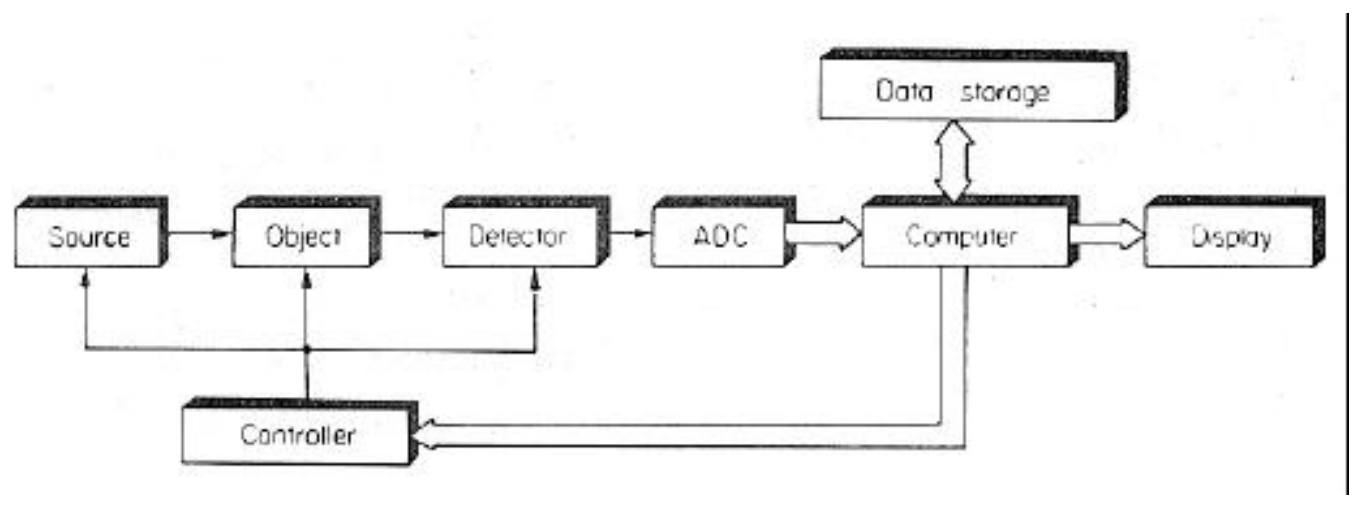

Figura 2 - Diagrama de blocos com os principais módulos de um sistema de tomografia computadorizada genérico."

\footnotetext{
* CHO, Z.H., Encyclopedia of Physical Science and Technology, v.3, p.517.
} 
A aquisição de dados é a parte mais importante do sistema e é ela que caracteriza cada modalidade. O subsistema de aquisição de dados abrange a fonte da energia que interage com o objeto em estudo, os detetores, controladores, os sistemas eletrônicos para a aquisição dos dados e o suporte ou local onde fica o objeto em estudo. Depois que este subsistema recebe os sinais analógicos que contêm as informações correspondentes às imagens, ele converte estes sinais para a forma digital e os transfere para o computador, que é o subsistema de processamento.

O computador é responsável, principalmente, por manipular e reconstruir as imagens à partir dos dados digitalizados pelo subsistema de aquisição de dados. Estas imagens fornecem informações sobre estruturas particulares ou funções metabólicas do objeto em estudo. A manipulação e o processamento dos dados é feito, em geral, utilizando computadores de propósito geral e, dependendo da configuração, do tipo de aquisição de dados e do tipo de algoritmo de reconstrução utilizado, são utilizados processadores de arranjo ou outros processadores dedicados para auxiliar no processamento.

O último subsistema é o de visualização, através do qual pode-se visualizar e analisar os resultados. Monitores são usados para mostrar as imagens durante e depois do processo de aquisição e processamento e, em geral, câmaras multiformato são ligadas nestes monitores para gravar as imagens em filmes.

Um sistema de MRI enquadra-se na estrutura geral de sistemas de tomografia computadorizada descrita acima. A parte de aquisição de dados é composta de equipamentos específicos para RMN e de sistemas eletrônicos; o processamento é feito por um computador principal com a ajuda, em geral, de um processador de arranjos; e a visualização é feita através de monitores de vídeo.

Os equipamentos específicos para RMN são: o magneto principal, responsável pelo campo magnético estático principal, que varia, em geral, de 0,05 a 2 Tesla; as bobinas de gradiente para a geração de gradientes de campo magnético de 0,01 a 1 Gauss/cm; e a bobina de RF, que transmite e recebe sinais de RF na faixa de 2 a 85 MHz. Os equipamentos eletrônicos incluem: um sintetizador de forma de onda; um componente para a aquisição de dados; e amplificadores de transmissão e recepção. O computador principal é responsável por definir as formas de onda de RF e de 
gradientes, controlar a operação do sistema, inclusive a temporização dos eventos durante a aquisição, além de reconstruir as imagens após a aquisição dos dados e controlar a visualização através dos monitores.

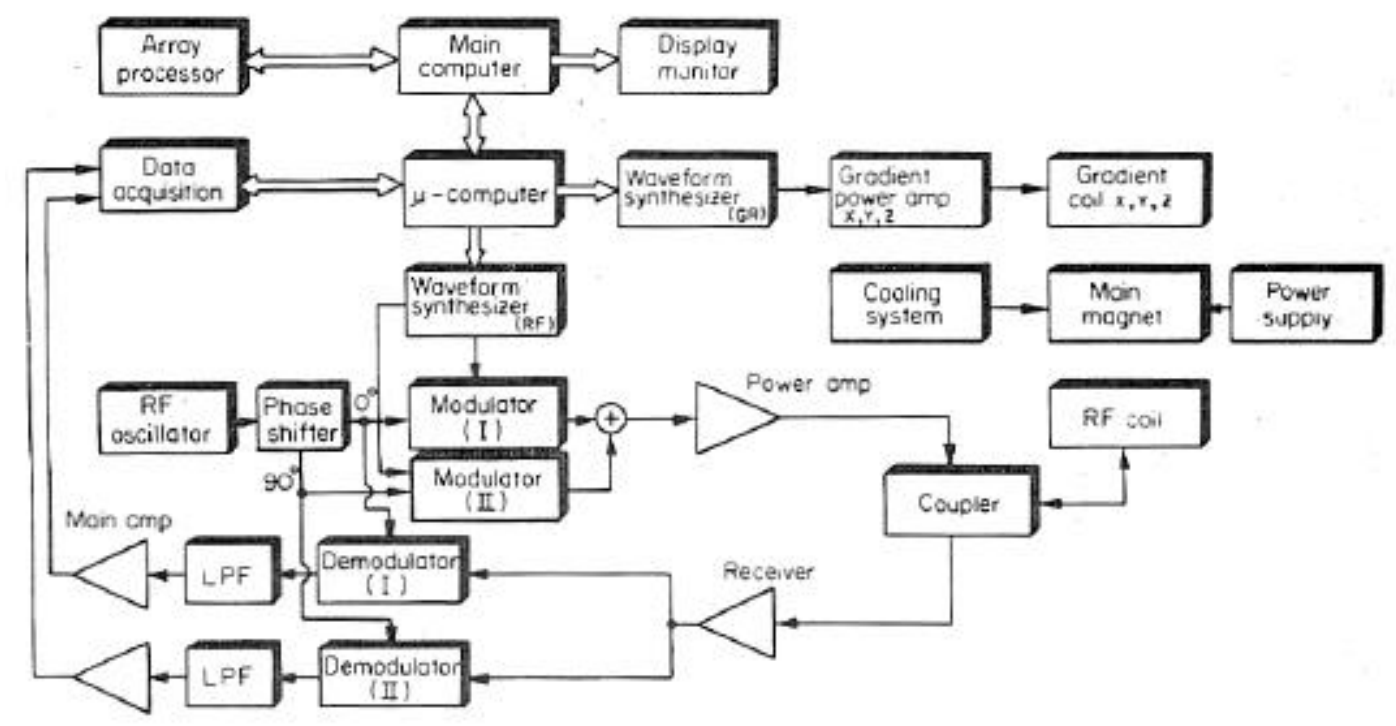

Figura 3 - Diagrama de blocos de um sistema de MRI genérico."

As formas de onda dos pulsos de RF e de gradientes, definidas no computador principal, são transferidas para um microcomputador e depois para o sintetizador de formas de onda, onde os dados na forma digital são transformados para a forma analógica. Os sinais de gradiente de campo são amplificados pelo amplificador de gradientes e, depois, são aplicados nas bobinas de gradiente $x, y$ e $z$. O sinal de áudio produzido pelo sintetizador de forma de onda é utilizado para modular um sinal de RF de referência através de moduladores. A RF modulada é então amplificada por um amplificador de potência de RF e, finalmente, é transferida para a bobina de RF através de um acoplador. O circuito acoplador discrimina as operações de transmissão e recepção e direciona o sinal de excitação para a bobina de RF e o sinal de recepção para o receptor.

O pulso de RF transmitido excita os spins nucleares da amostra e o sinal induzido na bobina de RF devido a precessão dos spins nucleares é transmitido para o amplificador de recepção pelo acoplador. Em seguida, o sinal dos spins é demodulado, usando o sinal de RF de referência, e é enviado para o sistema de

${ }^{*}$ CHO, Z.H., Encyclopedia of Physical Science and Technology, v.3, p.543. 
aquisição que digitaliza os dados e os envia para o sistema computacional. No computador, as imagens são reconstruídas, em geral com a ajuda de processadores de arranjos para aumentar a velocidade do processamento, e depois são visualizadas através de monitores de vídeo.

\subsubsection{O sistema ToRM-005}

O Grupo de Ressonância do Instituto de Física de São Carlos, que vem estudando e desenvolvendo tecnologia para MRI desde 1983, construiu um tomógrafo de ressonância magnética de baixo campo, com magneto resistivo de 0,05 Tesla. Este equipamento, batizado de ToRM-005, é atualmente utilizado para as atividades de pesquisa do grupo e também para exames clínicos que atendem a comunidade da cidade e da região. ${ }^{2}$

O diagrama a seguir apresenta os principais módulos do sistema ToRM-005 e os detalhes técnicos deste sistema são resumidos no Apêndice I relativo a este sistema. 


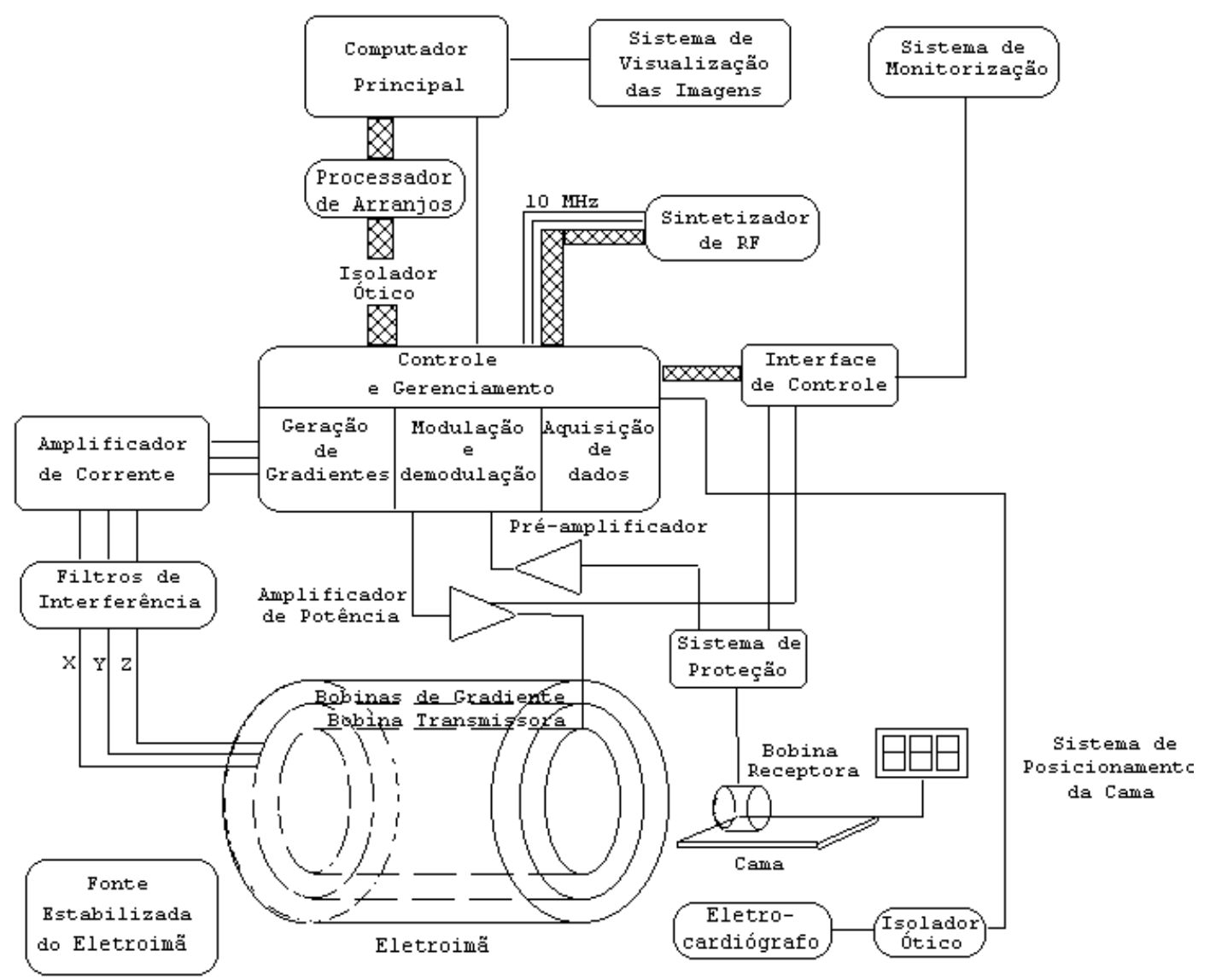

Figura 4 - Diagrama de blocos do sistema ToRM-005."

O sistema ToRM-005 usa a técnica de aquisição e reconstrução baseada em transformada de Fourier (Direct Fourier Imaging) para imagens bidimensionais (2D). A seqüência de aquisição mais utilizada em estudos clínicos é a Spin-Echo MultiSlice, mas também estão implementadas e já foram usadas as sequiências Inversion Recovery e Gradient Recall Echo. Já para estudos acadêmicos, existem variações destas seqüências e de diversas outras, como, por exemplo, diversas seqüências de Steady State Free Precession.

A plataforma computacional do ToRM-005 consiste de: um minicomputador microVAX 3300 com sistema operacional microVMS 5.4-1 para programação e comunicação com o espectrômetro do tomógrafo, coleta de dados de aquisição e processamento destes para gerar as imagens; um microcomputador Macintosh II-FX, operando com Unix e Finder, usado para a visualização das imagens; e um processador de arranjos AP500 usado para fazer as médias dos sinais de RMN adquiridos e enviar o resultado para o microVAX. 
Neste sistema, o armazenamento e gerenciamento dos dados é manual, realizado pelo operador através dos sistemas de arquivos dos sistemas operacionais dos computadores utilizados, e em fichas de pedidos de estudo preenchidas manualmente. Este sistema atende às necessidades locais onde é gerado um volume de dados de aquisição e de imagens de 6 a 35 Mbytes por semana, mas possui diversas limitações que não seriam aceitáveis em um ambiente de utilização com um maior volume de dados e que exigisse uma maior diversidade de informações sendo obrigatoriamente armazenadas. As principais limitações atuais são:

- há duplicação de dados, principalmente de imagens, no microVAX e no Macintosh, acarretando desperdício de espaço em disco e falta de sincronia entre imagens que são editadas em um computador, mas não em outro;

- as informações armazenadas se limitam às existentes nos arquivos de parâmetros das aquisições e nos dados preenchidos nas fichas de pedidos de estudos. Muitas outras informações relevantes não são arquivadas e são esquecidas com o tempo;

- a consulta aos dados é feita manualmente entre as fichas de pedidos de estudo, que são ordenadas cronologicamente na ordem da realização dos estudos, e através do sistema de gerenciamento de arquivos dos sistemas operacionais, onde os dados de aquisição são armazenados em uma árvore de diretórios. Assim, não há nenhuma possibilidade de realização de buscas mais elaboradas e de pesquisas entre os dados;

- devido à limitações de espaço em disco dos computadores, são realizadas cópias de segurança periódicas. Estas cópias eram feitas, até o final do ano de 1996, em fitas seqüenciais que não possibilitam busca a dados específicos, além da relativa lentidão para a realização das cópias e restauração dos dados, quando comparado a outras tecnologias já existentes; ${ }^{\dagger}$

- a estratégia de busca e consulta aos dados é geralmente baseada na memória do operador que, para estudos recentes, consegue se lembrar da localização das informações desejadas.

\footnotetext{
* MARTINS, M.J., 1995, p.20.

† A partir de janeiro de 1997 as cópias de segurança passaram a ser armazenadas em discos de CDROM com capacidade de armazenamento de até 650 Mbytes. Os dados são transferidos para um microcomputador IBM/PC compatível onde se encontra instalado o gravador de CD-ROM.
} 
A experiência com este sistema de armazenamento de informações deixou claro que, para acompanhar o novo sistema de MRI, o ToRM-05, seria necessário um sistema de armazenamento e gerenciamento de informações mais robusto, que, além de eliminar as limitações do sistema atual, proporcionasse a possibilidade de se armazenar uma maior variedade de dados, e que fosse possível executar consultas e pesquisas mais elaboradas. Assim, chegou-se a conclusão que era necessário desenvolver um sistema de banco de dados para MRI, capaz de atender as necessidades de armazenamento e gerenciamento de dados do ToRM-05.

Atualmente, o sistema ToRM-005 está servindo de testes para a utilização de uma nova plataforma computacional, esta baseada em um microcomputador do tipo IBM/PC compatível. Esta nova plataforma será utilizada no ToRM-05, e um dos requisitos do novo sistema de armazenamento e gerenciamento de dados é funcionar neste ambiente computacional. 


\subsection{Padrão DICOM 3.0}

Digital Imaging and Communications in Medicine (DICOM) é um padrão para comunicação de imagens médicas e informações associadas. Ele pode ser utilizado por diversas modalidades de equipamentos de imagens médicas, como, por exemplo, tomografia computadorizada, imagens por ressonância magnética, medicina nuclear e ultra-som. $^{11}$

Este padrão foi desenvolvido por um comitê de trabalho formado por membros do American College of Radiology (ACR) e do National Electrical Manufactures Association (NEMA) que iniciou os trabalhos em 1983. ${ }^{12}$ A primeira versão do padrão, chamada de ACR-NEMA 300-1985 (ou ACR-NEMA Version 1.0), foi apresentada em 1985. Em 1988, uma segunda versão, com novos elementos de dados e vários erros e inconsistências da versão anterior corrigidos, foi distribuída com o nome de ACR-NEMA 300-1988 (ou ACR-NEMA Version 2.0). Naquele momento, o comitê de trabalho percebeu que os usuários em potencial do padrão queriam uma interface entre seus equipamentos que possibilitasse a comunicação através de redes. A versão 2.0 não possuía as partes necessárias para uma comunicação em rede robusta, pois ela apenas permitia comunicação ponto-a-ponto entre equipamentos de imagens ou com outros tipos de sistemas, e não uma comunicação direta com uma rede. $\mathrm{O}$ comitê percebeu que seriam necessários mais que simples alterações e adições à versão 2.0, sendo necessário refazer toda a estrutura do padrão, mas mantendo ainda compatibilidade com as versões anteriores. Daí surgiu a atual versão, o ACR-NEMA DICOM, também chamado de DICOM 3.0, que foi apresentado em 1993. 
O padrão DICOM baseia-se em um modelo explícito e detalhado dos vários aspectos relevantes para a área de radiologia e imagens médicas (pacientes, imagens, relatórios, etc.), bem como descrições detalhadas destes aspectos e como eles estão relacionados. O modelo geral foi desenhado usando-se diagramas Entidade-relacionamento (ER - Entity-relationship) e tem como objetivo garantir que usuários e fabricantes tenham um entendimento comum da estrutura de dados usada no padrão. O modelo fornece os elementos de dados abordados pelo padrão e toda a estrutura de relacionamentos e hierarquia destes elementos. 


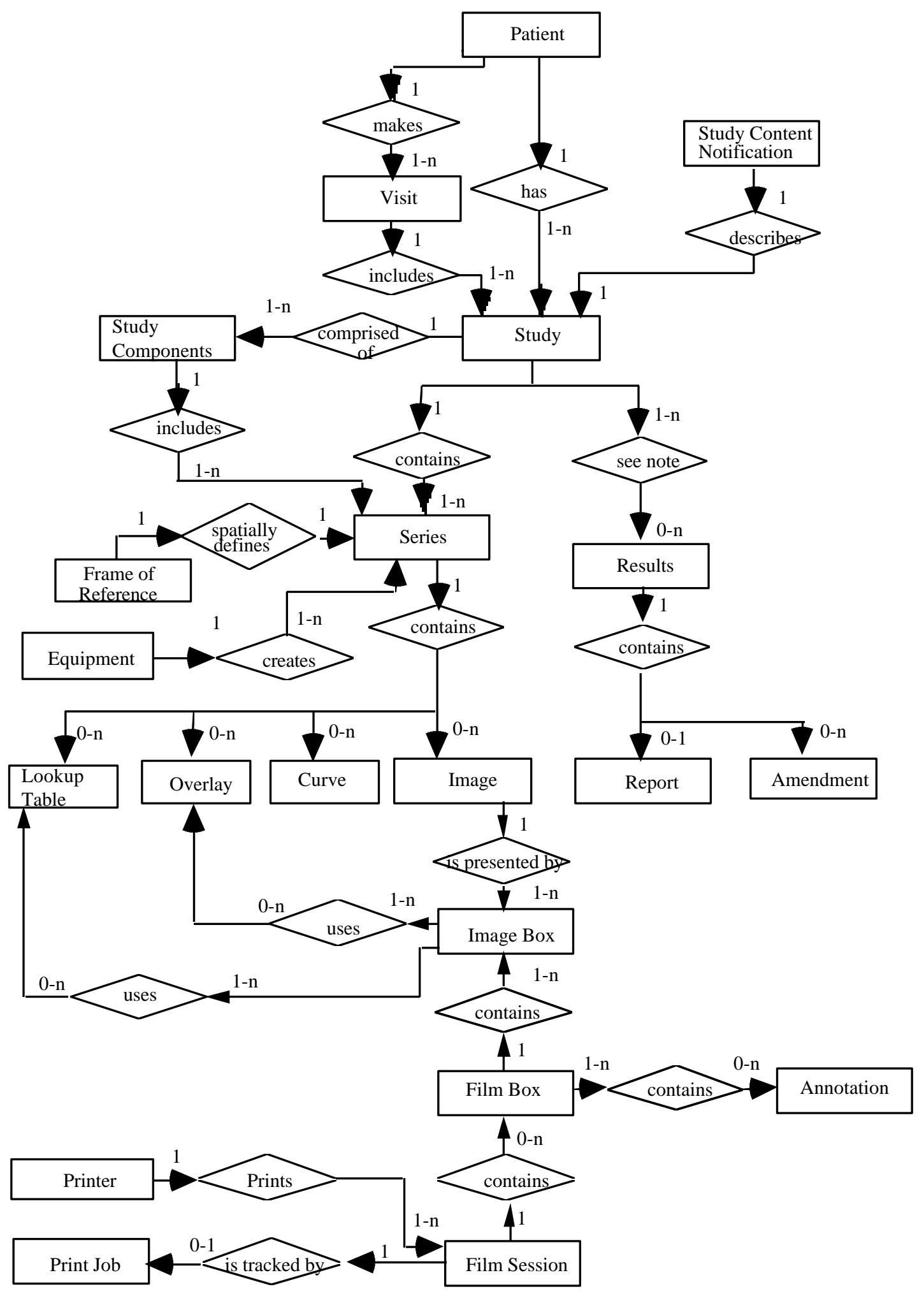

Figura 5 - Modelo ER do mundo real usado pelo DICOM 3.0.*

* ACR-NEMA DICOM 3.0, Part 3: Information Object Definitions, figura 7. 
O desenvolvimento deste modelo usou uma metodologia de orientação a objetos, onde os objetos são as entidades, ou coleção de entidades, definidas no modelo. Para descrever as características de cada objeto existem os atributos (ver o Apêndice II, referente ao padrão DICOM, para uma lista completa das entidades e atributos do padrão). O padrão DICOM chama os objetos que são baseados no modelo ER do mundo real de objetos de informação (IO - information object), e os modelos e tabelas com os atributos que definem os IOs de definições dos objetos de informação (IOD - information object definition). Se valores reais são substituídos pelos atributos temos então uma entidade chamada de instância.

A orientação a objetos proporciona não apenas uma maneira de descrever as informações existentes no modelo, mas o que fazer com estas informações ou como obter informações sobre a coleção de objetos existentes. O padrão DICOM faz uso deste conceito para definir serviços, como "armazenar imagem" ou "obter informações do paciente". Estes serviços são implementados no DICOM usando construções chamadas de operações e notificações. É definido um conjunto de operações e notificações genéricas que são chamadas de elementos do serviço de mensagem do DICOM (DIMSE - DICOM message service elements). A combinação de um IO e um serviço DIMSE é chamada de par serviço-objeto (SOP service object pair). Um IO pode ser usado com um conjunto de serviços e o resultado desta combinação é chamado de classe SOP (SOP class) (Figura 6). 


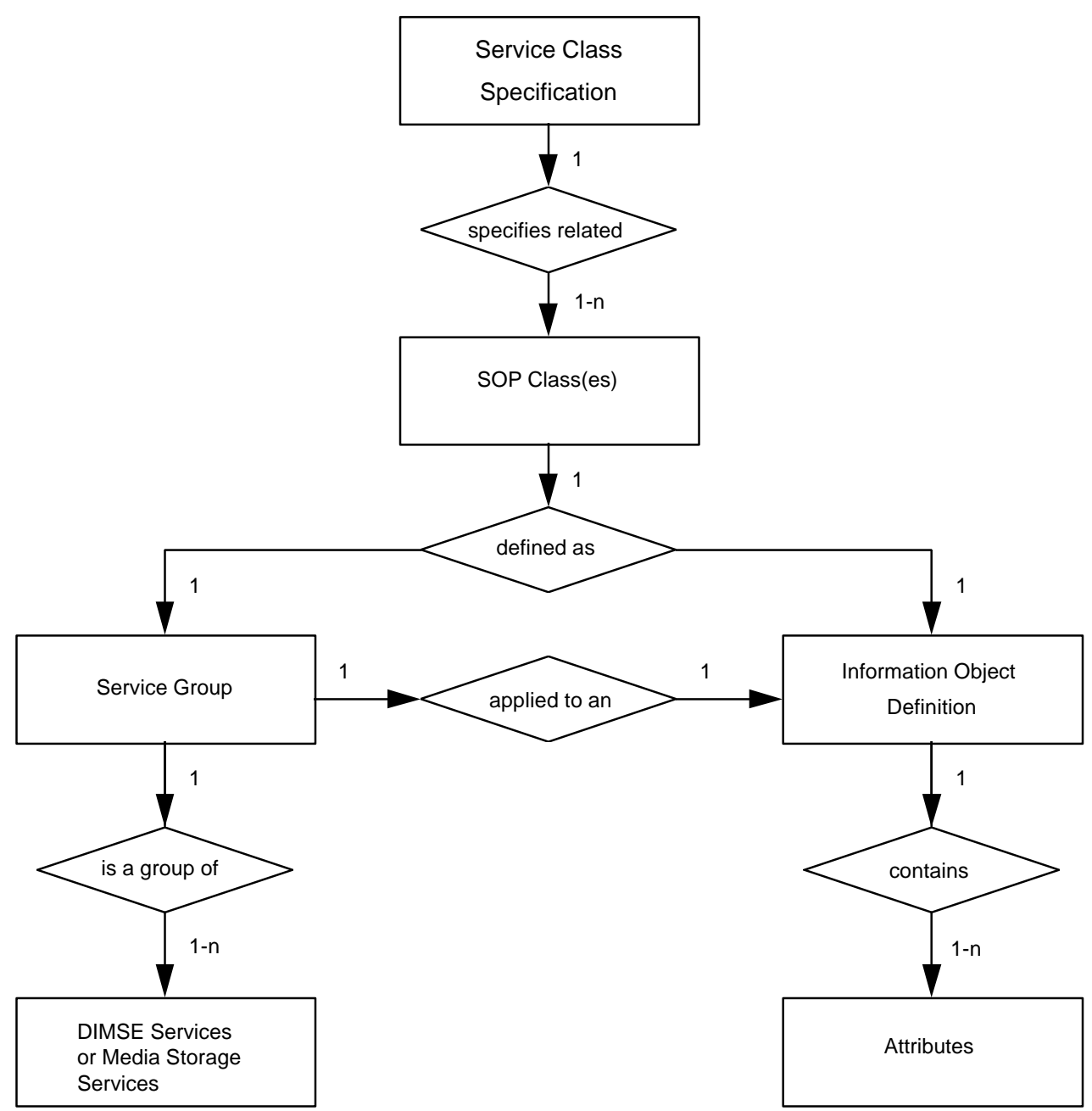

Figura 6 - Estruturas principais do modelo de informações do DICOM.*

Para exemplificar esta estrutura do modelo de informação do DICOM, podemos fazer uma analogia entre criar uma sentença e os conceitos definidos pelo padrão. Os elementos a esquerda no exemplo abaixo representam parte de uma sentença e a direita estão os conceitos correspondentes do DICOM.

\begin{tabular}{|c|c|}
\hline Verbo: "Armazenar" & $\rightarrow$ Serviço DIMSE \\
\hline Substantivo: "Imagem de MRI" & $\rightarrow \mathrm{IOD}$ \\
\hline Sentença genérica: "Armazenar imagem de MRI" & $\rightarrow$ Classe SOP \\
\hline $\begin{array}{l}\text { Sentença específica: "Armazenar esta imagem de } \\
\text { MRI" }\end{array}$ & $\rightarrow$ Instância da classe SOP \\
\hline
\end{tabular}

Um determinado equipamento, para uma classe SOP em particular, pode exercer um de dois papeis distintos. Como provedor da classe de serviço (SCP service class provider), ele disponibiliza e executa os serviços da classe SOP. Já como

\footnotetext{
*ACR-NEMA DICOM 3.0, Part 4: Service Class Specifications, figura 6-1.
} 
usuário da classe de serviço (SCU - service class user), ele utiliza os serviços. Para cada combinação de classe SOP e papel exercido pelo equipamento, SCP ou SCU, o padrão define um conjunto básico de comportamentos padrões que irão governar a comunicação, como por exemplo, especificar qual equipamento deve começar a comunicação.

As classes SOP são os elementos fundamentais da funcionalidade definida pelo DICOM. Ao especificar a classe SOP a qual um equipamento é compatível e o papel que ele suporta, seja como SCP ou SCU, é possível definir, sem nenhuma ambigüidade, o subconjunto preciso de funcionalidade disponível, incluindo os tipos de mensagem a serem trocadas, os dados a serem transferidos nestas mensagens e o contexto semântico em que os dados devem ser entendidos.

A versão atual do padrão DICOM 3.0 consiste de nove partes, como mostrado na Figura 7. As partes 10 e 11 indicam as próximas extensões ao padrão para suportar a comunicação de arquivos em meios removíveis (discos, fitas, etc.). Atualmente, o padrão suporta apenas serviços de comunicação ponto-a-ponto e por redes, representados na parte esquerda do esquema da Figura 7. Os módulos do lado direito farão parte de futuras versões do padrão. É importante notar que as partes 1, 2, 3, 5 e 6 são utilizadas tanto pelos módulos da parte esquerda quanto pelos módulos da parte direita, como sugere a diagramação em camadas da figura. 
Part 1: 0ueruiew

Part 2: Conformance

\begin{tabular}{|l|l|l|}
\hline $\begin{array}{l}\text { Part 4: } \\
\text { Seruice Class } \\
\text { Specifications }\end{array}$ & $\begin{array}{l}\text { Part 5: } \\
\text { Information 0bjects }\end{array}$ & $\begin{array}{l}\text { Part 1 : } \\
\text { Media Storage } \\
\text { fpplication Profiles }\end{array}$ \\
\hline
\end{tabular}

Part 5: Data Structures and Semantics

Part 6: Data Dictionary

\begin{tabular}{|c|c|c|c|c|}
\hline \multirow{2}{*}{\multicolumn{2}{|c|}{$\begin{array}{l}\text { Part 7: Message Enchange } \\
\text { (Network 0perations) }\end{array}$}} & \multicolumn{3}{|c|}{ Part 10: Media Storage \& File Fonmat } \\
\hline & & Part $X$ & $\mathrm{Par}$ & \\
\hline $\begin{array}{l}\text { art 8: Network } \\
\text { Support } \\
\text { CP/IP \& 0SI }\end{array}$ & $\begin{array}{l}\text { Part 9: } \\
\text { Point } \\
\text { to } \\
\text { Point }\end{array}$ & \multicolumn{3}{|c|}{$\begin{array}{c}\text { Specific Media Formats } \\
|\& \&| \\
\text { Physical Media }\end{array}$} \\
\hline
\end{tabular}

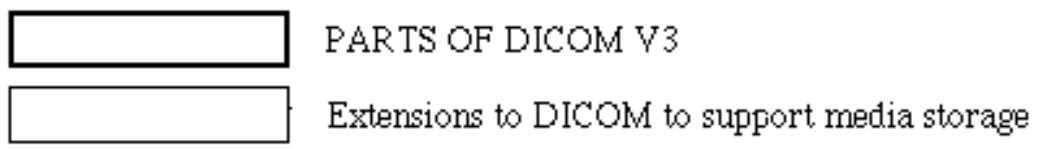

Figura 7 - Partes correntes do padrão DICOM e partes propostas para extensão do padrão."

A tabela a seguir resume o conteúdo de cada parte do padrão:

Tabela 3 - Resumo das partes do padrão DICOM 3.0

\begin{tabular}{ll}
\hline \hline Parte 1: Overview & $\begin{array}{l}\text { Apresentação do padrão, com uma descrição dos princípios de } \\
\text { desenvolvimento utilizados, definição da terminologia e descrição } \\
\text { das demais partes do padrão. }\end{array}$ \\
\hline Parte 2: Conformance & $\begin{array}{l}\text { Define os termos de conformidade com o padrão, indicando } \\
\text { como os fabricantes devem descrever sem ambigüidade como } \\
\text { seus produtos estão em conformidade com o padrão. }\end{array}$ \\
\hline Parte 3: Information & $\begin{array}{l}\text { Descreve como os IOs são definidos e especifica as diversas } \\
\text { classes de IO usadas no padrão. Muitos IODs possuíam grupos } \\
\text { de atributos comuns ou similares, de forma que estes foram } \\
\text { reunidos para criar módulos comuns que podem ser usados por } \\
\text { mais de um IOD. Assim foram criados IODs compostos e IODs } \\
\text { normalizados. }\end{array}$ \\
\hline
\end{tabular}

${ }^{*}$ HORIIL, S.C. et al., figura 4. 


\begin{tabular}{ll}
\hline Parte 4: Service Class & Contém as especificações das classes de serviço, que são: \\
Specifications & Certification Service Class \\
& Storage Service Class \\
& Query/Retrieve Service Class \\
& Study Content Notification Service Class \\
& Patient Management Service Class \\
& Study Management Service Class \\
& Results Management Service Class \\
& Print Management Service Class \\
& \\
\hline Parte 5: Data Structure & Define como um conjunto de informações provenientes de \\
and Semantics & objetos de informação e de classes de serviços devem ser \\
& codificadas para fazerem parte de uma mensagem. \\
\hline Parte 6: Data Dictionary & Fornece uma lista de todos elementos de dados, ou atributos, que \\
& compõe todos os IOs. Para cada elemento de dado é fornecido o \\
& seu código numérico, o seu nome, a sua representação (texto, \\
& número em ponto-flutuante, etc.), a multiplicidade e o domínio \\
& de valores permitidos. \\
\hline Parte 7: Message & Aqui é descrita a dinâmica de comunicação, indicando o que é \\
necessário para uma aplicação interagir no padrão de \\
comunicação do DICOM. Esta parte define como são construídas \\
Operations) & as seqüências de comandos, da mesma forma que a parte 5 define \\
como são construídas as seqüências de dados.
\end{tabular}

A parte 3 do padrão DICOM descreve duas classes de IODs, os compostos e os normalizados. Os primeiros são objetos compostos que contêm todos os atributos que são realmente inerentes a entidade do mundo real correspondente, mais os atributos relacionados e não inerentes. Por exemplo, o IOD para imagem de ressonância magnética possui o atributo "image date", que é inerente a imagem de ressonância magnética, mas ele também possui o atributo "patient name" que é relacionado com este IOD, mas não é inerente a esta entidade. Já os IODs normalizados contêm apenas atributos que são inerentes à entidade em questão. 
Tabela 4 - Lista dos objetos de informação do DICOM

\begin{tabular}{l|l}
\hline \hline \multicolumn{1}{c|}{ IODs compostos } & \multicolumn{1}{c}{ IODs normalizados } \\
\hline Computed Radiography Image & Patient Information \\
Computed Tomography Image & Visit Information \\
Magnetic Resonance Image & Study Information \\
Ultrasound Image & Study Component Information \\
Ultrasound Multi-Frame Image & Results Information \\
Secondary Capture Image & Interpretation Information \\
Stand alone Overlay & Basic Film Session \\
Stand alone Curve & Basic Film Box \\
Basic Study Description & Basic Annotation Presentation \\
Stand alone Modality Lookup Table (LUT) & Basic Print Job Information \\
Stand alone Value of Interest (VOI) LUT & Basic Printer Information \\
& VOI LUT \\
\hline \hline
\end{tabular}

Fonte: Adaptado de HORIIL, S.C. et al., tabela 1.

Cada IOD composto corresponde a um modelo de dados composto que é subparte do modelo geral proposto pelo DICOM. Estes modelos compostos reúnem todas as informações inerentes e relacionadas ao IOD em questão. Desta forma, quando uma instância de um IOD composto é comunicada, todo o contexto de informações relacionadas também é comunicada.

Como exemplo, a Figura 8 a seguir mostra o modelo ER do IOD composto para imagem por ressonância magnética. $\mathrm{O}$ modelo apresenta o conjunto mínimo de entidades, e seus relacionamentos, que foram definidas como fazendo parte do contexto de informação para ressonância magnética. As entidades que estão rachuradas fazem parte do modelo composto geral proposto pelo DICOM 3.0, mas não estão incluídas no modelo composto para MRI. A figura também destaca as módulos que estão presentes nas entidades obrigatórias para MRI e indica a obrigatoriedade da presença de cada módulo. 


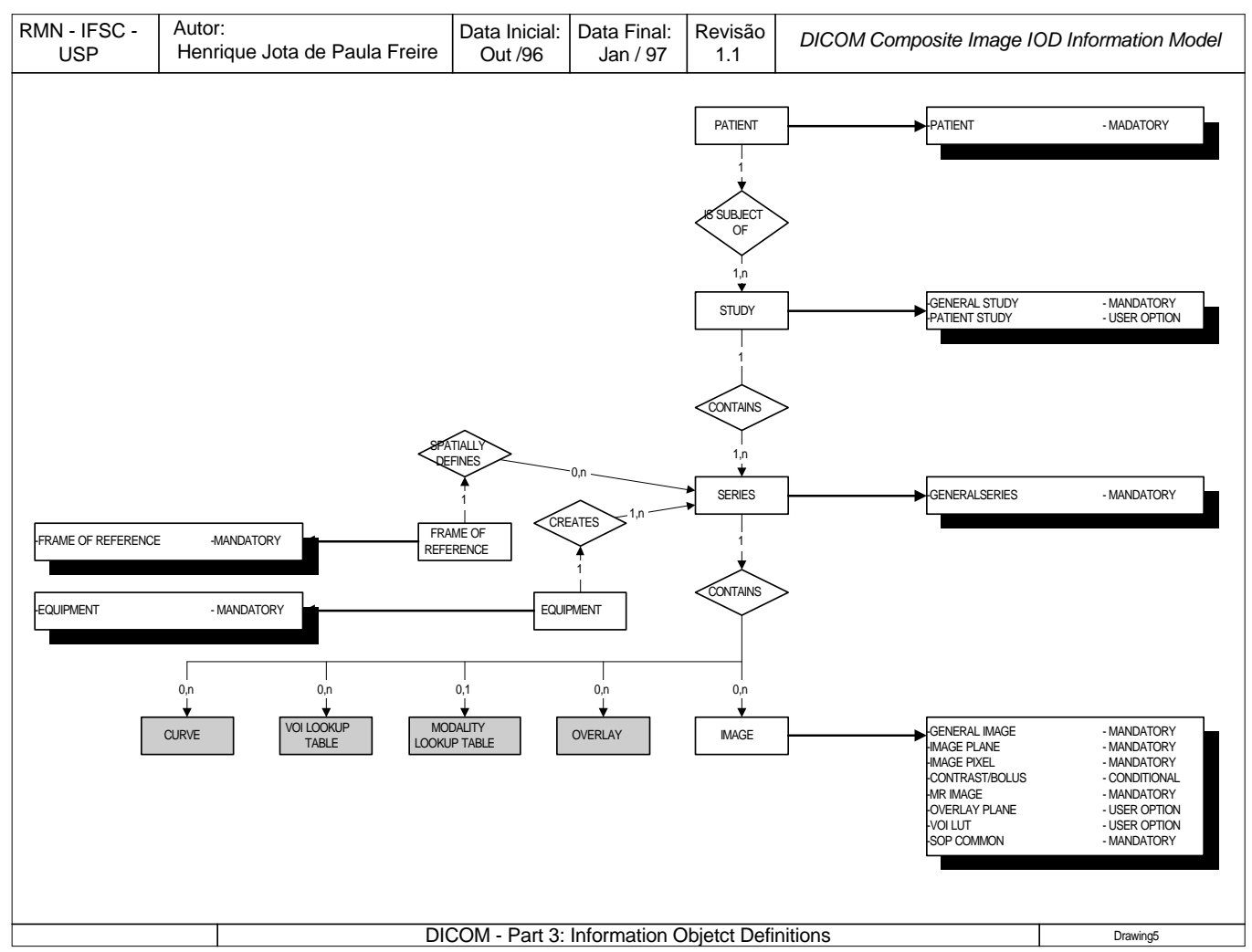

Figura 8 - Modelo ER composto para a modalidade ressonância magnética."

Uma lista completa com todos os módulos que fazem parte do IOD composto para ressonância magnética, bem como as tabelas com as listas de atributos de cada módulo, estão no Apêndice II referente ao padrão DICOM.

A parte 4 do padrão descreve uma classe de serviço que deve ser destacada, pois foi utilizada neste trabalho para definir o mínimo de funcionalidade que o sistema de banco de dados para MRI deveria fornecer. A classe Query/Retrieve Service Class descreve três modelos hierárquicos básicos para consulta aos dados. A tabela a seguir mostra estes três modelos de consulta e os respectivos grupos de serviços e IODs.

\footnotetext{
Figura preparada à partir das informações obtidas em ACR-NEMA DICOM 3.0, Part 3: Information Object Definitions, tabelas A.1.4 e A.4.3 e figura A.1.2.
} 
Tabela 5 - Query/Retrieve Service Class

\begin{tabular}{|c|c|c|}
\hline Service Class: & \multicolumn{2}{|c|}{ Query/Retrieve Service Class } \\
\hline SOP Class & DIMSE service group & IOD \\
\hline $\begin{array}{l}\text { Patient Root } \\
\text { Query/Retrieve } \\
\text { Information Model }\end{array}$ & $\begin{array}{l}\text { DIMSE-C C-FIND } \\
D I M S E-C C-M O V E \\
D I M S E-C C-G E T\end{array}$ & $\begin{array}{l}\text { Patient information level } \\
\text { Study information level } \\
\text { Series information level } \\
\text { Image information level }\end{array}$ \\
\hline $\begin{array}{l}\text { Study Root Query/Retrieve } \\
\text { Information Model }\end{array}$ & $\begin{array}{l}\text { DIMSE-C C-FIND } \\
\text { DIMSE-C C-MOVE } \\
\text { DIMSE-C C-GET } \\
\end{array}$ & $\begin{array}{l}\text { Study information level } \\
\text { Series information level } \\
\text { Image information level }\end{array}$ \\
\hline $\begin{array}{l}\text { Patient/Study Only Root } \\
\text { Query/Retrieve } \\
\text { Information Model }\end{array}$ & $\begin{array}{l}\text { DIMSE-C C-FIND } \\
\text { DIMSE-C C-MOVE } \\
\text { DIMSE-C C-GET } \\
\end{array}$ & $\begin{array}{l}\text { Patient information level } \\
\text { Study information level }\end{array}$ \\
\hline
\end{tabular}

Fonte: Tabela elaborada baseada em ACR-NEMA DICOM 3.0, Part 4: Service Class Specifications, anexo C, seção C.6.

Nesta classe de serviço, o "Information Model" desempenha o papel do IOD.

A figura a seguir mostra o modelo de informação associada a cada classe SOP da classe de serviço Query/Retrieve Service Class. A lista completa de atributos de cada modelo de informação encontra-se no apêndice relativo ao padrão DICOM. Note que, para esta classe de serviço, cada modelo de informação desempenha o papel de IOD. 


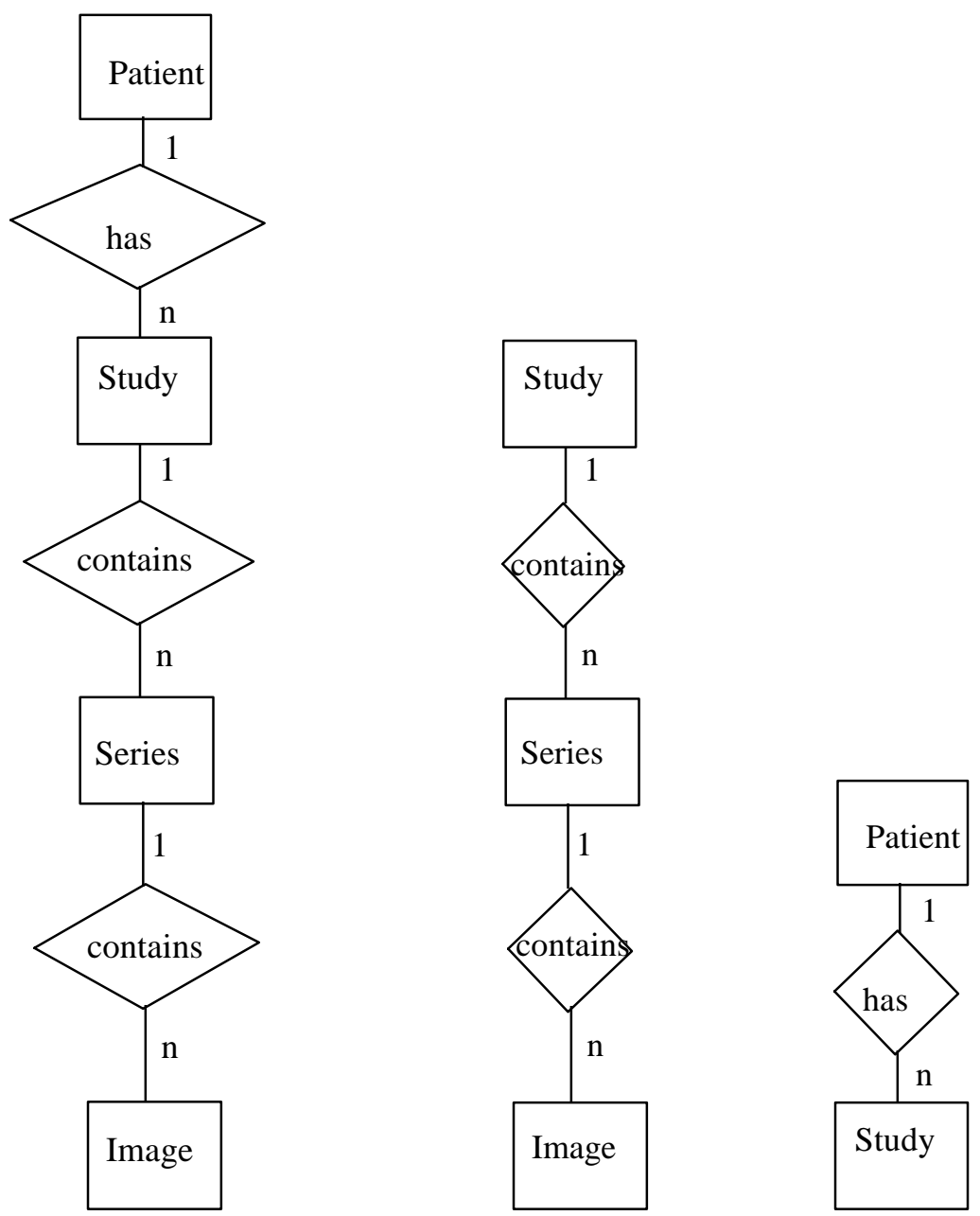

Figura 9 - Modelos ER das classes SOP da classe de serviço Query/Retrieve Service Class."

Os serviços usados pelas três classes SOP da classe de serviço Query/Retrieve Service Class são:

- DIMSE-C C-FIND: O serviço C-FIND é invocado por um SCU com o objetivo de comparar o conteúdo de uma série de atributos por ele definido com os atributos de instâncias de SOPs armazenados em um SCP. O serviço C-FIND retorna a lista de atributos encontrados e seus respectivos valores;

- DIMSE-C C-MOVE: O serviço C-MOVE é invocado por um SCU para mover informações de uma ou mais instâncias de SOPs compostos do SCP para um terceiro SCP. A seleção é baseada em atributos fornecidos pelo SCU;

\footnotetext{
* Baseada em ACR-NEMA DICOM 3.0, Part 4: Service Class Specifications, figuras C.6.1.1.1-1, C.6.2.1.1-1 e C.6.3.1.1-1.
} 
- DIMSE-C C-GET: O serviço C-GET é invocado pelo SCU para receber informações sobre uma ou mais instâncias de SOPs compostos armazenados no SCP. A seleção é baseada em atributos fornecidos pelo SCU.

As especificações detalhadas dos serviços estão na parte 7 do padrão. A indicação DIMSE-C em cada um dos serviços acima significa que eles são aplicáveis apenas a IODs compostos. Os serviços DIMSE-C executam apenas operações, ao contrário de serviços do tipo DIMSE-N, aplicáveis a IODs normalizados, que realizam operações e notificações.

A versão 3.0 do padrão DICOM é essencialmente voltada para comunicação entre equipamentos, seja através de redes ou por ligações ponto-a-ponto. A idéia é que cada equipamento pode usar os seus próprios padrões e formatos para armazenar e gerenciar os seus dados, mas quando se deseja comunicar com outros equipamentos, torna-se importante a existência de uma linguagem comum que equipamentos de diversos fabricantes sejam capazes de entender. Por outro lado, muitos laboratórios ou centros de diagnóstico não operam em rede e os resultados muitas vezes devem mostrados de maneira especial para especialistas externos, como por exemplo, um conjunto de imagens cardíacas apresentadas em forma de cinema. Para estes casos, surge a necessidade de armazenar as informações em meios físicos removíveis para que ela possa ser transportada. Um primeiro passo para atender esta necessidade foi a criação da parte número 10 do padrão, que faz descrições genéricas de estruturas de arquivos e diretórios para meios físicos removíveis, além de serviços básicos de gerenciamento dos arquivos. Para especificar completamente o armazenamento em meios removíveis, ainda estão sendo elaboradas as partes 11 e 12 . A parte 11 irá exercer um papel semelhante à parte 4 do padrão. Já a parte 12 irá especificar os detalhes de armazenamento em cada tipo de meio físico escolhido para fazer parte do padrão, como por exemplo disquetes, CD-R, fitas, etc. 


\subsection{Sistema de banco de dados}

\subsubsection{Introdução}

Um banco de dados (BD) é uma coleção lógica e coerente de dados relacionados e que possuem um significado implícito. Ele é projetado, construído e preenchido para um propósito específico, sendo direcionado para um grupo definido de usuários que, por sua vez, possui um conjunto preestabelecido de aplicações para os dados em questão. Um banco de dados representa alguns aspectos do mundo real, que é a sua fonte de dados, e é chamado de minimundo. Através de uma interação com eventos o mundo real, mudanças no minimundo são refletidas no banco de dados. ${ }^{13}$

Bancos de dados podem ser de diversos tamanhos e variar em complexidade. Uma agenda de telefones pessoal é um pequeno banco de dados se comparado com a lista telefônica de uma grande metrópole. Por outro lado, estes dois bancos de dados são relativamente simples, pois possuem poucos tipos de informações (nomes, endereços e telefones) que são, geralmente, organizados por ordem alfabética dos nomes. Um banco de dados de imagens médicas, como, por exemplo, o de um hospital como o da Tabela 1, já é um grande e complexo banco dados, devido, respectivamente, ao grande volume de dados e à diversidade e complexidade de dados e relacionamentos entre dados existente.

A criação e manutenção de bancos de dados computadorizados podem ser feitas por um grupo de programas aplicativos escritos especialmente para esta tarefa, ou por um sistema de gerenciamento de banco de dados (SGBD), que é um conjunto de programas de propósito geral que facilita na tarefa de definir, construir e manipular bancos de dados. A definição de um BD consiste em especificar os tipos de 
dados a serem armazenados, bem como descrever detalhadamente cada tipo de dado. A construção do BD é o processo de armazenar os dados propriamente ditos em algum meio físico controlado pelo SGBD. A manipulação de um BD possibilita ao usuário procurar, recuperar e atualizar os dados.

Desta forma, além do próprio BD, geralmente há uma quantidade considerável de programas utilizados para implementar e manipular o BD, sejam eles partes de um SGBD de propósito geral, ou programas especialmente escritos para uma determinada aplicação. À união destes programas com o banco de dados se dá o nome de sistema de banco de dados (SBD).

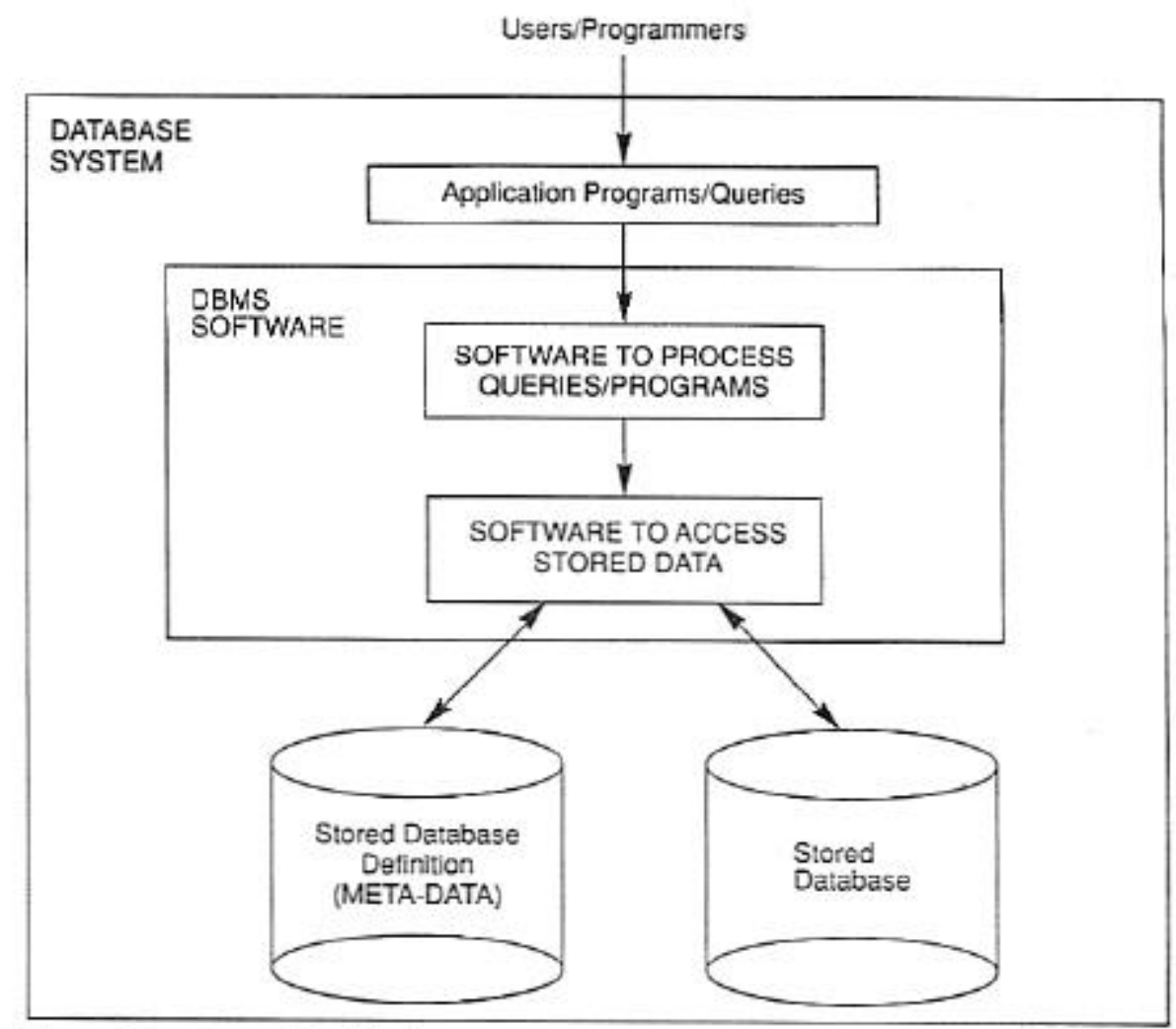

Figura 10 - Esquema básico da estrutura de um SBD.*

\subsubsection{Vantagens sobre método tradicional de armazenamento}

O método tradicional de armazenamento de dados baseia-se no processamento de arquivos, sejam eles computadorizados ou não. No caso em que computadores são usados, programas aplicativos específicos para cada tarefa são utilizados para lidar

\footnotetext{
*ELMASRI, R.; NAVATHE, S.B., 1989, p.5.
} 
com os arquivos, e cada usuário mantém o seu próprio conjunto de arquivos com as informações que lhe são necessárias. É comum, nesta abordagem, que diferentes usuários armazenem e gerenciem dados comuns, acarretando, assim, redundâncias desnecessárias e, conseqüientemente, desperdício de espaço de armazenamento e esforço adicional para manter informações comuns atualizadas. Já com a utilização de bancos de dados, um repositório único de dados é utilizado por vários usuários.

Uma característica fundamental de um SBD é que ele possui, além dos dados armazenados, uma descrição completa do BD. As estruturas de cada arquivo, os tipos de dados, os formatos de armazenamento e as várias restrições que devem ser impostas aos dados, informações estas chamadas de meta-dados, são armazenadas no catálogo de dados. O SGBD e, ocasionalmente, os usuários, utilizam o catálogo de dados para obter informações sobre a estrutura do BD. Desta forma, os programas que compõem o SGBD não são feitos para atender uma aplicação de banco de dados específica, mas, utilizando os catálogos de cada BD, eles podem ter acesso e manipular diversos bancos de dados. $\mathrm{Na}$ abordagem tradicional de processamento de arquivos, cada aplicativo define internamente a estrutura dos arquivos de dados com o qual ele trabalha. Desta forma, o aplicativo só é capaz de trabalhar com arquivos de dados próprios, e outros aplicativos não são capazes de ter acesso e manipular os seus dados.

$\mathrm{Na}$ abordagem tradicional, a estrutura dos arquivos está embutida nos programas. Se é necessário alterar o formato de um arquivo, para, por exemplo, adicionar um novo campo, é necessário alterar todos os programas que trabalham com este arquivo. Por outro lado, usando a abordagem de SBD, sendo o SGBD feito independente dos arquivos que ele terá acesso, só é necessário alterar o catálogo de dados e, automaticamente e sem que nenhum programa tenha que ser alterado e recompilado, a mudança no banco de dados é feita. Esta é uma outra caraterística importante de SBD, chamada de independência entre programas e dados.

Ao se utilizar um SBD, os detalhes da estrutura e organização dos arquivos do BD ficam armazenados no catálogo de dados e são transparentes para o usuário. O SGBD fornece ao usuário uma representação conceitual dos dados que não inclui os detalhes de implementação. Esta representação conceitual é obtida a partir de uma 
abstração de dados, chamada modelo de dados, que utiliza conceitos lógicos como, por exemplo, objetos, propriedades e relacionamentos. Esta abstração de dados através de modelos de dados facilita o entendimento do usuário, deixando, assim, os detalhes de armazenamento para o SGBD e o catálogo de dados.

Um banco de dados possui, em geral, vários usuários, cada um com interesses específicos e, conseqüientemente, com uma perspectiva ou visão diferente do banco de dados. Esta visão pode ser um subconjunto do banco de dados ou dados virtuais, que são calculados à partir dos dados existentes no $\mathrm{BD}$, mas que não são armazenados. Um SGBD para múltiplos usuários é, em geral, capaz de proporcionar aos usuários e suas aplicações a possibilidade de definir diferentes visões sobre os dados.

\subsubsection{Desenvolvedores, administradores e usuários}

Para pequenos bancos de dados, geralmente uma única pessoa define e constrói o banco de dados, e, muitas vezes, esta mesma pessoa é a única usuária direta do banco de dados. Já em casos de bancos de dados maiores, em geral existem várias pessoas envolvidas diretamente com as atividades de desenvolvimento, utilização e manutenção. Os principais grupos de pessoas são os administradores, os desenvolvedores, os analistas de sistemas, os programadores de aplicação e os usuários finais.

Os administradores de bancos de dados são responsáveis por autorizar o acesso ao $\mathrm{BD}$, coordenar e monitorar o uso e providenciar soluções para os problemas que surgem. Em casos de grandes BD, os administradores coordenam uma equipe de operadores e pessoal de manutenção que realizam as tarefas necessárias para manter o SBD funcionando. Os desenvolvedores, à partir de um estudo detalhado das necessidades dos usuários, identificam os dados que devem fazer parte do $\mathrm{BD}$, escolhem as estruturas apropriadas para representar e armazenar os dados e implementam o BD. Os analistas de sistemas são responsáveis por determinar os requisitos dos usuários finais, principalmente daqueles que utilizam sistematicamente o BD, e, então, desenvolvem especificações para as transações que atendam os requisitos dos usuários. O programadores de aplicação implementam as especificações na forma de programas que são usados pelos usuários. O trabalho, tanto dos analistas, 
quanto dos programadores de aplicação, é sobre o BD já existente, utilizando para isso o SGBD para criar várias visões distintas do BD apropriadas para cada grupo de usuários.

Os usuários finais são aqueles cujas atividades requerem que eles tenham acesso ao BD para realizar consultas, atualizações e gerar relatórios. Existem três tipos básicos de usuários finais:

- paramétricos ou inexperientes: correspondem à maioria dos usuários de BD. Suas transações são padrões (transações canônicas), bem programadas e testadas, e os usuários precisam aprender pouco sobre o SGBD para efetuar as transações;

- casuais: têm acesso ao BD ocasionalmente, mas a cada momento necessitam diferentes tipos de informação. Eles utilizam vários recursos do SGBD para atingir seus objetivos;

- sofisticados: são usuários que conhecem em detalhes os recursos e as limitações do SGBD, e utilizam-se deste conhecimento para executar procedimentos complexos no BD.

Em geral, os SGBD proporcionam várias formas de acesso ao $\mathrm{BD}$, satisfazendo, assim, os requisitos dos vários tipos de usuários. Em especial, o SGBD MS Access 2.0, utilizado neste trabalho, possibilita a criação de formulários e relatórios padrões que atendem às necessidades de usuários paramétricos; ele possui recursos de busca e filtros para usuários casuais; e possibilita que usuários sofisticados utilizem todos os seus recursos, até mesmo de programação, para executar tarefas complexas.

\subsubsection{Características do SGBD}

Um SGBD deve possuir uma série de características necessárias para atingir vários objetivos relacionados com projeto, administração e uso de grandes bancos de dados multiusuários. Muitas destas características não são possíveis na forma tradicional de processamento de arquivos, e as principais são descritas à seguir.

Controle de redundâncias. Um projeto de banco de dados deve colocar cada elemento lógico de informação em um único lugar, fazendo com que não haja 
nenhuma redundância e, consequientemente, eliminando a possibilidade de inconsistências e desperdícios de espaço de armazenamento. Em alguns casos, é importante que alguma redundância exista, mas o SGBD deve ser capaz de controlar estas redundâncias e impor automaticamente que a integridade e a consistência dos dados seja mantida.

Compartilhamento de dados. Um SGBD multiusuário deve possibilitar e controlar o acesso ao BD de vários usuários ao mesmo tempo, possibilitando, assim, que diversos usuários tenham acesso ao mesmo dado, mas de uma maneira controlada.

Restrição de acesso aos dados. Em bancos de dados com muitos usuários, em geral, nem todos podem ter acesso a todos os dados contidos no BD, e o tipo de acesso permitido para cada grupo de usuários (apenas consulta, atualização, etc.) pode ser diferente. O SGBD deve permitir que o administrador do banco de dados defina os vários tipos de restrição de acesso aos dados.

Interfaces múltiplas com o usuário. Devido à existência de vários tipos de usuários com conhecimento técnico variável e com diferentes necessidades, o SGBD deve proporcionar vários tipos de interfaces com o usuário. Os tipos de interfaces com o usuário podem ser: linguagens de consulta, que podem ser usadas por usuários casuais; linguagem de programação para programadores; formulários para usuários paramétricos; menus para usuários inexperientes; e interfaces de linguagem natural. Os principais tipos de linguagens existentes são:

- linguagem de definição de dados (DDL - Data Definition Language);

- linguagem de definição de armazenamento (SDL - Storage Definition Language);

- linguagem de definição de visões (VDL - View Definition Language);

- linguagem de manipulação de dados (DML - Data Manipulation Language).

Em geral, as linguagens existentes misturam as características dos vários tipos acima, como, por exemplo, a linguagem SQL, que é uma DDL e DML ao mesmo tempo, além de incorporar funções para também servir de VDL. 
Geralmente, os SGBD colocam a disposição do usuários vários tipos de interfaces com usuário, dependendo do usuário e da tarefa a ser realizada. Os principais tipos de interfaces com usuário são:

- interface baseada em menus;

- interfaces gráficas;

- interfaces baseadas em formulários;

- interfaces de linguagem natural;

- interfaces dedicadas para usuários paramétricos;

- interfaces especiais para administradores de banco de dados.

Representação de relacionamentos complexos entre dados. Muitos dos dados existentes em BDs são interrelacionados de várias formas. O SGBD deve ser capaz de representar complexos relacionamentos inerentes aos dados, bem como proporcionar consultas e atualizações de dados relacionados de maneira fácil e eficiente.

Restrições para garantia de integridade. A maioria de aplicações de banco de dados possuem restrições que devem ser obedecidas para manter a integridade de seus dados. Existem vários tipos de restrições possíveis, e os SGBD existentes variam bastante no conjunto de restrições que cada um é capaz de garantir. Um tipo de restrição comum é que cada item de dados deve possuir um tipo de dado específico. Outro tipo se refere a registros que são relacionados a outros registros. Algumas destas restrições podem ser garantidas automaticamente pelo SGBD; para outras devem ser criados programas específicos para atualização de dados que verifiquem se a integridade dos mesmos está sendo mantida.

Cópias de segurança e recuperação de dados. O SGDB deve ser capaz de recuperar os dados nos casos em que ocorrerem falhas de programas ou de equipamento. Se alguma falha ocorre durante alguma operação, o SGBD deve restabelecer o estado do BD anterior a esta operação. Em casos mais extremos cópias de segurança do BD também devem ser disponibilizadas. 


\subsubsection{Outras características}

Além das várias características já citadas sobre BD e SGBD, a utilização de SBD proporciona várias outra vantagens, entre elas:

- padronização: a utilização de um $\mathrm{BD}$ centralizado permite que haja uma padronização entre os usuários em uma grande organização, facilitando a comunicação e cooperação entre departamentos, projetos e usuários;

- flexibilidade: vários SGBD permitem que sejam feitas mudanças na estrutura do BD para atender novos requisitos, sem que isto afete os vários programas aplicativos já existentes;

- redução do tempo de desenvolvimento de aplicações: o tempo de desenvolvimento de aplicações baseadas em um BD já em funcionamento é bastante inferior ao desenvolvimento de aplicações semelhantes que utilizam o sistema tradicional de processamento de arquivos;

- disponibilidade de informações atualizadas: à medida que os dados são inseridos e atualizados pelos usuários, estas informações são imediatamente colocadas à disposição de todos os outros usuários;

- economia em escala: a utilização de SBD para a consolidação dos dados de grandes organizações permite que as várias atividades relacionadas com o armazenamento e gerenciamento de dados sejam realizadas de maneira mais eficiente.

Apesar das várias vantagens obtidas com o uso de SBD, há também casos em que sua utilização não é recomendável, sendo melhor optar pelo sistema tradicional de processamento de arquivos ou outra solução. De uma forma geral, as seguintes situações, ou combinações delas, requerem esta abordagem:

- o banco de dados e as aplicações correspondentes são simples, bem definidas e não se espera que mudem;

- existem restrições rigorosas em requisitos de aplicações de tempo real que não podem ser garantidos pelo SGBD;

- o acesso múltiplo de usuários não é necessário. 


\subsubsection{Conceitos principais}

Uma das principais características da utilização de bancos de dados é a abstração de dados, já mencionada anteriormente (Item 2.4.1.1), onde os detalhes do armazenamento dos dados são transparentes para os usuários. A abstração de dados é obtida a partir de modelos de dados que são conjuntos de conceitos usados para se definir a estrutura do banco de dados e, em alguns casos, descrever as operações que podem ser realizadas.

Existem vários modelos de dados propostos e que variam bastante no nível de abordagem que oferecem para descrever a estrutura de bancos de dados. Os modelos de dados de alto nível, ou conceituais, fornecem conceitos que são bem próximos da maneira que os usuários vêem os dados. Os principais conceitos são:

- entidade: objeto que é representado no BD;

- atributo: propriedade que descreve algum aspecto do objeto;

- relacionamento: associação entre objetos.

Um exemplo de modelo de dados conceitual bastante popular, e que será descrito em detalhes mais adiante nesta seção, é o modelo Entidade-relacionamento.

Outro tipo de modelo de dados é o de baixo nível, ou físico. Ele possui elementos que descrevem em detalhes como os dados são armazenados fisicamente no computador.

Um tipo de modelo de dados intermediário entre os dois apresentados acima é o de implementação. Este tipo de modelo de dados reflete a estrutura física em que o BD vai ser implementado, sem entrar em detalhes, e ainda proporciona uma visão da estrutura do BD que é próxima do entendimento dos usuários. Os modelos de dados de implementação mais conhecidos são o relacional, de rede e o hierárquico. Os modelos de dados de implementação são úteis pois podem ser implementados de forma bastante direta.

O principal critério usado para classificar SGBD é o modelo de dados no qual ele é baseado. Os principais modelos de dados usados por sistemas comerciais são os de implementação mencionados acima. O modelo relacional, que será apresentado em 
mais detalhes adiante e é o modelo de implementação utilizado neste trabalho, representa o $\mathrm{BD}$ como uma coleção de tabelas que se parecem com arquivos. $\mathrm{O}$ modelo de rede representa os dados em registros e os relacionamentos 1:N entre tipos de registros diferentes em estruturas chamadas de conjuntos. $\mathrm{O}$ modelo hierárquico representa os dados na forma de estruturas de árvores hierárquicas, onde cada hierarquia representa um conjunto de registros relacionados.

Uma distinção importante a ser feita é entre a descrição do banco de dados e o banco de dados propriamente dito. A descrição do $\mathrm{BD}$, chamada de esquema, é feita durante o projeto do $\mathrm{BD}$ e espera-se que ela não mude com o decorrer do tempo. A maioria dos modelos de dados possuem convenções para desenhar os esquemas utilizando diagramas, mas estes diagramas dos esquemas mostram apenas alguns aspectos do esquema, como nomes de entidades e seus atributos, e não são capazes de representar outros aspectos, como restrições existentes nos dados.

Já o banco de dados propriamente dito é formado pelo conjunto de todos os dados armazenados nele, chamado de instância do banco de dados. A cada alteração feita no BD, como a inserção de um novo dado, uma nova instância do BD é criada.

Desta forma, o processo de definição do BD significa especificar para o SGDB o esquema do banco de dados, informação esta que é armazenada no catálogo de dados. Inicialmente tem-se uma instância vazia do BD. À medida que novos dados são armazenados no BD, novas instâncias vão sendo criadas, ficando a cargo do SGBD garantir que estas instâncias satisfaçam a estrutura e as restrições definidas no esquema.

Uma arquitetura genérica para sistemas de banco de dados é utilizada com o objetivo de fazer com que estes sistemas possuam três importantes características já mencionadas: independência entre programas e dados; suporte a múltiplas visões dos dados; e utilização do catálogo de dados para armazenar o esquema do BD. Esta arquitetura, chamada de arquitetura dos três esquemas ou arquitetura ANSI/SPARC, separa as aplicações, usadas pelos usuários, do BD físico. Os três níveis desta arquitetura são: 
1. Nível interno: descreve a estrutura de armazenamento físico do BD utilizando um modelo de dados físico;

2. Nível conceitual: descreve a estrutura de todo o BD sem os detalhes de implementação utilizando um modelo de dados conceitual ou de implementação;

3. Nível externo: inclui vários esquemas externos que correspondem às visões de diferentes grupos de usuários sobre os dados. Cada visão, em geral, descreve uma parte do BD para os usuários e esconde o restante. Os esquemas deste nível são descritos utilizando modelos de dados conceituais ou de implementação.

Esta arquitetura fornece múltiplas visões dos dados através do nível externo e utiliza o catálogo de dados para armazenar o esquema físico do nível interno. A independência de dados ocorre quando a alteração do esquema em um nível não acarreta mudanças no nível superior.

\subsubsection{Modelagem de dados}

O processo de projeto e implementação de um banco de dados é composto por várias etapas, descritas simplificadamente na Figura 11. O primeiro passo, a coleção e a análise de requisitos, consiste no levantamento e na organização detalhada dos requisitos de dados dos usuários. Ela é feita através de entrevistas com usuários, estudo do sistema atual que será substituído pelo novo, etc. 
Phase 1: REQUIREMENTS
COLLECTION AND ANALYSIS

Phase 3: CHOICE OF DBMS

Phase 4: DATA MODEL MAPPING (LOGICAL DESIGN)

Phase 6: IMPLEMENTATION

Phase 5: PHYSICAL

DESIGN

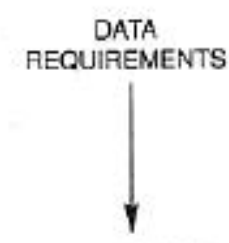

CONCEPTUAL\&

EXTEANAL

SCHEMADESIGN

(DBMS-independent]

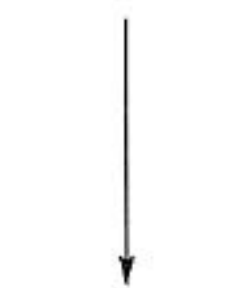

CONCEPTUAL \&

EXTERNAL.

SCHEMADESIGN

(DBMS-dependent)

Figura 11 - Fases do projeto de um banco de dados."

À partir dos requisitos levantados, o próximo passo é criar um esquema conceitual usando, preferencialmente, um modelo de dados conceitual de alto nível. Este processo é chamado de projeto conceitual do banco de dados. O esquema conceitual resultante é uma descrição concisa dos requisitos de dados de todos os usuários e contém descrições detalhadas dos tipos de dados, relacionamentos e restrições aos dados. Estas descrições são feitas utilizando-se os conceitos disponíveis no modelo de dados de alto nível e, como neste tipo de modelo os conceitos não possuem detalhes de implementação, o esquema conceitual é geralmente mais fácil de se entender e, por isso, serve para uma comunicação adequada com os usuários. $\mathrm{O}$ esquema conceitual pode ser usado para verificar se todos os requisitos dos usuários são satisfeitos e se eles não incluem qualquer tipo de conflito. Nesta fase de

* ELMASRI, R.; NAVATHE, S.B., 1989, p.459. 
elaboração do modelo conceitual do $\mathrm{BD}$, os desenvolvedores podem se concentrar na tarefa de especificar as propriedades dos dados sem ter que se preocupar com os detalhes de armazenamento.

O próximo passo no desenvolvimento de um BD é a implementação do banco de dados utilizando um SGBD. Como a maioria dos SGBDs usam um modelo de dados de implementação, o esquema conceitual deve ser transformado do modelo de alto nível para o modelo de dados de implementação do SGBD. Este processo é chamado de mapeamento do modelo de dados.

O último passo é o projeto físico do banco de dados, onde são especificados os detalhes de armazenamento, como as estruturas de armazenamento e a organização de arquivos do banco de dados.

O modelo de dados conceitual de alto nível usado neste trabalho foi o modelo Entidade-relacionamento Estendido (EER - Enhanced Entity-relationship). Este modelo é uma extensão do popular modelo de dados Entidade-relacionamento (ER Entity-relationship), em que são incluídos novos conceitos semânticos. Este modelo foi mapeado para o modelo de dados relacional, que é o modelo de implementação existente no SGBD MS Access 2.0 usado neste trabalho. O projeto físico do BD restringiu-se à definição da estrutura de arquivos que o SGBD deveria criar, já que os detalhes da implementação do BD ficava a cargo do próprio SGBD.

O modelo de dados ER é descrito no próximo item desta seção. Em seguida, é descrito o modelo EER, que é uma extensão do modelo ER. Na última parte da seção, são descritos o modelo relacional de dados e o processo de mapeamento do modelo ER e EER para o modelo relacional.

\subsubsection{Modelo de dados ER}

\subsubsection{Conceitos básicos do modelo ER}

O principal objeto do modelo ER é a entidade, que é algo do mundo real que possui existência própria. Ela pode ser um objeto físico (pessoas, imagens, bobinas, etc.) ou conceitual (estudos, séries, visitas, etc.). Cada entidade possui propriedades que a descrevem e que são chamadas de atributos. Cada entidade em particular possui 
valores para cada um dos seus atributos, e são estes valores dos atributos que constituem a maior parte dos dados que são armazenados em um banco de dados.

Alguns atributos podem ser divididos em subpartes menores com significados próprios e independentes, como no caso de um endereço residencial, que pode ser dividido em, por exemplo, "Endereço", "Cidade", "Estado" e "CEP". Um atributo formado pela união de atributos mais simples é chamado de composto, enquanto que um atributo que não é divisível em partes menores é chamado de simples ou atômico. Os atributos compostos são úteis quando os usuários ora referem-se ao atributo composto como sendo uma unidade, ora referem-se às partes do atributo individualmente. $\mathrm{O}$ valor do atributo composto é a concatenação dos valores dos atributos simples que o forma.

A maioria dos atributos admitem apenas um valor e são chamados de atributos singelos. Por exemplo, o atributo "Idade de uma pessoa", pois cada pessoa possui apenas uma idade. Existem casos em que atributos podem ter mais de um valor e eles são, então, chamados de atributos múltiplos. Como exemplo, uma imagem de ressonância pode ser obtida a partir de mais de um eco e, conseqüentemente, o atributo "NúmeroDoEco" deve possuir os vários números correspondentes aos ecos usados. Para os atributos múltiplos, podem ser especificadas as quantidades mínimas e máximas de valores que o atributo de uma entidade pode possuir.

Em alguns casos, os valores de dois ou mais atributos podem estar associados. É o caso, por exemplo, de "Idade" e "DataDeNascimento", em que o valor do atributo "Idade" pode ser calculado à partir da "DataDeNascimento" e da data atual. Neste caso, "Idade" é chamado de atributo derivado e diz-se, então, que ele é derivado de o atributo "DataDeNascimento". Já alguns outros valores de atributos são derivados de entidades relacionadas, como, por exemplo, o número de imagens de uma série, que é calculado contando-se o número de imagens existentes que são relacionadas a uma série específica.

Em alguns casos, pode acontecer que não exista um valor para o atributo de uma entidade, seja porque este valor é desconhecido, ou porque este atributo não é aplicável ao caso específico da entidade. Nestes casos, é então utilizado um valor especial chamado de nulo. 


\subsubsection{Tipos de entidade, conjunto de valores e atributos chave}

Um banco de dados normalmente possui grupos de entidades que são similares, compartilhando os mesmos atributos, mas com valores distintos para os atributos de cada entidade. Estas entidades similares são chamadas de tipo de entidade e são descritas por um nome e uma lista de atributos. A descrição de um tipo de entidade é chamada de esquema do tipo de entidade e especifica a estrutura comum compartilhada pelas entidades individuais do tipo correspondente. $\mathrm{O}$ esquema possui o nome do tipo de entidade, o nome e o significado dos seus atributos, e qualquer restrição que deve existir nos valores dos atributos das entidades individuais. O conjunto de instâncias de entidades individuais em um determinado momento é chamado de extensão do tipo de entidade. O esquema não muda com freqüência, mas a cada momento que é adicionada ou removida uma entidade, uma extensão diferente daquele tipo de entidade é criada.

Geralmente um tipo de entidade possui um atributo cujos valores são distintos em cada entidade individual. Este atributo é chamado de atributo chave, e seus valores são usados para identificar unicamente cada entidade. Algumas vezes, vários atributos formam uma chave, o que significa que a combinação dos valores destes atributos deve ser distinta para cada entidade. O conjunto de atributos com esta propriedade pode ser agrupado para formar um atributo composto que será, por sua vez, um atributo chave do tipo de entidade. Um tipo de entidade pode possuir mais de um atributo que seja chave.

A cada atributo simples de um tipo de entidade está associado um domínio, que é o conjunto de valores que podem ser atribuídos ao atributo para cada entidade individual. Por exemplo, como a idade de uma pessoa não pode ser negativa, pode-se determinar que o domínio para o atributo "Idade" são os números maiores que zero.

\subsubsection{Relacionamentos, papeis e restrições estruturais}

A maioria dos bancos de dados possuem vários tipos de entidade e, além dos valores dos atributos das entidades que pertencem a cada tipo de entidade, existem relacionamentos entre as entidades. 
Um tipo de relacionamento é um conjunto de associações entre tipos de entidade. Cada uma destas associações, chamadas de instâncias de relacionamento, inclui exatamente uma entidade de cada tipo de entidade participante. Cada instância de relacionamento representa o fato que entidades que participam do relacionamento estão relacionadas de alguma forma no minimundo correspondente. A figura a seguir exemplifica um relacionamento onde instâncias do tipo de entidade "IMAGEM" estão relacionadas a instâncias do tipo de entidade "AQUISIÇÃO" através do tipo de relacionamento "POSSUI".

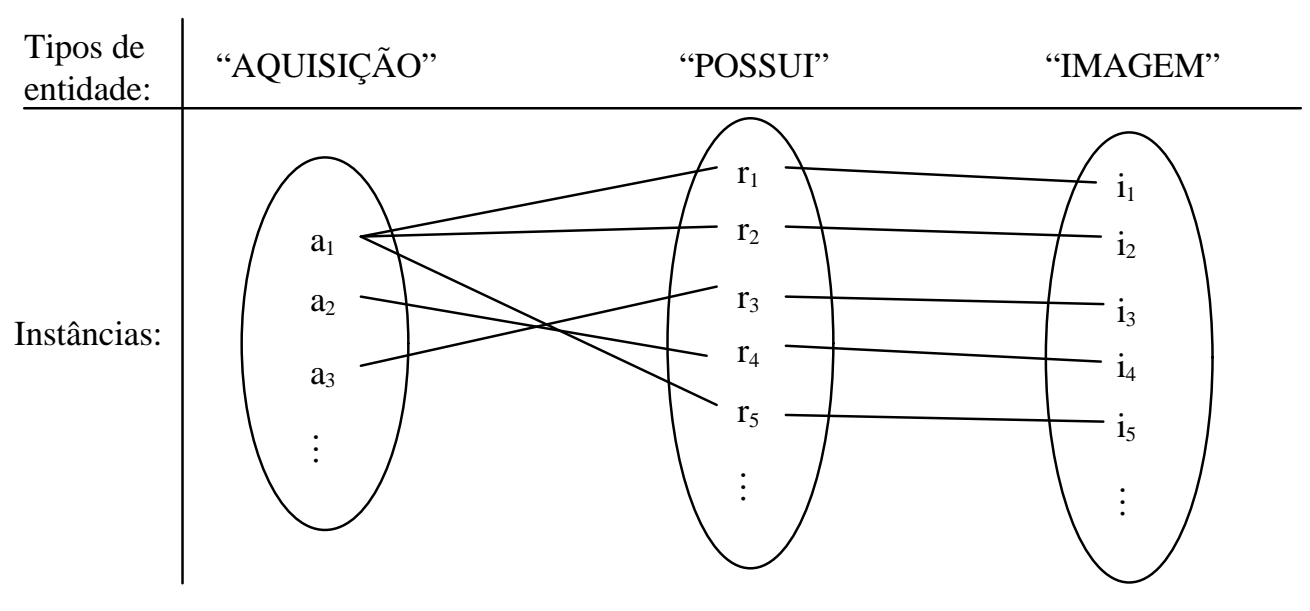

Figura 12 - Exemplo de relacionamento entre entidades.

O grau de um tipo de relacionamento é igual ao número de tipos de entidade participantes. O exemplo da Figura 12 corresponde a um relacionamento binário. Se houver três tipos de entidade, o relacionamento será terciário, e assim sucessivamente.

Algumas vezes é conveniente representar os tipos de relacionamento como sendo atributos do tipo de entidade. No caso do exemplo da Figura 12, o tipo de entidade "IMAGEM" poderia possuir um atributo "Aquisição" cujo valor para cada imagem seria a aquisição da qual ela faz parte. Desta forma, o domínio para o atributo "Aquisição" é o conjunto de todas as entidades aquisição, que é o próprio tipo de entidade "AQUISIÇÃO”.

Cada tipo de entidade que participa em um tipo de relacionamento exerce um papel particular no relacionamento. $O$ nome do papel significa o papel que a entidade participante exerce em cada instância do relacionamento. O nome do papel é 
importante principalmente quando um tipo de entidade participa mais de uma vez no tipo de relacionamento em papeis diferentes. Este tipo de relacionamento é chamado de recursivo e é exemplificado na Figura 13, onde o tipo de relacionamento "DERIVAÇÃO" relaciona imagens originais e imagens derivadas das originais. Assim, o tipo de entidade imagem participa duas vezes em "DERIVAÇÃO”: uma vez no papel de "Original" (linha sólida) e outra vez no papel de "Derivada" (linha pontilhada). Cada instância de relacionamento $r_{i}$ associa duas imagens $i_{j}$ e $i_{k}$, uma no papel de "Original" e outro no papel de "Derivada".

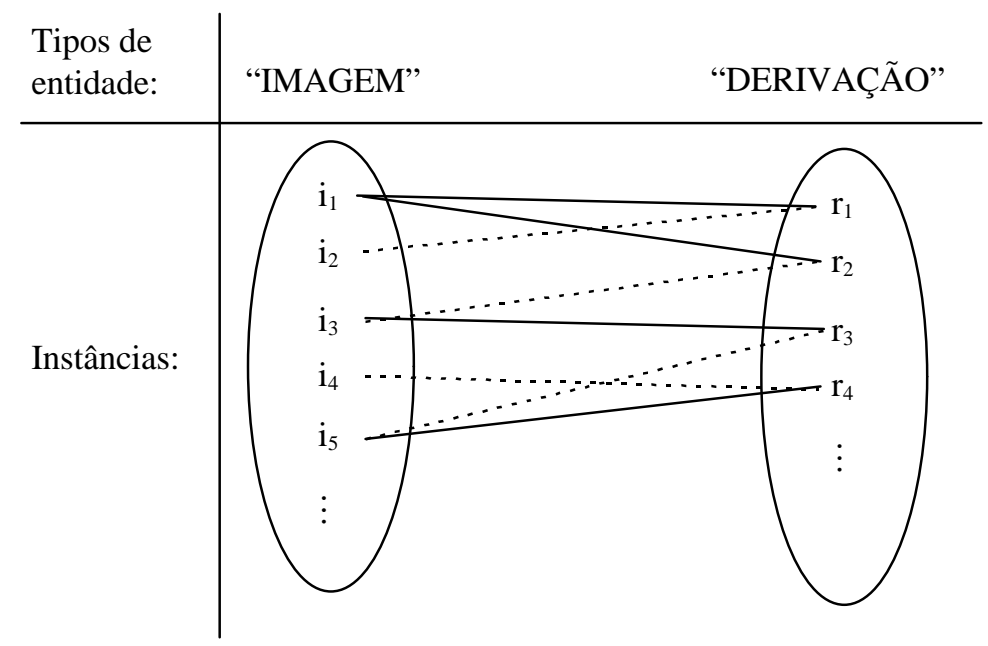

Figura 13 - Exemplo de relacionamento recursivo.

Tipos de relacionamento normalmente possuem restrições que limitam as possíveis combinações de entidades que participam das instâncias de relacionamento. Estas restrições são determinadas à partir do minimundo que os relacionamentos representam e existem dois tipos principais e mais comuns: razão de cardinalidade e restrição de participação, chamadas conjuntamente de restrições estruturais.

A razão de cardinalidade é uma restrição que especifica o número de instâncias de relacionamento em que uma entidade pode participar. Tomando como exemplo a Figura 12, as entidades de "AQUISIÇÃO" podem estar relacionadas a mais de uma imagem, enquanto cada entidade de "IMAGEM" só pode estar relacionada a uma aquisição. Desta forma, a razão de cardinalidade do tipo de relacionamento "POSSUI" é 1:N. Para tipos de relacionamento binários, as razões de cardinalidade mais comuns são 1:1, 1:N e M:N. Um exemplo de tipo de relacionamento M:N é o da Figura 13, em que uma imagem "Original” pode estar relacionada a várias imagens 
"Derivada", e uma imagem "Derivada" pode estar relacionada a várias imagens "Original".

A restrição de participação especifica se a existência de uma entidade depende dela estar relacionada a outra entidade via um tipo de relacionamento. Existem dois tipos de restrição de participação: a total, em que todas as entidades de um tipo de entidade devem obrigatoriamente estar relacionadas a outras entidades, sejam estas de um outro tipo de entidade ou do mesmo tipo de entidade (relacionamento recursivo); e a parcial, que ocorre quando entidades de um tipo de entidade podem estar relacionadas a outras entidades, mas não necessariamente.

As restrições estruturais podem ser representadas de uma maneira simples através da associação de um par de números inteiros (min, max) a cada participação de um tipo de entidade $E$ em um tipo de relacionamento $R$, onde $0 \leq \min \leq \max$ e $\max$ $\geq 1$. Os números indicam que cada entidade $e$ em $E$ deve participar em pelo menos min e no máximo $\max$ instâncias de relacionamento de $R$ em qualquer momento. Se $\min =0$, a participação é parcial, enquanto se $\min >0$ a participação é total. As vantagens desta forma de representação das restrições estruturais são a sua precisão e a possibilidade de representação das restrições estruturais em relacionamentos de qualquer grau.

Um tipo de relacionamento pode possuir atributos da mesma forma que tipos de entidade. Este tipo de situação ocorre quando determinados atributos não fazem sentido se colocados em tipos de entidade separados, mas passam a possuir um significado quando entidades estão relacionadas. Para tipos de relacionamento 1:1 e 1:N estes atributos podem ser colocados nos tipos de entidade participantes sem que ocorra problemas, pois, nos dois casos, há entidades que estão relacionadas a apenas uma outra entidade. Já no caso de cardinalidade de M:N, o atributo deve estar necessariamente no tipo de relacionamento.

Alguns tipos de entidade podem não possuir um atributo chave, o que significa que algumas de suas entidades podem não ser distinguíveis pois as combinações dos 
valores de seus atributos podem ser idênticas. Elas são chamadas de tipos de entidade fracos e suas entidades são identificadas entre si através de relacionamentos com outras entidades em combinação com os valores de alguns de seus atributos. Este outro tipo de entidade é chamado de identificador, e o tipo de relacionamento entre o tipo de entidade fraco e o identificador é chamado de relacionamento de identificação. O tipo de entidade fraco sempre possui participação total com relação ao relacionamento de identificação, pois não é possível identificar uma entidade fraca sem uma entidade identificadora. Um tipo de entidade fraco possui uma chave parcial, que é um conjunto de atributos que pode identificar unicamente entidades fracas relacionadas a apenas uma entidade identificadora.

\subsubsection{Diagramas do modelo ER}

Os diagramas ER são utilizados para representar esquemas de banco de dados, contrastando, então, com o tipo de representação usado na Figura 12 e na Figura 13, onde a extensão de parte de um BD foi exemplificada. A representação de esquemas é mais interessante pois, ao contrário das instâncias de um BD, os esquemas raramente sofrem alterações. O esquema também é mais simples de ser mostrado pois ele é bem menor que a extensão do BD.

Os principais conceitos do modelo de dados ER (entidade, atributo e relacionamento) possuem representações gráficas. Podem existir pequenas diferenças nestas representações gráficas dependendo do autor, mas elas são todas equivalentes. Os tipos de entidade são representados por retângulos; os tipos de relacionamento são representados por caixas na forma de diamantes que são ligados aos tipos de entidade participantes do relacionamento; os atributos possuem um diagrama oval e são ligados aos correspondentes tipos de entidade ou tipos de relacionamento. A tabela a seguir apresenta resumidamente as notações gráficas usadas nos diagramas ER.

\footnotetext{
* Para relacionamentos com razão de cardinalidade 1:N, o atributo do relacionamento só pode ser colocado no tipo de entidade do lado $\mathrm{N}$ da associação, pois as suas entidades estão relacionadas a, no máximo, uma outra entidade. Para um relacionamento 1:1, tanto faz em qual tipo de entidade o atributo será colocado.
} 
Tabela 6 - Resumo da notação gráfica dos diagramas ER

Significado
Tipo de entidade
Tipo de entidade fraco
Tipo de relacionamento
Tipo de relacionamento de
identificação
Atributo
Atributo chave
Atributo múltiplo
Atributo composto
Atributo derivado
Participação total de $E_{2}$ em $R$
Razão de cardinalidade $1: \mathrm{N}$
para $E_{1}: E_{2}$ em $R$
Restrição estrutural $(\min , \max )$
na participação de $E$ em $R$

Fonte: Notação adotada em ELMASRI, R.; NAVATHE, S.B., 1989, cap.3.

\subsubsection{Modelo de dados EER}

\subsubsection{Introdução}

Os conceitos do modelo de dados ER permitem que sejam elaborados modelos conceituais para vários tipos de aplicações de bancos de dados. Entretanto, muitas aplicações de bancos de dados modernas, como projetos de engenharia, multimídia, sistemas de informações geográficas, bases de conhecimento para aplicações de inteligência artificial e sistemas de arquivamento e comunicação de imagens médicas, requerem conceitos semânticos adicionais para que seja possível criar modelos do minimundo com maior precisão.

Muitos modelos de dados semânticos foram propostos na literatura, entre eles, vários modelos que utilizam orientação a objetos, que são atualmente os mais populares. Os conceitos mais importantes foram incorporados ao modelo ER 
resultando no modelo Entidade-relacionamento Estendido (EER - Enhanced Entityrelationship). Além de todos os conceitos do modelo de dados ER, o modelo EER inclui os conceitos de subclasse e especialização, superclasse e generalização, categoria, e herança de atributos. Estes conceitos são rapidamente descritos a seguir, bem como as respectivas notações gráficas que compõem os diagramas do modelo EER.

\subsubsection{Conceitos básicos}

Como visto anteriormente, um tipo de entidade é usado para representar entidades do mesmo tipo, mas, em muitos casos, as entidades de um tipo de entidade podem pertencer a subgrupos menores que precisam ser representados no esquema do banco de dados. Estes subgrupos são chamados de subclasses do tipo de entidade, enquanto a classe mais geral que agrega as subclasses é chamada de superclasse. As entidades que fazem parte de subclasses são as mesmas entidades do mundo real que fazem parte da correspondente superclasse, mas elas exercem, em cada subclasse, um papel específico. Note que uma entidade não pode existir no BD apenas sendo membro de uma subclasse, ela precisa ser membro da superclasse também. Já uma entidade que é membro de uma superclasse não precisa ser obrigatoriamente membro de alguma de suas subclasses.

O relacionamento entre uma superclasse e uma de suas subclasses é chamado de relacionamento superclasse/subclasse. ${ }^{*}$ Ao contrário dos tipos de relacionamento mencionados anteriormente, que associavam entidades distintas, o relacionamento superclasse/subclasse associa as mesmas entidades do mundo real.

Um conceito importante relacionado às subclasses é a herança de atributos. Como as entidades das subclasses são as mesmas entidades do mundo real que compõem a superclasse, além dos valores para os seus atributos específicos, elas também possuem os valores dos seus atributos como membro da superclasse. Uma entidade de uma subclasse também herda todas as instâncias de relacionamento dos tipos de relacionamento nos quais a superclasse participa.

\footnotetext{
* O relacionamento subclasse/superclasse também é chamado de relacionamento É-UM ou É-UMA, tradução do inglês $I S-A$.
} 
Existem duas razões básicas para se incluir estruturas superclasse/subclasse em um modelo de dados. O primeiro é que certos atributos muitas vezes só fazem sentido para subgrupos de entidades da superclasse e não para todas as entidades. Para se resolver este problema, basta definir uma subclasse com estes atributos especiais. Desta forma, os membros da subclasse irão compartilhar os atributos comuns com os outros membros da superclasse enquanto possuem seus próprios atributos. A segunda motivação para a utilização de subclasses é que, para determinados tipos de relacionamento, apenas um grupo de entidades podem participar, o que também pode ser resolvido com a utilização de uma subclasse.

Relacionado com os conceitos de superclasse e subclasse existem os conceitos de especialização e generalização. A especialização é o processo de definir subclasses de um dado tipo de entidade, esta última chamada então de superclasse, e em seguida atribuir atributos específicos para as subclasses e estabelecer tipos de relacionamento específicos entre cada subclasse e outros tipos de entidade. O processo inverso, chamado de generalização, consiste em identificar características comuns entre vários tipos de entidade e então criar uma única superclasse que possua estas características. Os tipos de entidade originais permanecem com os seus atributos específicos e passam a ser subclasses. Como será visto adiante, a menos que seja explicitamente indicado, os diagramas resultantes de um processo de especialização ou generalização são os mesmos e indistingüíveis. A escolha de um processo ou outro para o desenho do esquema do BD é subjetivo e, em geral, reflete a maneira que o projetista percebe o minimundo que ele está modelando.

Um outro conceito importante do modelo EER surge da necessidade de se criar um relacionamento superclasse/subclasse com mais de uma superclasse, onde estas superclasses representam tipos de entidade diferentes. Neste caso, a subclasse é chamada de categoria e ela é um subconjunto da união das superclasses. Ao contrário do relacionamento superclasse/subclasse, onde há apenas uma superclasse e as entidades das subclasses são as mesmas entidades da superclasse, cada entidade da categoria é entidade de apenas uma das superclasses e ela herda os valores dos atributos da entidade nesta superclasse (herança seletiva). 


\subsubsection{Restrições de especialização e de generalização}

Existem três tipos básicos e mais comuns de restrições que podem ser aplicadas em relacionamentos superclasse/subclasse de especializações e generalizações: restrição de definição, de disjunção e de completeza.

Em alguns relacionamentos superclasse/subclasse, pode-se definir exatamente quais entidades serão membros de cada subclasse utilizando uma condição sobre o valor de um atributo da superclasse. Estas subclasses são então chamadas de definidas por predicado (ou definidas por condição), e a condição é chamada de predicado definição. Esta condição é uma restrição que diz que todas as entidades da subclasse devem satisfazer o predicado de definição e todas as entidades da superclasse que satisfazem o predicado de definição devem pertencer à subclasse.

Se todas as subclasses de uma especialização/generalização compartilharem o mesmo atributo da superclasse para estabelecer um predicado de definição, a especialização/generalização é dita definida por atributo, e o atributo é chamado de atributo de definição.

Nos casos em que não há nenhuma condição preestabelecida que indica automaticamente a qual subclasse uma entidade pertence, a subclasse é dita definida pelo usuário. Os usuários do $\mathrm{BD}$, ao inserir uma nova entidade, é que determinam se ela é membro de uma subclasse e qual é a subclasse.

A restrição de disjunção determina que as subclasses de uma especialização/generalização devem ser disjuntas, isto é, uma entidade só pode ser membro de uma subclasse da especialização/generalização. Caso as subclasses não sejam disjuntas, seus conjuntos de entidades irão se sobrepor, o que significa que uma entidade pode pertencer a uma ou mais subclasses da especialização/generalização.

A restrição de completeza determina se a especialização/generalização é total ou parcial. Se ela é total, toda entidade membro de uma superclasse deve ser membro de pelo menos uma subclasse da especialização. Já se ela é parcial, as entidades da superclasse não são obrigadas a pertencer a alguma subclasse. As categorias também podem ser totais ou parciais. No primeiro caso, todas as entidades das superclasses 
devem ser membros da categoria; já no segundo caso, todas as entidades das superclasses podem ser ou não membros da categoria.

As restrições descritas acima são determinadas à partir das características do mundo real e que são representadas no esquema utilizando os conceitos do modelo EER. Estas restrições determinam que certas regras devem ser obedecidas quando entidades são inseridas ou eliminadas. Algumas destas regras são:

- apagar uma entidade de uma superclasse implica em apagá-la automaticamente de todas as subclasses as quais ela pertence;

- inserir uma entidade em uma superclasse implica necessariamente inseri-la em todas as subclasses definidas por predicado nas quais o predicado de definição é satisfeito;

- inserir uma entidade em uma superclasse com especialização/generalização total implica inseri-la também em pelo menos uma das subclasses.

\subsubsection{Diagramas do modelo EER}

A notação gráfica do modelo EER é a mesma utilizada pelo modelo ER adicionada de novas estruturas relativas aos conceitos semânticos adicionais deste modelo. A tabela a seguir mostra a notação gráfica dos novos conceitos.

Tabela 7 - Resumo da notação gráfica dos diagramas EER

\begin{tabular}{ll}
\hline \multicolumn{1}{c}{ Significado } \\
\hline Especialização disjunta, total \\
Especialização disjunta, parcial \\
Especialização sobreposta, total
\end{tabular}




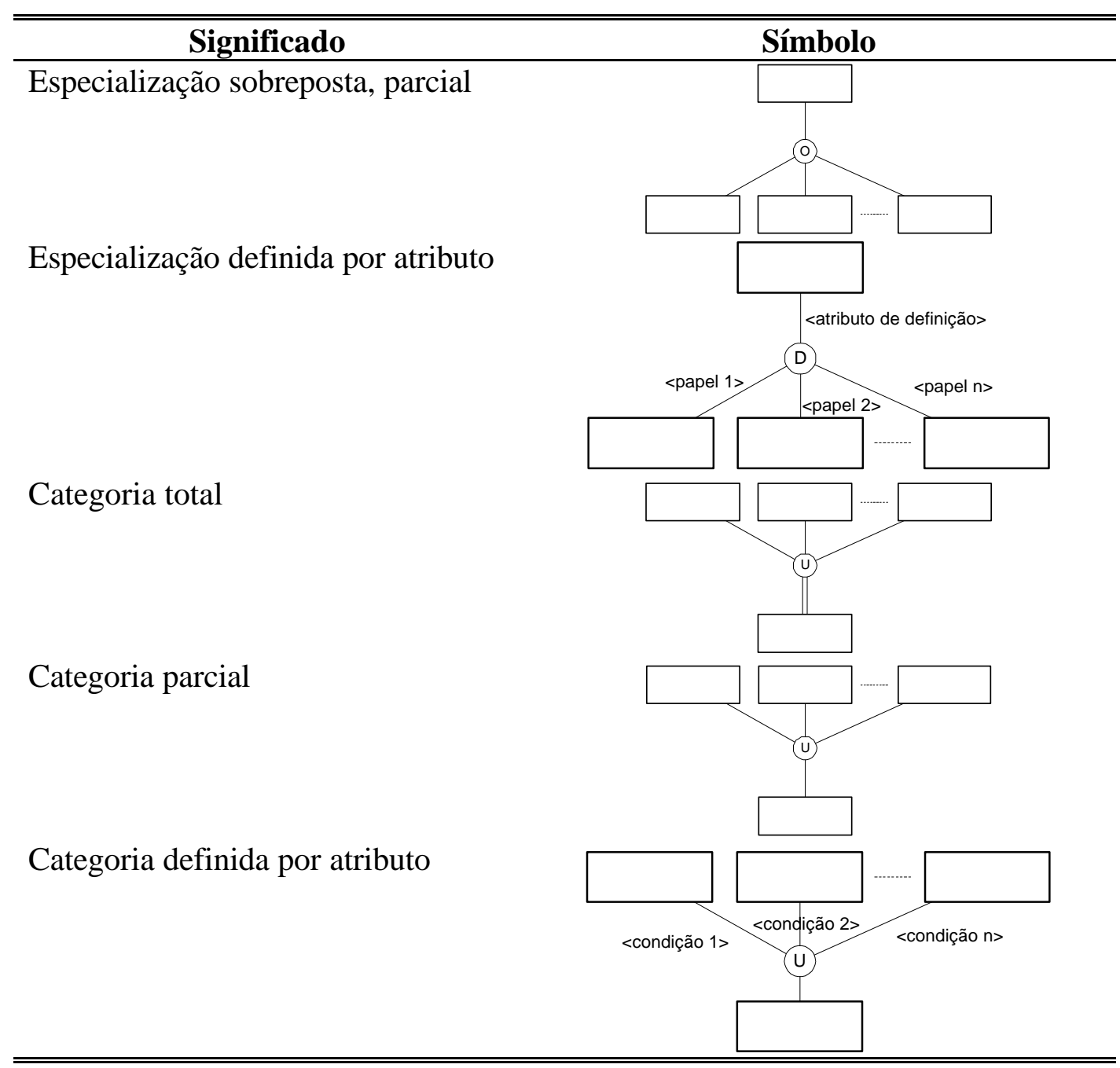

Fonte: Notação usada por ELMASRI, R.; NAVATHE, S.B., 1989, capítulo 15.

Os vários elementos da notação mostrados na Tabela 7 podem ser combinados para criar estruturas de dados mais complexas. Subclasses podem possuir subclasses, formando hierarquias e redes de especialização/generalização. Subclasses podem possuir mais de uma superclasse, sendo portando uma subclasse compartilhada. Este caso é diferente da categoria pois, ao contrário desta, em que a categoria herda os atributos de apenas uma superclasse, a subclasse herda os atributos de todas as superclasses.

É importante notar que no modelo EER é feita uma extensão da definição do tipo de relacionamento, agora permitindo que classes, e não apenas tipos de entidade, façam parte de relacionamentos. Desta forma, substitui-se o termo tipo de entidade por classe e a notação gráfica continua consistente porque todas as classes são representadas por retângulos. 


\subsubsection{Modelo de dados relacional}

\subsubsection{Conceitos básicos}

O Modelo Relacional de Dados (MRD) representa dados em um BD como uma coleção de relações. Pode-se entender mais facilmente o significado de uma relação comparando-a com uma tabela ou um arquivo simples que armazena dados em linhas e colunas. Apesar desta analogia servir para introduzir estes conceitos, existem diferenças importantes que serão apresentadas no restante desta seção. A tabela abaixo mostra os principais conceitos usados no MRD e os seus correspondentes em uma representação na forma de tabela:

Tabela 8 - Comparação entre os conceitos do MRD e uma representação de dados em tabela

\begin{tabular}{l|l|l}
\hline \hline \multicolumn{1}{c|}{ MRD } & \multicolumn{1}{c|}{$\begin{array}{c}\text { Exemplos na notação } \\
\text { do MRD }\end{array}$} & \multicolumn{1}{|c}{ Representação em tabela } \\
\hline \hline Relação & $\mathrm{Q}, \mathrm{R}, \mathrm{S}$ & Tabela \\
\hline Tupla & $\mathrm{t}, \mathrm{u}, \mathrm{v}$ & Linha \\
\hline Atributo & $\mathrm{A}_{1}, \mathrm{~A}_{2}, \mathrm{~A}_{3}$ & Nome da coluna \\
\hline Domínio & $\mathrm{D}$ & Tipo de dados de uma coluna \\
\hline \hline
\end{tabular}

Um domínio D é um conjunto de valores atômicos, isto é, cada valor no domínio é indivisível. A um domínio normalmente são atribuídas três características principais: nome do domínio, tipo dos dados e formato. Como exemplo, um domínio para números de telefones usados no Brasil poderia ser: [BR_número_telefone, cadeia de caracteres, (ddd) ddd-dddd]. Outras informações, como, por exemplo, a unidade de medida de um domínio numérico, também podem ser indicadas. Outros exemplos de domínios, e que foram utilizados neste trabalho, são:

Tabela 9 - Exemplos de especificações de domínios

\begin{tabular}{c|l|l}
\hline \hline $\begin{array}{c}\text { Nome do } \\
\text { domínio }\end{array}$ & \multicolumn{1}{|c|}{ Tipo de dado } & \multicolumn{1}{|c}{ Formato } \\
\hline \hline Cadeia_curta & cadeia de caracteres & $\begin{array}{l}\text { comprimento máximo } \\
\text { de } 16\end{array}$ \\
\hline Cadeia_longa & cadeia de caracteres & $\begin{array}{l}\text { comprimento máximo } \\
\text { de } 64\end{array}$ \\
\hline \hline
\end{tabular}




\begin{tabular}{l|l|l}
\hline \hline \multicolumn{1}{c|}{$\begin{array}{c}\text { Nome do } \\
\text { domínio }\end{array}$} & \multicolumn{1}{|c}{ Tipo de dado } & \multicolumn{1}{c}{ Formato } \\
\hline \hline Decimal & $\begin{array}{l}\text { número em ponto flutuante de 4 } \\
\text { bytes }\end{array}$ & - \\
\hline Longo & número inteiro de 4 bytes & - \\
\hline Hora & data/hora & hh:nn \\
\hline Texto_longo & $\begin{array}{l}\text { conjunto de caracteres com tamanho } \\
\text { até 64 Kbytes }\end{array}$ & - \\
\hline \hline
\end{tabular}

Um esquema relacional $R$, representado por $R\left(A_{1}, A_{2}, \ldots, A_{n}\right)$, é um conjunto de atributos $R=\left\{A_{l}, A_{2}, \ldots, A_{n}\right\}$. Cada atributo $A_{i}$ é um papel desempenhado por um domínio $D$ no esquema relacional $R$. Desta forma, $D$ é chamado de domínio de $A_{i}$ e é representado por $\operatorname{dom}\left(A_{i}\right)$. O esquema relacional é usado para descrever uma relação; $R$ é o nome dado à relação; e o número de atributos $n$ de um esquema relacional é chamado de grau da relação. Um exemplo de relação de grau 8 que descreve a aplicação de uma substância de contraste em um paciente é:

\section{CONTRASTE}

\begin{tabular}{|l|l|l|l|l|l|l|l|}
\hline IdContraste & Agente & Rota & Volume & DoseTotal & HoraInicial & HoraFinal & Comentários \\
\hline
\end{tabular}

Os domínios dos atributos da relação "CONTRASTE” são:

- $\operatorname{dom}(\operatorname{IdContraste})=$ Longo;

- $\operatorname{dom}($ Agente $)=$ Cadeia_longa;

- $\operatorname{dom}($ Rota $)=$ Cadeia_longa;

- $\operatorname{dom}($ Volume $)=$ Decimal;

- $\operatorname{dom}($ DoseTotal $)=$ Decimal;

- $\operatorname{dom}($ HoraInicial $)=$ Hora;

- $\operatorname{dom}($ HoraInicial $)=$ Hora;

- $\operatorname{dom}($ Comentários $)=$ Texto_longo.

Uma relação, ou instância da relação, $r$ de um esquema relacional $R\left(A_{1}, A_{2}\right.$, $\left.\ldots, A_{n}\right)$, também representada por $r(R)$, é um conjunto de tuplas-n $r=\left\{t_{1}, t_{2}, \ldots, t_{m}\right\}$, onde cada tupla-n é uma lista ordenada de n valores $t=\left\langle v_{1}, v_{2}, \ldots, v_{n}\right\rangle$ e cada valor $v_{i}, 1 \leq i \leq n$, é um elemento de $\operatorname{dom}\left(A_{i}\right)$ ou é um valor especial nulo. Um outra maneira equivalente de definir uma relação é dizer que $r(R)$ é um subconjunto do produto cartesiano dos domínios que definem $R$ : 


$$
r(R) \subseteq\left(\operatorname{dom}\left(A_{1}\right) \times \operatorname{dom}\left(A_{2}\right) \times \cdots \times \operatorname{dom}\left(A_{n}\right)\right) .
$$

Entre todas as possíveis combinações de valores entre os domínios, uma instância da relação em um momento específico, instância atual da relação, possui apenas as tuplas que representam o estado atual do mundo real. A cada mudança no mundo real que é atualizada no banco de dados, uma nova instância da relação é criada. Já o esquema da relação é relativamente estático, sendo alterado apenas quando a estrutura do BD é mudada.

Sendo uma relação definida como um conjunto de tuplas, pela definição de conjunto, todos os elementos da relação devem ser distintos, isto é, nenhum par de tuplas pode possuir a mesma combinação de valores para todos os seus atributos. Freqüentemente, existe um subconjunto $S K$ de atributos do esquema relacional $R$ com a propriedade de que nenhum par de tuplas em qualquer instância da relação $r$ de $R$ possui a mesma combinação de valores para seus atributos, ou seja, $t_{1}[S K] \neq t_{2}[S K]$, para quaisquer tuplas $t_{1}$ e $t_{2}$ distintas de $r$. Qualquer conjunto de atributos com esta propriedade é chamado de superchave do esquema relacional. Todo esquema relacional possui, então, pelo menos uma superchave, que é o conjunto de todos os seus atributos.

Uma chave $K$ do esquema relacional $R$ é uma superchave de $R$ que possui a propriedade adicional de que, se algum de seus atributos for removido, o subconjunto $K$ ' resultante não é superchave de $R$. Em geral, um esquema relacional pode possuir mais de uma chave, sendo cada uma delas chamada de chave candidata. É comum que uma destas chaves seja designada como sendo a chave primária da relação, chave candidata esta que é usada para identificar as tuplas da relação e geralmente é representada sublinhando-se os nomes de seus atributos.

As definições apresentadas para a relação implicam em certas características que fazem com que uma relação seja diferente de uma tabela ou um arquivo. A primeira característica se refere ao ordenamento das tuplas na relação. Ao contrário das tabelas e arquivos, onde as linhas e os registros são armazenados seqüiencialmente, isto é, possuem uma posição definida com relação ao resto das linhas ou registros, a relação foi definida como um conjunto de tuplas e, por ser um conjunto, os seus elementos não possuem nenhuma ordem particular. Pode-se definir 
uma ordem lógica para se mostrar uma relação, ou escolher uma ordem física para se implementar uma relação em um arquivo, mas a relação propriamente dita não impõe nenhuma ordem aos seus elementos.

Outra característica das definições feitas é que, sendo uma tupla-n uma lista ordenada de $n$ valores, a ordem dos valores na tupla é importante. Esta ordem é usada para associar cada valor da tupla ao seu correspondente atributo no esquema relacional. Esta ordenação não seria necessária, desde que se indicasse o atributo correspondente a cada valor da tupla. Assim, uma definição alternativa para tupla é que ela é um conjunto de pares (<atributo>, <valor>).

A terceira característica importante se refere aos valores existentes nas tuplas. Como cada valor em uma tupla é atômico, atributos múltiplos e compostos não são permitidos. Para implementar o correspondente de um atributo múltiplo, deve-se criar uma relação separada; já o atributo composto é implementado utilizando os seus componentes como atributos simples.

\subsubsection{Esquemas de BD relacionais e restrições de integridade}

Um banco de dados relacional é formado, geralmente, por várias relações cujas tuplas são relacionadas de diversas maneiras. Para que a informação contida neste BD não perca a sua integridade, determinadas restrições devem ser obedecidas.

Um esquema de banco de dados relacional $S$ é um conjunto de esquemas relacionais $S=\left\{R_{1}, R_{2}, \ldots, R_{m}\right\}$ e um conjunto de restrições de integridade RI. Uma instância de banco de dados relacional $B D^{*}$ de $S$ é um conjunto de instâncias de relações $B D=\left\{r_{1}, r_{2}, \ldots, r_{m}\right\}$, onde cada $r_{i}$ é uma instância de $R_{i}$ e os $r_{i}^{\prime}$ 's satisfazem as restrições de integridade RI especificadas.

As restrições de integridade são especificadas no esquema de banco de dados e espera-se que elas sejam satisfeitas em todas as instâncias deste banco de dados. Existem três tipos básicos de restrições de integridade: chave, entidade e referencial. As duas primeiras se referem a restrições em relações individuais. Já o último tipo de

\footnotetext{
* A sigla BD tem sido utilizada neste texto como abreviatura para banco de dados . Neste caso ela está se referindo a uma instância de banco de dados relacional. A distinção entre as duas utilizações é possível através do contexto onde a sigla é utilizada.
} 
restrição é especificada entre relações e é usada para manter a consistência entre tuplas de duas relações.

As restrições de chave especificam quais são as chaves candidatas de cada esquema relacional.

A restrição de integridade de entidade determina que nenhuma chave primária pode possuir o valor especial nulo. Como a chave primária é utilizada para identificar individualmente as tuplas das relação, a ocorrência de valores nulos na chave primária impossibilitaria a identificação de algumas tuplas.

A restrição de integridade referencial determina que, para uma tupla $t_{1}$ de um esquema relacional $R_{1}$ se referir a um outro esquema relacional $R_{2}$, ela deve se referir a uma tupla $t_{2}$ que exista na instância do esquema relacional $R_{2}$. Esta referência entre relações é feita através de um conjunto de atributos $F K$ de $R_{l}$, chamado de chave estrangeira, que satisfaz as seguintes condições:

1. os atributos de $F K$ possuem os mesmos domínios que os atributos da chave primária $P K$ do esquema relacional $R_{2}$. Diz-se que os atributos de $F K$ se referem à relação $R_{2}$;

2. os valores dos atributos de $F K$ na tupla $t_{l}$ de $R_{l}$ devem ser iguais aos valores dos atributos de $P K$ de alguma tupla $t_{2}$ de $R_{2}$, ou devem ser nulos. No primeiro caso tem-se que $t_{1}[F K]=t_{2}[P K]$ e diz-se que a tupla $t_{1}$ de $R_{1}$ se refere a tupla $t_{2}$ de $R_{2}$.

As restrições de integridade referencial são geralmente mostradas ligando-se cada chave estrangeira com a relação a qual ela se referencia, como mostrado no esquema a seguir:

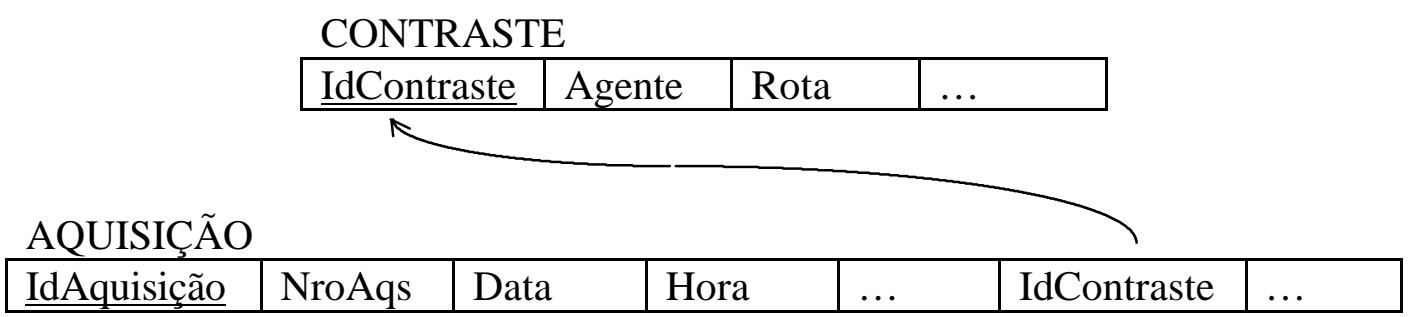


Fora estes três tipos de restrições de integridade, que são gerais para o modelo relacional, existem as restrições de integridade semânticas, que são específicas para cada aplicação. Estas restrições devem ser especificadas e garantidas, automaticamente ou não pelo SGBD, no banco de dados relacional.

Existem três operações básicas de atualização de relações:

- inserção, que insere novas tuplas na relação;

- eliminação, que apaga tuplas; e

- modificação, que modifica os valores de atributos de tuplas.

Sempre que alguma destas operações é executada, deve-se testar se as restrições de integridade especificadas no esquema do banco de dados relacional não estão sendo violadas. Caso alguma restrição esteja sendo violada, pode-se rejeitar a atualização ou pode-se fornecer a possibilidade corrigir o problema de forma alternativa e que não viole as restrições de integridade estabelecidas.

\subsubsection{3 Álgebra relacional}

A álgebra relacional é uma linguagem de alto nível que, apesar de ser pouco utilizada na prática, é bastante ilustrativa, devido a sua sintaxe simples e uniforme, para descrever os tipos de operações que podem ser aplicadas em um BD relacional.

A álgebra relacional compreende um conjunto de operações usadas para manipular relações com o propósito de efetuar buscas em um banco de dados relacional. Elas são utilizadas para:

- selecionar tuplas dentro de uma relação particular;

- combinar tuplas relacionadas provenientes de várias relações.

O resultado de cada operação é uma nova relação que, conseqüentemente, também pode ser manipulada pelas operações da álgebra relacional. As principais operações da álgebra relacional e as notações correspondentes estão resumidas na tabela a seguir. 
Tabela 10 - Resumo das operações da álgebra relacional

\begin{tabular}{|c|c|c|}
\hline Operação & Propósito & Notação \\
\hline SELECT & $\begin{array}{l}\text { Seleciona todas as tuplas da relação } \\
R \text { que satisfazem a condição de } \\
\text { seleção. }\end{array}$ & $\sigma_{<\text {condição de seleção }>}(\mathrm{R})$ \\
\hline PROJECT & $\begin{array}{l}\text { Produz uma nova relação com } \\
\text { apenas alguns atributos de } R \mathrm{e} \\
\text { removendo as tuplas duplicadas. }\end{array}$ & $\pi_{<\text {lista de atributos }>}(\mathrm{R})$ \\
\hline THETA JOIN & $\begin{array}{l}\text { Produz todas as combinações de } \\
\text { tuplas entre } R_{1} \text { e } R_{2} \text { que satisfazem a } \\
\text { condição do join. }\end{array}$ & $\mathrm{R}_{1} \bigotimes_{<\text {condição do join }>} \mathrm{R}_{2}$ \\
\hline EQUI JOIN & $\begin{array}{l}\text { Produz todas as combinações de } \\
\text { tuplas entre } R_{1} \text { e } R_{2} \text { que satisfazem } \\
\text { condições de join que usam apenas } \\
\text { comparações de igualdade. }\end{array}$ & $\begin{array}{l}\mathrm{R}_{1} \boldsymbol{}_{\text {<condição do join }} \mathrm{R}_{2}, \\
\text { ou } \mathrm{R}_{1} \bigotimes_{\text {(<atributos do join 1), <atributos do join }} \\
2 \gg \mathrm{R}_{2}\end{array}$ \\
\hline NATURAL JOIN & $\begin{array}{l}\text { O mesmo que EQUI JOIN, exceto } \\
\text { que os atributos de join de } R_{2} \text { não } \\
\text { são incluídos na relação resultante; } \\
\text { Se os atributos do join têm o mesmo } \\
\text { nome eles não precisam ser } \\
\text { especificados. }\end{array}$ & $\begin{array}{l}\mathrm{R}_{1} *<\text { condição do join }>\mathrm{R}_{2}, \\
\text { ou } \\
\mathrm{R}_{1} * \text { (<atributos do join 1>, <atributos do join } 2>\mathrm{R}_{2}, \\
\text { Ou } \\
\mathrm{R}_{1} * \mathrm{R}_{2}\end{array}$ \\
\hline UNION & $\begin{array}{l}\text { Produz uma relação que inclui todas } \\
\text { as tuplas de } R_{1} \text { ou } R_{2} \text { ou em ambas } \\
R_{1} \text { e } R_{2} \text {; } \\
R_{1} \text { e } R_{2} \text { devem ser união- } \\
\text { compatíveis. }\end{array}$ & $\mathrm{R}_{1} \cup \mathrm{R}_{2}$ \\
\hline INTERSECTION & $\begin{array}{l}\text { Produz uma relação que inclui todas } \\
\text { as tuplas que estão em } R_{l} \text { e } R_{2} \text { ao } \\
\text { mesmo tempo; }\end{array}$ & $\mathrm{R}_{1} \cap \mathrm{R}_{2}$ \\
\hline DIFFERENCE & $\begin{array}{l}\text { Produz uma relação com todas as } \\
\text { tuplas que estão em } R_{1} \text { e que não } \\
\text { estão em } R_{2} \text {. }\end{array}$ & $\mathrm{R}_{1}-\mathrm{R}_{2}$ \\
\hline $\begin{array}{l}\text { CARTESIAN } \\
\text { PRODUCT }\end{array}$ & $\begin{array}{l}\text { Produz uma relação que possui os } \\
\text { atributos de } R_{l} \text { e } R_{2} \text { e inclui como } \\
\text { tuplas todas as combinações } \\
\text { possíveis entre } R_{1} \text { e } R_{2} \text {. }\end{array}$ & $\mathrm{R}_{1} \times \mathrm{R}_{2}$ \\
\hline DIVISION & $\begin{array}{l}\text { Produz uma relação } R(X) \text { que inclui } \\
\text { todas as tuplas } t\{X\} \text { em } R_{l}(Z) \text { que } \\
\text { aparecem em } R_{l} \text { em combinação } \\
\text { com todas as tuplas de } R_{2}(Y) \text {, onde } \\
Z=X \cup Y \text {. }\end{array}$ & $\mathrm{R}_{1}(\mathrm{Z}) \div \mathrm{R}_{2}(\mathrm{Y})$ \\
\hline
\end{tabular}

Fonte: Tabela traduzida de ELMASRI, R.; NAVATHE, S.B., 1989, p.169.

* Duas relações, $\mathrm{R}\left(\mathrm{A}_{1}, \mathrm{~A}_{2}, \ldots, \mathrm{A}_{\mathrm{n}}\right)$ e $\mathrm{S}\left(\mathrm{B}_{1}, \mathrm{~B}_{2}, \ldots, \mathrm{B}_{\mathrm{m}}\right)$ são união-compatíveis se:

i. R e $\mathrm{S}$ têm o mesmo grau, isto é, $\mathrm{n}=\mathrm{m}$;

ii. $\operatorname{dom}\left(\mathrm{A}_{\mathrm{i}}\right)=\operatorname{dom}\left(\mathrm{B}_{\mathrm{i}}\right)$ para $1 \leq \mathrm{I} \geq \mathrm{n}$. 
Existem requisições frequientes em bancos de dados que não podem ser executadas pelas operações padrões da álgebra relacional. Desta forma, vários SGBDs disponíveis no mercado incluem operações adicionais para viabilizar estas requisições. Para se ter uma idéia da importância destas operações adicionais, as quatro operações que são apresentadas a seguir, que a literatura indica como as mais importantes e freqüentes, foram utilizadas neste trabalho.

Um tipo de requisição comum é a aplicação de funções de agregação a um conjunto de valores do banco de dados. As funções mais comumente usadas são: SUM, AVERAGE, MAXIMUM, MINIMUM e COUNT. Por exemplo, pode-se contar quantos estudos estão registrados na relação ESTUDO de um banco de dados.

Outro tipo de requisição comum é o agrupamento de tuplas de uma relação de acordo com o valor de alguns de seus atributos e depois aplicar funções de agregação em cada grupo resultante independentemente. Um exemplo usado neste trabalho é agrupar os dados pela aquisição a que eles pertencem e, em seguida, contar quantos dados cada aquisição possui.

Para implementar os dois tipos de requisição descritos acima, é definida a

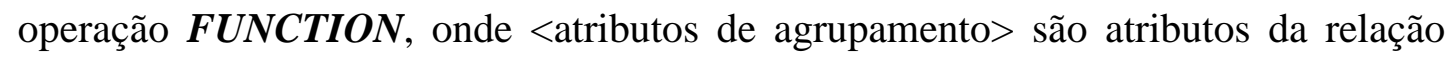
indicada por <nome da relação> e <lista de funções> é uma lista de pares (<função>, <atributo>):

$$
\text { <atributos de agrupamento }>F_{<\text {lista de funções }>}(<\text { nome da relação }>) .
$$

Assim, os dois exemplos de requisições mencionados podem ser executados mediante as seguintes operações:
1. R1(NroEstudos $) \leftarrow \mathrm{F}_{\text {COUNT IdEstudo }}($ ESTUDO);
2. R2(Aqs, NroDados $) \leftarrow_{\text {IdAquisição }} F_{\text {COUNT IdDados }}(D A D O S)$.

O resultado da primeira operação será a relação "R1(NroEstudos)" que irá possuir apenas uma tupla na qual o valor do único atributo, "NroEstudos", será igual ao número de tuplas existentes na relação "ESTUDO” no momento da operação. Já a segunda operação irá resultar em uma relação com dois atributos, com o número de 
tuplas igual ao número de aquisições existentes, e para cada aquisição será indicado o número de dados correspondentes que existem.

As operações de JOIN, sejam elas NATURAL JOIN, THETA JOIN ou EQUI $J O I N$, aplicadas entre duas relações, por exemplo $R$ e $S$, resultam em tuplas de $R$ que tenham tuplas correspondentes em $S$, e vice-versa. Desta forma, todas as tuplas que não possuem uma correspondente na outra relação são eliminadas do resultado, mas nem sempre este resultado é o desejado. Um conjunto de operações chamadas de OUTER JOIN foi criado para permitir que tuplas que não possuam correspondentes na outra relação apareçam no resultado. Uma destas operações é o LEFT OUTER $J O I N$, cujo símbolo é $\leftarrow \bigotimes$, que mantém todas a tuplas da relação da esquerda, seja $R$ na operação $R \leftarrow \bigotimes S$, e para as tuplas de $R$ que não tiverem correspondentes em $S$, os valores dos atributos de $S$ são preenchidos com NULO. A outra operação é o RIGHT OUTER JOIN, simbolizado por $\bowtie \rightarrow$, que funciona da mesma forma, mas agora mantendo todas as tuplas da relação que estiver do lado direito, $S$ no caso de $R$ $\rightarrow S$. Uma terceira operação, a FULL OUTER JOIN, cujo símbolo é $\leftarrow$ $\rightarrow$, mantêm todas as tuplas das duas relações.

A operação OUTER UNION foi elaborada para fazer a união de relações que não são união-compatíveis. Ela é capaz de unir relações parcialmente compatíveis ${ }^{*}$ atribuindo valores nulos para os atributos que não são compatíveis.

Outra possibilidade normalmente oferecida por sistemas comerciais, que também não faz parte da álgebra relacional, é a de aplicar funções sobre valores de atributos quando estes são extraídos do banco de dados. Estas funções podem ser aritméticas, de manipulação de caracteres e até mesmo funções definidas pelo usuário.

\subsubsection{SQL}

A álgebra relacional, apresentada na seção anterior, é uma linguagem de alto nível porque suas operações são aplicadas sobre relações completas, mas poucas linguagens de SGBD a usam diretamente. Isto ocorre porque uma consulta em

\footnotetext{
* A notação para as operações de OUTER JOIN foram adaptadas da notação utilizada por ELMASRI, R.; NAVATHE, S.B., 1989, capítulo 6.
} 
álgebra relacional é feita através de uma seqüência de operações que produz o resultado desejado, mas a escolha das operações e a sua seqüência fica a cargo do usuário. Por outro lado, existem outras linguagens de alto nível, como a linguagem SQL, onde o usuário especifica apenas qual é o resultado desejado, ficando a cargo do SGBD decidir como executar a consulta.

A linguagem SQL (Structured Query Language) é a linguagem disponível no SGBD utilizado neste trabalho, o MS Access 2.0. Ela possui estruturas para definição de dados, de consultas e de manipulação, sendo portanto uma DDL e uma DML simultaneamente. Ela também possibilita a definição de visões do $\mathrm{BD}$, criação de índices nos arquivos que representam as relações, e pode ser incorporada em linguagens de programação de propósito geral.

Outro tipo de linguagem disponível na MS Access 2.0 é a QBE (Query By Example), que fornece uma interface gráfica para a especificação das consultas. No caso específico do MS Access 2.0, esta linguagem é uma opção adicional para a especificação de vários tipos de consultas e filtros, mas todas as especificações feitas utilizando QBE são traduzidas para SQL. Assim, esta seção apresenta apenas um resumo da linguagem SQL, que foi a mais utilizada neste trabalho.

Tabela 11 - Resumo da sintaxe da linguagem SQL

\begin{tabular}{|c|c|}
\hline $\begin{array}{c}\text { Tipo de } \\
\text { operação } \\
\end{array}$ & Sintaxe \\
\hline \multirow[t]{3}{*}{$\begin{array}{l}\text { Definição de } \\
\text { dados }\end{array}$} & $\begin{aligned} \text { CREATE TABLE <nome tabela }> & (<\text { nome coluna }><\text { tipo coluna }>\text { [NOT NULL] } \\
& \{,<\text { nome coluna }><\text { tipo coluna }>[\text { NOT NULL] }\})\end{aligned}$ \\
\hline & DROP TABLE <nome tabela $>$ \\
\hline & ALTER TABLE $<$ nome tabela $>$ ADD $<$ nome coluna $><$ tipo coluna $>$ \\
\hline Consultas & 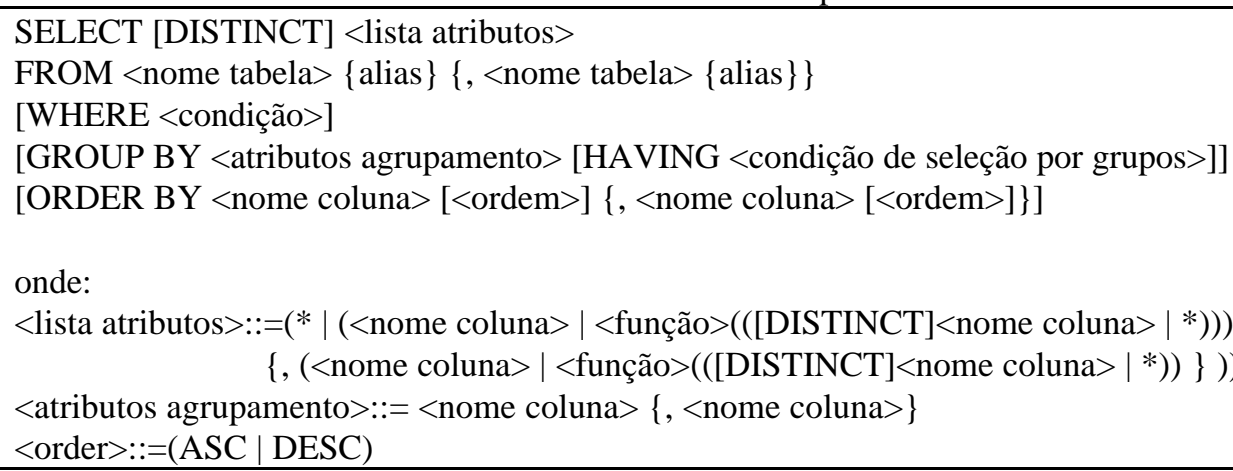 \\
\hline
\end{tabular}

\footnotetext{
* Relações parcialmente compatíveis são aquelas nas quais apenas um subconjunto dos seus atributos são união-compatíveis.
} 


\begin{tabular}{|c|c|}
\hline $\begin{array}{c}\text { Tipo de } \\
\text { operação } \\
\end{array}$ & Sintaxe \\
\hline \multirow[t]{3}{*}{ Atualização } & $\begin{array}{l}\text { INSERT INTO <nome tabela }>[(<\text { nome coluna }>\{,<\text { nome coluna }>\})] \\
(\text { VALUES }(<\text { valor constante }>,\{<\text { valor constante }>\}) \mid<\text { estrutura select }>)\end{array}$ \\
\hline & $\begin{array}{l}\text { DELETE FROM < nome tabela> } \\
\text { [WHERE < condição seleção>] }\end{array}$ \\
\hline & $\begin{array}{l}\text { UPDATE }<\text { nome tabela }> \\
\text { SET <nome coluna }>=<\text { expressão }>\{,<\text { nome coluna }>=<\text { expressão }>\} \\
\text { WHERE }<\text { condição seleção }>\end{array}$ \\
\hline \multirow[t]{2}{*}{ Índices } & $\begin{array}{l}\text { CREATE [UNIQUE] INDEX <nome índice }> \\
\text { ON <nome tabela }>(<\text { nome coluna }>\text { [ORDER] }\{,<\text { nome coluna }>[\text { ORDER] }\}) \\
{[\text { CLUSTER] }}\end{array}$ \\
\hline & DROP INDEX <nome índice> \\
\hline \multirow[t]{2}{*}{ Visões } & $\begin{array}{l}\text { CREATE VIEW < nome view> }[(<\text { nome coluna }>\{,<\text { nome coluna }>\})] \\
\text { AS <estrutura select }>\end{array}$ \\
\hline & DROP VIEW <nome view> \\
\hline
\end{tabular}

Fonte: Adaptado de ELMASRI, R.; NAVATHE, S.B., 1989, p.206.

A versão da linguagem SQL existente no MS Access 2.0 comporta todas as estruturas sintáticas mostradas na Tabela 11, com exceção das visões de BD. Como o SGBD do MS Access permite que as consultas sejam salvas para posterior utilização, cada consulta destas pode ser utilizada como uma visão específica do BD, dispensando a necessidade de comandos específicos.

Dos tipos de comandos da linguagem SQL, o que foi mais utilizado neste trabalho é o de consulta. As funções correspondentes às outras estruturas sintáticas da linguagem estão disponíveis ao usuário através de diversas interfaces gráficas do SGBD, tornando a utilização destas estruturas transparentes ao usuário ou até mesmo dispensáveis. Este é o caso, por exemplo, da criação e edição das tabelas do BD, que foi feita através da interface gráfica do SGBD e não através de comandos CREATE TABLE, DROP TABLE e ALTER TABLE.

\subsubsection{Dependências funcionais e normalização de BD relacionais}

Os conceitos de dependência funcional (DF) e normalização tratam da qualidade do esquema relacional, o primeiro medindo se os atributos foram adequadamente distribuídos nas relações, e o segundo apresentando condições que devem ser satisfeitas para que as relações sejam apropriadas.

De uma forma geral, quando se fala de qualidade de relações, está sendo abordado: 
- semântica dos atributos;

- redução de redundâncias nas tuplas;

- redução de valores nulos;

- não criação de tuplas espúrias.

Cada um destes aspectos é importante para um esquema relacional pelos seguintes motivos:

- semântica: um bom esquema de uma relação deve ser tal que seja fácil explicar o seu significado a partir de seus atributos constituintes. Para isso, não se pode misturar atributos de diferentes tipos de entidade e tipos de relacionamento em uma mesma relação;

- redundâncias: elas podem gerar anomalias de atualização (inserção, eliminação e modificação). Deve-se estabelecer o esquema relacional de maneira que as anomalias de atualização não ocorram. Caso seja necessário manter alguma característica que incorra em anomalias, deve-se ter o cuidado de manter estas sob controle;

- valores nulos: esquemas muito grandes podem conter atributos que muitas vezes não são usados. Estes valores nulos nas tuplas acarretam desperdício no armazenamento e dificuldades na interpretação do fato de um valor ser nulo. Devese fazer relações usando atributos que realmente sejam utilizados. Caso haja algum atributo pertinente, mas pouco usado, este deve ser colocado em outra relação relacionado à primeira;

- tuplas espúrias: dependendo de como as relações são montadas, ao serem efetuadas operações como Natural Join podem aparecer tuplas espúrias que correspondam a informações erradas. Os esquemas devem ser projetados de maneira que eles possam ser "agrupados" em condições de igualdade de atributos. Os atributos usados nestas operações devem ser chaves primárias ou estrangeiras de maneira a garantir que tuplas espúrias não sejam criadas.

Dependência funcional é uma restrição existente entre dois conjuntos de atributos de um banco de dados. Uma DF entre $X$ e $Y$, denotada por $X \rightarrow Y$, onde $X$ e $Y$ são subconjuntos de uma relação $R$, indica que existe uma interdependência entre as 
possíveis tuplas que podem formar a instância $r$ de $R$. Esta interdependência é tal que, dadas duas tuplas $t_{1}$ e $t_{2}$ quaisquer de $r$ onde $t_{1}[X]=t_{2}[X]$, necessariamente temos que $t_{1}[Y]=t_{2}[Y]$. Isto significa que os valores correspondentes aos atributos $Y \mathrm{de}$ uma tupla em $r$ dependem dos valores correspondentes aos atributos $X$. Diz-se, então, que $Y$ é funcionalmente dependente de $X$, indicado por $X \rightarrow Y$, quando, dado $X$, é possível determinar univocamente $Y$. Quando $Y$ não é funcionalmente dependente de $X$ escreve-se $X x \rightarrow Y$.

A DF é uma propriedade semântica da relação e de seus atributos. Desta forma é, através do entendimento das relações e interdependências existentes no mundo real, que o projetista do BD especifica quais as dependências funcionais existem. Quando é identificada uma DF entre dois conjuntos de atributos, está dependência é especificada como uma restrição que deve ser sempre satisfeita.

Um exemplo simples de DF é quando $X$ é chave candidata de uma relação. Neste caso, como a combinação de valores para $X$ deve ser única para todas as instâncias da relação, existe uma DF $X \rightarrow Y$ para todo subconjunto $Y$ da relação.

À partir de um conjunto de DFs, $F$ por exemplo, pode-se inferir novas DFs do tipo $X \rightarrow Y$. Representa-se por $F \mid=X \rightarrow Y$, que diz que a DF $X \rightarrow Y$ é inferida a partir do conjunto de DFs $F$.

Existem várias regras de inferência $(\mathrm{RI})$, das quais três são suficientes, pois as demais são variações ou consequiências destas:

RI1: (Reflexiva). Se $X \supseteq Y$, então $\mathrm{X} \rightarrow \mathrm{Y}$;

RI2: (Compositiva). $\{\mathrm{X} \rightarrow \mathrm{Y}\} \mid=\mathrm{XZ} \rightarrow \mathrm{YZ}$;

RI3: (Transitiva). $\{\mathrm{X} \rightarrow \mathrm{Y}, \mathrm{Y} \rightarrow \mathrm{Z}\} \mid=\mathrm{X} \rightarrow \mathrm{Z}$.

O objetivo da normalização é garantir que esquemas de relações tenham um bom projeto e evitar, assim, que ocorram anomalias de atualização. No processo de normalização, verifica-se se as relações satisfazem ou não determinada forma normal e, se necessário, esquemas relacionais não satisfatórios são decompostos em esquemas relacionais menores que possuem as características desejáveis.

As quatro formas normais apresentadas a seguir são baseadas em chaves primárias e dependências funcionais existentes entre os atributos das relações. 
Existem outras formas normais, mas elas não serão apresentadas neste texto pois a normalização até a terceira forma normal ou até a forma normal Boyce-Cood é a mais comum e suficiente para a maioria dos casos. Isto não significa dizer, necessariamente, que um BD normalizado até uma destas formas normais tenha um bom esquema relacional.

Primeira forma normal - 1NF. Os domínios dos atributos podem incluir apenas valores atômicos, e o valor de qualquer atributo em uma tupla tem que ser simples no domínio deste atributo. É importante notar que a primeira forma normal já faz parte da definição de uma relação.

Segunda forma normal - 2NF. Uma relação está na segunda forma normal se todo atributo $A$ não-primário for completamente funcionalmente dependente ${ }^{*}$ da chave primária da relação. ${ }^{\dagger}$

Terceira forma normal - 3NF. Uma relação $R$ está na terceira forma normal se ela esta na segunda forma normal e nenhum atributo não-primário de $R$ é transitivamente dependente da chave primária. ${ }^{\ddagger}$ Escrito de outra forma, para toda DF $X \rightarrow A$ existente na relação, ou $X$ é chave primária de $R$, ou $A$ é um atributo primário de $R$.

Forma normal Boyce-Cood - BCNF. A forma normal Boyce-Cood corresponde a uma restrição adicional à terceira forma normal. Nesta forma normal, se existe a DF $X \rightarrow A, X$ é superchave de $R$. A diferença com relação à 3NF é que, naquela forma, se $X$ não é superchave, $A$ pode ser atributo primário e a relação ainda satisfaz a terceira forma normal. Esta condição não existe na forma Boyce-Cood. Note que toda relação nesta forma normal também está necessariamente satisfazendo a terceira forma normal.

Quando uma relação não satisfaz qualquer uma das formas normais mencionadas, a solução é quebrar a relação em relações menores que satisfaçam as

\footnotetext{
* Seja $\mathrm{X} \rightarrow \mathrm{Y}$ e $\mathrm{A} \in \mathrm{X}$, defini-se então:

1. Dependência funcional completa: $(X-\{A\}) x \rightarrow Y$;

2. Dependência funcional parcial: $(X-\{A\}) \rightarrow Y$.

${ }^{\dagger} \mathrm{Na}$ definição mais geral da segunda forma normal, todo atributo A não-primário deve ter dependência funcional completa com relação a qualquer chave de $\mathrm{R}$.

* A definição mais geral para a terceira forma normal não restringe as dependências funcionais à chave-primária, mas generaliza para todas as chaves de $\mathrm{R}$
} 
formas normais, processo este chamado de normalização. Estas relações são relacionadas entre si através de chaves primárias e chaves estrangeiras.

\subsubsection{Mapeamento do modelo EER no modelo relacional}

Os modelos conceituais ER e EER podem ser mapeados nos diversos tipos de modelos de implementação, como, por exemplo, o de rede, hierárquico e, inclusive, no modelo relacional. Esta seção resume o mapeamento dos modelos ER e EER no modelo relacional, que é o modelo de implementação usado neste trabalho.

Todos os conceitos lógicos apresentados para o modelo de dados ER podem ser mapeados diretamente no modelo de dados relacional. Já os conceitos adicionais existentes no modelo EER não possuem correspondentes diretos no modelo relacional, mas o mapeamento pode ser feito através de relacionamentos entre relações, havendo neste caso uma perda da semântica que era possível representar usando o modelo EER.

A tabela a seguir apresenta os conceitos do modelo ER com as respectivas regras de mapeamento para o modelo relacional. Os conceitos do modelo EER e as regras de mapeamento, por serem mais complicadas, são apresentadas com mais detalhes em uma outra tabela logo em seguida.

Tabela 12 - Regras de mapeamento do modelo ER para o modelo relacional

\begin{tabular}{|c|c|}
\hline Conceito no modelo ER & Regra para mapear para o modelo relacional \\
\hline Tipo de entidade & $\begin{array}{l}\text { Um tipo de entidade } E \text { é mapeado como uma relação } R \\
\text { com todos os atributos simples de } E \text {. Para atributos } \\
\text { compostos são inseridos os atributos simples que os } \\
\text { compõe. Um dos atributos chave de } E \text { é escolhido para } \\
\text { ser chave primária de } R \text {. }\end{array}$ \\
\hline Tipo de entidade fraco & $\begin{array}{l}\text { Um tipo de entidade fraco } W \text { que possui um tipo de } \\
\text { entidade identificador } E \text { é mapeado como uma relação } \\
R \text {, incluindo nesta relação, como sendo chave } \\
\text { estrangeira, os atributos da chave primária da relação } \\
\text { que corresponde ao tipo de entidade identificador } E \text {. }\end{array}$ \\
\hline $\begin{array}{l}\text { Tipo de relacionamento } \\
1: 1\end{array}$ & $\begin{array}{l}\text { Incluir a chave primária de uma relação como chave } \\
\text { estrangeira da outra relação, ou unir as relações } \\
\text { relacionadas em uma única relação. }\end{array}$ \\
\hline $\begin{array}{l}\text { Tipo de relacionamento } \\
1: \mathrm{N}\end{array}$ & $\begin{array}{l}\text { Incluir a chave primária da relação que está do "lado 1" } \\
\text { do relacionamento como sendo chave estrangeira da } \\
\text { relação que está do "lado N" do relacionamento. }\end{array}$ \\
\hline
\end{tabular}




\begin{tabular}{ll}
\hline \hline Conceito no modelo ER & \multicolumn{1}{c}{ Regra para mapear para o modelo relacional } \\
\hline Tipo de relacionamento & $\begin{array}{l}\text { Criar uma nova relação que inclui, como chaves } \\
\text { estrangeiras, as chaves primárias das relações } \\
\text { participantes. }\end{array}$ \\
$\begin{array}{l}\text { Tipo de relacionamento } \\
\text { de grau n }\end{array}$ & $\begin{array}{l}\text { Ídem ao tipo de relacionamento M-N. } \\
\text { Atributo múltiplo }\end{array}$ \\
$\begin{array}{l}\text { Criar uma relação com o atributo múltiplo } A \text { mais a } \\
\text { chave primária } K \text { da relação correspondente ao tipo de } \\
\text { entidade que possui o atributo múltiplo. A chave } \\
\text { primária desta relação é composta pelos atributos } A \text { e } K .\end{array}$ \\
\hline \hline
\end{tabular}

Fonte: ELMASRI, R.; NAVATHE, S.B., 1989, cap.15.

Tabela 13 - Regras de mapeamento do modelo EER para o modelo relacional

\begin{tabular}{|c|c|}
\hline $\begin{array}{c}\text { Conceito no modelo } \\
\text { EER }\end{array}$ & Regra para mapear para o modelo relacional \\
\hline \multirow[t]{2}{*}{$\begin{array}{l}\text { Relacionamento } \\
\text { superclasse/subclasse }\end{array}$} & $\begin{array}{l}\text { Dada uma especialização com } m \text { subclasses }\left\{S_{1}, S_{2}, \ldots, S_{m}\right\} \\
\text { e uma superclasse } C \text {, onde os atributos de } C \text { são }\left\{k, a_{1}, a_{2} \text {, }\right. \\
\left.\ldots, a_{n}\right\} \text { e } k \text { é a sua chave primária: }\end{array}$ \\
\hline & $\begin{array}{l}\text { Criar uma relação } L \text { para } C \text { e seus atributos e definir } k \\
\text { como a chave primária desta relação. Criar uma relação } L_{i} \\
\text { para cada subclasse } L_{i}, 1 \leq i \leq m \text {, com os atributos } \\
\text { Atrib }\left(L_{i}\right)=\{k\} \cup\left\{\text { atributos de } S_{i}\right\} \text { e } k \text { como chave } \\
\text { primária de cada } L_{i} \text {. }\end{array}$ \\
\hline Opção 2: & $\begin{array}{l}\text { Criar uma relação } L_{i} \text { para cada subclasse } S_{i}, 1 \leq i \leq m \text {, com } \\
\text { os atributos } \operatorname{Atrib}\left(L_{i}\right)=\{k\} \cup\left\{k, a_{1}, a_{2}, \ldots, a_{n}\right\} \text { e } k \text { como } \\
\text { chave primária de cada } L_{i} \text {. }\end{array}$ \\
\hline Opção 3: & $\begin{array}{l}\text { Criar uma única relação } L \text { com os atributos } \operatorname{Atrib}(L)=\{k \text {, } \\
\left.\left.a_{1}, a_{2}, \ldots, a_{n}\right\} \cup\left\{\text { atributos de } S_{1}\right\} \cup \ldots \text { atributos de } S_{m}\right\} \\
\cup\{t\} \text { e } k \text { como chave primária de } L \text {. Esta opção é para } \\
\text { subclasses disjuntas, e } t \text { é um atributo que indica a qual } \\
\text { subclasse a tupla pertence, se ela pertence a alguma. }\end{array}$ \\
\hline Opção 4: & $\begin{array}{l}\text { Criar uma única relação } L \text { com os atributos } \operatorname{Atrib}(L)=\{k \text {, } \\
\left.\left.a_{1}, a_{2}, \ldots, a_{n}\right\} \cup\left\{\text { atributos de } S_{1}\right\} \cup \ldots \text { atributos de } S_{m}\right\} \\
\cup\left\{t_{1}, t_{2}, \ldots, t_{m}\right\} \text { e } k \text { como chave primária de } L . \text { Esta opção } \\
\text { é para subclasses que não são disjuntas, e cada } t_{i} \text {, } \\
1 \leq i \leq m \text {, é um atributo que indica se a tupla pertence à } \\
\text { classe } S_{i} \text {. Esta opção pode gerar uma grande quantidade } \\
\text { de valores nulos. }\end{array}$ \\
\hline $\begin{array}{l}\text { Subclasses } \\
\text { compartilhadas }\end{array}$ & $\begin{array}{l}\text { Pode-se aplicar qualquer uma das opções usadas para } \\
\text { mapear o relacionamento superclasse/subclasse, mas todas } \\
\text { elas devem usar o mesmo atributo como chave, pois do } \\
\text { contrário elas seriam mapeadas como categorias. }\end{array}$ \\
\hline
\end{tabular}




\begin{tabular}{cc}
\hline \hline $\begin{array}{c}\text { Conceito no modelo } \\
\text { EER }\end{array}$ & \multicolumn{1}{c}{ Regra para mapear para o modelo relacional } \\
Categorias & $\begin{array}{l}\text { Cria-se uma relação para a categoria e adiciona-se um } \\
\text { novo atributo para ser a sua chave primária, chamada de } \\
\text { chave surrogate. Em cada relação das superclasses da } \\
\text { categoria adiciona-se um atributo que é a chave surrogate. } \\
\text { A chave surrogate faz a relação entre cada instância da } \\
\text { categoria com a chave de cada superclasse, podendo estas } \\
\text { serem de tipos diferentes. }\end{array}$ \\
\hline \hline
\end{tabular}

Fonte: ELMASRI, R.; NAVATHE, S.B., 1989, cap.15. 


\subsection{Formação de imagens por RMN}

\subsubsection{Introdução}

A técnica de MRI para a obtenção de imagens tomográficas utilizando Ressonância Magnética Nuclear (RMN) consiste, basicamente, no mapeamento da densidade espacial de spins nucleares. Este procedimento é possível através da utilização de algumas espécies nucleares que possuem a propriedade de, na presença de um campo magnético externo, produzir uma pequena magnetização proporcional à densidade de spins nucleares.

Para a área de diagnóstico médico, esta técnica é de extrema importância, pois ela é capaz de distinguir e mapear diferenças substanciais nas propriedades de relaxação de spin nuclear de tecidos normais, necrosados e tumorosos. Estas diferenças também ocorrem entre tecidos de mesma natureza mas em estados fisiológicos diferentes.

A descrição da técnica de MRI abrange vários aspectos, desde a origem do fenômeno da RMN, até os detalhes da montagem dos equipamentos que são usados para a aquisição das imagens. Nesta seção, será feita uma descrição geral da técnica abrangendo o spin nuclear, magnetização, excitação e relaxação, codificação espacial para a geração de imagens, sequiências de aquisição e mecanismos de contraste. $\mathrm{O}$ nível da abordagem será o necessário para um entendimento geral da técnica e para apresentar uma série de parâmetros importantes para a sua aplicação e para a interpretação dos resultados, sendo assim, importantes do ponto de vista dos dados que devem ser armazenados. Uma descrição mais aprofundada destes tópicos e de outros tópicos, como por exemplo, o funcionamento do equipamento que gera as 
imagens de MRI, fogem do âmbito deste trabalho, mas quando necessário são mencionados.

\subsubsection{Spin nuclear, momentos de dipolo magnético e magnetização ${ }^{15}$}

Os núcleos atômicos possuem duas propriedades físicas importantes e que, quando não nulas, dão origem ao fenômeno da RMN: o spin nuclear e o momento de dipolo magnético. O spin nuclear é o momento angular total do núcleo, dado por $\vec{I} \hbar$, e corresponde à soma dos momentos angulares intrínsecos com os momentos angulares orbitais dos prótons e nêutrons do núcleo. Já o momento de dipolo magnético, representado por $\vec{\mu}$, resulta da soma dos momentos de dipolo intrínsecos dos prótons e nêutrons com os momentos de dipolo de origem orbital dos prótons. Na escala de energia onde ocorre o fenômeno da RMN, da ordem de $10^{-6} \mathrm{eV}$, e que é muito abaixo da faixa de energia de $\mathrm{keV}$ em que ocorrem as transições nucleares, é perfeitamente possível assumir que o momento de dipolo magnético de um núcleo é colinear e proporcional ao seu momento angular total, dado então por

$$
\vec{\mu}=\gamma \vec{I} \hbar,
$$

onde $\gamma$ é uma constante característica de cada núcleo, chamada de fator giromagnético.

$\mathrm{Na}$ presença de um campo magnético externo, o momento de dipolo magnético de cada núcleo sofre um torque $\vec{\mu} \times \vec{B}_{0}$ devido a sua interação com o campo. Este torque, sendo normal ao vetor de momento angular do núcleo, faz com que este gire em torno da direção do campo magnético. Sendo o torque igual a variação de momento angular no tempo, podemos escrever:

$$
\frac{d(\vec{I} \hbar)}{d t}=\vec{\mu} \times \vec{B}_{0} .
$$

Sendo $\vec{\mu}=\gamma \vec{I} \hbar$, temos então a seguinte expressão para o movimento do momento de dipolo em torno do campo $\vec{B}_{0}$ :

$$
\frac{d \vec{\mu}}{d t}=\gamma \vec{\mu} \times \vec{B}_{0}=-\gamma \vec{B}_{0} \times \vec{\mu}
$$


A expressão acima diz que a componente de $\vec{\mu}$ perpendicular ao campo externo gira em torno $\vec{B}_{0}$ com freqüência angular igual a $\omega_{0}=\gamma B_{0}$, chamada de Freqüência de Larmor.

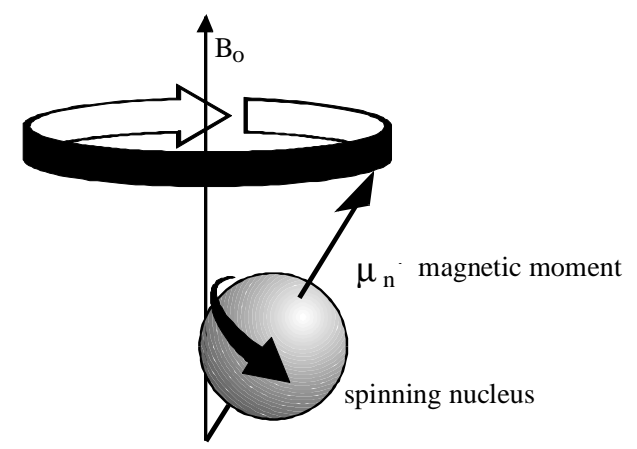

Figura 14 - Momento de dipolo sob ação de um campo magnético.*

Tanto o spin nuclear quanto o momento de dipolo magnético apresentados acima são propriedades características dos núcleos atômicos. Ao considerar uma amostra macroscópica, que consiste de um grande número núcleos, a propriedade importante para o fenômeno da RMN é a magnetização, que é igual a soma vetorial de todos os momentos de dipolo magnético $\vec{\mu}$ existentes na amostra, dada por $\vec{M}=\sum \vec{\mu}$. A técnica de MRI consiste justamente em medir a magnetização resultante em volumes elementares (voxels) de amostras macroscópicas e associar a intensidade da magnetização em cada voxel aos valores do pixels da imagem correspondente.

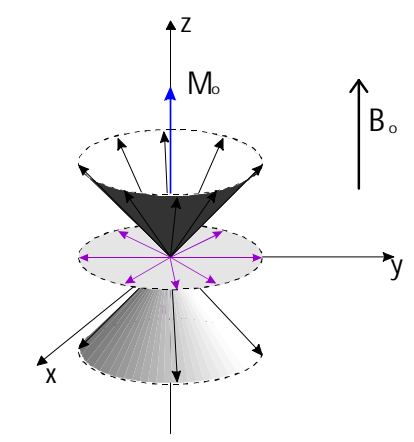

Figura 15 - Magnetização devido a presença de um campo magnético na direção $z .^{\dagger}$

\footnotetext{
* PANEPUCCI, H.; TANNÚS, A., 1994, p.4, figura 1.

${ }^{\dagger}$ Adaptado de PANEPUCCI, H.; TANNÚS, A., 1994, p.2, figura 2.
} 
Na ausência de um campo magnético, os momentos de dipolo magnético ficam orientados aleatoriamente, resultando numa magnetização total nula. Na presença de um campo magnético $\vec{B}_{0}$, os momentos de dipolo giram em torno da direção do campo com frequiência $w_{0}$, mas com fases aleatórias quando em equilíbrio térmico, resultando, então, numa magnetização transversal ao campo $\vec{B}_{0}$ nula:

$$
\vec{M}_{T}=0 \text {. }
$$

Já na direção longitudinal ao campo, devido à agitação térmica, existem componentes dos momentos de dipolo paralelas e antiparalelas ao campo, mas com uma pequena fração de componentes paralelas ao campo em excesso, da ordem de $\mu B_{0} / k T$ (tipicamente uma parte em $10^{4}$ ), cada uma com momento de dipolo magnético $\vec{\mu}$, gerando uma magnetização resultante dada pela Lei de Curie:

$$
\vec{M}_{L}=\vec{M}_{0}=\chi \vec{B}_{0},
$$

onde $\chi=\left(N \gamma^{2} \hbar^{2} I(I+1)\right) / 3 k T$ é a suscetibilidade nuclear.

Da expressão acima é possível entender o porquê da extensa utilização de núcleos de átomos de hidrogênio para a realização de MRI. Por um lado, o núcleo do átomo de hidrogênio possui o maior $\gamma$, e por outro lado, como grande parte da constituição dos tecidos vivos é água $\left(\mathrm{H}_{2} \mathrm{O}\right)$, a quantidade $N$ de spins deste átomo é relativamente grande, contribuindo para uma maior magnetização resultante. Como a intensidade $M_{0}$ é diretamente proporcional à intensidade do campo magnético externo $B_{0}$, altos campos magnéticos são utilizados em MRI para se obter a maior magnetização resultante possível.

\subsubsection{O fenômeno da RMN, relaxação e ecos de spin}

O fenômeno básico que permite a medida da magnetização dos voxels é a Ressonância Magnética Nuclear (RMN), que consiste na excitação ressonante, através de radiofreqüência $(\mathrm{RF})$, dos spins nucleares em um campo magnético, e a subseqüente observação da resposta do sistema de spins. Este fenômeno foi descoberto simultaneamente por F. Bloch e N. Bloembergen em 1946. 
A excitação ressonante ocorre com a aplicação de um campo magnético oscilante e transversal com freqüência próxima à de precessão dos momentos de dipolo nucleares. Como as frequiências de Larmor para spins nucleares em campos de alguns Teslas são sempre da ordem de $\mathrm{MHz}$, a excitação é obtida através da aplicação de um campo oscilatório de radiofreqüência.

Para entender como um campo de RF pode agir sobre a magnetização de um sistema, considere-se o seguinte exemplo em que um gerador de RF, capaz de gerar pulsos de duração $\tau$ segundos, é conectado em uma bobina cuja configuração permite produzir um campo magnético perpendicular ao campo $B_{0}$.

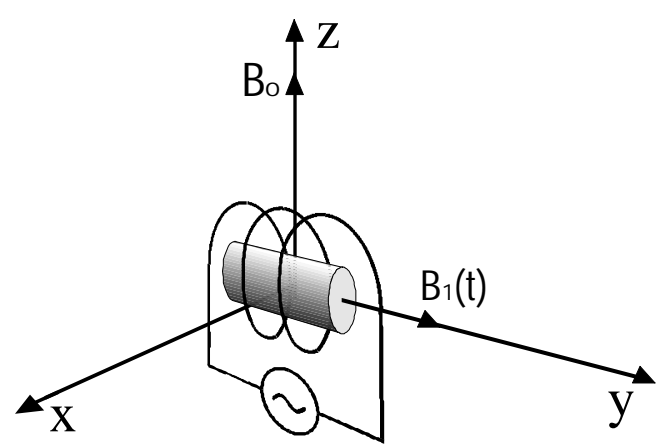

\section{Figura 16 - Esquema de um gerador de RF produzindo um campo $B_{I}(t)$ perpendicular a $B_{0}{ }^{*}$}

Considere que o campo está oscilando com uma freqüência $\omega_{l}$ igual à de Larmor $\omega_{0}$, e que a sua amplitude é igual a $2 B_{1}$. Como pode-se ver na figura abaixo, este campo oscilante pode ser visto como a superposição de dois campos circularmente polarizados, mas girando em sentidos opostos, cada um com freqüência $\omega_{l}$ e amplitude $B_{l}$.

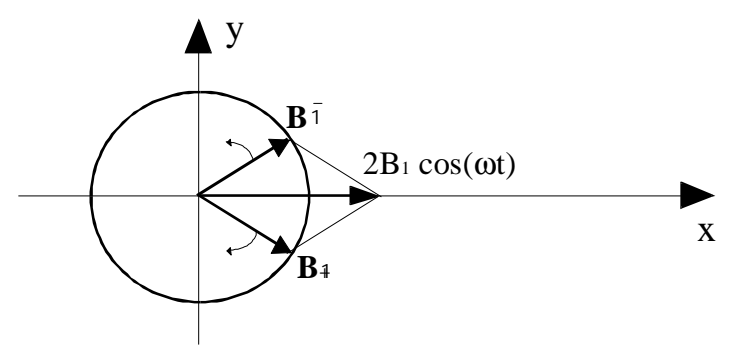

Figura 17 - Decomposição do campo de RF em dois campos circularmente polarizados.

\footnotetext{
* PANEPUCCI, H.; TANNÚS, A., 1994, p.4, figura 5.
} 
Para os spins nucleares precessionando com freqüência $w_{0}$ devido ao campo $B_{0}$, um dos campos girantes vai parecer estacionário, enquanto o outro vai parecer estar girando muito rapidamente. O efeito deste último pode ser desprezado em uma primeira aproximação, restando, então, observar a ação do primeiro campo que gira em fase com a precessão dos spins. Imaginando a situação de um sistema de coordenadas girante que acompanha o campo $B_{1}$, os momentos de dipolo nucleares sentem apenas um campo "estático" $B_{1}$, perpendicular à magnetização $M_{0}$. Este campo exerce um torque sobre os spins e faz com que eles girem em torno da direção definida por $B_{1}$ com uma freqüência angular de $\omega_{1}=\gamma B_{1}$. Como a magnetização total é igual a soma de todos os momentos de dipolo, ela conseqüentemente também gira em torno de $B_{l}$ com uma freqüência $\omega_{l}$.

Como o gerador de RF deste exemplo produz um pulso de $\tau$ segundos, a magnetização, que inicialmente era paralela a $M_{0}$, gira ao redor de $B_{1}$ de um ângulo, chamado de ângulo de flip, dado por:

$$
\theta=\omega_{1} \tau=\gamma B_{1} \tau .
$$

Desta forma, cria-se uma magnetização transversal $M_{T}=M_{0} \operatorname{sen} \theta$ que, sob ação do campo $B_{0}$, gira em torno deste campo com freqüência $\omega_{0}$. Controlando-se o tempo $\tau$ de duração do pulso de RF pode-se, então, escolher o ângulo de flip da magnetização. A figura abaixo mostra uma rotação genérica da magnetização e dois casos importantes, onde os ângulos de flip são $\pi / 2$ e $\pi$, em que os pulsos são usados, respectivamente, para excitar e inverter a magnetização.

\footnotetext{
* PANEPUCCI, H.; TANNÚS, A., 1994, p.4, figura 6.
} 


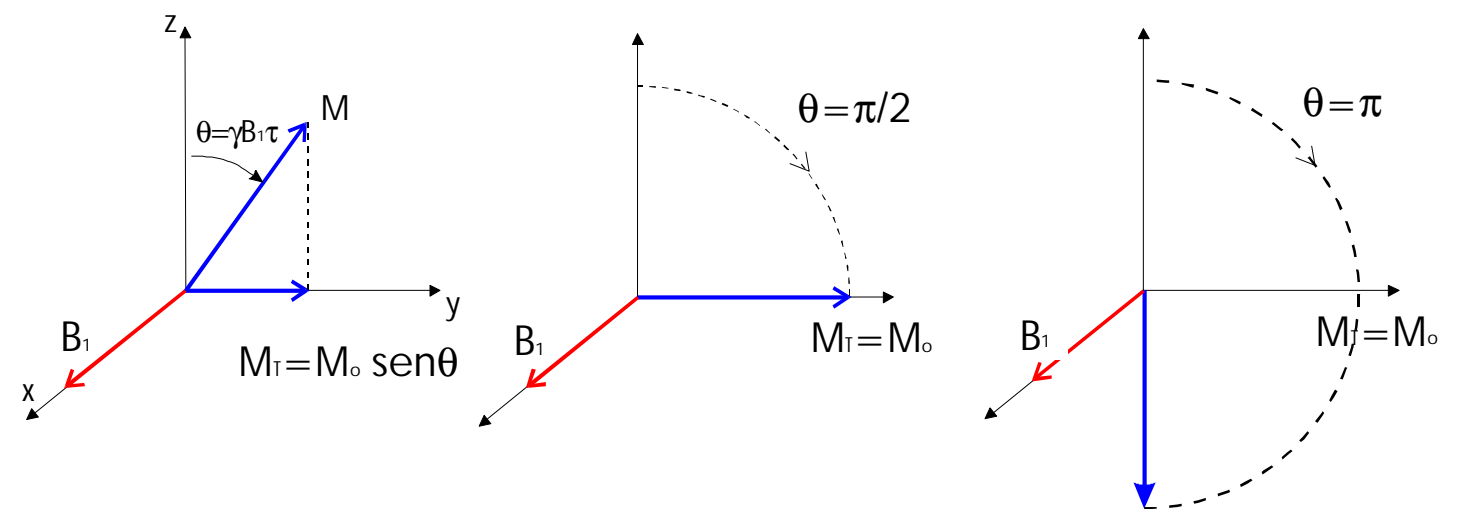

Figura 18 - Aplicação de pulsos com ângulos de flip $\theta, \pi / 2$ e $\pi{ }^{*}$

Se após a aplicação de um pulso de excitação, por exemplo, um pulso de $\pi / 2$ em que a magnetização é completamente jogada para o plano transversal, não houvessem mecanismos para o sistema de spins retornar ao equilíbrio, isto é, com $\vec{M}$ ao longo do eixo $z$, a magnetização permaneceria precessionando em torno de $B_{0}$ indefinidamente. Entretanto, o que se observa é que o sistema retorna exponencialmente a configuração original de equilíbrio térmico com $M_{L}=M_{0}$ e $M_{T}=0$. Este processo é chamado de relaxação e possui tempos característicos $\boldsymbol{T}_{\boldsymbol{I}} \mathrm{e}$ $\boldsymbol{T}_{2}$, respectivamente chamados de tempo de relaxação longitudinal e tempo de relaxação transversal.

Os processos de relaxação envolvem mecanismos microscópicos em que ocorrem flutuações aleatórias nas interações entre os spins. No caso de prótons em tecidos, a interação mais relevante é de dipolo-dipolo existente entre os momentos $\mu_{i}$. Cada dipolo magnético produz um campo local nos outros dipolos, fazendo com que existam flutuações locais no campo magnético efetivo sentido por cada spin. Como a freqüência de precessão é proporcional ao campo, os spins precessionam com velocidades angulares diferentes, fazendo com que eles percam a fase que existia logo após a excitação para o plano transversal. Após algum tempo, a direção dos dipolos é completamente distribuída no plano transversal e, conseqüentemente, a magnetização transversal resultante fica nula.

Já a relaxação longitudinal ocorre através da perda de energia do sistema para a rede. Este processo é induzido pelas componentes perpendiculares ao campo

\footnotetext{
* PANEPUCCI, H.; TANNÚS, A., 1994, p.5, figura 8.
} 
magnético principal dos campos flutuantes existentes na amostra, e contribui para o alinhamento dos spins com o campo magnético externo. Como este processo também faz com que a magnetização transversal diminua, o tempo característico $T_{2}$ é sempre menor, ou no máximo igual, ao tempo $T_{1}$.

Considerando que no instante $t=0$ a magnetização acabou de ser jogada no plano transversal por um pulso $\pi / 2$, isto é, $M_{L}=0$ e $M_{T}=M_{0}$, tem-se então as seguintes expressões para a evolução das duas componentes da magnetização:

$$
\begin{gathered}
M_{L}(t)=M_{0}\left(1-e^{-t / T_{1}}\right), \\
M_{T}(t)=M_{0} e^{-t / T_{2}} .
\end{gathered}
$$

A expressão para a magnetização transversal acima assume que o sistema é visto do referencial girante que acompanha a precessão dos spins em torno de $B_{0}$. Se observada do sistema de coordenadas do laboratório, a Equação 9 é escrita da seguinte forma:

$$
M_{T}(t)=M_{0} e^{i \omega_{0} t} e^{-t / T_{2}} .
$$

Como já dito anteriormente, a magnetização transversal, estando sujeita ao campo externo, precessiona e, conseqüentemente, produz um campo oscilante no plano transversal. Ao utilizar uma bobina normal ao campo externo, como no exemplo da Figura 19, e ligada a um sistema de recepção, como, por exemplo, um osciloscópio, pode-se observar a força eletromotriz induzida nesta bobina de recepção pela variação do fluxo do campo magnético oscilante da magnetização. O sinal observado no osciloscópio é chamado de Free Induction Decay (FID). Ele oscila com uma freqüência $w_{0}$ e sua amplitude, que é proporcional a quantidade de núcleos originalmente excitados, diminui com o tempo devido a relaxação transversal e longitudinal. 

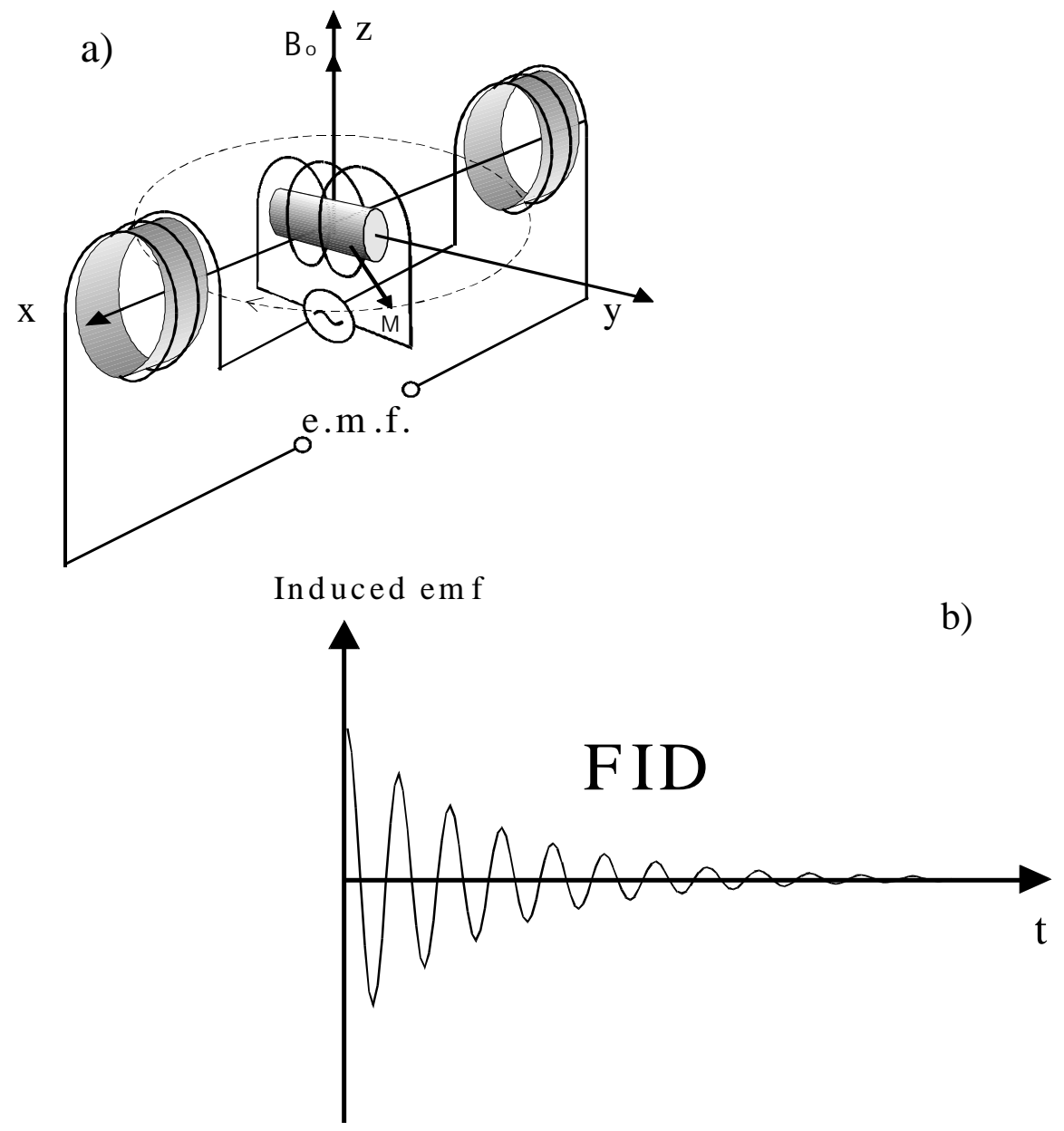

Figura 19 - Esquema do sistema de recepção (a) e o sinal do FID (b).*

Um aspecto importante a ser considerado é a impossibilidade prática de se ter um campo $B_{0}$ completamente homogêneo. Mesmo os melhores magnetos possuem uma pequena falta de homogeneidade que acarreta uma dispersão na freqüência de precessão dos spins. Considerando $\langle\Delta B\rangle$ o valor médio quadrático dos desvios do campo $B_{0}$ em torno de um voxel, as freqüências de precessão dos spins terão uma variação média de $\Delta \omega=\gamma\langle\Delta B\rangle$, acarretando um aumento na taxa de defasagem dos spins e, conseqüentemente, diminuindo a magnetização transversal mais rapidamente. Usualmente, em tecidos biológicos, este efeito é maior que a ação dos campos internos, fazendo com que os spins fiquem defasados por um ciclo completo de $2 \pi \mathrm{em}$ um tempo $T_{2}^{*}$ tal que $\Delta \omega T_{2}^{*} \approx 2 \pi$. Como geralmente $T_{2}^{*} \ll<T_{2}, T_{2}^{*}$ é o tempo efetivo de relaxação transversal, sendo ele o tempo característico observado no decaimento

\footnotetext{
*PANEPUCCI, H.; TANNÚS, A., 1994, p.6, figura 9.
} 
do sinal do FID. Exemplificando, para um magneto de campo de 0,5 Tesla e homogeneidade de $10 \mathrm{ppm}$, tem-se que $T_{2}^{*} \approx 5 \mathrm{~ms}{ }^{16}$

Ao contrário do processo de relaxação por $T_{2}$, originário de interações aleatórias entre os spins, que é um processo termodinâmico irreversível de aumento de entropia do sistema, a relaxação por $T_{2}^{*}$, tendo como origem variações estáticas da homogeneidade do campo, é um processo, em princípio, reversível. Uma forma de recuperar a fase dos spins que sofreram relaxação por $T_{2}^{*}$ é a aplicação de um pulso $\pi$ algum tempo após o pulso de $\pi / 2$, como mostrado na figura a seguir.

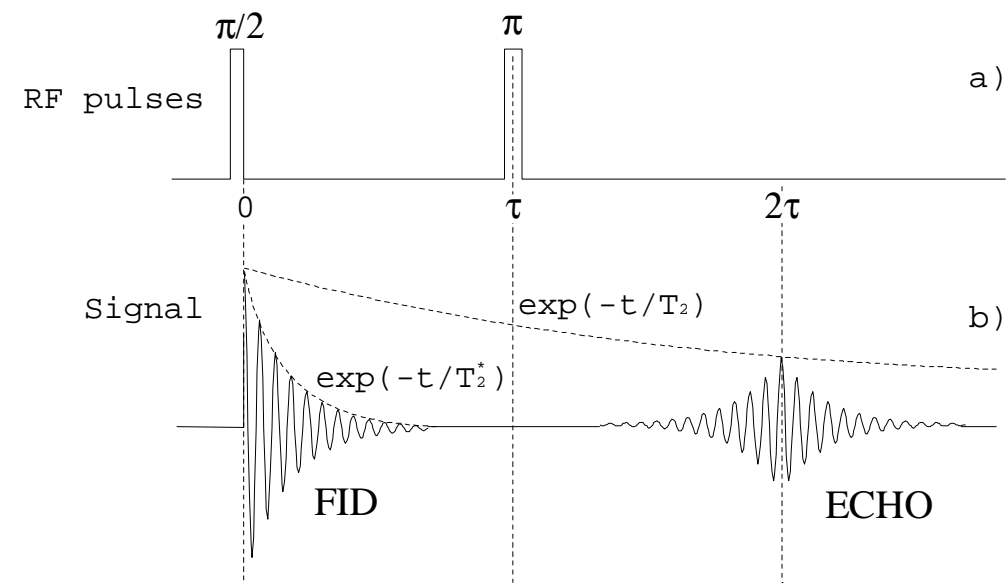

Figura 20 - Formação de um eco de spin.

Após a excitação do sistema com um pulso de $\pi / 2$, observa-se o FID com o tempo relaxação característico de $T_{2}^{*}$. Se depois de um tempo $\tau$ da aplicação do primeiro pulso for aplicado um pulso $\pi$, será possível observar o ressurgimento da magnetização transversal, com um máximo no instante $2 \tau$, seguido de um novo decaimento. Este fenômeno é chamado de eco de spin. Após o pulso de $\pi / 2$, os spins perdem a fase pois alguns precessionam com uma freqüência maior que $\omega_{0}$ e outros com uma freqüência menor. $\mathrm{O}$ pulso de $\pi$ gira todos os momentos de dipolo de $180^{\circ}$ em torno do eixo de excitação. Nesta nova posição, os momentos de dipolo continuam a precessionar com a mesma freqüência de antes, só que desta vez eles voltam a recuperar a fase e depois continuam a relaxação perdendo a fase novamente. Note que a amplitude do sinal no instante em que todos os spins recuperam a fase é

\footnotetext{
* PANEPUCCI, H.; TANNÚS, A., 1994, p.9, figura 12.
} 
inferior a amplitude inicial, e isso se deve à relaxação por $T_{2}$ que continua ocorrendo simultaneamente a este processo.
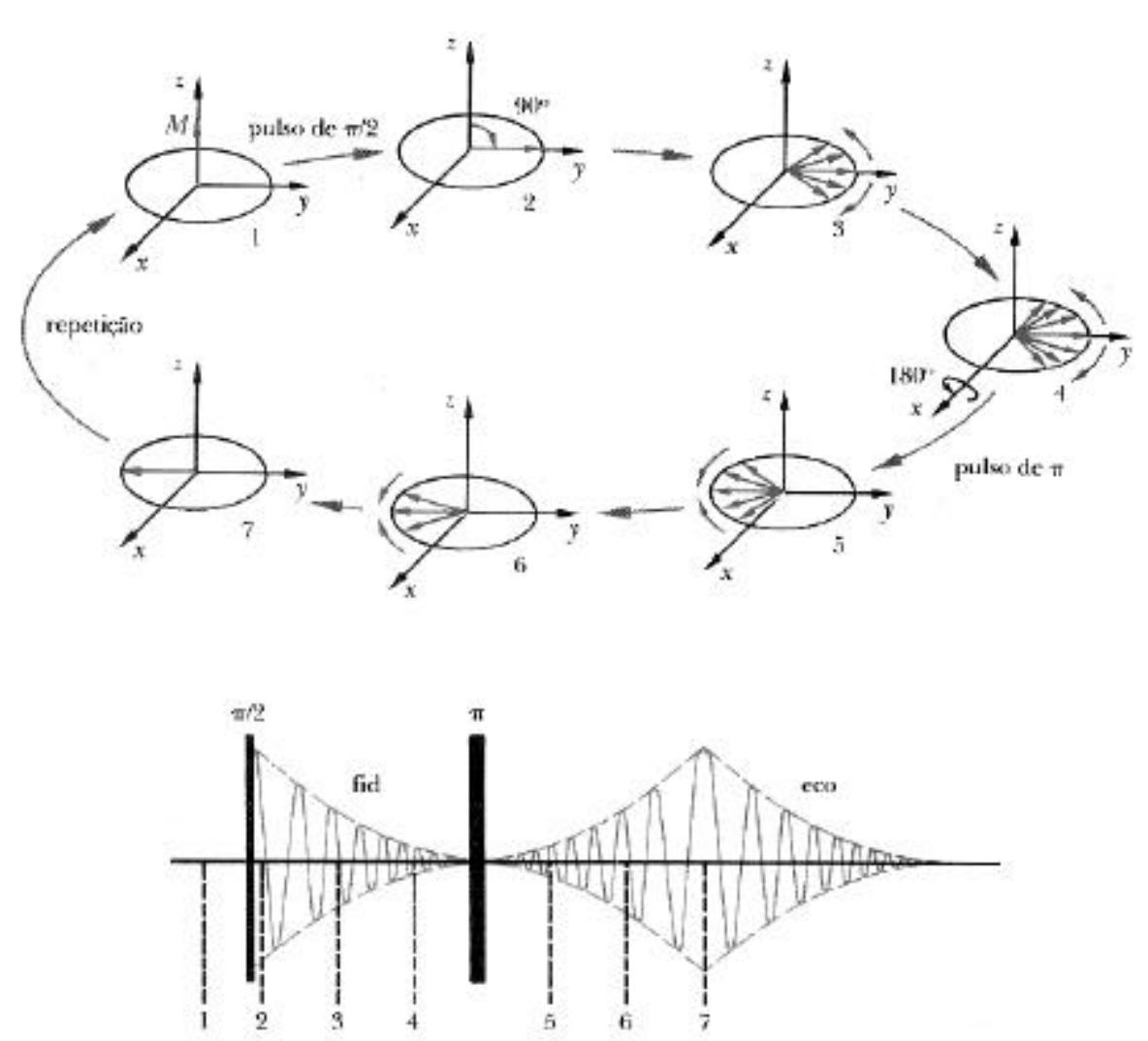

Figura 21 - Formação do eco de spin, com destaque à magnetização no plano transversal.*

Apesar da técnica de RMN ser conhecida desde a década de 40, apenas a partir de 1971 é que se percebeu o potencial de aplicação desta técnica para a identificação e caracterização de tecidos biológicos, com a observação de que existiam diferenças sistemáticas nas propriedades de relaxação nuclear de tecidos normais, necrosados e tumorosos. ${ }^{2}$ Como mostra a Tabela 14, os valores de $T_{1}$ e $T_{2}$ dependem não apenas das espécies nucleares usadas, mas também da composição química do material. Valores típicos para $T_{1}$ são de 300 a $600 \mathrm{~ms}$, e de $T_{2}$ são de 30 a 80 ms para tecidos biológicos. ${ }^{16}$

\footnotetext{
* PANEPPUCCI, H. et al., Ciência Hoje, 1985, p.54, figura 10.
} 
Tabela 14 - Tempos de relaxação $T_{1}$ e $T_{2}$ de prótons em biópsias de doenças em seio humano.

\begin{tabular}{lccc}
\hline \hline \multicolumn{1}{c}{ Tecido } & Amostragem & $\mathbf{T}_{\mathbf{1}}(\mathbf{m s})$ & $\mathbf{T}_{\mathbf{2}}(\mathbf{m s})$ \\
\hline Normal & 7 & $682 \pm 32$ & $35,5 \pm 3,5$ \\
Fibrocystic & 21 & $655 \pm 21$ & $37,0 \pm 3,0$ \\
Fibroadenoma & 8 & $980 \pm 51$ & $62,5 \pm 7,3$ \\
Adenocarconoma & 17 & $874 \pm 28$ & $68,6 \pm 2,3$ \\
\hline \hline
\end{tabular}

Fonte: Adaptado de MEDINA apud BEALL.

Como será mostrado adiante, estas diferenças entre os tempos de relaxação de diferentes tecidos pode ser usado para obter imagens com contraste que distinguem estes tecidos.

\subsubsection{Descrição qualitativa da codificação espacial}

Quando a amostra está apenas submetida a um campo magnético homogêneo e constante no tempo, o sinal induzido na bobina de recepção, que é proporcional à magnetização resultante, contém informação apenas sobre a freqüência de presseção $\omega_{0}$ e sobre a relaxação transversal por $T_{2}$. Nesta situação não existe nenhuma informação adicional sobre a distribuição espacial dos spins nucleares embutida no sinal do FID.

A codificação espacial se baseia na dependência da freqüência de Larmor de precessão dos spins nucleares com a intensidade do campo magnético que atua sobre os spins. Se, ao invés de um campo magnético homogêneo e constante, for aplicado sobre uma amostra um campo magnético que possua uma dependência espacial e temporal, cada spin nuclear irá precessionar com uma freqüência determinada pelo campo local, da mesma forma que a magnetização transversal de cada volume elementar da amostra. Assim, a expressão para a freqüência de Larmor para um campo magnético genérico é dada por

$$
\omega(\vec{r}, t)=\gamma B(\vec{r}, t) .
$$

\footnotetext{
* MEDINA, D. et al. Nuclear magnetic resonance studies on human breast dysplasias and neoplasms. J. Natl. Cancer Inst., v.54, n.813, 1975.
} 
Em geral, o campo $B(\vec{r}, t)$ é obtido com a superposição de um campo magnético principal $B_{0}$, homogêneo e constante, com gradientes de campo magnético nas direções $x, y$ e $z$ que podem variar de amplitude em função do tempo.

Para exemplificar como é possível realizar a codificação espacial utilizando a dependência da freqüência de Larmor com a intensidade do campo local, é ilustrativo iniciar com um caso em apenas uma dimensão, onde três tubos de ensaio com diferentes quantidades de água são colocados em posições diferentes ao longo do eixo $x$, como mostrado na figura a seguir. 
(a)
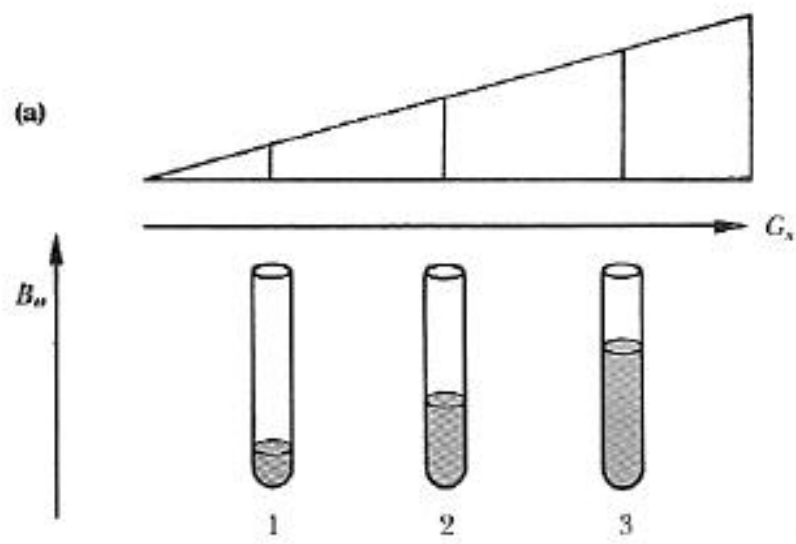

(b) fids individuais
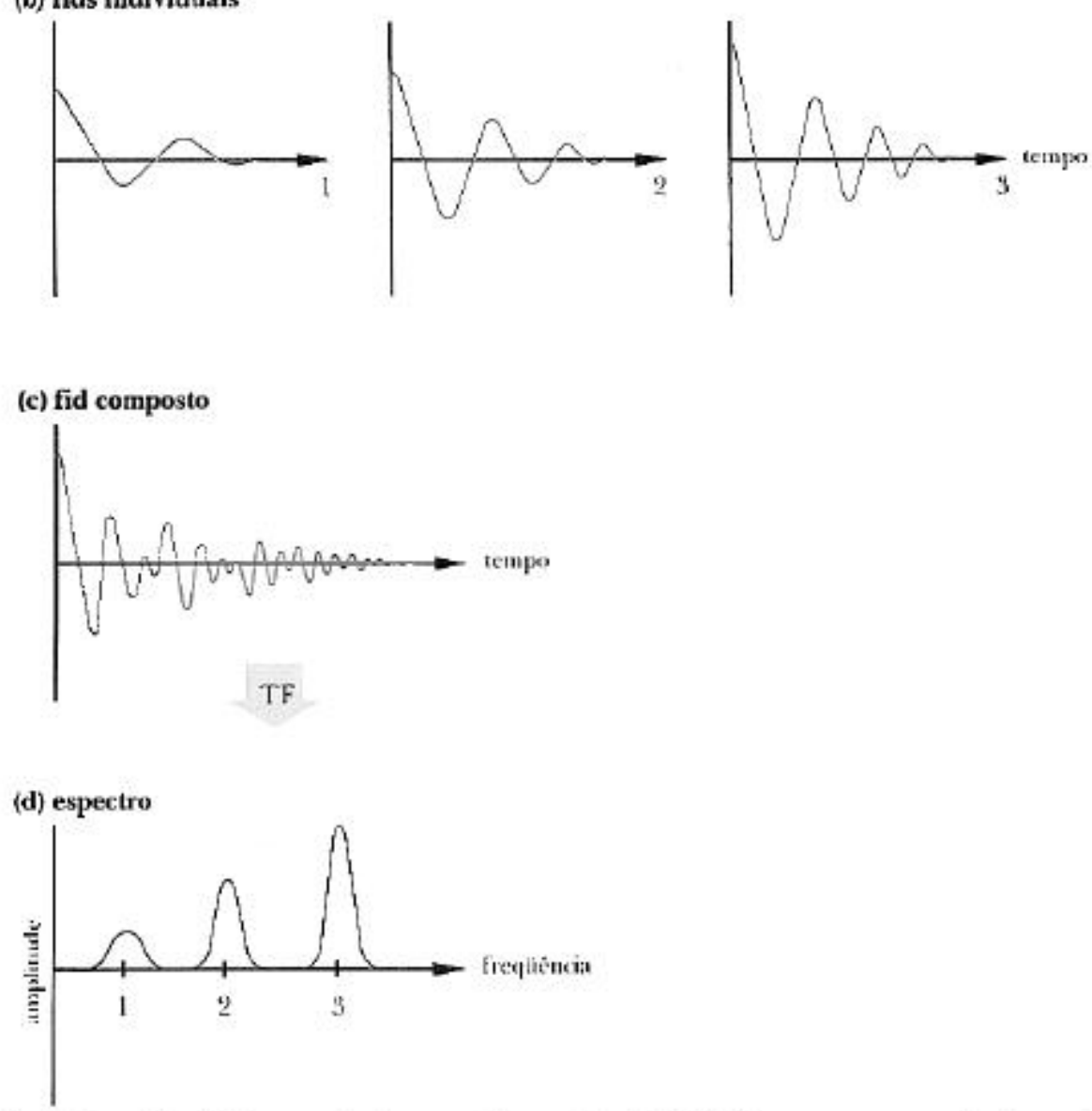

Figura 22 - Exemplo de codificação espacial em usando três tubinhos com água.*

O gradiente $G_{x}$ faz com que cada tubo esteja submetido a um campo magnético diferente, de acordo com a sua posição no eixo $x$ (Figura 22-a). Aplicando um pulso de RF de $\pi / 2$ com um espectro que contenha as frequiências de Larmor dos núcleos de cada tubo, a magnetização de cada um será jogada no plano $x$-y e começará a precessionar com a freqüência de Larmor dada por: 


$$
\omega(x)=\gamma B(x)=\gamma\left(B_{0}+G_{x} x\right) .
$$

O FID de cada tubo terá uma freqüência específica (Figura 22-b) dada pela Equação (12), mas o sinal resultante será a soma dos três FIDs (Figura 22-c). Através de uma transformada de Fourier deste sinal, é possível obter o seu espectro de frequiências, onde as freqüências e intensidades relativas indicam, respectivamente, as posições e as quantidades de spins de cada tubo (Figura 22-d). É importante destacar, porém, que a codificação espacial deste exemplo foi realizada apenas na direção $x$. Cada um dos tubos também possui uma extensão nas outras direções espaciais, $y$ e $z$, e os FIDs individuais produzidos por cada tubo são provenientes de toda a extensão do tubo. Assim, se houver uma distribuição espacial da água nos tubos que dependa das coordenadas $y$ e $z$, ela não será observada no resultado final, o que significa dizer, em outras palavras, que cada FID individual é proveniente de todos os spins nucleares existentes no plano $y-z$ do espaço correspondente a região $x$ de cada tubo.

Este exemplo em uma dimensão possui uma aplicação prática imediata, que é a seleção de planos para imagens bidimensionais. Se, ao invés de aplicar um pulso de excitação que contenha todas as freqüências de Larmor da amostra, usar um pulso seletivo com um espectro freqüências restrito a um faixa de valores correspondente a uma região do eixo $x$, apenas os spins do tubo nesta região serão excitados. Consequientemente, o FID resultante terá apenas o sinal proveniente deste tubo.

A excitação seletiva é o primeiro passo para se obter uma imagem bidimensional correspondente a um plano de um objeto. Da mesma forma que um gradiente na direção $x$ seleciona um plano perpendicular a esta direção, um gradiente numa direção $\zeta$ qualquer seleciona um plano perpendicular a esta direção. Assim, para excitar uma fatia de espessura $\Delta \zeta$ centrada em $\zeta_{0}$, é necessário aplicar um pulso de RF com frequiência central igual a $\omega\left(\zeta_{0}\right)$ e largura espectral de $\Delta \omega=\gamma G_{\zeta} \Delta \zeta$. Este pulso de seleção deve ser aplicado na presença de um gradiente de seleção $G_{\zeta}$ que faz com que a frequiência de Larmor dos núcleos varie ao longo da direção $\zeta$ de acordo $\operatorname{com} \omega(\zeta)=\gamma\left(B_{0}+G_{\zeta} \zeta\right)$

\footnotetext{
* PANEPPUCCI, H. et al., Ciência Hoje, 1985, p.48.
} 
Para o caso de imagens bidimensionais, uma vez selecionado o plano para a imagem, por exemplo o plano $z$, resta codificar as posições do plano nas outras direções, neste caso, $x$ e $y$. O principal método para realizar esta codificação é o método da transformada de Fourier direta (DFI - Direct Fourier Imaging), que é o mais utilizado devido a relação direta entre a transformada de Fourier de um sinal de RMN sujeito a gradientes de campo e a posição e quantidade de spins da amostra.

Ao contrário do exemplo dado para seleção de um plano através de gradiente de campo, no qual ocorre a seleção de apenas uma coordenada espacial, um campo magnético que varie em um plano, por exemplo $B(x, y)$, não é suficiente para codificar unicamente uma dada posição $(x, y)$ do plano. Isto ocorre devido a continuidade do campo magnético, que impossibilita a existência de um campo $B(x, y)$ diferente para cada coordenada $(x, y)$. A solução para este problema é utilizar campos magnéticos que sejam função da posição e também do tempo. Este tipo de campo é obtido sobrepondo-se gradientes de campo magnético dependentes do tempo sobre o campo magnético principal.

Os detalhes de como são aplicados os gradientes de campo e como é feita a leitura do sinal varia para cada tipo de seqüência de aquisição. Para a aquisição de imagens bidimensionais no plano $x-y$, a técnica de codificação é basicamente a seguinte:

1. cada etapa da aquisição inicia-se com uma excitação seletiva da fatia da amostra de onde se deseja obter a imagem. Para isso é utilizado um gradiente de seleção na direção $z$ e é aplicado um pulso de RF de $\pi / 2$. Após a excitação, a fatia do objeto terá a magnetização em todos os seus voxels precessionando em fase e com a mesma freqüência no plano $x-y$ (Figura 23-a);

2. é então aplicado um gradiente na direção y por um tempo determinado e amplitude Gy. Na presença deste gradiente, a magnetização dos voxels irá evoluir com uma freqüência $\omega(y, t)$ que é função da coordenada $y$ do voxel. Após a aplicação deste gradiente, a magnetização de todos os voxels volta a precessionar com a mesma frequiência, mas com fases diferentes ao longo da direção $y$. Essa etapa é chamada de codificação de fase (Figura 23-b); 
3. Durante a aquisição do sinal de RMN resultante, na etapa de codificação de freqüência, é aplicado um gradiente na direção $x$ que faz com que a freqüência de precessão dos spins seja proporcional à coordenada $x$ dos voxels (Figura 23-c).

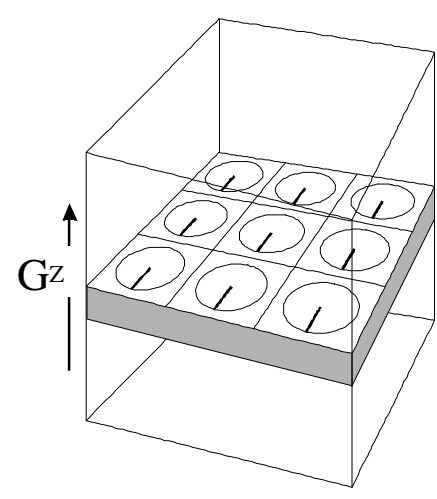

(a)

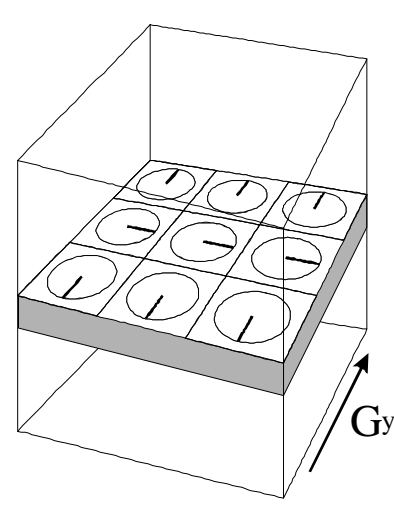

(b)

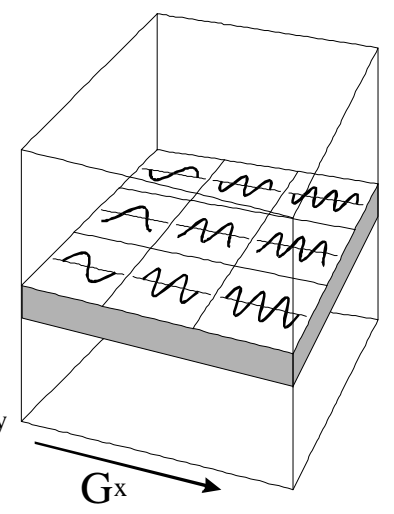

(c)

Figura 23 - Esquema das codificações em fase e freqüência em um plano."

Todo o processo é repetido utilizando um gradiente de codificação de fase, $G y$ neste exemplo, diferente a cada etapa, com o objetivo de obter o sinal de RMN para as diferentes fases aplicadas aos spins na direção $y$. Desta forma é possível codificar o espaço $x$-y usando a codificação de frequiência, através de $G x$, e a codificação de fase, através de $G y$. Realizando uma transformada de Fourier bidimensional nas variáveis $t$ e $G y$ obtém-se a distribuição da magnetização $M(x, y)$ ao longo do plano. O número de etapas de codificação de fase define o número de linhas da imagens final, e o número de pontos obtidos na leitura do sinal corresponde ao número de colunas da imagem.

\footnotetext{
* PANEPUCCI, H.; TANNÚS, A., 1994, p.18, figura 18.
} 


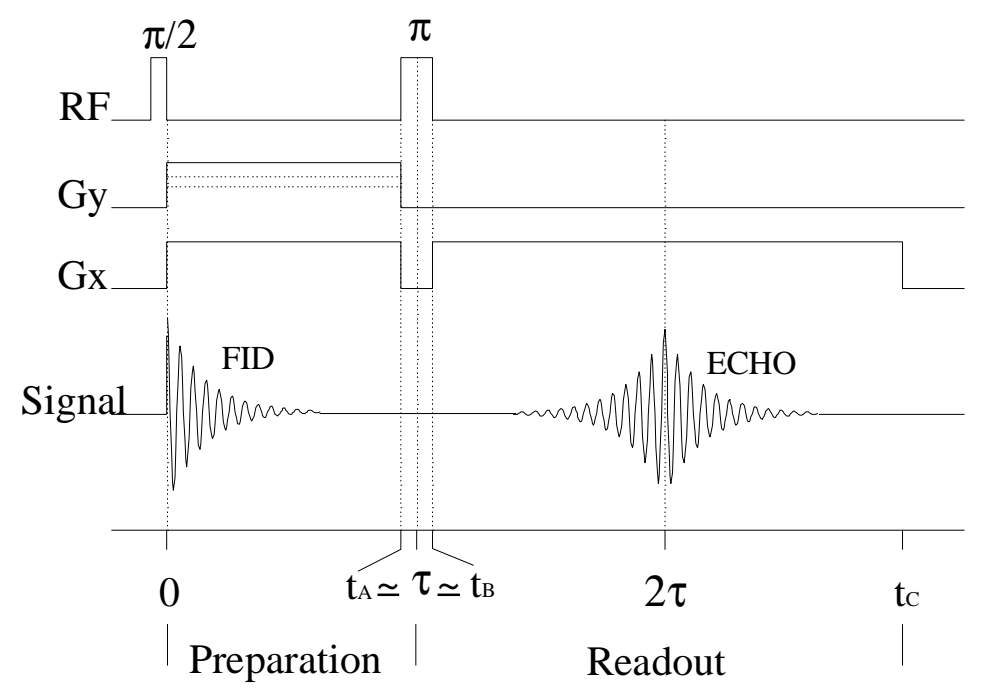

Figura 24 - Seqüiência de aquisição Spin-echo."

A Figura 24 mostra uma seqüência típica, chamada de Spin-eco, que utiliza a metodologia explicada acima:

1. durante a aplicação de um gradiente de seleção na direção $z$ (não indicado na figura), é aplicado um pulso de seleção de $\pi / 2$.

2. na fase de preparação, é aplicado o gradiente de codificação de fase $G y$ e um gradiente de codificação de freqüência $G_{x}$;

3. com apenas o gradiente de seleção acionado, é então aplicado um pulso de $\pi$ para inverter a magnetização e produzir um eco;

4. o sinal do eco é adquirido em $N$ amostragens, simultaneamente a aplicação do gradiente de codificação de freqüência $G_{x}$ (gradiente de leitura);

5. todo o processo é repetido $M$ vezes, com diferentes gradientes $G y$, para se obter a codificação em $M$ diferentes fases.

Ao final de todo o processo, tem-se uma matriz com $M$ linhas, cada uma com os sinais do eco adquiridos em cada fase e amostrados em $N$ pontos, o que corresponde a $N$ colunas na matriz de dados final. A transformada de Fourier bidimensional é aplicada nesta matriz, resultando numa imagem da magnetização no plano $x-y$ selecionado.

Neste exemplo, o plano usado é perpendicular a direção z. Em um caso geral, com combinações de gradientes nas direções $x, y$ e $z$, é possível criar gradientes de

\footnotetext{
*PANEPUCCI, H.; TANNÚS, A., 1994, p.18, figura 18.
} 
seleção e codificação em qualquer direção desejada, possibilitando assim obter imagens de planos em qualquer direção.

Uma descrição mais formal da codificação espacial usando gradientes de campo é apresentada no Apêndice III. Nele é apresentado o conceito de espaço-k e a sua relação com as imagens. Também são apresentadas algumas condições teóricas que devem ser satisfeitas para se obter imagens com boa resolução.

\subsubsection{Seqüências de aquisição e tipos de contraste}

Em MRI, existem várias combinações de aplicação de pulsos de excitação e gradientes de seleção, codificação e leitura. Cada combinação é chamada de sequiência, e existem várias sequiências que são largamente utilizadas. Dependendo da sequiência utilizada é possível obter sinal de um ponto da amostra, de um plano e até de um volume inteiro. ${ }^{17}$ Embutido neste sinal está a codificação espacial, de forma que é possível, à partir dele, reconstruir uma imagem que represente a distribuição de núcleos na amostra.

Os métodos mais utilizados são os planares, que permitem obter planos tomográficos do objeto em estudo. Nestes métodos, o primeiro passo é realizar uma excitação seletiva do plano cuja imagem se deseja obter. Assim, se apenas os núcleos de uma fatia forem excitados, o sinal observado resultante da relaxação será proveniente apenas desta fatia. Algumas seqüências tradicionais estão exemplificadas na figura a seguir. 

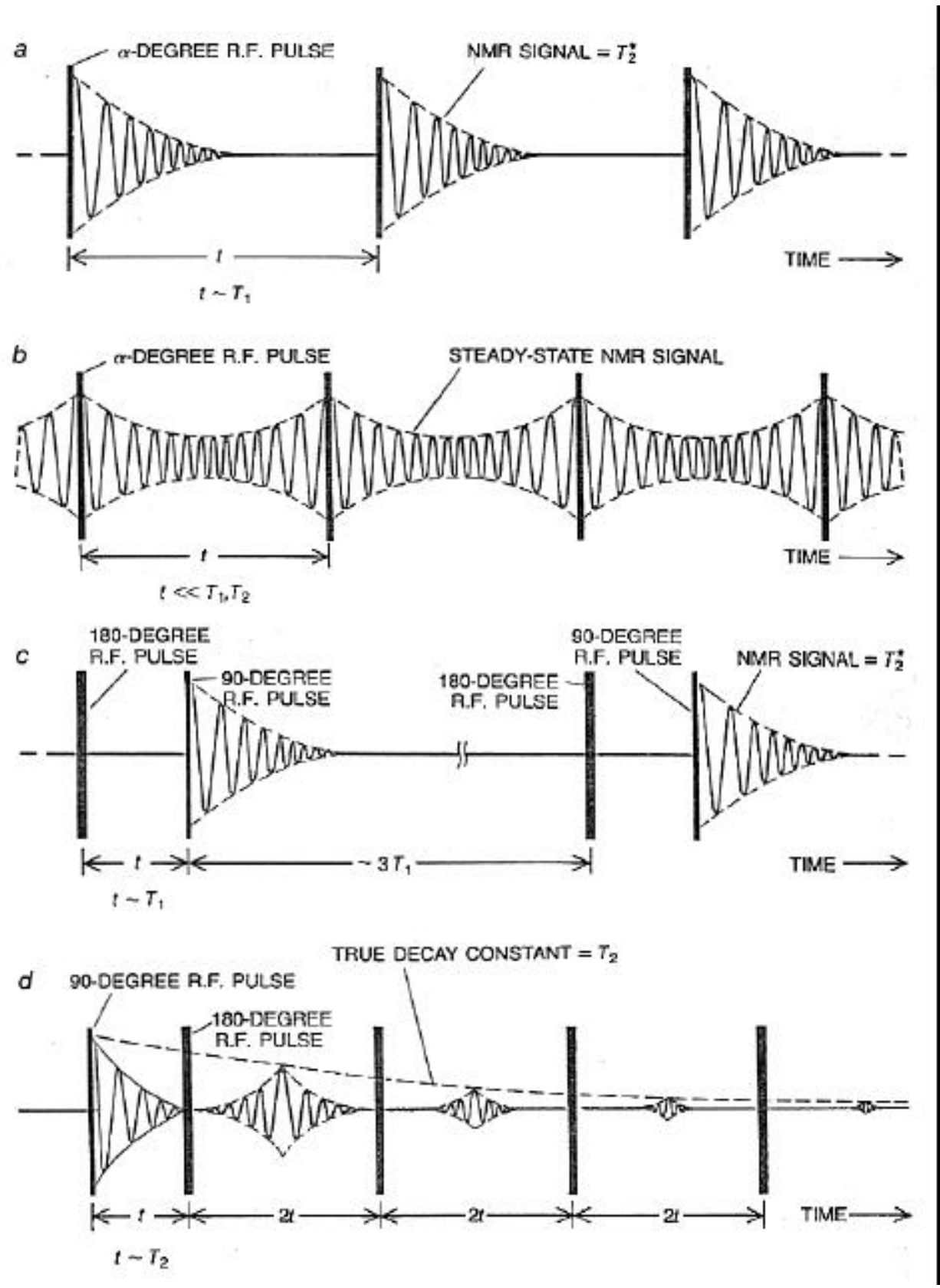

Figura 25 - Seqüências Saturation-recovery (a), steady-state free precession (b), inversion recovery ( c), Carr-Purcell spin-echo (d).

As várias técnicas de aquisição utilizam de maneira distinta pulsos de RF de seleção, preparação e inversão combinados com a aplicação de gradientes. Todo o processo é repetido várias vezes para realizar a codificação de fase. Desta forma, a temporização e sincronismo dos eventos é um aspecto importante na utilização destas seqüências. Para cada seqüência específica existem parâmetros de tempo característicos que indicam as condições em que a seqüência é aplicada.

* PYKETT, I.L., Scientific American, 1982, p.59. 
Dois parâmetros importantes, e que são comuns a diversos tipos de sequiências, são definidos: o tempo ao eco (TE) e o tempo de repetição (TR). O primeiro é o intervalo decorrido entre o pulso de excitação seletiva e o centro do eco. Como a amostragem do sinal de RMN é feita durante o eco nas seqüências que utilizam este parâmetro, é importante que TE seja menor que o tempo de relaxação transversal $T_{2}$, caso contrário a amplitude de eco será muito pequena e dificultará a aquisição dos dados. O tempo de repetição é o intervalo decorrido entre dois pulsos de excitação seletiva. Este parâmetro deve ser maior que o tempo de relaxação longitudinal $T_{1}$, para que a magnetização tenha tempo de voltar para a direção do campo $\mathrm{B}_{0}$ antes de ser jogada para o plano transversal novamente. Se a magnetização não tiver voltado para o plano longitudinal completamente, apenas a parte que voltou será excitada, fazendo com que o sinal de RMN tenha menor amplitude.

Estas restrições para TE e TR são importantes pois, como materiais diferentes possuem diferentes $T_{1}$ e $T_{2}$, a escolha adequada de TE e TR permite fazer imagens que identifiquem os diferentes materiais. Esta característica é importante, pois distingue a modalidade de MRI de outras modalidades de sistemas de imagens para diagnóstico médico. Uma imagem de MRI representa a densidade de núcleos de determinado tipo existente no material. Até este ponto o resultado é similar a uma tomografia computadorizada de raio x. Se o material em estudo possuir diferentes partes que tenham a mesma densidade de núcleos, uma imagem de densidade não irá distinguir estas partes. Como existem tecidos biológicos que, apesar de terem a mesma densidade, possuem $T_{1}$ e $T_{2}$ diferentes, é possível escolher valores de TE e TR que possibilitem distinguir estes tecidos. Um exemplo típico é o caso da esclerose múltipla, uma patologia que não aparece em imagens de tomografia por raio x, mas aparece em imagens de MRI.

Os três principais tipos de contraste são densidade, $T_{1}$ e $T_{2}$. Uma imagem de densidade representa apenas a distribuição espacial da densidade de núcleos da espécie nuclear utilizada. Para isso, o tempo TR deve ser bem maior que o tempo $T_{1}$ da parte da amostra com maior $T_{l}$, permitindo que toda a amostra relaxe a cada repetição do experimento e, conseqüentemente, não haja nenhum contraste entre tecidos de diferentes $T_{1}$, a não ser por densidade. Se o tempo TR é intermediário entre 
os tempos $T_{1}$ de regiões diferentes da amostra, a cada repetição do experimento, a magnetização longitudinal da região que possui $T_{l}$ maior que TR não se recupera completamente, acarretando uma diminuição do sinal resultante desta região, que aparecerá escura na imagem. Assim, a imagem resultante apresenta um contraste entre as duas regiões, chamado de contraste por $T_{l}$. De maneira similar ocorre o contraste por $T_{2}$, mas neste caso o TR é grande o suficiente para a magnetização longitudinal de todos os tecidos se recuperar, e o tempo TE é que utilizado para diferenciar as regiões com diferentes $T_{2}$. Neste caso, ajustando o tempo TE para um valor intermediário entre os $T_{2}$ das regiões de interesse, a região com menor $T_{2}$ já terá sofrido uma relação transversal enquanto a outra ainda possui magnetização no plano transverso. Assim, está última região é que contribuirá para a formação do eco e, conseqüentemente, ela aparecerá como a parte mais brilhante da imagem. 


\subsection{Engenharia de programação}

Uma das primeiras definições de engenharia de programação foi proposta por Fritz Bauer na primeira grande conferência dedicada ao assunto:

"The establishment and use of sound engineering principles in order to obtain economically software that is reliable and works efficiently on real machines."* (NAUR apud PRESSMAM). ${ }^{\dagger}$

Embora muitas definições já tenham sido propostas, o aspecto importante é que todas elas destacam o requisito de se utilizar a disciplina da engenharia no desenvolvimento de programas. Ela possui três elementos chaves: métodos, ferramentas e procedimentos. Estes elementos proporcionam a possibilidade de tornar o desenvolvimento de programas um processo controlável e oferecem os fundamentos para se construir programas de qualidade de maneira produtiva.

Os métodos proporcionam as "receitas" técnicas de como desenvolver programas. Eles abrangem uma grande variedade de aspectos que incluem o planejamento do projeto, análise de requisitos de sistemas e seus programas, desenho de estrutura de dados, elaboração da arquitetura e algoritmos do programa, codificação, teste e manutenção. Em geral, os métodos da engenharia de programação utilizam notações baseadas na linguagem e/ou notações gráficas. Eles também introduzem um conjunto de critérios relacionados com a qualidade dos programas.

As ferramentas da engenharia de programação proporcionam meios automatizados ou semiautomatizados para auxiliar a aplicação dos métodos.

\footnotetext{
* "O estabelecimento e uso de princípios da engenharia de maneira a obter programas que sejam economicamente viáveis, confiáveis e que funcionem eficientemente em máquinas reais."

${ }^{\dagger}$ NAUR, P.; RANDELL, B. (eds.) Software Engineering: A report on a Conference sponsored by the NATO Science Committee, NATO, 1969.
} 
Atualmente existem ferramentas para cada um dos tipos de métodos citados. Quando estas ferramentas estão integradas de maneira que as informações criadas por uma ferramenta podem ser utilizadas por outra, tem-se, então, um sistema integrado de desenvolvimento de programas (CASE - computer-aided software engineering).

Os procedimentos organizam a utilização dos métodos e ferramentas e proporcionam um desenvolvimento racional de programas. Os procedimentos definem sequiências em que os métodos devem ser aplicados, os subprodutos necessários, os mecanismos de controle para assegurar a qualidade e coordenar mudanças, e metas para proporcionar meios de avaliar o progresso do desenvolvimento dos programas.

A engenharia de programação se desenvolve em uma série de passos que envolvem métodos, ferramentas e procedimentos. Estes passos são chamados de paradigmas da engenharia de programação. $O$ paradigma a ser utilizado, ou combinação de paradigmas, é escolhido de acordo com a natureza do projeto e aplicação, os métodos e ferramentas a serem utilizados, os tipos de controles e subprodutos necessários. Existem quatro paradigmas principais que são extensamente conhecidos e utilizados. Eles são: ${ }^{19}$

- o ciclo de vida clássico;

- prototipagem;

- o modelo espiral;

- técnicas de quarta-geração.

O paradigma que inspirou o desenvolvimento deste trabalho foi o do ciclo de vida clássico (Figura 26). Ele estabelece uma abordagem sistemática e seqüencial para o desenvolvimento de programas. O processo de desenvolvimento de programas neste paradigma inicia-se no nível de sistemas, e continua com análise, desenho, codificação, teste e manutenção. 


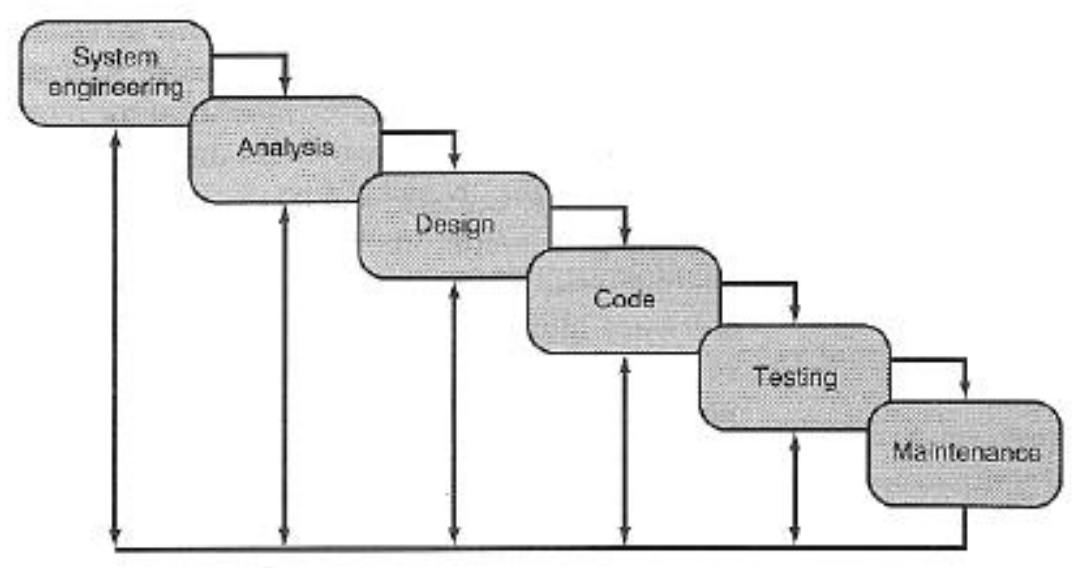

\section{Figura 26 - Ciclo de vida clássico da engenharia de programação."}

A análise e engenharia de sistemas estabelece o contexto em que o programa deve ser desenvolvido. Considerando que programas são sempre parte de sistemas maiores, nesta fase são levantados os requisitos do programa no que se refere o sistema global.

A análise de requisitos estabelece as condições necessárias para o programa preencher o objetivo proposto. Historicamente, as metodologias de engenharia de programação concentraram-se na representação de sistemas, mas pouca atenção foi dada a tarefa de se descobrir o que de fato ele deveria fazer. O processo de análise de requisitos se concentra nesta tarefa, e os resultados desta atividade são os subsídios para a fase seguinte, de especificação, que descreve minuciosamente a estrutura e o funcionamento de um sistema. ${ }^{20}$

A fase de desenho, ou especificação, se concentra em quatro características básicas de programas: estrutura de dados, arquitetura do programa, detalhamento dos procedimentos e definição da interface. A especificação traduz os requisitos para uma representação detalhada do programa que pode ser extensivamente avaliada antes de se iniciar a codificação. Enquanto a análise de requisitos estabelece "o que" o programa deve ser, a especificação mostra "como" ele deve funcionar.

A codificação é a tradução da especificação para uma forma que possa ser entendida e executada pelo computador. Quanto maior for o detalhamento da especificação, mais automática é a tarefa de codificação. 
O processo de teste avalia a estrutura lógica interna de um programa e a sua funcionalidade externa. Ele tem como objetivo verificar se os resultados obtidos estão de acordo com os resultados esperados.

A manutenção abrange todas as tarefas que acarretam alguma mudança no programa. Ela pode ocorrer para corrigir erros existentes; para adaptar o programa devido a mudanças no ambiente externo de operação; e para adicionar novos aspectos ao programa, atendendo a novos requisitos ou melhorando o desempenho.

O ciclo de vida clássico é o mais antigo e o mais utilizado paradigma da engenharia de programação. Várias críticas já foram levantadas abordando, principalmente, o fato dele não considerar aspectos práticos presentes no dia a dia do desenvolvimento de programas.

Entre os vários outros paradigmas propostos, merece atenção o modelo espiral (Figura 27), pois, como explicado no Capítulo 4, DISCUSSÃO, este modelo poderia ter sido mais adequado para o desenvolvimento deste trabalho.

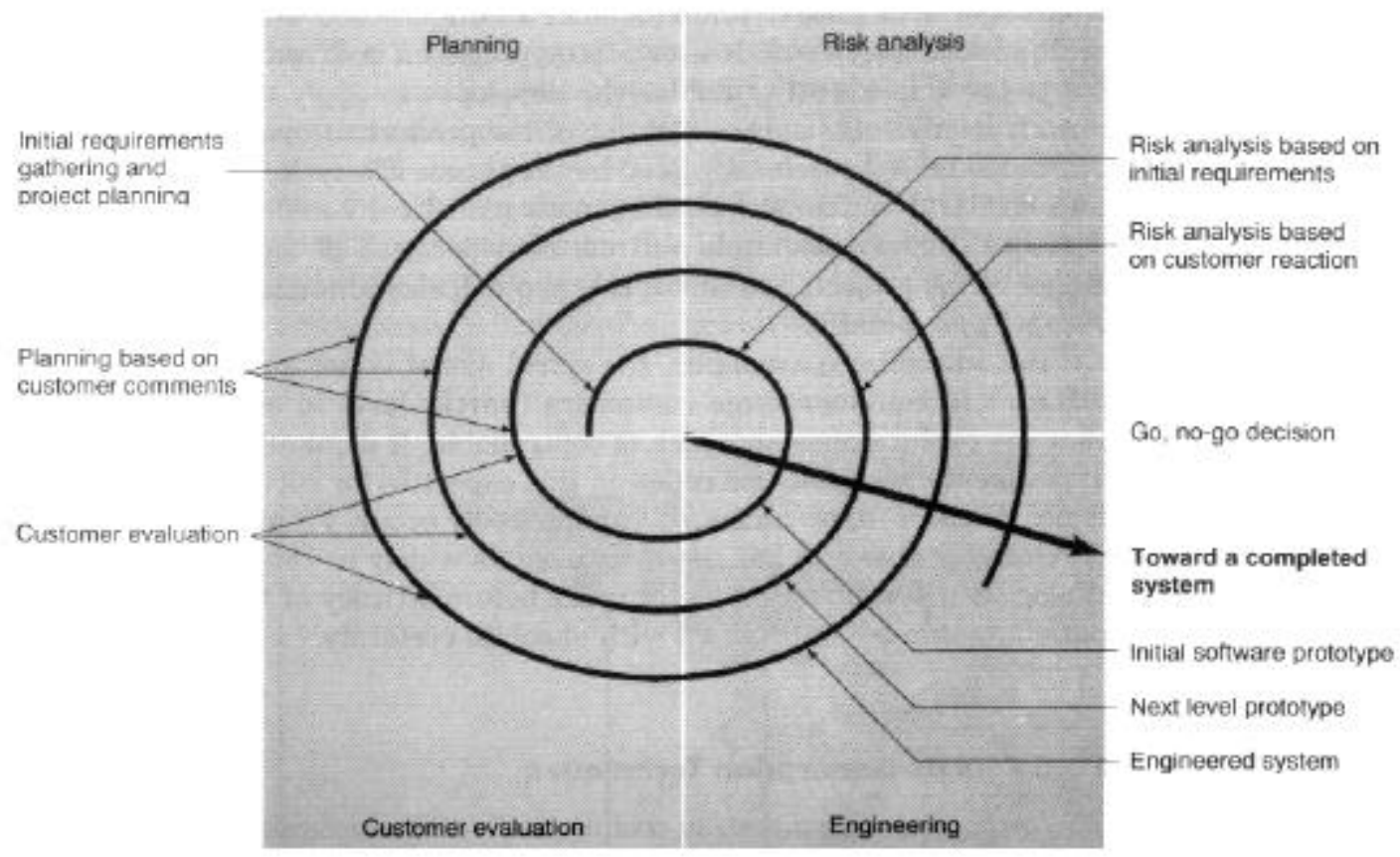

Figura 27 - Modelo espiral da engenharia de programação. ${ }^{\dagger}$

* PRESSMAN, R.S., 1992, p.25.

${ }^{\dagger}$ PRESSMAN, R.S., 1992, p.29. 
Este modelo aproveita as melhores características do ciclo de vida clássico e da prototipagem e acrescenta um novo elemento, a análise de risco. O principal aspecto deste modelo é a sua característica evolucionária. A cada volta pela espira da Figura 27 novas versões do programas são obtidas, cada uma mais completa que as outras anteriores. Estas características fazem com que este modelo seja considerado o mais realista para o desenvolvimento de grandes sistemas e programas. 
3 METODOLOGIA E RESULTADO 


\subsection{Introdução}

O desenvolvimento deste trabalho envolve três áreas de conhecimento principais: sistemas de banco de dados, imagens por ressonância magnética e engenharia de programação.

A primeira área de conhecimento, sistemas de banco de dados, corresponde ao tipo de aplicação desenvolvido. Desta área são utilizados os conceitos básicos de modelagem de banco de dados, metodologias e tecnologias bem estabelecidas. A modelagem de dados foi diagramada usando-se o modelo Entidade-relacionamento Estendido. Deste modelo foi especificado um banco de dados relacional que foi implementado com um sistema de gerenciamento de banco de dados relacional comercial, o MS Access 2.0.

Imagem por ressonância magnética é chamado de domínio da aplicação, pois a proposta de banco de dados elaborada e implementada é específica para esta área de conhecimento. O desenvolvimento do sistema de banco de dados inicia-se com um estudo deste domínio, abrangendo desde princípios de RMN, sistemas de MRI, até PACS e o padrão industrial DICOM 3.0, com o objetivo de fazer um levantamento de todo conjunto de informações que são relevantes e que devem estar presentes na estrutura de dados final. O estudo deste domínio também esclarece quais são os tipos de usuários mais comuns e quais são as transações mais importantes.

A engenharia de programação é a área de conhecimento que fornece a metodologia geral para o desenvolvimento e implementação do sistema de banco de dados. Ela proporciona uma estrutura básica para tornar o desenvolvimento de um programa um processo controlado, possibilitando que o resultado final atenda aos 
objetivos iniciais propostos. O desenvolvimento do DataTORM adotou o paradigma do ciclo de vida clássico de desenvolvimento de programas, com fases de análise de requisitos, especificação, implementação, testes e manutenção. Foram usados métodos bem estabelecidos e conhecidos, como os modelos EER e MRD, e ferramentas de desenvolvimento, como o SGBD MS Access 2.0 e o editor de diagramas Visioß.

Na fase de análise de requisitos foram levantadas informações sobre o domínio da aplicação e o principal resultado foi um modelo conceitual EER do banco de dados. Os estudos das diversas áreas relacionadas com o tema desta dissertação, e que originaram os tópicos apresentados na revisão da literatura, também fizeram parte desta fase, juntamente com o estudos sobre o sistema atual ToRM-005, o projeto do novo sistema, o ToRM-05, e um levantamento de informações sobre sistemas comerciais através de manuais, visitas e entrevistas estruturadas.

Utilizando as informações obtidas durante a análise de requisitos, foi possível elaborar modelos para refletir as visões existentes sobre o sistema e o seu contexto. Alguns dos modelos refletem aspectos do sistema ToRM-005 e dos sistemas comerciais; os outros refletem propostas para o sistema DataTORM e para outros subsistemas do ToRM-05 relacionados com este trabalho.

Em seguida, na fase de especificação, o modelo de dados conceitual foi mapeado para um modelo de implementação relacional e foi criado um dicionário de dados. A implementação consistiu em criar, utilizando o MS Access 2.0, tabelas do banco de dados, consultas, formulários, relatórios e módulos de programa. A fase de testes foi realizada com dados obtidos pelo sistema ToRM-005 e os erros encontrados, somados às sugestões dos usuários, foram usados para correções e alterações do sistema.

A principal forma de análise feita sobre os modelos elaborados foi através do retorno obtido à partir da especificação e da implementação efetuadas. À medida que era elaborada uma especificação detalhada de várias partes do sistema e eram feitas implementações destas partes, vários problemas foram detectados, incluindo, principalmente, dados importantes que não foram levantados na análise de requisitos, 
inconsistências nos modelos e inadequação do modelo, ou partes dele, para representar a situação real ou os requisitos do sistema.

Quando estes problemas ocorriam, era necessário retornar à etapa de modelagem, corrigir os problemas e, em seguida, propagar as alterações para os documentos e modelos de especificação e para as implementações em curso. Estas idas e vindas do processo de desenvolvimento foram documentadas através de controle de versões dos modelos e nesta dissertação é apresentada a última versão obtida para cada modelo.

Este processo em que etapas posteriores de desenvolvimento, neste caso especificação e implementação, retroalimentam as etapas iniciais, trazendo mais informações relevantes e/ou indicando erros existentes, é comum em todo processo de criação de programas. O impacto deste processo sobre o desenvolvimento do DataTORM é discutido em detalhes no Capítulo 4, DISCUSSÃO.

As seções a seguir apresentam os detalhes do desenvolvimento e os resultados parciais para cada etapa deste trabalho. Na Seção 3.2, Levantamento do contexto do problema, são apresentadas as atividades iniciais do trabalho que serviram, juntamente com a revisão da literatura, para definir o problema e levantar os diversos aspectos relacionados que deveriam ser levados em consideração na proposta do sistema de banco de dados e na posterior implementação. A Seção 3.3, Proposta para o sistema de banco de dados, apresenta os modelos de dados elaborados, incluindo uma proposta para a distribuição dos arquivos e uma discussão de como os tipos de dados não-convencionais podem ser tratados no banco de dados. Vários dos aspectos apresentados nesta seção já levam em consideração a decisão de projeto de se utilizar o MS Access 2.0 como aplicativo de desenvolvimento. Os detalhes desta escolha são apresentados juntamente com o descrição da plataforma computacional do ToRM-05 na subseção 3.2.2. Finalmente, na Seção 3.4, Implementação do DataTORM, é descrita a implementação do DataTORM realizada a partir da proposta da seção anterior. Como será discutido no Capítulo 4, DISCUSSÃO, a seqüência de atividades não seguiu rigidamente a ordem do ciclo de vida proposto, havendo constantes idas e vindas entre as diversas etapas. 
3.2 Levantamento do contexto do problema

\subsubsection{Estudo de sistemas existentes}

\subsubsection{Sistema ToRM-005}

\subsection{Introdução}

O ToRM-005 foi uma das primeiras fontes de informação utilizadas para a aquisição de conhecimento na área de MRI e posterior levantamento dos requisitos para o sistema DataTORM. Paralelamente à revisão da literatura sobre os princípios físicos de RMN e sobre o funcionamento de sistemas de MRI, foi feito um estudo sobre este sistema utilizando técnicas de entrevistas, análise de protocolos e observação.

Na seção Sistemas de imagens por RMN da revisão da literatura, o sistema ToRM-005 é introduzido e os seus detalhes técnicos são apresentados no Apêndice I - Especificações técnicas do ToRM-005. A seguir são apresentadas informações específicas sobre este sistema que são pertinentes ao desenvolvimento do DataTORM. As atividades que compreenderam a elaboração do diagrama de contexto, o levantamento do léxico ampliado da linguagem, o levantamento da situação atual de armazenamento e gerenciamento de dados no ToRM-005 e o desenvolvimento do aplicativo PosProc proporcionaram uma visão geral do ToRM005 e serviram de aprendizado inicial para vários aspectos de deveriam ser levados em consideração no desenvolvimento do sistema de banco de dados.

\subsection{Diagrama de contexto}


O contexto do sistema refere-se ao ambiente no qual ele está inserido. Este é composto por diversas entidades do mundo real (pessoas, instituições, etc.) que comunicam entre si através de fluxos de informação (FI), ou interagem com o sistema através de interfaces com o sistema (IS). ${ }^{20}$

A definição do contexto do ambiente de operação do sistema ToRM-05 é importante para a especificação do DataTORM, pois este contém informações sobre as entidades do contexto deste sistema de MRI. Também são estas entidades que, diretamente ou não, irão interagir com o DataTORM, inserindo novos dados e consultando os dados existentes.

Para o sistema atual ToRM-005 foram identificados três níveis básicos de contexto:

- Sala de Tomografia (ST);

- Grupo de Ressonância (GR);

- Contexto Externo (CE).

O diagrama de contexto da Figura 28 representa estes três níveis, juntamente com as entidades de cada nível. As interfaces com o sistema são os únicos contatos diretos com o ToRM-005. Já os fluxos de informação são indiretamente relacionados com o sistema. Na Tabela 15 são resumidos os fluxos de informação e as interfaces com o sistema da Figura 28. 


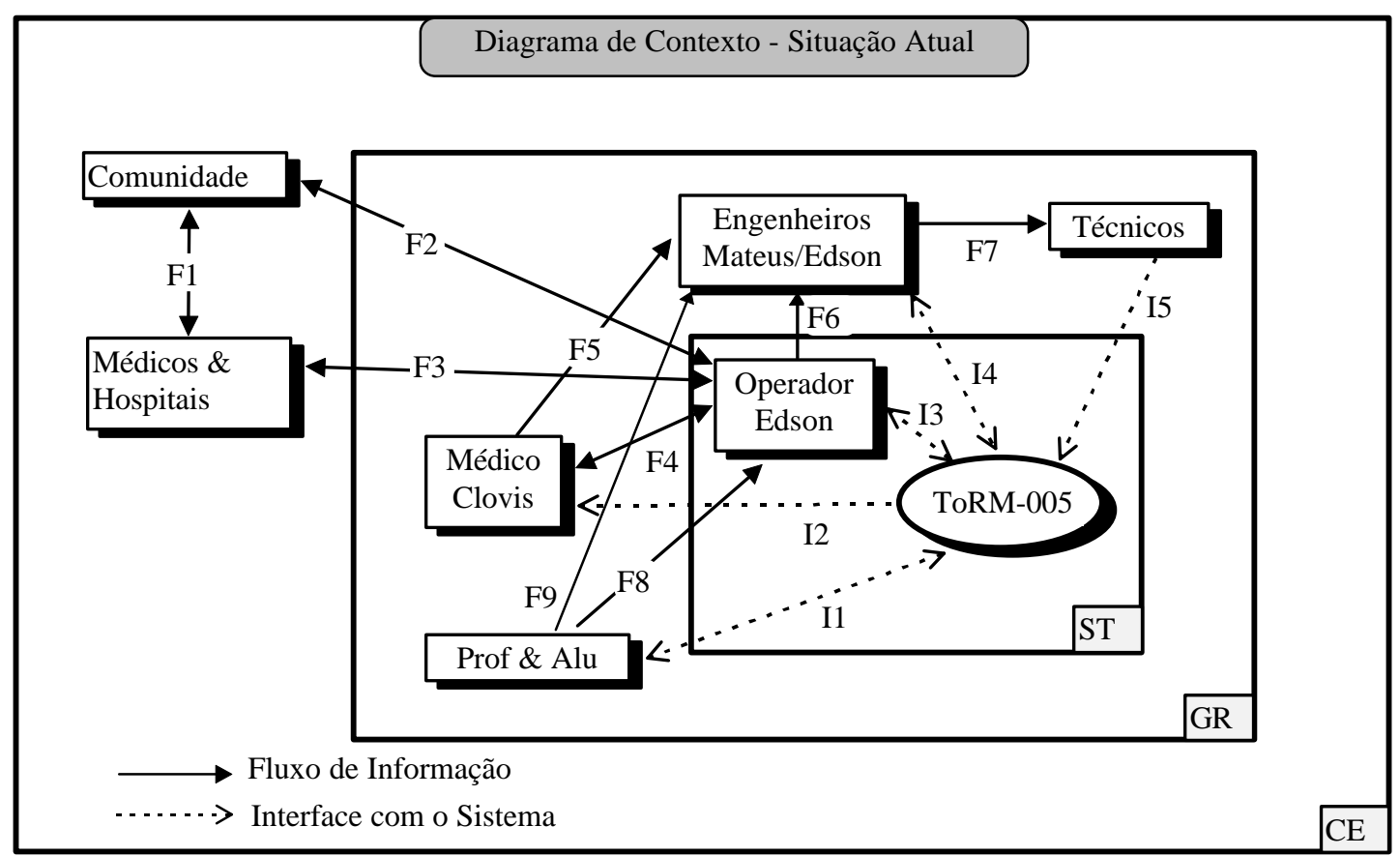

Figura 28 - Diagrama de contexto do ToRM-005.

Tabela 15 - Descrição dos fluxos de informações e interfaces com o sistema do diagrama de contexto do ToRM-005

\begin{tabular}{ll}
\hline \hline \multicolumn{1}{c}{ Fluxos de Informação (FI) } & \multicolumn{1}{c}{ Interfaces com o Sistema (IS) } \\
\hline F1: A Comunidade interage com Médicos e & II: Professores e Alunos operam diretamente \\
Hospitais para consultas e tratamentos. & o sistema ToRM-005. \\
F2: A Comunidade procura diretamente o & I2: O Médico visualiza as imagens na tela de \\
Operador para entregar o pedido de exame, & visualização do sistema ToRM-005. \\
marcar o exame e pegar os resultados. & \\
F3: Médicos e Hospitais requisitam serviços & I3: O Operador opera o sistema ToRM-005. \\
através do operador do sistema que orienta & \\
sobre como devem ser os procedimentos. Os & \\
resultados dos exames são entregues para os & \\
Médicos ou Hospitais que requisitaram. & \\
F4: O Médico instrui o Operador quanto às & I4: Os Engenheiros realizam atividades de \\
características do exame. O Operador entrega & manutenção e desenvolvimento de \\
os resultados finais ao Médico para a sua & equipamentos e programas do ToRM-005. \\
interpretação. & \\
F5: O Médico fornece opiniões sobre o & I5: Os Técnicos realizam atividades sobre o \\
sistema (qualidade das imagens, etc.) aos & sistema ToRM-005. \\
Engenheiros. & \\
F6: Operador informa aos Engenheiros dados & \\
e opiniões sobre a operação e funcionamento & \\
do sistema. & \\
F7: Os Engenheiros determinam aos Técnicos & \\
as atividades a serem feitas sobre o sistema & \\
ToRM-005. & \\
\hline \hline
\end{tabular}


F8: Professores e Alunos instruem o Operador quanto às características da atividade.

F9: Professores e Alunos informam aos

Engenheiros dados e opiniões sobre a operação e funcionamento do sistema.

O diagrama de contexto acima descreve um ambiente pouco usual para uma instalação médica, pois reflete várias características específicas de um ambiente de pesquisa e desenvolvimento existente em uma universidade. Neste ambiente, existem diversos usuários que interagem diretamente com o sistema, como professores, alunos, engenheiros e técnicos, e que executam diversas atividades, como desenvolvimento de equipamentos e programas para MRI, experimentos acadêmicos e exames clínicos. O médico que trabalha em parceria com o grupo de ressonância é responsável por avaliar a viabilidade da execução de exames clínicos que são requisitados e por acompanhar estes exames, mas ele não emite laudos baseado nos resultados.

A utilização do diagrama de contexto serviu para organizar uma primeira visão superficial do ambiente de operação do ToRM-005. Através de um maior detalhamento do conteúdo dos FI e IS seria possível elaborar um modelo mais completo do contexto do sistema, modelo este que forneceria uma descrição detalhada dos dados e dos aspectos funcionais deste sistema. Como pretendia-se utilizar outros tipos de modelos de dados para descrever o sistema em profundidade, optou-se por limitar a utilização dos diagramas de contexto apenas para proporcionar uma descrição geral inicial.

\subsection{Léxico Ampliado da Linguagem}

Uma das metodologias utilizadas no levantamento de informações sobre o sistema ToRM-005 foi a análise do léxico utilizado no contexto de operação do sistema. O Léxico Ampliado da Linguagem (LAL) é uma forma de representação simples da linguagem utilizada em determinado contexto e ambiente. Ele se baseia na idéia de que coisas observáveis em um ambiente têm sua semântica definida neste mesmo ambiente. ${ }^{20}$ 
O esquema de representação do LAL possui três estruturas básicas: símbolo, noção e impacto. O símbolo é uma palavra-chave existente no vocabulário usado no ambiente. A noção descreve o significado geral do símbolo, e o impacto descreve o efeito do uso ou ocorrência do símbolo. Tanto as noções quanto os impactos são descrições semânticas dos símbolos e estas descrições seguem os princípios de circularidade e vocabulário mínimo. ${ }^{20}$

Foi desenvolvido um pequeno aplicativo, o Lex, ${ }^{*}$ para auxiliar a criação do LAL para o sistema ToRM-005. Este programa, desenvolvido utilizando Microsoft ${ }^{\circledR}$ Visual Basic ${ }^{\dagger}{ }^{\dagger}$ versão 3.0, implementa um pequeno banco de dados de símbolos, noções e impactos. A circularidade do vocabulário é implementada na forma de hipertexto, onde as palavras-chave são indicadas entre colchetes. A figura a seguir mostra a janela principal do programa, com os campos para inserir os símbolos e as respectivas noções e impactos.

\footnotetext{
* O programa Lex, cujo nome é uma abreviação da palavra léxico, e as demais atividades relacionadas com o levantamento do LAL do sistema ToRM-005 foram desenvolvidos no Grupo de Ressonância do IFSC pelo mestrando Rodrigo Villares Portugal e pelo autor desta dissertação no segundo semestre de 1994.

${ }^{\dagger}$ Microsoft e Visual Basic são marcas registradas da Microsoft Corporation.
} 


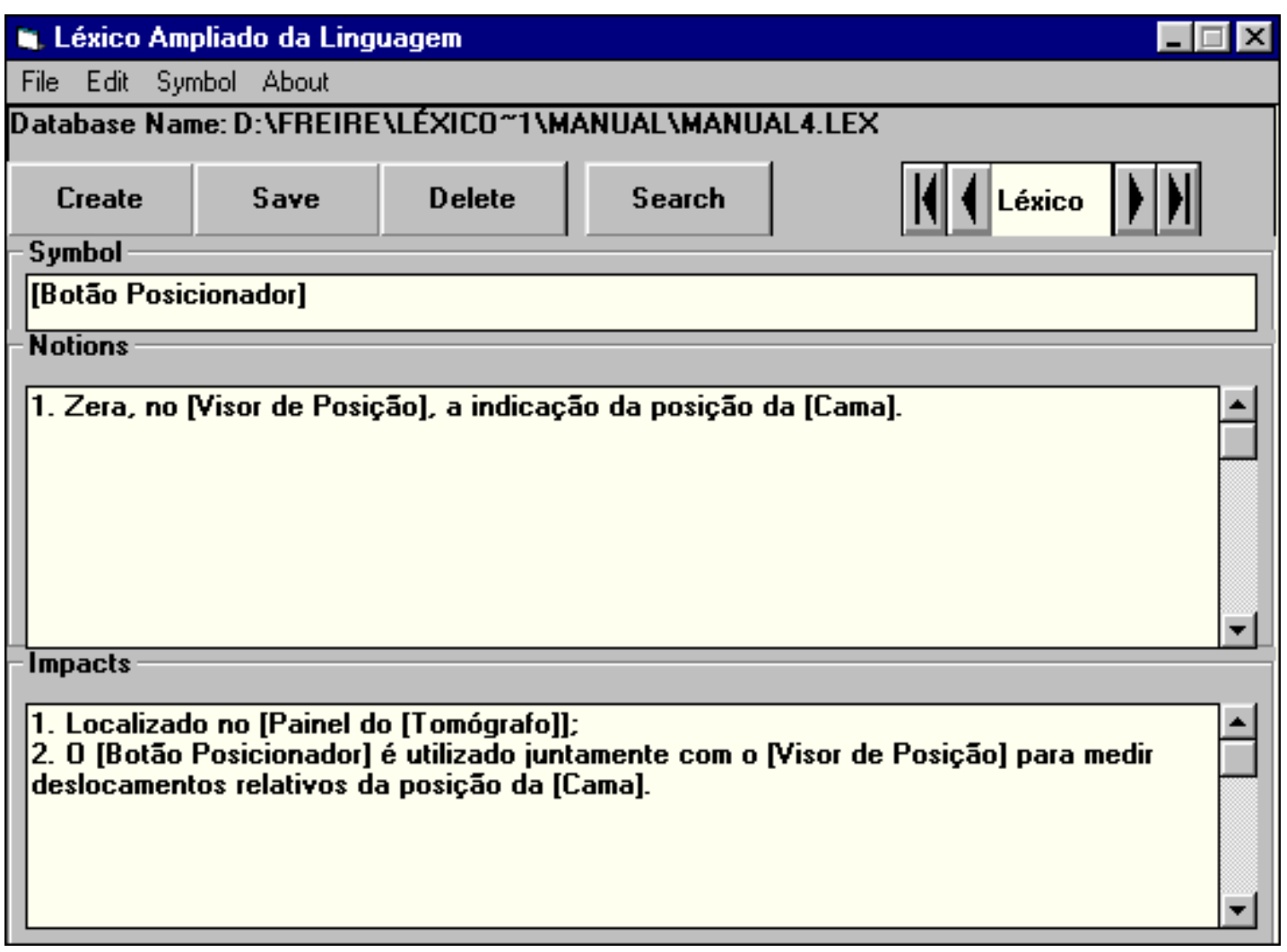

Figura 29 - Janela principal do programa Lex.

Baseado na observação do sistema e em entrevistas com vários especialistas que o operam, foram feitos três textos de descrição do sistema: um com a descrição dos diversos equipamentos que compõe o tomógrafo; outro com figuras esquemáticas dos equipamentos indicados no primeiro texto; e um último com descrições detalhadas do protocolo de operação.

Nestes textos foram indicadas entre colchetes as principais palavras-chave do vocabulário utilizado. Estas palavras foram inseridas no programa Lex na forma de símbolos. Noções e impactos dos símbolos foram extraídos dos textos ou através de consultas a manuais ou especialistas. Baseado nesta primeira versão do LAL do ToRM-005, os textos de descrição de equipamentos e de protocolos foram editados para utilizar apenas os símbolos do léxico ao invés de sinônimos. Ao final, foram identificados 181 símbolos, cujas noções e impactos foram especificados. Os textos finais ficaram mais concisos e com um vocabulário autoconsistente. (Os textos utilizados como fonte para o levantamento do léxico e o LAL propriamente dito estão no Apêndice V). 
Foram duas as principais contribuições do levantamento do léxico do sistema ToRM-005. Primeiramente, esta atividade serviu como um dos primeiros contatos com o sistema, possibilitando o aprendizado sobre as suas partes, seu funcionamento e sua operação. Em segundo lugar, o desenvolvimento do programa Lex foi uma primeira experiência com a programação de um aplicativo de banco de dados e a utilização do MS Visual Basic 3.0.

\subsection{Armazenamento e gerenciamento de dados no ToRM-005}

Os dados de operação são armazenados em arquivos digitais. Nos casos de exames clínicos, também existem fichas de pedidos de estudo, preenchidas pelo médico responsável, e fichas de exame, para identificação e acompanhamento, preenchidas pelo médico que acompanha o estudo. Todos os arquivos correspondentes aos dados de operação e resultados ficam em diretórios no computador microVAX. As imagens também são armazenados no computador Macintosh em diretórios correspondentes a cada paciente ou voluntário, ocorrendo assim duplicação das imagens. Estes arquivos são armazenados também em cópias de segurança. Toda manutenção destes arquivos é manual e fica a cargo do operador.

Os dados de manutenção do sistema são armazenados, quando o são, pelos técnicos e engenheiros responsáveis. O controle desta atividade, como no caso do desenvolvimento, não é sistematizado de forma que os dados de manutenção fiquem estruturados a ponto de se poder fazer um histórico destas atividades.

Os dados de operação são principalmente:

- arquivos de parâmetros de aquisição;

- dados de aquisição;

- imagens no formato PAC;

- imagens no formato TIFF;

- dados de pacientes.

São gerados, em média, 1,6 Mbytes de imagens tomográficas por semana, além de respectivos 6,4 Mbytes de dados de aquisição. 
Os arquivos digitais são armazenados em diretórios nos discos rígidos dos computadores microVAX e Macintosh. Os arquivos de parâmetros, os dados de aquisição e os arquivos de imagens PAC ficam no disco do microVAX. Para o Macintosh são copiadas as imagens PAC que são convertidas para o formato TIFF para visualização. Os dados ficam no disco do computador enquanto houver espaço disponível. Em seguida, são feitas cópias de segurança que são armazenadas em fitas magnéticas. ${ }^{*}$ Um conjunto especial de imagens TIFF, usadas para demonstrações, são mantidas no disco do Macintosh. Os dados dos pacientes são escritos em fichas de exame, que são armazenados em arquivos manuais, e em um caderno de exames, que contem a lista de todos os exames.

O gerenciamento dos dados é feito manualmente pelo operador do sistema através do sistema de gerenciamento de arquivos dos sistemas operacionais. As principais operações são:

- inserção: ocorre com a realização de aquisições. Durante a aquisição, os dados de aquisição são escritos diretamente no disco do microVAX. À partir destes dados, são calculadas as imagens tomográficas que são armazenadas em formato PAC;

- consulta e atualização: os dados, identificados pelo nome do arquivo e sua localização, são consultados utilizando programas específicos como editor de texto, programa de visualização, programa de edição de parâmetros, etc. A atualização é feita através destes mesmos programas. Fica a cargo do operador cuidar se o dado será substituído ou será criada uma nova versão usando um nome de arquivo diferente. Não existe um controle de versões automático;

- eliminação: a eliminação de qualquer arquivo, seja de imagem, dados de aquisição ou de parâmetros, é feita pelos comandos de apagar arquivos dos sistemas operacionais. Todo o controle fica a cargo do operador.

\subsection{Aplicativo PosProc}

A impressão das imagens obtidas no ToRM-005 era feita em uma impressora térmica através de um microcomputador IBM/PC compatível. As imagens no formato TIFF

\footnotetext{
* A partir de janeiro de 1997 as cópias de segurança passaram a ser armazenadas em discos de CDROM com capacidade de armazenamento de até 650 Mbytes. Os dados são transferidos para um microcomputador IBM/PC compatível onde se encontra instalado o gravador de CD-ROM.
} 
eram transferidas por rede através de FTP a partir do computador Macintosh II-FX, onde eram realizadas as edições e marcações nas imagens, para o microcomputador, onde eram então impressas. O processo total de preparação e impressão das imagens era bastante demorado, principalmente devido a etapa de marcação das imagens posicionadoras, que era manual e realizado com um editor de imagens simples.

Desta forma foi desenvolvido o programa PosProc com dois objetivos principais:

1. entender o sistema de coordenadas utilizado no sistema ToRM-005, que é usado para definir a região em que as imagens são adquiridas e que, conseqüentemente, define as coordenadas das marcações na imagem posicionadora;

2. facilitar o processo de marcação e impressão das imagens.

O programa PosProc, cujo nome é uma abreviação de pós-processamento, foi desenvolvido no Grupo de Ressonância do IFSC pelo mestrando Rodrigo Villares Portugal, responsável pela interface com o usuário, pelo engenheiro Mateus José Martins, que programou a importação e impressão dos dados, e pelo autor desta dissertação, que criou os módulos de cálculo das coordenadas das marcações e de preparação das demais informações que devem ser impressas com as imagens. Este programa prepara as imagens geradas pelo ToRM-005 para serem impressas ou armazenadas em disco. Ele importa as imagens no formato PAC, efetua as marcações automaticamente à partir dos parâmetros de aquisição, mostra as imagens para o usuário e permite imprimi-las na impressora térmica elou salvá-las em disco no formato BMP.

A figura a seguir mostra a janela principal de interface com o usuário do programa PosProc com uma imagem posicionadora processada. 


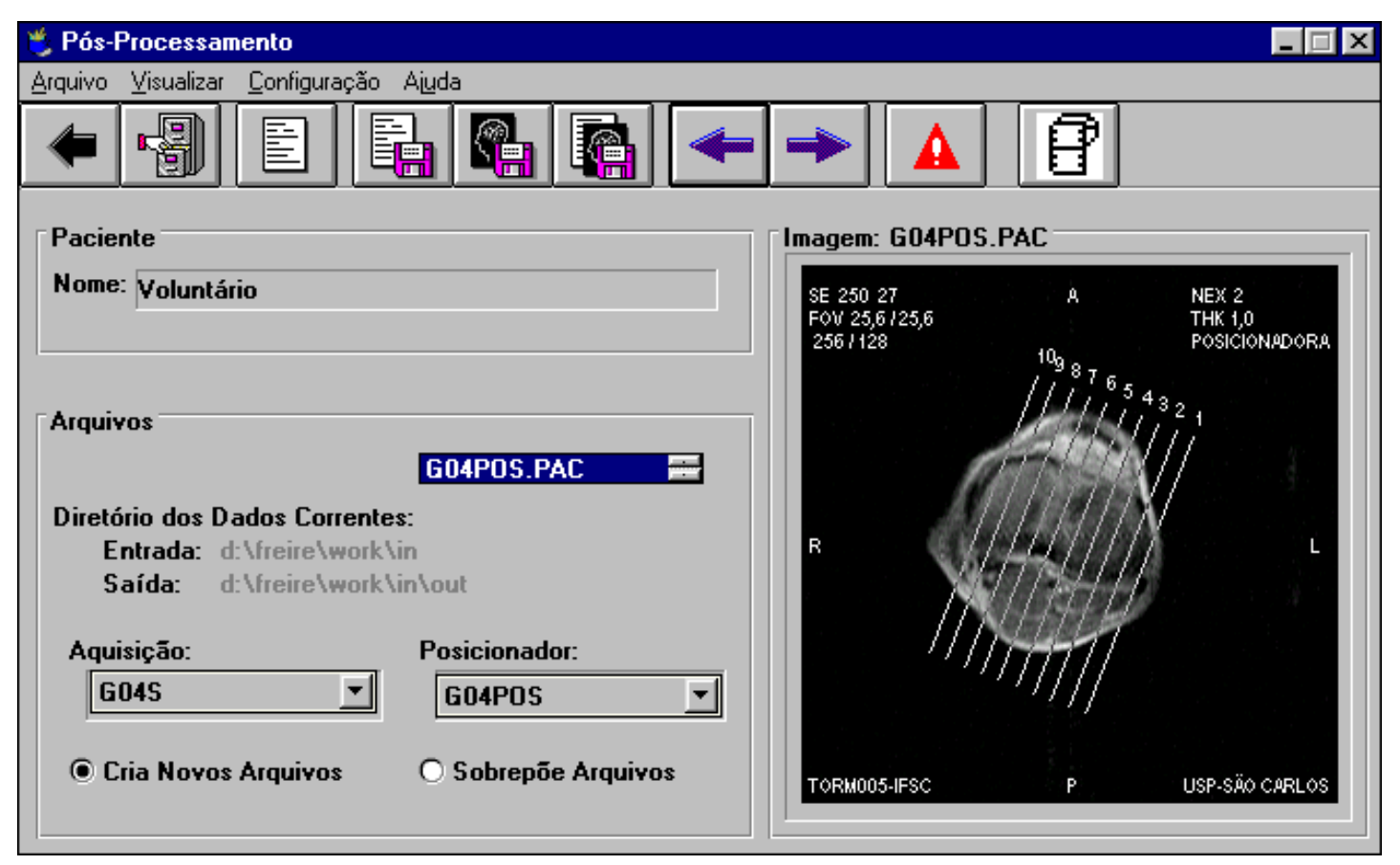

Figura 30 - Janela principal do aplicativo PosProc.

\subsubsection{Sistemas comerciais}

Foram visitados três departamentos de MRI de instalações médicas diferentes: na Faculdade de Medicina de Botucatu (UNESP), no INCOR (USP) e no hospital Beneficência Portuguesa. Nestes locais foram feitas entrevistas com médicos e operadores de sistemas de MRI e foi observada a operação típica nos sistemas comerciais instalados. Na ocasião das visitas (março/1995), estas instalações médicas estavam equipadas com os equipamentos apresentados na tabela a seguir.

\section{Tabela 16 - Equipamentos de MRI visitados}

\begin{tabular}{lcll}
\hline \hline Instalação médica & Quantidade & \multicolumn{1}{c}{ Modelo } & \multicolumn{1}{c}{ Fabricante } \\
\hline Botucatu & 1 & MRMAX $(0,5 \mathrm{~T})$ & General Eletric \\
INCOR & 1 & Gyroscan 85 $(0,5 \mathrm{~T})$ & Philips \\
& 1 & Gyroscan 515 $(0,5 \mathrm{~T})$ & Philips \\
Beneficência & 1 & MRMAX $(0,5 \mathrm{~T})$ & General Eletric \\
Portuguesa & 2 & Signa $(1,5 \mathrm{~T})$ & General Eletric \\
\hline \hline
\end{tabular}

Do ponto de vista de PACS e de sistemas de banco de dados, as visitas às instalações médicas acima permitiram observar as seguintes características:

- as imagens resultantes são impressas em filmes para serem avaliadas e arquivadas em arquivos tradicionais; 
- alguns sistemas armazenam os resultados na forma digital em repositórios de longo prazo, mas apenas com o objetivo de possuir cópias de segurança;

- os sistemas de MRI não se comunicam com os RIS e/ou HIS das instalações hospitalares;

- o INCOR está implementando algumas características de PACS em seus sistemas de imagens médicas, sendo que a proposta para o sistema final abrange inclusive os equipamentos de MRI. O padrão DICOM 3.0 está sendo usado como modelo de armazenamento e comunicação dos dados. ${ }^{21}$

Baseado nas características observadas, as visitas a estas instalações médicas permitiram chegar às seguintes conclusões:

- a implementação de sistemas PACS no Brasil está apenas começando;

- a cultura médica no Brasil ainda não está completamente receptível a realização de diagnóstico através de imagens digitais, sendo a impressão em filmes, então, um requisito indispensável a ser proporcionado pelo sistema de MRI ou pelo SBD que armazena os resultados.

\subsubsection{O DataTORM no contexto do projeto do ToRM-05}

O projeto de desenvolvimento e construção do ToRM-05 consiste de uma evolução do sistema ToRM-005 já em funcionamento. As duas principais alterações são:

- mudança da freqüência de operação para $21 \mathrm{MHz}$; e

- mudança para uma plataforma computacional baseada em microcomputadores IBM/PC compatíveis. ${ }^{22}$

A tabela a seguir resume as especificações propostas para o sistema:

Tabela 17 - Especificações do sistema ToRM-05

\begin{tabular}{ll}
\hline \hline \multicolumn{1}{c}{ Item } & \multicolumn{1}{c}{ Especificação } \\
\hline Campo & 0,5 Tesla em um magneto supercondutor de corpo inteiro \\
$\begin{array}{l}\text { Frequiência de } \\
\text { operação }\end{array}$ & $21 \mathrm{MHz}$ \\
$\begin{array}{l}\text { Sequências de } \\
\text { exame }\end{array}$ & $\begin{array}{l}\text { Spin-Echo Multi-slice e Multi-Echo, Gradient Recalled } \\
\text { Echo, Inversion Recovery e Steady State Free Precession }\end{array}$ \\
\hline \hline
\end{tabular}




\begin{tabular}{ll}
\hline \hline \multicolumn{1}{c}{ Item } & \multicolumn{1}{c}{ Especificação } \\
\hline Tempo de exame & SE/MS/1000/100: 4 minutos. Scout view: 15 segundos \\
Resolução & no plano: 3 mm. Espessura da fatia: 5 mm \\
Matriz de aquisição & 2D 256 x 128 ou 256 x 256 \\
& 3D 256 x 128 x 64 \\
Orientação das fatias & Oblíqua qualquer \\
Armazenamento & Magnético de 2 Gbytes. Magneto-ótico com disco \\
& removível de 258 Mbytes \\
Impressão & Dry silver print (processo Kodak) \\
Computador & IBM/PC compatível com processador da família \\
principal & Pentium/Intel \\
Sistema operacional & Windows 95 \\
\hline \hline
\end{tabular}

Do ponto de vista deste trabalho, o aspecto mais importante é a nova plataforma computacional. A Figura 31 a seguir descreve a arquitetura básica do sistema. Um microcomputador com um processador Pentium de $166 \mathrm{MHz}$ será dedicado exclusivamente à operação do sistema. Após cada estudo, os dados adquiridos são enviados para outro microcomputador que exercerá o papel de estação de consulta principal, onde os dados serão armazenado no banco de dados DataTORM. As duas estações estarão ligadas entre si por uma rede Ethernet de 10 Mbps. Em uma rede separada, mas com acesso à estação de consulta, poderão ser conectados outros computadores que poderão ter acesso aos resultados remotamente. 


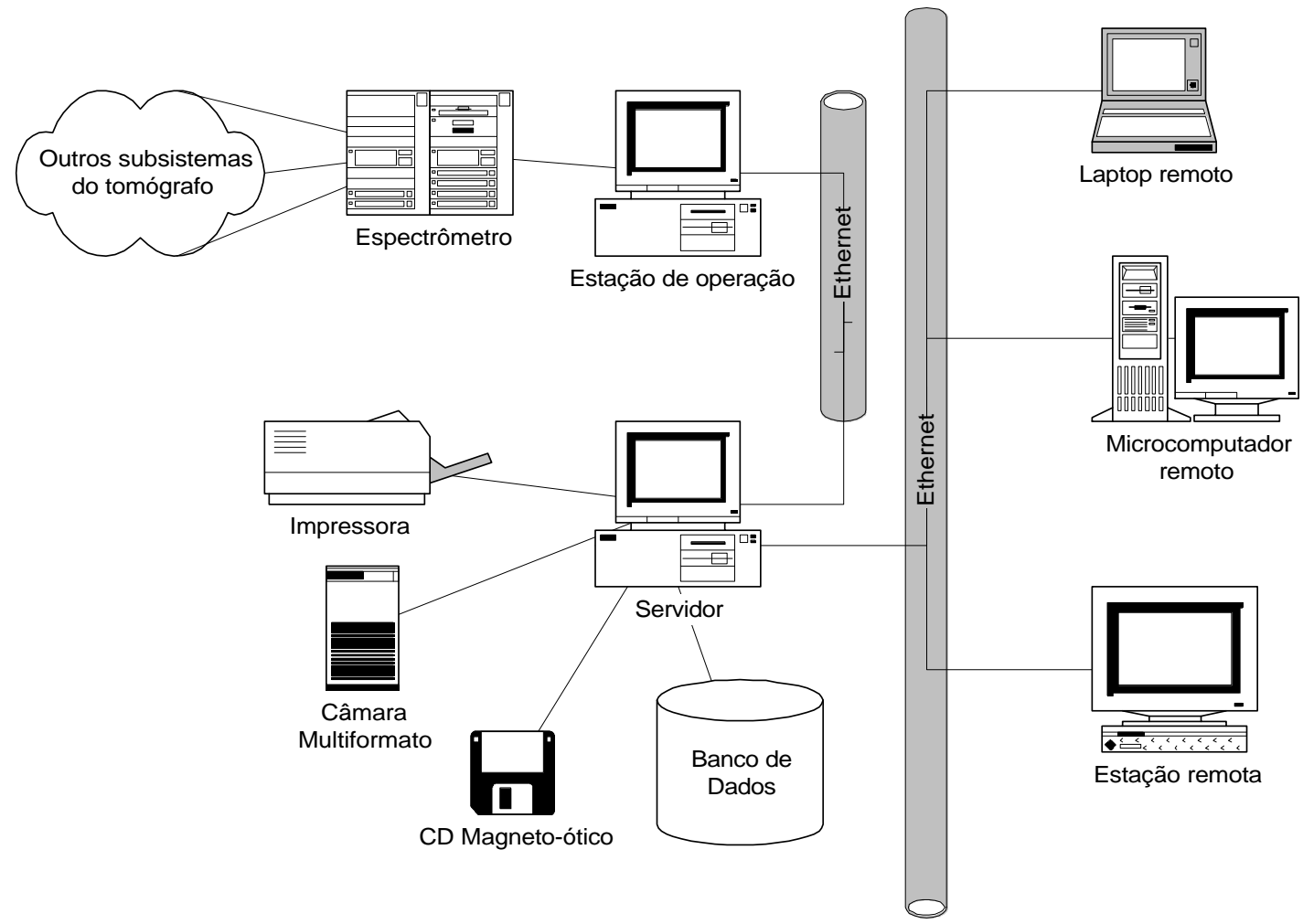

Figura 31 - Configuração dos computadores que compõem o ToRM-05.

$\mathrm{Na}$ estação de operação estarão instalados três módulos de programa principais:

- SPECTOS: programa o espectrômetro para a aquisição;

- TORMOCX: controla a aquisição dos dados provenientes do espectrômetro e processa os dados;

- TORMGUI: interface com o usuário responsável pela coordenação geral da operação do sistema.

Na estação de consulta estará o sistema de banco de dados DataTORM e nela poderão ser acoplados equipamentos para impressão dos resultados e armazenamento em meios removíveis.

Os módulos de programa estão organizados em uma estrutura de camadas estabelecida para promover uma independência funcional entre estes módulos e, conseqüentemente, facilitar o desenvolvimento. A Figura 32 a seguir, inspirada no modelo de referência ECMA/NIST, usado originalmente para descrever ambientes integrados de engenharia de programação, ${ }^{23}$ apresenta a arquitetura básica dos módulos de programa do ToRM-05, independente se estes módulos estão em um 
mesmo computador ou se estão instalados em computadores diferentes ligados por rede.

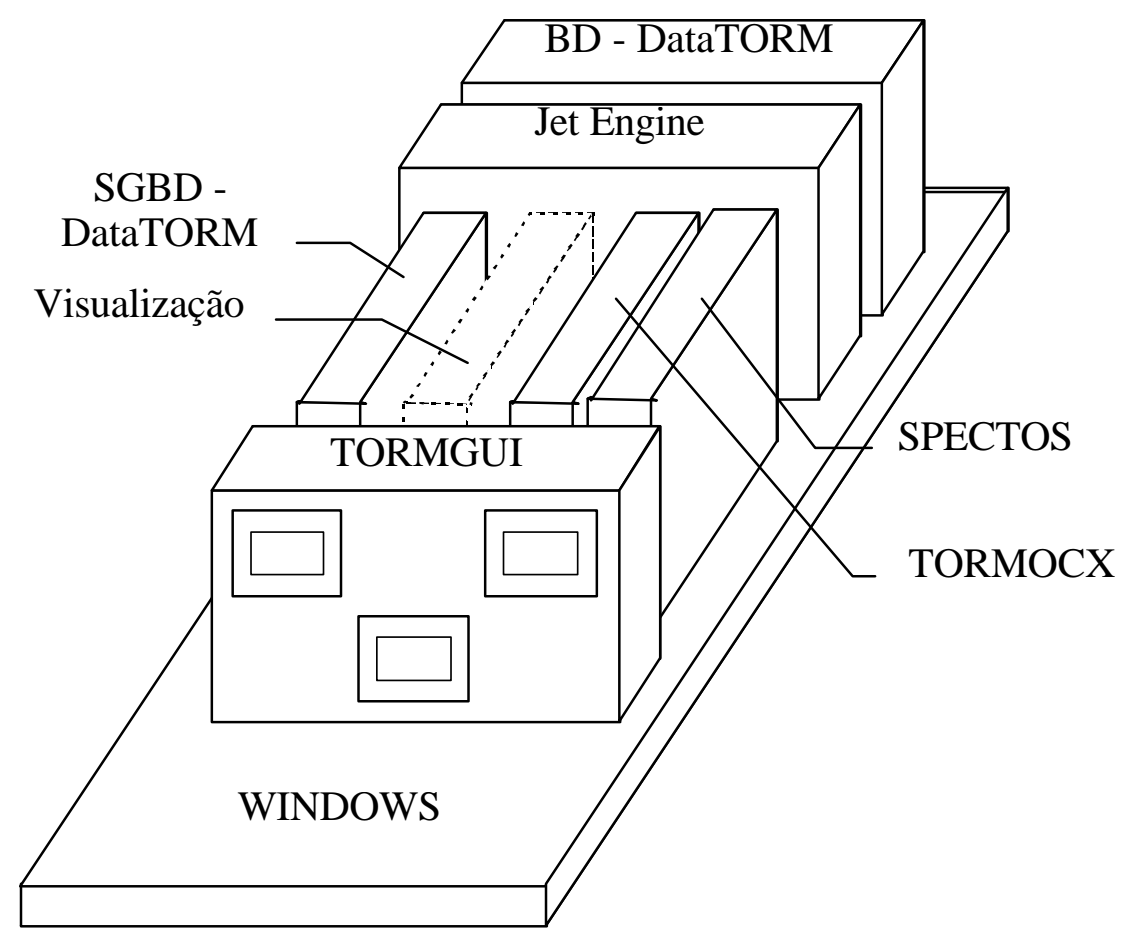

Figura 32 - Diagrama dos módulos de programa do sistema ToRM-05.

$\mathrm{Na}$ base da figura está o sistema operacional Windows 95, que gerencia a utilização dos recursos do computador e proporciona os meios de comunicação entre os diversos módulos de programa do sistema. Durante a operação do sistema de MRI, o usuário interage principalmente com o módulo TORMGUI, que incorpora e executa um modelo completo de operação do tomógrafo, sendo ele o responsável por ter acesso e utilizar os demais módulos de programa de maneira transparente ao usuário. Os dados são armazenados em arquivos de banco de dados relacionais do

\footnotetext{
* Ao contrário do modelo de referência ECMA/NIST, o DataTORM não é um repositório de objetos distribuídos que pode ser utilizado por todas as aplicações de maneira transparente e automática. Uma representação mais fiel seria colocar o DataTORM como uma aplicação adicional, juntamente com os módulos SPECTOS, TORMOCX e um módulo de visualização, e, na parte posterior da Figura 32, substituir o Jet Engine pelos módulos de OLE 2.0 e colocar no lugar do BD - DataTORM os objetos a serem distribuídos, como, por exemplo, o objeto "Dados", proposto na seção 3.3.2.2, que pode ser utilizado para manipular os dados não-convencionais. O OLE 2.0 é parte de um padrão proprietário de objetos distribuídos chamado $\mathrm{DCOM}^{24}$ e que opera na plataforma Windows. Outras possíveis escolhas poderiam ser os padrões CORBA ${ }^{25}$ ou CORBAmed, ${ }^{26}$ que são padrões abertos de objetos distribuídos. O propósito da figura mencionada, da maneira como ela está, é apenas destacar as diversas partes do DataTORM do restante dos módulos de programa do sistema ToRM-05.
} 
DataTORM. O acesso a estes dados é feito através do SGBD Jet Engine $e^{*}$ pelo SGBD DataTORM desenvolvido no MS Access 2.0, ou por um outro aplicativo capaz de utilizar o SGBD Jet Engine para ter acesso ao BD DataTORM, como, por exemplo, pelo TORMGUI,

O TORMGUI utiliza os módulos SPECTOS e TORMOCX para interagir com o espectrômetro e processar os dados de aquisição. O SGBD DataTORM é um aplicativo de banco de dados para ter acesso aos dados de forma independente. Outros módulos podem ser inseridos nesta estrutura, sejam eles produtos comerciais comprados ou aplicativos desenvolvidos localmente, como, por exemplo, um aplicativo responsável para visualização de imagens de MRI que está sendo desenvolvido.

A decisão de projeto referente a escolha da plataforma computacional limitou o número de possíveis escolhas para as ferramentas de desenvolvimento do DataTORM. Para facilitar a implementação do SBD, decidiu-se por utilizar um SGBD comercialmente disponível e conhecido. O produto escolhido foi o MS Access 2.0..$^{\dagger}$ A escolha foi baseada no fato do produto ser da empresa Microsoft e, como outros produtos desta empresa já estavam sendo utilizados para o desenvolvimento de programas do ToRM-05, esperava-se assim facilitar a compatibilidade entre os vários subsistemas de programa. Outra razão era a simplicidade de aprendizado e uso do produto. Ele foi usado, então, para construir o BD e para implementar a aplicação de banco de dados que serve de interface com o usuário.

Alguns meses mais tarde foi lançado nos Estados Unidos da América o produto FoxPro 3.0 que, em parte, atenderia os requisitos relativos ao armazenamento e manipulação de dados não convencionais. Como levaria muito tempo para se importar este programa ou esperar que fosse lançado no mercado nacional, a sua utilização foi descartada. Aproximadamente um ano depois desta escolha, foi lançada uma nova versão do MS Access, a versão 7.0, também chamado de MS Access 95. Esta versão inicial possuía problemas de "vazamento de memória",

\footnotetext{
" O Jet Engine é o SGBD utilizado pelo MS Access e pelo MS Visual Basic. O Apêndice IV, Microsoft Access Versão 2.0, fornece detalhes adicionais sobre este módulo.

${ }^{\dagger}$ O Apêndice IV, Microsoft Access Versão 2.0, fornece alguns detalhes adicionais sobre este aplicativo de banco de dados.
} 
que consumia rapidamente os recursos do sistema operacional disponíveis para a aplicação. Este era um problema grave que não ocorria na versão 2.0 do produto. Por esta razão, e apesar das diversas melhorias desta nova versão, decidiu-se manter o desenvolvimento na versão 2.0 do MS Access. 


\subsection{Proposta para o sistema de banco de dados}

\subsubsection{Descrição dos modelos de dados}

\subsubsection{Diagrama de contexto geral}

Da mesma forma que foi elaborado um diagrama de contexto para a situação atual do ambiente de operação do sistema ToRM-005 (Item 3.2.1.1.2), elaborou-se uma proposta de contexto geral para ser usada como uma descrição geral do ambiente de utilização do ToRM-05 e do DataTORM.

Um diagrama de contexto abordando uma situação geral deve ser capaz de representar as diferentes possibilidades no qual o sistema pode se inserir. Isto significa que a descrição deve ser geral o suficiente para que, dado um ambiente qualquer no qual o sistema seja instalado, seja possível relacionar o contexto deste ambiente com o contexto geral no qual o sistema é baseado. Desta forma, cada ambiente é uma instância do contexto geral.

O diagrama de contexto geral descrito abaixo apresenta dois níveis:

- Sala de Tomografia (ST);

- Contexto Externo (CE). 


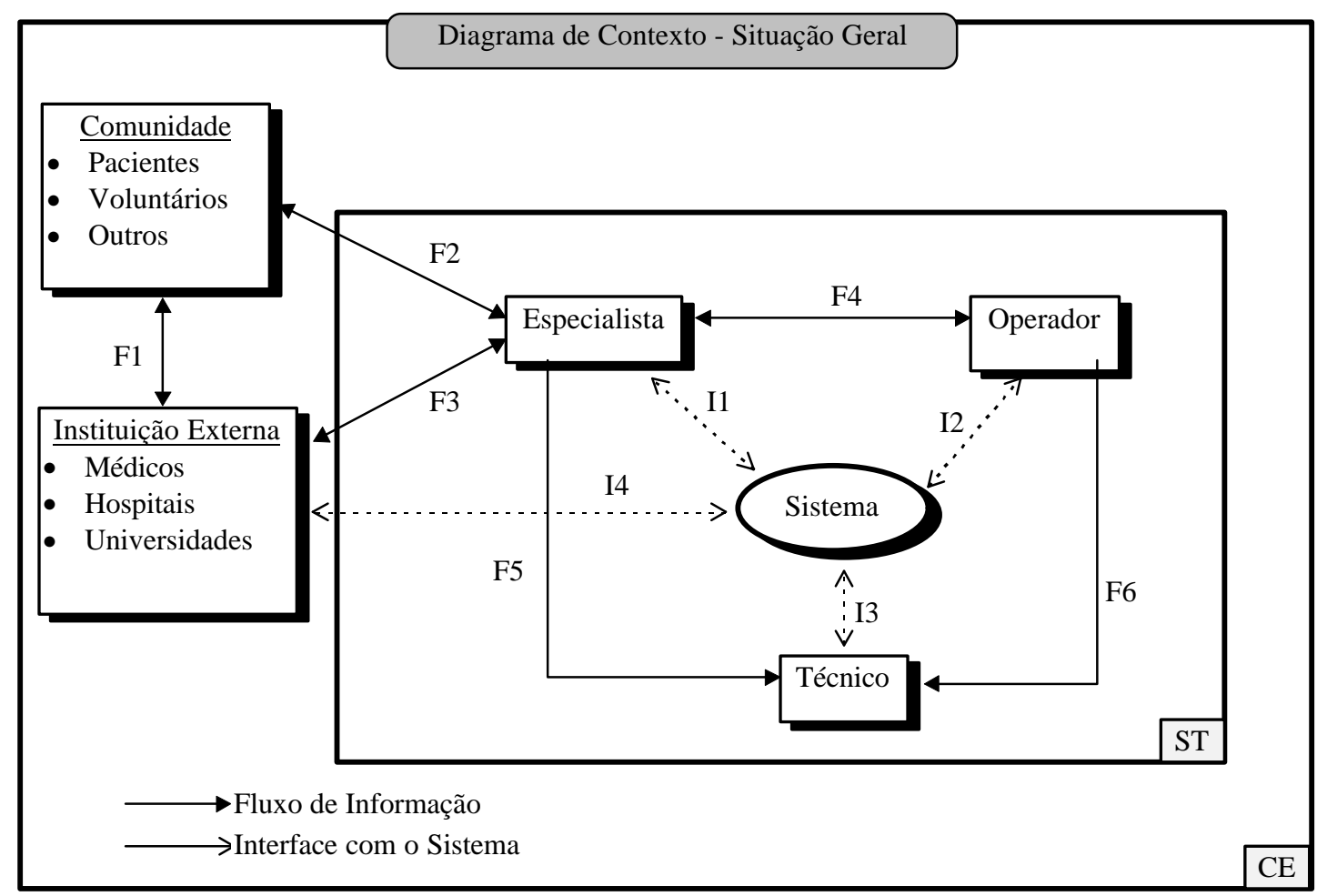

Figura 33 - Proposta de diagrama de contexto para o sistema ToRM-05.

Tabela 18 - Descrição de FI e IS da proposta de diagrama de contexto geral

\begin{tabular}{|c|c|}
\hline Fluxos de Informação (FI) & Interfaces com o Sistema (IS) \\
\hline F1: A Comunidade procura Instituição & I3: O Especialista visualiza as imagens \\
\hline $\begin{array}{l}\text { Externa para atividades que resultam na } \\
\text { utilização do Sistema. A Instituição Externa } \\
\text { retorna resultados para a Comunidade. }\end{array}$ & na tela de visualização do Sistema. \\
\hline $\begin{array}{l}\text { F2: A Comunidade procura diretamente o } \\
\text { Especialista para atividades que resultam na } \\
\text { utilização do Sistema. O Especialista retorna } \\
\text { resultados para a Comunidade. }\end{array}$ & I2: O Operador opera o Sistema. \\
\hline F3: A Instituição Externa procura o & I3: O Técnico realiza atividades de \\
\hline $\begin{array}{l}\text { Especialista para atividades que resultam na } \\
\text { utilização do Sistema. O Especialista retorna } \\
\text { resultados para a Instituição Externa. }\end{array}$ & $\begin{array}{l}\text { manutenção evolutiva, adaptativa e } \\
\text { corretiva sobre o Sistema. }\end{array}$ \\
\hline $\begin{array}{l}\text { F4: O Especialista instrui o Operador quanto } \\
\text { a operação a ser realizada. O Operador } \\
\text { retorna os resultados ao Especialista. }\end{array}$ & $\begin{array}{l}\text { I4: Interface entre o sistema de } \\
\text { aquisição e PACS, RIS e/ou HIS. }\end{array}$ \\
\hline F5: O Especialista fornece análises e opiniões & \\
\hline $\begin{array}{l}\text { sobre a qualidade dos resultados do sistema } \\
\text { ao Técnico. }\end{array}$ & \\
\hline F6: O Operador fornece análises e opiniões & \\
\hline $\begin{array}{l}\text { sobre o estado operacional do sistema ao } \\
\text { Técnico. }\end{array}$ & \\
\hline
\end{tabular}


A posição de cada entidade no diagrama depende da abrangência de sua atuação. Por exemplo, no diagrama da Figura 33, assume-se que o Especialista, que pode ser um radiologista que prescreve e acompanha os estudos, atua exclusivamente na ST, já médicos externos, como radiologistas responsáveis por laudos ou aqueles que requisitam o exame, possuem uma atuação mais geral, com várias outras ocupações no CE. Com relação ao Técnico, uma proposta alternativa poderia incluílo no $\mathrm{CE}$, provavelmente relacionado ao fabricante do sistema de MRI, e a ST não teria que manter um Técnico especialista em equipamentos de MRI.

\subsubsection{Modelo de dados conceitual}

O primeiro passo no desenvolvimento do SBD DataTORM foi, baseado nas características e necessidades tanto de uma instalação médica típica quanto de um ambiente acadêmico, desenvolver um modelo de dados de alto nível que representasse as necessidades e visões de dados dos usuários em potencial destes dois tipos de ambientes.

Baseado em observações feitas durante visitas a três instalações médicas que realizam exames de MRI (Botucatu, INCOR e Beneficência Portuguesa), foram detectadas as seguintes características típicas destes ambientes:

- os resultados sempre são impressos em filmes;

- os resultados no formato digital são armazenados em sistemas de curto prazo até serem impressos em filmes. Depois eles são apagados à medida que surge a necessidade de espaço para o armazenamento de novos resultados;

- em algumas instalações os resultados no formato digital são armazenados em sistemas de médio e longo prazo como cópias de segurança dos resultados já impressos em filmes;

- juntamente com os resultados dos estudos, isto é, os dados de aquisição e/ou as imagens finais, são armazenados todos os dados que caracterizam os estudos, as suas séries e as imagens. Em geral, apenas alguns dados demográficos do paciente são incluídos, como nome, peso, idade e identificação. Outros dados que são às vezes incluídos são o nome do operador e do médico que requisitou o estudo; 
- dos três sistemas visitados, dois possuíam os equipamentos interligados em rede e com um sistema de armazenamento de imagens de médio e longo prazo central, com características de um PACS simples. Estes sistemas, restritos aos departamentos de radiologia e de informática médica, não possuíam conexões com os sistemas HIS das instalações médicas, sistemas de informações estes que cuidavam dos dados dos pacientes, como, por exemplo, registros dos pacientes, pedidos e resultados de exames, etc.

Já no ambiente acadêmico do Grupo de Ressonância do IFSC, outras características específicas podem ser observadas:

- cada usuário do sistema ToRM-005 que o utiliza com objetivos acadêmicos possui a sua própria maneira de armazenar os resultados. Os dados que contextualizam os resultados, sejam eles parâmetros de operação ou dados característicos do voluntário, phantom ou amostra, são armazenados de acordo com as necessidades do momento do usuário, não havendo nenhuma padronização quanto ao formato, local de armazenamento, conjunto mínimo de dados a ser armazenado e registro de estudos realizados;

- no caso de exames clínicos, existe uma padronização mínima no gerenciamento dos dados. Em arquivos manuais são armazenadas folhas com os pedidos de exame e neste pedido encontram-se, além das informações clínicas, as informações demográficas dos pacientes. Nos computadores são armazenados os resultados, que são os dados de aquisição e as imagens finais, e os arquivos de parâmetros utilizados pela aquisição;

- os resultados são armazenados localmente apenas na forma digital, organizados em uma hierarquia de diretórios dos computadores utilizados. Eles são impressos através de uma impressora térmica apenas quando devem ser enviados para o médico que requisitou o exame.

Considerando as características dos ambientes de operação de instalações médicas, o DataTORM deve satisfazer os seguintes requisitos de dados:

- armazenar prioritariamente com os resultados todos dados que caracterizam o estudo, suas séries, aquisições e imagens. Neste ambiente, os demais dados 
relativos ao sistema de informação local são armazenados por outros sistemas, sejam eles digitais ou não;

- os resultados devem ser impressos em filmes, pois as análises raramente são feitas utilizando monitores de computadores;

- os dados na forma digital devem ser armazenados para, no curto prazo, esperar a impressão, e no longo prazo, servir como cópias de segurança;

- como existe a tendência de sistemas isolados evoluírem para sistemas integrados em PACS, o que já está ocorrendo em alguns hospitais grandes do país, como o INCOR, o modelo de dados deve seguir padrões já existentes para facilitar a comunicação de dados.

Para atender as necessidades do ambiente acadêmico onde se encontra o ToRM-005, os seguintes requisitos adicionais também devem ser satisfeitos:

- como neste ambiente o controle sobre os dados de pacientes, pedidos de estudo e agendamento de visitas é relativamente precário, é desejável que o DataTORM ajude a automatizar estas tarefas e padronizar e organizar estes dados;

- neste ambiente, o armazenamento digital e automático é preferível ao armazenamento em filmes ou outros meios materiais, pois nem sempre há recursos físicos e humanos que podem ser alocados especificamente para esta tarefa.

Além das informações específicas sobre os sistemas comerciais visitados, o sistema ToRM-005 em operação e o projeto do sistema ToRM-05, o levantamento de requisitos de dados também utilizou como uma das principais fontes de informações o padrão DICOM 3.0, mais especificamente, o modelo composto para a modalidade Ressonância Magnética, descrito no Apêndice A.4 da parte número três do padrão. ${ }^{11}$

Desta forma, a proposta elaborada em EER possui duas partes principais: o Sistema de Informação Administrativo (SIA) e o Sistema de Informação para RMN (SIRMN). A primeira atende, principalmente, as necessidades de dados de um ambiente acadêmico, possuindo tipos de entidade para pessoas, phantoms, pedidos de estudo e agendamento de visitas. O SIRMN possui os tipos de entidade para armazenar os resultados da operação de um sistema de MRI, organizando estes resultados em uma hierarquia de estudos, séries, aquisições e dados. 
O SIA é apresentado resumidamente na Figura 34, apenas com os tipos de entidades mas sem os respectivos atributos. Os principais tipos de entidades deste modelo são:

- COMUNIDADE;

- ESPECIALISTA;

- EQUIPAMENTO;

- PEDIDO DE ESTUDO;

- VISITA.

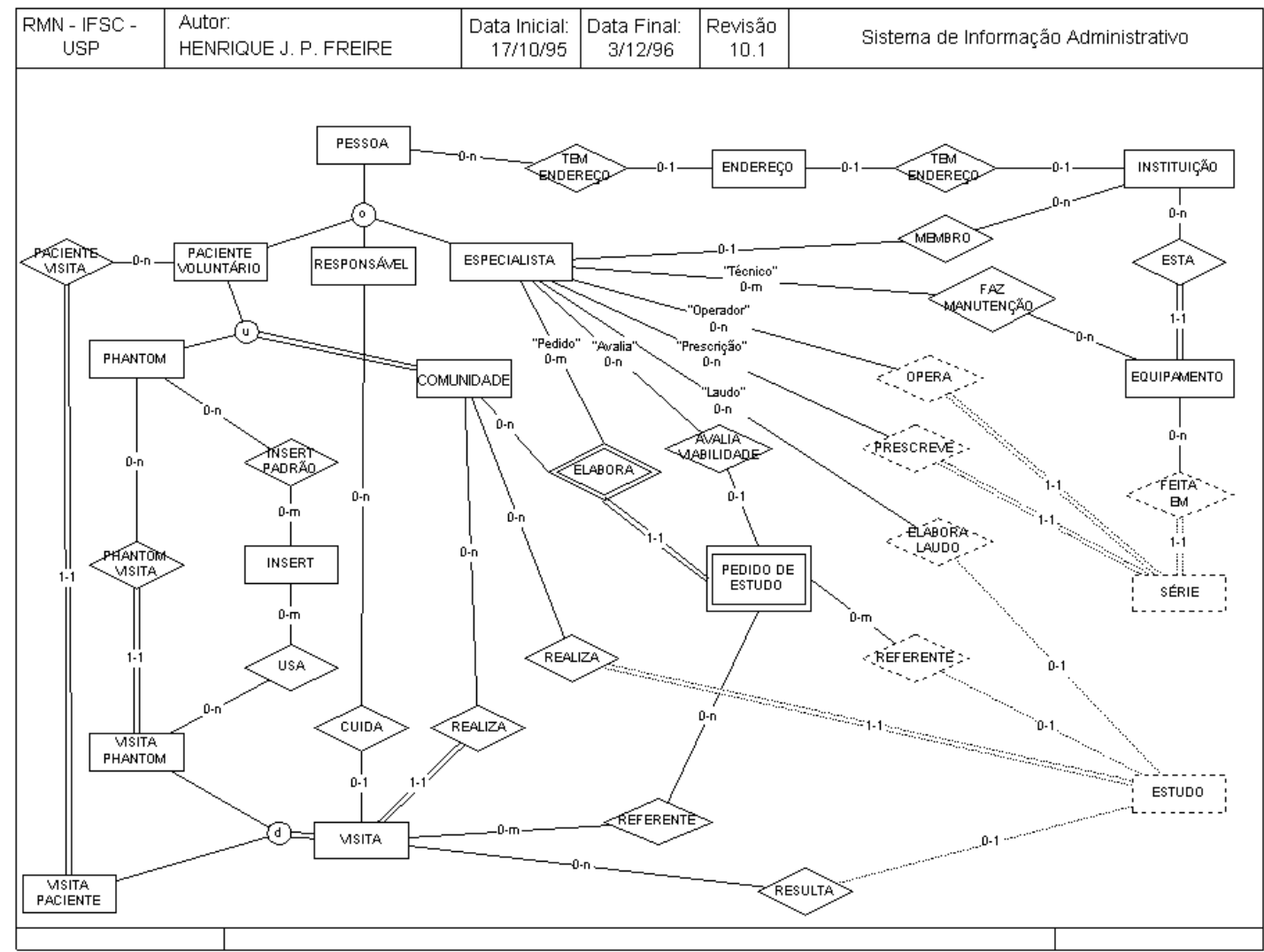

Figura 34 - Modelo EER do SIA.

A COMUNIDADE ${ }^{\dagger}$ é uma categoria que agrega tipos de entidades que podem ser submetidos a um estudo. No presente modelo, a COMUNIDADE pode ser PACIENTE/VOLUNTÁRIO (subclasse de PESSOA) ou PHANTOM. Como os

\footnotetext{
* Os diagramas completos do modelo EER proposto, incluíndo os atributos das entidades, estão no Apêndice VI, Modelo EER completo do DataTORM.

† O nome "COMUNIDADE" será substituído por "OBJETO DE ESTUDO" em uma futura versão do modelo de dados e do DataTORM.
} 
demais tipos de entidades, como VISITA, PEDIDO DE ESTUDO e ESTUDO, ${ }^{*}$ se relacionam apenas com o tipo entidade COMUNIDADE, fica fácil inserir novos tipos de entidade que podem ser submetidas a estudos devido a herança seletiva proporcionada pela categoria.

As entidades do tipo de entidade ESPECIALISTA, que é subclasse de PESSOA, podem assumir vários papeis:

- Pedido: especialista que elabora o pedido de estudo. Pode ser, por exemplo, um clínico geral, um cardiologista ou um neurocirurgião;

- Avalia: especialista da instituição que possui o aparelho de MRI que avalia se é possível fazer o estudo requisitado no pedido de estudo com o equipamento disponível. Em geral este especialista é um radiologista com especialização em MRI;

- Prescrição: especialista que prescreve e acompanha a realização do estudo. Em geral ele é um radiologista;

- Laudo: especialista que, à partir dos resultados do estudo, elabora o laudo final;

- Operador: especialista que opera o equipamento para a realização dos estudos. Em geral ele é um biomédico;

- Técnico: pode ser um engenheiro, técnico de nível médio ou outro especialista que executa atividades de manutenção corretiva, adaptativa e evolutiva no sistema.

Dependendo do papel do especialista, ele se relaciona com diferentes tipos de entidades. Pode ocorrer que o mesmo especialista assuma vários papeis, como, por exemplo, é comum um mesmo especialista assumir os papeis Avalia, Prescrição e Laudo.

O tipo de entidade EQUIPAMENTO resume as principais características de um ou mais equipamentos de MRI registrados. São estes equipamentos que são utilizados na realização de estudos. Através do relacionamento FAZ MANUTENÇÃO entre EQUIPAMENTO e ESPECIALISTA, pode-se armazenar informações sobre manutenções efetuadas sobre o equipamento.

\footnotetext{
*A entidade ESTUDO faz parte do SIRMN que será apresentado mais adiante.
} 
PEDIDO DE ESTUDO é um tipo de entidade fraca cujos tipos de entidades de identificação são COMUNIDADE e ESPECIALISTA. Os estudos são baseados nos pedidos de estudo, que também fornecem o pré-diagnóstico do especialista que pediu o estudo, o resumo clínico do membro da comunidade e resultados de outros exames.

O tipo de entidade VISITA possibilita a agenda de visitas para a realização de estudos. Ela também indica a situação atual de cada visita.

Os tipos de entidades COMUNIDADE, ESPECIALISTA, PEDIDO DE ESTUDO, VISITA e EQUIPAMENTO do SIA se relacionam com os tipos de entidades ESTUDO e SÉRIE do SIRMN. Estes tipos de relacionamentos é que ligam as duas partes do modelo.

A maioria das informações do SIA não fazem parte do modelo composto para MRI do padrão DICOM 3.0. Muitas delas estão no modelo normalizado daquele padrão e outras foram obtidas das necessidades locais dos sistemas ToRM-005 e ToRM-05, como, por exemplo, a entidade PHANTOM.

O SIRMN é, basicamente, uma adaptação do modelo composto para RMN do padrão DICOM 3.0. Ele possui a mesma estrutura hierárquica principal, com a diferença que existe um nível adicional, AQUISIÇÃO, entre SÉRIE e DADO. Este nível foi adicionado pois percebeu-se que muitas informações são repetidas no DICOM 3.0 para cada dado, e estas informações poderiam ser agrupadas para evitar a duplicação excessiva de dados.

Os significados dos principais tipos de entidades da hierarquia desta parte do modelo são:

- ESTUDO: compreende à obtenção de imagens médicas com um objetivo específico definido, quando presente, pelo pedido de estudo. Um estudo é composto de nenhuma, uma ou várias séries;

- SÉRIE: é um conjunto de dados espacialmente relacionados obtidos por uma determinada modalidade. A série pode ser composta por dados de várias aquisições; 
- AQUISIÇÃO: é o conjunto de dados obtidos pela execução de uma sequiência de aquisição pelo aparelho de MRI. Se entre uma aquisição e outra não for feita nenhuma alteração que acarrete numa perda de referência no sistema de coordenadas, como a movimentação do paciente, estas aquisições podem ser parte de uma mesma série e, conseqüentemente, os dados podem ser espacialmente relacionados. Cada aquisição pode possuir vários dados;

- DADO: os dados são, em uma definição mais geral, os resultados da aquisição. Eles podem ser de vários tipos e formatos, entre eles, dados de aquisição, dados transformados, dados de módulo e dados de fase. Estes dados são armazenados em matrizes de números reais ou complexos, sendo possível utilizar os valores destas matrizes para criar imagens ${ }^{*}$ que podem ser visualizadas ou impressas.

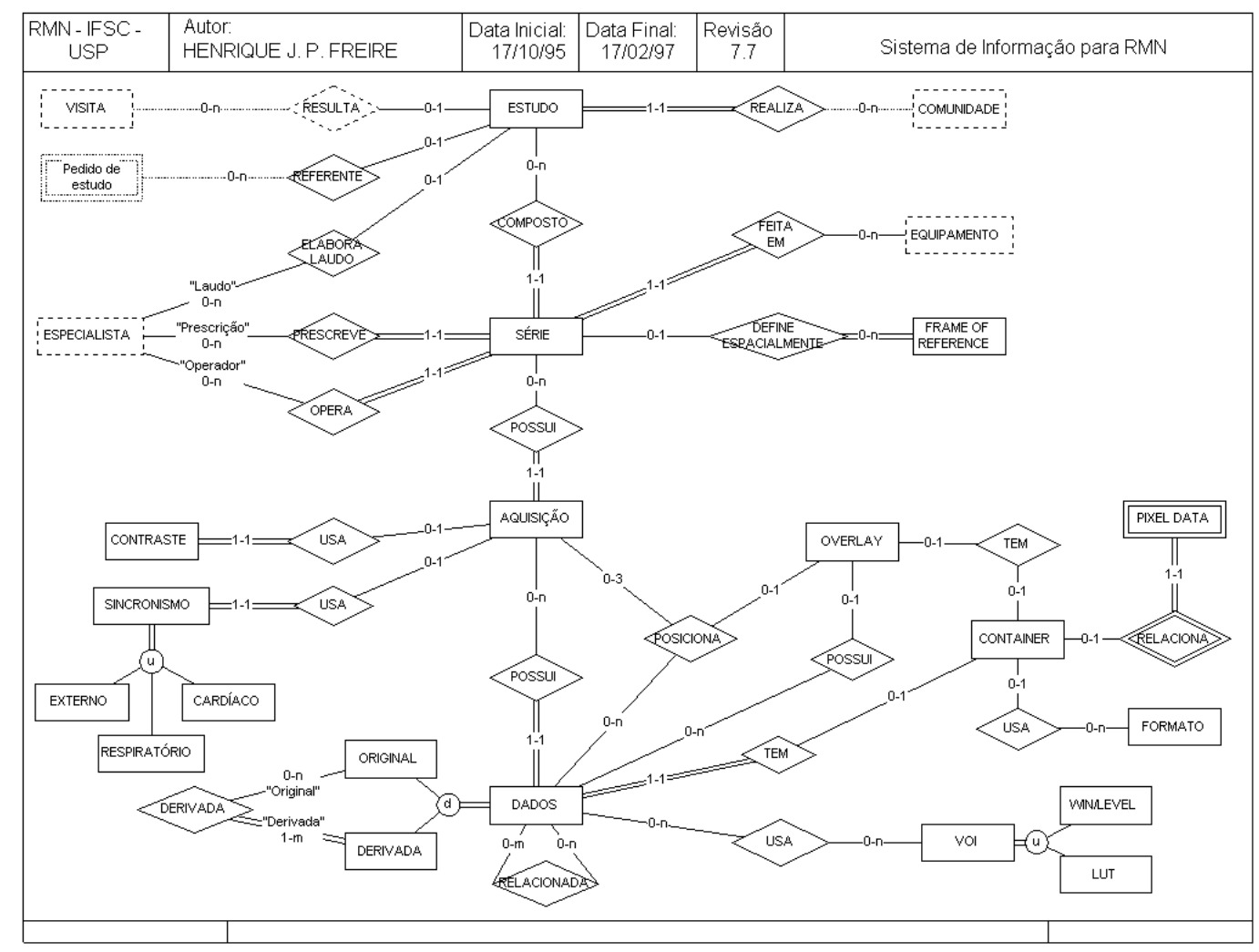

Figura 35 - Modelo EER do SIRMN.

\footnotetext{
* No ambiente de desenvolvimento para MRI, é comum utilizar o termo imagem para se referir aos dados de módulo. Como este termo é muito genérico, aqui uma imagem é considerada apenas como um conjuto de pixels em formato apropriado para ser utilizado por um sistema de visualização ou impressão. A imagem pode ser extraída não apenas dos dados de módulo, mas também dos outros tipo de dados.
} 
Um aspecto importante existente no SIRMN é a forma em que os dados binários dos DADOS e de OVERLAYS são separados dos restantes dos dados. Como estes dados é que correspondem ao maior volume de armazenamento físico, eles são armazenados em um tipo de entidade específico chamado PIXEL DATA. Este é um tipo de entidade fraco que contêm apenas os dados binários e seus identificadores. O tipo de entidade identificador é o CONTAINER, que indica a localização física de cada entidade PIXEL DATA, possibilitando, assim, a implementação de uma hierarquia de armazenamento físico, como descrito na seção sobre PACS.

\subsubsection{Modelo de implementação relacional}

O modelo de implementação relacional é elaborado na fase de especificação do sistema e, como as especificações servem como um guia para a fase de implementação, algumas decisões de projeto devem ser levadas em consideração nesta etapa para restringir o escopo das especificações.

Dentre os vários tipos de bancos de dados (relacional, rede, hierárquico e orientado a objetos), o relacional é o mais difundido e os SGBDs comerciais mais conhecidos são relacionais. Para aplicações do tipo PACS, a principal restrição dos sistemas relacionais comuns é a necessidade de extensões para comportar tipos de dados não convencionais, como imagem, som e vídeo. Sistemas orientados a objetos são mais flexíveis neste sentido, mas, até o momento em que esta decisão de projeto foi tomada, em junho de 1995, não havia nenhum SGBD para SBD orientado a objetos comercialmente difundido e que satisfizesse as necessidades do projeto. Desta forma, conscientes das limitações de sistemas relacionais tradicionais, mas considerando ser esta uma tecnologia mais difundida e bem estabelecida, decidiu-se que a implementação deveria ser de um banco de dados relacional.

Como consequiência desta decisão, na fase de especificação, foi criado um modelo de dados de implementação relacional, baseado no modelo de dados conceitual elaborado em EER. Também foi criado um dicionário de dados correspondente às tabelas do modelo relacional. 
O modelo de implementação relacional foi obtido à partir do modelo conceitual em EER através de um mapeamento feito utilizando as regras apresentadas na seção sobre sistemas de banco de dados (Item 2.4.6.6). Para mapear os relacionamentos superclasse/subclasse foi utilizada a opção número 1 (Tabela 13), onde é criada uma relação para a superclasse e uma relação para cada subclasse correspondente. Foram criadas relações para tipos de relacionamentos apenas nos casos de cardinalidade N-M.

O modelo resultante é apresentado nas figuras do final desta seção. Neles são mostradas as relações, seus atributos e os relacionamentos. A chave primária de cada relação, seja ela um atributo simples ou composto, é destacada com negrito.

As linhas ligando as relações indicam os relacionamentos, e os números nas extremidades das linhas indicam a cardinalidade do relacionamento, seja ela 1-1 ou 1N. As cardinalidades nestes relacionamentos refletem as cardinalidades definidas para os relacionamentos do modelo EER. Já as restrições de participação não aparecem nos diagramas, mas são indicadas no dicionário de dados quando é indicado se há a obrigatoriedade da chave estrangeira em uma tupla possuir um valor, participação total, ou não, participação parcial.

Nos casos em que a chave estrangeira não faz parte da chave primária da relação, é direto perceber no diagrama que é esta relação que se relaciona com a outra, isto é, do ponto de vista da integridade referencial, para existir uma tupla nesta relação, é necessário que o valor de cada chave estrangeira desta relação seja igual ao valor de chaves primárias de outras relações ou nulo, sendo esta última opção para o caso de participação parcial.

Se a chave estrangeira também for chave primária, ou fizer parte desta, a representação não indica diretamente qual é a relação primária e qual é a relação relacionada. Este é o caso, por exemplo, de todas as relações criadas para implementar relacionamentos M-N e para implementar atributos múltiplos. Esta distinção é importante pelos seguintes motivos: 1) ela reflete a semântica dos dados e, por isso, deve obedecer o esquema estabelecido no modelo conceitual; 2) esta distinção é importante para a implementação dos relacionamentos do banco de dados para que o SGBD saiba manter a integridade referencial das relações da maneira que 
foi planejado. Neste caso, a indicação de que um atributo é chave estrangeira para outra relação é anotada no dicionário de dados.

Outra informação existente nos diagramas usados é o tipo de operação JOIN padrão para ser usado em consultas a relações que possuem relacionamentos entre si. Os tipos JOIN usados, descritos na seção sobre álgebra relacional da revisão da literatura, são LEFT OUTER JOIN, RIGHT OUTER JOIN e EQUI JOIN. Os dois primeiros são indicados com setas nas extremidades das linhas que ligam as relações. No caso de EQUI JOIN, não há nenhuma seta na ligação.

As relações do modelo relacional proposto satisfazem, em sua maioria, a forma normal Boyce-Cood. Algumas exceções foram detectadas, mas ficaram propositadamente em uma forma normal inferior. Por exemplo, a relação "PESSOA" não satisfaz a $3 \mathrm{NF}$ pois os atributos "IdadeValor" e "IdadeUnidade" são transitivamente dependentes dos atributos "DataNascimento" e "HoraNascimento", que não são atributos primários da relação. Esta relação está apenas normalizada até a 2NF, mas a opção por esta situação foi para deixar a cargo do usuário a escolha entre indicar a data de nascimento de uma pessoa ou indicar apenas a idade. Já a relação "ENDPESSOA" não satisfaz a 2NF pois o atributo "TipoEnd" possui DF parcial com relação a chave primária, e não DF completa. Esta situação ocorre pois esta relação implementa um relacionamento $1-\mathrm{N}$, que poderia ser implementado satisfazendo a 2NF se os atributos do relacionamento tivessem sido incorporados no "lado N" do relacionamento, como normalmente é feito. Como a relação "INSTITUIÇÃO" também se relaciona com "ENDEREÇO”, não seria adequado incluir uma chave estrangeira para "PESSOA" na relação "ENDEREÇO" enquanto o relacionamento com "INSTITUIÇÃO" é feito com uma chave estrangeira para "ENDEREÇO" naquela relação. Desta forma decidiu-se criar a relação "ENDPESSOA", mesmo sabendo que ela não estaria satisfazendo a $2 \mathrm{NF}$.

As consequiências das relações exemplificadas terem mantido um esquema relacional pobre, isto é, não satisfazendo formas normais superiores, foi a necessidade de implementar módulos de programa para garantir a integridade dos dados para estes casos, pois os recursos do SGBD não eram suficientes nestes casos. Para a DF relacionada com idade, se o usuário indica a data de nascimento, a idade é calculada e 
é armazenada, também, no atributo "IDADE". Se apenas a idade é indicada, o atributo para a data de nascimento é mantido sem valor. Para a forma em que foi implementado o relacionamento entre "PESSOA" e "ENDEREÇO", toda vez que uma instância de "PESSOA" é eliminada, um módulo de programa deve pesquisar a relação "ENDEREÇO" e apagar todas a tuplas relacionadas com a instância de "PESSOA" eliminada.

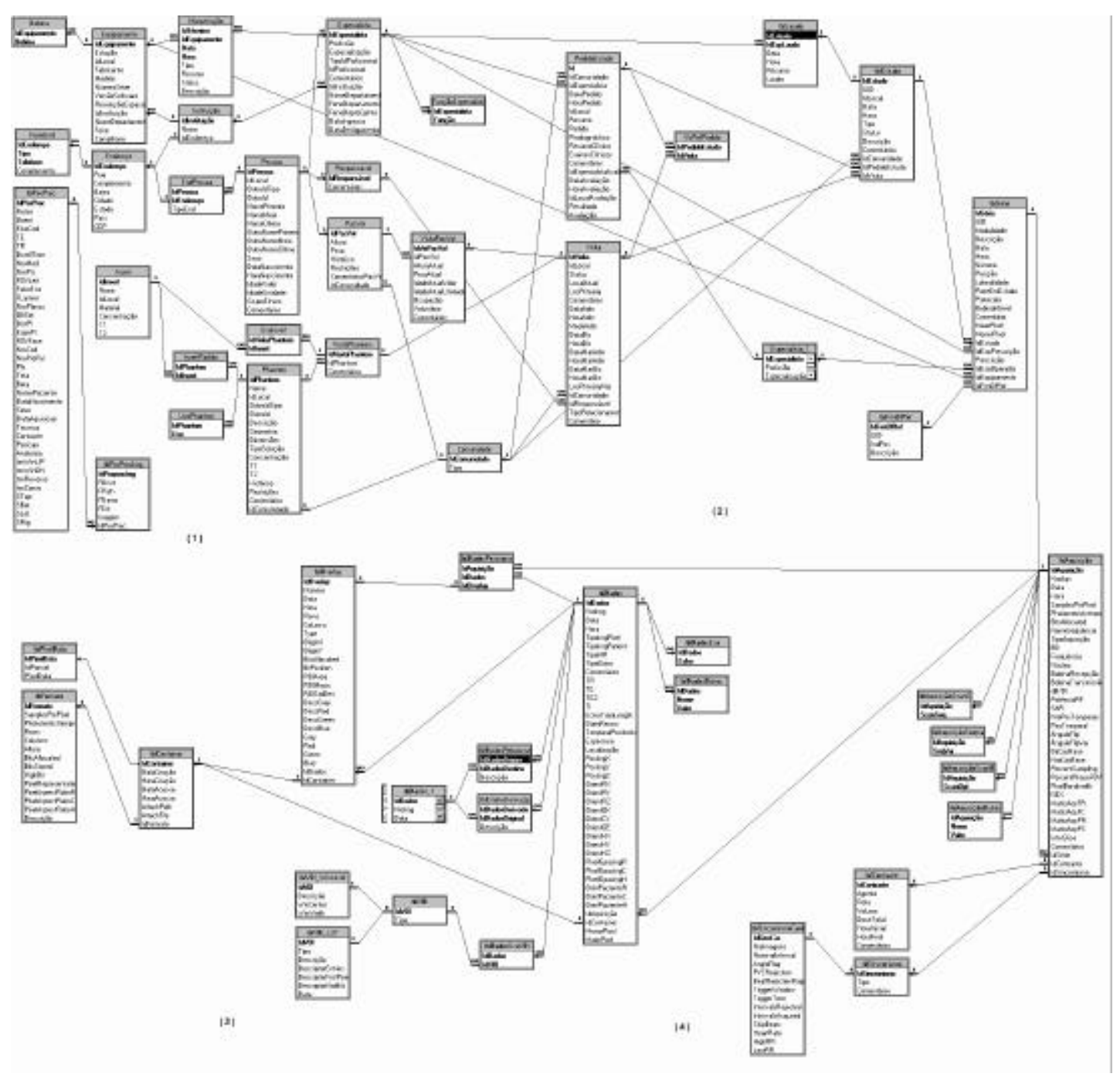

Figura 36 - Visão geral do modelo de implementação relacional."

\footnotetext{
* Esta figura serve apenas para proporcionar uma vista completa do diagrama do modelo de implementação relacional. As quatro figuras que seguem mostram os detalhes desta figura.
} 


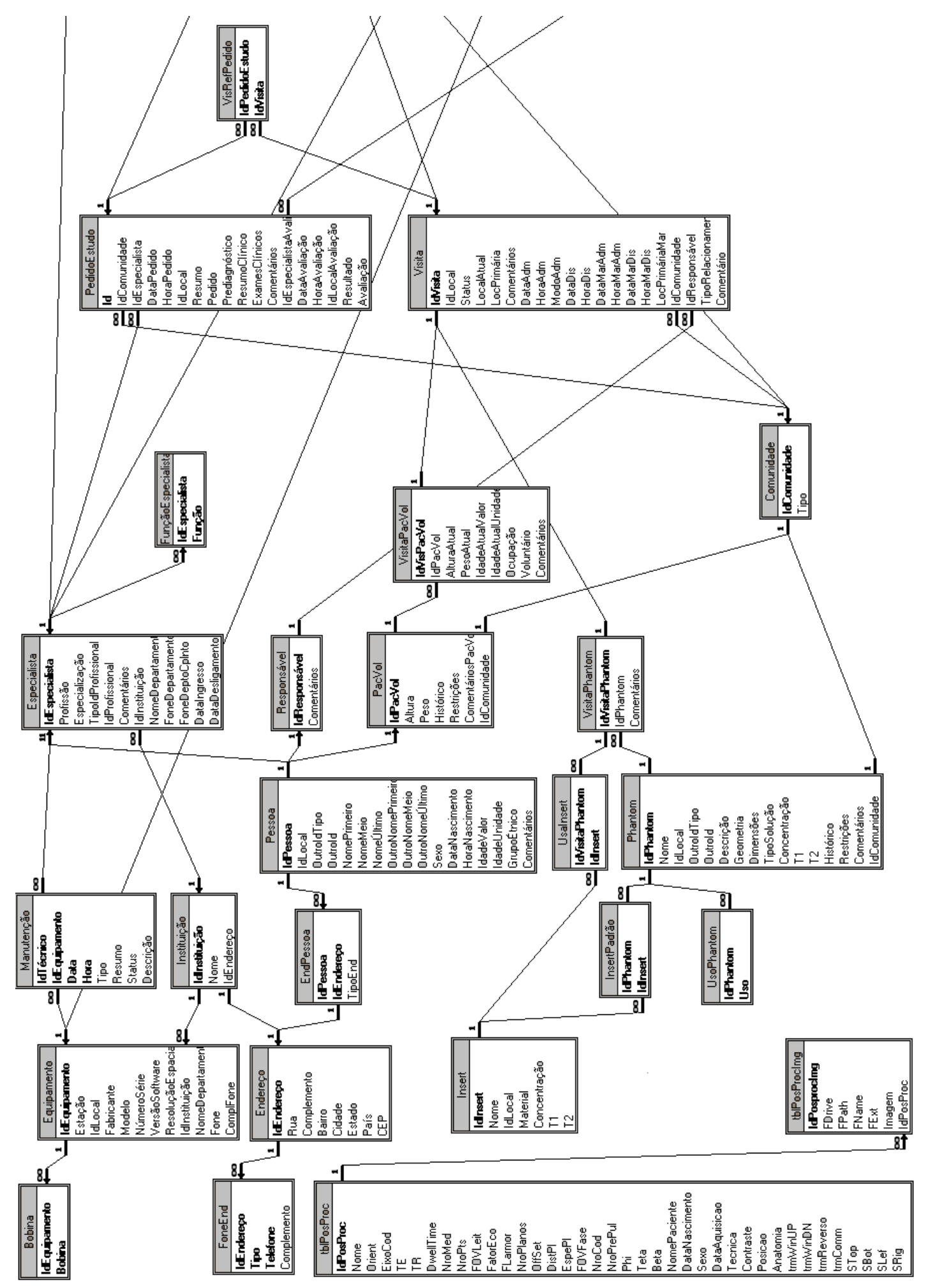

Figura 37 - Parte 1 do modelo de implementação relacional: SIA. 


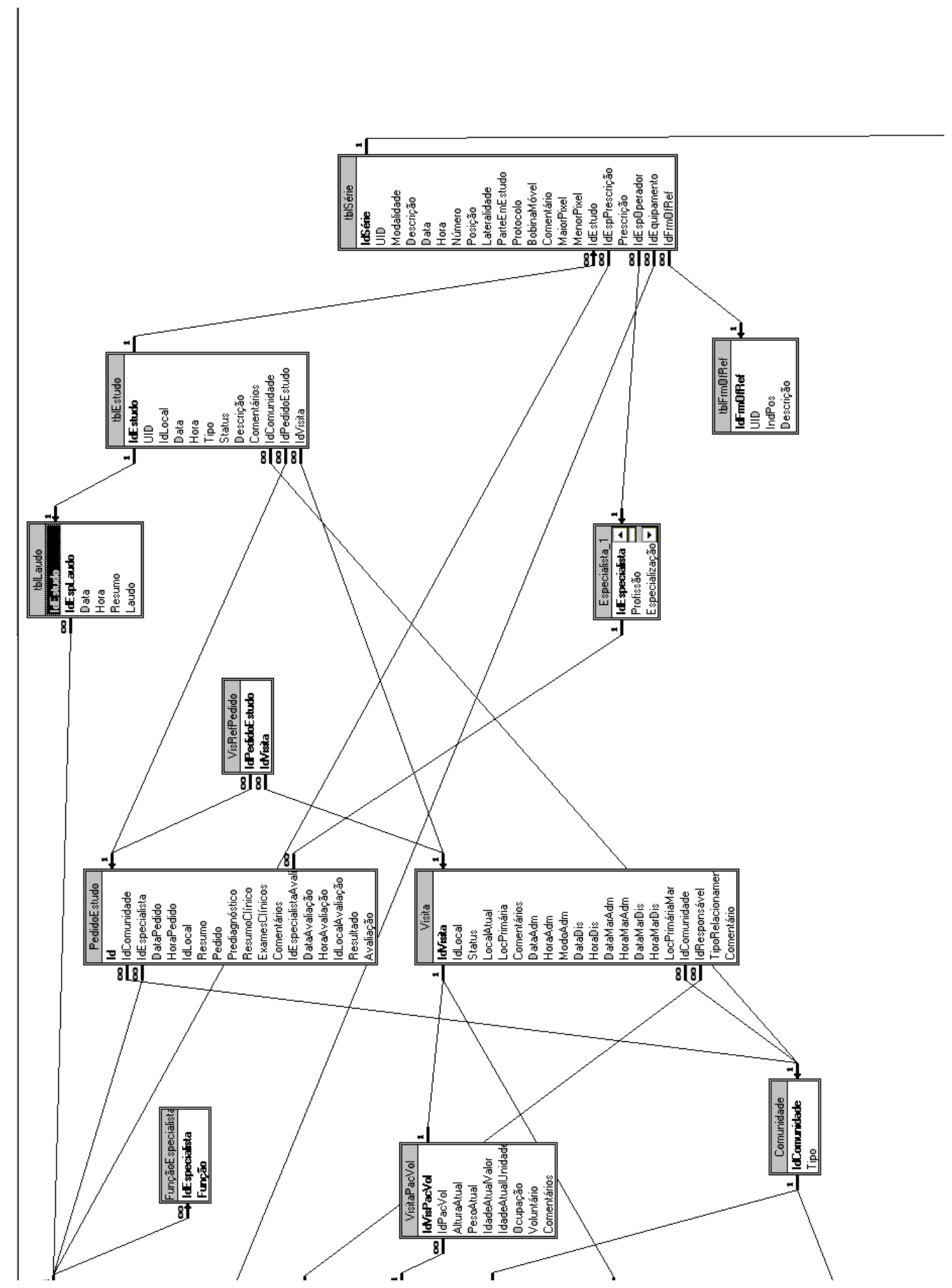

Figura 38 - Parte 2 do modelo de implementação relacional: Estudo e Série. 


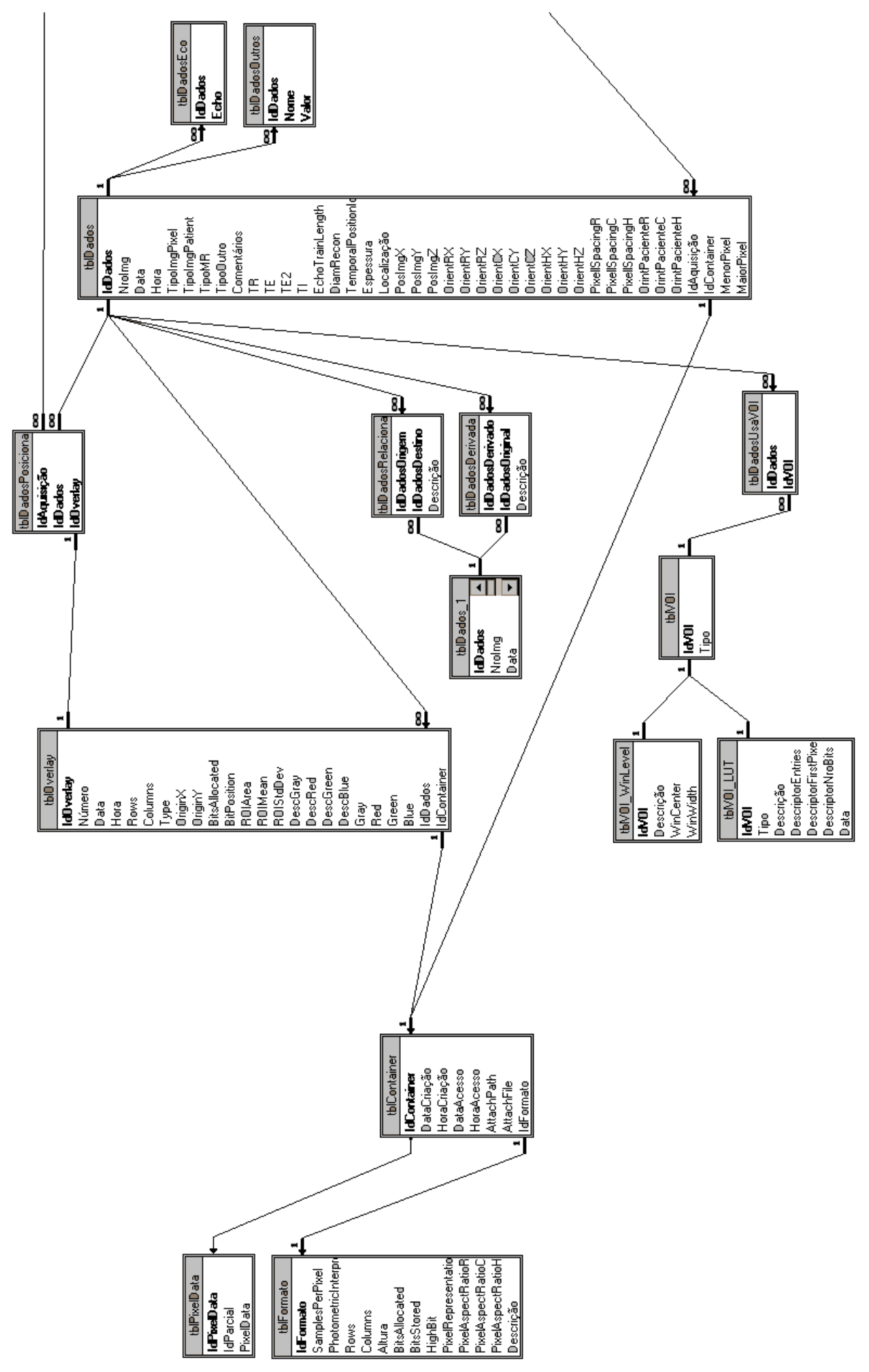

Figura 39 - Parte 3 do modelo de implementação relacional: Dados. 


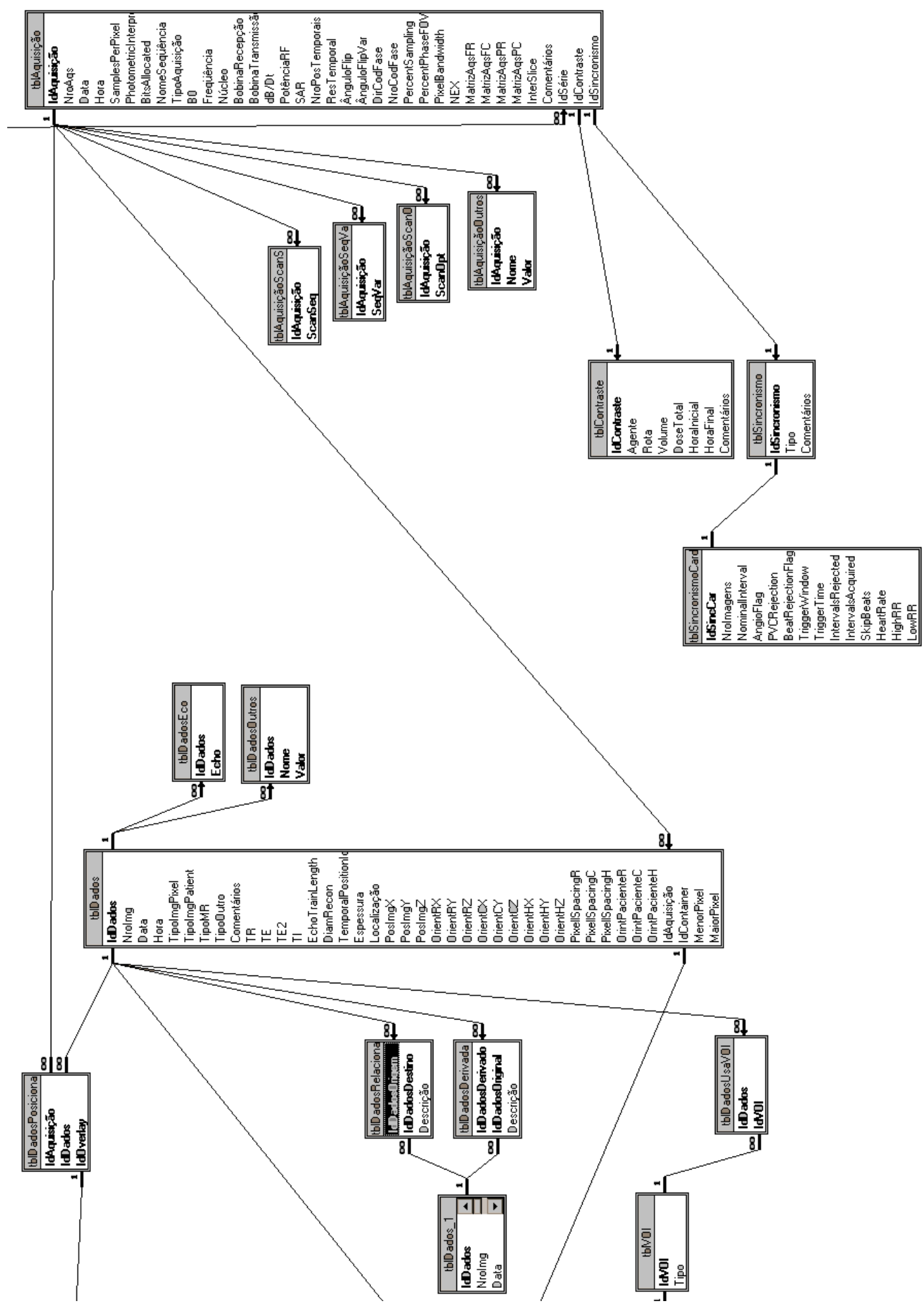

Figura 40 - Parte 4 do modelo de implementação relacional: Aquisição.

O diagrama do modelo relacional do DataTORM foi elaborado no próprio aplicativo MS Access 2.0. À medida que era feito o mapeamento do modelo EER para o relacional, as relações eram especificadas como tabelas do MS Access 2.0 e os relacionamentos eram criados no editor de relacionamentos deste aplicativo. As 
figuras do modelo relacional são, então, apenas cópias da tela do editor de relacionamentos. Desta forma, como a implementação do BD do DataTORM também foi feita no aplicativo MS Access 2.0, a atividade de especificação do modelo de implementação relacional foi também o início da implementação do banco de dados.

\subsubsection{Dicionário de dados}

O dicionário de dados descreve todos os atributos de todas as relações do modelo de implementação relacional. Para cada relação, ele apresenta todos os atributos. Para cada atributo é indicado o seu nome, o tipo de dados, o número de bytes e a descrição do atributo. O dicionário de dados propriamente dito encontra-se no Apêndice VII Dicionário de dados.

Os tipos de dados utilizados no dicionário de dados são os tipos existentes no aplicativo MS Access 2.0, descritos na tabela a seguir.

Tabela 19 - Tabela com os tipos de dados do Access

\begin{tabular}{|c|c|c|}
\hline $\begin{array}{c}\text { Tido de } \\
\text { dados }\end{array}$ & Descrição & Tamanho \\
\hline Text & Caracteres alfanuméricos & Até 255 bytes ( 1 byte por caracter) \\
\hline Memo & $\begin{array}{l}\text { Caracteres alfanuméricos } \\
\text { (geralmente várias sentenças ou } \\
\text { parágrafos) }\end{array}$ & Até 64 Kbytes \\
\hline Number & $\begin{array}{l}\text { Valores numéricos (inteiros ou } \\
\text { fracionários) }\end{array}$ & $\begin{array}{l}\text { Byte: } 1 \text { byte ( } 0 \text { a } 255) \\
\text { Integer: } 2 \text { bytes }(-32.768 \text { a } 32.767) \\
\text { Long integer: } 4 \text { bytes }(-2.147 .483 .648 \text { a } \\
2.147 .483 .647) \\
\text { Single: } 4 \text { bytes }\left(-3,4 \times 10^{38} \text { a } 3,4 \times 10^{38} \text {, }\right. \\
\text { com até } 7 \text { casas decimais) } \\
\text { Double: } 8 \text { bytes }\left(-1,797 \times 10^{308} \text { a }\right. \\
1,797 \times 10^{308} \text {, com até } 15 \text { casas decimais) }\end{array}$ \\
\hline Data/Time & Datas e horas & 8 bytes \\
\hline Currency & Valores monetários & 8 bytes \\
\hline Counter & $\begin{array}{l}\text { Valor numérico que o MS Access } \\
\text { incrementa automaticamente } \\
\text { quando um novo registro é } \\
\text { adicionado }\end{array}$ & 4 bytes \\
\hline Yes/No & Valores boleanos & 1 bit \\
\hline OLE Object & Objetos OLE & Até 1 Gbyte \\
\hline
\end{tabular}

Fonte: Adaptado de Microsoft Corporation, Microsoft Access®: User’s Guide, 1994, p.117, 135. 
Para manter compatibilidade com o padrão DICOM 3.0, aos atributos do DataTORM que possuem um equivalente naquele padrão foram atribuídos tipos de dados e número de bytes equivalentes. Na tabela a seguir, são apresentados os tipos de dados daquele padrão que são usados neste trabalho e os equivalentes no MS Access 2.0.

Tabela 20 - Equivalência entre tipos de dados do DICOM 3.0 e do MS Access 2.0

\begin{tabular}{|c|c|c|c|c|c|}
\hline \multicolumn{2}{|c|}{$\begin{array}{c}\text { Nome da } \\
\text { representação }\end{array}$} & Definição & Repertório & Bytes & $\begin{array}{c}\text { MS Access } \\
\mathbf{2 . 0} \\
\end{array}$ \\
\hline $\mathrm{LO}$ & $\begin{array}{l}\text { Long } \\
\text { string }\end{array}$ & $\begin{array}{l}\text { Cadeia de caracteres sem } \\
\text { espaços anteriores e } \\
\text { posteriores, excluindo também } \\
\text { o caracter "I" usado em } \\
\text { atributos múltiplos. }\end{array}$ & $\begin{array}{l}\text { Repertório de } \\
\text { caracteres } \\
\text { padrão }\end{array}$ & 64 & Text 64 \\
\hline $\mathrm{DS}$ & $\begin{array}{l}\text { Decimal } \\
\text { string }\end{array}$ & $\begin{array}{l}\text { Cadeia de caracteres } \\
\text { representando um inteiro fixo } \\
\text { ou um ponto flutuante. }\end{array}$ & $\begin{array}{l}\text { “0”-“9”, “+”, } \\
\text { “-”, “"E”, “e”, } \\
\text { “.," }\end{array}$ & 16 & Single \\
\hline$\overline{\mathrm{SH}}$ & $\begin{array}{l}\text { Short } \\
\text { string }\end{array}$ & $\begin{array}{l}\text { Cadeia de caracteres que pode } \\
\text { ter espaços no começo e no } \\
\text { final. Não deve ser utilizados o } \\
\text { caracter "l" e os de controle. }\end{array}$ & $\begin{array}{l}\text { Repertório de } \\
\text { caracteres } \\
\text { padrão }\end{array}$ & 16 & Text 16 \\
\hline $\mathrm{DA}$ & Date & $\begin{array}{l}\text { Cadeia de caracteres no } \\
\text { formato yyyymmdd. }\end{array}$ & “"0”-“9" & 8 & $\begin{array}{l}\text { Short date } \\
\text { dd/mm/yyyy } \\
\text { 99/99/000;0; }\end{array}$ \\
\hline TM & Time & $\begin{array}{l}\text { Cadeia de caracteres no } \\
\text { formato hhmmss.frac. A faixa } \\
\text { de valores vai de } \\
000000.000000 \text { a } \\
235959.999999 .\end{array}$ & "“0”-“9”, “.” & 16 & $\begin{array}{l}\text { Short time } \\
00: 00 ; 0 ; 0\end{array}$ \\
\hline $\mathrm{LT}$ & Long text & $\begin{array}{l}\text { Cadeia de caracteres que pode } \\
\text { conter um ou mais parágrafos. } \\
\text { São aceitos os caracteres CR, } \\
\text { LF e FF. Os dados não devem } \\
\text { conter o caracter de atributo } \\
\text { múltiplo ""." }\end{array}$ & $\begin{array}{l}\text { Repertório de } \\
\text { caracteres } \\
\text { padrão }\end{array}$ & 10240 & $\begin{array}{l}\text { Memo } \\
(64 \mathrm{~Kb})\end{array}$ \\
\hline $\mathrm{PN}$ & $\begin{array}{l}\text { Person } \\
\text { name }\end{array}$ & $\begin{array}{l}\text { Cadeia de caracteres com } \\
\text { cinco componentes: sobre } \\
\text { nome, primeiro nome, nome } \\
\text { do meio, prefixo, sufixo. O } \\
\text { delimitador usado é “^” (5EH). }\end{array}$ & $\begin{array}{l}\text { Repertório de } \\
\text { caracteres } \\
\text { padrão } \\
\text { excluindo os } \\
\text { caracteres de } \\
\text { controle LF, } \\
\text { FF e CR. }\end{array}$ & 64 & Text 64 \\
\hline
\end{tabular}




\begin{tabular}{|c|c|c|c|c|c|}
\hline \multicolumn{2}{|c|}{$\begin{array}{c}\text { Nome da } \\
\text { representação }\end{array}$} & \multirow{2}{*}{\begin{tabular}{l}
\multicolumn{1}{c}{ Definição } \\
Cadeia de caracteres com \\
espaços antes e depois não- \\
significativos.
\end{tabular}} & \multirow{2}{*}{\begin{tabular}{l}
\multicolumn{1}{c}{ Repertório } \\
Repertório de \\
caracteres \\
padrão, “0”- \\
"9”, caracter \\
de espaço e \\
“_",
\end{tabular}} & \multirow{2}{*}{$\begin{array}{l}\text { Bytes } \\
16\end{array}$} & \multirow{2}{*}{$\begin{array}{c}\text { MS Access } \\
\mathbf{2 . 0} \\
\text { Text } 16\end{array}$} \\
\hline$\overline{\mathrm{CS}}$ & $\begin{array}{l}\text { Code } \\
\text { string }\end{array}$ & & & & \\
\hline US & $\begin{array}{l}\text { Unsigned } \\
\text { short }\end{array}$ & $\begin{array}{l}\text { Inteiro sem sinal de } 16 \text { bits na } \\
\text { faixa de valores de } 0 \text { a } 2^{16}(0 \text { a } \\
65536) \text {. }\end{array}$ & & 2 & $\begin{array}{l}\text { Long integer } \\
(0 \text { a 65536) }\end{array}$ \\
\hline SS & $\begin{array}{l}\text { Signed } \\
\text { short }\end{array}$ & $\begin{array}{l}\text { Inteiro com sinal na forma de } \\
\text { complemento de } 2 \text {. A faixa de } \\
\text { valor é de }-\left(2^{15}-1\right) \text { a }\left(2^{15}-1\right)(- \\
32767 \text { a } 32767)\end{array}$ & (não aplicável) & 2 & Integer \\
\hline IS & $\begin{array}{l}\text { Integer } \\
\text { string }\end{array}$ & $\begin{array}{l}\text { Cadeia de caracteres } \\
\text { representando um inteiro de } \\
\text { base } 10 \text { (decimal). A faixa de } \\
\text { valores é }-\left(2^{31}-1\right) \text { a }\left(2^{31}-1\right) \text {. (- } \\
2147483647 \text { a } 2147483647)\end{array}$ & $\begin{array}{l}\text { “0”-“99”, “+”, } \\
\text { “_”, }\end{array}$ & 12 & Long integer \\
\hline ST & Short text & $\begin{array}{l}\text { Cadeia de caracteres que pode } \\
\text { conter um ou mais parágrafos. } \\
\text { Pode conter caracteres } \\
\text { gráficos, CR, LF, FF. Espaços } \\
\text { iniciais são significantes mas os } \\
\text { finais não são considerados. } \\
\text { Os dados não devem usar o } \\
\text { caracter de atributo múltiplo } \\
\text { "॥". }\end{array}$ & $\begin{array}{l}\text { Repertório de } \\
\text { caracteres } \\
\text { padrão }\end{array}$ & 1024 & Memo \\
\hline OW & $\begin{array}{l}\text { Other } \\
\text { word } \\
\text { string }\end{array}$ & $\begin{array}{l}\text { Cadeia de palavras de } 16 \text { bits. } \\
\text { Deve ser feita troca na ordem } \\
\text { dos bytes em cada palavra na } \\
\text { troca do ordenamento de bytes } \\
\text { entre bytes Little e Big } \\
\text { Endian. }\end{array}$ & (não aplicável) & & \\
\hline OB & $\begin{array}{l}\text { Other } \\
\text { byte } \\
\text { string }\end{array}$ & $\begin{array}{l}\text { Cadeia de bytes. Não é } \\
\text { sensível ao ordenamento de } \\
\text { bytes Little/Big Endian. Se } \\
\text { necessários deve-se adicionar } \\
\text { um byte nulo }(00 \mathrm{H}) \text { para se ter } \\
\text { um tamanho par. }\end{array}$ & (não aplicável) & & \\
\hline$\overline{\mathrm{AS}}$ & $\begin{array}{l}\text { Age } \\
\text { string }\end{array}$ & $\begin{array}{l}\text { Cadeia de caracteres, sendo } \\
\text { espaços }(20 \mathrm{H}) \text { não } \\
\text { significantes. }\end{array}$ & $\begin{array}{l}\text { "0"-“9", "D", } \\
\text { "W", "M", "Y" }\end{array}$ & 4 & Text 4 \\
\hline US & $\begin{array}{l}\text { Unique } \\
\text { Identifier } \\
\text { (UID) }\end{array}$ & & “0”-“9”, “.” & $\begin{array}{l}64 \\
(\max )\end{array}$ & Text64 \\
\hline
\end{tabular}




\begin{tabular}{c|c|c|c|c}
\hline \hline $\begin{array}{c}\text { Nome da } \\
\text { representação }\end{array}$ & Definição & Repertório & Bytes & $\begin{array}{c}\text { MS Access } \\
\mathbf{2 . 0}\end{array}$ \\
\hline \hline
\end{tabular}

Fonte: Tabela elaborada baseada em ACR-NEMA DICOM 3.0, Part 5: Data Structures and Encoding, seção 6.2, tabela 6.2-1 e em Microsoft Corporation, Microsoft Access®: User’s Guide, 1994, p.117, 135.

No campo de descrição do dicionário de dados, outras informações também são indicadas:

1. se o campo é chave, é indicado se é chave primária, estrangeira ou surrogate;

2. quando o campo possui um correspondente no padrão DICOM 3.0, é indicado o nome original no padrão, o identificador do atributo e o tipo de dados;

3. o domínio para os valores dos atributos, quando este é um subconjunto do domínio implicitamente definido pelo tipo de dado.

Da mesma forma que os diagramas do modelo relacional, o dicionário de dados também foi elaborado no aplicativo MS Access 2.0. À medida que as relações e atributos do banco de dados eram registrados na forma de tabelas e campos, as propriedades dos campos, incluindo tipo de dados, formato e descrição, eram estabelecidos.

O MS Access 2.0 possui uma função de documentação do banco de dados que pode criar uma tabela com todas as informações sobre os objetos definidos. Estes objetos são: Database, Tables, Queries, Forms, Reports, Macros e Modules. A relação correspondente a tabela criada é:

TABLES DEFINITION*

\begin{tabular}{|l|l|l|l|l|l|l|}
\hline$\underline{\text { Id }}$ & ParentID & Object Type & Name & Extra1 & Extra2 & Extra3 \\
\hline
\end{tabular}

Cada um dos atributos armazena as seguintes informações:

Tabela 21 - Atributos da tabela de documentação de objetos do MS Access 2.0

\begin{tabular}{llll}
\hline \hline \multicolumn{3}{c}{ Tabela: TABLES DEFINITION } & \\
\hline Campo & $\begin{array}{c}\text { Tipo de } \\
\text { dado }\end{array}$ & Bytes & \multicolumn{1}{c}{ Descrição } \\
\hline ID & $\begin{array}{l}\text { Number } \\
\text { (Long) }\end{array}$ & 4 & $\begin{array}{l}\text { Identificador único para cada objeto criado } \\
\text { no MS Access } 2.0\end{array}$
\end{tabular}

\footnotetext{
* O nome original da tabela criada pelo MS Access 2.0 é Object Definition. Como neste caso a tabela possui informações apenas sobre as tabelas criadas, o nome foi trocado para Tables Definition.
} 


\begin{tabular}{|c|c|c|c|}
\hline \multicolumn{4}{|c|}{ Tabela: TABLES DEFINITION } \\
\hline Campo & $\begin{array}{c}\text { Tipo de } \\
\text { dado }\end{array}$ & Bytes & Descrição \\
\hline ParentID & $\begin{array}{l}\text { Number } \\
\text { (Long) }\end{array}$ & 4 & $\begin{array}{l}\text { Chave estrangeira para um relacionamento } \\
\text { recursivo entre tuplas da tabela TABLES } \\
D E F I N I T I O N \text {. Serve para indicar, por } \\
\text { exemplo, que um determinado objeto do tipo } \\
C O L U M N \text { pertence a um objeto do tipo } \\
\text { TABLE }\end{array}$ \\
\hline $\begin{array}{l}\text { Object } \\
\text { Type }\end{array}$ & Memo & - & $\begin{array}{l}\text { Indica o tipo do objeto. Os valores possíveis } \\
\text { são: Column, Group Permissions, Index, } \\
\text { Index Field, Property, Relationships, Table e } \\
\text { User Permissions }\end{array}$ \\
\hline Name & Text & 255 & $\begin{array}{l}\text { Nome dado ao objeto, seja ele definido pelo } \\
\text { usuário ou pelo próprio MS Access }\end{array}$ \\
\hline Extra1 & Memo & - & $\begin{array}{l}\text { Usado para registrar informações sobre } \\
\text { objetos que não são do tipo COLUMN }\end{array}$ \\
\hline Extra2 & Text & 255 & $\begin{array}{l}\text { Utilizado apenas quando o objeto é do tipo } \\
\text { COLUMN. Neste campo é indicado o tipo de } \\
\text { dado e os valores possíveis são: Date/Time, } \\
\text { Memo, Number (Byte), Number (Integer), } \\
\text { Number (Long), Number (Single), OLE } \\
\text { Object, Text, Yes/No ou Nulo }\end{array}$ \\
\hline Extra3 & Text & 255 & $\begin{array}{l}\text { Utilizado apenas quando o objeto é do tipo } \\
C O L U M N \text {. É indicado o número de bytes de } \\
\text { armazenamento usado pelos campos das } \\
\text { tabelas. Os valores possíveis são Nulo, “_“"e } \\
1 \text { a } 255 \text {. O valor "“-“é usado quando o valor } \\
\text { do campo Extra2 é } O L E \text { Object ou Memo }\end{array}$ \\
\hline
\end{tabular}

Para criar o documento do dicionário de dados, foram efetuadas consultas na tabela TABLES DEFINITION. Primeiramente, três consultas auxiliares foram criadas: uma com a lista de todas as tabelas, outra com a listas de todos os campos das tabelas e suas propriedades e uma terceira com todas as descrições. Estas consultas são apresentadas a seguir em SQL:

\section{TABELAS:}

SELECT DISTINCTROW [Tables Definition].ID, [Tables Definition]. Name AS [Table name]

FROM [Tables Definition]

WHERE (([Tables Definition]. [Object Type]="Table"));

TABELASCOLUNAS:

SELECT DISTINCTROW [Tables Definition].ID, [Tables Definition].ParentID, [Tables Definition].Name AS [Column name], [Tables Definition].Extra1, [Tables 


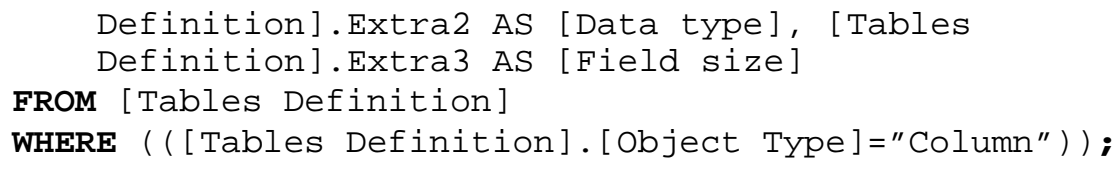

Utilizando estas consultas auxiliares, foi então elaborada uma consulta agregando informações sobre nome das tabelas, nomes das colunas, tipo de dados, tamanho do campo e descrições das colunas. Esta consulta, apresentada logo a seguir, é utilizada para criar um relatório que dá origem ao documento Dicionário de Dados.

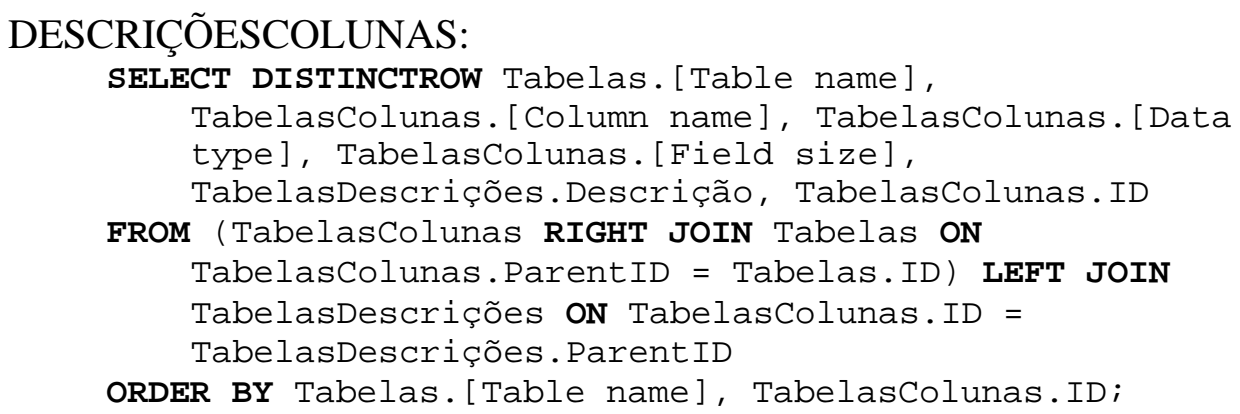

\subsubsection{Propostas para a implementação do DataTORM}

\subsubsection{Proposta de arquitetura de distribuição dos arquivos de dados}

O SGBD MS Access 2.0 assume os detalhes de implementação física do BD, de forma que não é necessário criar um modelo físico de dados detalhado. Conseqüentemente, a especificação do sistema fica mais simples, sendo necessário apenas definir a distribuição dos arquivos do BD e definir as funções específicas que o SGBD deve executar, já que funções padrões, como cópias de segurança e recuperação de arquivos corrompidos, são disponíveis neste SGBD.

A proposta para distribuição dos arquivos do DataTORM estabelece uma divisão entre dados e aplicação. Os dados ficam em arquivos de banco de dados que são distribuídos em três partes: um arquivo para os dados convencionais, outro para armazenamento de curto prazo de dados não-convencionais, e arquivos de dados não- 
convencionais para armazenamento de longo prazo. A aplicação pode ser implementada com o aplicativo MS Access, versão 2.0 ou superior, ou através de programas aplicativos que sejam capazes de utilizar os MS Jet Engine, ou outro SGBD compatível, para ter acesso aos arquivos de banco de dados.

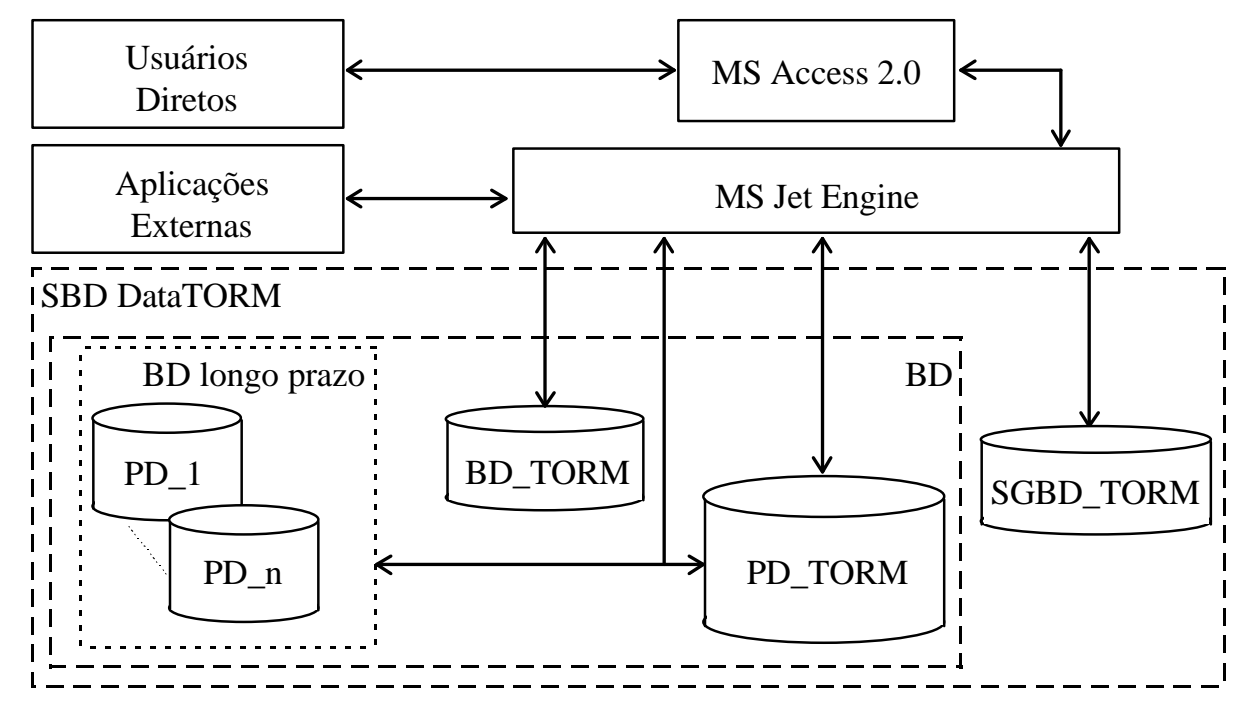

Figura 41 - Especificação da arquitetura de arquivos do DataTORM.

Os usuários podem consultar os dados diretamente com a aplicação SGBD DataTORM, que será descrita adiante, implementada no MS Access 2.0 e cuja definição é armazenada em um arquivo do tipo MDB, o SGBD_TORM. O MS Access 2.0 utiliza o MS Jet Engine para ter acesso à definição deste aplicativo e interpretar, durante a execução do programa, as definições de Forms, Modules, Reports, Scripts, SysRel, Databases, Relationships e Tables. ${ }^{27}$

Desta forma, esta proposta determina que o arquivo de definição do SGBD DataTORM fique isolado dos dados. Esta separação entre dados e programas visa:

- facilitar a manutenção do sistema, podendo serem feitas modificações no SGBD DataTORM sem que seja necessário trabalhar nos arquivos de repositório dos dados;

- possibilitar que usuários usuais e sofisticados tenham uma versão própria do SGBD DataTORM e que eles possam personalizar o aplicativo de acordo com as suas necessidades; 
- proporcionar segurança aos dados, pois, como haverá uma versão básica do SGBD DataTORM na estação de consulta para ser usado por usuários paramétricos e esta é a mesma estação que armazenará os arquivos DB_TORM e PD_TORM, não é adequado que os usuários trabalhem diretamente no mesmo arquivo que armazena os dados.

As aplicações externas, como, por exemplo, outros módulos de programa do sistema ToRM-05, podem se comunicar diretamente com o SGBD Jet Engine para ter acesso diretamente ao banco de dados.

$\mathrm{O}$ arquivo para dados convencionais, cujo nome é $B D \_T O R M$, corresponde à união dos esquemas relacionais do SIA e SIRMN, com exceção da relação "PIXEL DATA". Ele constitui o arquivo principal do banco de dados central pois armazena todas as informações do BD com exceção dos dados binários de dados nãoconvencionais da relação "PIXEL DATA".

A relação "PIXEL DATA", por armazenar os dados binários nãoconvencionais e, por isso, necessitar de um grande volume de espaço de armazenamento, possui os seus dados distribuídos em vários arquivos. O arquivo PD_TORM armazena os dados de curto prazo que foram adquiridos ou requisitados a pouco tempo. Os dados mais antigos são transferidos para arquivos de armazenamento de longo prazo que podem estar localizados em diferentes meios físicos de armazenamento, seja localmente ou remotamente. Quando um destes arquivos atinge a sua capacidade máxima de armazenamento, 1 Gbyte para os arquivos do tipo MDB do MS Access 2.0, ou a capacidade determinada pelo administrador do sistema, um novo arquivo é criado, e assim sucessivamente. Os nomes destes arquivos de armazenamento de longo prazo são $P D_{-}{ }^{*}$, onde o caracter * é substituído por letras e números para possibilitar a criação de diversos volumes de dados.

A relação "CONTAINER" do SIRMN, apresentada logo a seguir e que fica no arquivo BD_TORM, armazena a localização física de todos os dados binários de "PIXEL DATA", estejam eles no arquivo PD_TORM ou em algum dos volumes de armazenamento de longo prazo. 


\begin{tabular}{|l|l|l|l|l|l|l|l|}
\hline$\underline{\text { Id }}$ & DataCriação & HoraCriação & DataAcesso & HoraAcesso & AttachVolume & AttachPath & AttachFile \\
\hline
\end{tabular}

Caso os dados ainda não tenham sido armazenados em arquivos de longo prazo, o atributo "AttachFile" conterá o valor nulo. Caso contrário, este atributo indicará o nome do arquivo de armazenamento e, opcionalmente, os atributos "AttachPath" e "AttachVolume" poderão indicar informações adicionais sobre a localização do arquivo. Automaticamente, ou sob o comando do operador ou administrador do sistema, o SGBD pesquisa na relação "CONTAINER" quais dados ainda não foram armazenados em arquivos de longo prazo e armazena estes dados nestes arquivos.

Quando os dados binários de uma instância de "PIXEL DATA" são consultados, é feita uma busca no arquivo de curto prazo para verificar se os dados estão disponíveis. Caso eles não estejam disponíveis, os dados são copiados dos arquivos de longo prazo para o arquivo PD_TORM. Em intervalos regulares, ou através da intervenção do administrador do sistema, faz-se uma consulta a todos os dados que estão no arquivo PD_TORM. Nesta operação, o atributo "DataAcesso" da relação "CONTAINER" é utilizado para determinar quais tuplas ainda devem permanecer no armazenamento de curto prazo e quais já podem ser apagadas. Os dados que excederam o limite de tempo de permanência no nível de armazenamento de curto prazo são, então, transferidos para um dos arquivos de longo prazo, caso isto ainda não tenha sido feito antes, ou são apenas eliminados deste nível.

\subsubsection{Extensão para dados não convencionais}

Para a implementação do DataTORM são necessários tipos de dados convencionais e não-convencionais. Os tipos do primeiro conjunto são os tipos numéricos e de caracteres. Tipos de dados não-convencionais são necessários para armazenar os dados de aquisição, dados transformados, dados de parte real, dados de parte imaginária, dados de módulo, dados de fase, overlays e LUT. Os valores dos atributos destes dados não-convencionais são matrizes multi-dimensionais de números complexos e reais. 
Os dados de aquisição são matrizes de dados obtidos através de uma aquisição no sistema de MRI. No caso do exemplo de aquisição bidimensional descrito na revisão da literatura, os dados de aquisição são matrizes bidimensionais cujo número de linhas é igual ao número de codificações de fase, e cada linha é formada pelo sinal do eco digitalizado. Os valores dos elementos desta matriz são números complexos, pois o sinal de RMN é adquirido simultaneamente com duas partes, fase e quadratura. A digitalização destes dados é feita em 16 bits, mas eles são convertidos para 32 bits para não ocorrerem perdas de informação durante o processo de médias e de processamento. Ao final da aquisição e de pré-processamentos, os dados de aquisição podem ser armazenados e o formato utilizado é de matrizes de inteiros complexos de 32 bits com sinal.

Para obter as imagens de MRI, é necessário efetuar uma transformada de Fourier bidimensional sobre a matriz dos dados de aquisição. O resultado é uma outra matriz de números inteiros, complexos e de 32 bits com sinal, chamada de dados transformados. O módulo desta matriz complexa representa a distribuição espacial da densidade de prótons da amostra. Estes são os dados de módulo, que são armazenados em matrizes de inteiros reais de 16 bits sem sinal, e é a partir deles que se obtém as imagens tomográficas que são comumente mostradas nos monitores dos computadores.

Além dos dados de módulo, que são os mais comumente usados para diagnóstico médico, também é comum extrair os dados de fase à partir dos dados transformados e a parte real ou parte imaginária tanto dos dados de aquisição quanto dos dados transformados. As matrizes destes dados são de inteiros reais de 16 bits sem sinal.

As imagens também são matrizes de dados, mas a faixa dinâmica dos seus elementos é limitada à resolução de 8 bits, na melhor das hipóteses, devido ao padrão RGB de codificação de imagens. Elas são obtidas à partir dos outros tipos de dados e são usadas para a visualização dos dados em monitores ou para a impressão em filmes ou em outros meios físicos.

Os overlays são imagens que são sobrepostas a outras imagens e são usados para marcar regiões de interesse (ROI - Region of Interest) ou para fazer anotações 
e/ou desenhos diretamente sobre as imagens. No padrão DICOM 3.0, o overlay pode ser armazenado separado dos dados, em uma matriz de inteiros reais de 16 bits sem sinal, ou incorporado aos dados, neste caso usando um ou mais bits de cada elemento da matriz de dados para armazenar o overlay.

As imagens que são mostradas no monitor possuem uma faixa dinâmica menor que os dados originais. No caso do ToRM-05, as imagens são criadas no formato BMP com 256 tons de cinza, isto é, com uma faixa dinâmica de 8 bits. Desta forma, é realizada uma transformação linear nos dados (16 bits) para restringir os seus valores à faixa dinâmica de visualização. O Padrão DICOM 3.0 utiliza, para a modalidade de MRI, o esquema de Window/Level (correspondente a contraste/brilho), também usado no ToRM-05, para fazer esta transformação. Para realizar uma transformação que não seja linear, aquele padrão utiliza LUT (Lookup Table), que é um vetor de números inteiros cujos valores indicam para quais valores os dados originais devem ser mapeados na formação da imagem.

Em resumo, os tipos de dados não-convencionais necessários no sistema ToRM-05 são matrizes multi-dimensionais, nos domínios real e complexo, de inteiros de 16 e 32 bits, com e sem sinal. A figura a seguir resume os vários dados, as relações entre eles e os tipos de dados utilizados.

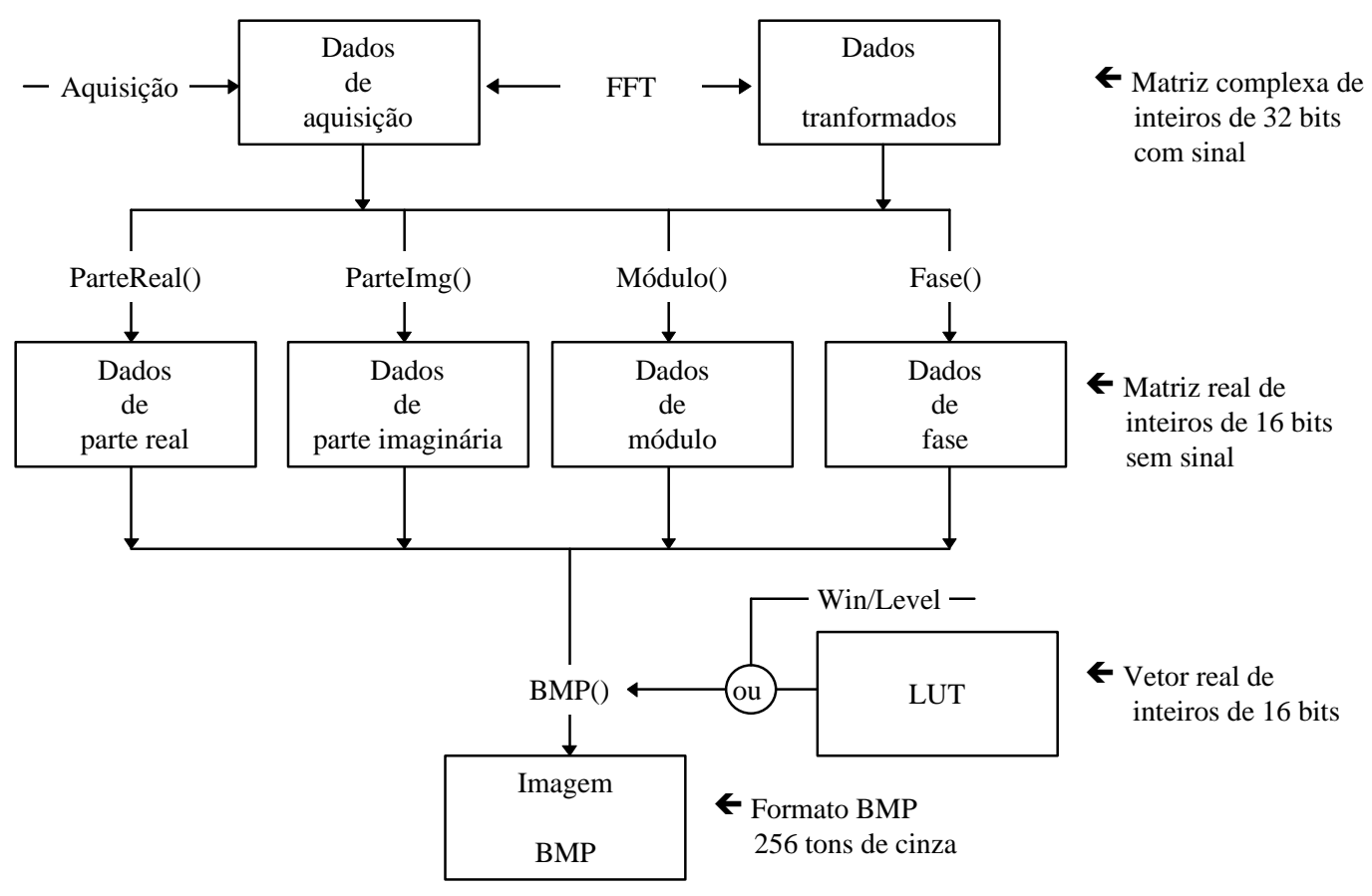

Figura 42 - Tipos de dados não-convencionais. 
Para armazenar dados binários, o MS Access 2.0 dispõe de um tipo de dados chamado OLE Object. Em campos com este tipo de dados é possível fazer uma ligação com arquivos externos ou incorporar arquivos no banco de dados, desde que exista uma aplicação registrada no sistema que seja servidora de OLE para o tipo de arquivo em questão.

Quando se tenta inserir ou ligar um arquivo que não seja associado a nenhum aplicativo servidor de OLE, o MS Access 2.0 utiliza automaticamente o programa Microsoft Object Packager para efetuar a operação. Este aplicativo é um servidor de OLE genérico que apenas cria ligações ou ajuda incorporar arquivos em documentos que aceitam OLE. Depois que o objeto OLE já está incorporado no aplicativo cliente, por exemplo em um campo do tipo OLE Object do MS Access, ele possibilita copiar e colar o objeto em outros aplicativos ou salvar o conteúdo em um arquivo em disco.

Outra possibilidade para armazenar os dados binários no BD DataTORM é utilizar diretamente os métodos AppendChunk e GetChunck do objeto Field do MS Jet Engine. Esta solução poderá resolver o problema de armazenar arquivos de dados não-convencionais no $\mathrm{BD}$, mas ela não fornece a flexibilidade de se utilizar os recursos disponíveis para OLE, como, por exemplo, os controles para OLE nos formulários do MS Access 2.0 que servem para visualizar imagens de objetos OLE.

\subsubsection{Comunicação com outros módulos}

O DataTORM será responsável por armazenar dados referentes à operação do sistema ToRM-05 e os resultados gerados por outros módulos de equipamento e de programa deste sistema. Uma vez obtidos os dados, tanto usuários trabalhando na estação de consulta, quanto outros módulos de programa do sistema, poderão ter acesso ao banco de dados. Desta forma, é necessário que existam mecanismos de comunicação de dados entre o DataTORM e os demais módulos que criam e consultam os dados. A figura a seguir resume os tipos básicos de comunicação necessários no sistema. 


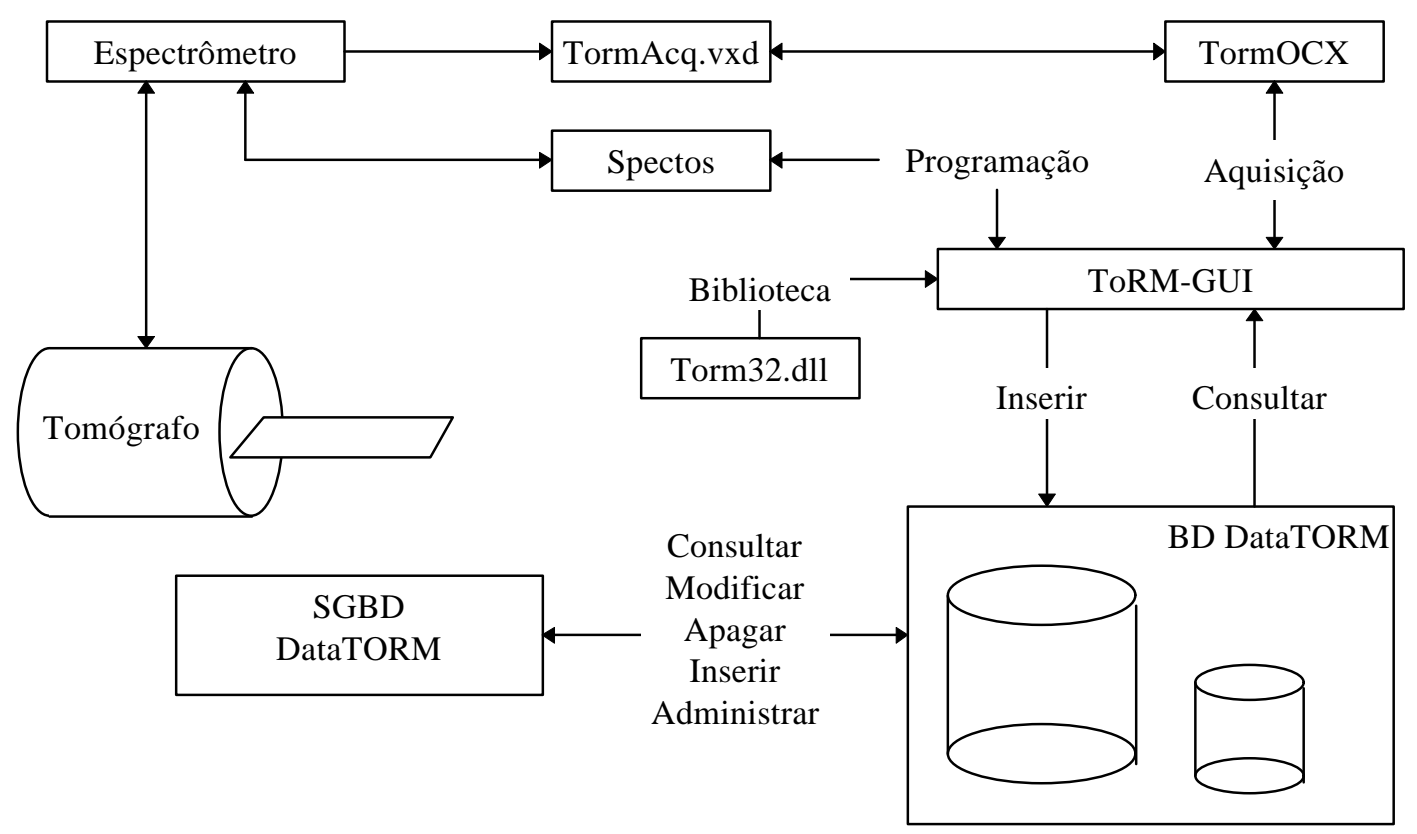

Figura 43 - Requisitos de comunicação de dados entre o DataTORM e demais módulos do ToRM-05.

$\mathrm{Na}$ presente proposta, a comunicação entre o SGBD DataTORM e os arquivos do repositório BD DataTORM é direta, realizada através do MS Access 2.0. Os detalhes desta comunicação, em que é utilizado o MS Jet Engine, é transparente para o usuário final. Do ponto de vista do desenvolvimento e configuração do sistema, o desenvolvedor precisa apenas indicar para o MS Access 2.0 a localização dos arquivos do DataTORM.

Para a comunicação entre o módulo TORMGUI, responsável pela interface com o usuário e controle geral da operação do ToRM-05, e o BD DataTORM, a proposta desta dissertação é a utilização, por parte do TORMGUI, de objetos de acesso a dados (DAO - Data Access Objects) e controles de acesso a dados (VBX, OCX ou ActiveX), ambos tipos disponíveis no MS Visual Basic 4.0. O DAO é uma interface de programação de alto nível orientada a objetos que é usada no MS Visual Basic 4.0 para ter acesso aos objetos e métodos do MS Jet Engine. Os controles proporcionam uma interface visual de navegação pelos dados que pode ser usada em um aplicativo em Visual Basic, o TORMGUI neste caso.

Nesta proposta, a segurança e integridade dos dados no BD DataTORM é mantida de duas formas: 
1. o controle de acesso dos usuários ao BD DataTORM continua sendo mantido de acordo com as permissões de acesso definidas para cada grupo de usuários. $\mathrm{O}$ aplicativo desenvolvido em Visual Basic deve indicar o nome do usuário e a sua senha para habilitar o acesso ao banco de dados;

2. os relacionamentos entre as tabelas do BD DataTORM foram implementados com a opção de que a integridade referencial deve ser mantida automaticamente. Desta forma, todo aplicativo que tem acesso aos arquivos de dados, seja ele o SGBD DataTORM ou outro aplicativo externo que use o MS Jet Engine, deve obedecer as condições de integridade referencial estabelecida no esquema do banco de dados.

Para o aplicativo desenvolvido em Visual Basic ter acesso ao BD DataTORM, ele deve possuir um arquivo de inicialização com extensão .INI com a indicação da localização do arquivo de sistema (arquivo com extensão .MDA) que possui as definições dos grupos, usuários e permissões de acesso necessário para ter acesso aos arquivos do BD DataTORM. Este arquivo de inicialização deve possuir uma entrada do seguinte tipo:

SystemDB=C : \DATATORM $\backslash$ Tormgrp.mda

Para ter acesso aos dados nos arquivos do BD DataTORM, o aplicativo deve criar uma sessão de trabalho no MS Jet Engine com indicação de qual é o usuário corrente e qual é a sua senha. O trecho de código a seguir exemplifica estes passos.

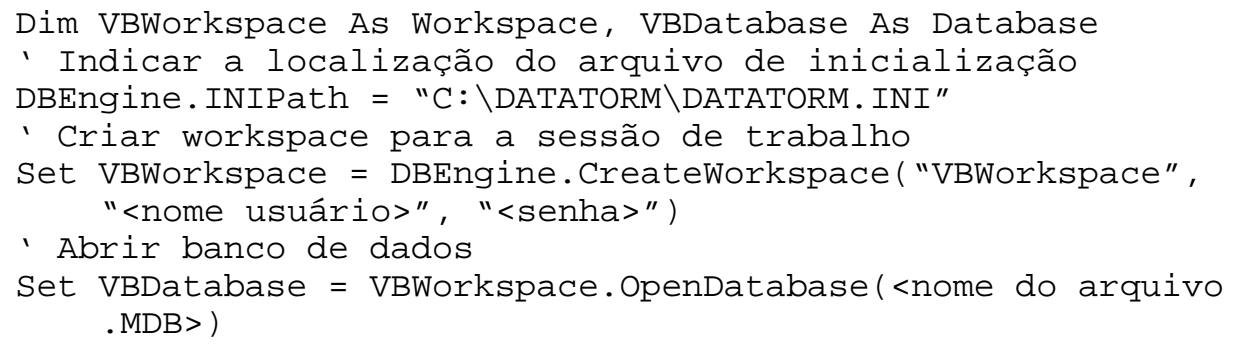

Depois de criada a sessão de trabalho e aberto o arquivo de banco de dados, o aplicativo pode criar objetos do tipo Recordset, que representam registros de tabelas, e ter acesso aos dados através destes objetos. A classe de serviço Query/Retrieve Service Class do padrão DICOM 3.0, apresentada na seção Padrão DICOM 3.0 da revisão da literatura, pode ser usada como um modelo para a definição dos objetos 
recordsets. O exemplo a seguir mostra um trecho de código usado para criar um objeto do tipo Recordset.

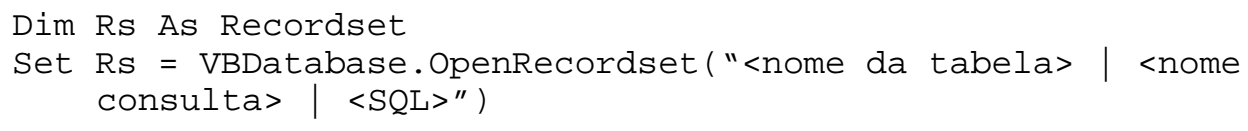

Um ou mais controles de acesso a dados podem ser usados nos formulários do aplicativo. Para isso, ele deve ser associado ao recordset que contém os dados consultados. Considerando um controle com o nome "DataCtr", a seguinte linha de código faz com que a fonte de dados para o controle seja o recordset "Rs":

Set DataCtr.Recordset $=$ Rs

\subsubsection{Segurança e restrições de acesso}

A segurança dos dados é um dos aspectos importantes que motiva a utilização de um sistema de banco de dados. Dois tipos básicos de segurança são importantes: integridade e controle de acesso.

Manter a integridade dos dados significa garantir que as informações armazenadas no BD não serão perdidas. Neste sentido, vários tipos de situações podem comprometer a integridade dos dados, como defeito no disco, corrupção dos arquivos armazenados, atualização incorreta em tabelas relacionadas de forma a comprometer a integridade referencial. Para proteger os dados dos problemas lógicos internos no banco de dados, os relacionamentos entre tabelas do BD DataTORM foram feitos com a opção de automaticamente assegurar a integridade referencial ativada. Com esta opção ativa, qualquer manipulação nos dados que infringe a integridade referencial é rejeitada pelo SGBD. Para corrigir ou amenizar as conseqüências oriundas de defeitos físicos e lógicos nas unidades de armazenamento, podem ser feitas cópias de segurança periódicas dos arquivos de dados. O DataTORM não possui rotinas específicas para realizar manutenções de segurança, mas o administrador do sistema pode utilizar as funções disponíveis no MS Access 2.0, que são:

- Repair Database: recupera arquivos de banco de dados corrompidos; 
- Compact Database: compacta o arquivo de dados desfragmentando-o e liberando espaço de armazenamento. $\mathrm{O}$ arquivo compactado resultante pode ser usado como cópia de segurança.

Para realizar cópias de segurança é necessário utilizar o próprio sistema de arquivos do sistema operacional para copiar o arquivo de dados para um repositório de armazenamento de segurança. A periodicidade desta operação fica a cargo do operador ou administrador do sistema.

O controle de acesso aos dados é importante por dois motivos principais:

1. os dados de pacientes são de natureza sigilosa e a identidade de voluntários deve ser, em geral, preservada;

2. a variedade de possíveis tipos de usuários, cada um exercendo papeis diferentes no ambiente de operação, requer um controle sobre os tipos de ações no SBD que cada um pode executar, isto para impedir que informações sejam apagadas indevidamente, que a estrutura do BD seja alterada por engano, etc.

Para assegurar o sigilo dos dados, o MS Access 2.0 possui funções para criptografar e descriptografar os arquivos de banco de dados. Quando um arquivo está criptografado, não é possível identificar o conteúdo utilizando processadores de texto ou outros aplicativos. Apenas usuários autorizados utilizando uma cópia do MS Access 2.0 que esteja associada ao grupo de trabalho que criptografou o arquivo de banco de dados é capaz de ler o conteúdo dos dados.

O MS Access 2.0 também permite que sejam atribuídas permissões de acesso diferenciadas para os usuários. É possível criar grupos de usuários e, ou invés de atribuir as permissões para cada usuário individualmente, basta inserir o usuário em um ou mais grupos que ele herda as permissões do grupo. Desta forma, os usuários são divididos de acordo com as operações que eles podem realizar no SBD. Por exemplo, um usuário que não seja administrador do sistema não pode, por engano, modificar a estrutura de dados do BD.

A proposta para o DataTORM utiliza três grupos com permissões distintas, sendo que cada usuário pertence a um destes grupos. A Tabela 22 a seguir resume as 
restrições de acesso atribuídas a cada grupo. O grupo "Guests" não possui nenhuma permissão, mas é possível, futuramente, incluir um conjunto restrito de permissões para este grupo para atender, por exemplo, um conjunto de usuários que só pode consultar dados de voluntários ou que não pode alterar os dados.

Tabela 22 - Grupos de usuários e restrições de acesso

\begin{tabular}{r|l|l|l}
\hline \hline BD & \multicolumn{1}{|c|}{ DataTORM Admins } & DataTORM Users & Guests \\
& Abrir/executar & Abrir/executar & - \\
Tabela & Ler e modificar definição & $\begin{array}{l}\text { Ler definição } \\
\text { Ler, atualizar, inserir e } \\
\text { apagar dados }\end{array}$ & - \\
& $\begin{array}{l}\text { Administrar } \\
\text { Ler, atualizar, inserir e apagar } \\
\text { dados }\end{array}$ & Abrir/executar & - \\
\hline $\begin{array}{r}\text { Formulário } \\
\text { Relatório } \\
\text { Macro }\end{array}$ & $\begin{array}{l}\text { Abrir/executar } \\
\text { Ler e modificar definição }\end{array}$ & & \\
\hline Módulo & Ler e modificar definição & - & - \\
\hline \hline
\end{tabular}




\subsection{Implementação do DataTORM}

\subsubsection{Introdução}

O aplicativo MS Access 2.0 foi utilizado na fase de implementação para criar o banco de dados e os módulos funcionais do sistema, isto é, as tabelas, consultas, formulários para interface com o usuário, relatórios e módulos de programa para funções específicas. A tabela a seguir resume a estrutura básica do sistema implementado.

Tabela 23 - Resumo dos itens implementados no DataTORM com o MS Access 2.0

\begin{tabular}{l|l}
\hline \hline \multicolumn{1}{c|}{ Item } & \multicolumn{1}{c}{ Situação atual } \\
\hline Tabelas & $\begin{array}{l}\text { Divididas em 3 arquivos de banco de dados: } \\
\text { datatorm.mdb: arquivo com 50 tabelas que } \\
\text { armazena todos os dados que possuem tipos de } \\
\text { dados convencionais; } \\
\text { pd_torm.mdb: arquivo de banco de dados com 1 } \\
\text { tabela que armazena a relação PIXEL_DATA; } \\
\text { posproc.mdb: arquivo com 2 tabelas usado para } \\
\text { armazenar, provisoriamente, dados obtidos no } \\
\text { formato atual do sistema ToRM-005. }\end{array}$ \\
\hline Consultas & $\begin{array}{l}\text { 82 consultas em SQL utilizadas em formulários e } \\
\text { relatórios. }\end{array}$ \\
\hline Formulários para & $\begin{array}{l}\text { 49 formulários distribuídos em formulários principais e } \\
\text { subformulários. }\end{array}$ \\
\hline usuário & 9 relatórios básicos pré-definidos. \\
\hline Relatórios & $\begin{array}{l}\text { 2 módulos de programação com diversas funções } \\
\text { específicas para o funcionamento do sistema. }\end{array}$ \\
\hline Módulos de &
\end{tabular}

Nesta primeira versão, como o sistema ainda está em fase de testes e ainda sofrerá algumas alterações, as definições de consultas, formulários, relatórios e módulos de programa estão no mesmo arquivo do banco de dados, isto é, 
datatorm.mdb. Uma das alterações futuras será justamente separar os dados dos módulos de aplicação para satisfazer a arquitetura definida na especificação do sistema.

\subsubsection{BD DataTORM: arquivos, tabelas e relacionamentos}

A atual versão do SBD DataTORM ainda não segue a proposta de arquitetura para os arquivos de dados e programas. A versão implementada, esquematizada na Figura 42, é uma simplificação desta proposta e contêm três arquivos: o datatorm.mdb, o pd_torm.mdb e o posproc.mdb.

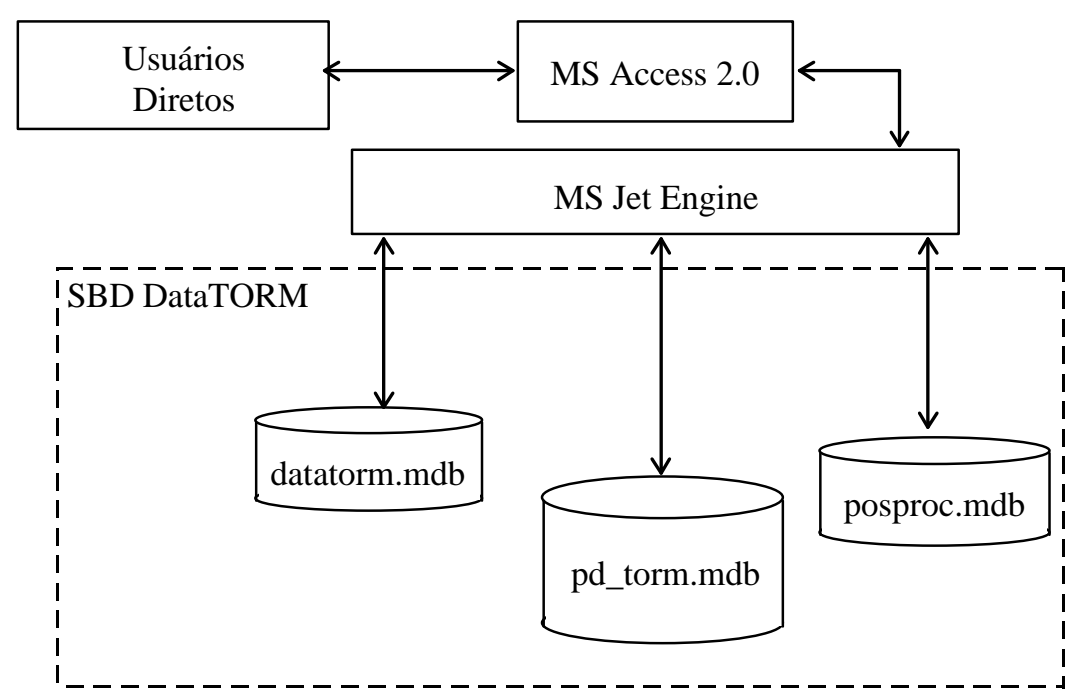

Figura 44 - Arquitetura de arquivos do DataTORM implementada.

$\mathrm{O}$ arquivo datatorm.mdb corresponde à união do arquivo de dados BD_TORM com o de programa SGBD_TORM definidos na proposta original. Já o arquivo pd_torm.mdb é um único arquivo com a relação "PIXEL DATA", pois, nesta primeira versão, a divisão entre arquivos de curto e longo prazo ainda não foi implementada.

$\mathrm{O}$ arquivo posproc.mdb, criado para provisoriamente armazenar os dados no formato atual do sistema ToRM-005 e realizar testes com o DataTORM, possui uma tabela chamada tblPosProc que armazena os parâmetros de aquisição do ToRM-005. Ele também possui a tabela tblPosProcImg, semelhante a tabela da relação "PIXEL DATA”, que armazena as imagens geradas pelo sistema ToRM-005 no formato BMP, depois de processadas pelo programa PosProc. 
As tabelas constituem a implementação do esquema do banco de dados e elas foram criadas nos três arquivos descritos: dois do sistema DataTORM propriamente dito e um temporário, apenas para manter compatibilidade com o sistema ToRM-005 atual. Durante a criação das tabelas, é possível estabelecer algumas condições de integridade, como definir chaves primárias, indicar a obrigatoriedade ou não de atributos em determinados campos e indicar se os campos são chaves candidatas.

Após a criação das tabelas, o MS Access 2.0 permite que sejam indicados os relacionamentos entre as tabelas e as condições de integridade referencial que devem ser satisfeitas. Para cada relacionamento, pode-se optar por fazer com que o SGBD reforçe a integridade referencial ou não. Em caso afirmativo, pode-se estabelecer as seguintes propriedades para os relacionamentos:

- cardinalidade do relacionamento: indica-se se o relacionamento é 1-1 ou 1-N;

- atualização em cascata: se esta opção é ativada, quando a chave primária de um registro da tabela primária é alterada, as chaves estrangeiras dos registros nas tabelas relacionadas são automaticamente atualizadas. Quando esta opção não é ativada, se existe algum registro relacionado ao registro da tabela primária, o SGBD impede que o valor da chave primária seja alterado;

- eliminação automática: com esta opção, se um registro é eliminado, todos os registros relacionados nas tabelas relacionadas também são eliminados. Sem esta opção, se há algum registro relacionado, o SGBD impede que o registro na tabela primária seja eliminado. A figura a seguir exemplifica este caso: se um endereço é eliminado, todos os telefones associados a este endereço são automaticamente eliminados. 


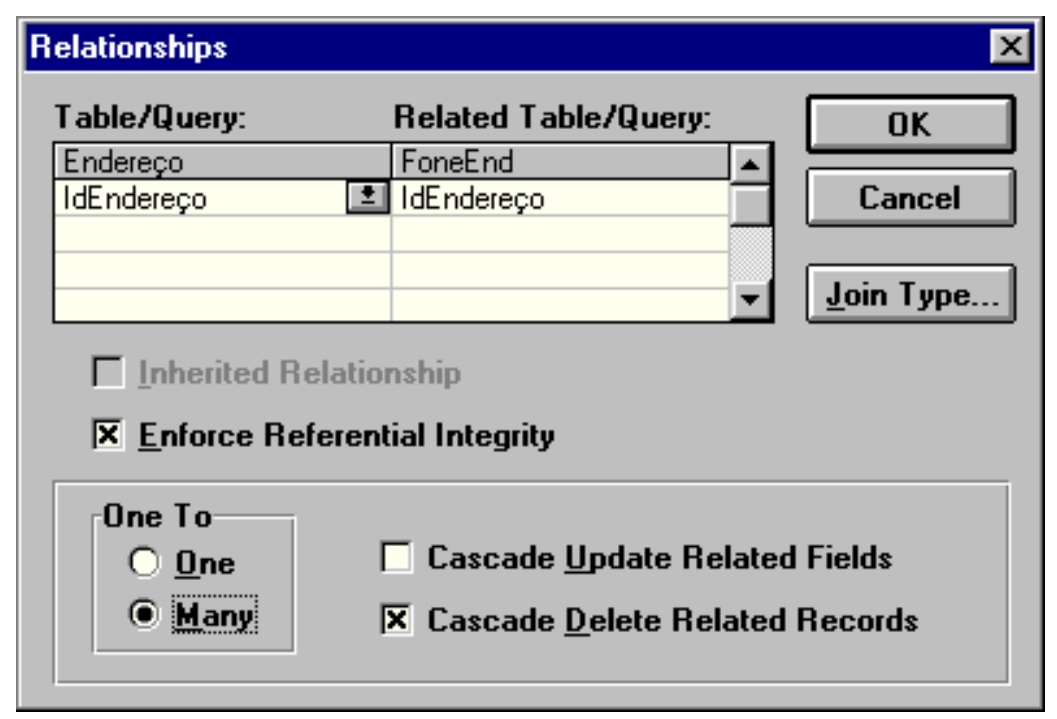

Figura 45 - Formulário de opções de integridade referencial do MS Access 2.0.

Para satisfazer a proposta de arquitetura de arquivos de dados apresentada na subseção 3.3.2.1, é necessário ainda:

1. implementar as rotinas de gerenciamento dos dados não-convencionais, responsáveis pela migração de dados do arquivo de curto-prazo para volumes de longo-prazo, e vice-versa. Com estas rotinas implementadas, é então possível dividir o arquivo pd_torm.mdb (Figura 44) nos arquivos PD_TORM e os volumes $P D_{-} *($ Figura 41$)$;

2. efetuar a divisão entre dados e programa através da divisão do arquivo datatorm.mdb (Figura 44) em dois arquivos: o BD_TORM e o SGBD_TORM (Figura 41);

3. criar aplicações externas que utilizam o MS Jet Engine diretamente. Esta tarefa é opcional e fica a cargo de usuários sofisticados que queiram realizar consultas especiais aos dados que não são atendidas pelo aplicativo SGBD DataTORM. Estas aplicações externas também podem ser outros módulos de programa do próprio sistema ToRM-05 e que utilizariam o MS Jet Engine para transferir dados diretamente para o BD DataTORM ou para realizar consultas.

Os itens 1 e 2 acima ainda não foram implementados por falta de tempo, mas está planejado que a próxima versão do DataTORM contemple estes itens. Já o terceiro item depende de decisões no âmbito do projeto global do ToRM-05 que até o presente momento ainda não foram tomadas ou não foram suficientemente discutidas. 
O armazenamento de dados não-convencionais utiliza apenas arquivos de imagens do tipo Windows Bitmap (BMP), e o aplicativo OLE associado é o MS Paint. Como ainda não foi desenvolvido nenhum aplicativo que seja servidor de OLE e que aceite os arquivos de dados nos formatos usados pelo ToRM-05, a próxima versão do sistema irá utilizar o MS Object Packager para possibilitar o armazenamento dos diversos tipos de dados não-convencionais no $\mathrm{BD}$, e não apenas as imagens no formato BMP.

\subsubsection{Aplicativo SGBD DataTORM}

O SGBD DataTORM é o aplicativo de banco de dados desenvolvido no MS Access 2.0 para possibilitar o acesso ao BD DataTORM de forma independente do restante do sistema ToRM-05. Ele é constituído principalmente de formulários para serem usados pelos usuários para consultar, inserir, apagar e modificar os dados. Como já explicado anteriormente, na atual versão do DataTORM o arquivo de definição do SGBD DataTORM está no mesmo arquivo datatorm.mdb que contém as tabelas de dados convencionais.

A maioria dos formulários e relatórios são associados a consultas pré-definidas e os seus campos são ligados aos campos das tabelas que aparecem nas consultas. Desta forma, quando dados são inseridos, modificados ou apagados nos formulários, estas operações são automaticamente atualizadas nas tabelas. Cada formulário é baseado em uma consulta principal, mas ele pode conter também subformulários que são, por sua vez, associados a outras consultas.

Os formulários e subformulários são ligados entre si quando as propriedades Link Child Fields e Link Master Fields do subformulário contêm, respectivamente, o nome do campo correspondente à chave primária da tabela/consulta relacionada do subformulário, e o nome do campo da chave estrangeira da tabela/consulta do formulário principal. Desta forma, quando o usuário navega por vários registros do formulário principal, o subformulário é automaticamente preenchido com os dados correspondentes ao registro corrente do formulário principal.

O usuário que trabalha diretamente com a interface do aplicativo SGBD DataTORM utiliza formulários pré-definidos. Os principais formulários estão 
divididos em seis grupos principais que estão disponíveis através de uma barra de serviços. A figura a seguir apresenta a barra de serviços nas diferentes configurações para cada um dos seis grupos de opções.
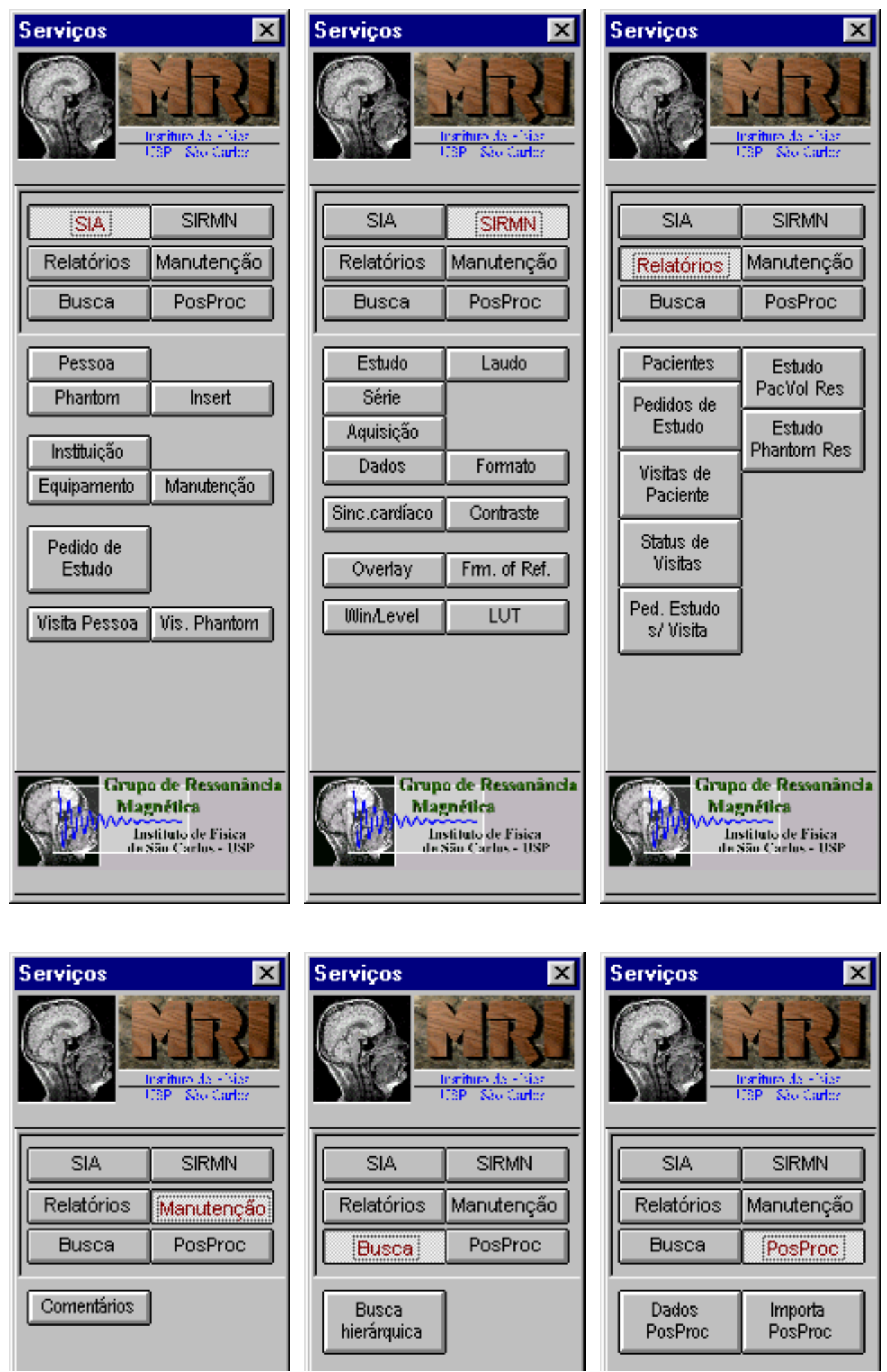

Figura 46 - Grupos de serviços disponíveis no formulário da barra de serviços do SGBD DataTORM. 
Cada grupo de serviço disponibiliza ao usuário os formulários pertinentes ao assunto do grupo, que são:

SIA: formulários relativos ao sistema de informação administrativo, destinados principalmente ao ambiente de operação acadêmico para registrar pessoas, phantoms, pedidos de estudo, agendas de visitas e manutenções feitas sobre o equipamento de MRI;

SIRMN: formulários do sistema de informação para RMN que são utilizados para registrar os estudos, suas séries, aquisições e imagens;

Relatórios: são relatórios pré-definidos correspondentes às consultas mais comuns;

Manutenção: este grupo é destinado a manutenção do próprio sistema DataTORM, armazenando informações sobre erros encontrados no sistema pelos usuários e registrando as alterações realizadas;

Busca: ao contrário dos grupos SIA e SIRMN, que possuem formulários que seguem a divisão do modelo de dados e por isso são chamados de formulários normalizados, este grupo possui formulários que consultam o banco de dados de maneira mais eficiente, voltado para usuários paramétricos. A partir destes formulários, o usuário pode ter acesso aos formulários normalizados para obter informações mais detalhadas ou para editar os dados;

PosProc: este grupo dá acesso aos dados do arquivo de dados posproc.mdb, que é utilizado nesta versão do DataTORM para armazenar os dados do sistema ToRM005 e para testar o próprio sistema de banco de dados DataTORM.

Os formulários desenvolvidos no MS Access 2.0 têm como objetivo servir de interface com o usuário para, principalmente, consulta e edição dos dados, podendo também servir para a inserção de novos dados. Para os usuários que trabalham diretamente com o banco de dados através do DataTORM, estes formulários são a principal parte da aplicação, pois, além dos formulários de acesso aos dados, há também formulários para acesso aos relatórios, funções de manutenção e importação de dados externos.

Os formulários dos seis grupos de serviços estão resumidos na Tabela 24 a seguir. Na tabela, quando não indicado o contrário, os formulários são para consulta, 
edição e inserção de dados. (O Apêndice VIII contêm os formulários indicados na Tabela 24).

Tabela 24 - Lista dos formulários do DataTORM

\begin{tabular}{|c|c|c|}
\hline Grupo & $\begin{array}{l}\text { Formulários } \\
\text { principais }\end{array}$ & Descrição \\
\hline \multirow[t]{9}{*}{ SIA } & Pessoa & $\begin{array}{l}\text { Dados demográficos de pessoas, sejam elas } \\
\text { pacientes ou voluntários, especialistas e } \\
\text { responsáveis. }\end{array}$ \\
\hline & Phantom & Dados da entidade Phantom. \\
\hline & Insert & $\begin{array}{l}\text { Dados dos Insert padrões que podem ser } \\
\text { utilizados nos Phantoms. }\end{array}$ \\
\hline & Instituição & Dados de instituições. \\
\hline & Equipamento & $\begin{array}{l}\text { Dados descritivos dos equipamentos de } \\
\text { imagens médicas registrados no sistema. }\end{array}$ \\
\hline & Manutenção & Dados de manutenções efetuadas no sistema. \\
\hline & Pedido de Estudo & Registro dos pedidos de estudos. \\
\hline & Visita Pessoa & Agenda das visitas de pacientes ou voluntários. \\
\hline & Visita Phantom & $\begin{array}{l}\text { Agenda de visita de Phantom. É utilizado } \\
\text { principalmente em um ambiente acadêmico } \\
\text { onde são feitos muitos estudos com Phantoms. }\end{array}$ \\
\hline \multirow[t]{8}{*}{ SIRMN } & Estudo & $\begin{array}{l}\text { Dados de estudos, com informações sobre a } \\
\text { quantidade de séries, aquisições e dados. }\end{array}$ \\
\hline & Laudo & $\begin{array}{l}\text { Laudos dos estudos elaborados por } \\
\text { especialistas. }\end{array}$ \\
\hline & Série & $\begin{array}{l}\text { Dados característicos de séries, com } \\
\text { informações sobre a quantidade de aquisições } \\
\text { e dados. }\end{array}$ \\
\hline & Aquisição & $\begin{array}{l}\text { Dados característicos de aquisições, com } \\
\text { informações sobre a quantidade de dados. }\end{array}$ \\
\hline & Dados & $\begin{array}{l}\text { Dados resultantes de aquisições, podendo ser } \\
\text { no formato de dados de aquisição, dados } \\
\text { transformados, dados de módulo e dados de } \\
\text { fase, parte real e parte imaginária. Nos casos } \\
\text { de dados de módulo, fase, parte real e } \\
\text { imaginária, a imagem correspondente pode ser } \\
\text { mostrada. }\end{array}$ \\
\hline & Formato & Descrição de formato de dados. \\
\hline & $\begin{array}{l}\text { Sincronismo } \\
\text { Cardíaco }\end{array}$ & $\begin{array}{l}\text { Dados de sincronismo cardíaco usado em } \\
\text { aquisições. }\end{array}$ \\
\hline & Contraste & $\begin{array}{l}\text { Dados que caracterizam o contraste usado em } \\
\text { aquisições. }\end{array}$ \\
\hline
\end{tabular}

\footnotetext{
* Na versão atual, a imagem dos dados só é mostrada se a imgem BMP correspondente também foi armazenada.
} 


\begin{tabular}{|c|c|c|}
\hline \multirow[t]{5}{*}{ Grupo } & $\begin{array}{c}\text { Formulários } \\
\text { principais }\end{array}$ & Descrição \\
\hline & Overlay & $\begin{array}{l}\text { Os Overlays podem ser usados para sobrepor } \\
\text { informações sobre as imagens dos dados. Este } \\
\text { formulário aceita o armazenamento de } \\
\text { Overlays, mas a utilização destes juntamente } \\
\text { com as imagens ainda não foi implementada. }\end{array}$ \\
\hline & Frame of reference & $\begin{array}{l}\text { Registra sistemas de referência. Todas as } \\
\text { séries que utilizam o mesmo Frame of } \\
\text { reference possuem dados que estão } \\
\text { espacialmente relacionados. }\end{array}$ \\
\hline & Win/Level & $\begin{array}{l}\text { Registra a faixa dinâmica padrão, para cada } \\
\text { dado, que deve ser utilizada para criar as } \\
\text { imagens correspondentes. Corresponde a um } \\
\text { ajuste de brilho e contraste padrão para cada } \\
\text { dado. }\end{array}$ \\
\hline & LUT & $\begin{array}{l}\text { Possibilita armazenar LUT (Lookup Table) } \\
\text { para definir a formas padrões de visualização } \\
\text { de imagens. A utilização do LUT ainda não foi } \\
\text { implementada. }\end{array}$ \\
\hline Relatórios & - & $\begin{array}{l}\text { Obs.: os relatórios deste grupo de serviço são } \\
\text { apresentados na Tabela } 25 .\end{array}$ \\
\hline Manutenção & Comentários & $\begin{array}{l}\text { Formulário utilizado para registrar } \\
\text { comentários dos usuários sobre o DataTORM, } \\
\text { incluindo sugestões e identificação de erros. }\end{array}$ \\
\hline Busca & Busca Hierárquica & $\begin{array}{l}\text { Relatório de busca para consultar os estudos } \\
\text { de membros da categoria comunidade. Para } \\
\text { cada membro de Comunidade selecionado são } \\
\text { apresentados os seus estudos, séries, } \\
\text { aquisições e imagens. A partir deste } \\
\text { formulário, o usuário pode ter acesso às } \\
\text { informações detalhadas de cada nível da } \\
\text { hierarquia de busca. }\end{array}$ \\
\hline \multirow[t]{2}{*}{ PosProc } & Dados PosProc & $\begin{array}{l}\text { Formulário utilizado para importar e consultar } \\
\text { dados de aquisição utilizados pelo sistema } \\
\text { ToRM-005 e processados pelo aplicativo } \\
\text { PosProc. }\end{array}$ \\
\hline & Importa PosProc & $\begin{array}{l}\text { Formulário utilizado para importar e visualizar } \\
\text { imagens produzidas pelo sistema ToRM-005 e } \\
\text { processadas pelo aplicativo PosProc. }\end{array}$ \\
\hline
\end{tabular}

Foram definidos sete relatórios padrões cujas funções são resumidas na Tabela 25. Cada um dos relatórios é baseado em uma consulta específica elaborada em SQL. À medida que os usuários vão se familiarizando com o sistema, eles podem rapidamente preparar relatórios específicos utilizando os recursos do MS Access 2.0. 
Os relatórios podem ser impressos em qualquer impressora que esteja instalada no computador e que esteja devidamente registrada pelo sistema operacional.

Tabela 25 - Lista dos relatórios padrões implementados no DataTORM

\begin{tabular}{l|l}
\hline \hline \multicolumn{1}{c|}{ Relatório } & \multicolumn{1}{c}{ Conteúdo } \\
\hline \hline Pacientes & $\begin{array}{l}\text { Todas as informações demográficas de cada } \\
\text { Paciente/Voluntário. }\end{array}$ \\
\hline Pedidos de Estudo & $\begin{array}{l}\text { Todos os pedidos de estudo de todos os } \\
\text { membros da categoria Comunidade. }\end{array}$ \\
\hline Visitas de Paciente & $\begin{array}{l}\text { Todos os dados de visitas de } \\
\text { Paciente/Voluntário. }\end{array}$ \\
\hline Status de Visitas & $\begin{array}{l}\text { Relatório resumido de visitas de membros da } \\
\text { Comunidade com informações apenas de status } \\
\text { e datas da agenda. }\end{array}$ \\
\hline Pedidos de Estudo sem Visitas & $\begin{array}{l}\text { Relatório resumido que indica todos os pedidos } \\
\text { de estudo que não possuem uma agenda de } \\
\text { visita. }\end{array}$ \\
\hline Estudo de Paciente/Voluntário & $\begin{array}{l}\text { Relatório resumido de estudos de } \\
\text { Paciente/Voluntário com todas as imagens } \\
\text { Reparadas por séries. }\end{array}$ \\
\hline Estudo de Phantom Resumido & $\begin{array}{l}\text { Relatório resumido de estudos de Phantom com } \\
\text { todas as imagens separadas por séries. }\end{array}$ \\
\hline \hline
\end{tabular}

A atual versão do DataTORM recebe dados apenas através de operações de inserção de dados em seus formulários e através de importação de imagens no formato BMP. Os dados convencionais devem ser digitados pelo usuário nos formulários do SGBD DataTORM. Para importar as imagens, é necessário indicar o diretório em que o aplicativo PosProc salvou as imagens e selecionar o arquivo de parâmetros de aquisição correspondente às imagens a serem importadas. A função de importação de dados utiliza o controle para objetos OLE disponível no MS Access 2.0 para incorporar as imagens no banco de dados.

O trecho de código a seguir exemplifica como a imagem é incorporada no controle OLE e depois ela é armazenada no BD. A propriedade OLEtypeAllowed indica qual tipo de associação deve ser feita com o arquivo; a propriedade Class indica o aplicativo servidor de OLE associado ao arquivo; SourceDoc contém a localização e o nome do arquivo; e a propriedade Action determina o tipo de ação que deve ser executada no objeto OLE. 
'Especificar que é embedded (OLE_LINKED=0, OLE_EMBEDDED=1, OLE_NONE=3)

Me! [PixelData]. OLEtypeAllowed $=1$

'Especificar a classe do objeto

Me! [PixelData].Class = "Paint.Picture"

'Especificar o arquivo com o objeto original.

Me! [PixelData]. SourceDoc = "<arquivo BMP $>$ "

'Criar o objeto (OLE_CREATE_EMBED = 0)

Me! [PixelData].Action = 0

'Atualiza o registro antes de passar para um próximo Me.Refresh 
4 DISCUSSÃO 


\subsection{PACS}

Sistemas de armazenamento e comunicação de imagens, mais conhecidos como PACS, são atualmente a melhor proposta tecnológica para lidar com o crescente volume de imagens médicas de diversas modalidades gerado nas instalações médicas de todo o mundo, bem como no aumento crescente da demanda por comunicações rápidas e de longas distâncias de resultados de exames. Por outro lado, a implementação destes sistemas requer investimentos volumosos e compreende tecnologias complexas e em constantes mudanças, já que ainda não foram apresentadas propostas universalmente aceitas e persistentes. Os diversos sistemas já implementados ou em fase de desenvolvimento, principalmente em grandes instalações médicas americanas, representam o atual estado da arte desta tecnologia, e muito estudo e trabalho deve ser feito para, no Brasil, serem criados sistemas semelhantes que atendam as necessidades de armazenamento digital que já há alguns anos estão surgindo nas principais instalações médicas brasileiras.

Com relação ao presente trabalho, a sua relação com PACS não estava clara inicialmente. Apenas com o melhor entendimento da abrangência de PACS é que foi possível melhor posicionar qual deveria ser o papel do DataTORM. Inicialmente achava-se que o modelo proposto para um SBD para MRI e a sua implementação na forma do DataTORM seria uma espécie de pequeno PACS, restrito a um ambiente de utilização reduzido a um só equipamento de MRI, poucos usuários e um volume de dados bem menor que o existente em grandes instalações médicas.

Não estava claro que o contexto de PACS era bem maior, onde equipamentos de imagens médicas possuem, independente de estarem incorporados em PACS, seus próprios sistemas de armazenamento de dados, que até podem possuir formatos 
próprios, mas que, preferencialmente, possam exportar e/ou comunicar os dados em um formato padrão, como, por exemplo, o DICOM 3.0.

Também não estava clara a distinção entre as funções do SBD e as funções de sistemas de visualização de imagens médicas, o que acarretou a criação do BD DataTORM e do SGBD DataTORM, este último para tentar suprir as necessidades mais básicas de um sistema de visualização. Em PACS, estes sistemas são bem distintos, o que facilita o desenvolvimento, a manutenção e proporciona flexibilidade de utilização. Por estes mesmos motivos também é preferível que, em um sistema de imagens médicas, os módulos de visualização e de SBD também estejam separados. Como ficou claro durante o desenvolvimento deste trabalho, os requisitos para estes dois tipos de sistema são bem distintos, cada um deles voltados para objetivos distintos: o primeiro deve servir de repositório para os dados gerados e o segundo atender as necessidades específicas de visualização de imagens médicas e consultas objetivas e eficientes a dados clínicos de exames de pacientes.

Se esta visão sobre o papel de cada componente já existisse no início do trabalho, o contexto do trabalho poderia ter sido mais restrito, o que poderia ter proporcionado, do ponto de vista do sistema implementado para ser usado no ToRM05, resultados mais eficazes e que atendessem melhor as necessidades específicas de armazenamento de dados do projeto global. Por outro lado, o trabalho abordando requisitos diversos proporcionaram experiências em um grupo maior de aspectos relativos a PACS e sistemas de imagens médicas, todas elas válidas, mesmo com a impossibilidade de aprofundamento maior devido, justamente, à diversidade. 


\subsection{DICOM 3.0}

Os padrões para comunicação e armazenamento de imagens médicas propostos pelo American College of Radiology e pela National Electrical Manufactures Association, desde a versão 1.0 até a versão atual 3.0, possuem o grande mérito de criar condições práticas para uma padronização na área de armazenamento e comunicação de imagens médicas, sendo este passo um pré-requisito indispensável para implementações viáveis e duradouras de PACS.

O padrão DICOM 3.0 é bastante extenso e complicado, de forma que seria necessário um estudo detalhado para implementar uma aplicação de armazenamento e comunicação de imagens médicas que realmente satisfizesse os requisitos de conformidade impostos pelo padrão. No início deste trabalho, quando foram feitas as primeiras leituras sobre este padrão, desejava-se criar um sistema que fosse capaz de, pelo menos, importar e exportar dados no formato do padrão. À medida que o DataTORM foi sendo implementado e o padrão era melhor entendido, descobriu-se que:

- o MS Access 2.0 não possui a flexibilidade para se criar todos os tipos de dados definidos no padrão;

- as partes do padrão DICOM 3.0 referentes ao armazenamento em meios físicos (partes 10 e 11) ainda estavam em desenvolvimento;

- o DataTORM possui requisitos adicionais que não são atendidos pelo DICOM 3.0, como, por exemplo, a existência do tipo de entidade PHANTOM;

- se a comunicação do DataTORM com módulos ou aplicações externas fosse feita segundo este padrão, os demais módulos do sistema ToRM-05 teriam que ser alterados, ou pelo menos novos módulos funcionais teriam que ser criados para 
este fim, situação esta que não correspondia às necessidades mais imediatas do projeto.

Desta forma decidiu-se limitar a influência do padrão DICOM 3.0 no desenvolvimento do DataTORM a dois pontos principais que atendiam ao objetivo deste trabalho de ser um primeiro contato na área de PACS e SBD para MRI. Estes pontos são:

- utilizar o modelo conceitual de dados proposto pelo DICOM 3.0 como referência para o modelo do DataTORM. Assim, o modelo EER elaborado neste trabalho engloba o modelo composto para MRI daquele padrão, incluindo todas as entidades e atributos obrigatórios;

- todos os atributos das entidades do DataTORM que possuem um equivalente no modelo composto do DICOM 3.0 possuem domínios equivalentes. Desta forma, se futuramente forem criadas funções para exportação e importação de dados no formato definido pelo padrão, não ocorrerão perdas de dados devido a incompatibilidade de domínios. 


\subsection{Dados não-convencionais}

Como apresentado na seção sobre a implementação do BD DataTORM (Item 3.3.2), os dados não-convencionais merecem uma atenção especial. Isto ocorre pois os principais resultados da operação de um equipamento de MRI são armazenados utilizando este tipo de dados, e porque eles possuem requisitos adicionais que normalmente não são atendidos na abordagem relacional de sistemas de bancos de dados.

Especificamente no que se relaciona a este trabalho, para o tratamento destes dados foram usados os recursos proporcionados pelo MS Access 2.0, isto é, a tecnologia OLE. A versão atual do DataTORM armazena imagens apenas no formato BMP pois é utilizado o aplicativo MS Paint como aplicativo servidor de OLE, mas este aplicativo não comporta os formatos de dados que serão usados no ToRM-05. Para armazenar estes dados, esta planejado que a próxima versão utilize o MS Object Packager. Este aplicativo permitirá o armazenamento e a recuperação dos dados, mas o SGBD DataTORM ainda não será capaz de manipular e criar imagens a partir destes dados, limitando então a consulta aos dados não-convencionais à possibilidade de salvá-los em arquivos separados ou no clipboard do sistema operacional.

Como os dados não-convencionais são utilizados por vários módulos de programa do sistema ToRM-05, a solução para estes problemas deve ser, preferencialmente, comum e de uso geral. Desta forma, a sugestão deste trabalho é que seja criado um esquema conceitual orientado a objetos de uma classe para os dados não-convencionais. Como os formatos dos dados já estão definidos, deve ser criada uma biblioteca de funções de manipulação destes dados. Esta biblioteca deve seguir o padrão da plataforma Windows para poder ser utilizada por vários aplicativos 
diferentes que compõe os programas do ToRM-05. Algumas destas funções já existem e atualmente estão agrupadas em um arquivo de biblioteca, o torm32.dll. Para integrar e proporcionar uma interface de alto nível de utilização desta classe, a sugestão é criar um aplicativo servidor de OLE. Ele passaria a ser o servidor de OLE para os dados não-convencionais no DataTORM e proporcionaria toda funcionalidade relacionada a estes dados para todos os módulos de programa do ToRM-05.

\footnotetext{
* O módulo torm32.dll foi desenvolvido pelo engenheiro Mateus José Martins.
} 


\subsection{Comunicação}

Os mecanismos naturais de comunicação entre aplicações da plataforma Windows são o Dynamic Data Exchange (DDE) e o Object Linking and Embedding (OLE). Para os desenvolvedores, bibliotecas de funções, objetos e controles de uso compartilhado podem também ser criados e/ou utilizados. No caso dos programas que estão sendo desenvolvidos para o projeto do sistema ToRM-05, a integração das diversas partes é feita através da utilização de bibliotecas comuns (DLL - Dynamic Link Library), utilização de um controle OCX desenvolvido para a aquisição, o TORMOCX, e desenvolvimento de módulos de programa que podem ser incorporados no código fonte dos módulos principais antes destes serem recompilados, que é o caso de alguns módulos que estão sendo desenvolvidos para o TORMGUI.

Para a comunicação com o banco de dados desenvolvido neste trabalho, estão disponíveis o MS Jet Database Engine e a tecnologia Open Database Connectivity (ODBC). O primeiro permite a criação a sistemas de bancos de dados remotos e o segundo permite a criação de sistemas do tipo cliente/servidor. A opção escolhida foi a de um sistema remoto, implementada na forma do SGBD DataTORM através do MS Access 2.0, que utiliza o Jet Engine como núcleo do SGBD.

Como os dados gerados pelo tomógrafo são adquiridos e processados por outros módulos de programa, seria interessante que estes módulos se comunicassem com o DataTORM e inserissem automaticamente os dados no repositório assim que estejam disponíveis. Para isso, seja para a utilização do BD DataTORM como um sistema remoto ou na forma de cliente/servidor, seria necessário que os outros módulos, as aplicações clientes do BD, criassem módulos específicos para ter acesso ao BD. Como isto ainda não foi planejado no projeto do sistema ToRM-05, o 
DataTORM possui apenas funções de importação de dados. Assim, os dados são armazenados em arquivos localizados em pastas do sistema de arquivos do computador e o operador utiliza o SGBD DataTORM para importar estes arquivos. Como a atual versão utiliza apenas arquivos de imagens no formato BMP, apenas imagens deste tipo estão sendo incorporadas no BD DataTORM.

A solução de importação de dados, da maneira que foi implementada, é pouco prática para a operação normal pretendida para o tomógrafo e para o DataTORM, pois requer uma intensa intervenção do operador, inclusive para digitar dados que provavelmente já haviam sido inseridos durante a operação do sistema. Desta forma, a escolha, e posterior implementação, de uma das alternativas mencionadas para a comunicação dos dados e, principalmente, para a inserção automática de dados no BD DataTORM é de vital importância para que a utilização do DataTORM seja justificada. Outra possibilidade possível é estabelecer um formato padrão em que os outros módulos exportem os dados e aperfeiçoar as funções de importação de dados do DataTORM. 


\subsection{Metodologia utilizada}

A metodologia geral utilizada para o desenvolvimento do DataTORM procurou seguir vários conceitos definidos pela engenharia de programação, entre eles, ciclo de vida, modelagem de dados, ferramentas de desenvolvimento e prototipagem. Independente de discussões específicas sobre cada um destes conceitos e tecnologias utilizados, uma discussão geral relacionando a utilização das metodologias de engenharia de programação e maturidade do processo de desenvolvimento de programas deve ser feita. Esta discussão fica mais clara exemplificando a abordagem adotada e os problemas encontrados no desenvolvimento do DataTORM.

Desde o início do desenvolvimento deste trabalho procurou-se seguir a risca as etapas de desenvolvimento do ciclo de vida tradicional para desenvolvimento de programas, isto é, com as etapas de análise de requisitos, especificação, implementação e testes. Em cada uma das etapas tentou-se esgotar todo o desenvolvimento necessário para a etapa antes de passar para a etapa posterior. Por exemplo, o modelo de dados foi trabalhado exaustivamente até se obter uma versão considerada ideal e só então iniciou-se a próxima fase, também trabalhada até a situação considerada "final" antes de seguir adiante. Está é uma abordagem horizontal (que não deve ser entendido como sendo uma abordagem superficial) por procurar finalizar cada grande etapa do ciclo de vida de uma só vez, deixando a retroalimentação apenas para ajustes finos.

Enquanto esta abordagem foi seguida, freqüentemente acorreu de se perceber que na etapa anterior não haviam sido levados em consideração aspectos essenciais e que deveriam ser definidos antes de prosseguir no desenvolvimento. Desta forma, voltava-se para a etapa anterior e procurava-se completar todos os aspectos 
pendentes antes de continuar a etapa seguinte, isto quando esta última não tinha que ser completamente refeita. Este tipo de situação ocorreu, por exemplo, quando na etapa de implementação iniciou-se a implementação do armazenamento dos dados não-convencionais, onde foram detectados requisitos que não haviam sido levados em consideração na fase de análise de requisitos, isto além de determinadas limitações do MS Access 2.0 que só foram descobertas quando a implementação já havia iniciado.

Estes problemas fizeram com que muito tempo fosse perdido nas sucessivas idas e vindas pelas etapas do ciclo de vida de desenvolvimento e, conseqüentemente, todo o processo de desenvolvimento demorasse muito mais que o originalmente planejado. Este processo levou a uma re-interpretação das metodologias gerais da engenharia de programação sob a luz do conceito de maturidade do processo de desenvolvimento de programas.

O processo de desenvolvimento do DataTORM foi a primeira experiência, não relacionada a cursos acadêmicos, de aplicação de metodologias, técnicas de modelagem e programas de desenvolvimento. Desta forma, não havia uma experiência anterior necessária para justificar a abordagem horizontal utilizada. A conclusão é que uma abordagem em profundidade, que foi adotada ao final do trabalho para algumas tarefas restantes, poderia ter sido mais eficaz. Esta abordagem seria, ao contrário da primeira, concentrada em pequenas tarefas correspondentes a aspectos restritos do desenvolvimento do DataTORM e que deveriam ser desenvolvidas por toda sua extensão, isto é, desde a análise de requisitos até a implementação e testes. Os benefícios desta abordagem seriam:

- o escopo de cada tarefa seria bem limitado e especificado, viabilizando a obtenção de resultados concretos e passíveis de avaliação crítica em pouco tempo;

- as várias metodologias de desenvolvimento seriam experimentadas para casos restritos e específicos, havendo, portanto, um aprendizado dos vários aspectos importantes, principalmente no que se trata da utilização dos resultados de uma metodologia por outra no decorrer do ciclo de vida do programa. Como cada tarefa seria restrita, erros cometidos em uma fase poderiam ser corrigidos sem que, com isso, muito tempo de desenvolvimento fosse desperdiçado; 
- as ferramentas propostas para o desenvolvimento, como por exemplo o MS Access 2.0, seriam testadas em todos os seus aspectos logo no início do trabalho. Assim, suas características particulares, limitações e benefícios seriam logo conhecidos, o que permitiria uma avaliação sobre a adequação destas ferramentas em tempo hábil para qualquer mudança desejável.

A escolha da abordagem de desenvolvimento deve ser, então, compatível com o grau de maturidade para desenvolvimento de programas existente no ambiente de desenvolvimento, no grupo de desenvolvedores, ou apenas no único desenvolvedor. A abordagem horizontal é adequada para quando já se conhece, por experiência de desenvolvimento passado, o tipo de aplicação em questão, neste caso SBD, e as metodologias e tecnologias propostas para serem utilizadas, como EER, MRD, MS Access 2.0 e Visio®. Neste caso, esta experiência já adquirida em trabalhos anteriores permitiria que o ciclo de vida para o desenvolvimento do programa fosse feito por etapas completas do ciclo de vida já para o sistema como um todo.

Já a abordagem em profundidade é adequada para a situação em que tanto o tipo de aplicação quanto as metodologias e tecnologias não são dominadas completamente pelos desenvolvedores, mesmo se o domínio da aplicação e os objetivos finais do trabalho sejam bem conhecidos por eles. A experimentação durante o desenvolvimento de pequenas partes do projeto global permite, por um lado, o aprendizado dos diversos aspectos relevantes, e por outro lado, a passagem pelas diversas etapas de desenvolvimento objetivando adquirir um conhecimento global do processo.

A maturidade no desenvolvimento de programas vária, para um mesmo ambiente de desenvolvimento, dependendo do tipo de aplicação e metodologias em questão. Como discutido por Curtis, ${ }^{28}$ o conceito de maturidade do processo de desenvolvimento de programas é bastante amplo e abrange diversos aspectos. Neste neste trabalho, o principal aspecto a ser salientado é que as metodologias e tecnologias da engenharia de programação, que são vastamente apresentadas em livros e cursos acadêmicos, devem ser entendidas e utilizadas sob o ponto de vista de

\footnotetext{
* O aplicativo Visio® foi utilizado, principalmente, para desenhar os diagramas EER.
} 
uma auto-avaliação. Esta auto-avalição deve determinar se existe maturidade para a utilização destas técnicas. As mais modernas metodologias, técnicas, ferramentas de desenvolvimento de última geração prometem resultados maravilhosos, mas se não se está adequadamente preparado para usar tudo isso, os resultados podem ser frustrantes e a conclusão pode ser que os métodos tradicionais de desenvolvimento são melhores que todas estas tecnologias de desenvolvimento e programação, métodos estes chamados por alguns de métodos "incrementais", e por outros de métodos "pensar-codificar". ‘

As várias considerações apontadas acima sobre a metodologia de desenvolvimento indicam que o modelo espiral da engenharia de programação poderia ter sido o paradigma mais adequado para o desenvolvimento deste trabalho. Este paradigma leva em consideração a maturidade no processo de desenvolvimento e determina uma abordagem em profundidade que, como discutido acima, é adequado para um desenvolvimento que segue paralelo ao processo de aprendizagem.

\footnotetext{
* MALDONADO, J.C. (Instituto de Ciências Matemáicas de São Carlos - USP) Comunicação pessoal, 1993.

${ }^{\dagger}$ MAGON, C.J. (Instituto de Física de São Carlos - USP) Comunicação pessoal, 1993.
} 


\subsection{Utilização do MS Access 2.0}

A utilização do MS Access 2.0 para o desenvolvimento e implementação do DataTORM foi motivada basicamente pela simplicidade de utilização deste SGBD e pela expectativa de portabilidade dos resultados na plataforma operacional do Windows 95. A opção pela versão 2.0 deste produto, compatível com o Windows 3.x e Windows 95, resultou da constatação de problemas de "vazamento de memória"* existentes na versão 7.0, específica para Windows 95 e Windows NT.

Como o modelo de dados escolhido para implementação foi o relacional, o MS Access 2.0 proporcionou, do ponto de vista da implementação, todos os requisitos para criar o banco de dados, suas tabelas, relacionamentos, restrições de integridade e permissões de acesso. Para o desenvolvimento do aplicativo de consulta SGBD DataTORM, os recursos para criar formulários, relatórios, macros e módulos de programa atenderam aos requisitos mais básicos, mais foram insuficientes para outras questões que serão apresentadas logo a seguir.

Os dois principais problemas relativos a escolha do MS Access 2.0 para a implementação do DataTORM foram:

1. limitação de utilização de dados binários a apenas tipos de dados que são objetos de aplicativos servidores de OLE;

2. número limitado de elementos de interface com o usuário para a criação de formulários.

\footnotetext{
* Aparentemente, o MS Access 7.0 não liberava memória para o sistema operacional depois de executar determinadas tarefas, como, por exemplo, preparar um relatório extenso. Desta forma, o sistema operacional passava a emitir mensagens de falta de memória, mesmo quando havia bastante memória livre. A única maneira de corrigir esta situação era reinicializando o computador.
} 
Como os dados não-convencionais usados pelo ToRM-05 e, conseqüentemente, pelo DataTORM, possuem um formato próprio, desejava-se que eles pudessem ser incorporados no banco de dados pelo MS Access 2.0 sem a necessidade de associá-los a outro aplicativo. Desta forma seria possível armazenar de imediato os dados binários, mesmo ainda não possuindo funções para trabalhar com eles, e depois, se for o caso, incluir no sistema a funcionalidade necessária para consultar e/ou manipular estes dados.

Como o MS Access 2.0 requer um aplicativo servidor de OLE associado, a atual versão do DataTORM incorpora apenas imagens no formato BMP e utiliza o aplicativo MS Paint como servidor de OLE. Planeja-se que a próxima versão utilize o aplicativo Microsoft Object Packager para incorporar todos os tipos de dados nãoconvencionais, mas ainda não será possível mostrar imagens de dados que não estejam no formato BMP, pois este aplicativo não possui as funções necessárias para extrair as imagens destes dados. Este problema permaneceria mesmo se fosse feita uma atualização para as versões mais novas do MS Access. Para resolvé-lo definitivamente existem algumas opções:

- criar um aplicativo servidor de OLE que suporte os dados usados no ToRM-05 e que possua métodos específicos para a manipulação destes dados nãoconvencionais. Este aplicativo poderia, então, ser utilizado pelo MS Access 2.0 através do OLE 2.0 e, conseqüentemente, pelo DataTORM;

- utilizar o aplicativo Microsoft Object Packager para incorporar os dados nãoconvencionais no BD DataTORM e usar funções da API* do Windows para criar funções de visualização dos dados no SGBD DataTORM;

- utilizar o MS Jet Engine diretamente para inserir os dados não-convencionais no BD DataTORM e usar as funções da API do Windows para criar funções de visualização dos dados no SGBD DataTORM.

O MS Access 2.0 possui recursos limitados de elementos interface para criação de formulários para o usuário. Um recurso existente no MS Access 97 é o controle de "tab", que possibilita organizar melhor os campos nos formulários,

\footnotetext{
* Application Programming Interface. Biblioteca de funções que possibilita o programador utilizar os recursos do sistema operacional.
} 
principalmente quando existem muitos campos para o mesmo formulário. No caso do MS Access 2.0 e MS Access 95, as opções são utilizar controles de tabs desenvolvidos por terceiros ou distribuir os campos em várias páginas de formulário. Os controles deste tipo fornecidos por terceiros que foram testados não foram considerados satisfatórios e, por isso, optou-se pela segunda opção. 


\subsection{Considerações sobre a instalação do ToRM-05}

As reais necessidades do ambiente de operação na instalação hospitalar onde o ToRM-05 será instalado não foram estudadas. As características específicas do sistema de informação local não foram levantadas e muito menos comparadas com o modelo geral proposto neste trabalho. Desta forma, é difícil avaliar, do ponto de vista do futuro usuário do DataTORM, quais características deste trabalho são positivas e atendem as necessidades locais e quais não.

Como o sistema ToRM-05 e seus componentes não possuem como objetivo funcionar integrados em um sistema PACS, duas características básicas devem estar necessariamente presentes:

- impressão das imagens e suas informações associadas: para que estes resultados possam ser incorporados na estrutura de armazenamento e roteamento de resultados radiológicos já existente no sistema de informação local da instalação médica;

- proporcionar uma interface com o usuário que estimule a utilização do sistema. Um impacto positivo inicial pode tornar os usuários abertos a novidades em futuras versões do sistema. Desta forma, é preferível que a interface seja simplificada ao máximo, mesmo deixando de oferecer várias funcionalidades que poderiam ser potencialmente úteis.

Tendo em vista estas considerações, a impressão de imagens é um ponto importante que ainda não foi abordado no DataTORM e nos outros módulos do sistema. Este aspecto é importante pois os métodos e as tecnologias de impressão de imagens radiológicas não são tão simples como as impressões de textos em 
impressoras convencionais. Primeiramente deve ser feita a escolha do tipo de impressão a ser feita, se será em filme, papel, transparência, etc. Depois, o tipo de tecnologia para fazer a impressão, seja câmara multiformato, impressoras a laser, jato de tinta, sublimação de tinta, impressão térmica, etc. Alguns destes dispositivos são de instalação relativamente complicada, se comparados com a instalação de uma impressora comum. Por exemplo, a comunidade médica está acostumada a observar os resultados radiológicos em filmes geralmente produzidos em câmaras multiformato. Para não criar muito impacto no novo ambiente de operação, seria interessante que existisse esta possibilidade de impressão, mesmo que outras formas também estejam disponíveis. Atualmente, nenhum dos módulos de programas e equipamentos do sistema já estão preparados para trabalhar com este tipo de dispositivo.

Atualmente as imagens do ToRM-005 são impressas em uma impressora térmica. Foi desenvolvido um driver especial para que esta impressora pudesse funcionar ligada a um microcomputador com o sistema operacional Windows.* Pretendia-se que a atual versão do DataTORM fosse capaz de imprimir as imagens nesta impressora, mas restrições do MS Access 2.0 não permitiram que isto fosse implementado. Para usar a impressora térmica é necessário utilizar uma função desenvolvida especificamente para este fim e que já é utilizada pelo programa PosProc. Entre os vários parâmetros desta função, um é um ponteiro para a janela que contem a imagem e outro é uma variável que contém a imagem propriamente dita, mas no formato do Windows. Ao contrário da linguagem Visual Basic, a linguagem Access Basic existente no MS Access 2.0 não possui os elementos necessários para passar estes dois parâmetros. É necessário, então, pesquisar as funções da API do Windows para implementar a impressão, o que ainda não foi realizado.

\footnotetext{
* O driver para impressão na impressora térmica foi desenvolvido pelo engenheiro Mateus José Martins, do Instituto de Física de São Carlos - USP/SãoCarlos.
} 


\section{CONCLUSÃO}

A avaliação deste trabalho deve ser feita considerando os dois objetivos principais: 1) o objetivo geral de obtenção gradual de tecnologia na área de armazenamento e gerenciamento de dados para sistemas de MRI; e 2) desenvolver um sistema de banco de dados para ser utilizado pelo sistema ToRM-05 a ser instalado no hospital Santa Casa de São Carlos.

O primeiro objetivo foi atingido, principalmente, através da revisão da literatura realizada, onde, além do levantamento de diversos aspectos relacionados com sistemas PACS, também foi abordado o padrão DICOM 3.0. As diversas propostas e modelos apresentadas e implementadas neste trabalho, todas inspiradas nos aspectos levantados na revisão da literatura e, com especial destaque, no padrão DICOM 3.0, serviram como uma experiência que abrangeu diversos aspectos práticos relacionados com a implementação deste tipo de sistema.

Já com relação ao segundo objetivo, nem todos os requisitos para que o DataTORM possa operar no sistema ToRM-05 foram plenamente satisfeitos. A tabela a seguir resume alguns dos principais aspectos relacionados com o trabalho e destaca aqueles que foram abordados na forma de propostas e modelos e aqueles realmente implementados no DataTORM. 
Tabela 26 - Resumo dos resultados do trabalho

\begin{tabular}{lcc}
\hline \hline \multicolumn{1}{c}{ Objetivo } & Proposta & Implementação \\
\hline Modelo de dados & $\sqrt{ }$ & $\sqrt{ }$ \\
Modelo funcional & $\mathrm{x}$ & $\mathrm{x}$ \\
Dados não-convencionais & $\sqrt{ }$ & $\mathrm{x}$ \\
Comunicação & $\sqrt{ }$ & $\mathrm{x}$ \\
Segurança & $\sqrt{ }$ & $\sqrt{ }$ \\
Hierarquia de armazenamento & $\sqrt{ }$ & $\mathrm{x}$ \\
físico & & $\mathrm{x}$ \\
Divisão programa/dados & $\sqrt{ }$ & $\sqrt{ }$ \\
Aplicativo consulta & $\sqrt{ }$ & parcial \\
Compatibilidade DICOM & parcial & $\mathrm{x}$ \\
Impressão de dados & $\mathrm{x}$ &
\end{tabular}

O trabalho não inclui nenhum modelo funcional, o que teria sido útil no desenvolvimento do SGBD DataTORM. Na realidade, existiram duas tentativas de criação de um modelo funcional, uma utilizando diagramas de Jackson ${ }^{29}$ e outra utilizando os diagramas SADT, ${ }^{30}$ mas a demanda de trabalho na parte do modelo de dados e na sua respectiva implementação acabou por deixar de lado a criação de um modelo funcional mais formal.

Outro aspecto importante, mas que não foi abordado, é a impressão dos dados. Mencionado com destaque neste texto, a impressão dos resultados em meios físicos é extremamente importante, mas até o presente momento ainda não foi decidido como o sistema ToRM-05 realizará a impressão dos resultados. Como o sistema ToRM-005 utiliza uma impressora térmica para imprimir os resultados, um dos possíveis próximos passos nesta área é fazer com que o DataTORM seja capaz de imprimir nesta impressora.

Dos aspectos que foram abordados na forma de proposta ou modelo, mas que não foram implementados, a divisão entre programa e dados só não foi implementada por conveniência de implementação. Ao se estabelecer uma versão considerada final, basta salvar as tabelas em um arquivo .MDB diferente do arquivo que contem os demais módulos e anexar as tabelas neste último arquivo.

A utilização de dados não-convencionais e a comunicação com os demais módulos do sistema ToRM-05 foram abordados no trabalho, mas a implementação 
final ainda não satisfaz os requisitos para uma operação plena e integrada do sistema. Como já mencionado no texto, do ponto de vista da utilização dos dados nãoconvencionais, a sugestão para o próximo passo é a utilização do MS Object Packager para incluir qualquer tipo de dado não-convencional no arquivo do banco de dados. Esta solução de curto prazo, que é de implementação rápida, possibilitará a inclusão de todos os dados do ToRM-05 no banco de dados. Futuramente, uma solução mais robusta e que possibilite uma maior flexibilidade e funcionalidade no armazenamento e manipulação dos dados pode ser desenvolvida. A comunicação com os demais módulos do sistema ToRM-05 é de extrema importância, mas a sua implementação depende de uma integração com o desenvolvimento dos demais módulos do sistema.

A implementação do sistema de armazenamento de curto e de longo prazo, como proposta neste trabalho, é outra possível continuação deste trabalho. Esta implementação possibilitará o armazenamento e gerenciamento organizado de um grande volume de dados, o que será importante para a operação do sistema em uma instalação hospitalar. 


\section{REFERÊNCIAS BIBLIOGRÁFICAS}

[1] LEOTTA, D.F.; KIM, Y. Requirements for picture archiving and communications. IEEE Engineering in Medicine and Biology, p.62-69, mar. 1993.

[2] PANEPUCCI, $\mathrm{H}$. et al. Tomografia por ressonância magnética nuclear: novas imagens do corpo. Ciência Hoje, vol.4, n.20, p.46-56, set/out. 1985.

[3] SHENG, O.R.L. et al. Requirement Analysis for PACS database system. SPIE Medical Imaging IV: PACS System Design and Evaluation, vol.1234, p.842-54, 1990 .

[4] ALLEN L.; FRIEDER, O. Exploiting Database technology in the medical arena: a critical assessment of integrated systems for picture archiving and communications. IEEE Engineering in Medicine and Biology, p.42-49, mar.1992.

[5] HEDGCOCK, M.W. et al. Database requirements for PACS. SPIE Medical Imaging IV: PACS System Design and Evaluation, vol.1234, p.588-92, 1990.

[6] MUN, S.K.; FREEDMAN M.; KAPUR, R. Image management and communications for radiology: the revolutionary use of imaging modalities requires companion advances in management of films and data. IEEE Engineering in Medicine and Biology, p.70-93, mar.1993.

[7] MELO, C. P.; FERREIRA, D. P. Aspectos legais do resgistro médico eletrônico no Brasil. In: FÓRUM NACIONAL DE CIÊNCIA E TECNOLOGIA EM SAÚDE, Campos do Jordâo. Anais. 1996.

[8] CRC Handbook of Chemistry and Physics. 64.ed, CRC Press Inc., 1983-1984.

[9] PARTAIN, C.L. et al. Nuclear magnetic resonance (NMR) imaging. Saunders, 1983.

[10] CHO, Z.H. Computerized Tomography. Encyclopedia of Physical Science and Technology, v.3, p.507$44,1987$. 
[11] American College of Radiology; National Electrical Manufacturers Association. Digital Imaging and Communications in Medicine (DICOM): Version 3.0. Draft Standard, ACR-NEMA Committee, Working Group VI, Washington, DC, 1993.

[12] HORIIL, S.C. et al. DICOM: an introduction to the standard. http://www.xray.hmc.psu.edu/dicom/dico m_intro/DICOMIntro.html.

[13] ELMASRI, R.; NAVATHE, S.B. Fundamentals of database systems. Addison-Wesley - World Student Series Edition, 1989.

[14] BEALL, P.T.; HAZLEWOOD, C.F. Distinction of the normal, preneoplastic, and neoplastic states by water proton NMR relaxation times. In: PARTAIN, C.L. et al. Nuclear magnetic resonance (NMR) imaging. Saunders, 1983.

[15] FREITAS, J.C.C. Espectroscopia de alta resolução por ressonância magnética multinuclear aplicada ao estudo de Zeólitas. São Carlos, 1994. Dissertação (Mestrado) - Instituto de Física de São Carlos, Universidade de São Paulo.

[16] PANEPUCCI, H.; TANNÚS, A. The Principles of Magnetic Resonance Imaging. São Carlos, IFSC, 1994. (Apostila).

[17] BOTTOMLEY, P.A. NMR imaging techniques and applications: a review. Rev. Sci. Instrum., p.1319-35, v.53, n.9, set.1982.

[18] PYKETT, I.L. NMR imaging in medicine. Scientific American, p.54-64, v.246, n.5, mai.1982.

[19] PRESSMAN, R.S. Software engineering: a practioner's approach. 3.ed. McGraw-Hill, 1992.

[20] LEITE, J.C.S.P. Engenharia de Requisitos. Notas de aula. jan.1994.

[21] ALCOCER, P.R.C. et al. O Projeto Pacs: um sistema para visualização dinâmica e armazenamento de imagens de angiografia digital no incor. In: FÓRUM NACIONAL DE CIÊNCIA E TECNOLOGIA EM SAÚDE, Campos do Jordâo. Anais. 1996.

[22] MARTINS, M.J. Desenvolvimento de um tomógrafo de ressonância magnética: integração e otimização. São Carlos, 1995. Tese (Doutorado) - Instituto de Física de São Carlos, Universidade de São Paulo.

[23] GIMENES, I.M.S. Uma introdução ao processo de engenharia de software. Notas de aula, Maringá, jul.1994. 
[24] BROCKSCHMIDT, K. Inside OLE. 2.ed. Microsoft Press, 1995.

[25] Object Management Group. OMG Home Page. http: //www.omg.org/.

[26] Object Management Group. CORBAmed Homepage. http://www.omg.org/corbamed/home.htm.

[27] Microsoft Corporation. Microsoft Access®: Building Applications, 1994.

[28] CURTIS, B. Maintaining the software process. IEEE, p.2-8, 1992 .

[29] JACKSON, M. A. System Development. Prentice-Hall, 1983.

[30] ROSS, D. T. Structured Analysis (SA): A Language for Communicating Ideas. IEEE Transactions on Software Engineering, p.16-33, v.SE-3, n.1, jan.1977. 



\section{APÊNDICES}

APÊNDICE I - Especificações técnicas do ToRM-005

APÊNDICE II - DICOM 3.0

APÊNDICE III - Descrição formal da codificação espacial com gradientes de campo

APÊNDICE IV - Microsoft Access Versão 2.0

APÊNDICE V - Documentos do LAL do sistema ToRM-005

APÊNDICE VI - Modelo EER completo do DataTORM

APÊNDICE VII - Dicionário de dados

APÊNDICE VIII - Formulários do SGBD DataTORM 


\section{APÊNDICE I - Especificações técnicas do ToRM-005}

As tabelas deste apêndice resumem as principais especificações técnicas do sistema ToRM-005 em operação no Grupo de Ressonância do Instituto de Física de São Carlos.

Tabela 1 - Sistema computacional: controlador

\begin{tabular}{l|l}
\hline \hline Processador principal & MicroVax-3300 \\
\hline Sistema operacional & VMS - DEC Windows \\
\hline Bus & QBus-Q22 \\
\hline Array processor & AP 508 - Analogic \\
\hline Disco rígido & $140 \mathrm{MB}$ \\
\hline Disco magnético & $1,2 \mathrm{~GB}$ \\
\hline Memória RAM & $12 \mathrm{MB}$ \\
\hline Unidade de fita & TK 70 (160 MB) \\
\hline Canais de I/O & 8 seriais RS232 \\
& 1 paralela e SCSI para disco ótico remoto \\
\hline Comunicação em rede & Ethernet/TCP-IP e DecNet \\
\hline \hline Fonte: VIDOTTO, E. L. G. (Instituto de Física de São Carlos, USP - Campus de São Carlos) Comunicação \\
pessoal, 1994.
\end{tabular}

Tabela 2 - Sistema computacional: console e sistema de visualização de imagens

\begin{tabular}{l|l}
\hline \hline Processador principal & Macintosh IIfx \\
\hline Sistema operacional & AppleUnix - Xwindows \\
\hline Disco rígido & $140 \mathrm{MB}$ \\
\hline Disco removível & $40 \mathrm{MB}$ \\
\hline Memória RAM & $12 \mathrm{MB}$ \\
\hline Floppy disk & $1,4 \mathrm{MB}$ \\
\hline Monitor & $\begin{array}{l}13 \text { ”, appleColor High resolution com } 256 \\
\text { cores, 640 pixels horizontais por } 480 \text { linhas } \\
\text { verticais }\end{array}$ \\
\hline Processador e monitor de vídeo & $\begin{array}{l}19 \text { ” escala de cinza com 256 níveis (1024 } \\
\text { pontos por 768 linhas) }\end{array}$ \\
\hline \hline
\end{tabular}


Fonte: VIDOTTO, E. L. G. (Instituto de Física de São Carlos, USP - Campus de São Carlos) Comunicação pessoal, 1994.

Tabela 3 - Sistema magnético e de RF: magneto

\begin{tabular}{l|l}
\hline \hline Tipo & resistivo, acesso livre de diâmetro de $61 \mathrm{~cm}$ \\
\hline Intensidade de campo & 0,05 Tesla \\
\hline Homogeneidade & 100 ppm em $30 \mathrm{~cm}$ DSV \\
\hline \hline
\end{tabular}

Fonte: VIDOTTO, E. L. G. (Instituto de Física de São Carlos, USP - Campus de São Carlos) Comunicação pessoal, 1994.

Tabela 4 - Sistema magnético e de RF: gradiente de campo

\begin{tabular}{l|l}
\hline \hline Intensidade máxima & $0,45 \mathrm{G} / \mathrm{cm}$ \\
\hline Rise time & $700 \mu \mathrm{s}$ \\
\hline \hline
\end{tabular}

Fonte: VIDOTTO, E. L. G. (Instituto de Física de São Carlos, USP - Campus de São Carlos) Comunicação pessoal, 1994.

Tabela 5 - Sistema magnético e de RF: sistema de radiofreqüiência

\begin{tabular}{l|l}
\hline \hline Bobina de transmissão & tipo de sela de corpo inteiro, sintonia fixa \\
\hline Potência de transmissão & $1 \mathrm{~kW}$ \\
\hline Sistema de limitação da potência transmitida & $\begin{array}{l}\text { automático com duty cycle da seqüência de } \\
\text { pulsos }\end{array}$ \\
\hline Freqüência de operação & $2,35 \mathrm{MHz}$ \\
\hline Geração de RF & síntese digital direta (DDS) \\
\hline Resolução em freqüência & $9,53 \mathrm{~Hz}$ \\
\hline Estabilidade em freqüência & $<1 \mathrm{ppm}$ \\
\hline Programação para a fase da RF & contínua \\
\hline Figura de ruído (NF) do pré-amplificador & NF =1,2 dB (ganho de 50 dB) \\
\hline Bobinas de recepção & $\begin{array}{l}\text { cabeça e coluna cervical; abdomem e tórax; } \\
\text { membros e articulações; superficiais para } \\
\text { regiões particulares em geral }\end{array}$ \\
\hline \hline
\end{tabular}

Fonte: VIDOTTO, E. L. G. (Instituto de Física de São Carlos, USP - Campus de São Carlos) Comunicação pessoal, 1994.

Tabela 6 - Aquisição e processamento de dados

\begin{tabular}{l|l}
\hline \hline Principais seqüências de aquisição & $\begin{array}{l}\text { Spin-eco (SE); spin-eco multi-slice (MS); } \\
\text { gradient eco GE); inversion recovery (IR) }\end{array}$ \\
\hline Modalidades de aquisição & 2DFT single ou multislice (MS); com \\
& possibilidade de escolha do eixo de fase e de \\
& aquisição sincronizada externamente; \\
& aquisição de planos contíguos; aquisição de \\
& dados com matrizes arbitrárias (típica: \\
& 256x128) \\
\hline Campo de visão & retangular (mínimo $10 \mathrm{~cm} \times 10 \mathrm{~cm})$ \\
\hline \hline
\end{tabular}


APÊNDICE I - 3

\begin{tabular}{l|l}
\hline \hline Número de planos simultâneos & variável, típico: 16 \\
\hline Espessura do plano & variável, mínimo: $5 \mathrm{~mm}$ \\
\hline Orientação do plano & arbitrária \\
\hline Tempo ao eco (TE) & $\begin{array}{l}\text { variável: mínimo } 25 \mathrm{~ms} \text { (SE, ME, IR) e 18 } \\
\text { ms (GE) }\end{array}$ \\
\hline Tempo de repetição (TR) & variável, mínimo: 60 ms \\
\hline Matrizes de visualização & de 256 x 256 a 1024 x 1024 \\
\hline Tempo de reconstrução da imagem & $\begin{array}{l}7 \text { s (matriz } 256 \text { x 256) na CPU MicroVax- } \\
3300\end{array}$ \\
\hline Processamento da imagem & $\begin{array}{l}\text { controle de brilho e contraste; zoom; } \\
\text { medidas de distâncias e estatísticas da região } \\
\text { de interesse; relação sinal/ruído; filtragem } \\
\text { digital; histograma; introdução de } \\
\text { comentários; etc }\end{array}$ \\
\hline \hline
\end{tabular}

Fonte: VIDOTTO, E. L. G. (Instituto de Física de São Carlos, USP - Campus de São Carlos) Comunicação pessoal, 1994.

Tabela 7 - Tempo típico de exame

\begin{tabular}{|c|c|}
\hline $\begin{array}{l}16 \text { planos (multislice; } \mathrm{TR}=1000 \mathrm{~ms} \text { e } \mathrm{TE}= \\
45 \mathrm{~ms} ; 4 \text { excitações) }\end{array}$ & 9 minutos \\
\hline
\end{tabular}




\section{APÊNDICE II - DICOM 3.0}

Este apêndice contem as principais tabelas e figuras do padrão DICOM 3.0 que foram utilizados neste trabalho. Estas informações estão reproduzidas no texto desta dissertação pois, devido à extensão e complexidade do padrão DICOM 3.0, a consulta ao padrão é trabalhosa. Como este trabalho utiliza apenas algumas partes específicas do padrão, este apêndice procura facilitar a consulta a estas informações.

O modelo composto que se refere à modalidade de MRI é apresentado na primeira seção. Nela está o diagrama ER deste modelo. Em seguida, para cada Entidade de Informação (IE - Information Entity) do modelo, são apresentados os módulos IOD e seus atributos. As informações desta seção foram retiradas da parte 3 do padrão DICOM 3.0. ${ }^{1}$

A classe de serviço Query/Retrieve Service Class é apresentada na segunda seção. Esta classe estabelece um conjunto mínimo de informações que devem ser trocadas entre equipamentos durante operações de consulta. As informações desta seção foram retiradas da parte 4 do padrão DICOM 3.0.

As tabelas e figuras deste apêndice foram extraídas diretamente do texto do padrão DICOM 3.0. Os números de cada uma, indicados nos respectivos títulos, correspondem à numeração usada no texto do próprio padrão. Esta opção para a apresentação destas tabelas e figuras visa facilitar eventuais consultas ao referido texto.

Os atributos usados nas tabelas incorporadas neste apêndice são descritos na tabela a seguir: 
APÊNDICE II - 2

Tabela 1 - Significado dos atributos usados para descrever algumas estruturas do DICOM 3.0

\begin{tabular}{|c|c|}
\hline Atributo & Descrição \\
\hline$I E$ & $\begin{array}{l}\text { (Information Entity). Nome de entidades de informação } \\
\text { definidas por IODs compostos. }\end{array}$ \\
\hline Module & $\begin{array}{l}\text { Nome do conjunto de atributos, logicamente relacionados } \\
\text { entre si, de um IE ou um IOD normalizado. }\end{array}$ \\
\hline Reference & $\begin{array}{l}\text { Número da seção do texto do padrão DICOM } 3.0 \text { que faz } \\
\text { referência ao item. No caso do modelo composto para MRI, } \\
\text { a seção é da parte } 3 \text { do padrão. Já para a classe de serviço } \\
\text { Query/Retrieve Service Class, a referência é para a parte } \\
\text { número 4. }\end{array}$ \\
\hline Usage & $\begin{array}{l}\text { Indica se existe ou não a obrigatoriedade da utilização do } \\
\text { módulo. O valores usados são: } \\
\text { - M: (mandatório). A implementação deve possuir os } \\
\text { módulos mandatórios para cada IOD utilizado, e também } \\
\text { deve satisfazer todos os requisitos definidos no padrão } \\
\text { para estes módulos; } \\
\text { - C: (Condicional). São módulos mandatórios se condições } \\
\text { específicas são satisfeitas. Se as condições não forem } \\
\text { satisfeitas, estes módulos não devem ser utilizados; } \\
\text { - U: (Definido pelo usuário). Módulos opcionais cuja } \\
\text { utilização ou não é deixada a cargo do usuário. No caso } \\
\text { de se utilizar estes módulos, todos os requisitos definidos } \\
\text { no padrão devem ser satisfeitos. }\end{array}$ \\
\hline Attribute Name & Nome do atributo. \\
\hline Tag & $\begin{array}{l}\text { Identificador único para cada atributo dentro do padrão. Ele } \\
\text { é utilizado na própria codificação de mensagens para } \\
\text { identificar o atributo, e no dicionário de dados da parte } 6 \text { do } \\
\text { padrão. }\end{array}$ \\
\hline Type & $\begin{array}{l}\text { Indica a obrigatoriedade do atributo e seus valores. Os } \\
\text { valores usados são: } \\
\text { - 1: o atributo é obrigatório e deve conter um valor válido; } \\
\text { - 2: o atributo é obrigatório mas pode conter nenhum valor; } \\
\text { - 3: a presença do atributo e respectivo valor é opcional; } \\
\text { - C: quando colocado juntamente com os valores acima, } \\
\text { indica que a obrigatoriedade do atributo depende de que } \\
\text { certas condições sejam satisfeitas. } \\
\text { Os valores abaixo são usados nas descrições dos atributos } \\
\text { dos modelos de informação Query/Retrieve: } \\
\text { - U: (Unique key attribute). O atributo é chave primária; } \\
\text { - R: (Required key attribute). O atributo deve estar sempre } \\
\text { presente para poder ser usado como chave de busca; } \\
\text { - O: (Optional key attribute). A presença do atributo é } \\
\text { opcional. Ele pode ser usado como chave de busca } \\
\text { quando esta presente. }\end{array}$ \\
\hline
\end{tabular}


APÊNDICE II - 3

\begin{tabular}{l|l}
\hline \hline \multicolumn{1}{c|}{ Atributo } & \multicolumn{1}{c}{ Descrição } \\
\hline \hline Attribute Description & Descrição do atributo. \\
\hline Description & $\begin{array}{l}\text { É o próprio nome do atributo nos modelos de informação } \\
\text { Query/Retrieve. }\end{array}$ \\
\hline \hline
\end{tabular}




\section{Modelo composto para MRI}

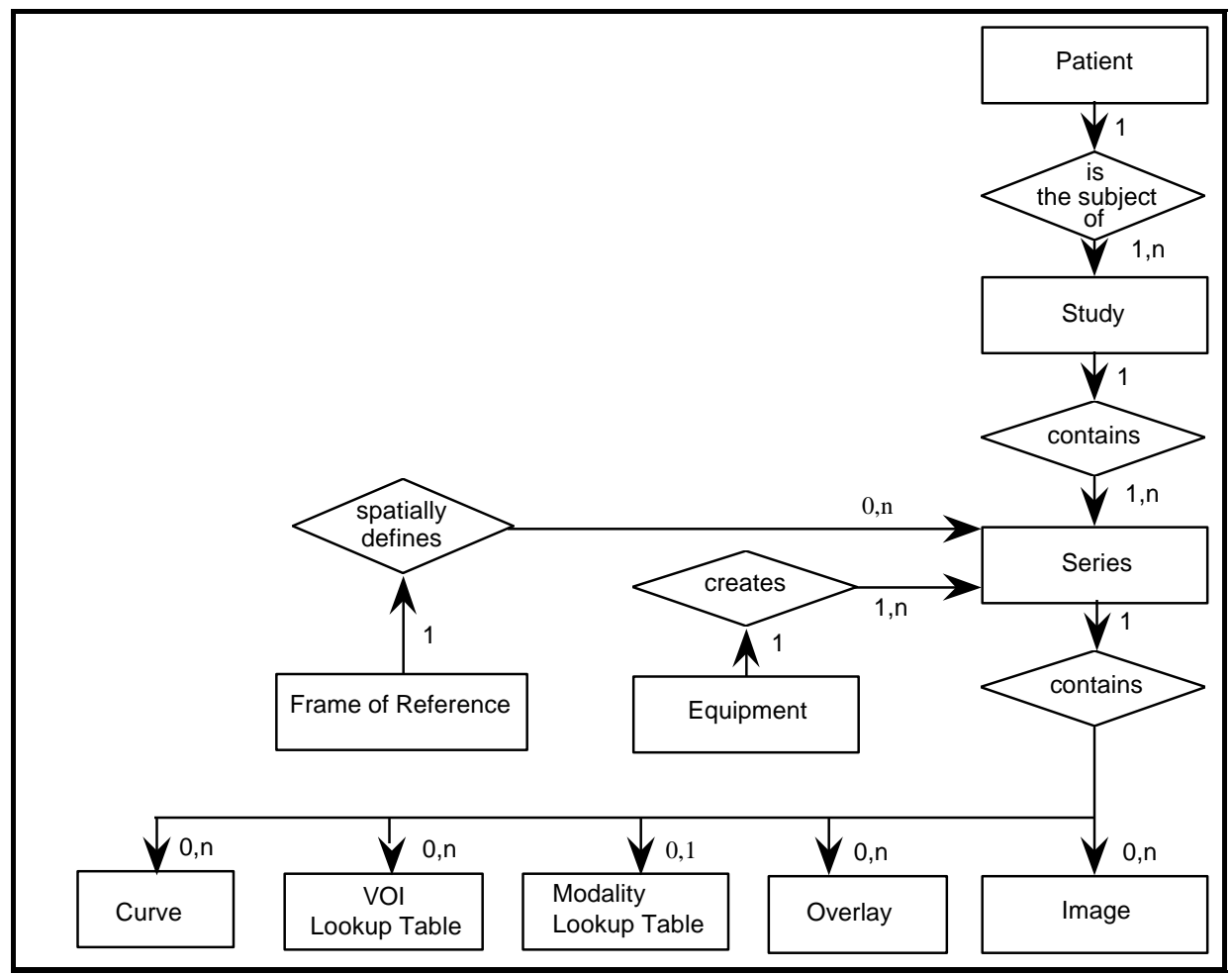

Figura A.1.2 - DICOM Composite Image IOD Information Model.

Tabela A.4.3 - MR Image IOD Modules

\begin{tabular}{|l|l|c|c|}
\hline IE & Module & Reference & Usage \\
\hline Patient & Patient & C.7.1.1 & $M$ \\
\hline \multirow{2}{*}{ Study } & General Study & $C .7 .2 .1$ & $M$ \\
\cline { 2 - 4 } & Patient Study & $C .7 .2 .2$ & $U$ \\
\hline Series & General Series & $C .7 .3 .1$ & $M$ \\
\hline \multirow{2}{*}{$\begin{array}{l}\text { Frame of } \\
\text { Reference }\end{array}$} & Frame of Reference & $C .7 .4 .1$ & $M$ \\
\hline Equipment & General Equipment & $C .7 .5 .1$ & $M$ \\
\hline \multirow{3}{*}{ Image } & General Image & $C .7 .6 .1$ & $M$ \\
\cline { 2 - 4 } & Image Plane & $C .7 .6 .2$ & $M$ \\
\cline { 2 - 4 } & Image Pixel & $C .7 .6 .3$ & $M$ \\
\cline { 2 - 4 } & & & \\
\hline
\end{tabular}




\begin{tabular}{|l|c|c|}
\hline Contrast/bolus & C.7.6.4 & $\begin{array}{c}\text { C Required if contrast } \\
\text { media was used in this } \\
\text { image }\end{array}$ \\
\hline MR Image & $C .8 .3 .1$ & $M$ \\
\hline Overlay Plane & $C .9 .2$ & $U$ \\
\hline VOI LUT & $C .11 .2$ & $U$ \\
\hline SOP Common & $C .12 .1$ & $M$ \\
\hline
\end{tabular}

Tabela C.7.1.1 - Patient Module Attributes

\begin{tabular}{|c|c|c|c|}
\hline Attribute Name & Tag & Type & Attribute Description \\
\hline Patient's Name & $(0010,0010)$ & 2 & Patient's full legal name. \\
\hline Patient ID & $(0010,0020)$ & 2 & $\begin{array}{l}\text { Primary hospital identification } \\
\text { number or code for the patient. }\end{array}$ \\
\hline Patient's Birth Date & $(0010,0030)$ & 2 & Birth date of the patient. \\
\hline Patient's Sex & $(0010,0040)$ & 2 & $\begin{array}{l}\text { Sex of the named patient. } \\
\text { Enumerated Values are: } \\
M=\text { male } \\
F=\text { female } \\
O=\text { other }\end{array}$ \\
\hline Referenced Patient Sequence & $(0008,1120)$ & 3 & $\begin{array}{l}\text { A sequence which provides reference } \\
\text { to a Patient SOP Class/Instance pair. } \\
\text { Only a single reference is allowed. } \\
\text { Encoded as sequence of items: } \\
(0008,1150) \text { and }(0008,1155)\end{array}$ \\
\hline >Referenced SOP Class UID & $(0008,1150)$ & $1 C$ & $\begin{array}{l}\text { Uniquely identifies the referenced } \\
\text { SOP Class. Required if Referenced } \\
\text { Patient Sequence }(0008,1120) \text { is sent. }\end{array}$ \\
\hline $\begin{array}{l}>\text { Referenced SOP Instance } \\
\text { UID }\end{array}$ & $(0008,1155)$ & $1 C$ & $\begin{array}{l}\text { Uniquely identifies the referenced } \\
\text { SOP Instance. Required if } \\
\text { Referenced Patient } \\
\text { Sequence }(0008,1120) \text { is sent. } \\
\end{array}$ \\
\hline Patient's Birth Time & $(0010,0032)$ & 3 & Birth time of the Patient. \\
\hline Other Patient ID & $(0010,1000)$ & 3 & $\begin{array}{l}\text { Other identification numbers or codes } \\
\text { used to identify the patient. }\end{array}$ \\
\hline Other Patient Names & $(0010,1001)$ & 3 & $\begin{array}{l}\text { Other names used to identify the } \\
\text { patient. }\end{array}$ \\
\hline Ethnic Group & $(0010,2160)$ & 3 & Ethnic group or race of the patient. \\
\hline Patient Comments & $(0010,4000)$ & 3 & $\begin{array}{l}\text { User-defined additional information } \\
\text { about the patient. }\end{array}$ \\
\hline
\end{tabular}

Tabela C.7.2.1 - General Study Module Attributes

\begin{tabular}{|l|c|c|l|}
\hline Attribute Name & Tag & Type & Attribute Description \\
\hline Study Instance UID & $(0020,000 D)$ & 1 & Unique identifier for the Study. \\
\hline Study Date & $(0008,0020)$ & 2 & Date the Study started. \\
\hline Study Time & $(0008,0030)$ & 2 & Time the Study started. \\
\hline Referring Physician's Name & $(0008,0090)$ & 2 & Patient's referring physician \\
\hline
\end{tabular}




\begin{tabular}{|c|c|c|c|}
\hline Study ID & $(0020,0010)$ & 2 & $\begin{array}{l}\text { User or equipment generated Study } \\
\text { identifier. }\end{array}$ \\
\hline Accession Number & $(0008,0050)$ & 2 & $\begin{array}{l}\text { A RIS generated number which } \\
\text { identifies the order for the Study. }\end{array}$ \\
\hline Study Description & $(0008,1030)$ & 3 & $\begin{array}{l}\text { Institution-generated description or } \\
\text { classification of the Study } \\
\text { (component) performed. }\end{array}$ \\
\hline $\begin{array}{l}\text { Name of Physician(s) Reading } \\
\text { Study }\end{array}$ & $(0008,1060)$ & 3 & Physician(s) reading the Study. \\
\hline Referenced Study Sequence & $(0008,1110)$ & 3 & $\begin{array}{l}\text { A sequence which provides reference } \\
\text { to a Study SOP Class/Instance pair. } \\
\text { Only a single reference is allowed. } \\
\text { Encoded as sequence of items: } \\
(0008,1150) \text { and }(0008,1155)\end{array}$ \\
\hline$>$ Referenced SOP Class UID & $(0008,1150)$ & $1 C$ & $\begin{array}{l}\text { Uniquely identifies the referenced } \\
\text { SOP Class. Required if Referenced } \\
\text { Study Sequence }(0008,1110) \text { is sent. }\end{array}$ \\
\hline $\begin{array}{l}>\text { Referenced SOP Instance } \\
\text { UID }\end{array}$ & $(0008,1155)$ & $1 C$ & $\begin{array}{l}\text { Uniquely identifies the referenced } \\
\text { SOP Instance. Required if } \\
\text { Referenced Study } \\
\text { Sequence }(0008,1110) \text { is sent. }\end{array}$ \\
\hline
\end{tabular}

Tabela C.7.2.2 - Patient Study Module Attributes

\begin{tabular}{|l|c|c|l|}
\hline Attribute Name & Tag & Type & Attribute Description \\
\hline $\begin{array}{l}\text { Admitting Diagnoses } \\
\text { Description }\end{array}$ & $(0008,1080)$ & 3 & $\begin{array}{l}\text { Description of the admitting } \\
\text { diagnosis (diagnoses })\end{array}$ \\
\hline Patient's Age & $(0010,1010)$ & 3 & Age of the Patient. \\
\hline Patient's Size & $(0010,1020)$ & 3 & $\begin{array}{l}\text { Length or size of the Patient, in } \\
\text { meters. }\end{array}$ \\
\hline Patient's Weight & $(0010,1030)$ & 3 & Weight of the Patient, in kilograms. \\
\hline Occupation & $(0010,2180)$ & 3 & Occupation of the Patient. \\
\hline Additional Patient's History & $(0010,21 B 0)$ & 3 & $\begin{array}{l}\text { Additional information about the } \\
\text { Patient's medical history. }\end{array}$ \\
\hline
\end{tabular}

Tabela C.7.3.1 - General Series Module Attributes

\begin{tabular}{|l|c|c|l|}
\hline Attribute Name & Tag & Type & Attribute Description \\
\hline Modality & $(0008,0060)$ & 1 & $\begin{array}{l}\text { Type of equipment that originally } \\
\text { acquired the data used to create the } \\
\text { images in this Series. } \\
\text { See C.7.3.1.1.1 for Defined Terms. }\end{array}$ \\
\hline Series Instance UID & $(0020,000 E)$ & 1 & Unique identifier of the Series. \\
\hline Series Number & $(0020,0011)$ & 2 & A number that identifies this Series. \\
\hline Laterality & $(0020,0060)$ & $2 C$ & $\begin{array}{l}\text { Laterality of (paired) body part } \\
\text { examined. Required if the body part } \\
\text { examined is a paired structure. } \\
\text { Enumerated Values: } \\
\text { R= right, L Left }\end{array}$ \\
\hline
\end{tabular}




\begin{tabular}{|c|c|c|c|}
\hline Series Date & $(0008,0021)$ & 3 & Date the Series started. \\
\hline Series Time & $(0008,0031)$ & 3 & Time the Series started. \\
\hline Performing Physicians' Name & $(0008,1050)$ & 3 & $\begin{array}{l}\text { Name of the physicians administering } \\
\text { the Series. }\end{array}$ \\
\hline Protocol Name & $(0018,1030)$ & 3 & $\begin{array}{l}\text { User-defined description of the } \\
\text { conditions under which the Series was } \\
\text { performed. }\end{array}$ \\
\hline Series Description & $(0008,103 E)$ & 3 & $\begin{array}{l}\text { User provided description of the } \\
\text { Series }\end{array}$ \\
\hline Operators' Name & $(0008,1070)$ & 3 & Technologist $(s)$ supporting the Series. \\
\hline $\begin{array}{l}\text { Referenced Study Component } \\
\text { Sequence }\end{array}$ & $(0008,1111)$ & 3 & $\begin{array}{l}\text { Uniquely identifies the Study } \\
\text { Component SOP Instances to which } \\
\text { the Series is related. }\end{array}$ \\
\hline >Referenced SOP Class UID & $(0008,1150)$ & $1 C$ & $\begin{array}{l}\text { Uniquely identifies the referenced } \\
\text { SOP Class. Required if Referenced } \\
\text { Study Component } \\
\text { Sequence }(0008,1111) \text { is sent. } \\
\end{array}$ \\
\hline $\begin{array}{l}\text { > Referenced SOP Instance } \\
\text { UID }\end{array}$ & $(0008,1155)$ & $1 C$ & $\begin{array}{l}\text { Uniquely identifies the referenced } \\
\text { SOP Instance. Required if } \\
\text { Referenced Study Component } \\
\text { Sequence }(0008,1111) \text { is sent. } \\
\end{array}$ \\
\hline Body Part Examined & $(0018,0015)$ & 3 & $\begin{array}{l}\text { Text description of the part of the } \\
\text { body examined. Defined Terms: } \\
\text { SKULL, CSPINE, TSPINE, LSPINE, } \\
\text { SSPINE, COCCYX, CHEST, } \\
\text { CLAVICLE, BREAST, ABDOMEN, } \\
\text { PELVIS, HIP, SHOULDER, ELBOW, } \\
\text { KNEE, ANKLE, HAND, FOOT, } \\
\text { EXTREMITY }\end{array}$ \\
\hline Patient Position & $(0018,5100)$ & $2 C$ & $\begin{array}{l}\text { Patient position descriptor relative to } \\
\text { the equipment. Required for CT and } \\
\text { MR images. See C.7.3.1.1.2. for } \\
\text { Defined Terms and further } \\
\text { explanation. }\end{array}$ \\
\hline Smallest Pixel Value in Series & $(0028,0108)$ & 3 & $\begin{array}{l}\text { The minimum value of all images in } \\
\text { this Series. }\end{array}$ \\
\hline Largest Pixel Value in Series & $(0028,0109)$ & 3 & $\begin{array}{l}\text { The maximum value of all images in } \\
\text { this Series. }\end{array}$ \\
\hline
\end{tabular}

Tabela C.7.4.1 - Frame Of Reference Module Attributes

\begin{tabular}{|l|c|c|l|}
\hline Attribute Name & Tag & Type & Attribute Description \\
\hline Frame of Reference UID & $(0020,0052)$ & 1 & $\begin{array}{l}\text { Uniquely identifies the frame of } \\
\text { reference for a Series. } \\
\text { See C.7.4.1.1.1 for further } \\
\text { explanation. }\end{array}$ \\
\hline
\end{tabular}




\begin{tabular}{|l|l|l|l|}
\hline Position Reference Indicator & $(0020,1040)$ & 2 & $\begin{array}{l}\text { Part of the patient's anatomy used as } \\
\text { a reference, such as the iliac crest, } \\
\text { orbital-medial, sternal notch, } \\
\text { symphysis pubis, xiphoid, lower } \\
\text { coastal margin, external auditory } \\
\text { meatus. See C.7.4.1.1.2 for further } \\
\text { explanation. }\end{array}$ \\
\hline
\end{tabular}

Tabela C.7.5.1 - General Equipment Module Attributes

\begin{tabular}{|c|c|c|c|}
\hline Attribute Name & Tag & Type & Attribute Description \\
\hline Manufacturer & $(0008,0070)$ & 2 & $\begin{array}{l}\text { Manufacturer of the equipment that } \\
\text { produced the digital images. }\end{array}$ \\
\hline Institution Name & $(0008,0080)$ & 3 & $\begin{array}{l}\text { Institution where the equipment is } \\
\text { located that produced the digital } \\
\text { images. }\end{array}$ \\
\hline Institution Address & $(0008,0081)$ & 3 & $\begin{array}{l}\text { Mailing address of the institution } \\
\text { where the equipment is located that } \\
\text { produced the digital images. }\end{array}$ \\
\hline Station Name & $(0008,1010)$ & 3 & $\begin{array}{l}\text { User defined name identifying the } \\
\text { machine that produced the digital } \\
\text { images. }\end{array}$ \\
\hline Institutional Department Name & $(0008,1040)$ & 3 & $\begin{array}{l}\text { Department in the institution where } \\
\text { the equipment is located that } \\
\text { produced the digital images }\end{array}$ \\
\hline Manufacturer's Model Name & $(0008,1090)$ & 3 & $\begin{array}{l}\text { Manufacturer's model number of the } \\
\text { equipment that produced the digital } \\
\text { images. }\end{array}$ \\
\hline Device Serial Number & $(0018,1000)$ & 3 & $\begin{array}{l}\text { Manufacturer's serial number of the } \\
\text { equipment that produced the digital } \\
\text { images. }\end{array}$ \\
\hline Software Versions & $(0018,1020)$ & 3 & $\begin{array}{l}\text { Manufacturer's designation of } \\
\text { software version of the equipment } \\
\text { that produced the digital images. }\end{array}$ \\
\hline Spatial Resolution & $(0018,1050)$ & 3 & $\begin{array}{l}\text { The inherent limiting resolution in } \\
\text { mm of the equipment for high } \\
\text { contrast objects for the data } \\
\text { gathering and reconstruction } \\
\text { technique chosen. If variable across } \\
\text { the images of the series, the value at } \\
\text { the image center. }\end{array}$ \\
\hline Date of Last Calibration & $(0018,1200)$ & 3 & $\begin{array}{l}\text { Date when the image acquisition } \\
\text { device calibration was last changed } \\
\text { in any way. Multiple entries may be } \\
\text { used for additional calibrations at } \\
\text { other times. See C.7.5.1.1.1 for } \\
\text { further explanation. }\end{array}$ \\
\hline
\end{tabular}




\begin{tabular}{|l|l|l|l|}
\hline Time of Last Calibration & $(0018,1201)$ & 3 & $\begin{array}{l}\text { Time when the image device was last } \\
\text { changed in any way. Multiple entries } \\
\text { may be used. See C.7.5.1.1.1 for } \\
\text { further explanation. }\end{array}$ \\
\hline Pixel Padding Value & $(0028,0120)$ & 3 & $\begin{array}{l}\text { Value of pixels added to non- } \\
\text { rectangular image to pad to } \\
\text { rectangular format. See C.7.5.1.1.2 } \\
\text { for further explanation. }\end{array}$ \\
\hline
\end{tabular}

Tabela C.7.6.1 - General Image Module Attributes

\begin{tabular}{|c|c|c|c|}
\hline Attribute Name & Tag & Type & Attribute Description \\
\hline Image Number & $(0020,0013)$ & 2 & A number that identifies this image \\
\hline Patient Orientation & $(0020,0020)$ & $2 C$ & $\begin{array}{l}\text { Patient direction of the rows and columns of } \\
\text { the image. Required if image is part of a } \\
\text { series which does not require the Image Plane } \\
\text { Module. See C.7.6.1.1.1 for more explanation. }\end{array}$ \\
\hline Image Date & $(0008,0023)$ & $2 C$ & $\begin{array}{l}\text { The date the image pixel data creation } \\
\text { started. } \\
\text { Required if image is part of a series in which } \\
\text { the images are temporally related. }\end{array}$ \\
\hline Image Time & $(0008,0033)$ & $2 C$ & $\begin{array}{l}\text { The time the image pixel data creation } \\
\text { started. } \\
\text { Required if image is part of a series in which } \\
\text { the images are temporally related. }\end{array}$ \\
\hline Image Type & $(0008,0008)$ & 3 & $\begin{array}{l}\text { Image identification characteristics. } \\
\text { See C.7.6.1.1.2 for Defined Terms and further } \\
\text { explanation. }\end{array}$ \\
\hline Acquisition Number & $(0020,0012)$ & 3 & $\begin{array}{l}\text { A number identifying the single continuous } \\
\text { gathering of data over a period of time which } \\
\text { resulted in this image }\end{array}$ \\
\hline Acquisition Date & $(0008,0022)$ & 3 & $\begin{array}{l}\text { The date the acquisition of data that resulted } \\
\text { in this image started }\end{array}$ \\
\hline Acquisition Time & $(0008,0032)$ & 3 & $\begin{array}{l}\text { The time the acquisition of data that resulted } \\
\text { in this image started }\end{array}$ \\
\hline $\begin{array}{l}\text { Referenced Image } \\
\text { Sequence }\end{array}$ & $(0008,1140)$ & 3 & $\begin{array}{l}\text { A sequence which provides reference to a set } \\
\text { of Image SOP Class/Instance identifying } \\
\text { other images significantly related to this } \\
\text { image (e.g. post-localizer CT image) Encoded } \\
\text { as sequence of items: }(0008,1150) \text { and } \\
(0008,1155)\end{array}$ \\
\hline $\begin{array}{l}\text { >Referenced SOP Class } \\
\text { UID }\end{array}$ & $(0008,1150)$ & $1 C$ & $\begin{array}{l}\text { Uniquely identifies the referenced SOP Class. } \\
\text { Required if Referenced Image } \\
\text { Sequence }(0008,1140) \text { is sent. }\end{array}$ \\
\hline $\begin{array}{l}\text { > Referenced SOP } \\
\text { Instance UID }\end{array}$ & $(0008,1155)$ & $1 C$ & $\begin{array}{l}\text { Uniquely identifies the referenced SOP } \\
\text { Instance. Required if Reference Image } \\
\text { Sequence }(0008,1140) \text { is sent. }\end{array}$ \\
\hline
\end{tabular}




\begin{tabular}{|l|c|c|l|}
\hline Derivation Description & $(0008,2111)$ & 3 & $\begin{array}{l}\text { A text description of how this image was } \\
\text { derived. See C.7.6.1.1.3 for more explanation. }\end{array}$ \\
\hline Source Image Sequence & $(0008,2112)$ & 3 & $\begin{array}{l}\text { A sequence which identifies the set of Image } \\
\text { SOP Class/Instance pairs of the Images which } \\
\text { were used to derive this Image. } \\
\text { Encoded as sequence of items: }(0008,1150) \\
\text { and }(0008,1155) \text { See C.7.6.1.1.4 for further } \\
\text { explanation. }\end{array}$ \\
\hline $\begin{array}{l}>\text { Referenced SOP Class } \\
\text { UID }\end{array}$ & $(0008,1150)$ & $1 C$ & $\begin{array}{l}\text { Uniquely identifies the referenced SOP Class. } \\
\text { Required if Source Image } \\
\text { Sequence(0008,2112) is sent. }\end{array}$ \\
\hline $\begin{array}{l}>\text { Referenced SOP } \\
\text { Instance UID }\end{array}$ & $(0008,1155)$ & $1 C$ & $\begin{array}{l}\text { Uniquely identifies the referenced SOP } \\
\text { Instance. Required if Source Image } \\
\text { Sequence(0008,2112) is sent. }\end{array}$ \\
\hline Images in Acquisition & $(0020,1002)$ & 3 & $\begin{array}{l}\text { Number of images that resulted from this } \\
\text { acquisition of data }\end{array}$ \\
\hline Image Comments & $(0020,4000)$ & 3 & \begin{tabular}{l} 
User-defined comments about the image \\
\hline
\end{tabular}
\end{tabular}

Tabela C.7.6.2 - Image Plane Module Attributes

\begin{tabular}{|l|c|c|l|}
\hline Attribute Name & Tag & Type & Attribute Description \\
\hline Pixel Spacing & $(0028,0030)$ & 1 & $\begin{array}{l}\text { Physical distance in the patient between the center of } \\
\text { each pixel, specified by a numeric pair - row value } \\
\text { (delimiter) column value in mm } .\end{array}$ \\
\hline $\begin{array}{l}\text { Image } \\
\text { Orientation } \\
\text { (Patient) }\end{array}$ & $(0020,0037)$ & 1 & $\begin{array}{l}\text { The direction cosines of the first row and the first } \\
\text { column with respect to the patient. See C.7.6.2.2.1 for } \\
\text { further explanation. }\end{array}$ \\
\hline $\begin{array}{l}\text { Image Position } \\
(\text { Patient })\end{array}$ & $(0020,0032)$ & 1 & $\begin{array}{l}\text { The } x, y \text {, and } z \text { coordinates of the upper left hand } \\
\text { corner } \text { (first pixel transmitted }) \text { of the image. See } \\
\text { C.7.6.2.2.1 for further explanation. }\end{array}$ \\
\hline Slice Thickness & $(0018,0050)$ & 2 & Nominal slice thickness, in mm. \\
\hline Slice Location & $(0020,1041)$ & 3 & $\begin{array}{l}\text { Relative position of exposure expressed in mm. } \\
\text { C.7.6.2.2.2 for further explanation. }\end{array}$ \\
\hline
\end{tabular}

Tabela C.7.6.3 - Image Pixel Module Attributes

\begin{tabular}{|l|c|c|l|}
\hline Attribute Name & Tag & Type & Attribute Description \\
\hline Samples per Pixel & $(0028,0002)$ & 1 & $\begin{array}{l}\text { Number of samples (planes) in this } \\
\text { image. See C.7.6.3.1.1 for further } \\
\text { explanation. }\end{array}$ \\
\hline Photometric Interpretation & $(0028,0004)$ & 1 & $\begin{array}{l}\text { Specifies the intended interpretation } \\
\text { of the pixel data. See C.7.6.3.1.2 for } \\
\text { further explanation. }\end{array}$ \\
\hline Rows & $(0028,0010)$ & 1 & Number of rows in the image. \\
\hline Columns & $(0028,0011)$ & 1 & Number of columns in the image \\
\hline
\end{tabular}




\begin{tabular}{|c|c|c|c|}
\hline Bits Allocated & $(0028,0100)$ & 1 & $\begin{array}{l}\text { Number of bits allocated for each } \\
\text { pixel sample. Each sample shall have } \\
\text { the same number of bits allocated. } \\
\text { See Part } 5 \text { of the DICOM Standard } \\
\text { for further explanation. }\end{array}$ \\
\hline Bits Stored & $(0028,0101)$ & 1 & $\begin{array}{l}\text { Number of bits stored for each pixel } \\
\text { sample. Each sample shall have the } \\
\text { same number of bits stored. See Part } \\
5 \text { of the DICOM Standard for further } \\
\text { explanation. }\end{array}$ \\
\hline High Bit & $(0028,0102)$ & 1 & $\begin{array}{l}\text { Most significant bit for pixel sample } \\
\text { data. Each sample shall have the } \\
\text { same high bit. See Part } 5 \text { of the } \\
\text { DICOM Standard for further } \\
\text { explanation. }\end{array}$ \\
\hline Pixel Representation & $(0028,0103)$ & 1 & $\begin{array}{l}\text { Data representation of the pixel } \\
\text { samples. Each sample shall have the } \\
\text { same pixel representation. } \\
\text { Enumerated Values: } \\
\text { OOOOH = unsigned integer. } \\
\text { OOO1H = 2's complement }\end{array}$ \\
\hline Pixel Data & $(7 F E 0,0010)$ & 1 & $\begin{array}{l}\text { A data stream of the pixel samples } \\
\text { which comprise the Image. See } \\
\text { C.7.6.3.1.4 for further explanation. }\end{array}$ \\
\hline Planar Configuration & $(0028,0006)$ & $1 C$ & $\begin{array}{l}\text { Indicates whether the pixel data are } \\
\text { sent color-by-plane or color-by-pixel. } \\
\text { Required if Samples per Pixel } \\
\text { (0028,0002) has a value greater than } \\
\text { 1. See C.7.6.3.1.3 for further } \\
\text { explanation. }\end{array}$ \\
\hline Pixel Aspect Ratio & $(0028,0034)$ & $1 C$ & $\begin{array}{l}\text { Ratio of the real world spacing of the } \\
\text { pixels in the image, specified by a } \\
\text { numeric pair: row value (delimiter) } \\
\text { column value. } \\
\text { Required if the aspect ratio is not } \triangle I \\
\text { and the Image Plane Module is not } \\
\text { applicable to this Image. }\end{array}$ \\
\hline Smallest Image Pixel Value & $(0028,0106)$ & 3 & $\begin{array}{l}\text { The minimum actual pixel value } \\
\text { encountered in this image. }\end{array}$ \\
\hline Largest Image Pixel Value & $(0028,0107)$ & 3 & $\begin{array}{l}\text { The maximum actual pixel value } \\
\text { encountered in this image. }\end{array}$ \\
\hline $\begin{array}{l}\text { Red Palette Color Lookup } \\
\text { Table Descriptor }\end{array}$ & $(0028,1101)$ & $1 \mathrm{C}$ & $\begin{array}{l}\text { Specifies the format of the Red } \\
\text { Palette Color Lookup Table Data } \\
\text { (0028,1201) Required if Photometric } \\
\text { Interpretation }(0028,0004) \text { has a } \\
\text { value of PALETTE COLOR or } \\
\text { ARGB. See C.7.6.3.1.5 for further } \\
\text { explanation. }\end{array}$ \\
\hline
\end{tabular}




\begin{tabular}{|c|c|c|c|}
\hline $\begin{array}{l}\text { Green Palette Color Lookup } \\
\text { Table Descriptor }\end{array}$ & $(0028,1102)$ & $1 \mathrm{C}$ & $\begin{array}{l}\text { Specifies the format of the Green } \\
\text { Palette Color Lookup Table Data } \\
\text { (0028,1202) Required if Photometric } \\
\text { Interpretation }(0028,0004) \text { has a } \\
\text { value of PALETTE COLOR or } \\
\text { ARGB. See C.7.6.3.1.5 for further } \\
\text { explanation. }\end{array}$ \\
\hline $\begin{array}{l}\text { Blue Palette Color Lookup } \\
\text { Table Descriptor }\end{array}$ & $(0028,1103)$ & $1 \mathrm{C}$ & $\begin{array}{l}\text { Specifies the format of the Blue } \\
\text { Palette Color Lookup Table Data } \\
\text { (0028,1203) Required if Photometric } \\
\text { Interpretation (0028,0004) has a } \\
\text { value of PALETTE COLOR or } \\
\text { ARGB. See C.7.6.3.1.5 for further } \\
\text { explanation. }\end{array}$ \\
\hline $\begin{array}{l}\text { Red Palette Color Lookup } \\
\text { Table Data }\end{array}$ & $(0028,1201)$ & $1 \mathrm{C}$ & $\begin{array}{l}\text { Red Palette Color Lookup Table } \\
\text { Data. } \\
\text { Required if Photometric } \\
\text { Interpretation (0028,0004) has a } \\
\text { value of PALETTE COLOR or } \\
\text { ARGB. See C.7.6.3.1.6 for further } \\
\text { explanation. }\end{array}$ \\
\hline $\begin{array}{l}\text { Green Palette Color Lookup } \\
\text { Table Data }\end{array}$ & $(0028,1202)$ & $1 C$ & $\begin{array}{l}\text { Green Palette Color Lookup Table } \\
\text { Data. Required if Photometric } \\
\text { Interpretation (0028,0004) has a } \\
\text { value of PALETTE COLOR or } \\
\text { ARGB. See C.7.6.3.1.6 for further } \\
\text { explanation. }\end{array}$ \\
\hline $\begin{array}{l}\text { Blue Palette Color Lookup } \\
\text { Table Data }\end{array}$ & $(0028,1203)$ & $1 \mathrm{C}$ & $\begin{array}{l}\text { Blue Palette Color Lookup Table } \\
\text { Data. Required if Photometric } \\
\text { Interpretation (0028,0004) has a } \\
\text { value of PALETTE COLOR or } \\
\text { ARGB. } \\
\text { See C.7.6.3.1.6 for further } \\
\text { explanation. }\end{array}$ \\
\hline
\end{tabular}

Tabela C.7.6.4 - Contrast/Bolus Module Attributes

\begin{tabular}{|l|c|c|l|}
\hline Attribute Name & Tag & Type & Attribute Description \\
\hline Contrast/Bolus Agent & $(0018,0010)$ & 2 & Contrast or bolus agent \\
\hline Contrast/Bolus Route & $(0018,1040)$ & 3 & $\begin{array}{l}\text { Administration route of contrast } \\
\text { agent }\end{array}$ \\
\hline Contrast/Bolus Volume & $(0018,1041)$ & 3 & $\begin{array}{l}\text { Volume of contrast agent in cubic } \\
\text { centimeters }\end{array}$ \\
\hline Contrast/Bolus Start Time & $(0018,1042)$ & 3 & Time of start of injection \\
\hline Contrast/Bolus Stop Time & $(0018,1043)$ & 3 & Time of end of contrast injection \\
\hline Contrast/Bolus Total Dose & $(0018,1044)$ & 3 & $\begin{array}{l}\text { Total amount of the active ingredient } \\
\text { in injection }\end{array}$ \\
\hline
\end{tabular}


Tabela C.8.3.1 - MR Image Module Attributes

\begin{tabular}{|c|c|c|c|}
\hline Attribute Name & Tag & Type & Attribute Description \\
\hline Image Type & $(0008,0008)$ & 1 & $\begin{array}{l}\text { Image identification characteristics. } \\
\text { See C.8.3.1.1.1 for specialization. }\end{array}$ \\
\hline Samples per Pixel & $(0028,0002)$ & 1 & $\begin{array}{l}\text { Number of samples(planes) in this } \\
\text { image. See C.8.3.1.1.2 for } \\
\text { specialization. }\end{array}$ \\
\hline Photometric Interpretation & $(0028,0004)$ & 1 & $\begin{array}{l}\text { Specifies the intended interpretation } \\
\text { of the pixel data. See C.8.3.1.1.3 for } \\
\text { specialization. }\end{array}$ \\
\hline Bits Allocated & $(0028,0100)$ & 1 & $\begin{array}{l}\text { Number of bits allocated for each } \\
\text { pixel sample. Each sample shall have } \\
\text { the same number of bits allocated. } \\
\text { See C.8.3.1.1.4 for specialization. }\end{array}$ \\
\hline Scanning Sequence & $(0018,0020)$ & 1 & $\begin{array}{l}\text { Description of the type of data taken. } \\
\text { Enumerated Values: } \\
\text { SE = Spin Echo } \\
I R=\text { Inversion Recovery } \\
\text { GR = Gradient Recalled } \\
E P=\text { Echo Planar } \\
R M=\text { Research Mode } \\
\text { NOTE: Multi-valued, but not all } \\
\text { combinations are valid (e.g. SE/GR, } \\
\text { etc.). }\end{array}$ \\
\hline Sequence Variant & $(0018,0021)$ & $\overline{1}$ & $\begin{array}{l}\text { Variant of the Scanning Sequence. } \\
\text { Defined Terms: } \\
\text { SK = segmented } k \text {-space } \\
M T C=\text { magnetization transfer } \\
\text { contrast } \\
S S=\text { steady state } \\
T R S S=\text { time reversed steady state } \\
S P \quad=\text { spoiled } \\
M P=\text { MAG prepared } \\
O S P=\text { oversampling phase } \\
N O N E=\text { no sequence variant }\end{array}$ \\
\hline Scan Options & $(0018,0022)$ & 2 & $\begin{array}{l}\text { Parameters of scanning sequence. } \\
\text { Defined Terms: } \\
P E R=\text { Phase Encode Reordering } \\
R G=\text { Respiratory Gating } \\
C G=\text { Cardiac Gating } \\
P P G=\text { Peripheral Pulse Gating } \\
F C=\text { Flow Compensation } \\
P F F=\text { Partial Fourier }- \text { Frequency } \\
P F P=\text { Partial Fourier }- \text { Phase } \\
S P=\text { Spatial Presaturation } \\
F S=\text { Fat Saturation }\end{array}$ \\
\hline
\end{tabular}




\begin{tabular}{|c|c|c|c|}
\hline MR Acquisition Type & $(0018,0023)$ & 2 & $\begin{array}{l}\text { Identification of data encoding } \\
\text { scheme. Enumerated Values: } \\
2 D=\text { frequency } x \text { phase } \\
3 D=\text { frequency } x \text { phase } x \text { phase }\end{array}$ \\
\hline Repetition Time & $(0018,0080)$ & $2 C$ & $\begin{array}{l}\text { The period of time in msec between } \\
\text { the beginning of a pulse sequence } \\
\text { and the beginning of the succeeding } \\
\text { (essentially identical) pulse sequence. } \\
\text { Required except when Scanning } \\
\text { Sequence }(0018,0020) \text { is EP and } \\
\text { Sequence Variant(0018,0021) is not } \\
\text { SK. }\end{array}$ \\
\hline Echo Time & $(0018,0081)$ & 2 & $\begin{array}{l}\text { Time in ms between the middle of the } \\
\text { excitation pulse and the peak of the } \\
\text { echo produced }(k x=0) \text {. In the case of } \\
\text { segmented } k \text {-space, the TE(eff) is the } \\
\text { time between the middle of the } \\
\text { excitation pulse to the peak of the } \\
\text { echo that is used to cover the center } \\
\text { of } k \text {-space (i.e.-kx=0,ky=0). }\end{array}$ \\
\hline Echo Train Length & $(0018,0091)$ & 2 & $\begin{array}{l}\text { Number of lines in k-space acquired } \\
\text { per excitation per image. }\end{array}$ \\
\hline Inversion Time & $(0018,0082)$ & $2 C$ & $\begin{array}{l}\text { Time in msec after the middle of } \\
\text { inverting RF pulse to middle of } \\
\text { excitation pulse to detect the amount } \\
\text { of longitudinal magnetization } \\
\text { Required if Scanning Sequence } \\
(0018,0020) \text { has values of IR. }\end{array}$ \\
\hline Trigger Time & $(0018,1060)$ & $2 C$ & $\begin{array}{l}\text { Time, in msec, between peak of the } R \\
\text { wave and the peak of the echo } \\
\text { produced. In the case of segmented } k \text { - } \\
\text { space, the TE(eff) is the time between } \\
\text { the peak of the echo that is used to } \\
\text { cover the center of k-space. Required } \\
\text { for Scan Options }(0018,0022) \text { which } \\
\text { include heart gating (e.g. CG, PPG, } \\
\text { etc.) }\end{array}$ \\
\hline Sequence Name & $(0018,0024)$ & 3 & $\begin{array}{l}\text { User defined name for the Scanning } \\
\text { Sequence }(0018,0020) \text { and Sequence } \\
\text { Variant }(0018,0021) \text { combination. }\end{array}$ \\
\hline Angio Flag & $(0018,0025)$ & 3 & $\begin{array}{l}\text { Angio Image Indicator. Primary } \\
\text { image for Angio processing. } \\
\text { Enumerated Values: } \\
Y=\text { Image is Angio } \\
N=\text { Image is not Angio }\end{array}$ \\
\hline Number of Averages & $(0018,0083)$ & 3 & $\begin{array}{l}\text { Number of times a given pulse } \\
\text { sequence is repeated before any } \\
\text { parameter is changed }\end{array}$ \\
\hline
\end{tabular}




\begin{tabular}{|c|c|c|c|}
\hline Imaging Frequency & $(0018,0084)$ & 3 & $\begin{array}{l}\text { Precession frequency in } \mathrm{MHz} \text { of the } \\
\text { nucleus being addressed }\end{array}$ \\
\hline Imaged Nucleus & $(0018,0085)$ & 3 & $\begin{array}{l}\text { Nucleus that is resonant at the } \\
\text { imaging frequency. } \\
\text { Examples: } 31 \mathrm{P}, 1 \mathrm{H}\end{array}$ \\
\hline Echo Number & $(0018,0086)$ & 3 & $\begin{array}{l}\text { The echo number used in generating } \\
\text { this image. In the case of segmented } \\
k \text {-space, it is the effective Echo } \\
\text { Number. }\end{array}$ \\
\hline Magnetic Field Strength & $(0018,0087)$ & 3 & $\begin{array}{l}\text { Nominal field strength of MR } \\
\text { magnet, in Tesla }\end{array}$ \\
\hline Spacing Between Slices & $(0018,0088)$ & 3 & $\begin{array}{l}\text { Spacing between slices, in mm. The } \\
\text { spacing is measured from the center- } \\
\text { to-center of each slice. }\end{array}$ \\
\hline $\begin{array}{l}\text { Number of Phase Encoding } \\
\text { Steps }\end{array}$ & $(0018,0089)$ & 3 & $\begin{array}{l}\text { Total number of lines in } k \text {-space in } \\
\text { the ' } y \text { ' direction collected during } \\
\text { acquisition. }\end{array}$ \\
\hline Percent Sampling & $(0018,0093)$ & 3 & $\begin{array}{l}\text { Fraction of acquisition matrix lines } \\
\text { acquired, expressed as a percent. }\end{array}$ \\
\hline Percent Phase Field of View & $(0018,0094)$ & 3 & $\begin{array}{l}\text { Ratio of field of view dimension in } \\
\text { phase direction to field of view } \\
\text { dimension in frequency direction, } \\
\text { expressed as a percent. }\end{array}$ \\
\hline Pixel Bandwidth & $(0018,0095)$ & 3 & $\begin{array}{l}\text { Reciprocal of the total sampling } \\
\text { period, in hertz per pixel. }\end{array}$ \\
\hline Nominal Interval & $(0018,1062)$ & 3 & $\begin{array}{l}\text { Average } R \text { - } R \text { interval used for the } \\
\text { scant, in } m s e c\end{array}$ \\
\hline Beat Rejection Flag & $(0018,1080)$ & 3 & $\begin{array}{l}\text { Beat length sorting has been applied. } \\
\text { Enumerated Values: } \\
Y=\text { yes } \\
N=\text { no }\end{array}$ \\
\hline Low $R-R$ Value & $(0018,1081)$ & 3 & $\begin{array}{l}R-R \text { interval low limit for beat } \\
\text { rejection, in msec }\end{array}$ \\
\hline High $R-R$ Value & $(0018,1082)$ & 3 & $\begin{array}{l}R-R \text { interval high limit for beat } \\
\text { rejection, in msec }\end{array}$ \\
\hline Intervals Acquired & $(0018,1083)$ & 3 & Number of $R$ - $R$ intervals acquired. \\
\hline Intervals Rejected & $(0018,1084)$ & 3 & Number of $R-R$ intervals rejected. \\
\hline PVC Rejection & $(0018,1085)$ & 3 & $\begin{array}{l}\text { Description of type of } P V C \text { rejection } \\
\text { criteria used. }\end{array}$ \\
\hline Skip Beats & $(0018,1086)$ & 3 & $\begin{array}{l}\text { Number of beats skipped after a } \\
\text { detected arrhythmia }\end{array}$ \\
\hline Heart Rate & $(0018,1088)$ & 3 & Beats per minute. \\
\hline Cardiac Number of Images & $(0018,1090)$ & 3 & Number of Images per cardiac cycle. \\
\hline Trigger Window & $(0018,1094)$ & 3 & $\begin{array}{l}\text { Percent of } R-R \text { interval, based on } \\
\text { Heart Rate }(0018,1088), \text { prescribed } \\
\text { as a window for a valid/usable } \\
\text { trigger. }\end{array}$ \\
\hline
\end{tabular}




\begin{tabular}{|c|c|c|c|}
\hline Reconstruction Diameter & $(0018,1100)$ & 3 & $\begin{array}{l}\text { Diameter in mm. of the region from } \\
\text { within which data were used in } \\
\text { creating the reconstruction of the } \\
\text { image. Data may exist outside this } \\
\text { region and portions of the patient } \\
\text { may exist outside this region. }\end{array}$ \\
\hline Receiving Coil & $(0018,1250)$ & 3 & Receiving coil used \\
\hline Transmitting Coil & $(0018,1251)$ & 3 & Transmitting coil used \\
\hline Acquisition Matrix & $(0018,1310)$ & 3 & $\begin{array}{l}\text { Dimensions of the acquired } \\
\text { frequency/phase data before } \\
\text { reconstruction. Multi-valued: } \\
\text { frequency rowsyrequency } \\
\text { columns phase rows phase columns. }\end{array}$ \\
\hline Phase Encoding Direction & $(0018,1312)$ & 3 & $\begin{array}{l}\text { The axis of phase encoding with } \\
\text { respect to the image. } \\
\text { Enumerated Values: } \\
\text { ROW = phase encoded in rows } \\
\text { COL = phase encoded in columns }\end{array}$ \\
\hline Flip Angle & $(0018,1314)$ & 3 & $\begin{array}{l}\text { Steady state angle in degrees to } \\
\text { which the magnetic vector is flipped } \\
\text { from the magnetic vector of the } \\
\text { primary field. }\end{array}$ \\
\hline$S A R$ & $(0018,1316)$ & 3 & $\begin{array}{l}\text { Calculated whole body Specific } \\
\text { Absorption Rate in watts/kilogram. }\end{array}$ \\
\hline Variable Flip Angle Flag & $(0018,1315)$ & 3 & $\begin{array}{l}\text { Flip angle variation applied during } \\
\text { image acquisition. Enumerated } \\
\text { Values: } \\
\quad Y=\text { yes } \\
\quad N=\text { no }\end{array}$ \\
\hline$d B / d t$ & $(0018,1318)$ & 3 & $\begin{array}{l}\text { The rate of change of the gradient } \\
\text { coil magnetic flux density with time } \\
(T / s) \text {. }\end{array}$ \\
\hline Temporal Position Identifier & $(0020,0100)$ & 3 & $\begin{array}{l}\text { Temporal order of a dynamic or } \\
\text { functional set of Images. }\end{array}$ \\
\hline Number of Temporal Positions & $(0020,0105)$ & 3 & $\begin{array}{l}\text { Total number of temporal positions } \\
\text { prescribed. }\end{array}$ \\
\hline Temporal Resolution & $(0020,0110)$ & 3 & $\begin{array}{l}\text { Time delta between Images in a } \\
\text { dynamic of functional set of Images. }\end{array}$ \\
\hline
\end{tabular}

Tabela C.9.2 - Overlay Plane Module Attributes

\begin{tabular}{|l|c|c|l|}
\hline Attribute Name & Tag & Type & Attribute Description \\
\hline Rows & $(60 x x, 0010)$ & 1 & Number of rows in Overlay. \\
\hline Columns & $(60 x x, 0011)$ & 1 & Number of columns in Overlay. \\
\hline
\end{tabular}




\begin{tabular}{|c|c|c|c|}
\hline Overlay Type & $(60 x x, 0040)$ & 1 & $\begin{array}{l}\text { Indicates whether this overlay } \\
\text { represents a region of interest or } \\
\text { other graphics. } \\
\text { Enumerated Values: } \\
G=\text { Graphics } \\
R=\text { ROI. }\end{array}$ \\
\hline Origin & $(60 x x, 0050)$ & 1 & $\begin{array}{l}\text { Location of first overlay point with } \\
\text { respect to pixels in the image, given } \\
\text { as row and column. }\end{array}$ \\
\hline Bits Allocated & $(60 x x, 0100)$ & 1 & $\begin{array}{l}\text { Number of bits allocated in the } \\
\text { overlay }\end{array}$ \\
\hline Bit Position & $(60 x x, 0102)$ & 1 & Bit in which overlay is stored \\
\hline Overlay Data & $(60 x x, 3000)$ & $1 C$ & $\begin{array}{l}\text { Overlay data shall be contained in } \\
\text { this Attribute or imbedded with the } \\
\text { image pixel data in Group } 7 F E 0 . \\
\text { Required if overlay data are in this } \\
\text { Group. See C.9.2.1.1 for further } \\
\text { explanation }\end{array}$ \\
\hline ROI Area & $(60 x x, 1301)$ & 3 & $\begin{array}{l}\text { Number of pixels in ROI area. See } \\
\text { C.9.2.1.2 for further explanation. }\end{array}$ \\
\hline ROI Mean & $(60 x x, 1302)$ & 3 & $\begin{array}{l}\text { ROI mean. See C.9.2.1.2 for further } \\
\text { explanation. }\end{array}$ \\
\hline ROI Standard Deviation & $(60 x x, 1303)$ & 3 & $\begin{array}{l}\text { ROI standard deviation. See } \\
\text { C.9.2.1.2 for further explanation. }\end{array}$ \\
\hline Overlay Descriptor - Gray & $(60 x x, 1100)$ & 3 & $\begin{array}{l}\text { The number of bits in each entry of } \\
(60 x x, 1200)\end{array}$ \\
\hline Overlay Descriptor - Red & $(60 x x, 1101)$ & 3 & $\begin{array}{l}\text { The number of bits in each entry of } \\
(60 x x, 1201)\end{array}$ \\
\hline Overlay Descriptor - Green & $(60 x x, 1102)$ & 3 & $\begin{array}{l}\text { The number of bits in each entry of } \\
(60 x x, 1202)\end{array}$ \\
\hline Overlay Descriptor - Blue & $(60 x x, 1103)$ & 3 & $\begin{array}{l}\text { The number of bits in each entry of } \\
(60 x x, 1203)\end{array}$ \\
\hline Overlays- Gray & $(60 x x, 1200)$ & 3 & $\begin{array}{l}\text { Overlay bits. A value of } 1 \text { indicted } \\
\text { that the pixel is part of the overlay } \\
\text { plane. }\end{array}$ \\
\hline Overlays - Red & $(60 x x, 1201)$ & 3 & $\begin{array}{l}\text { Overlay bits. A value of } 1 \text { indicted } \\
\text { that the pixel is part of the overlay } \\
\text { plane. }\end{array}$ \\
\hline Overlays - Green & $(60 x x, 1202)$ & 3 & $\begin{array}{l}\text { Overlay bits. A value of } 1 \text { indicted } \\
\text { that the pixel is part of the overlay } \\
\text { plane. }\end{array}$ \\
\hline Overlays- Blue & $(60 x x, 1203)$ & 3 & $\begin{array}{l}\text { Overlay bits. A value of } 1 \text { indicted } \\
\text { that the pixel is part of the overlay } \\
\text { plane. }\end{array}$ \\
\hline
\end{tabular}


Tabela C.11.2 - VOI LUT Module Attributes

\begin{tabular}{|l|l|l|l|}
\hline Attribute Name & \multicolumn{1}{|c|}{ Tag } & Type & Attribute Description \\
\hline VOI LUT Sequence & $(0028,3010)$ & 3 & Defines a sequence of VOI LUTs. \\
\hline$>$ LUT Descriptor & $(0028,3002)$ & $1 C$ & $\begin{array}{l}\text { Specifies the format of the LUT } \\
\text { Data in this Sequence. See } \\
\text { C.11.1.1 for further explanation. } \\
\text { Required if the VOI LUT Sequence } \\
\text { (0028,3010) is sent. }\end{array}$ \\
\hline$>$ LUT Explanation & $(0028,3003)$ & 3 & $\begin{array}{l}\text { Free form text explanation of the } \\
\text { meaning of the LUT. }\end{array}$ \\
\hline$>$ LUT Data & $(0028,3006)$ & $1 C$ & $\begin{array}{l}\text { LUT Data in this Sequence. If } \\
\text { padding is required to complete a } \\
\text { full word, the padding value shall } \\
\text { be 0. Required if the VOI LUT } \\
\text { Sequence(O028,3010) is sent. }\end{array}$ \\
\hline Window Center & $(0028,1050)$ & 3 & $\begin{array}{l}\text { Window Center for display. See } \\
\text { C.11.2.1.3 for further explanation. }\end{array}$ \\
\hline Window Width & $(0028,1051)$ & $1 C$ & $\begin{array}{l}\text { Window Width for display. See } \\
\text { C.11.2.1.3 for further explanation. } \\
\text { Required if Window Center } \\
\text { (0028,1050) is sent. }\end{array}$ \\
\hline $\begin{array}{l}\text { Window Center \& Width } \\
\text { Explanation }\end{array}$ & $\begin{array}{l}\text { Free form explanation of the } \\
\text { meaning of the Window Center and } \\
\text { Width. Multiple values correspond } \\
\text { to multiple Window Center and } \\
\text { Width values. }\end{array}$ \\
\hline
\end{tabular}

Tabela C.12.1 - SOP Common Module Attributes

\begin{tabular}{|l|c|c|l|}
\hline Attribute Name & Tag & Type & Attribute Description \\
\hline SOP Class UID & $(0008,0016)$ & $\begin{array}{c}\text { see } \\
\text { C.12.1.1.1 }\end{array}$ & $\begin{array}{l}\text { Uniquely identifies the SOP Class. } \\
\text { See Part 4 of the DICOM Standard. }\end{array}$ \\
\hline SOP Instance UID & $(0008,0018)$ & $\begin{array}{c}\text { see } \\
\text { C.12.1.1.1 }\end{array}$ & $\begin{array}{l}\text { Uniquely identifies the SOP Instance. } \\
\text { See Part 4 of the DICOM Standard. }\end{array}$ \\
\hline Specific Character Set & $(0008,0005)$ & $1 C$ & $\begin{array}{l}\text { Character Set that expands or } \\
\text { replaces the Basic Graphic Set } . \\
\text { Required if an expanded or } \\
\text { replacement character set is used. } \\
\text { See C.12.1.1.2 for Defined Terms. }\end{array}$ \\
\hline Instance Creation Date & $(0008,0012)$ & 3 & Date the SOP Instance was created. \\
\hline Instance Creation Time & $(0008,0013)$ & 3 & Time the SOP Instance was created. \\
\hline Instance Creator UID & $(0008,0014)$ & 3 & $\begin{array}{l}\text { Uniquely identifies device which } \\
\text { created the SOP Instance. }\end{array}$ \\
\hline
\end{tabular}




\section{Classe de serviço Query/Retrieve Service Class}

\subsection{Patient Root}

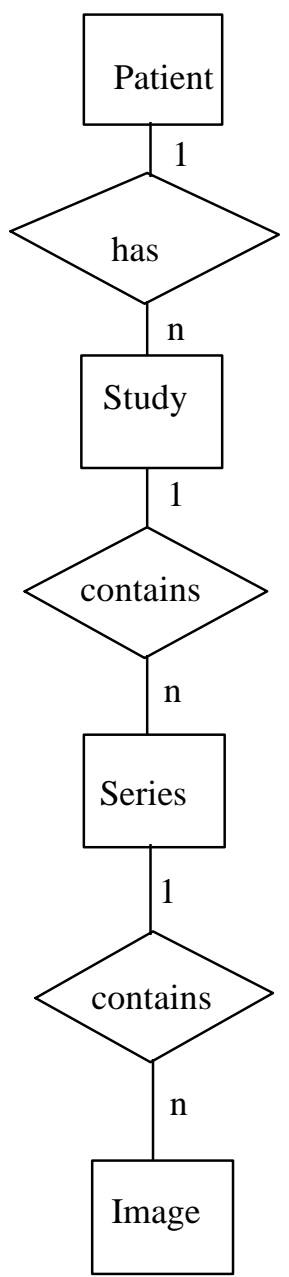

Figura C.6.1.1.1-1 - Patient Root Query/Retrieve Information Model E/R Diagram. 
Tabela C.6.1.1.2-1 - Patient Level Attributes for the Patient Root Query/Retrieve Information Model

\begin{tabular}{|l|l|l|}
\hline Description & Tag & Type \\
\hline Patient's Name & $(0010,0010)$ & $R$ \\
\hline Patient ID & $(0010,0020)$ & $U$ \\
\hline Referenced Patient Sequence & $(0008,1120)$ & $O$ \\
\hline > Referenced SOP Class UID & $(0008,1150)$ & $O$ \\
\hline $\begin{array}{l}\text { >Referenced SOP Instance } \\
\text { UID }\end{array}$ & $(0008,1155)$ & $O$ \\
\hline Patient's Birth Date & $(0010,0030)$ & $O$ \\
\hline Patient's Birth Time & $(0010,0032)$ & $O$ \\
\hline Patient's Sex & $(0010,0040)$ & $O$ \\
\hline Other Patient IDs & $(0010,1000)$ & $O$ \\
\hline Other Patient Names & $(0010,1001)$ & $O$ \\
\hline Ethnic Group & $(0010,2160)$ & $O$ \\
\hline Patient Comments & $(0010,4000)$ & $O$ \\
\hline $\begin{array}{l}\text { Number of Patient Related } \\
\text { Studies }\end{array}$ & $(0020,1200)$ & $O$ \\
\hline $\begin{array}{l}\text { Number of Patient Related } \\
\text { Series }\end{array}$ & $(0020,1202)$ & $O$ \\
\hline $\begin{array}{l}\text { Number of Patient Related } \\
\text { Images }\end{array}$ & $(0020,1204)$ & $O$ \\
\hline
\end{tabular}

Tabela C.6.1.1.3-1 - Study Level Keys for the Patient Root Query/Retrieve Information Model

\begin{tabular}{|l|l|l|}
\hline Description & Tag & Type \\
\hline Study Date & $(0008,0020)$ & $R$ \\
\hline Study Time & $(0008,0030)$ & $R$ \\
\hline Accession Number & $(0008,0050)$ & $R$ \\
\hline Study ID & $(0020,0010)$ & $R$ \\
\hline Study Instance UID & $(0020,000 D)$ & $U$ \\
\hline Referring Physician's Name & $(0008,0090)$ & $O$ \\
\hline Study Description & $(0008,1030)$ & $O$ \\
\hline Procedure Code Sequence & $(0008,1032)$ & $O$ \\
\hline >Code Value & $(0008,0100)$ & $O$ \\
\hline >Coding Scheme Designator & $(0008,0102)$ & $O$ \\
\hline >Code Meaning & $(0008,0104)$ & $O$ \\
\hline $\begin{array}{l}\text { Name of Physician(s) Reading } \\
\text { Study }\end{array}$ & $(0008,1060)$ & $O$ \\
\hline $\begin{array}{l}\text { Admitting Diagnoses } \\
\text { Description }\end{array}$ & $(0008,1080)$ & $O$ \\
\hline Referenced Study Sequence & $(0008,1110)$ & $O$ \\
\hline$>$ Referenced SOP Class UID & $(0008,1150)$ & $O$ \\
\hline $\begin{array}{l}\text { > Referenced SOP Instance } \\
\text { UID }\end{array}$ & $(0008,1155)$ & $O$ \\
\hline Patient's Age & $(0010,1010)$ & $O$ \\
\hline
\end{tabular}




\begin{tabular}{|l|l|l|}
\hline Patient's Size & $(0010,1020)$ & $O$ \\
\hline Patient's Weight & $(0010,1030)$ & $O$ \\
\hline Occupation & $(0010,2180)$ & $O$ \\
\hline Additional Patient History & $(0010,21 B 0)$ & $O$ \\
\hline Other Study Numbers & $(0020,1070)$ & $O$ \\
\hline Number of Study Related Series & $(0020,1206)$ & $O$ \\
\hline $\begin{array}{l}\text { Number of Study Related } \\
\text { Images }\end{array}$ & $(0020,1208)$ & $O$ \\
\hline Interpretation Author & $(4008,010 C)$ & $O$ \\
\hline
\end{tabular}

Tabela C.6.1.1.4-1 - Series Level Attributes for the Patient Root Query/Retrieve Information Model

\begin{tabular}{|l|l|l|}
\hline Description & Tag & Type \\
\hline Modality & $(0008,0060)$ & $R$ \\
\hline Series Number & $(0020,0011)$ & $R$ \\
\hline Series Instance UID & $(0020,000 E)$ & $U$ \\
\hline $\begin{array}{l}\text { All Other Attributes at Series } \\
\text { Level }\end{array}$ & & $O$ \\
\hline
\end{tabular}

Tabela C.6.1.1.5-1 - Image Level Keys for the Patient Root Query/Retrieve Information Model

\begin{tabular}{|l|l|l|}
\hline Description & Tag & Type \\
\hline Image Number & $(0020,0013)$ & $R$ \\
\hline SOP Instance UID & $(0008,0018)$ & $U$ \\
\hline $\begin{array}{l}\text { All Other Attributes at Image } \\
\text { Level }\end{array}$ & & $O$ \\
\hline
\end{tabular}




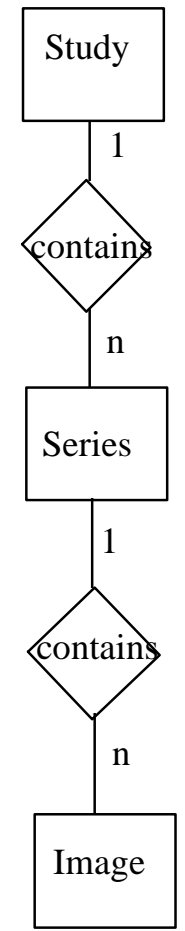

Figura C.6.2.1.1-1 - Study Root Query/Retrieve Information Model E/R Diagram.

Tabela C.6.2.1.2-1 - Study Level Keys for the Study Root Query/Retrieve Information Model

\begin{tabular}{|l|l|l|}
\hline Description & Tag & Type \\
\hline Study Date & $(0008,0020)$ & $R$ \\
\hline Study Time & $(0008,0030)$ & $R$ \\
\hline Accession Number & $(0008,0050)$ & $R$ \\
\hline Patient's Name & $(0010,0010)$ & $R$ \\
\hline Patient ID & $(0010,0020)$ & $R$ \\
\hline Study ID & $(0020,0010)$ & $R$ \\
\hline Study Instance UID & $(0020,000 D)$ & $U$ \\
\hline Referring Physician's Name & $(0008,0090)$ & $O$ \\
\hline Study Description & $(0008,1030)$ & $O$ \\
\hline Procedure Code Sequence & $(0008,1032)$ & $O$ \\
\hline >Code Value & $(0008,0100)$ & $O$ \\
\hline >Coding Scheme Designator & $(0008,0102)$ & $O$ \\
\hline >Code Meaning & $(0008,0104)$ & $O$ \\
\hline $\begin{array}{l}\text { Name of Physician(s) Reading } \\
\text { Study }\end{array}$ & $(0008,1060)$ & $O$ \\
\hline $\begin{array}{l}\text { Admitting Diagnoses } \\
\text { Description }\end{array}$ & $(0008,1080)$ & $O$ \\
\hline Referenced Study Sequence & $(0008,1110)$ & $O$ \\
\hline$>$ Referenced SOP Class UID & $(0008,1150)$ & $O$ \\
\hline
\end{tabular}




\begin{tabular}{|l|l|l|}
\hline $\begin{array}{l}>\text { Referenced SOP Instance } \\
\text { UID }\end{array}$ & $(0008,1155)$ & $O$ \\
\hline Referenced Patient Sequence & $(0008,1120)$ & $O$ \\
\hline >Referenced SOP Class UID & $(0008,1150)$ & $O$ \\
\hline $\begin{array}{l}\text { >Referenced SOP Instance } \\
\text { UID }\end{array}$ & $(0008,1155)$ & $O$ \\
\hline Patient's Birth Date & $(0010,0030)$ & $O$ \\
\hline Patient's Birth Time & $(0010,0032)$ & $O$ \\
\hline Patient's Sex & $(0010,0040)$ & $O$ \\
\hline Other Patient IDs & $(0010,1000)$ & $O$ \\
\hline Other Patient Names & $(0010,1001)$ & $O$ \\
\hline Patient's Age & $(0010,1010)$ & $O$ \\
\hline Patient's Size & $(0010,1020)$ & $O$ \\
\hline Patient's Weight & $(0010,1030)$ & $O$ \\
\hline Ethnic Group & $(0010,2160)$ & $O$ \\
\hline Occupation & $(0010,2180)$ & $O$ \\
\hline Additional Patient History & $(0010,21 B 0)$ & $O$ \\
\hline Patient Comments & $(0010,4000)$ & $O$ \\
\hline Other Study Numbers & $(0020,1070)$ & $O$ \\
\hline $\begin{array}{l}\text { Number of Patient Related } \\
\text { Studies }\end{array}$ & $(0020,1200)$ & $O$ \\
\hline $\begin{array}{l}\text { Number of Patient Related } \\
\text { Series }\end{array}$ & $(0020,1202)$ & $O$ \\
\hline $\begin{array}{l}\text { Number of Patient Related } \\
\text { Images }\end{array}$ & $(0020,1204)$ & $O$ \\
\hline Number of Study Related Series & $(0020,1206)$ & $O$ \\
\hline $\begin{array}{l}\text { Number of Study Related } \\
\text { Images }\end{array}$ & $(0020,1208)$ & $O$ \\
\hline Interpretation Author & $(4008,010 C)$ & $O$ \\
\hline
\end{tabular}

Os atributos de Série (Series Level) para Study Root Query/Retrieve Information Model são os mesmos atributos para Série do Patient Root Query/Retrieve Information Model apresentados anteriormente.

Os atributos de Imagem (Image Level) para Study Root Query/Retrieve Information Model são os mesmos atributos para Imagem do Patient Root Query/Retrieve Information Model apresentados anteriormente. 
APÊNDICE II - 24

\subsection{Patient/Study Root}

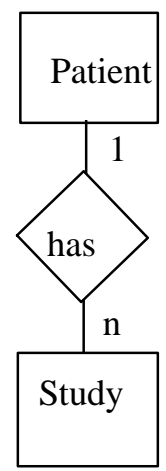

Figure C.6.3.1.1-1 Patient/Study Only Query/Retrieve Information Model E/R Diagram

Os atributos de Paciente (Patient Level) para Patient/Study Only Query/Retrieve Information Model são os mesmos atributos para Paciente do Patient Root Query/Retrieve Information Model apresentados anteriormente.

Os atributos de Estudo (Study Level) para Patient/Study Only Query/Retrieve Information Model são os mesmos atributos para Estudo do Patient Root Query/Retrieve Information Model apresentados anteriormente.

\subsection{Additional Query/Retrieve Attributes}

Tabela C.3.4-1 — Additional Query/Retrieve Attributes

\begin{tabular}{|l|l|l|}
\hline Attribute Name & Tag & Attribute Description \\
\hline $\begin{array}{l}\text { Number of Patient Related } \\
\text { Studies }\end{array}$ & $(0020,1200)$ & $\begin{array}{l}\text { The number of studies that match the } \\
\text { Patient level Query/Retrieve search } \\
\text { criteria }\end{array}$ \\
\hline Number of Patient Related Series & $(0020,1202)$ & $\begin{array}{l}\text { The number of series that match the } \\
\text { Patient level Query/Retrieve search } \\
\text { criteria }\end{array}$ \\
\hline $\begin{array}{l}\text { Number of Patient Related } \\
\text { Images }\end{array}$ & $(0020,1204)$ & $\begin{array}{l}\text { The number of images that match the } \\
\text { Patient level Query/Retrieve search } \\
\text { criteria }\end{array}$ \\
\hline Number of Study Related Series & $(0020,1206)$ & $\begin{array}{l}\text { The number of series that match the } \\
\text { Study level Query/Retrieve search criteria }\end{array}$ \\
\hline Number of Study Related Images & $(0020,1208)$ & $\begin{array}{l}\text { The number of studies that match the } \\
\text { Patient level Query/Retrieve search } \\
\text { criteria }\end{array}$ \\
\hline
\end{tabular}


APÊNDICE II - 25

\section{Referências Bibliográficas}

[1] American College of Radiology; National Electrical Manufacturers Association. Digital Imaging and Communications in Medicine (DICOM): Version 3.0. Draft Standard, ACR-NEMA Committee, Working Group VI, Washington, DC, 1993. 


\section{APÊNDICE III - Descrição formal da codificação espacial com gradientes de campo ${ }^{1}$}

A técnica de MRI consiste em obter a magnetização transversal gerada pelo pulso de excitação em cada voxel do objeto em estudo e atribuir a amplitude desta magnetização ao brilho dos correspondentes pixels da imagem. Como esta magnetização é proporcional à densidade de núcleos e depende de $T_{1}$ e $T_{2}$, a imagem resultante corresponde a um mapa da densidade de núcleos na amostra, afetado, porém, pelas características locais de relaxação.

Como dito no Capítulo 2.5, Formação de imagens por RMN, o procedimento para codificar espacialmente as posições dos núcleos é baseado na dependência da freqüência de Larmor de precessão dos spins nucleares com o campo magnético, $\omega=\gamma B$. Assim, campos magnéticos dependentes da posição e do tempo são utilizados para realizar a codificação espacial necessária para se obter imagens em mais de uma dimensão, de forma que a freqüência de Larmor de cada volume elementar sujeito a um campo local $\vec{B}(\vec{r}, t)$ também é função da posição e do tempo, isto é,

$$
\omega(\vec{r}, t)=\gamma B(\vec{r}, t),
$$

e a fase acumulada pela magnetização de cada voxel desde a excitação até um instante $t$ é dada por:

$$
\phi(\vec{r}, t)=\int_{0}^{t} \omega\left(\vec{r}, t^{\prime}\right) d t^{\prime}=\gamma \int_{0}^{t} B\left(\vec{r}, t^{\prime}\right) d t^{\prime} .
$$


A magnetização transversal total da amostra, a cada instante $t$, é a soma das contribuições da magnetização de cada voxel excitado, onde cada um possui uma fase dada pela Equação 2. Assim, expressando a densidade de magnetização da amostra por unidade de volume como $\rho_{0}(\vec{r})$, a expressão geral para a magnetização transversal pode ser escrita como

$$
M_{T}(t)=e^{-t / T_{2}} \int_{V} \rho_{0}(\vec{r}) e^{i \phi(\vec{r}, t)} d V
$$

Se após a excitação a amostra ficar submetida somente ao campo magnético principal, isto é, $\vec{B}(\vec{r}, t)=B_{0} \widehat{z}$, a evolução da magnetização transversal será apenas

$$
M_{T}(t)=e^{-t / T_{2}} e^{i \omega_{0} t} \int_{V} \rho_{0}(\vec{r}) d V=e^{-t / T_{2}} e^{i \omega_{0} t} M_{0}
$$

com $\omega_{0}=\gamma B_{0}$, como já visto anteriormente na Equação 10 do Capítulo 2.5. Nesta condição, a medida do sinal induzido pela magnetização transversal $M_{T}(t)$ permite apenas observar a precessão de todo o conjunto de spins e a relaxação transversal, sem que nenhuma informação sobre a distribuição espacial da magnetização $\rho_{0}(\vec{r})$ esteja embutida neste sinal.

O campo magnético $\vec{B}(\vec{r}, t)$ usado na codificação espacial é formado pela sobreposição do campo magnético principal $B_{0}$ na direção $z$ e gradientes de campo magnético nas direções $x, y$ e $z$, que variam de amplitude em função do tempo e que podem ser representados genericamente por

$$
\vec{G}(t)=\left\{G_{x}(t)=\left.\frac{\partial B_{z}}{\partial x}\right|_{t}, \quad G_{y}(t)=\left.\frac{\partial B_{z}}{\partial y}\right|_{t}, \quad G_{z}(t)=\left.\frac{\partial B_{z}}{\partial z}\right|_{t}\right\} .
$$

O campo magnético resultante continua apenas na direção do eixo $z$, dado por

$$
\vec{B}(\vec{r}, t)=\left[B_{0}+\vec{r} \cdot \vec{G}(t)\right] \widehat{z}
$$

e a freqüência de Larmor $\omega=\gamma B$ passa a ser

$$
\omega(\vec{r}, t)=\omega_{0}+\gamma \vec{r} \cdot \vec{G}(t),
$$

onde $\omega_{0}=\gamma B_{0}$ é a frequiência central de precessão dos spins na região onde o gradiente é nulo. Já a fase acumulada até o instante $t$ pela magnetização sujeita ao campo $\vec{B}(\vec{r}, t)$ é então dada por 


$$
\phi(\vec{r}, t)=\int_{0}^{t} \omega\left(\vec{r}, t^{\prime}\right) d t^{\prime}=\omega_{0} t+\vec{r} \cdot \gamma \int_{0}^{t} \vec{G}\left(t^{\prime}\right) d t^{\prime} .
$$

Neste instante, é conveniente definir a variável $\vec{k}(t)$

$$
\vec{k}(t)=\gamma \int_{0}^{t} \vec{G}\left(t^{\prime}\right) d t^{\prime}
$$

que incorpora todo o efeito da ação do gradiente de campo $\vec{G}(t)$ sobre os spins nucleares até o instante $t$. Da mesma forma que $\vec{r}$ é uma variável no domínio do espaço tridimensional, a variável $\vec{k}$ está no domínio do espaço recíproco, chamado de espaço-k. Usando esta definiç̧ão, a expressão para a fase acumulada fica

$$
\phi(\vec{r}, t)=\omega_{0} t+\vec{r} \cdot \vec{k}(t),
$$

e a Equação 3 para a evolução da magnetização transversal pode ser reescrita como

$$
M_{T}(t)=e^{-t / T_{2}} \int_{-\infty}^{\infty} \rho_{0}(\vec{r}) e^{i\left[\omega_{0} t+\vec{r} \cdot \vec{k}(t)\right]} d V=e^{i \omega_{0} t} e^{-t / T_{2}} \int_{-\infty}^{\infty} \rho_{0}(\vec{r}) e^{i \vec{r} \cdot \vec{k}(t)} d V
$$

onde os limites de integração foram estendidos para todo o espaço pois a densidade de magnetização $\rho_{0}(\vec{r})$ é nula fora da amostra.

Durante um experimento de medida da magnetização, o sinal de RMN induzido nas bobinas de recepção é proporcional a magnetização transversal $M_{T}(t)$. Como pode ser visto na Equação 11, o sinal resultante é um sinal de RF na frequiência de Larmor $w_{0}$, modulado por um envelope que contem a informação sobre a distribuição espacial da densidade de magnetização dado por:

$$
S_{e n v}(t)=e^{-t / T_{2}} \int_{-\infty}^{\infty} \rho_{0}(\vec{r}) e^{i \vec{r} \cdot \vec{k}(t)} d V
$$

O sinal que é captado pelas bobinas de recepção é proveniente de toda a amostra, ou pelo menos de uma região específica previamente selecionada na amostra. A cada instante $t$, este sinal é a composição da contribuição de cada elemento de volume da amostra que, devido a presença dos gradientes de campo, possuem uma fase diferente dada por $\phi(\vec{r}, t)$. Descontando a fase $\omega_{0} t$ que é comum a todos os spins nucleares da amostra, cada posição da amostra possui uma fase adicional dada por $\vec{r} \cdot \vec{k}(t)$. Desta forma, uma série de medidas do sinal da magnetização transversal, 
cada uma com um $\vec{k}$ diferente - obtido através da utilização de diferentes instantes $t$ para a medida, ou diferentes gradientes $\vec{G}(t)$, ou ambos conjuntamente - permite criar uma representação, no espaço-k, da densidade de magnetização da amostra. Esta representação pode ser observada na Equação 12 onde, sendo a integração realizada na variável $\vec{r}$, o resultado é uma função de $\vec{k}$, isto é, $S_{e n v}(t) \equiv S_{e n v}(\vec{k}(t))$.

A integral existente dentro das Equações 11 e 12, escrita com os novos limites de integração, é a transformada de Fourier* da função $\rho_{0}(\vec{r})$, de forma que a Equação 12 para a magnetização transversal pode ser reescrita como

$$
S_{\text {env }}(\vec{k}(t))=e^{-t / T_{2}} \hat{\rho}_{0}(\vec{k}(t)),
$$

onde $\hat{\rho_{0}}(\vec{k})=\mathfrak{I}\left\{\rho_{0}(\vec{r})\right\}$. Desta forma, a menos do termo referente à relaxação transversal, que para $t$ « $T_{2}$ pode ser considerado, em primeira aproximação, igual à unidade, o envelope do sinal medido é igual à transformada de Fourier da densidade de magnetização. Assim, ao realizar a transformada de Fourier inversa da função $S_{e n v}(\vec{k}(t))$ é possível obter a densidade de magnetização $\rho_{0}(\vec{r})$ da amostra.

O efeito do termo de relaxação $e^{-t / T_{2}}$ no resultado final pode ser melhor entendido se for realizada uma transformada de Fourier inversa, na variável $\vec{k}$, de $S_{e n v}(\vec{k}(t))$. Usando o teorema da convolução, onde a transformada de Fourier de um produto de funções é igual ao produto de convolução das transformadas de Fourier das funções, tem-se que

$$
\begin{aligned}
\mathfrak{I}^{-1}\left\{S_{\text {env }}(\vec{k}(t))\right\} & =\mathfrak{I}^{-1}\left\{e^{-t / T_{2}} \widehat{\rho}_{0}(\vec{k}(t))\right\} \\
& =\mathfrak{I}^{-1}\left\{e^{-t / T_{2}}\right\} \otimes \mathfrak{I}^{-1}\left\{\hat{\rho}_{0}(\vec{k}(t))\right\}=P(\vec{r}) \otimes \rho_{0}(\vec{r})
\end{aligned}
$$

\footnotetext{
* Pares de transformada de Fourier em três dimensões usadas neste trabalho: ${ }^{2}$

Transformada direta: $\hat{f}(\vec{k})=\mathfrak{I}\{f(\vec{r})\}=\iiint f(\vec{r}) e^{i \vec{r} \cdot \vec{k}} d \vec{r}$;

Transformada inversa: $f(\vec{r})=\mathfrak{I}^{-1}\{\hat{f}(\vec{k})\}=\frac{1}{(2 \pi)^{3}} \iiint \hat{f}(\vec{k}) e^{-i \vec{r} \cdot \vec{k}} d \vec{k}$.
}

As integrais são realizadas sobre todos os valores dos respectivos vetores. 
Como a transformada de Fourier acima é realizada na variável $\vec{k}$, que por sua vez é parametrizada por $t$, é necessário conhecer a relação entre $\vec{k}$ e $t$ para se calcular a função $P(\vec{r})$, que é chamada de Point Spread Function (PSF). Esta relação varia de acordo com técnica utilizada (seqüência de aquisição), como será exemplificado logo a seguir, mas em geral existem condições que, quando satisfeitas, fazem com que a função $P(\vec{r})$ possa ser aproximada pela função delta de Dirac e, conseqüentemente, a transformada de Fourier inversa de $S_{e n v}(\vec{k}(t))$ passa a ser aproximadamente igual à densidade de magnetização $\rho_{0}(\vec{r})$.

Considerando a discussão feita acima sobre o processo de codificação espacial da densidade de magnetização usando campos magnéticos e gradientes de campo dependentes do tempo, a técnica MRI para obtenção de imagens consiste em realizar um conjunto de medidas de RMN cujos resultados, os sinais de RMN, formam um mapa de codificação no espaço-k. Em seguida, realizando uma transformada de Fourier inversa na variável $\vec{k}$ sobre estes dados, obtêm-se a densidade de magnetização $\rho_{0}(\vec{r})$, que geralmente é visualizada na forma de uma imagem. A maneira como é realizada a codificação no espaço-k depende da técnica utilizada. Esta escolha também define qual é a influência do termo de relaxação transversal no resultado final, dada pela função PSF.

Uma forma possível de obter o mapa de sinais de RMN no espaço-k é medir apenas um valor por vez de $S_{e n v}(\vec{k})$, mas para diferentes valores de $\vec{k}$. Medindo o sinal sempre no instante $\tau$ depois do pulso de excitação, mas variando os gradientes aplicados antes da medida para obter diferentes valores de $\vec{k}$, o conjunto de todas as medidas fornece o seguinte resultado:

$$
S_{\text {env }}(\vec{k})=e^{-\tau / T_{2}} \widehat{\rho_{0}}(\vec{k}) .
$$

A figura a seguir ilustra esta situação para o caso específico onde a sequiência de aquisição Spin-echo é utilizada para adquirir uma imagem de um determinado plano $x-y$. No instante $\tau$ a intensidade do sinal é medida. A intensidade e duração dos gradientes $G_{x}$ e $G_{y}$ aplicados até o instante $\tau$ é que determina a posição no espaço-k da medida. 


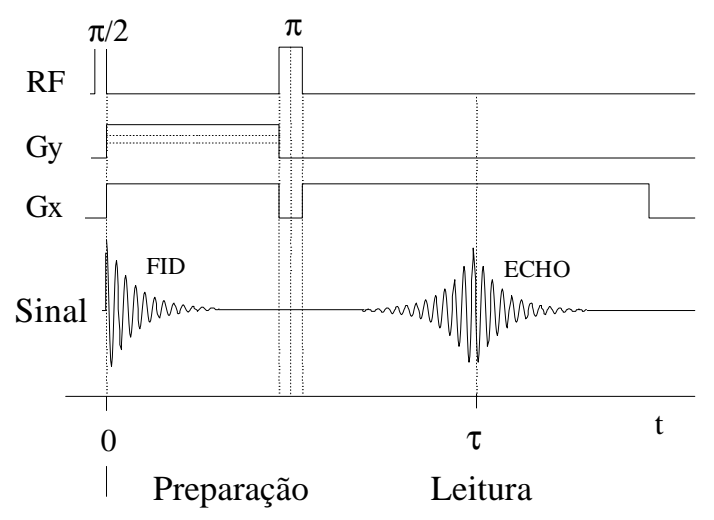

Figura 1 - Exemplo de aquisição com medida de um ponto do espaço-k por ciclo de aquisição e leitura.

Neste exemplo, o gradiente de leitura deve ser ajustado para que o intervalo entre a excitação e a medida do sinal seja sempre constante, de forma que o termo de relaxação contribui apenas com uma constante, dada por $e^{-\tau / T_{2}}$. Neste caso, a função PSF é dada por

$$
P(\vec{r})=\mathfrak{I}^{-1}\left\{e^{-\tau / T_{2}}\right\}=e^{-\tau / T_{2}} \boldsymbol{\delta}(\vec{r}),
$$

cuja convolução com $\rho_{0}(\vec{r})$ fornece:

$$
\begin{aligned}
\mathfrak{I}^{-1}\left\{S_{e n v}(\vec{k})\right\} & =\left[e^{-\tau / T_{2}} \delta(\vec{r})\right] \otimes \rho_{0}(\vec{r}) \\
& =\int_{-\infty}^{\infty} e^{-\tau / T_{2}} \delta(\vec{r}-\vec{\xi}) \rho_{0}(\vec{\xi}) d \vec{\xi}=e^{-\tau / T_{2}} \rho_{0}(\vec{r})
\end{aligned}
$$

Assim, o resultado da transformada de Fourier inversa de $S_{\text {env }}(\vec{k})$ é diretamente proporcional à densidade de magnetização $\rho_{0}(\vec{r})$. Se o conjunto de medidas para diferentes valores de $\vec{k}$ abrange o espaço-k em suas três dimensões, o resultado após a transformada de Fourier será uma função tridimensional que resultará em uma imagem tridimensional. Se a variável $\vec{k}$ variar tal que ela forme um plano no espaço-k, o resultado final será um plano correspondente no espaço tridimensional de $\vec{r}$. Para que, neste último caso, a imagem final seja correspondente a um plano tomográfico da amostra, o plano deve ser previamente selecionado com gradientes de campo, como será mostrado adiante, para que apenas os spins nucleares deste plano sejam excitados e, assim, contribuam para o sinal que é medido. 
O exemplo descrito acima é apenas didático para ilustrar que o termo de relaxação deve ser analisado separadamente para cada técnica de aquisição. Para a aquisição de imagens, esta técnica é muito pouco eficiente pois, como será mostrado no próximo exemplo, as técnicas utilizadas na prática leem o sinal do FID por inteiro e com isto obtêm uma amostragem mais ampla no espaço-k.

Uma maneira bastante utilizada de obter-se a codificação do espaço-k é realizar uma série de medidas onde o sinal é amostrado durante um intervalo definido de tempo, e não mais em um determinado e único instante por medida. Desta forma, obtêm-se, com uma única medida, um conjunto de pontos no espaço-k para diferentes valores de $t$ e, conseqüentemente, diferentes valores de $\vec{k}(t)$. Como os dispositivos de medida realizam a amostragem do sinal em intervalos regulares de tempo, e também é desejável que a amostragem de valores no espaço-k também seja feita de maneira uniforme para se poder usar os algoritmos de transformada de Fourier discreta na variável $\vec{k}$, os gradientes de campo aplicados durante a captação do sinal, chamados de gradientes de leitura, são mantidos constantes no tempo, de forma que, durante a leitura, a variação de $\vec{k}(t)$ seja constante, isto é,

$$
\frac{d \vec{k}(t)}{d t}=\gamma \vec{G}_{L}
$$

Cada medida completa resulta em uma reta no espaço-k, e são necessárias várias medidas, com gradientes de leitura iguais mas com a fases iniciais diferentes, para obter-se um mapa em todo espaço-k da codificação da densidade de magnetização. A fase inicial diferente, que possibilita que todo o espaço-k seja percorrido ao final de todas as leituras, é obtida através dos gradientes de preparação aplicados no intervalo entre a excitação e o início da leitura. Assim, se cada preparação ocorre durante um intervalo de tempo pré-definido $\tau$, a fase adquirida pelo sistema de spins até o início da leitura é $\phi(\vec{k}(\tau))$. À partir deste instante, apenas o gradiente de leitura $\vec{G}_{L}$ é aplicado, e a leitura do sinal a intervalos de tempo regulares corresponde a $S_{\text {env }}(\vec{k})$ amostrado em intervalos regulares sobre uma reta no espaçok. O envelope do sinal medido é então dado pela Equação 13, com

$$
\vec{k}(t)=\vec{k}(\tau)+\gamma \vec{G}_{L}(t-\tau)
$$


para $t>\tau$.

A figura a seguir exemplifica esta técnica para o caso onde a seqüiência de aquisição Spin-echo é utilizada para adquirir uma imagem de um determinado plano $x-y$. A leitura é realizada durante a ocorrência do eco enquanto apenas o gradiente de leitura, neste caso $G_{x}$, é mantido ligado. A fase acumulada até o instante $\tau$ é definida pela combinação de gradientes $G_{x}$ e $G_{y}$ aplicados até este instante.

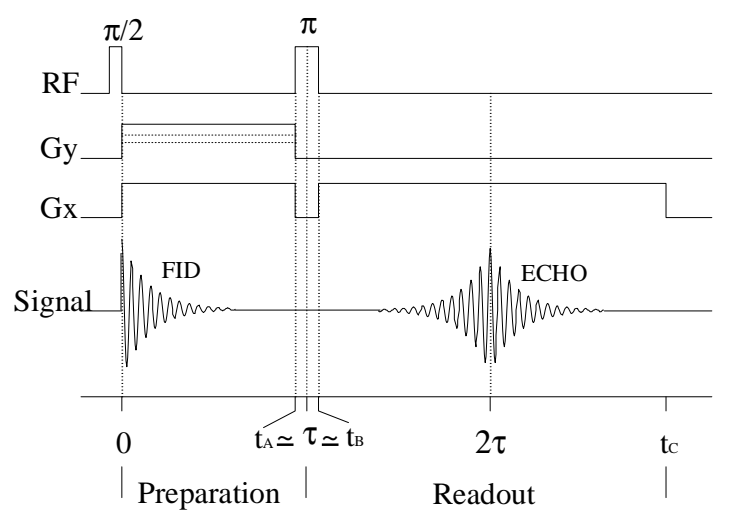

Figura 2 - Exemplo de aquisição com medida de uma linha do espaço-k por ciclo de aquisição e leitura.

Neste momento, é interessante utilizar um sistema de coordenadas mais adequado para apresentar os resultados. Este sistema, com eixos nas direções $\left\{\widehat{x}^{\prime}, \widehat{y}^{\prime}, \widehat{z}^{\prime}\right\}$, é definido de acordo com a direção do gradiente de leitura de maneira que a direção de um dos eixos deste novo sistema de coordenadas, por exemplo a direção $\widehat{x}^{\prime}$, coincida com a direção de $\vec{G}_{L}$. Assim, o vetor do gradiente de leitura, antes escrito no sistema de coordenadas $\{\hat{x}, \hat{y}, \bar{z}\}$ como sendo $\vec{G}_{L}=\left\{G_{L}^{x}, G_{L}^{y}, G_{L}^{z}\right\}$, passa a ser escrito como $\vec{G}_{L}=\left\{G_{L}, 0,0\right\}$, ou $\vec{G}_{L}=G_{L} \widehat{x}^{\prime}$. Os vetores $\vec{k}$ e $\vec{r}$ do sistema de coordenadas inicial passam a ser escritos como $\vec{k}^{\prime}=\left\{k_{x^{\prime}}, k_{y^{\prime}}, k_{z^{\prime}}\right\}$ e $\vec{r}^{\prime}=\left\{x^{\prime}, y^{\prime}, z^{\prime}\right\}$ neste novo sistema.

Este sistema de coordenadas é bastante interessante porque, na aplicação prática desta técnica de aquisição, a transformada de Fourier para obtenção da densidade de magnetização é realizada neste novo sistema de coordenadas definido pela direção do gradiente de leitura. Ao final de todo o processo, ao invés de se obter uma função $\rho_{0}(\vec{r})$ no sistema de coordenadas original, obtém-se a função $\rho_{0}\left(\vec{r}^{\prime}\right)$ 
escrita neste novo sistema de coordenadas. A equação para o envelope do sinal medido escrito neste sistema de coordenadas é dada então por

$$
S_{e n v}\left(\vec{k}^{\prime}(t)\right)=e^{-t / T_{2}} \widehat{\rho}_{0}\left(\vec{k}^{\prime}(t)\right)
$$

com

$$
\vec{k}^{\prime}(t)=\vec{k}^{\prime}(\tau)+\gamma G_{L}(t-\tau) \widehat{x}^{\prime}
$$

para $t>\tau$

Para determinar a influência do termo de relaxação transversal nesta técnica de aquisição, pode-se usar o fato que, durante a leitura do sinal, o espaço-k' é percorrido proporcionalmente ao tempo, dado pela Equação 21. Para facilitar a visualização da relação entre $\vec{k}^{\prime}(t)$ e t, é adequado escrever a Equação 21 mostrando todas as suas componentes:

$$
\vec{k}^{\prime}(t) \equiv\left(\begin{array}{c}
k_{x^{\prime}}(t) \\
k_{y^{\prime}}(t) \\
k_{z^{\prime}}(t)
\end{array}\right)=\left(\begin{array}{l}
k_{x^{\prime}}(\tau) \\
k_{y^{\prime}}(\tau) \\
k_{z^{\prime}}(\tau)
\end{array}\right)+\left(\begin{array}{c}
\gamma G_{L} \\
0 \\
0
\end{array}\right)(t-\tau)
$$

para $t>\tau$. Desta forma, na direção de $x^{\prime}$ tem-se a seguinte relação:

$$
k_{x^{\prime}}(t)=k_{x^{\prime}}(\tau)+\gamma G_{L}(t-\tau)
$$

para $\mathrm{t}>\tau$.

Observando a Figura 2, percebe-se que o eco é simétrico com relação ao instante $t=2 \tau$. Isto ocorre pois, neste instante, todos os spins recuperam a fase que haviam perdido devido ao gradiente $G_{L}$ e devido a relaxação por $T_{2}{ }^{*}$ (válido quando $T_{2} \gg T_{2}{ }^{*}$ ). Desta forma é conveniente trabalhar em um sistema de coordenadas deslocado no eixo $x^{\prime}$ tal que o seu centro coincida com o instante $t=2 \tau$. Isto é equivalente a reescrever a Equação 20 como

$$
S_{e n v}\left(\vec{K}\left(t^{\prime}\right)\right)=e^{-\left|t^{\prime}\right| / T_{2}^{*}} \widehat{\rho}_{0}\left(\vec{K}\left(t^{\prime}\right)\right),
$$

onde

$$
t^{\prime}=t-2 \tau
$$

$\mathrm{e}$

$$
K_{x^{\prime}}=\gamma G_{L} t^{\prime} .
$$


Assim, invertendo a última equação, tem-se que

$$
t^{\prime}=\frac{K_{x^{\prime}}}{\gamma G_{L}}
$$

e a Equação 24 pode ser reescrita como sendo

$$
S_{e n v}(\vec{K}(t))=e^{-\frac{\left|K_{x_{x}}\right|}{\gamma G_{L} T_{2}^{*}}} \hat{\rho}_{0}(\vec{K}(t)) .
$$

Usando as seguintes transformadas de Fourier conhecidas:

$$
\mathfrak{I}\left\{A e^{-a \mid K_{x^{\prime}}}\right\}=\frac{2 A}{a} \frac{a^{2}}{a^{2}+x^{\prime 2}}
$$

$\mathrm{e}$

$$
\mathfrak{I}\{A\}=A \delta\left(x^{\prime}\right)
$$

a PSP é pode ser calculada como sendo

$$
P\left(\vec{r}^{\prime}\right)=\mathfrak{J}^{-1}\left\{e^{-\frac{\left|K_{x^{\prime}}\right|}{\gamma G_{L} T_{2}^{*}}}\right\}=\delta\left(y^{\prime}\right) \delta\left(z^{\prime}\right) \frac{2}{\gamma G_{L} T_{2}^{*}} \frac{1}{1+\left(\gamma G_{L} T_{2}^{*}\right)^{2} x^{\prime 2}} .
$$

No caso deste exemplo, a PSF é, a menos de fatores constantes, a função Lorentziana no espaço tridimensional. Ela possui uma meia largura na direção $\hat{x}^{\prime}$ do gradiente de leitura dada por

$$
\Delta x^{\prime}=\frac{1}{\gamma G_{L} T_{2}^{*}}
$$

que determina a largura mínima possível na direção $\widehat{x}^{\prime}$ para os pontos da imagem. Este fato, inerente a este método de aquisição, limita a resolução e, portanto, a acurácia em que a imagem representa a amostra.

Na realidade, devido às propriedades da transformada de Fourier, há uma relação entre o tamanho dos pixels, ou a distância interpixels, da imagem resultante na direção de leitura, $\delta x^{\prime}$, e a máxima freqüência espacial $K_{x^{\prime}}^{\max }$ contida no sinal amostrado. Esta relação é $\delta x^{\prime}=1 / K_{x^{\prime}}^{\max }$. Como $K_{x^{\prime}}=\gamma G_{L} t^{\prime}$,

$$
\delta x^{\prime}=\frac{1}{\gamma G_{L} t_{\max }} .
$$


Desta forma, para que os pixels de uma imagem sejam distinguíveis, de acordo com o critério de Rayleigh, a separação $\delta x^{\prime}$ entre eles deve ser maior que a largura $\Delta x^{\prime}$, isto é:

$$
\delta x^{\prime}>\Delta x^{\prime} \Rightarrow \frac{1}{\gamma G_{L} t_{\max }}>\frac{1}{\gamma G_{L} T_{2}^{*}} \Rightarrow t_{\max }<T_{2}^{*} .
$$

Para satisfazer estas condições, pode-se aumentar a amplitude dos gradientes, que implica em um $t_{\max }$ proporcionalmente menor, ou melhorar a homogeneidade do campo para aumentar $T_{2}^{*}$. De qualquer forma, quanto maior for $T_{2}^{*}$, maior será o $t_{\max }$ útil e maior será a resolução máxima possível.

Nas demais direções, que não são direções de leitura, a resolução fica limitada pela maior freqüência espacial imposta nestas direções pelos respectivos gradientes de campo.

Quando $t_{\max } \ll T_{2}^{*}$, a função $P(\vec{r})$ se aproxima da função delta de Dirac e, conseqüentemente, a transformada de Fourier inversa da Equação 28 passa a ser aproximadamente, e a menos de constantes,

$$
\mathfrak{I}^{-1}\left\{S_{e n v}(\vec{K})\right\} \propto \delta(\vec{r}) \otimes \rho_{0}(\vec{r})=\rho_{0}(\vec{r})
$$


APÊNDICE III - 12

\section{REFERÊNCIAS BIBLIOGRÁFICAS}

[1] PANEPUCCI, H.; TANNÚS, A. The Principles of Magnetic Resonance Imaging. São Carlos, IFSC, 1994. (Apostila).

[2] CHAMPENEY, D.C. Fourier Tranforms and their physical applications. 5.ed. Academic Press, 1973. 


\section{APÊNDICE IV - Microsoft Access Versão 2.0}

O Microsoft Access ${ }^{\circledR}$ versão 2.0 é um sistema de gerenciamento de banco de dados relacional para microcomputadores IBM/PC compatíveis com sistema operacional da família Microsoft Windows ${ }^{\mathrm{TM}}$. Ele é um aplicativo de alto nível que proporciona para o usuário uma interface simples para criação e acesso a bancos de dados relacionais e para a criação de aplicações de bancos de dados.

O MS Access utiliza o Microsoft Jet Database Engine como núcleo de acesso e manipulação dos dados fisicamente armazenados." Este núcleo permanece em arquivos de biblioteca (DLL - Dynamic Link Library) que são utilizados para traduzir as chamadas do MS Access para as operações de acesso e manipulação física dos dados. Desta forma, o núcleo Jet acompanha a aplicação que tem acesso aos dados, caracterizando, assim, um uma configuração de banco de dados remoto, e não um sistema do tipo cliente/servidor, onde o núcleo de acesso aos dados permanece junto ao repositório de dados. Exemplificando, se o arquivo de dados está em um computador central e vários outros computadores remotos têm acesso aos dados, cada um deles deve possuir a sua própria cópia do núcleo Jet.

O núcleo Jet proporciona uma interface de programação orientada a objetos, chamada de Objetos de Acesso a Dados (DAO - Data Access Objets). O modelo de acesso aos dados obedece à estrutura do DAO, que possui uma hierarquia de classes usadas para definir um sistema de banco de dados relacional (Figura 1). Cada classe do modelo possui propriedades e métodos que são utilizadas para definir, criar, ter

\footnotetext{
* Microsoft Corporation. Microsoft Access®: Building Applications, 1994.
} 
acesso e modificar o banco de dados, que podem ser utilizados pelas linguagens DDL e DML definidas no Jet ou através da linguagem SQL.

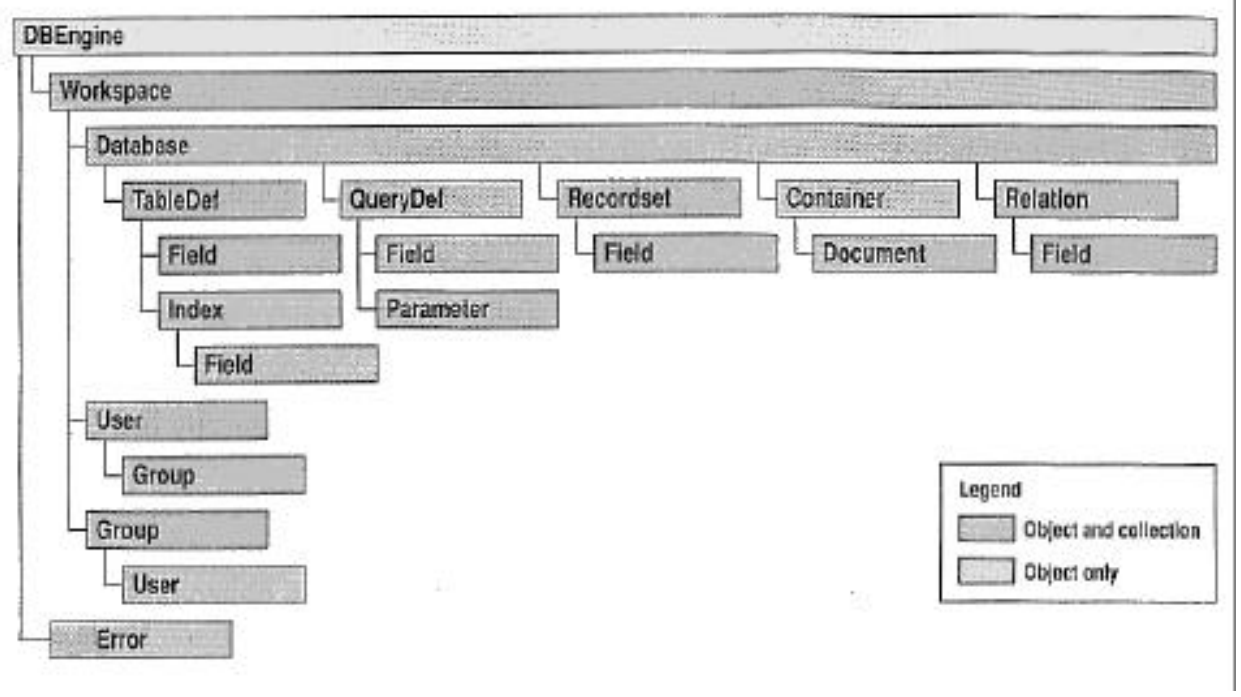

Figura 1 - Hierarquia de classes do DAO."

O MS Access utiliza objetos próprios e objetos do núcleo Jet para definir sistemas de banco de dados. Os objetos próprios do MS Access são Application, Control, Debug, Form, Forms, Module, Report, Reports, Screen e Section. A classe Container do DAO é utilizada juntamente com a classe Document para enumerar todos os objetos armazenados no banco de dados, inclusive aqueles definidos pela aplicação cliente. É desta forma, então, que o MS Access armazena nos próprios arquivos de banco de dados a definição da aplicação através dele criada. São usados oito objetos Container principais, sendo cinco deles definidos pelo MS Access (Forms, Modules, Reports, Scripts e SysRel) e três definidos pelo núcleo Jet (Databases, Relationships e Tables).

\footnotetext{
${ }^{*}$ Microsoft Corporation. Microsoft $®$ Visual Basic $®$ : Programming System for Windows $₫$, Version 4.0. Professional Features: Guide to Data Access Objects, 1995.
} 


\section{APÊNDICE V - Documentos do LAL do sistema}

\section{ToRM-005}

Este apêndice contem quatro documentos que foram resultantes do levantamento do Léxico Ampliado da Linguagem do ambiente do operação do ToRM-005:

1. layout.doc: contem diagramas dos equipamentos do ToRM-005;

2. desc.txt: descreve a função de todos os equipamentos indicados no documento layout.doc;

3. protoc1.txt: descreve os procedimentos de operação do sistema ToRM-005. Está dividido em duas partes. Na primeira, que se estende da página 20 a 29, são descritos os protocolos de operação de cada subsistema, indicando como ele é inicializado, operado e desligado/finalizado. Na segunda parte, das páginas 30 a 38, são apresentados protocolos compostos de operação. Neles são descritos os procedimentos para ligar e preparar o tomógrafo, realizar uma aquisição de dados, e desligar o equipamento. Estes protocolos utilizam os protocolos de operação de cada subsistema descritos no começo do arquivo;

4. manual.lex: apresenta o LAL com os seus símbolos, noções e impactos. 


\section{Layout dos equipamentos: "layout.doc"}

\subsection{Sala de Tomografia}

\subsubsection{Layout 1}

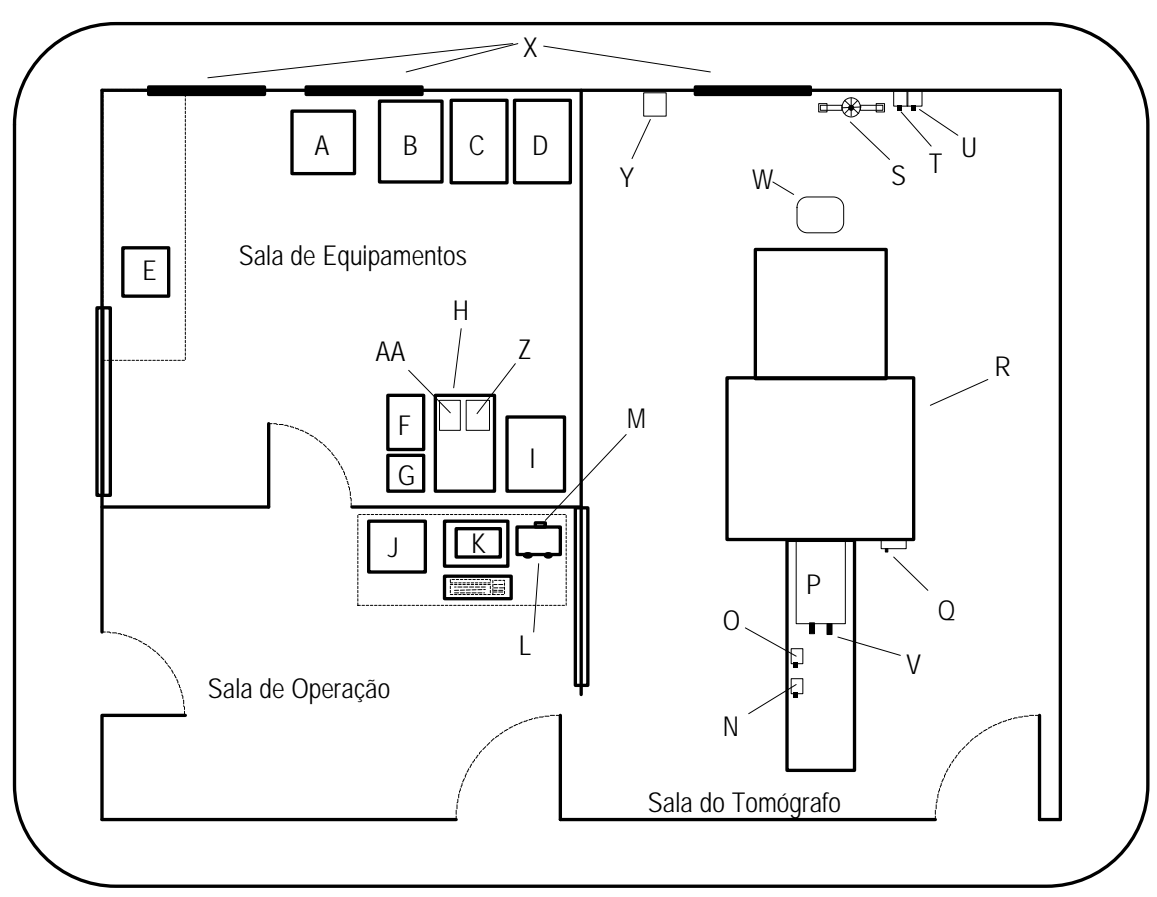

\subsubsection{Legenda}
A. Estabilisador de Tensão
B. Amplificador de Gradientes
C. Fonte de Alimentação do Magneto
D. Transformador Magneto
E. Sintetizador de RF
F. Disco de Sistema do MicroVax
G. MicroVax 
H. Disco de Usuários do MicroVax

I. Sistema do Espectrômetro

J. Tela de Visualisação

K. Macintosh

L. Controle de Nível de Sinal

M. Chave Geral do Sistema do Espectrômetro

N. Sintonizador

O. Proteção do Pré-Amplificador

P. Cama

Q. Painel do Tomógrafo

R. Tomógrafo

S. Registro do Circuito Externo de Refrigeração

T. Chave da Bomba de Água I

U. Chave da Bomba de Água II

V. Botões de Sintonia

W. Ventilador

X. Sistema de Refrigeração de Ambiente

Y. Tomada do Exaustor

Z. Osciloscópio I

AA. Osciloscópio II

1.2 Painel do Tomógrafo

\subsubsection{Layout 2}

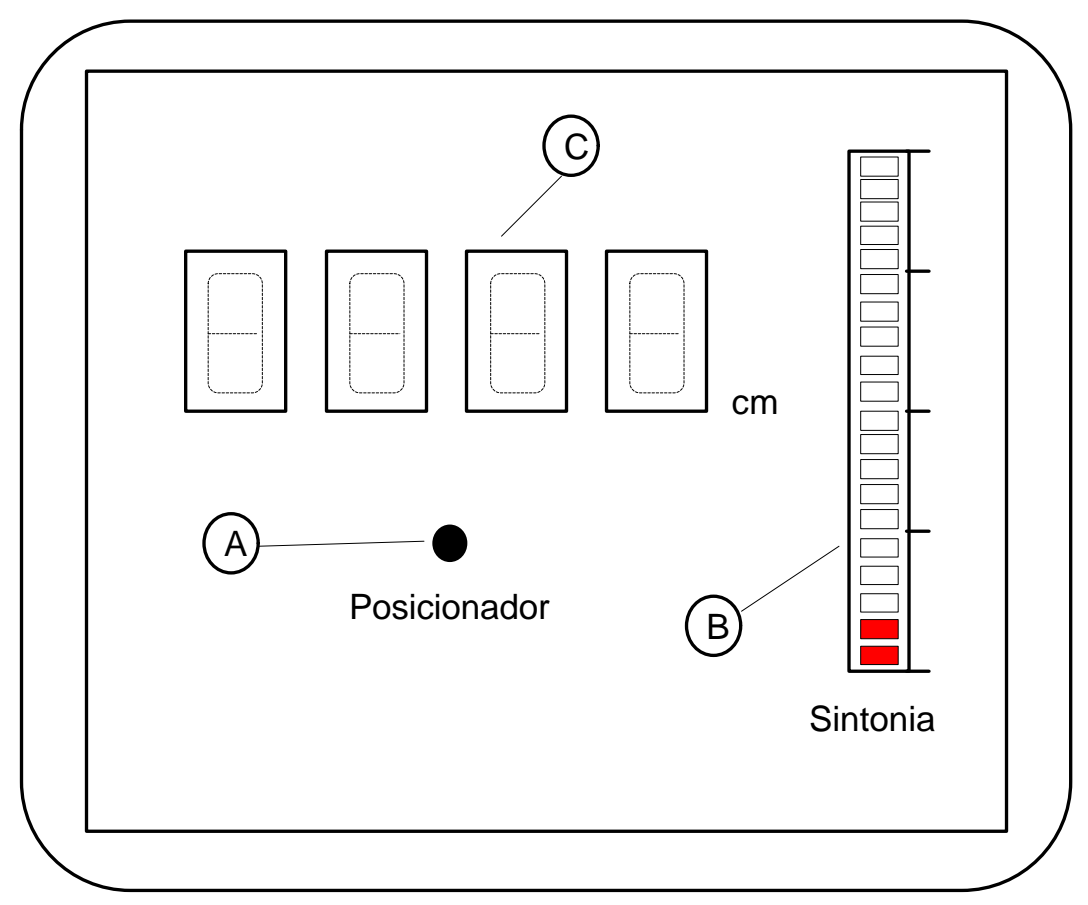

\subsubsection{Legenda}

A. Botão Posicionador 
B. Indicador de Sintonia

C. Visor de Posicão

\subsection{Sintetisador de RF}

\subsubsection{Layout 3}

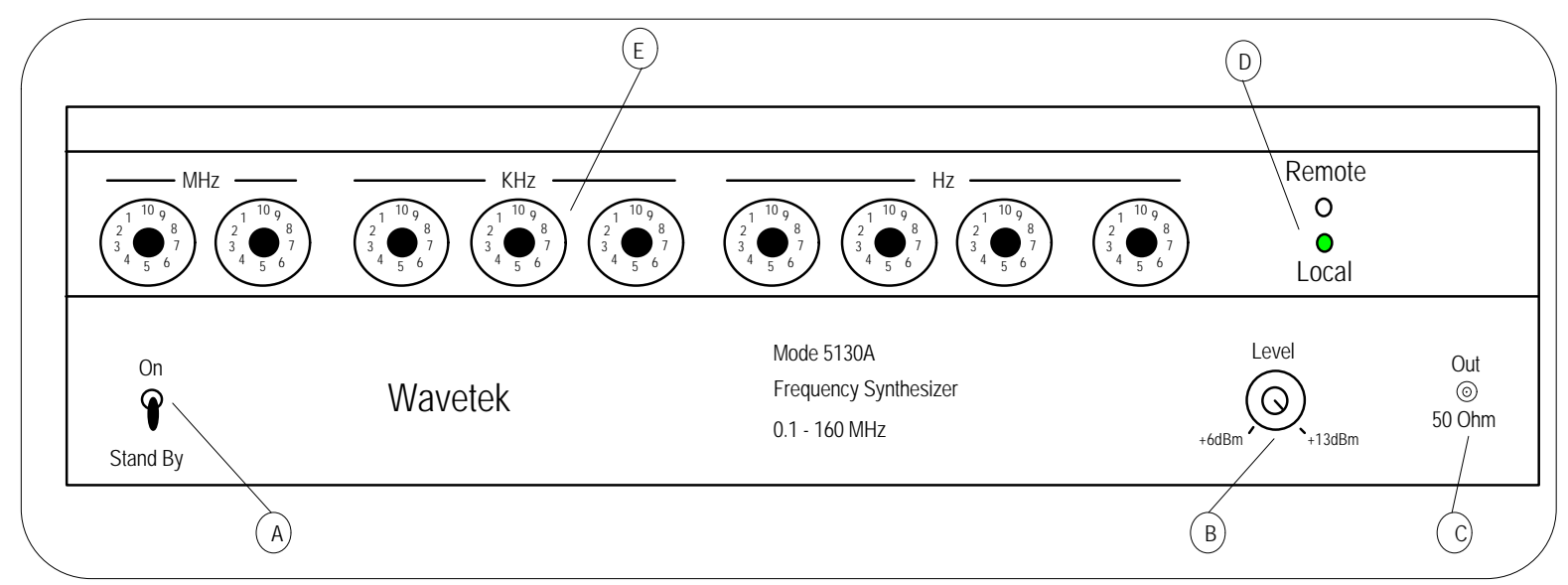

\subsubsection{Legenda}
A. Chave Stand By/On
B. Ajuste Level
C. Conector Output
D. Indicadores Remote/Local
E. Seletores de Frequência 
1.4 Painel da Fonte de Alimentação do Magneto

\subsubsection{Layout 4}

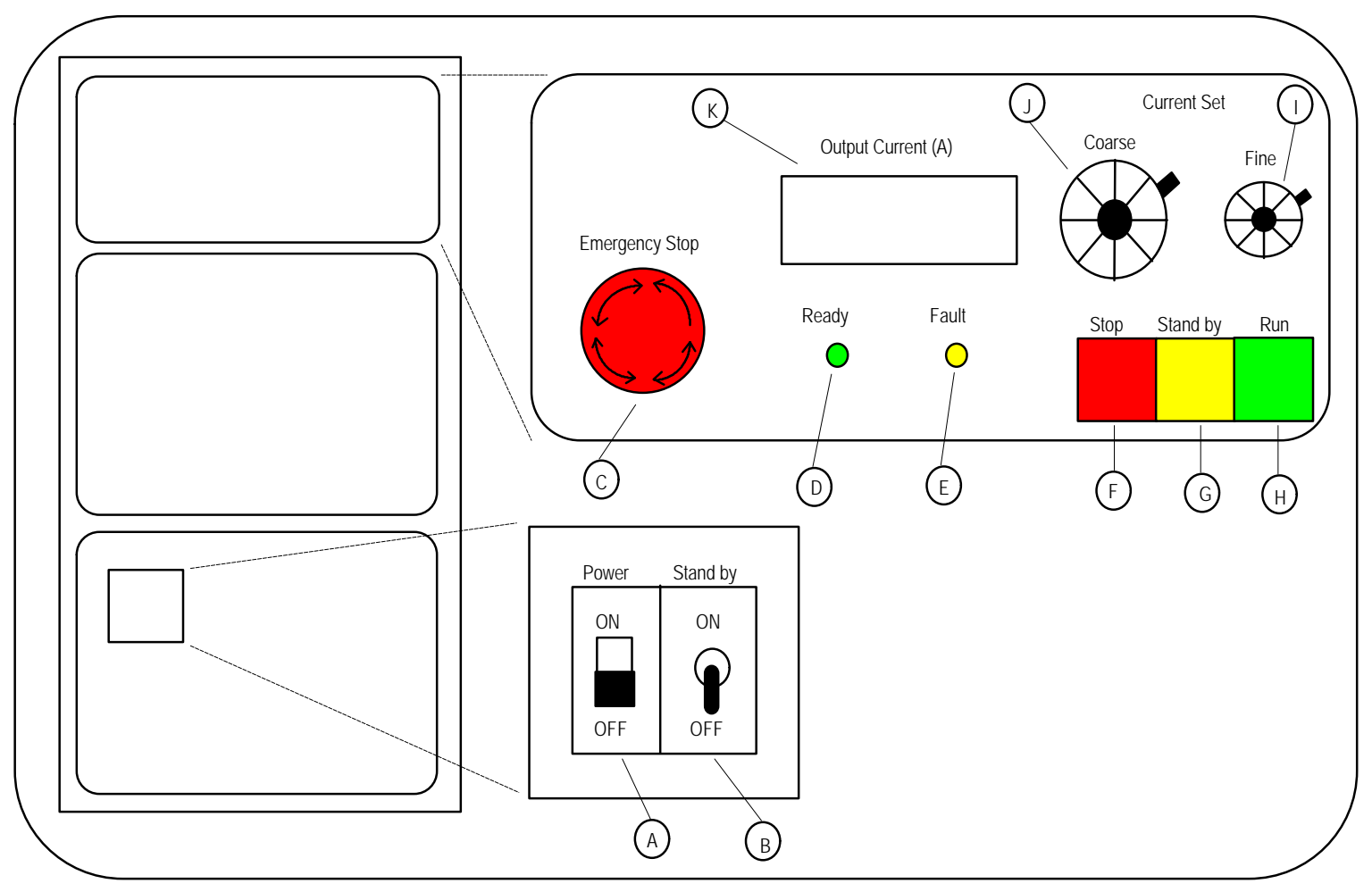

\subsubsection{Legenda}
A. Chave Power
B. Chave Stand By
C. Botão Emergency Stop
D. Indicador Ready da Fonte de Alimentação Magneto
E. Indicador Fault da Fonte de Alimentação do Magneto
F. Botão Stop da Fonte de Alimentação do Magneto
G. Botão Stand By
H. Botão Run
I. Ajuste de Corrente Fine
J. Ajuste de Corrente Coarse
K. Visor Output Current 


\subsection{Painel do Amplificador de Gradientes}

\subsubsection{Layout 5}

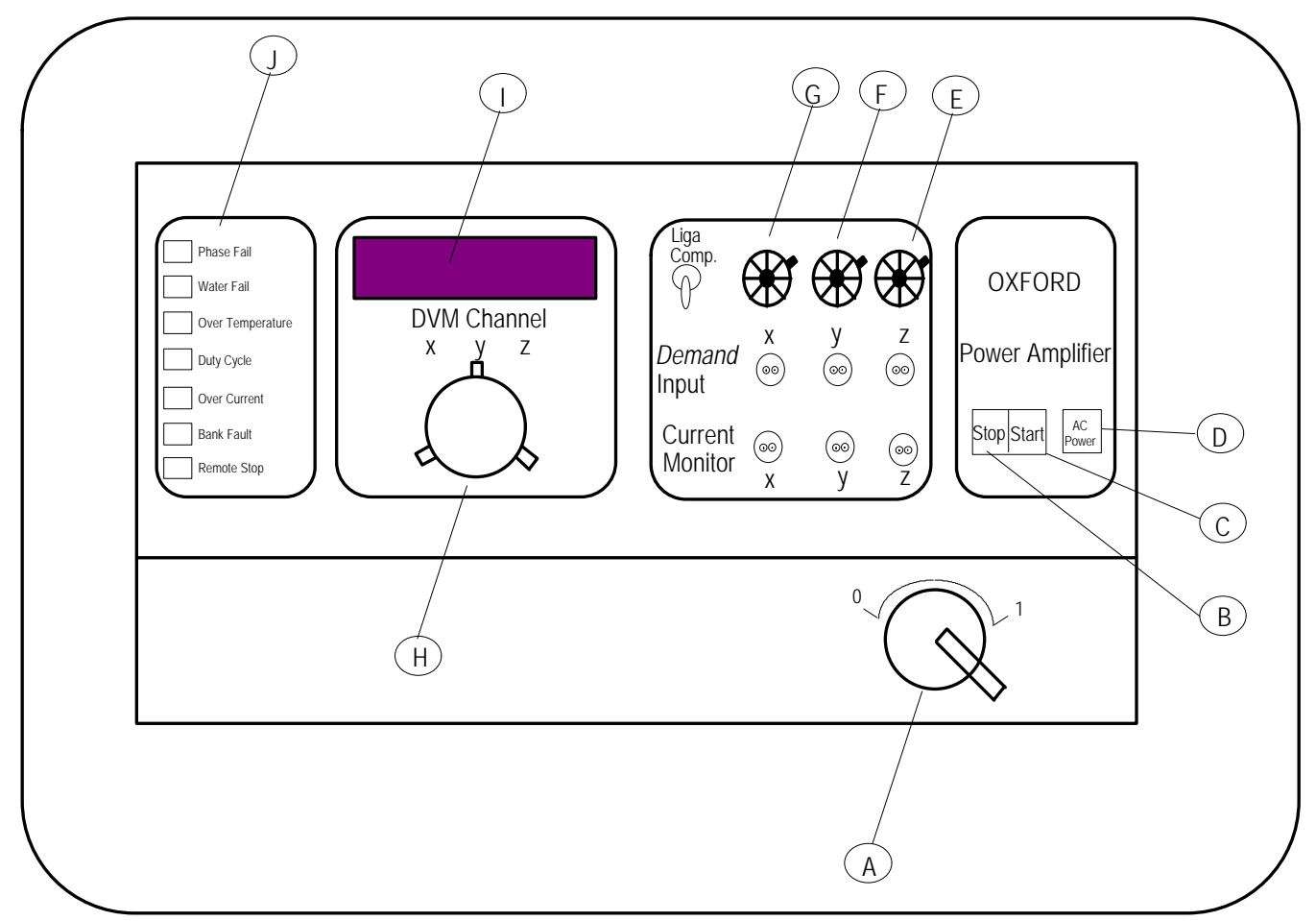

\subsubsection{Legenda}
A. Chave Liga/Desliga
B. Botão Stop do Amplificador de Gradientes
C. Botão Start
D. Indicador AC Power
E. Ajuste de Corrente Z
F. Ajuste de Corrente Y
G. Ajuste de Corrente X
H. Seletor DVM Channel
I. Visor DVM Channel
J. Painel de Falha do Amplificador de Gradientes 
1.6 Estabilizador de Tensão

\subsubsection{Layout 6}

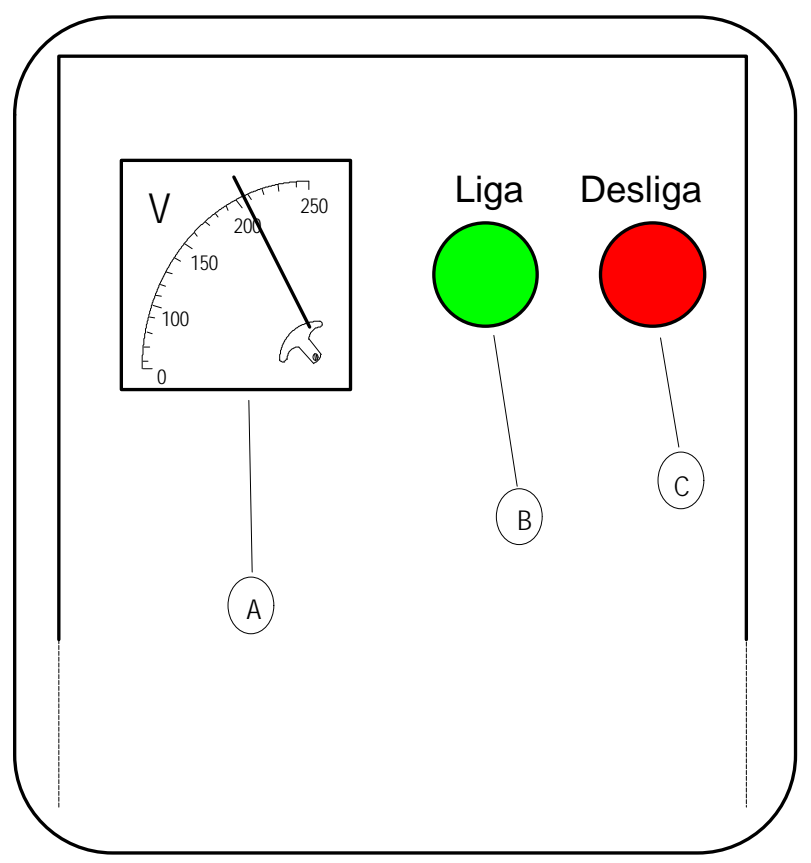

\subsubsection{Legenda}
A. Escala Medidora
B. Botão Liga
C. Botão Desliga 


\subsection{Sistema do Espectrômetro}

\subsubsection{Layout 7}

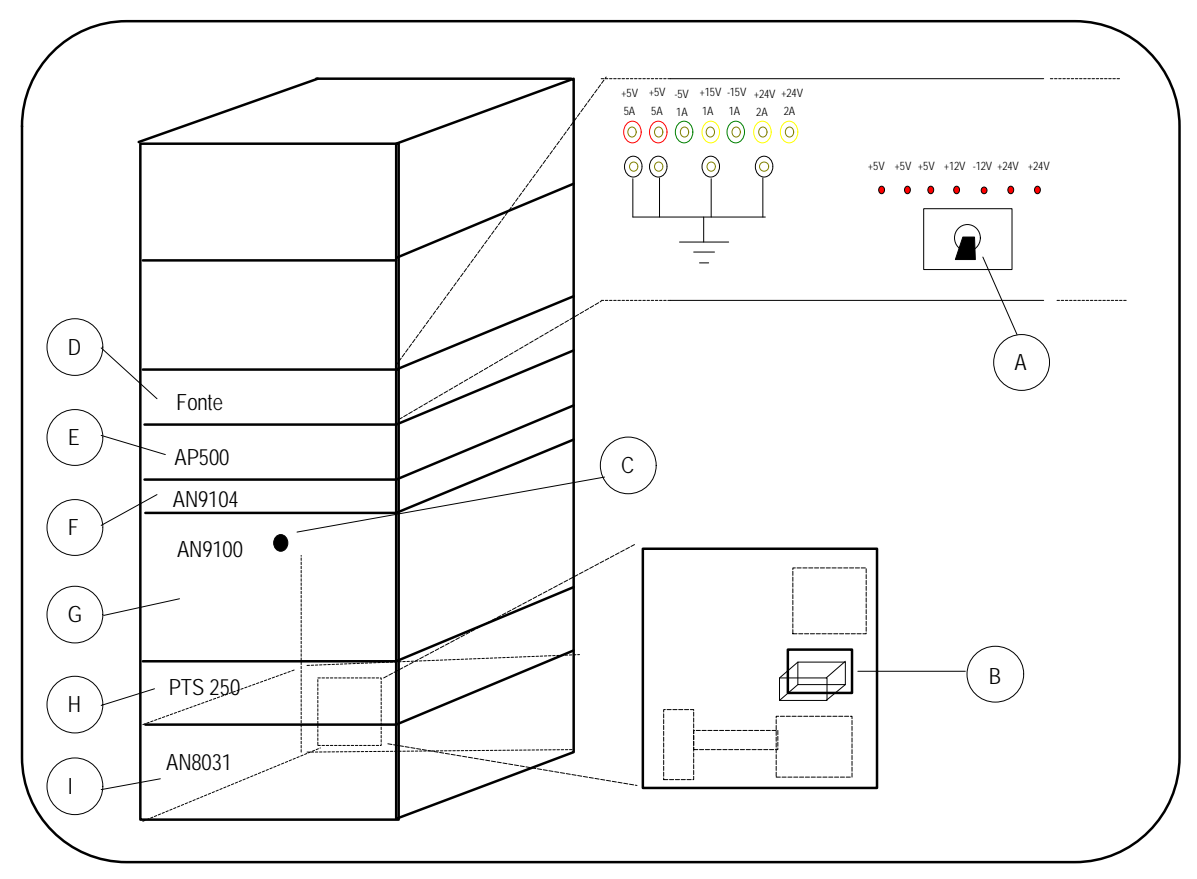

\subsubsection{Legenda}
A. Chave ON/OFF da Fonte do Sistema do Espectrômetro
B. Chave ON/OFF do Amplificador de Potência de RF
C. Botão Reset do Espectrômetro
D. Fonte do Sistema do Espectrômetro
E. Processador de Arranjos
F. Interface Óptica
G. Espectrômetro
H. Sintetizador de RF do Espectrômetro
I. Amplificador de Potência de RF 


\subsection{Controle de Nível de Sinal}

\subsubsection{Layout 8}

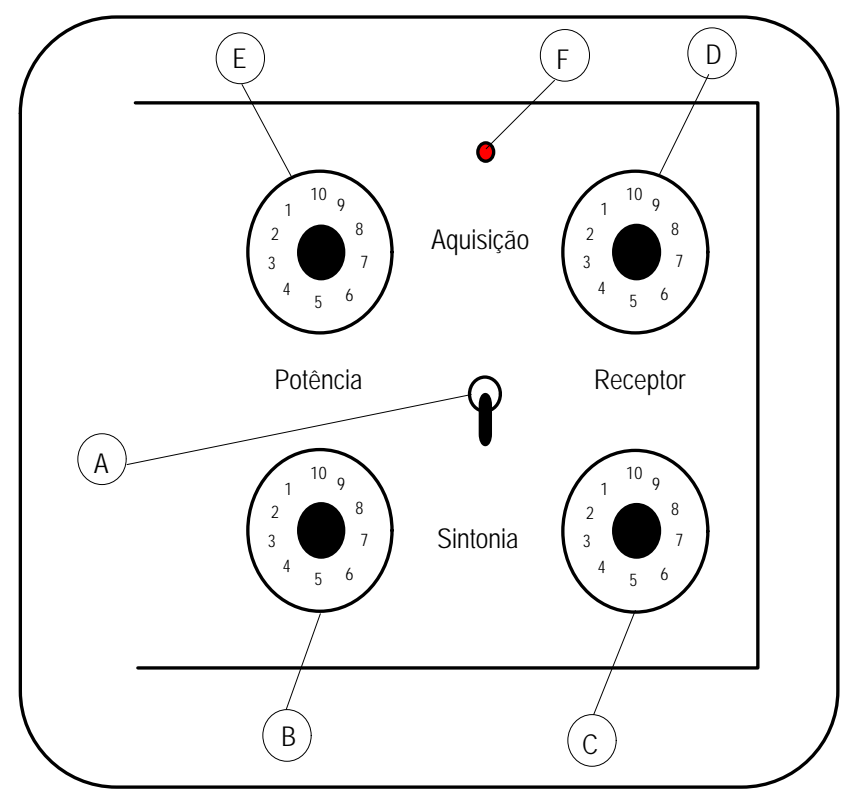

\subsubsection{Legenda}
A. Chave Sintonia/Aquisição
B. Seletor Fine do Controle de Nível de Potência
C. Seletor Fine do Controle de Nível de Recepção
D. Seletor Coarse do Controle de Nível de Recepção
E. Seletor Coarse do Controle de Nível de Potência
F. Indicador de Operação do Controle de Nível de Sinal 


\subsection{Processador de Arranjos}

\subsubsection{Layout 9}

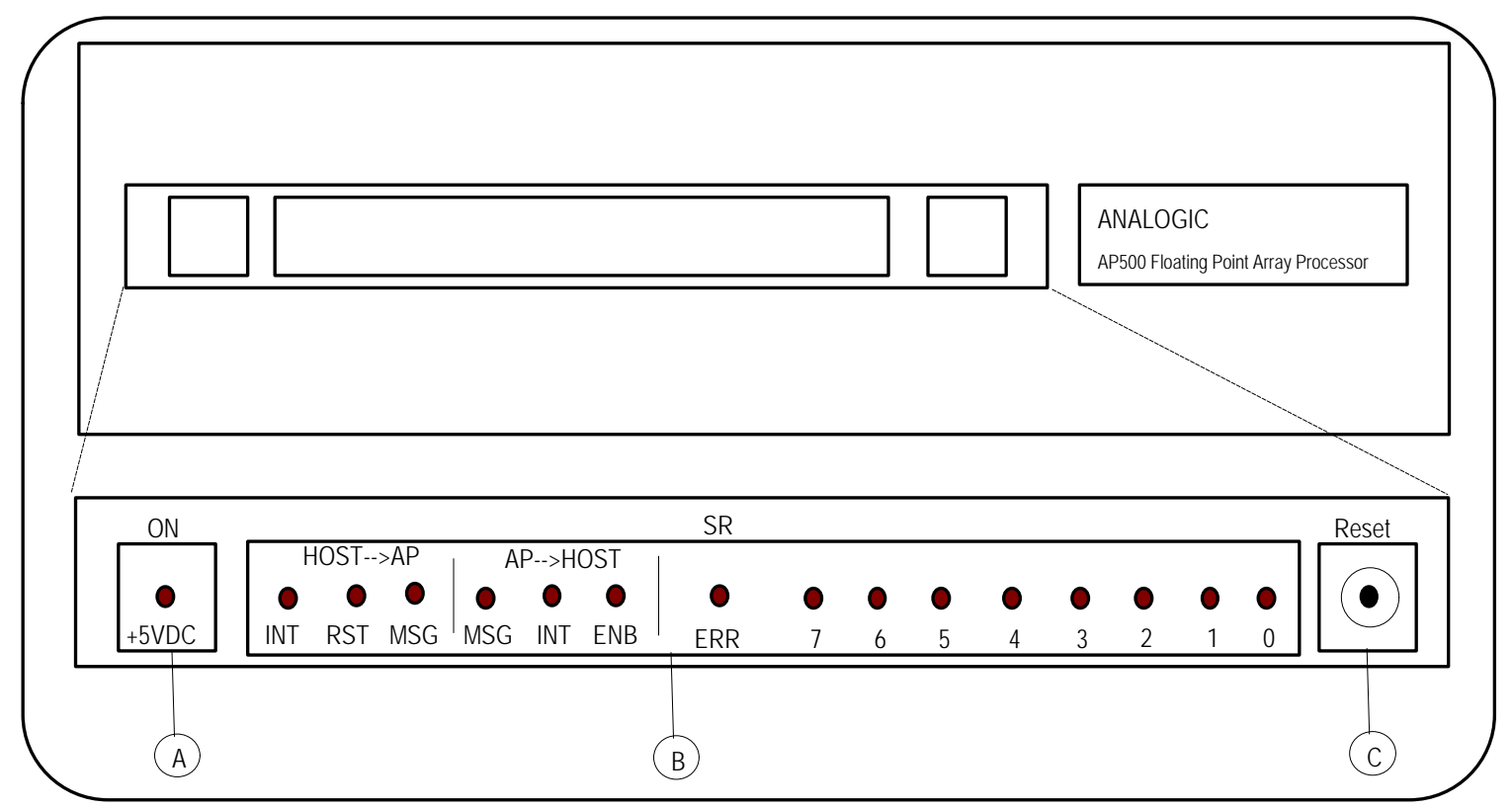

\subsubsection{Legenda}
A. Indicador de Operação do Processador de Arranjos
B. Indicadores de Status do Processador de Arranjos
C. Botão Reset do Processador de Arranjos 
1.10 Amplificador de Potência de RF

\subsubsection{Layout 10}

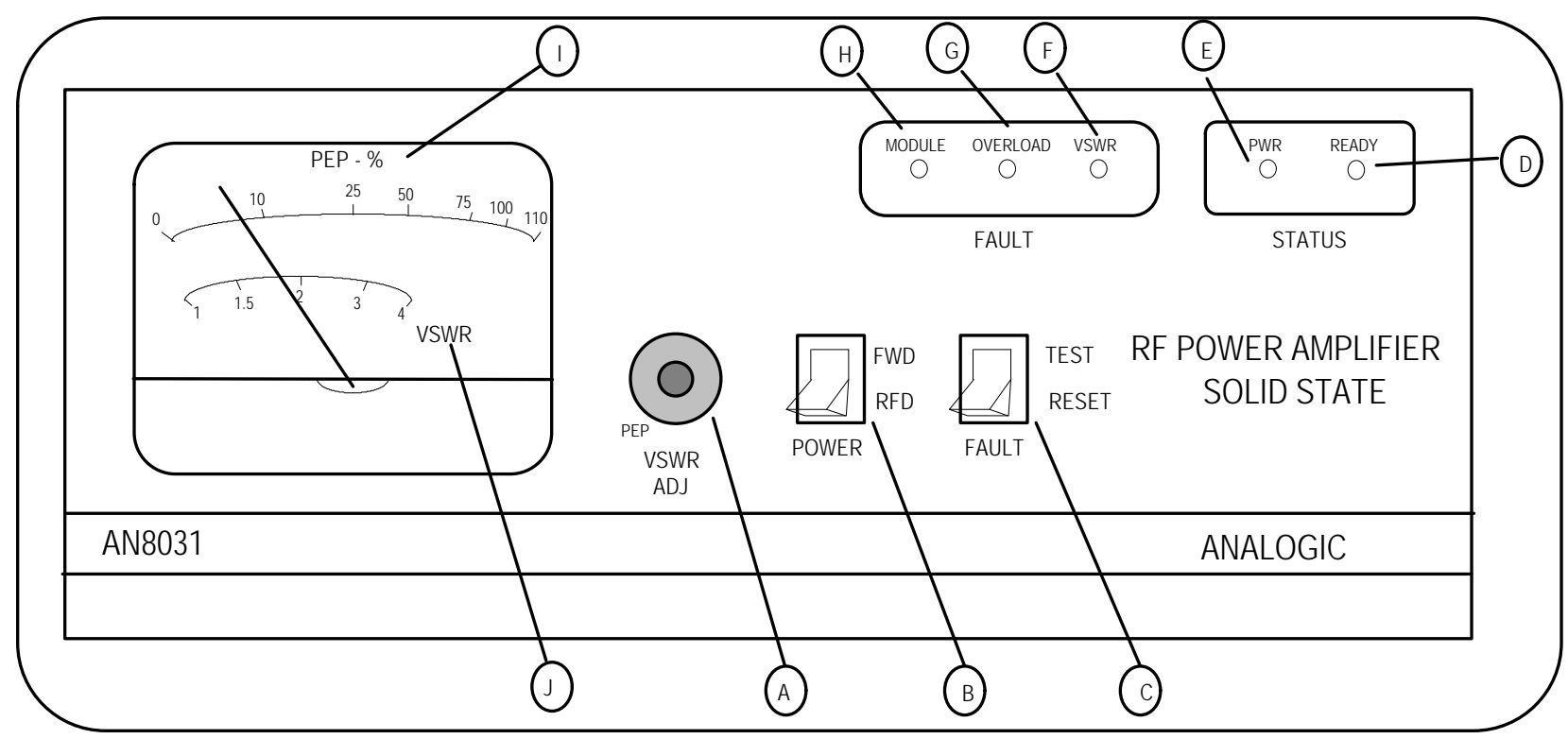

\subsubsection{Legenda}
A. Ajuste VSWR ADJ
B. Chave Power FWD/RFD
C. Botão Fault
D. Indicador Ready
E. Indicador PWR
F. Indicador VSWR
G. Indicador Overload
H. Indicador Module
I. Escala Medidora PEP
J. Escala Medidora VSWR 


\section{Descrição dos equipamentos: "desc.txt"}

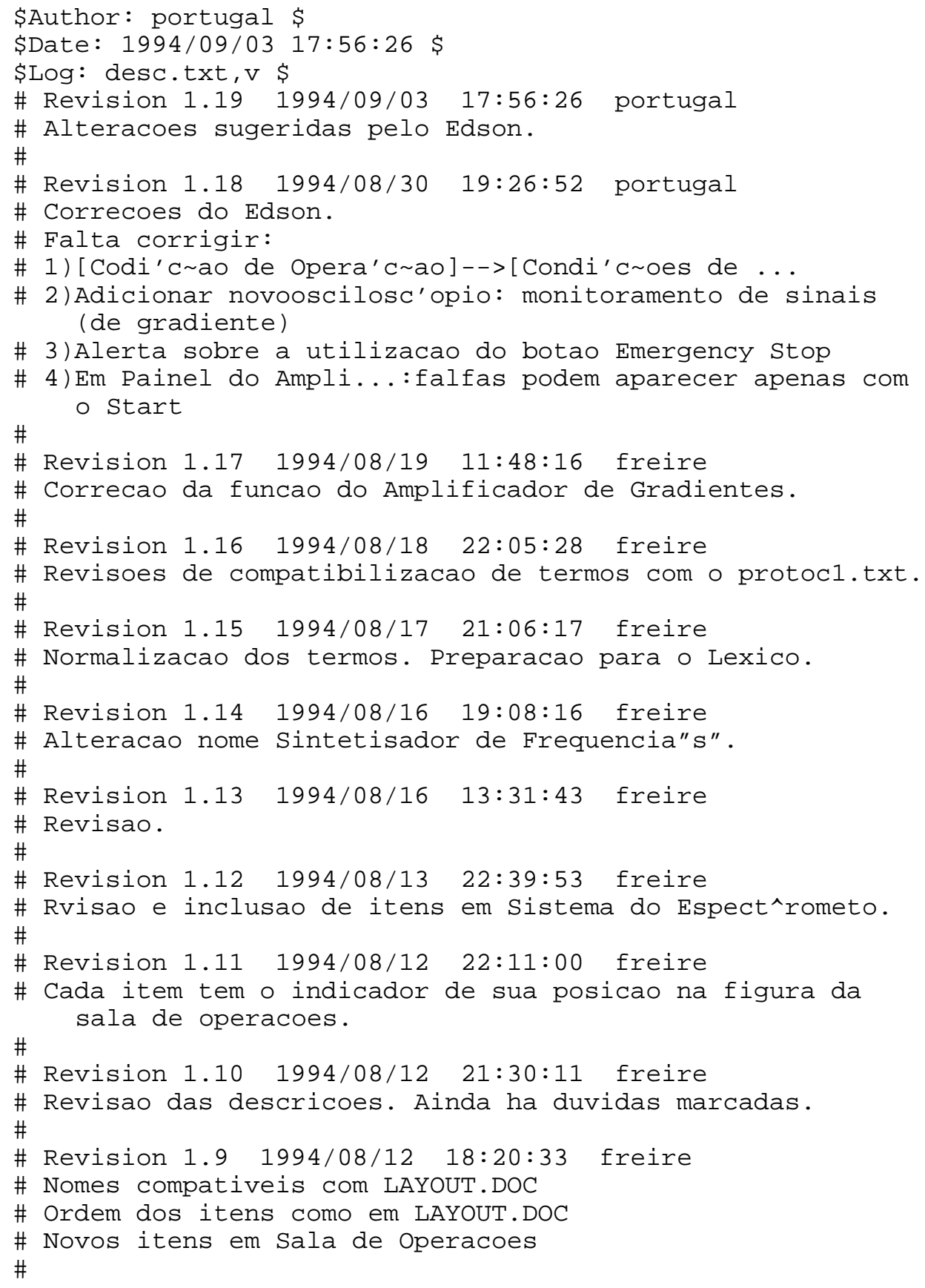




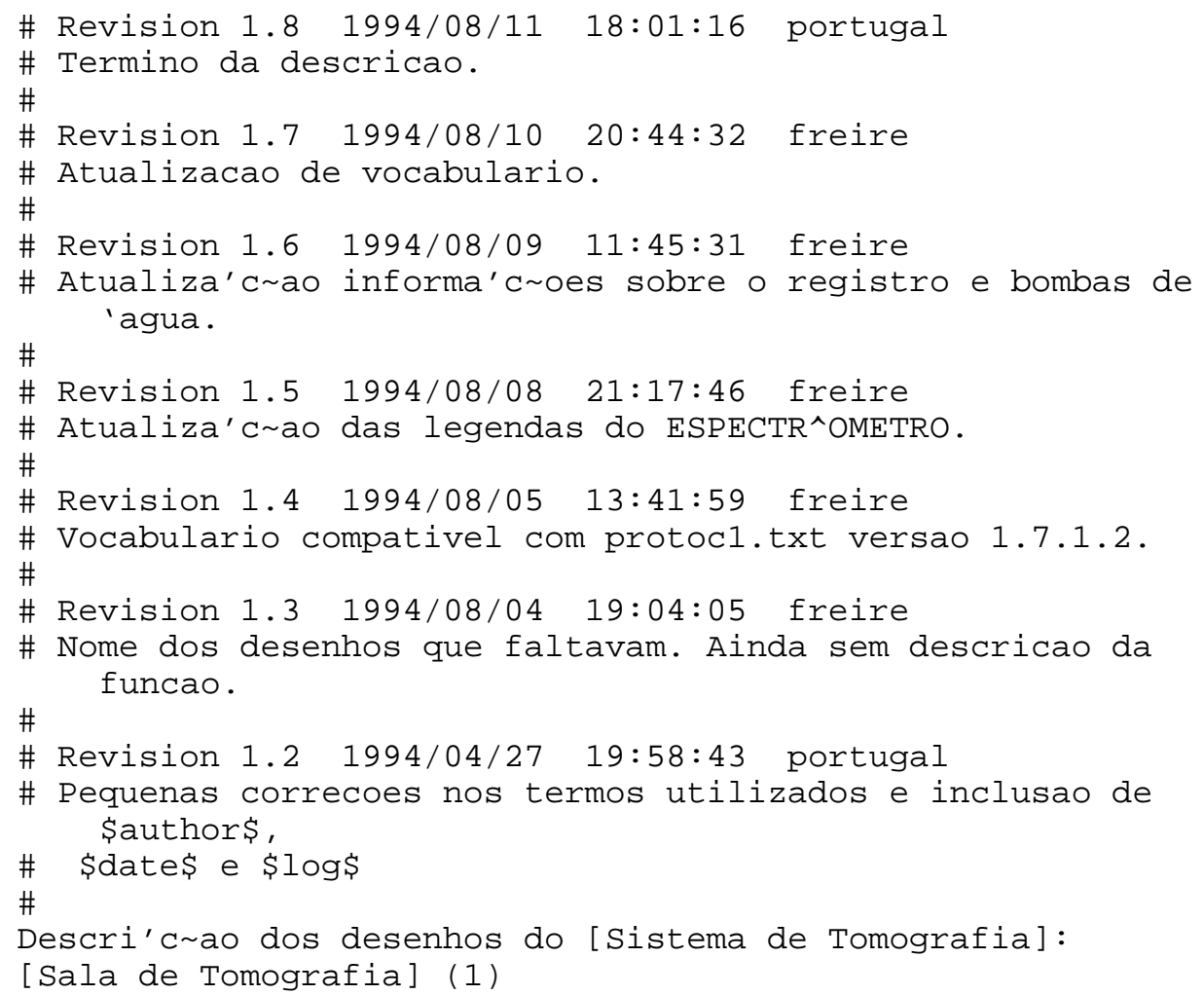

A. [Estabilisador de Tens ao] : regula a tens ao alternada em 110 ou 220 volts. 'E utilizado pelo [Sistema de Computadores] (1.F, 1.G, 1.H, 1.J, 1.K) e pelo [Sistema do [Espectr^ometro]] (1.I).

B. [Amplificador de Gradientes]: amplifica as formas de onda geradas pelo [Espect^ometro] usados nas [Bobinas de Gradiente] do [Tom'ografo] (1.R) e nas [Bobinas de Gradiente do [Magneto Supercondutor]].

C. [Fonte de Alimenta'c ao do [Magneto]]: fornece corrente cont'inua regulada ao [Magneto].

D. [Transformador do Magneto]: faz uma pr'e-regulagem da tens ao da [Fonte de Alimenta'c ao do [Magneto]].

E. [Sintetizador de RF]: utilizado para fazer o [Procedimento de Sintonia].

F. [Disco de Sistema do [ [MicroVax]]]: utilizado principalmente pelo [Sistema Operacional do [ [MicroVax ] ] ].

G. [MicroVax]: utilizado para programa' c ao do [Espectr^ometro] e processamento dos [Dados de Aquisi'c ao].

H. [Disco de Usu'arios do [[MicroVax]]]: utilizado para armazenamento dos [Dados de Aquisi'c ao] e das [ Imagens ] .

I. [Sistema do [Espectr^ometro]]: possui os m'odulos [Fonte do [Sistema do [Espectr^ometro]]], [Processador de Arranjos], [Interface 'Optica], [Espectr^ometro], [Sintetisador de RF do [Espect^ometro]] e o [Amplificador de Pot^encia de RF];

J. [Tela de Visualisa'c ao]: tela preto e branco, com 256 n'iveis de cinza, ligada ao [Macintosh].'E utilizada na visualiza'c ao de [Imagens].

K. [Macintosh]: Utilizado para gerenciar o [Sistema de Interfaces] de [Opera'c ao], [Visualiza'c ao] e [Tratamento de [Imagens]]. 
L. [Controle de $\mathrm{N}^{\prime}$ ivel de Sinal]: utilizado para atenuar a pot^encia do [Sinal de Transmi'c ao] e [Sinal de Recep' c ao] do [Tom'ografo].

M. [Chave Geral do [Sistema do [Espectr^ometro]]]: liga e desliga o [Sistema do [Espectr^ometro]].

N. [Sintonizador]: utilizado no [Procedimento de Sintonia].

O. [Prote' c ao do [Pr'e-Amplificador]]: protege o [Pr'eAmplificador] contra excesso de pot^encia na sua entrada.

P. [Cama]: local onde o [Paciente] ou [Amostra] 'e colocado.

Q. [Painel do [Tom'ografo]]: utilizado para posicionamento da [Cama] dentro do [Magneto] e para visualiza'crao do sinal gerado no [Procedimento de Sintonia].

?R. [Tom'ografo]: basicamente constitu'ido por um [Magneto], [Bobinas de Gradiente], .....---.Completar..?

S. [Registro do [Circuito Externo de Refrigera'crao]]: registro de 'agua do [Circuito Externo de Refrigera'c ao] que refrigera os [Circuitos Interno de Refrigera'c ao I] e [Circuitos Interno de Refrigera'c ao II].

T. [Chave da [Bomba de 'Agua I]]: liga e desliga a [Bomba de 'Agua I].

U. [Chave da [Bomba de 'Agua II]]: liga e desliga a [Bomba de 'Agua II].

V. [Bot oes de Sintonia]: utilizados para ajustar o [Acoplamento] da [Bobina de RF] no [Procedimento de Sintonia].

W. [Ventilador]: utilizado para ventila'c ao interna do [Tom'ografo], quando com [Paciente].

X. [Sistema de Refrigera'c ao de Ambiente]: utilizado para manter a temperatura da [Sala de Tomografia] em [Condi'croes de Opera'c ao].

Y. [Tomada do [Exaustor]]: utilizada para ligar o [Exaustor] do [Tom'ografo].

Z. [Oscilosc'opio I]: utilizado para visualisar o [FID] durante $\circ$ [Procedimento de Shimming].

AA. [Oscilosc'opio II]: utilizado para monitoramento de sinais de [Gradiente de Campo Magn'etico].

[Painel do [Tom'ografo]] (1.Q)

A. [Bot ao Posicionador]: Zera, no [Visor de Posi'c ao] (2.C), a indica'c ao da posi'c ao da [Cama].

B. [Indicador de Sintonia]: Indica o [Acoplamento] da [Bobina de RF].

C. [Visor de Posi'C ao]: Indica o deslocamento da [Cama], em cm, com rela'c ao 'a posi'crao onde o [Bot ao Posicionador] foi pressionado pela 'ultima vez.

[Sintetizador de RF] (1.E)

A. [Chave Stand By/On]: liga ou desliga o [Sintetizador de $\mathrm{RF}$ ] .

B. [Ajuste Level]: regula o n'ivel do sinal de sa'ida entre 3 e $13 \mathrm{~dB}$ (2 a $20 \mathrm{~mW})$.

C. [Conector Output]: conex ao para o cabo coaxial que ligar o [Sintetizador de RF] ao [Sintonizador] (1.N) no [Procedimento da Sintonia].

D. [Indicador Remote/Local]: indica o estado atual do [Sintetizador de RF];

E. [Seletores de Frequ^encia]: selecionam a frequ^encia do sinal de sa'ida. 
[Painel da [Fonte de Alimenta'c ao do [Magneto]]] (1.C)

A. [Chave Power]: Liga a [Fonte de Alimenta'c ao do [Magneto] ] (1.C).

B. [Chave Stand By]: Habilita (posi'c ao ON) ou n ao (posi'c ao OFF) a utiliza'c ao do [Bot ao Stand By] $(4 . G)$.

C. [Bot ao Emergency Stop]: Remove imediatamente a pot^encia de sa'ida da [Fonte de Alimenta'c ao do [Magneto]] quando pressionado. Deve ser pressionado apenas em casos de emerg^encia.

D. [Indicador Ready da [Fonte de Alimenta' c ao do [Magneto]]]: Fica aceso quando a corrente do [Magneto] est' a controlada no valor indicado no [Visor Output Current]. Ele 'e apagado quando a corrente est' a variando.

E. [Indicador Fault da [Fonte de Alimenta'c ao do [Magneto]]]: Indica a exist^encia de [Falha da [Fonte de Alimenta'c ao do [Magneto]]] que 'e especificada no [Painel de [Falha da [Fonte de Alimenta'c ao do [Magneto] ] ] .

F. [Bot ao Stop da [Fonte de Alimenta'crao do [Magneto]]]: Quando pressionado, a [Fonte de Alimenta' c ao do [Magneto]] (1.C) reduz a corrente do [Magneto]'a zero. Note que este bot ao n ao remove a pot^encia imediatamente.

G. [Bot ao Stand By]: Coloca a [Fonte de Alimenta' c ao do [Magneto]] em [Estado Stand By]. A corrente do [Magneto] passa a ser ajustada pelo [Controlador de Resist^encia do [Magneto]]. O [Circuito Interno de Refrigera' c ao I] 'e suposto estar desativado. Uma refrigera' c ao a 'agua da pr'opria da [Fonte de Alimenta'c ao do [Magneto]] deve estar ligada.

H. [Bot ao Run]: Quando pressionado faz com que a corrente do [Magneto] seja ajustada pelo [Ajuste da Corrente Fine] (4.I) e pelo [Ajuste da Corrente Coarse] (4.J).

I. [Ajuste da Corrente Fine]: Realiza o ajuste fino da corrente do [Magneto].

J. [Ajuste da Corrente Coarse]: Realiza o ajuste grosso da corrente do [Magneto].

K. [Visor Output Current]: Indica a corrente do [Magneto] em amperes.

[Painel do [Amplificador de Gradientes]] (1.B)

A. [Chave Liga/Desliga]: Na posi'C ao | liga-se os [Circuitos de Controle] e desconecta-se os [Circuitos de Altas Correntes]. A [L^ampada AC Power] (5.D) ir'a acender. Ap' os isto falhas poder ao ser indicadas no [Painel de Falha do [Amplificador de Gradientes]] $(5 . \mathrm{J})$.

B. [Bot ao Stop do [Amplificador de Gradientes]]: Desliga os [Circuitos de Altas Correntes].

C. [Bot ao Start]: Liga os [Circuitos de Altas Correntes]. $\mathrm{H}^{\prime}$ a um atraso de um segundo antes do [Amplificador de Gradientes] controlar a corrente para as [Bobinas de Gradiente]. Este bot ao $\mathrm{s}^{\prime} \mathrm{o}$ poder'a ser pressionado se n ao houver nenhuma indica'c ao no [Painel de Falha do [Amplificador de Gradientes]] (5.J). Algumas falhas $s^{\prime} 0$ ser ao indicadas ap' os este bot ao ser pressionado.

D. [Indicador AC Power]: Indica que o [Amplificador de Gradientes] est'a ligado, embora os [Circuitos de Altas Correntes] possam estar ligados ou n ao. 
E. [Ajuste de Corrente Z]: faz o ajuste fino do offset de corrente das [Bobinas de Gradiente] do eixo z.

F. [Ajuste de Corrente Y]: faz o ajuste fino do offset de corrente das [Bobinas de Gradiente] do eixo y.

G. [Ajuste de Corrente X]: faz o ajuste fino do offset de corrente das [Bobinas de Gradiente] do eixo $x$.

H. [Seletor DVM Channel]: Seleciona qual das [Bobinas de Gradiente] ter'a sua corrente mostrada no [Visor DVM Channel] (5.I).

I. [Visor DVM Channel]: Mostra o valor da corrente que est' a alimentando as [Bobinas de Gradiente] da eixo indicada pela [Seletor DVM Channel] (5.H) .

J. [Painel de [Falha do [Amplificador de Gradientes]]]: Indica a [Falha do [Amplificador de Gradientes]].

[Estabilizador de Tens ao] (1.A)

A. [Escala Medidora]: indica a tensùo de sa'ida em volts.

B. [Bot ao Liga]: liga o [Estabilizador de Tens ao].

C. [Bot ao Desliga]: desliga o [Estabilizador de Tens ao].

[Sistema do [Espectr^ometro]] (1.I)

A. [Chave ON/OFF da [Fonte do [Sistema do

[Espectr^ometro]]]]: liga e desliga a [Fonte do

[Sistema do [Espectr^ometro]]].

B. [Chave ON/OFF do [Amplificador de Pot^encia de RF]]: liga e desliga o [Amplificador de Pot^encia de RF].

C. [Bot ao Reset do [Espectr^ometro]]: reinicializa o [Espectr^ometro].

D. [Fonte do [Sistema do [Espectr^ometro]]]: Fonte de tens ao para os $\mathrm{m}^{\prime}$ odulos colocados no [Sistema do [Espectr^ometro] ].

E. [Processador de Arranjos]: realiza as m'edias dos [Sinais de NMR] e transmite os [Dados de Aquisi'c ao] para o [MicroVax].

F. [Interface 'optica]: liga opticamente o duto de dados do [Espectr^ometro] ao [Processador de Arranjos], isolando-os eletricamente.

G. [Espectr^ometro]: subsistema eletr^onico de monitoramento, controle e gera'c ao de sinais para [Espectroscopia por RMN] e [Aquisi'c ao de [Imagens] por RMN].

H. [Sintetizador de $\mathrm{RF}$ do [Espect^ometro]]: gera o sinal de $\mathrm{RF}$ e a [Base de Tempo do [Espectr^ometro]].

I. [Amplificador de Pot^encia de RF]: amplifica os sinais de $R F$ gerados pelo [Espect^ometro].

[Controle de $\mathrm{N}^{\prime}$ ivel de Sinal] (1.L)

A. [Chave Sintonia/Aquisi'c ao]: Sem fun'c ao.

B. [Seletor Fine do [Controle de $N^{\prime}$ ivel de Pot^encia]]: Faz - ajuste fino da pot^encia de RF emitida (1dB).

C. [Seletor Fine do [Controle de $\mathrm{N}^{\prime}$ ivel de Recep' Crao]]: Faz o ajuste fino do sinal de recep'c ao (1dB).

D. [Seletor Coarse do [Controle de $N^{\prime}$ ivel de Recep'c ao]]: Faz o ajuste grosso do sinal de recep' c ao (10dB).

E. [Seletor Coarse do [Controle de $N^{\prime}$ ivel de Pot^encia]]: Faz o ajuste grosso da pot^encia de RF emitida (10dB).

F. [Indicador de Opera' C ao do [Controle de $\mathrm{N}^{\prime}$ ivel de Sinal]]: Quando aceso indica que o [Controle de $N^{\prime}$ ivel de Sinal] esta em opera'c ao. 
[Processador de Arranjos] (1.I)

A. [Indicador de Opera' c ao do [Processador de Arranjos]]: quando aceso indica que o [Processador de Arranjos] est' a ligado.

B. [Indicadores de Status do [Processador de Arranjos]]: indicadores luminosos de status do [Processador de Arranjos].

C. [Bot ao Reset do [Processador de Arranjos]]: reinicializa o [Processador de Arranjos].

[Amplificador de Pot^encia de RF] (1.I)

A. [Ajuste VSWR ADJ]: 'E utilizado para medir a [Rela'c ao de Onda Estacion'aria] na sa'ida de RF do [Amplificador de Pot^encia de RF]. O [Ajuste VSWR ADJ] 'e posicionado de modo que a [Escala Medidora PEP] (10.I) leia a escala inteira (110\%) quando a [Chave Power FWD/RFD] (10.B) 'e colocada na posi'c ao FWD. A [Escala Medidora VSWR] (10.J) ir'a indicar a [Rela'c ao de Onda Estacion'aria] quando a [Chave Power FWD/RFD] (10.B) 'e colocada na posi'c ao RFD.

B. [Chave Power FWD/RFD] :

a) Colocada na posi'c ao FWD: a [Escala Medidora PEP] (10.I) ir'a indicar a pot^encia RF de pico transmitida para a carga. O [Ajuste VSWR ADJ] deve estar na posi'c ao PEP.

b) Colocada na posi'c ao RFD: a [Escala Medidora PEP] (10.I) ir'a indicar a pot^encia $\mathrm{RF}$ de pico refletida pela carga. O [Ajuste VSWR ADJ] deve estar na posi'C ao PEP.

C. [Bot ao Fault]:

a) Pressionado para a posi'c ao Test: Quando este bot ao 'e momentaneamente pressionado para esta posi'c ao, sem entrada $\mathrm{RF}$ e sem sinal BIAS ON COMMAND, a corrente de polariza'c ao 'e chaveada por aproximadamente $25 \mathrm{~ms}$ a todos os m'odulos e medida. Se os limites inferior e superior de amplitude da corrente de polariza'c ao para qualquer m'odulo forem excedidos, o [Indicador de Falha do $M^{\prime}$ odulo] e o [Indicador Module] (10.H) ir ao acender.

b) Pressionado para a posi'c ao Reset: Quando esta tecla for pressionada para a posi'c ao por uma dura'c ao $\mathrm{m}^{\prime}$ inima de 3 segundos o [Indicador VSWR] (10.F), [Indicador Overload] (10.G) e o [Indicador Module] (10.H) e o [Indicador de Falha do $\mathrm{M}^{\prime}$ odulo] ir ao desligar a n ao ser que haja uma falha presente.

D. [Indicador Ready]: Se n ao houver falha de instrumentos este indicador ir'a acender aproximadamente 3 segundos ap'os a aplica'c ao do [Sinal AC On].

E. [Indicador PWR]: Acende quando o ?main chassis circuit breaker? estiver fechado.

F. [Indicador VSWR]: Ir'a acender se a pot^encia refletida sobre o [Amplificador de Pot^encia de RF] for superior a um certo limite.

G. [Indicador Overload]: Ir'a acender se a sa'ida RF do [Amplificador de Pot^encia de RF] e os limites de ?BIAS ON COMMAND? forem excedidos.

H. [Indicador Module]: Ir'a acender se houver uma:

a) Falha de m'odulo (neste caso o [Indicador de Falha do M'odulo] em cada m'odulo com defeito ir'a acender);

b) ?Duto? de m'odulo desconectado;

I. [Escala Medidora PEP]: Indica a pot^encia RF de pico absorvida ou refletida no conector de sa'ida de $R F$ do 
[Amplificador de Pot^encia de RF], quando o [Ajuste VSWR ADJ] (10.A) est'a na posi'c ao PEP (posi'c ao calibrada).

J. [Escala Medidora VSWR]: Ir'a indicar a [Rela'crao de Onda Estacion'aria] na sa'ida de RF do [Amplificador de Pot^encia de RF]. 


\section{Descrição dos protocolos de operação: "protoc1.txt"}

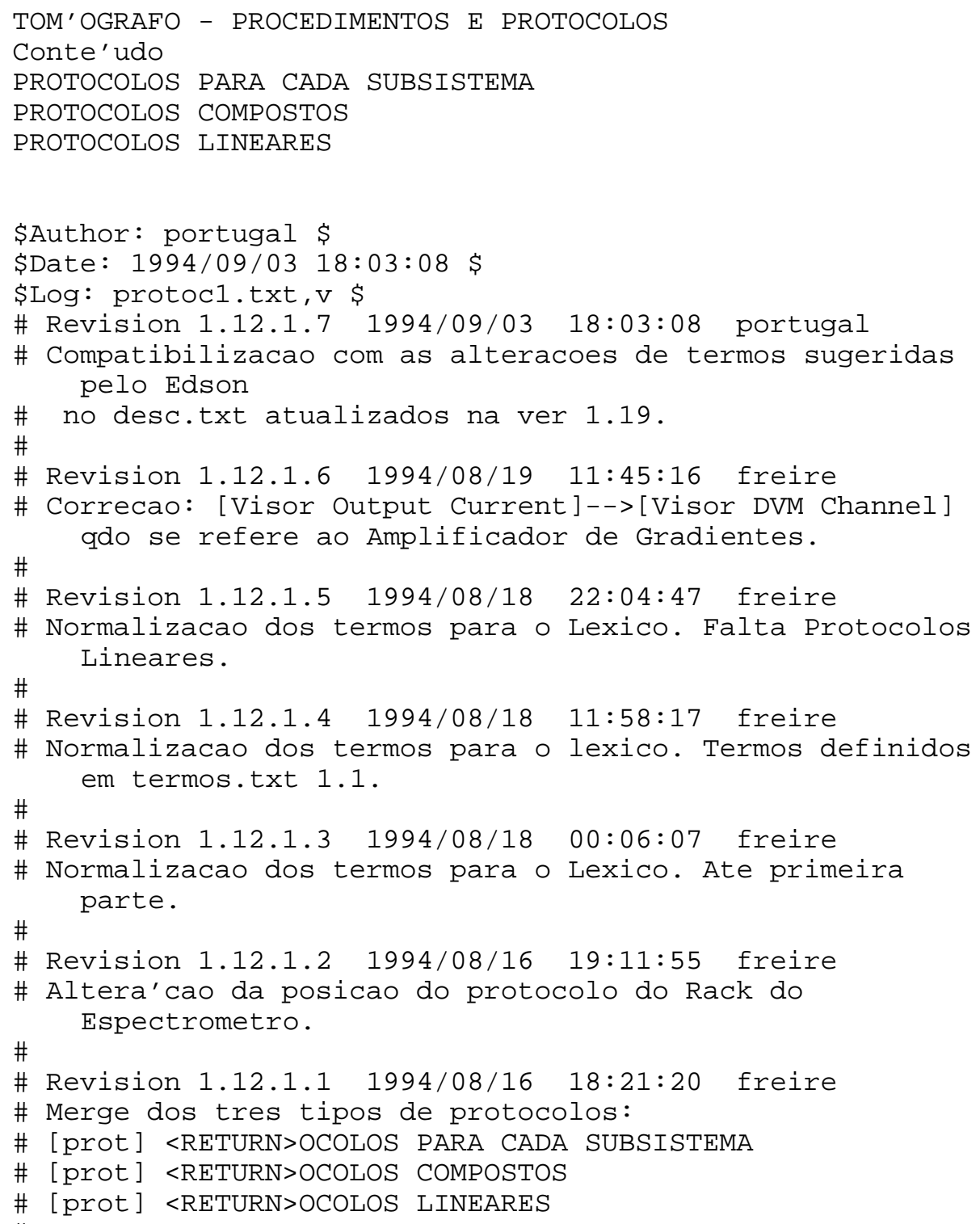




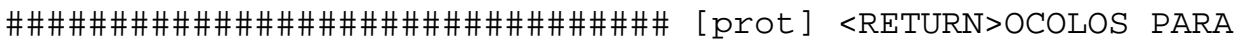
CADA SUBSISTEMA

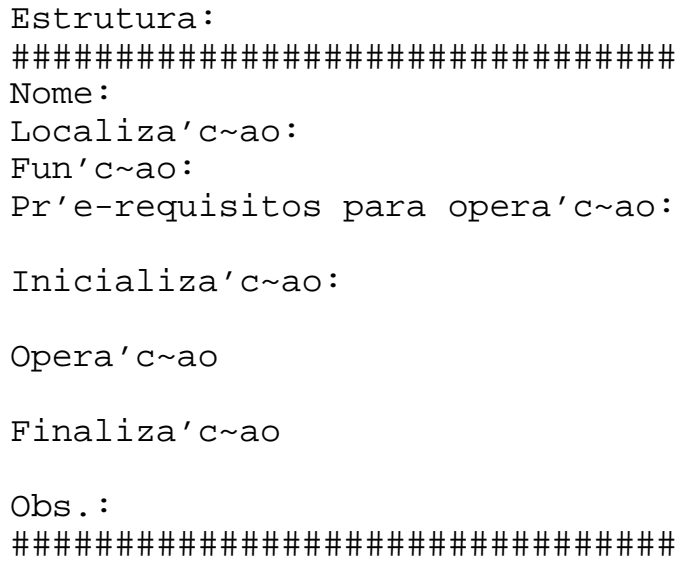


Nome: [Circuito Interno de Refrigera'c ao I]

Localiza'c ao: [Sala do [Tom'ografo]]

Fun'c ao: Dissipar o calor do [Magneto] e da [Fonte de Alimenta'c ao do [Magneto]] gerado durante a opera' c ao.

Pr'e-requisitos para opera'c ao:

- "Inicializar o [Circuito Externo de Refrigera'crao]".

Inicializa'c ao:

- Ligar a [Bomba de 'Agua I] usando a chave (1.T);

Opera' c ao

Finaliza'c ao

- Desligar a [Bomba de 'Agua I] usando a chave (1.T);

Obs.:

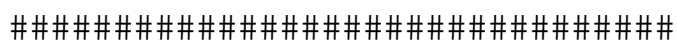

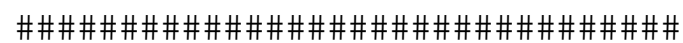

Nome: [Circuito Interno de Refrigera'c ao'II]

Localiza'c ao: [Sala do [Tom'ografo]]

Fun'crao: Dissipar o calor das [Bobinas de Gradiente] e do [Amplificador de Gradientes] gerado durante a opera' c ao.

Pr'e-requisitos para opera'c ao:

- "Inicializar o [Circuito Externo de Refrigera'crao]".

Inicializa'c ao:

- Ligar a [Bomba de 'Agua II] usando a chave (1.U);

Opera' c ao

Finaliza'c ao

- Desligar a [Bomba de 'Agua II] usando a chave (1.U);

Obs.:

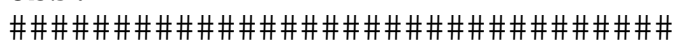

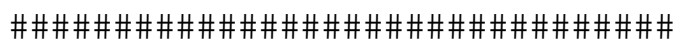

Nome: [Sintetizador de RF]

Localiza'c ao: [Sala de Equipamentos]

Fun'c ao: Gerar sinais de RF.

Pr'e-requisitos para opera'c ao:

Inicializa'c ao:

- Ligar [Sintetizador de RF] (1.E), utilizando a [Chave Stand By/On] (3.A);

Opera' C ao

- Ajustar o [Sintetizador de RF] (1.E) em $2.35 \mathrm{MHz}$, utilizando os [Seletores de Frequ^encia] (3.E);

- Ajustar a atenua' C ao do sinal de sa'ida usando o [Ajuste Level] (3.B);

- Conectar um cabo coaxial no [Conector Output] (3.C);

Finaliza'c ao

- Desligar [Sintetizador de RF] (1.E) utilizando a [Chave Stand By/On] (3.A);

Obs.:

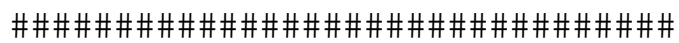

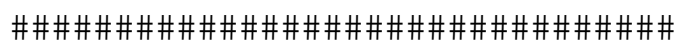

Nome: [Estabilizador de Tens ao].

Localiza'c ao: [Sala de Equipamentos]. 
Fun' Crao: Fonte de tens ao para o [Sistema de Computadores] (1.F, 1.G, 1.H, 1.J, 1.K) e para o [Sistema do [Espectr^ometro] ] (1.I).

Pr'e-requisitos para opera'c ao:

- "Inicializar o [Sistema de Refrigera'c ao de Ambiente]".

Inicializa' c ao:

- Ligar o [Estabilizador de Tens ao] (1.A) pressionando-se o [Bot ao Liga] (6.B).

Opera' c ao

Finaliza' C ao

- Desligar o [Estabilizador de Tens ao] (1.A) pressionandose o [Bot ao Desliga] (6.C).

Obs.:

- Em geral o [Estabilizador de Tens ao] fica constantemente ligado para que o [Sistema de Computadores] n ao sejam desligados.

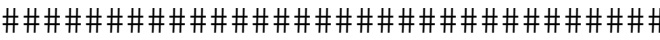

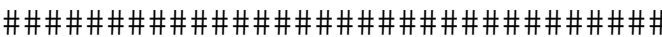

Nome: [Controle de $\mathrm{N}^{\prime}$ ivel de Sinal].

Localiza'c ao: Na [Sala de Opera'croes].

Fun'c ao: Utilizado para atenuar o [Sinal de Transmi'c ao] e o [Sinal de Recep' c ao].

Pr'e-requisitos para opera'c ao:

- "Inicializar o [Estabilizador de Tens ao]"

- "Inicializar a [Procedimento de [Controle de N'ivel de Sinal] ]".

Inicializa' c ao:

Opera'c ao

- Efetuar o [Procedimento de [Controle de $\mathrm{N}^{\prime}$ ivel de Sinal]] pelo painel do [Controle de $N^{\prime}$ ivel de Sinal] (1.L), observando os indicadores na [Janela de Comando do [Microvax]]. Para isto deve-se ajustar a atenua'c ao do [Sinal de Transmi'crao] e a atenua' c ao do [Sinal de Recep'c ao] de maneira a obter o maior sinal na [Janela de Comando do [Microvax]] sem que ele seja trao grande a ponto de chegar ao fim da [Janela de Comando do [Microvax]]. Para proceder o ajuste deve-se girar os [Seletores do [Controle de $\mathrm{N}^{\prime}$ ivel de Recep'c ao]] (8.C e 8.D) e os [Seletores do [Controle de $N^{\prime}$ ivel de Pot^encia]] (8.B e 8.E) para os valores desejados. Caso os indicadores na [Janela de Comando do [Microvax]] parem de piscar digite novamente o comando [go s ] $<$ RETURN $>$ e continue o ajuste.

Finaliza'c ao

Obs. :

- Ao se diminuir a atenua'c ao, deve-se evitar altera'croes bruscas. Por exemplo, para diminuir a atenua'c ao do [Sinal de Transmi'C ao] de $20 \mathrm{~dB}$ para $10 \mathrm{~dB}$, n ao se deve passar o [Seletor Coarse do [Controle de $\mathrm{N}^{\prime}$ ivel de Pot^encia]] de 2 para 1 diretamente. O procedimento correto e passar o [Seletor Fine do [Controle de $\mathrm{N}^{\prime}$ ivel de Pot^encia]] de 0 at'e 10 (atenua'c ao de $30 \mathrm{~dB}$ ), em seguida ajustar o [Seletor Coarse do [Controle de $\mathrm{N}^{\prime}$ ivel de Pot^encia]] em 1 (atenua' C ao de $20 \mathrm{~dB}$ ) e entrao diminuir o [Seletor Fine do [Controle de $\mathrm{N}^{\prime}$ ivel de Pot^encia]] de 10 at'e 0 (atenua' c ao de $10 \mathrm{~dB}$ ). Note que houve uma altera' c ao brusca de $30 \mathrm{~dB}$ para 20 


\author{
dB, mas como a atenua' c ao 'e logar'itmica, esta \\ altera'crao 'e bem menor que se fosse de $20 \mathrm{~dB}$ para 10 \\ $\mathrm{dB}$ diretamente. Isto Tamb'em vale para 0 [Seletor \\ Coarse do [Controle de $\mathrm{N}^{\prime}$ ivel de Recep' C ao]] e o \\ [Seletor Fine do [Controle de $N^{\prime}$ ivel de Recep'c ao]];

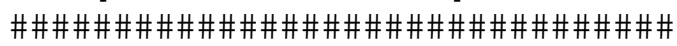

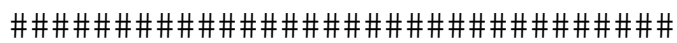

Nome: [Painel do [Tom'ografo]].

Localiza'c ao: Na parte da frente do [Tom'ografo] (1.R).

Fun'c ao: Utilizado para posicionamento da [Cama] dentro do [Magneto] e para leitura do [Indicador de Sintonia] durante [Procedimento de Sintonia].

Pr'e-requisitos para opera' c ao:

Inicializa'c ao:

Opera' c ao

- Zerar a posi'c ao da [Cama] pressionando o [Bot ao Posicionador] (2.A) do [Painel do [Tom'ografo]] (1.Q);

- Observar o [Indicador de Sintonia] (2.B), procurando obter o $\mathrm{m}^{\prime}$ inimo de indicadores acesos;

Finaliza'c ao

Obs.:

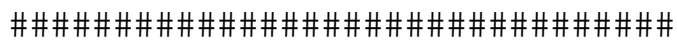

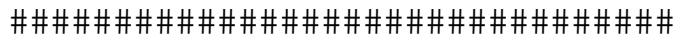

Nome: [Magneto].

Localiza'c ao: Dentro do [Tom'ografo] (1.R) na [Sala do [Tom' ografo] ] .

Fun' crao: Gera o [Campo Magn'etico Principal].

Pr'e-requisitos para opera'c ao:

- "Inicializar o [Sistema de Refrigera' c ao de Ambiente]".

Inicializa' c ao:

- "Inicializar o [Circuito Interno de Refrigera'crao I]".

- Ligar a [Fonte de Alimenta' C ao do [Magneto]] (1.C) colocando-se a [Chave Power] (4.A) na posi'c ao ON;

- Esperar entre 60 a 90 segundos para [Estabiliza'c ao El'etrica] e em seguida pressionar o [Bot ao Run] $(4 . \mathrm{H})$;

- Ligar o [Exaustor] na [Tomada do [Exaustor]] (1.Y). N ao 'e necess'ario esperar algum tempo para isto, mas 'e aconselh' avel ligar o [Exaustor] cerca de 4 horas ap'os o [Magneto] ser ligado;

- Esperar a [Estabililiza'c ao Mec^anica] e a [Estabililiza'c ao T'ermica] por pelo menos 8 horas para obter alta [Homogeneidade de Campo] constante no tempo, ou 4 horas para obter alta [Homogeneidade do Campo], vari'avel no tempo;

Opera' c ao

- Alterar o [Campo Magn'etico Principal] com o [Ajuste da Corrente Fine] (4.I) e com o [Ajuste da Corrente Coarse] (4.J) no painel da [Fonte de Alimenta'c ao do [Magneto] ];

- Ajustar o sistema para a [Resson^ancia], ajustando o [Ajuste da Corrente Fine] (4.I) no painel da [Fonte de Alimenta' c ao do [Magneto]];

- Tirar o sistema da [Resson^ancia], atrav'es de uma pequena varia'c ao do [Campo Magn'etico Principal], usando o [Ajuste da Corrente Fine] (4.I) no painel da [Fonte de Alimenta' c ao do [Magneto]]; 
- Apertar o [Bot ao Emergency Stop] (4.C) para, em caso de emerg^encia, remover imediatamente a pot^encia de sa'ida da [Fonte de Alimenta'c ao do [Magneto]];

Finaliza' C ao

- Desligar a [Fonte de Alimenta' C ao do [Magneto]] (1.C) apertando $O$ [Bot ao Stop da [Fonte de Alimenta' crao do [Magneto] ] ] (4.F);

- Esperar o valor indicado no [Visor Output Current] (4.K) zerar;

- Colocar a [Chave Power] (4.A) na posi'C ao OFF;

- "Finalizar o [Circuito Interno de Refrigera'crao I]".

OBS. :

\#Sintonisar

\#0- Retirar a [Blindagem] da [Cama] (1.P);

\#1- Colocar a [Amostra] na [Bobina de RF];

\#2- Posicionar a [Amostra] no centro do [Magneto], colocando a [Cama] na posi'c ao central (indicada pelas setas);

\#3- Zerar a posi'c ao da [Cama] no bot ao de reset (2.A) do [Painel do [Tom'ografo]];

\#4- Acoplar o cabo da [Bobina de RF] na [Sintonizador] (plug de baixo) (1.N);

\#5- Ligar [Sintetizador de RF] (1.E), utilizando a chave 3.A, e ajust'a-lo em $2.35 \mathrm{MHz}$, utilizando os bot oes 3. E;

\#6- Ajustar a sintonia com os [Bot oes de Sintonia] (situados sob a [Cama]) observando o [Indicador de Sintonia] (2.B);

\#7- Desligar [Sintetizador de RF] (1.E) utilizando a chave 3. A;

\#8- Desacoplar o cabo da [Bobina de RF] da [Sintonizador] $(1 . \mathrm{N})$;

\#9- Acoplar o cabo da [Bobina de RF] na [Prote'c ao do [Pr'e-Amplificador] ] (1.0);

\#10- Recolocar a [Blindagem] da [Cama] (1.P).

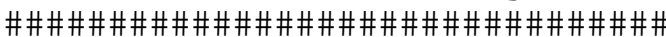

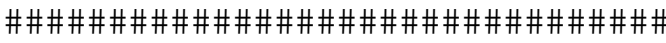

Nome: [Bobinas de Gradiente]

Localiza'c ao: Dentro do [Tom'ografo] (1.R) na [Sala do [Tom' ografo] ].

Fun' crao: Geram [Gradiente de Campo Magn'etico] nas dire'croes $x, y$ e $z$.

Pr'e-requisitos para opera'c ao:

- "Inicializar o [Sistema de Refrigera'crao de Ambiente]".

Inicializa'c ao:

- "Inicializar o [Circuito Interno de Refrigera'crao'II]";

- Ligar a [Amplificador de Gradientes] colocando a [Chave Liga/Desliga] (5.A) na posi'c ao |;

- Apertar o [Bot ao Start] (5.C) da [Amplificador de Gradientes] (o visor [Visor DVM Channel] (5.I) passa a indicar a corrente);

Opera' c ao

- Ajustar as correntes x, y e z de [Gradiente de Campo Magn'etico] utilizando os [Ajuste de Corrente X] (5.G), [Ajuste de Corrente Y] (5.F) e [Ajuste de Corrente Z] (5.E) e observando o valor da corrente selecionada pelo [Seletor DVM Channel] (5.H) no [Visor DVM Channel] (5.I); 
- Ajustar as correntes x, y e z de [Gradiente de Campo Magn'etico], utilizando os [Ajuste de Corrente X] (5.G), [Ajuste de Corrente Y] (5.F) e [Ajuste de Corrente Z] (5.E), de maneira que a envolt'oria do [FID] observado na tela do [Oscilosc'opio I] (1.Z) tenha um perfil exponencial longo e sem batimentos;

- Zerar as correntes x, y e z de [Gradiente de Campo Magn'etico] usando o [Seletor DVM Channel] (5.H) e os [Ajuste de Corrente X] (5.G), [Ajuste de Corrente Y] (5.F) e [Ajuste de Corrente Z] (5.E) do [Painel do [Amplificador de Gradientes]] (1.B);

Finaliza' c ao

- Apertar o [Bot ao Stop do [Amplificador de Gradientes]] (5.B);

- Desligar a [Amplificador de Gradientes] (1.B) utilizando a [Chave Liga/Desliga] (5.A);

- "Finalizar o [Circuito Interno de Refrigera'crao'II]";

Obs.:

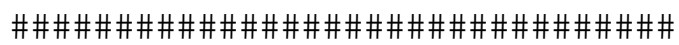

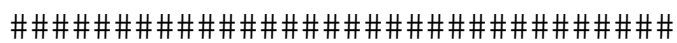

Nome: [Sistema do [Espectr^ometro]]

Localiza'c ao: [Sala de Equipamentos]

Fun' C ao: possui os m'odulos [Fonte do [Sistema do

[Espectr^ometro]]], [Processador de Arranjos],

[Interface 'Optica], [Espectr^ometro], [Sintetisador de $\mathrm{RF}$ do [Espect^ometro]] e o [Amplificador de Pot^encia de $R F$ ]

Pr'e-requisitos para opera' c ao:

- "Inicializar o [Sistema de Refrigera'c ao de Ambiente]".

- "Inicializar o [Estabilizador de Tens ao]"

Inicializa' c ao:

- Ligar a [Fonte do [Sistema do [Espectr^ometro]]] com a [Chave Geral do [Sistema do [Espectr^ometro]]] (1.M) ou [Chave ON/OFF da [Fonte do [Sistema do

[Espectr^ometro]]] (7.A);

Opera' c ao

Finaliza'c ao

- Desligar a [Fonte do [Sistema do [Espectr^ometro]] com a [Chave Geral do [Sistema do [Espectr^ometro]]] (1.M) e a [Chave ON/OFF da [Fonte do [Sistema do [Espectr^ometro]]] (7.A);

Obs.:

\#Ajustar a atenua'c ao da pot^encia

\#1- Girar os Seletores de Atenua'c ao de Pot^encia (8.C e 8.D) para o valor desejado.

$\#$

\#Obs.: Ao se diminuir a atenua'c ao, deve-se evitar altera'c oes bruscas. Por exemplo, para diminuir a atenua' c ao de $20 \mathrm{~dB}$ para $10 \mathrm{~dB}$, n ao se deve \#passar o seletor [Ajuste da Corrente Coarse] de 2 para 1 diretamente. O procedimento correto e passar o seletor FINE de 0 at'e 10 (atenua' c ao de $30 \mathrm{~dB}$ ), em seguida ajustar \#o seletor [Ajuste da Corrente Coarse] em 1 (atenua' crao de $20 \mathrm{~dB}$ ) e ent ao diminuir o seletor FINE de 10 at'e 0 (atenua'c ao de $10 \mathrm{~dB}$ ). Note que houve uma altera' c ao brusca \#de $30 \mathrm{~dB}$ para $20 \mathrm{~dB}$, mas como a 


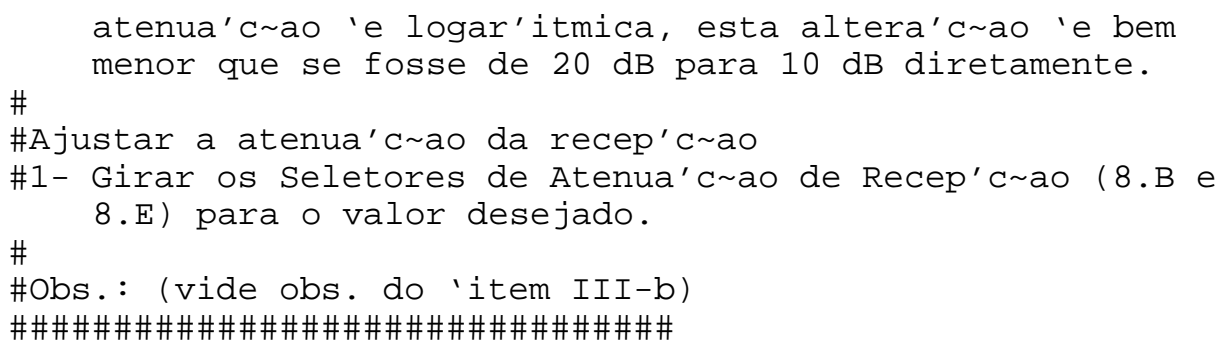

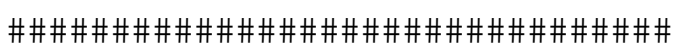

Nome: [Espectr^ometro]

Localiza'c ao: [Sistema do [Espectr^ometro]]

Fun' C ao:

Pr'e-requisitos para opera'c ao:

- "Inicializar o [Sistema do [Espectr^ometro]]"

Inicializa' c ao:

Opera' c ao

- Reinicializar o [Espectr^ometro] (7.C) apertando-se o [Bot ao Reset do [Espectr^ometro]] (7.C).

Finaliza' c ao

Obs.:

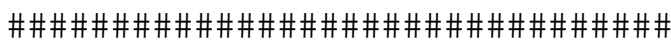

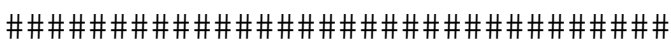

Nome: [Amplificador de Pot^encia de RF]

Localiza'c ao: [Sistema do [Espectr^ometro]]

Fun'crao: amplifica os sinais de RF gerados pelo [Espectr^ometro].

Pr'e-requisitos para opera'c ao:

- "Inicializar o [Sistema do [Espectr^ometro]]"

Inicializa' c ao:

- Ligar o [Amplificador de Pot^encia de RF] utilizando a [Chave ON/OFF do [Amplificador de Pot^encia de RF]];

Opera' C ao

- Medir a [Rela'c ao de Onda Estacion'aria] no conector de sa'ida RF do instrumento posicionado o [Ajuste VSWR $\mathrm{ADJ}$ ] (10.A) de modo que a [Escala Medidora PEP] (10.F) leia a escala inteira (110\%) quando a [Chave Power FWD/RFD] (10.B) 'e colocada na posi'c ao FWD. A [Escala Medidora VSWR] ir'a indicar a [Rela' c ao de Onda Estacion'aria] quando a [Chave Power FWD/RFD] (10.B) 'e colocada na posi'c ao RFD.

- Fazer a [Escala Medidora PEP] (10.I) indicar a pot^encia $\mathrm{RF}$ de pico absorvida pela carga colocando a [Chave Power FWD/RFD] (10.B) na posi'C ao FWD;

- Fazer a [Escala Medidora PEP] (10.I) indicar a pot^encia $\mathrm{RF}$ de pico refletida pela carga colocando a [Chave Power FWD/RFD] (10.B) na posi'C ao RFD;

- Testar o funcionamento dos m'odulos na aus^encia de sinais de RF pressionando momentaneamente a [Bot ao Fault] (10.C) para a posi'C ao TEST. Se houver alguma falha, $O$ [Indicador de Falha do $\mathrm{M}^{\prime}$ odulo] e o [Indicador Module] (10.H) ir ao acender;

- Reinicializar o [Amplificador de Pot^encia de RF] pressionando a [Bot ao Fault] (10.C) para a posi'c ao RESET por uma dura' c ao m'inima de 3 segundos. O [Indicador Module] (10.H), [Indicador Overload] (10.G) e o [Indicador VSWR] $(10 . \mathrm{F})$ e os [Indicadores de Falha 
do $\mathbf{M}^{\prime}$ odulo] ir ao desligar a $\mathrm{n}$ ao ser que haja uma falha presente;

Finaliza' C ao

- Desligar o [Amplificador de Pot^encia de RF] utilizando a [Chave ON/OFF do [Amplificador de Pot^encia de RF]];

Obs.:

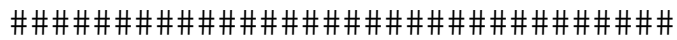

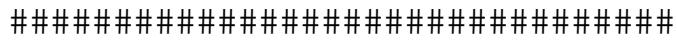

Nome: [Macintosh]

Localiza'c ao: Na mesa de controle da [Sala de Opera' c oes].

Fun'crao: Terminal de controle e visualisa'crao do [Tom' ografo].

Pr'e-requisitos para opera'c ao:

- "Inicializar o [Estabilizador de Tens ao]"

Inicializa'c ao:

- Ligar a [Tela de Visualiza'crao] (chave na parte lateral de $1 . J)$;

- Ligar a tela do [Macintosh] (chave na parte traseira do terminal de $\mathrm{V}^{\prime}$ ideo de $1 . \mathrm{K}$ );

- Na [Janela de Login], preencher os seguintes campos:

Login: tormscan <RETURN>

Passw: ????? <RETURN>

- Posicionar o cursor na ma'c a da [Tela de Visualiza'crao] e selecionar o [Commandshell] duas vezes. Ir ao surgir duas novas [Janelas de Comando do [Macintosh]]: a primeira janela 'e do [Console] e n ao deve ser utilizada para executar os comandos; a segunda 'e a janela de comando para executar os comandos;

Opera'c ao

- Criar janelas de comando posicionando o cursor na ma' c a da [Tela de Visualisa'c ao] e selecionando o [Commandshell]. A primeira janela 'e sempre do [Console] e n ao deve ser utilizado para executar os comandos. J'a as proximas s ao janelas de comando pr'oprias para a execu'c ao de comandos.

- Abrir uma conex ao com o [Microvax] digitando o comando [torm] <RETURN> numa janela de comando do [Macintosh];

- "Inicializar o [MicroVax]".

- Visualizar e trabalhar com as [Imagens] usando o aplicativo [IMAGE] .

- Os arquivos que s ao enviados para o [Diret'orio AVAX] pelos comandos [gaia] <RETURN> ou [proc] <RETURN> devem ser tranferidos para diret'orios espec'ificos, sendos estes dentro do [Diret'orio PACIENTES] ou [Diret'orio VOLUNT'ARIOS] no caso de [Imagens] feitas de pessoas. Neste 'ultimo caso, os diret'orios devem ter o nome das pessoas. Os arquivos ficam no [Disco do [Macintosh]] at'e a execu'c ao do [Protocolo de Manuten' c ao];

Finaliza'c ao

- "Finalizar o [MicroVax]".

- Sair do [Macintosh] selecionando a op'c ao [Logout] do menu [Special];

- Desligar a [Tela de Visualiza'crao] (chave na parte lateral de 1.J); 
- Desligar a tela do [Macintosh] (chave na parte traseira do terminal de $\mathrm{V}^{\prime}$ ideo de $1 . \mathrm{K}$ );

Obs.:

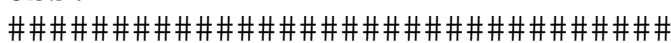

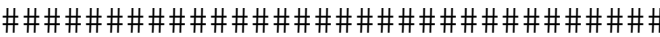

Nome: [MicroVax]

Localiza'c ao: [Sala de Equipamentos]

Fun' C ao: Programa' C ao do [Espectr^ometro] e [Processador de Arranjos], e processamento das [Imagens].

Pr'e-requisitos para opera'c ao:

- "Inicializar o [Estabilizador de Tens ao]".

- "Abrir uma conex ao com o [Microvax]".

Inicializa'c ao:

- Executar o procediemto de Login preenchendo os seguintes campos:

login name: tormscan <RETURN>

password: ?????? <RETURN>

- Ajustar o tipo de terminal digitando [vt100] <RETURN>;

Opera' c ao

- [Procedimento de Shimming]:

- Inicializar o [Procedimento de Shimming] digitando a seguinte sequ^encia de comandos na [Janela de Comando do [MicroVax] ] :

[cd shim] <RETURN> [rs] <RETURN> : reset do espect^ometro [set ver] <RETURN> : verify on do SC [SC] <RETURN> sequ^encia de shiming)

- Finalizar o [Procedimento de Shimming] digitando [quit] $<$ RETURN> na [Janela de Comando do [MicroVax]].

- [Sequ^encia SEMUL]:

- Inicializar a [Sequ^encia SEMUL] digitando o comando [cd semul y] <RETURN> na [Janela de Comando do [MicroVax]];

- Abrir a [Janela de Edi'c ao de Par^ametros] digitando o comando [prot] snr.ptc <RETURN> na [Janela de Comando do [MicroVax] ];

- Editar o [Arquivo de Par^ametros] snr.ptc de acordo com a imagem a ser feita;

- Na [Janela de Comando do [MicroVax]] digitar os seguintes comandos:

[setup] snr <RETURN>

[go] $S<$ RETURN>

- "Efetuar o [Procedimento de [Controle de N'ivel de Sinal]]". Caso a tela pare de piscar digite novamente o comando [go] s <RETURN $>$ e continue o ajuste.

- Espere a janela de comando parar de piscar ou digite [quit] <RETURN>;

- Abrir a [Janela de Edi'c ao de Par^ametros] digitando o comando [prot] arq.ptc <RETURN> na [Janela de Comando do [MicroVax]]. O nome arq representa o nome do protocolo que ser'a utilizado para gerar as [Imagens];

- Editar o [Arquivo de Par^ametros] arq.ptc de acordo com a [Imagem] a ser feita;

- Na [Janela de Comando do [MicroVax]] digitar os seguintes comandos:

[setup] arq <RETURN>

[go] a w <RETURN>

:(a=aquisi'c ao e w=wait) 
- Ap'os o t'ermino da[Aquisi'crao de [Imagens] por RMN] digite o seguinte comando na [Janela de Comando do [MicroVax]] para transferir e processar apenas a

'ultima aquisi'c ao:

[proc] <RETURN>

- Caso queira transferir e processar outra aquisi'c ao que n ao seja a 'ultima digite os seguintes comandos:

[pac] <RETURN>

[gaia] arq.pac <RETURN>

Finaliza' c ao

- Sair do [MicroVax] digitando o comando [logout] <RETURN> na [Janela de Comando do [MicroVax]];

Obs.:

- Os arquivos resultantes da [Aquisi'c ao de [Imagens] por RMN] devem permanecer no [Disco de Usu'arios do

[MicroVax]] onde foram criados at'e a execu'crao dos [Protocolos de Manuten'c ao].

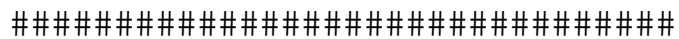

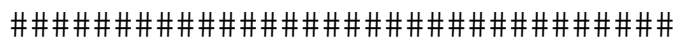

Nome: [Paciente]/[Amostra]

Localiza'c ao:

Fun' C ao:

Pr'e-requisitos para opera'c ao:

- Avaliar as condi'c oes para se fazer uma [Tomografia].

Inicializa'c ao:

- No caso de [Exame Cl'inico], preparar o [Paciente] retirando todos os ojetos met'alicos e cart oes magn'eticos que estejam com o mesmo.Se a roupa do [Paciente] possuir metais, por exemplo z'iper e/ou detalhes met'alicos, pr'oximos a regi ao a ser examinada, a mesma deve ser retirada. Deve-se providenciar algo para o [Paciente] vestir;

- Colocar o [Paciente] ou [Amostra] na [Cama] (1.P) posicionando a [Bobina de $\mathrm{RF}$ ];

- Verificar se o [Paciente] est'a confort'avel;

- Advertir o [Paciente] para que n ao se mexa e dizer quais as implica'c oes de movimentos para o exame;

- Colocar a [Campainha] na m ao do [Paciente] e instruir sobre o funcionamento (2 sinais para indicar que quer sair);

- Explicar que o barulho causado pelo [Tom'ografo] 'e normal;

- No caso de exame de cabe'ca, cal'car a cabe'ca do [Paciente] na [Bobina de RF] para que esta n ao mexa;

- Estimar o tempo de demora do exame e informar o [Paciente];

- Posicionar o [Paciente]/[Amostra] no centro do [Magneto], colocando a [Cama] (1.P) na posi'c ao central (indicada pelas setas);

Opera' c ao

Finaliza'c ao

- Retirar o [Paciente]/[Amostra] da [Bobina de RF];

Obs.:

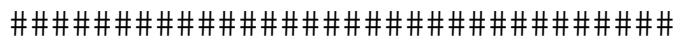




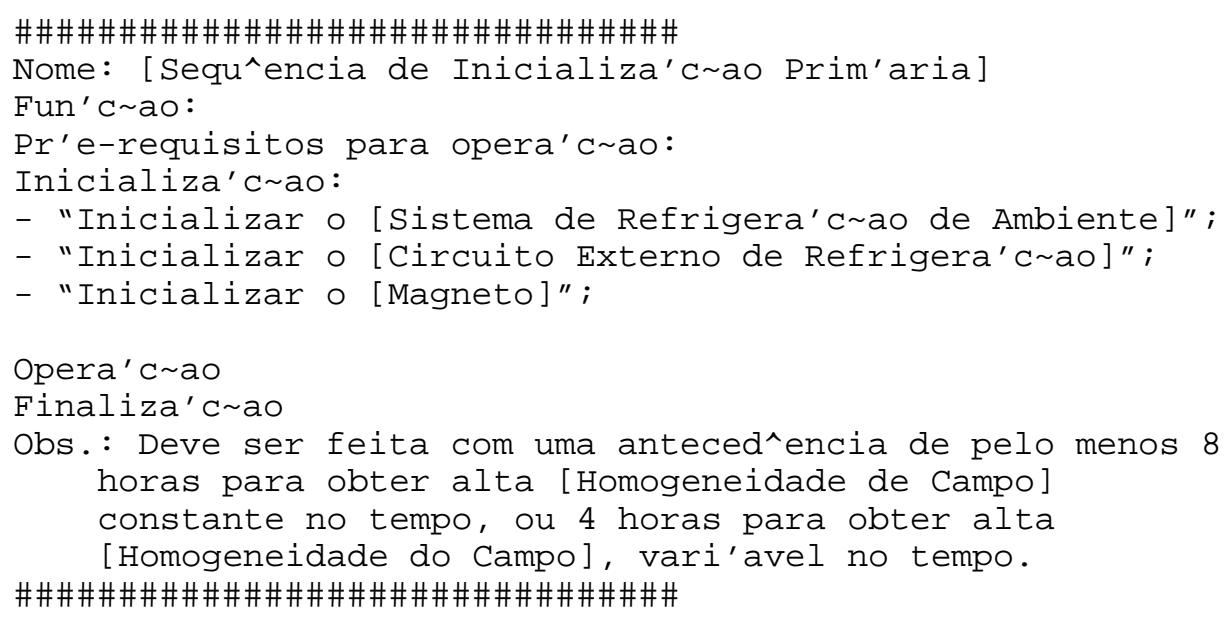

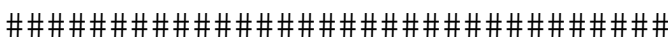

Nome: [Sequ^encia de Inicializa'c ao Secund'aria] Fun' C ao:

Pr'e-requisitos para opera'c coo:

- "Inicializar o [Sistema de Refrigera'crao de Ambiente]".

- "Inicializar o [Circuito Externo de Refrigera'crao]";

Inicializa'c ao:

- "Inicializar o [Estabilizador de Tens ao]";

- "Inicializar o [Sistema do [Espectr^ometro]]";

- "Inicializar o [Amplificador de Pot^encia de RF]";

- "Inicializar as [Bobinas de Gradiente]";

- "Inicializar o [Macintosh]";

- Abrir uma conex ao com o [Microvax] digitando o comando [torm] <RETURN> numa [Janela de Comando do [Macintosh] ]

- "Inicializar o [MicroVax]";

Opera' c ao

Finaliza'c ao

Obs.:Pode ser feita imediatamente antes da utiliza'crao do [Tom' ografo].

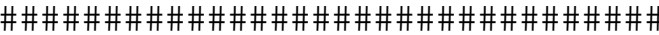

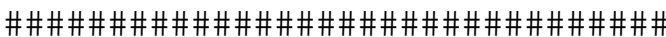

Nome: [Procedimento de Shimming]

Localiza'c ao:

Fun' C ao:

Pr'e-requisitos para opera'c ao:

- "Inicializar o [Sistema do [Espectr^ometro]]";

- "Inicializar o [Macintosh]";

- "Inicializar o [MicroVax]";

- "Inicializar o [Magneto]";

- "Inicializar as [Bobinas de Gradiente]";

Inicializa'c ao:

- Retirar a [Blindagem];

- Posicionar a [Bobina de RF] de cabe'ca na [Cama] (1.P);

- Colocar a [[Amostra] Padr ao] na [Bobina de RF];

- Posicionar a [[Amostra] Padr ao] no centro do [Magneto], colocando a [Cama] (1.P) na posi'c ao central (indicada pelas setas); 
- Zerar a posi'c ao da [Cama] com o [Bot ao Posicionador] (2.A) do [Painel do [Tom'ografo]] (1.Q);

- Acoplar o cabo da [Bobina de RF] na caixa do [Sintonizador] (plug de baixo) (1.N);

- "Inicializar o [Sintetizador de RF]";

- Ajustar a sintonia girando os [Bot oes de Sintonia] (1.U) observando o [Indicador de Sintonia] (2.B), procurando obter o $\mathrm{m}^{\prime}$ inimo de indicadores acesos;

- "Finalizar o [Sintetizador de RF]";

- Desacoplar o cabo da [Bobina de RF] do [Sintonizador] $(1 . N)$;

- Acoplar o cabo da [Bobina de RF] na [Prote'cuao do [Pr'eAmplificador] ] (1.0);

- Recolocar a [Blindagem];

- No [Painel do [Amplificador de Gradientes]] (1.B), usar a [Seletor DVM Channel] (5.H) e os utilizando os [Ajuste de Corrente X] (5.G), [Ajuste de Corrente Y] (5.F) e [Ajuste de Corrente Z] (5.E) para ajustar as correntes em zero nas tr^es dire'c oes;

- "Inicializar o [Procedimento de Shimming] no [MicroVax]";

- No m'odulo de [Controle de N'ivel de Sinal] (1.L), ajustar a atenua'c ao do [Sinal de Transmi'c ao] em $38 \mathrm{~dB}$ usando $\circ$ [Seletor Coarse do [Controle de $\mathrm{N}^{\prime}$ ivel de Pot^encia]] (8.D) e o [Seletor Fine do [Controle de $\mathrm{N}^{\prime}$ ivel de Pot^encia]] (8.C);

- Tirar o sistema de [Resson^ancia] atrav'es de uma pequena varia'c ao do [Campo Magn'etico Principal], usando o [Ajuste da Corrente Fine] (4.I) no Painel da [Fonte de Alimenta' c ao do [Magneto]];

- Ajustar as correntes x, y e z de [Gradiente de Campo Magn'etico], utilizando os [Ajuste de Corrente X] (5.G), [Ajuste de Corrente Y] (5.F) e [Ajuste de Corrente Z] (5.E), de maneira que a envolt'oria do [FID] observado na tela do [Oscilosc'opio I] (1.Z) tenha um perfil exponencial longo e sem batimentos;

- Voltar o sistema para a [Resson^ancia], ajustando o

[Ajuste da Corrente Fine] (4.I) no Painel da [Fonte de Alimenta'c ao do [Magneto]];

- "Finalizar o [Procedimento de Shimming] no [Microvax]";

- Retirar a [Blindagem];

- Mover a [Cama] (1.P) e retirar a [ [Amostra] Padr ao] da [Bobina de RF];

- Recolocar a [Blindagem].

Opera' c ao

Finaliza'c ao

Obs.:

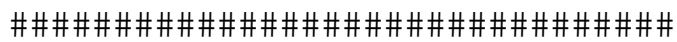

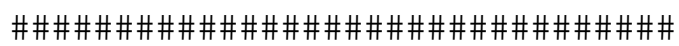

Nome: [Sequ^encia SEMUL]

Fun' C ao:

Pr'e-requisitos para opera'c ao:

- "Inicializar o [Sistema do [Espectr^ometro]]";

- "Inicializar o [Macintosh]";

- "Inicializar o [MicroVax]";

- "Inicializar o [Magneto]";

- "Inicializar as [Bobinas de Gradiente]";

Inicializa'c ao:

- Retirar a [Blindagem];

- Colocar sobre a [Cama] (1.P) a [Bobina de RF] correspodente ao tipo de aquisi'c ao; 
- Ligar o cabo na [Prote' c ao do [Pr'e-Amplificador]];

- "Inicializar o [Paciente]/[Amostra]"

- Zerar a posi'c ao da [Cama] com o [Bot ao Posicionador] (2.A) do [Painel do [Tom'ografo]];

- Acoplar o cabo da [Bobina de RF] no [Sintonizador] (plug de baixo) (1.N);

- "Inicializar o [Sintetizador de RF]";

- Ajustar a sintonia girando os [Bot oes de Sintonia] (1.U) observando o [Indicador de Sintonia] (2.B), procurando obter $0 \mathrm{~m}^{\prime}$ inimo de indicadores acesos;

- "Finalizar o [Sintetizador de RF]";

- Desacoplar o cabo da [Bobina de RF] do [Sintonizador] $(1 . N)$;

- Acoplar o cabo da [Bobina de RF] na [Prote'crao do [Pr'eAmplificador] ] (1.0);

- Recolocar a [Blindagem].

- "Inicializar a [Sequ^encia SEMUL] no [MicroVax]";

- Ap'os o t'ermino da aquisi'crao digite o seguinte comando na [Janela de Comando do [Microvax]] para transferir e processar apenas a 'ultima aquisi'c ao:

[proc] <RETURN>

- Caso queira transferir e processar outra aquisi'c ao que n ao seja a 'ultima digite os seguintes comandos:

[pac] <RETURN>

[gaia] arq.pac <RETURN>

- Utilizar o aplicativo [IMAGE], no [Macintosh], para visualizar e trabalhar com as [Imagens];

- Terminada a [Sequ^encia SEMUL] com o [Paciente] ou com a [Amostra], executar os passos seguintes:

- Retirar a [Blindagem];

- Puxar a [Cama];

- "Finalizar [Paciente]/[Amostra]";

- Recolocar a [Blindagem];

- Os arquivos resultantes da aquisi'c ao devem permanecer no [Disco de Usu'arios do [MicroVax]] onde foram criados at'e a execu' c ao dos [Protocolos de Manuten' c ao].

- Os arquivos que s ao enviados para o [Diret'orio AVAX] do [Macintosh] pelo programa [gaia] <RETURN> ou [proc] $<$ RETURN> devem ser tranferidos para diret'orios espec'ificos, sendos estes dentro do [Diret'orio PACIENTES] ou do [Diret'orio VOLUNT'ARIOS] no caso de [Imagens] feitas de pessoas. Neste 'ultimo caso, os diret'orios devem ter o nome das pessoas. Os arquivos ficam no [Disco do [Macintosh]] at'e a execu'c ao do [Protocolo de Manuten' c ao];

Opera' C ao

Finaliza' C ao

Obs.:

\# \# \# \# \# \# \# \# \# \# \# \# \# \# \# \# \# \# \# \# \# \# \# \# \# \# \# \# \# \# \# \#

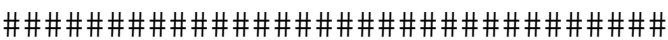

Nome: [Sequ^encia de Finaliza'c ao Primaria]

Fun' C ao:

Pr'e-requisitos para opera'c ao:

Inicializa'c ao:

- "Finalizar o [Amplificador de Pot^encia de RF]";

- "Finalizar o [Sistema do [Espectr^ometro]]";

- "Finalizar as [Bobinas de Gradiente]";

- "Finalizar o [MicroVax]";

- "Finalizar o [Macintosh]"; 


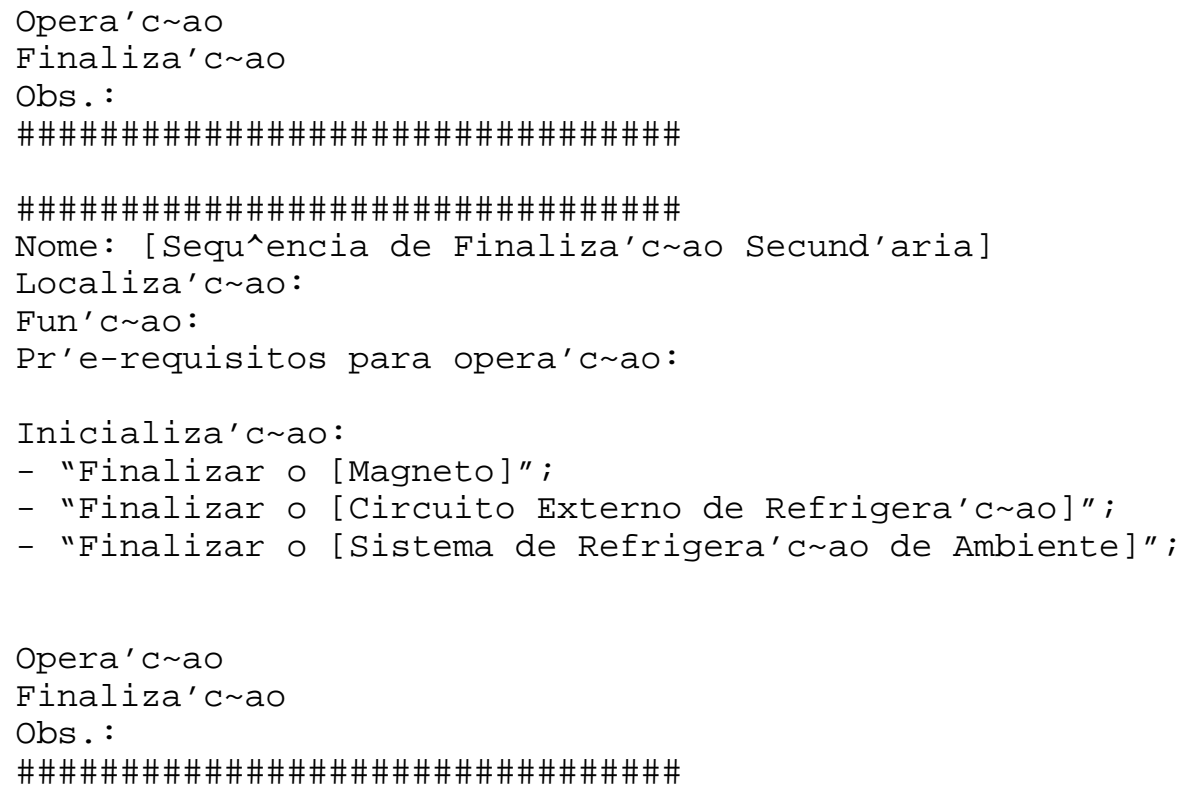

[Sequ^encia de Inicializa'c ao Prim'aria]: Deve ser feita com uma anteced^encia de pelo menos 8 horas para obter alta [Homogeneidade de Campo] constante no tempo, ou 4 horas para obter alta [Homogeneidade do Campo], vari'avel no tempo.

- Abrir o [Registro do [Circuito Externo de Refrigera'c ao] ] (1.S);

- Ligar a [Bomba de 'Agua I] (1.T);

- Ligar os aparelhos de Ar Condicionado (1.X) da [Sala de Equipamentos] e da [Sala do [Tom'ografo]];

- Ligar a [Fonte de Alimenta' c ao do [Magneto]] (1.C): coloca-se a [Chave Power] (4.A) na posi'c ao ON, espera-se entre 60 a 90 segundos para [Estabiliza'c ao El'etrica] e em seguida pressiona-se o [Bot ao Run] (4.H);

- Ligar o [Exaustor] do [Magneto] na [Tomada do [Exaustor]] $(1 . X)$. Embora n ao seja necess'ario esperar algum tempo para isto, 'e aconselh' avel que isto seja feito cerca de 4 horas ap'os o [Magneto] ser ligado;

- Esperar [Estabililiza'c ao Mec^anica] e [Estabililiza'c ao T'ermica] por pelo menos 8 horas para [Exame Cl'inico], ou 4 horas para atividades que n ao requerem alta homogenidade do campo;

SEQU^ENCIA DE INICIALIZA'C AO SECUND'ARIA: Pode ser feita imediatamente antes da utiliza' c ao do [Tom'ografo].

- Ligar o [Estabilizador de Tens ao] (1.A), caso esteja desligado, pressionando-se o [Bot ao Liga] (6.B). Em 
geral este estabilizador fica constantemente ligado para que os computadores n ao sejam desligados;

- Ligar a [Fonte do [Sistema do [Espectr^ometro]]] (7.A e 1.M) ;

- Ligar o [Amplificador de Pot^encia de RF] utilizando a [Chave ON/OFF do [Amplificador de Pot^encia de RF]];

- Ligar a [Bomba de 'Agua II] usando a chave da direita de (1.T);

- Ligar a [Amplificador de Gradientes] colocando a [Chave Liga/Desliga] (5.A) na posi'c ao |;

- Apertar o [Bot ao Start] (5.C) da [Amplificador de Gradientes] (o visor passa a indicar a corrente);

- Ligar a [Tela de Visualiza'c ao] (chave na parte lateral de $1 . J)$;

- Ligar a tela do [Macintosh] (chave na parte traseira do terminal de $\mathrm{V}^{\prime}$ ideo de $1 . \mathrm{K}$ );

- Na [Janela de Login], preencher os seguintes campos:

Login: tormscan <RETURN>

Passw: ????? <RETURN>

- Posicionar o cursor na ma' c a da [Tela de Visualiza'crao] e selecionar o [Commandshell] duas vezes. Ir ao surgir duas novas janelas: a primeira janela 'e do [Console] e n ao deve ser utilizada para executar os comandos; a segunda 'e a janela de comando para executar os comandos;

- Na janela de comando, digitar TORM. Ir'a surgir uma nova janela para o [Microvax];

- Nesta janela preencher os seguintes campos:

login name: tormscan <RETURN>

password: ?????? <RETURN>

- Ainda nesta janela digite: vt100 <RETURN>

[Procedimento de Shimming]:

- Retirar a [Blindagem] que fica sobre a [Cama] do [Tom'ografo] (1.P);

- Posicionar a [Bobina de RF] de exames de cabe'ca na [Cama] (1.P);

- Colocar a [[Amostra] Padr ao] na [Bobina de RF];

- Posicionar a [Amostra] no centro do [Magneto], colocando a [Cama] (1.P) na posi'c ao central (indicada pelas setas);

- Zerar a posi'c ao da [Cama] com o [Bot ao Posicionador] (2.A) do [Painel do [Tom'ografo]] (1.Q);

- Acoplar o cabo da [Bobina de RF] na caixa do [Sintonizador] (plug de baixo) (1.N);

- Ligar [Sintetizador de RF] (1.E), utilizando a [Chave Stand By/On] (3.A);

- Ajustar o [Sintetizador de RF] (1.E) em $2.35 \mathrm{MHz}$, utilizando os [Seletores de Frequ^encia] (3.E);

- Ajustar a sintonia girando os [Bot oes de Sintonia] (1.U) observando $O$ [Indicador de Sintonia] (2.B), procurando obter o m'inimo de LEDs acesos;

- Desligar [Sintetizador de RF] (1.E) utilizando a [Chave Stand By/On] (3.A);

- Desacoplar o cabo da [Bobina de RF] da [Sintonizador] $(1 . N)$;

- Acoplar o cabo da [Bobina de RF] na [Prote'crao do [Pr'eAmplificador] ] (1.0);

- Recolocar a [Blindagem].

- No [Painel do [Amplificador de Gradientes]] (1.B), usar a [Seletor DVM Channel] (5.H) e os Bot oes de Ajuste de 
Corrente (5.E, 5.F, 5.G) para ajustar as correntes em zero nas tr^es dire'c oes;

- Na [Janela de Comando do [MicroVax]] digitar a seguinte sequ^encia de comandos:

cd shim <RETURN>

rS <RETURN>

set ver $<$ RETURN $>$

$\mathrm{SC}<\mathrm{RETURN}>$

- No m'odulo de [Controle de $N^{\prime}$ ivel de Sinal] (1.L), ajustar a atenua' c ao de pot^encia em 38dB (bot oes 8.C e 8.D);

- Tirar o sistema de [Resson^ancia] atrav'es de uma pequena varia'c ao do [Campo Magn'etico Principal], usando o [Ajuste da Corrente Fine] (4.I) no Painel da [Fonte de Alimenta' c ao do [Magneto]];

- Ajustar as correntes x, y e z de [Gradiente de Campo Magn'etico], utilizando os [Ajuste de Corrente X] (5.G), [Ajuste de Corrente Y] (5.F) e [Ajuste de Corrente Z] (5.E), de maneira que a envolt'oria do [FID] observado na tela do [Oscilosc'opio I] (1.Z) tenha um perfil exponencial longo e sem batimentos;

- Voltar o sistema para a [Resson^ancia] (padr ao n ao oscilat'orio no sinal no [Oscilosc'opio I]), ajustando - [Ajuste da Corrente Fine] (4.I) no Painel da [Fonte de Alimenta' c ao do [Magneto]];

- Na janela de comando do [Microvax] digitar: quit $<$ RETURN>

- Retirar a [Blindagem];

- Mover a [Cama] (1.P) e retirar a [ [Amostra] Padr ao] da [Bobina de RF];

- Recolocar a [Blindagem].

SEQU^ENCIA DE AQUISI'C AO POR SPIN-ECO:

- Retirar a [Blindagem];

- Colocar sobre a [Cama] (1.P) a [Bobina de RF] correspodente ao tipo de aquisi'c ao;

- Ligar o cabo na [Prote' c ao do [Pr'e-Amplificador]];

- No caso de [Exame Cl'inico], preparar o [Paciente] retirando todos os ojetos met'alicos e cart oes magn'eticos que estejam com o mesmo.Se a roupa do [Paciente] possuir metais, por exemplo $z^{\prime}$ iper e/ou detalhes met'alicos, pr'oximos a regi ao a ser examinada, a mesma deve ser retirada. Deve-se providenciar algo para o [Paciente] vestir;

- Colocar o [Paciente] ou [Amostra] na [Cama] (1.P) e sobre ou dentro da [Bobina de RF];

- Verificar se o [Paciente] est'a confort'avel;

- Advertir o [Paciente] para que n ao se mexa e quais as implica'croes de movimentos para o exame;

- Colocar a [Campainha] na m ao do [Paciente] e instruir sobre o funcionamento (2 sinais para indicar que quer sair);

- Explicar que o barulho causado pelo [Tom'ografo] 'e normal;

- No caso de exame de cabe'ca, cal'car a cabe'ca do [Paciente] na [Bobina de $\mathrm{RF}$ ] para que esta n ao mexa;

- Estimar o tempo de demora do exame e informar o [Paciente];

- Posicionar o [Paciente]/[Amostra] no centro do [Magneto], colocando a [Cama] (1.P) na posi'c ao central (indicada pelas setas); 
- Zerar a posi'c ao da [Cama] com o [Bot ao Posicionador] (2.A) do [Painel do [Tom'ografo]];

- Acoplar o cabo da [Bobina de RF] na [Sintonizador] (plug de baixo) (1.N);

- Ligar [Sintetizador de RF] (1.E), utilizando a [Chave Stand By/On] (3.A);

- Ajustar o [Sintetizador de RF] (1.E) em $2.35 \mathrm{MHz}$, utilizando os [Seletores de Frequ^encia] (3.E);

- Ajustar a sintonia girando os [Bot oes de Sintonia] (1.U) observando o [Indicador de Sintonia] (2.B), procurando obter o m'inimo de LEDs acesos;

- Desligar [Sintetizador de RF] (1.E) utilizando a [Chave Stand By/On] (3.A);

- Desacoplar o cabo da [Bobina de RF] da [Sintonizador] $(1 . N)$;

- Acoplar o cabo da [Bobina de RF] na [Prote'crao do [Pr'eAmplificador] ] (1.0);

- Recolocar a [Blindagem].

- Na [Janela de Comando do [Microvax]] digitar os seguintes comandos:

cd semul y $<$ RETURN $>$

prot snr.ptc <RETURN>

- Editar, na [Janela de Comando do [Microvax]] o [Arquivo de Par^ametros] de acordo com a imagem a ser feita;

- $\mathrm{Na}$ [Janela de Comando do [MicroVax]] digitar os seguintes comandos:

setup snr <RETURN $>$

[go $\mathrm{S}$ ] $<$ RETURN $>$

?- Efetuar o [Procedimento de [Controle de $\mathrm{N}^{\prime}$ ivel de Sinal]] (do Espectr^ometro) pelo painel do $\mathrm{m}^{\prime}$ odulo de [Controle de $\mathrm{N}^{\prime}$ ivel de Sinal] (1.L), observando os indicadores na [Janela de Comando do [MicroVax]]. Para isto deve-se ajustar a atenua'c ao da pot^encia e a atenua' c ao da recep' c ao de maneira a obter o maior sinal na [Janela de Comando do [Microvax]] sem que ele seja trao grande 'a ponto de chegar ao fim da janela. Para proceder o ajuste deve-se girar os [Seletores do [Controle de $\mathrm{N}^{\prime}$ ivel de Recep' c ao]] (8.C e 8.D) e os [Seletores do [Controle de $\mathrm{N}^{\prime}$ ivel de Pot^encia]] (8.B e 8.E) para os valores desejados. Caso a tela pare de piscar digite novamente o comando [go s ] <RETURN> e continue o ajuste. Obs.: Ao se diminuir a atenua'c coo, deve-se evitar altera'c oes bruscas. Por exemplo, para diminuir a atenua' c ao de $20 \mathrm{~dB}$ para $10 \mathrm{~dB}$, n ao se deve passar o bot ao [Ajuste da Corrente Coarse] de 2 para 1 diretamente. O procedimento correto e passar o bot ao FINE de 0 at'e 10 (atenua' c ao de $30 \mathrm{~dB}$ ), em seguida ajustar o seletor [Ajuste da Corrente Coarse] em 1 (atenua' crao de $20 \mathrm{~dB}$ ) e ent ao diminuir o seletor FINE de 10 at'e 0 (atenua' crao de $10 \mathrm{~dB}$ ). Note que houve uma altera' c ao brusca de $30 \mathrm{~dB}$ para $20 \mathrm{~dB}$, mas como a atenua'crao 'e logar'itmica, esta altera'c ao 'e bem menor que se fosse de $20 \mathrm{~dB}$ para $10 \mathrm{~dB}$ diretamente;

- Espere a janela de comando parar de piscar ou digite quit;

- Na [Janela de Comando do [Microvax]] digitar: prot arq.ptc <RETURN>. O nome arq representa o nome do protocolo que ser'a utilizado para gerar as [Imagens].

- Editar, na [Janela de Comando do [Microvax]], o [Arquivo de Par^ametros] para a realiza'c ao da imagem;

- $\mathrm{Na}$ [Janela de Comando do [MicroVax]] digitar os seguintes comandos:

setup arq <RETURN $>$ 
go a w <RETURN>

- Ap'os o t'ermino da aquisi'c ao digite o seguinte comando na [Janela de Comando do [MicroVax]] para transferir e processar apenas a 'ultima aquisi'c ao:

prot <RETURN>

- Caso queira transferir e processar outra aquisi'c ao que n ao seja a 'ultima digite os seguintes comandos:

pac <RETURN>

gaia arq.pac <RETURN>

- Utilizar o aplicativo [IMAGE], no [Macintosh], para visualizar e trabalhar com as [Imagens];

- Terminada a(s) sequ^encia(s) de aquisi'c ao com o [Paciente] ou com a [Amostra], executar os passos seguintes:

- Retirar a [Blindagem];

- Puxar a [Cama] e retirar o [Paciente]/[Amostra] da [Bobina de RF];

- Recolocar a [Blindagem];

- Os arquivos resultantes da aquisi'c ao devem permanecer no [Disco de Usu'arios do [Microvax]] onde foram criados at'e a execu'c ao dos [Protocolos de Manuten' c ao].

- Os arquivos que s ao enviados para o [Diret'orio AVAX] do [Macintosh] pelo programa [gaia] <RETURN> ou [prot] $<$ RETURN> devem ser tranferidos para diret'orios espec'ificos, sendos estes dentro dos diret'orios [Diret'orio PACIENTES] ou [Diret'orio VOLUNT'ARIOS] no caso de [Imagens] feitas de pessoas. Neste 'ultimo caso, os diret'orios devem ter o nome das pessoas. Os arquivos ficam no [Disco do [Macintosh]] at'e a execu'c ao do [Protocolo de Manuten' c ao];

SEQU^ENCIA DE FINALIZA'C AO PRIMARIA

- Desligar o [Amplificador de Pot^encia de RF] utilizando a [Chave ON/OFF do [Amplificador de Pot^encia de RF]];

- Desligar a [Fonte do [Sistema do [Espectr^ometro]]] com as chaves (7.A e 1.M);

- Apertar o [Bot ao Stop do [Amplificador de Gradientes]] (5.B) na [Amplificador de Gradientes] (1.B);

- Desligar a [Amplificador de Gradientes] (1.B) utilizando a [Chave Liga/Desliga] (5.A);

- Sair do [MicroVax] digitando o comando [logout ] <RETURN> na janela de comando;

- Sair do [Macintosh] digitando o comando [logout ] $<$ RETURN $>$ na janela de comando e em seguida acionar a op'c ao [Logout] do menu [Special];

- Desligar a [Tela de Visualiza'crao] (chave na parte lateral de 1.J);

- Desligar a tela do [Macintosh] (chave na parte traseira do terminal de $\mathrm{V}^{\prime}$ ideo de $1 . \mathrm{K}$ );

SEQU^ENCIA DE FINALIZA'C AO SECUND'ARIA

- Desligar a [Fonte de Alimenta' C ao do [Magneto] ] (1.C) apertando o [Bot ao Stop da [Fonte de Alimenta' c ao do [Magneto]]] (4.F), esperar a corrente indicada no [Visor Output Current] (4.K) zerar, colocar a [Chave Power] (4.A) na posi'C ao OFF;

- Desligar o [Exaustor] do [Magneto];

- Desligar as duas Bombas de Agua (1.T);

- Fechar o [Registro do [Circuito Externo de Refrigera'c ao] ] (1.S); 
APÊNDICE V - 38

4 Léxico Ampliado da Linguagem 
Simbolo

[[Amostra] Padrão]

[Acoplamento]

[Ajuste de Corrente Coarse]

\section{Nocao}

1. Esfera preenchida com água usada no [Procedimento de Shimming].

1. Estado em que a transmissão de RF entre a [Bobina de RF] e o [Paciente], [Voluntário] ou [Amostra] submetidos ao [Campo Magnético Principal] é o mais eficiente possível.

1. Realiza o ajuste grosso da corrente do [Magneto].

\section{Impacto}

LAL - 1

1. A [[Amostra] Padrão] é colocada dentro da [Bobina de RF] de cabeça.

\section{A [[Amostra] Padrão] é um tipo de}

1. O [Acoplamento] é obtido através do [Procedimento de Sintonia];

2. O nível de [Acoplamento] é observado no [Indicador de Sintonia];

3. O [Acoplamento] é regulado com os [Ajustes de Sintonia].

1. Localizado no [Painel da [Fonte de Alimentação do [Magneto]]]; 2. A corrente do [Magneto] é indicada no [Visor Output Current]; 3. A alteração da corrente do [Magneto] leva a uma alteração no [Campo Magnético Principal].

1. Localizado no [Painel da [Fonte de Alimentação do [Magneto]]]; 2. A corrente do [Magneto] é indicada no [Visor Output Current]; 3. A alteração da corrente do [Magneto] leva a uma alteração no [Campo Magnético Principal].

1. Localizado no [Painel do [Amplificador de Gradientes]]; 2. A corrente das [Bobinas de Gradiente] é indicada no [Visor DVM Channel];

3. O [Ajuste de Corrente X] é utilizado no [Procedimento de Shimming] para obter [Homogeneidade do Campo].

1. Localizado no [Painel do [Amplificador de Gradientes]]; 2. A corrente das [Bobinas de Gradiente] é indicada no [Visor DVM Channel];

3. O [Ajuste de Corrente Y] é utilizado no [Procedimento de Shimming] para obter [Homogeneidade do Campo]. 


$\begin{array}{ll}\text { Simbolo } & \text { Nocao } \\ \text { [Ajuste de Corrente } & \begin{array}{l}\text { 1. Faz o ajuste fino do offset de } \\ \text { corrente das [Bobinas de Gradiente] } \\ \text { Z] }\end{array}\end{array}$

[Ajuste Level]

1. Regula o nível do [Sinal de Transmissão] no [Conector Output] do [Sintetizador de RF] entre 3 e 13 $\mathrm{dB}(20$ a $2 \mathrm{~mW})$.

[Ajuste VSWR ADJ] 1. Ajusta o valor máximo do [Sinal de Trnsmissão] na saída de RF do [Amplificador de Potência de RF] à máxima amplitude da [Escala Medidora PEP].

\section{Impacto}

LAL - 2

1. Localizado no [Painel do [Amplificador de Gradientes]]; 2. A corrente das [Bobinas de Gradiente] é indicada no [Visor DVM Channel];

3. O [Ajuste de Corrente Z] é utilizado no [Procedimento de Shimming] para obter [Homogeneidade do Campo].

1. Localizado no [Sintetizador de RF];

2. Durante o [Procedimento de Sintonia], o [Ajuste Level] deve estar em $13 \mathrm{~dB}$.

1. Localizado no [Amplificador de Potência de RF];

2. Quando o [Ajuste VSWR ADJ] é colocado na posição PEP a [Escala Medidora PEP] irá indicar o valor (x10

W) de potência do sinal selecionado pela [Chave Power FWD/RFD]. 3. Quando o [Ajuste VSWR ADJ] não estiver na posição PEP a [Escala Medidora PEP] irá indicar o valor relativo (\%) de potência do sinal selecionado pela [Chave Power FWD/RFD].

1. Localizados na extremidade da [Cama];

2. Durante a utilização dos [Ajustes de Sintonia], no [Procedimento de Sintonia] , o [Indicador de Sintonia] indica o [Acoplamento] da [Bobina de RF] .

1. A [[Amostra] Padrão] é um tipo de [Amostra].

1. Localizado na [Sala de Equipamentos];

2. As formas de onda amplificadas são utilizadas nas [Bobinas de Gradiente] do [Tomógrafo] e nas [Bobinas de Gradiente do [Magneto Supercondutor]] para gerar o [Gradiente de Campo Magnético]. 
Simbolo

[Amplificador de Potência de RF]

[Aquisição]

[Arquivo de Parâmetros]

[Base de Tempo do [Espectrômetro]]

[Blindagem]
Nocao

1. Amplifica o [Sinal de

Transmissão] gerado pelo [Espectrômetro].

1. Etapa da [Tomografia] controlada pelo [Espectrômetro] que leva a obtenção dos [Dados de [Aquisição]].

\section{Impacto}

LAL - 3

1. Localizado na [Sala de

Equipamentos];

2. O [sinal de Transmissão] amplificado é enviado para a [Bobina de RF].

1. A [Aquisição] é composta pelo envio do [Sinal de Transmissão] e recebimento do [Sinal de Recepção], que é digitalizado pelo

[Espectrômetro]. Em seguida o [Processador de Arranjos] faz as médias gerando os [Dados de [Aquisição]] e transferindo-os para o [MicroVax].

2. A [Aquisição] é iniciada através do comando [go], com os parâmetros a ou a w, digitado na [Janela de Comando do [MicroVax]].

3. Para interromper a [Aquisição] deve-se digitar, na [Janela de Comando do [MicroVax]], o comando [quit], caso tenha sido iniciada com o comando [go] com o parâmetro a, ou $\langle$ CTRL $>$ y, caso tenha sido iniciada com o comando [go] com o parâmetro a w.

1. É editado por um programa chamado pelo comando [prot] na [Janela de Comando do [MicroVax]]. uma [Aquisição].

1. Sinal bem definido gerado pelo [Sintetizador de RF do [Espectrômetro]] utilizado como referência temporal pelo [Rack de Equipamentos].

1. Grade metálica colocada sobre a [Cama] do [Tomógrafo] utilizada para isolar o interior do [Tomógrafo] de campos eletromagnéticos externos.
1. É utilizado pelo [Rack de Equipamentos] para a sincronização de todos os eventos entre os seus módulos.

1. Só deve ser removida para a colocação ou remoção de [Amostra], [Paciente] ou [Voluntário] ou durante o [Procedimento de Sintonia]. 
Simbolo

[Bobina de RF]

[Bobinas de

Gradiente do

[Magneto

Supercondutor]]
Nocao

1. Bobina móvel, colocada na [Amostra], [Paciente] ou [Voluntário], que recebe o [Sinal de Recepção].

2. Bobina fixa no interior do [Tomógrafo] que emite o [Sinal de Transmissão] para a [Amostra], [Paciente] ou [Voluntário]. Esta é chamada de bobina de corpo.

1. Conjunto de bobinas que, submetidas às correntes do [Amplificador de Gradientes], geram [Gradiente de Campo Magnético] linear nas direções x, y e z.
[Bobinas de Gradiente]
1. Conjunto de bobinas que, submetidas às correntes do [Amplificador de Gradientes], geram [Gradiente de Campo Magnético] linear nas direções $\mathrm{x}, \mathrm{y}$ e $\mathrm{z}$.

\section{Impacto}

LAL - 4

1. A [Bobina de RF] fixa no interior do [Tomógrafo] pode também receber o [Sinal de Recepção].

2. A [Bobina de RF] móvel são para exames específicos e podem ser dos tipos: cabeça, coluna e perna.

1. Localizadas dentro do [Magneto Supercondutor].

1. Localizadas dentro do [Tomógrafo].
[Bomba de Água I] 1. Responsável pela circulação de água no [Circuito Interno de Refrigeração I].

[Bomba de Água II] 1. Responsável pela circulação de água no [Circuito Interno de Refrigeração II].

[Botão Desliga]

\section{Desliga o [Estabilizador de} Tensão].
1. É acionada pela [Chave da [Bomba de Água I]].

1. É acionada pela [Chave da [Bomba de Água II]].

1. Localizado no [Estabilizador de Tensão];

2. Quando o [Botão Desliga] é acionado o [Sistema de Computadores] e o [Rack de Equipamentos] ficam sem energia para funcionar.

1. Localizado no [Painel da [Fonte de Alimentação do [Magneto]]];

2. Deve ser pressionado apenas em casos de emergência;

3. O [Magneto] fica desprovido de corrente e consequentemente o [Campo Magnético Principal] fica nulo. 
Simbolo

[Botão Fault]

[Botão Liga]

[Botão Posicionador] 1. Zera, no [Visor de Posição], a indicação da posição da [Cama].

[Botão Reset do

[Espectrômetro]]
Nocao

1. É utilizado para testar ou reinicializar o [Amplificador de Potência de RF].

1. Liga o [Estabilizador de Tensão]
Impacto

LAL - 5

1. Localizado no [Amplificador de Potência de RF];

2. Quando é momentaneamente pressionado para a posição Test, com o [Amplificador de Potência de $\mathrm{RF}$ ] ligado mas não em funcionamento, todos os módulos do [Amplificador de Potência de RF] são testados. Caso haja alguma falha o indicador de falha do módulo, localizado dentro do [Amplificador de Potência de RF], e o [Indicador

Module] irão acender;

3. Quando for pressionada para a posição Reset por uma duração mínima de 3 segundos o [Indicador VSWR], [Indicador Overload], [Indicador Module] e o indicador de falha do módulo, localizado dentro do [Amplificador de Potência de RF], irão desligar a não ser que haja uma falha presente.

1. Localizado no [Estabilizador de Tensão];

2. Quando o [Botão Liga] é acionado o [Sistema de Computadores] e o [Rack de Equipamentos] ficam com energia para funcionar.

1. Localizado no [Painel do [Tomógrafo]];

2. O [Botão Posicionador] é utilizado juntamente com o [Visor de Posição] para medir deslocamentos relativos da posição da [Cama].

1. Localizado no painel frontal do [Espectrômetro];

2. Após o [Botão Reset do [Espectrômetro]] ser pressionado deve-se recomeçar o [Procedimento SEMUL] através do comando [cd semul y] ou o [Procedimento de Shimming] através do comando [cd shim y]. 
Simbolo

[Botão Reset do [Processador de Arranjos]]

[Botão Run]

[Botão Stand By]
Nocao

1. Reinicializa o [Processador de Arranjos].

1. Quando pressionado faz com que a [Fonte de Alimentação do [Magneto]] passe a fornecer corrente ao [Magneto].

1. Coloca a [Fonte de Alimentação do [Magneto]] em [Estado Stand By].

\section{Impacto}

LAL - 6

1. Localizado no painel frontal do [Processador de Arranjos]. 2. Após o [Botão Reset do [Processador de Arranjos]] ser pressionado deve-se recomeçar o [Procedimento SEMUL] através do comando [cd semul y] ou o

[Procedimento de Shimming] através do comando [cd shim y].

1. Localizado no [Painel da [Fonte de Alimentação do [Magneto]]];

2. Com o [Botão Run] pressionado a corrente do [Magneto] passa a ser indicada no [Visor Output Current]; 3. Com o [Botão Run] pressionado a corrente do [Magneto] pode ser ajustada pelo [Ajuste de Corrente Fine] e pelo [Ajuste de Corrente Coarse].

4. Com o [Botão Run] pressionado passa a existir [Campo Magnético Principal].

1. Localizado no [Painel da [Fonte de Alimentação do [Magneto]]]; 2. Com o [Botão Stand By] pressionado a corrente do [Magneto] passa a ser ajustada por um controlador de resistência que faz com que a temperatura do [Magneto] permaneça constante;

3. Para a utilização do [Botão Stand By] o [Circuito Interno de Refrigeração I] é suposto estar desativado;

4. Para a utilização do [Botão Stand By] a refrigeração a água da [Fonte de Alimentação do [Magneto]] deve estar ligada. 
Simbolo

[Botão Start]

[Botão Stop da

[Fonte de

Alimentação do

[Magneto]]]
Nocao

1. Faz com que o [Amplificador de Gradientes] passe a amplificar as formas de onda para as [Bobinas de Gradiente] gerando [Gradiente de Campo Magnético].

1. Reduz a zero a corrente gerada pela [Fonte de Alimentação do [Magneto]] para o [Magneto].
Impacto

LAL - 7

1. Localizado no [Painel do [Amplificador de Gradientes]]; 2. Há um atraso de um segundo antes do [Amplificador de Gradientes] controlar a corrente para as [Bobinas de Gradiente];

3. O [Botão Start] só poderá ser pressionado se não houver nenhuma indicação no [Painel de Falha do [Amplificador de Gradientes]]; 4. Algumas falhas só serão indicadas após o [Botão Start] ser pressionado.

1. Localizado no [Painel da [Fonte de Alimentação do [Magneto]]];

2. O [Botão Stop da [Fonte de Alimentação do [Magneto]]] não remove a potência gerada para o [Magneto] imediatamente; 3. Quando o [Botão Stop da [Fonte de Alimentação do [Magneto]]] é pressionado, o [Magneto] fica desprovido de corrente e consequentemente o [Campo Magnético Principal] fica nulo.

1. Localizado no [Painel do [Amplificador de Gradientes]]; 2. Quando o [Botão Stop do [Amplificador de Gradientes]] é pressionado, as [Bobinas de Gradiente] do [Tomógrafo] e as [Bobinas de Gradiente do [Magneto Supercondutor]] param de produzir [Gradiente de Campo Magnético]. 
Simbolo

Nocao

[Cama]

[Campo Magnético

Principal]
1. Local onde o [Paciente],

[Voluntário] ou [Amostra] são colocados.
Impacto

LAL - 8

1. Localizada no [Tomógrafo];

2. Dentro do [Tomógrafo] há uma marca para onde a [Cama] deve ser deslocada de maneira que a

[[Amostra] Padrão] fique no centro do [Campo Magnético Principal], quando estiver dentro da [Bobina de $\mathrm{RF}$ ] de cabeça;

3. São utilizados o [Botão

Posicionador] e o [Visor de Posição]

do [Painel do [Tomógrafo]] para posicionar a [Cama] na posição desejada.

1. Campo magnético uniforme de 0.05 Tesla na direção logintudinal do [Magneto], gerado pela passagem da corrente fornecida pela [Fonte de Alimentação do [Magneto]] no [Magneto].

1. A intensidade do [Campo Magnético Principal] determina a frequência central de operação do [Tomógrafo].

2. O [Campo Magnético Principal] deve ter [Homogeneidade do Campo] para a operação do [Tomógrafo].

1. O comando [cd semul y] deve ser digitado na [Janela de Comando do [MicroVax]].

1. O comando [cd shim] deve ser digitado na [Janela de Comando do [MicroVax]].

1. Localizada na [Sala do [Tomógrafo]];

2. Quando a [Chave da [Bomba de Água I]] é acionada, o [Circuito Interno de Refrigeração I] é ativado.

1. Localizada na [Sala do [Tomógrafo]];

2. Quando a [Chave da [Bomba de Água II]] é acionada, o [Circuito Interno de Refrigeração II] é ativado. 
Simbolo

[Chave Geral do

[Rack de

Equipamentos]
Nocao

1. Liga e desliga o [Rack de Equipamentos].
Impacto

1. Localizada no painel traseiro do [Controle de Nível de Sinal];

2. Apenas a [Chave Geral do [Rack de Equipamentos]] é suficiente para ligar o [Rack de Equipamentos];

3. Para desligar o [Rack de Equipamentos], tanto a [Chave Geral do [Rack de Equipamentos]] como a [Chave ON/OFF da [Fonte do [Rack de Equipamentos]]] devem ser desligadas.
[Chave Liga/Desliga] 1. Liga e desliga o [Amplificador de Gradientes].
[Chave ON/OFF da [Fonte do [Rack de Equipamentos]]]
1. Liga e desliga a [Fonte do [Rack de Equipamentos]].

\section{Localizada no [Painel do}

2. Na posição | o [Amplificador de Gradientes] está ligado mas não amplifica os sinais para as [Bobinas de Gradiente];

3. Na posição 0 o [Amplificador de Gradientes] está desligado;

4. Na posição | a [Lâmpada AC Power] permanece acesa; 5. Após ser colocada na posição | falhas poderão ser indicadas no [Painel de Falha do [Amplificador de Gradientes]].

1. Localizada na [Fonte do [Rack de Equipamentos]];

2. Apenas a [Chave ON/OFF da [Fonte do [Rack de Equipamentos]]] é suficiente para ligar o [Rack de Equipamentos];

3. Para desligar o [Rack de Equipamentos], tanto a [Chave ON/OFF da [Fonte do [Rack de Equipamentos]]] como a [Chave Geral do [Rack de Equipamentos]] devem estar desligadas.

1. Localizada no painel traseiro do [Amplificador de Potência de RF]; 2. Com a [Chave ON/OFF do [Amplificador de Potência de RF]] na posição ON o [Indicador PWR] irá acender; 
Simbolo

[Chave Power FWD/RFD]
Nocao

1. Seleciona se a [Escala Medidora PEP] e a [Escala Medidora VSWR] irão indicar valores referentes ao [Sinal de Transmissão] (posição FWD) ou à parte refletida do [Sinal de Transmissão] (posição RFD).
Impacto

LAL - 10

1. Localizada no [Amplificador de Potência de RF];

2. Quando a [Chave Power FWD/RFD] é colocada na posição FWD a [Escala Medidora PEP] irá indicar o valor $(\mathrm{x} 10 \mathrm{~W})$ do [Sinal de Transmissão], caso o [Ajuste VSWR ADJ] esteja na posição PEP.

3. Quando a [Chave Power FWD/RFD] é colocada na posição RFD a [Escala Medidora PEP] irá indicar o valor $(\mathrm{x} 10 \mathrm{~W})$ da parte refletida do [Sinal de Transmissão], caso o [Ajuste VSWR ADJ] esteja na posição PEP.

4. Caso o [Ajuste VSWR ADJ] tenha sido posicionado de modo que a leitura do [Sinal de Transmissão] utilize a [Escala Medidora PEP] inteira $(110 \%)$ e a [Chave Power FWD/RFD] esteja na posição RFD, a [Escala Medidora VSWR] irá indicar a relação de onda estacionária e a [Escala Medidora PEP] o valor relativo da parte refletida do [Sinal de Transmissão] (\%). Caso a [Chave Power FWD/RFD] esteja na posição FWD a [Escala Medidora PEP] irá indicar o valor relativo do [Sinal de Transmissão] (\%).

1. Localizada no [Painel da [Fonte de Alimentação do [Magneto]]];

[Chave Alimentação do [Magneto]].

1. Sem função.

Sintonia/Aquisição]

[Chave Stand By/On] 1. Liga ou desliga o [Sintetizador de $\mathrm{RF}$.

[Chave Stand By]

1. Habilita (posição $\mathrm{ON}$ ) ou não (posição OFF) a utilização do [Botão Stand By].

1. Localizada no [Sintetizador de RF];

2. Com a [Chave Stand By/On] na posição ON um sinal de RF com frequência indicada nos [Seletores de Frequência] é transmitido através do [Conector Output].

1. Localizada no [Painel da [Fonte de Alimentação do [Magneto]]]. 


\section{Simbolo}

[Circuito Externo de Refrigeração]

[Circuito Interno de Refrigeração I]
Nocao

1. Circuito de água externo que refrigera o [Circuito Interno de Refrigeração I] e o [Circuito Interno de Refrigeração II].

1. Circuito de água destilada que refrigera o [Magneto] e a [Fonte de Alimentação do [Magneto]].
Impacto

LAL - 11

1. O [Circuito Externo de Refrigeração] pode ser aberto ou fechado pelo [Registro do [Circuito Externo de Refrigeração]].

1. O [Circuito Interno de Refrigeração I] é ativado quando a [Bomba de Água I] é ligada;

2. O [Circuito Interno de Refrigeração I] deve estar ativado quando o

[Magneto] for colocado em operação.

1. O [Circuito Interno de Refrigeração II] é ativado quando a [Bomba de Água II] é ligada;

2. O [Circuito Interno de Refrigeração II] deve estar ativado quando as [Bobinas de Gradiente] forem colocadas em operação.

1. Localizado no [Sintetizador de RF]; saída de [Sinal de Transmissão].

[Controle de Nível de 1. Utilizado para atenuar a potência Sinal] do [Sinal de Transmissão] e [Sinal de Recepção] no [Procedimento de [Controle de Nível de Sinal]].

[Dados de [Aquisição]]
2. O cabo coaxial que liga o

[Sintetizador de RF] ao [Sintonizador] no [Procedimento da Sintonia] é conectado ao [Sintetizador de RF] através do [Conector Output].

1. Localizado na [Sala de Operação];

1. Os [Dados de [Aquisição]] são tranferidos para o [MicroVax] e armazenados no [Disco de Usuários do [MicroVax]].
1. Conjunto de dados resultante da realização de médias, pelo

[Processador de Arranjos], sobre o [Sinal de Recepção]. 
Simbolo

[Diretório AVAX]

[Diretório

PACIENTES]

[Diretório

VOLUNTÁRIOS]

[Disco de Sistema do [MicroVax]]

1. Utilizado principalmente pelo sistema operacional do [MicroVax]

1. Diretório no [Disco do [Macintosh]] cujos subdiretórios armazenam as [Imagens] do [Voluntário] do qual foi feita [Tomografia].
Impacto

LAL - 12

1. O [Diretório AVAX] é o diretório default onde o aplicativo [NMR Image] busca as [Imagens]; 2. As [Imagens] são enviadas para o [Diretório AVAX] pelos comandos [gaia] ou [proc] e são transferidas para diretórios específicos. No caso de [Imagens] de [Paciente] ou [Voluntário] estes diretórios devem ter o nome do [Paciente] ou [Voluntário] e estar dentro do [Diretório PACIENTES] ou [Diretório VOLUNTÁRIOS], respectivamente.

1. As [Imagens] são enviadas para o [Diretório AVAX] pelos comandos [gaia] ou [proc] e são transferidas para diretórios específicos. No caso de [Imagens] de [Paciente] ou [Voluntário] estes diretórios devem ter o nome do [Paciente] ou [Voluntário] e estar dentro do [Diretório PACIENTES] ou [Diretório VOLUNTÁRIOS], respectivamente.

1. As [Imagens] são enviadas para o [Diretório AVAX] pelos comandos [gaia] ou [proc] e são transferidas para diretórios específicos. No caso de [Imagens] de [Paciente] ou [Voluntário] estes diretórios devem ter o nome do [Paciente] ou [Voluntário] e estar dentro do [Diretório PACIENTES] ou [Diretório VOLUNTÁRIOS], respectivamente.

1. Localizado na [Sala de Equipamentos];

2. O [Disco de Sistema do [MicroVax]] também é utilizado para atividades de desenvolvimento e manutenção.

1. Localizado na [Sala de Equipamentos]. do [Misco de Usuário
doax]]

1. Utilizado principalmente para armazenamento do software do [Tomógrafo], [Dados de [Aquisição]] e das [Imagens]. 
Simbolo

[Disco do

[Macintosh]]

[Escala Medidora PEP]
Nocao

1. Armazena principalmente o sistema operacional do [Macintosh], o aplicativo [NMR Image] e [Imagens].

1. Indica o [Sinal de Transmissão] ou a parte refletida do [Sinal de Transmissão] no conector de saída de RF do [Amplificador de Potência de RF].
Impacto

LAL - 13

1. Localizado na mesa do [Macintosh] na [Sala de Operação].

1. Localizada no [Amplificador de Potência de RF];

2. A [Escala Medidora PEP] indica o valor $(\mathrm{x} 10 \mathrm{~W})$ da potência do [Sinal de Transmissão] quando a [Chave Power FWD/RFD] está na posição FWD e o [Ajuste VSWR ADJ] na posição PEP;

3. A [Escala Medidora PEP] indica o valor $(\mathrm{x} 10 \mathrm{~W})$ da potência da parte refletida do [Sinal de Transmissão] quando a [Chave Power FWD/RFD] está na posição RFD e o [Ajuste VSWR ADJ] na posição PEP;

4. Com o [Ajuste VSWR ADJ] posicionado de modo que a leitura do [Sinal de Transmissão] utilize a [Escala Medidora PEP] inteira (110\%) e a [Chave Power FWD/RFD] na posição RFD, a [Escala Medidora VSWR] indicará a relação de onda estacionária e a [Escala Medidora PEP] indicará o valor relativo da parte refletida do [Sinal de Transmissão] (\%);

5. Com o [Ajuste VSWR ADJ] posicionado de modo que a leitura do [Sinal de Transmissão] utilize a [Escala Medidora PEP] inteira (110\%) e a [Chave Power FWD/RFD] na posição FWD, a [Escala Medidora PEP] indicará o valor relativo do [Sinal de Transmissão] (\%). 


Simbolo
[Escala Medidora
VSWR]

Nocao

1. Indica a relação de onda estacionária na saída de RF do [Amplificador de Potência de RF].

$\begin{array}{ll}\text { [Escala Medidora] } & \begin{array}{l}\text { 1. Indica a tensão de saída do } \\ \text { [Estabilizador de Tensão] em volts. }\end{array} \\ \text { [Espectrômetro] } & \begin{array}{l}\text { 1. Subsistema eletrônico, de } \\ \text { monitoramento e controle do [Rack } \\ \text { de Equipamentos], geração de sinais } \\ \text { de RF e formas de onda de } \\ \text { gradiente, para [Aquisição] em } \\ \text { [Tomografia]. }\end{array}\end{array}$

[Estabilização Elétrica]

[Estabilização Mecânica]

\section{Impacto}

LAL - 14

1. Localizada no [Amplificador de Potência de RF];

2. Com o [Ajuste VSWR ADJ] posicionado de modo que a leitura do [Sinal de Transmissão] utilize a [Escala Medidora PEP] inteira (110\%) e a [Chave Power FWD/RFD] na posição RFD, a [Escala Medidora VSWR] indicará a relação de onda estacionária e a [Escala Medidora $\mathrm{PEP}]$ indicará o valor relativo da parte refletida do [Sinal de Transmissão] $(\%)$

1. Localizado no [Estabilizador de Tensão].

1. Localizado na [Sala de Equipamentos];

2. O [Espectrômetro] recebe o [Sinal de Recepção] vindo da [Bobina de $\mathrm{RF}$ ] e o envia para o [Processador de Arranjos];

3. O [Espectrômetro] transmite o [Sinal de Transmissão] para o [Amplificador de Potência de RF];

4. O [Espectrômetro] transmite formas de onda de gradiente para o [Amplificador de Gradientes]; 5. O [Espectrômetro] modula em AM e FM o sinal de RF gerado pelo [Sintetizador de RF do [Espectrômetro]] para formar o [Sinal de Transmissão].

1. O [Botão Run] pode ser acionado após ser atingida a [Estabilização Elétrica] da [Fonte de Alimentação do [Magneto]].

1. A [Estabilização Mecânica] é necessária para para se obter [Homogeneidade do Campo]; 2. A [Estabilização Mecânica] está relacionada com a [Estabilização Térmica]. 
Simbolo

[Estabilização

Térmica]

Estabilizador de Tensão]

[Estado Stand By]

[Exame Clínico]

[Exaustor]

[FID]
Nocao

1. Estado em que o [Magneto] e as [Bobinas de Gradiente] não sofrem variações térmicas significativas.

2. Processo através do qual se atinge a [Estabilização Térmica].

1. Estabiliza a tensão alternada em 110 ou 220 volts.

1. Estado em que a potência dissipada pelo [Magneto] é mantida constante. Isto é feito através do controle de resistência da [Fonte de Alimentação do [Magneto]] que varia a corrente de acordo com a resistência do [Magneto].
Impacto

LAL - 15

1. A [Estabilização Térmica] é necessária para para se obter [Homogeneidade do Campo]; 2. A [Estabilização Térmica] está relacionada com a [Estabilização Mecânica].

1. Localizado na [Sala de Equipamentos];

2. O [Estabilizador de Tensão] é utilizado pelo [Sistema de Computadores] e pelo [Rack de Equipamentos].

1. O [Estado Stand By] mantêm a [Estabililização Térmica] e [Estabililização Mecânica] do [Magneto]. Com isso a [Homogeneidade do Campo] é mantida, possibilitando um rápido retorno à operação;

2. No [Estado Stand By] o circuito de refrigeração da [Fonte de Alimentação do [Magneto]] deve estar ligado, enquanto o circuito de refrigeração do [Magneto] deve estar desligado;

3. Como os circuitos de refrigeração da [Fonte de Alimentação do [Magneto]] e do [Magneto] estão ligados em série no [Circuito Interno de Refrigeração I], o [Estado Stand By] não pode ser atingido.

1. O [Paciente] deve ser preparado

1. [Tomografia] realizada com um pelo [Operador] no início do [Exame Clínico].

1. O [Exaustor] é ligado quando coloca-se o [Plug do [Exaustor]] numa tomada.

1. Sinônimo de [Sinais de RMN] e de [Sinal de Recepção].
[Paciente], [Voluntário] ou

[Amostra] submetidos ao [Campo Magnético Principal] e ao [Sinal de Transmissão]. 
Simbolo

[Fonte de

Alimentação do

[Magneto]]

[Fonte do [Rack de Equipamentos]]

[gaia]

[go]
Nocao

1. Fornece corrente contínua regulada ao [Magneto].

1. Fonte de tensão para os módulos colocados no [Rack de Equipamentos].

1. Comando que copia as [Imagens] do [Disco de Usuários do [MicroVax]] para o [Diretório AVAX] no [Disco do [Macintosh]].

1. Comando do [MicroVax] que faz com que o [Espectrômetro] entre em operação.
Impacto

LAL - 16

1. Localizada na [Sala de Equipamentos];

2. A corrente fornecida ao [Magneto], pela [Fonte de Alimentação do [Magneto]], gera o [Campo Magnético Principal].

1. Localizada no [Rack de Equipamentos].

1. O comando [gaia] deve ser digitado na [Janela de Comando do [MicroVax]];

2. Sintaxe: gaia arquivo.pac $<$ RETURN $>$. Onde arquivo é o nome do arquivo a ser transferido.

1. O comando [go] deve ser digitado na [Janela de Comando do [MicroVax]];

2. Sintaxe: go parâmetro <RETURN>. Onde parâmetro pode ser: s ->Faz o [MicroVax] ativar o

[Espectrômetro] para o

[Procedimento de [Controle de Nível de Sinal]];

a ->Faz o [MicroVax] ativar o

[Espectrômetro] para a [Aquisição].

Os [Dados de [Aquisição]] são

armazenados no [Disco de Usuários do [MicroVax]]. A [Janela de Comando do [MicroVax]] fica sob o prompt do comando [go]; w ->Faz o [MicroVax] aguardar o término da [Aquisição] para retornar o prompt de comando do sistema operacional do [MicroVax] para a [Janela de Comando do [MicroVax]];

3. Para interromper o comando [go] com parâmetros s ou a, digita-se o camando [quit];

4. Para interromper o comando [go] com parâmetro a w, digita-se $\langle\mathrm{CTRL}\rangle$ $\mathrm{y}$. 
[Gradiente de Campo 1. Variação espacial de intensidade Magnético] de campo magnético numa determinada direção gerada pelas [Bobinas de Gradiente].

[Homogeneidade do Campo]

[Imagens]

[Indicador AC Power]

1. Indica que o [Amplificador de Gradientes] está ligado.
1. Indica, em PPM (partes por milhão), o quanto a intensidade do [Campo Magnético Principal] é constante num determinado volume

1. Arquivos obtidos após o processamento dos [Dados de [Aquisição]] pelo [MicroVax]. espacial dentro do [Magneto].
1. Quanto maior for a [Homogeneidade do Campo] maior será a relação sinal/ruído; 2. A [Homogeneidade do Campo] é obtida através do [Procedimento de Shimming];

3. Para haver [Homogeneidade do Campo], é necessário haver [Estabilização Mecânica] e [Estabilização Térmica].

1. As [Imagens] são geradas pelos comandos [pac] ou [proc]; 2. As [Imagens] são armazenadas em formato PAC, com 256 níveis de cinza;

3. As [Imagens] são enviadas para o [Diretório AVAX] pelos comandos [gaia] ou [proc] e são transferidas para diretórios específicos. No caso de [Imagens] de [Paciente] ou [Voluntário] estes diretórios devem ter o nome do [Paciente] ou [Voluntário] e estar dentro do [Diretório PACIENTES] ou [Diretório VOLUNTÁRIOS], respectivamente.

1. Localizado no [Painel do [Amplificador de Gradientes]];

2. Com o [Indicador AC Power] aceso o [Amplificador de Gradientes] pode estar ou não amplificando as formas de onda de gradiente para as [Bobinas de Gradiente].

1. Localizado no [Controle de Nível de Sinal]. 
Simbolo

[Indicador de Operação do [Processador de Arranjos]]

[Indicador de Sintonia]
Nocao

1. Quando aceso indica que o [Processador de Arranjos] está ligado.

1. Indica o [Acoplamento] da [Bobina de RF].

1. Indica a existência de falha da [Fonte de Alimentação do [Magneto]].
Impacto

LAL - 18

1. Localizado no painel frontal do [Processador de Arranjos].

1. Localizado no [Painel do [Tomógrafo]];

2. O [Indicador de Sintonia] é utilizado, juntamente com os [Botões de Sintonia], durante o

[Procedimento de Sintonia].

1. Localizado no [Painel de Falha da [Fonte de Alimentação do

[Magneto]]];

2. Caso o [Indicador Fault da [Fonte de Alimentação do [Magneto]]] acenda, a falha da [Fonte de Alimentação do [Magneto]] será especificada no [Painel de Falha da [Fonte de Alimentação do

[Magneto]]].

1. Localizado no [Amplificador de Potência de RF];

2. Caso o [Indicador Module] acenda e haja uma falha de módulo, o indicador de falha do módulo defeituoso, localizado dentro do [Amplificador de Potência de RF], irá acender.

3. O [Indicador Module] e o indicador de falha do módulo irão desligar, a não ser que haja uma falha presente, quando o [Botão Fault] for pressionada para a posição Reset por uma duração mínima de 3 segundos. 
Simbolo

Nocao

[Indicador Overload] 1. Irá acender se houver sobrecarga nos circuitos de amplificação do [Amplificador de Potência de RF] durante a operação do aparelho, quando o [Botão Fault] é pressionado para a posição Test ou quando o [Amplificador de Potência de RF] é ligado.

[Indicador PWR]

1. Acende quando o [Amplificador de Potência de RF] estiver ligado.

[Indicador Ready da 1. Fica aceso quando a corrente do [Fonte de

Alimentação do

[Magneto]]]

[Magneto] está controlada no valor indicado no [Visor Output Current]. Ele é apagado quando a corrente está variando.

[Indicador Ready]

1. Se não houver falha no [Amplificador de Potência de RF] este indicador irá acender aproximadamente 3 segundos após o [Amplificador de Potência de RF] ser habilitado, pelo

[Espectrômetro], para amplificação.

[Indicador

Remote/Local]

1. Indica o estado atual do [Sintetizador de RF].
Impacto

LAL - 19

1. Localizado no [Amplificador de Potência de RF];

2. O [Indicador Overload] irá desligar, após o [Botão Fault] ser pressionado para a posição Reset por uma duração mínima de 3 segundos, se a origem da sobrecarga do [Amplificador de Potência de RF] tiver sido eliminada.

1. Localizado no [Amplificador de Potência de RF].

1. Localizado no [Painel da [Fonte de Alimentação do [Magneto]]].

1. Localizado no [Amplificador de Potência de RF];

2. Enquanto o [Indicador Ready] estiver aceso o [Amplificador de Potência de RF] amplificará os sinais de RF provenientes do

[Espectrômetro] e os enviará para as [Bobina de RF].

1. Localizado no [Sintetizador de RF];
2. Com o [Indicador Remote/Local] no estado Local, o controle de frequência é feito pelos [Seletores de Frequência] e a atenuação do sinal pelo [Ajuste Level];

3. Com o [Indicador Remote/Local] no estado Remote, o controle de frequência e de atenuação do sinal são feitos remotamente por um controlador externo ligado ao [Sintetizador de RF]. 
Simbolo

[Indicador VSWR]

[Indicadores de

Status do

[Processador de

Arranjos]]

[Interface Óptica]

[Janela de Comando do [MicroVax]]

[Janela de Edição de Parâmetros]

\section{Impacto}

LAL - 20

1. Localizado no [Amplificador de Potência de RF].

[Sinal de Transmissão] sobre o [Amplificador de Potência de RF] for superior a um certo limite.

2. O [Indicador VSWR] irá desligar, a não ser que a parte refletida do [Sinal de Transmissão] sobre o

[Amplificador de Potência de RF] seja superior a um certo limite, quando o [Botão Fault] for pressionada para a posição Reset por uma duração mínima de 3 segundos.

1. Localizado no [Processador de Arranjos].
[Processador de Arranjos].
1. Liga opticamente o [Espectrômetro] ao [Processador de Arranjos] para tranferência de dados.

\section{A [Janela de Comando do} [MicroVax]] é uma das [Janelas de Comando do [Macintosh]] na qual se digitou o comando [torm] para abrir uma conexão do [Macintosh] com o [MicroVax].

1. Nela são editados os parâmetros para [Aquisição].
1. Localizado no [Rack de Equipamentos];

2. A [Interface Óptica] isola eletricamente o [Espectrômetro] do [Processador de Arranjos].

1. Na [Janela de Comando do [MicroVax]] digita-se os comandos para realização da [Tomografia].

1. A [Janela de Edição de Parâmetros] ocupa a [Janela de Comando do [MicroVax]] quando digita-se o comando [prot];

2. Os parâmetros editados na [Janela de Edição de Parâmetros] são armazenados no [Arquivo de Parâmetros].

1. A [Janela de Login] aparece quando a [Opção Logout] do [Menu Special] é selecionada ou quando o [Macintosh] é ligado. 
[Janelas de Comando 1. As [Janelas de Comando do do [Macintosh]] [Macintosh]] são utilizadas para execução dos comandos do

[Macintosh].

[Lâmpada AC Power] 1. Indica se o [Amplificador de Gradientes] está ligado.

[logout]

1. Comando do [MicroVax] que fecha a conexão do [Macintosh] com o [MicroVax].

[Macintosh]

[Magneto Supercondutor]

1. Constituído basicamente por uma bobina supercondutora cuja corrente gera um campo magnético. gerenciar o sistema de interfaces de operação, visualização e tratamento de [Imagens] do [Tomógrafo].
Impacto

LAL - 21

1. As [Janelas de Comando do [Macintosh]] são criadas posicionando o cursor no [Menu Maçã] da [Tela de Visualização] e selecionando a [Opção CommandShell24]. Após isto seleciona-se a [Opção New] do [Menu File].

1. Localizada no [Painel do [Amplificador de Gradientes]]; 2. A [Lâmpada AC Power] acende quando a [Chave Liga/Desliga] for colocada na posição |

1. O comando [logout] deve ser digitado na [Janela de Comando do [MicroVax]];

2. Sintaxe: logout <RETURN>;

3. A [Janela de Comando do [MicroVax]] onde o comando [logout] é digitado torna-se uma das [Janelas de Comando do [Macintosh]].

1. Localizado na [Sala de Operação].

1. As [Bobinas de Gradiente do [Magneto Supercondutor]] são alimentadas pelo [Amplificador de Gradientes];

2. O [Magneto Supercondutor] não faz parte do [Tomógrafo].

1. A corrente que alimenta o [Magneto] é gerada pela [Fonte de Alimentação do [Magneto]]; 2. O [Campo Magnético Principal] gerado pelo [Magneto] é de 0.05 Tesla.

1. Para utilizar o [Menu File] deve-se selecionar a [Opção CommandShell24] do [Menu Maçã] na [Tela de Visualização]. 


\begin{tabular}{|c|c|c|}
\hline Simbolo & Nocao & LAL - 22 \\
\hline [Menu Maçã] & $\begin{array}{l}\text { 1. É utilizado para a seleção da } \\
\text { [Opção Finder], [Opção } \\
\text { CommandShell24] e [Opção [NMR } \\
\text { Image]]. }\end{array}$ & $\begin{array}{l}\text { 1. O [Menu Maçã] se localiza na [Tela } \\
\text { de Visualização]. }\end{array}$ \\
\hline [Menu Special] & $\begin{array}{l}\text { 1. É utilizado para finalizar a sessão } \\
\text { de trabalho do [Operador] no } \\
\text { [Macintosh] através da seleção da } \\
\text { [Opção Logout]. }\end{array}$ & $\begin{array}{l}\text { 1. Para utilizar o [Menu Special] } \\
\text { deve-se selecionar a [Opção Finder] } \\
\text { do [Menu Maçã] na [Tela de } \\
\text { Visualização]. }\end{array}$ \\
\hline [MicroVax] & $\begin{array}{l}\text { 1. Computador utilizado para } \\
\text { programação do [Espectrômetro] e } \\
\text { processamento dos [Dados de } \\
\text { Aquisição]. }\end{array}$ & $\begin{array}{l}\text { 1. Localizado na [Sala de } \\
\text { Equipamentos]; } \\
\text { 2. O acesso do usuário ou [Operador] } \\
\text { ao [MicroVax] é feito pelo comando } \\
\text { [torm] em [Janelas de Comando do } \\
\text { [Macintosh]]; } \\
\text { 3. O [MicroVax] programa o } \\
\text { [Espectrômetro] através de uma porta } \\
\text { serial; } \\
\text { 4. O [Espectrômetro] recebe os } \\
\text { [Sinais de RMN], digitaliza-os e os } \\
\text { transfere para o [MicroVax] através } \\
\text { do [Interface Óptica] e do } \\
\text { [Processador de Arranjos]. }\end{array}$ \\
\hline $\begin{array}{l}\text { [Opção [NMR } \\
\text { Image]] }\end{array}$ & $\begin{array}{l}\text { 1. Opção que ativa o conjunto de } \\
\text { menus do [NMR Image]. }\end{array}$ & $\begin{array}{l}\text { 1. Para utilizar a [Opção [NMR } \\
\text { Image]] deve-se selecionar o [Menu } \\
\text { Maçã] na [Tela de Visualização]. }\end{array}$ \\
\hline $\begin{array}{l}\text { [Opção } \\
\text { CommandShell24] }\end{array}$ & $\begin{array}{l}\text { 1. Opção que ativa o conjunto de } \\
\text { menus relativos às [Janelas de } \\
\text { Comando do [Macintosh]]. }\end{array}$ & $\begin{array}{l}\text { 1. Para utilizar a [Opção } \\
\text { CommandShell24] deve-se selecionar } \\
\text { o [Menu Maçã] na [Tela de } \\
\text { Visualização]. }\end{array}$ \\
\hline [Opção Finder] & $\begin{array}{l}\text { 1. Opção que ativa o conjunto de } \\
\text { menus relativos ao sistema } \\
\text { operacional do [Macintosh]. }\end{array}$ & $\begin{array}{l}\text { 1. Para utilizar a [Opção Finder] } \\
\text { deve-se selecionar o [Menu Maçã] } \\
\text { na [Tela de Visualização]. }\end{array}$ \\
\hline [Opção Logout] & $\begin{array}{l}\text { 1. Finaliza a sessão de trabalho do } \\
\text { [Operador] no [Macintosh]. }\end{array}$ & $\begin{array}{l}\text { 1. Para selecionar a [Opção Logout] } \\
\text { deve-se selecionar a [Opção Finder] } \\
\text { do [Menu Maçã] e em seguida a } \\
\text { [Opção Logout] do [Menu Special]. }\end{array}$ \\
\hline [Opção New] & $\begin{array}{l}\text { 1. Cria novas [Janelas de Comando } \\
\text { do [Macintosh]]. }\end{array}$ & $\begin{array}{l}\text { 1. Para utilizar a [Opção New] deve-se } \\
\text { selecionar a [Opção } \\
\text { CommandShell24] do [Menu Maçã] } \\
\text { da [Tela de Visualização] e em } \\
\text { seguida a [Opção New] do [Menu } \\
\text { File]. }\end{array}$ \\
\hline
\end{tabular}

[Operador] 1. Pessoa que opera o [Tomógrafo]. 
Simbolo

[Osciloscópio I]

[Osciloscópio II]

[pac]

[Paciente]

1. Pessoa que é submetida a um [Exame Clínico].

[Painel da [Fonte de Alimentação do [Magneto]]]

[Painel de Falha da [Fonte de Alimentação do [Magneto]]] durante o [Procedimento de Shimming]. sinais de [Gradiente de Campo Magnético].

1. Comando do [MicroVax] que gerando as [Imagens].

\section{Alimentação do [Magneto]].} [Fonte de Alimentação do [Magneto]].
1. Localizado na [Sala de Equipamentos].

1. Utilizado para monitoramento de processa os [Dados de [Aquisição]]

\section{Localizado na [Sala de} Equipamentos].

1. O comando [pac] deve ser digitado na [Janela de Comando do [MicroVax]];

2. Sintaxe: pac <RETURN>; 3. O comando [pac] armazena as [Imagens] no [Disco de Usuários do [MicroVax]];

4. O comando [pac] não apaga os [Dados de [Aquisição]] do [Disco de Usuários do [MicroVax]].

1. O [Paciente] não pode ser portador de marca-passo e não pode possuir objetos magnetizáveis implantados ou próximo à região a ser examinada .

1. Localizado na parte frontal da [Fonte de Alimentação do [Magneto]].

1. Possui os indicadores de falha da
1. Localizado na parte traseira da [Fonte de Alimentação do [Magneto]];

2. O [Painel de Falha da [Fonte de Alimentação do [Magneto]]] indicará a falha ocorrida quando o [Indicador Fault da [Fonte de Alimentação do [Magneto]]] estiver aceso.

1. Localizado no [Painel do [Amplificador de Gradientes]].
1. Localizado na parte frontal do [Amplificador de Gradientes].

\section{[Painel do [Amplificador de Gradientes]]}

1. Painel de controle do [Amplificador de Gradientes]. 


\begin{tabular}{|c|c|c|}
\hline Simbolo & Nocao & LAL - 24 \\
\hline $\begin{array}{l}\text { [Painel do } \\
\text { [Tomógrafo]] }\end{array}$ & $\begin{array}{l}\text { 1. Utilizado para posicionamento da } \\
\text { [Cama] dentro do [Magneto] e para } \\
\text { visualização do sinal gerado no } \\
\text { [Procedimento de Sintonia]. }\end{array}$ & 1. Localizado no [Tomógrafo] \\
\hline [Plug do [Exaustor]] & $\begin{array}{l}\text { 1. Utilizado para ligar o [Exaustor] } \\
\text { do [Tomógrafo]. }\end{array}$ & $\begin{array}{l}\text { 1. Localizado na [Sala de } \\
\text { Equipamentos]; } \\
\text { 2. O [Exaustor] é ligado quando } \\
\text { coloca-se o [Plug do [Exaustor]] } \\
\text { numa tomada. }\end{array}$ \\
\hline [proc] & $\begin{array}{l}\text { 1. Comando do [MicroVax] que } \\
\text { processa os últimos [Dados de } \\
\text { [Aquisição]] e copia as [Imagens] } \\
\text { geradas para o [Diretório AVAX] no } \\
\text { [Disco do [Macintosh]]. }\end{array}$ & $\begin{array}{l}\text { 1. O comando [proc] deve ser } \\
\text { digitado na [Janela de Comando do } \\
\text { [MicroVax]]; } \\
\text { 2. Sintaxe: proc <RETURN>. } \\
\text { 3. O comando [proc] grava as } \\
\text { [Imagens] no [Disco de Usuários do } \\
\text { [MicroVax]] antes de copiá-las para o } \\
\text { [Diretório AVAX] no [Disco do } \\
\text { [Macintosh]]. }\end{array}$ \\
\hline $\begin{array}{l}\text { [Procedimento de } \\
\text { [Controle de Nível de } \\
\text { Sinal]] }\end{array}$ & $\begin{array}{l}\text { 1. Procedimento que visa obter o } \\
\text { máximo [Sinal de Recepção], sem } \\
\text { saturar os conversores } \\
\text { analógico-digital do }\end{array}$ & $\begin{array}{l}\text { 1. No [Procedimento de [Controle de } \\
\text { Nível de Sinal]] atenua-se a potência } \\
\text { dos [Sinal de Transmissão] e [Sinal } \\
\text { de Recepção] do [Tomógrafo]; } \\
\text { 2. O [Procedimento de [Controle de } \\
\text { Nível de Sinal]] utiliza os [Seletores } \\
\text { de Controle de Nível de Potência] e } \\
\text { os [Seletores de Controle de Nível de } \\
\text { Recepção]. }\end{array}$ \\
\hline
\end{tabular}


Simbolo

[Processador de Arranjos]

[prot]

[Proteção do

Pré-Amplificador]

Protocolo de

Manutenção de

Disco]

[quit]
1. Realiza as médias dos [Sinais de $\mathrm{RMN}$ ] gerando os [Dados de [Aquisição]] e os transmite para o [MicroVax].

1. Comando do [MicroVax] que abre a [Janela de Edição de Parâmetros], para a definição dos parâmetros de [Aquisição], na [Janela de Comando do [MicroVax]].

1. Protege o pré-amplificador contra excesso de potência do [Sinal de Recepção].

1. Procedimento no qual as [Imagens] enviadas para o [Diretório AVAX] pelos comandos [gaia] ou [proc] são transferidas para diretórios específicos. No caso de [Imagens] de [Paciente] ou [Voluntário], estes diretórios devem ter o nome do [Paciente] ou [Voluntário] e estar dentro do [Diretório PACIENTES] ou [Diretório VOLUNTÁRIOS], respectivamente;

2. Realização de backup das [Imagens] para liberação de espaço do [Disco do [Macintosh]]; 3. Realização de backup das [Imagens], [Dados de [Aquisição]] e outros arquivos para liberação de espaço do [Disco do [Macintosh]].

1. Comando que finaliza o [Procedimento de [Controle de Nível de Sinal]];

2. Comando que finaliza o

[Procedimento de Shimming];

3. Comando que aborta a

[Aquisição] se esta foi iniciada com o comando [go] com parâmetro a.
1. Localizado no [Rack de Equipamentos];

2. Os [Sinais de RMN] são recebido do [Espectrômetro] através de uma [Interface Óptica].

1. O comando [prot] deve ser digitado na [Janela de Comando do [MicroVax]];

2. Sintaxe: prot arquivo.ptc $<$ RETURN>. Onde arquivo é o nome do [Arquivo de Parâmetros].

1. Localizado no [Tomógrafo], abaixo e à esquerda da [Cama]. 2. O cabo da [Bobina de RF] deve sempre estar ligado à [Proteção do Pré-Amplificador] a não ser durante o [Procedimento de Sintonia].
1. O comando [quit] deve ser digitado na [Janela de Comando do [MicroVax]];

2. Sintaxe: quit <RETURN>. 
Simbolo

[Rack de

Equipamentos]
Nocao

1. Possui os módulos [Fonte do

[Rack de Equipamentos]],

[Processador de Arranjos],

[Interface Óptica], [Espectrômetro],

[Sintetizador de RF do

Espectômetro]], [Amplificador de

Potência de RF] e [Sintetizador de

RF].

[Registro do [Circuito 1. Abre e fecha o [Circuito Externo

Externo de de Refrigeração].
Impacto

LAL - 26

1. Localizado na [Sala de Equipamentos].

1. Localizado na [Sala do [Tomógrafo]];

2. Com o [Registro do [Circuito Externo de Refrigeração]] aberto há refrigeração dos [Circuitos Interno de Refrigeração I] e [Circuitos Interno de Refrigeração II].

1. O ajuste da [Ressonância] é feito através da variação da corrente do [Magneto], que por sua vez altera a intensidade do [Campo Magnético Principal];

2. A [Ressonância] é condição necessária para a operação do [Tomógrafo];

3. No [Procedimento de Shimming] é necessário retirar o [Magneto] da [Ressonância] para realizar o ajuste de [Homogeneidade do Campo], e em seguida recolocá-lo em

[Ressonância];

4. Na [Ressonância] observa-se um padrão não oscilatório do [FID] no [Osciloscópio I],

[rs]

1. Comando que faz o [MicroVax] reinicializar o [Espectrômetro].

1. O comando [rs] deve ser digitado na [Janela de Comando do [MicroVax]];

2. Sintaxe: rs <RETURN>;

3. O comando [rs] não altera a configuração feita pelo [MicroVax] no [Espectrômetro].

1. A [Sala de [Tomografia]] deve fornecer a infra-estrutura necessária para a instalação e operação do [Tomógrafo], tal como o [Sistema de Refrigeração de Ambiente]. 
Simbolo

[Sala de
Equipamentos]

Nocao

1. Sala na qual estão: [Estabilizador de Tensão], [Amplificador de Gradientes], [Fonte de Alimentação do [Magneto]], [Transformador do [Magneto]], [Sintetizador de RF], [Disco de Sistema do [MicroVax]], [MicroVax], [Disco de Usuários do [MicroVax]], [Rack de Equipamentos], [Osciloscópio I] e [Osciloscópio II].

[Sala de Operação]

[Sala do [Tomógrafo]]

[sc]

[Seletor Coarse do Controle de Nível de Potência]
1. Sala de onde é feito o controle do [Tomógrafo] através do [Sistema de Computadores]. Nesta sala estão: [Tela de Visualização], [Macintosh], [Controle de Nível de Sinal] e [Chave Geral do [Rack de Equipamentos]].

1. Nesta sala estão: [Tomógrafo], [Ventilador], [Registro do Circuito Externo de Refrigeração], [Chave da [Bomba de Água I]], [Chave da [Bomba de Água II]] e [Plug do [Exaustor]].

1. Comando que faz o [MicroVax] configurar o [Espectrômetro] para o [Procedimento de Shimming], e iniciá-lo.

1. Faz o ajuste grosso (passo de 10dB) do [Sinal de Transmissão] no [Procedimento de [Controle de Nível de Sinal]].
Impacto

LAL - 27

1. Localiza-se na [Sala de [Tomografia]].

1. Localiza-se na [Sala de [Tomografia]].

1. Localiza-se na [Sala de [Tomografia]].

1. O comando [sc] deve ser digitado na [Janela de Comando do [MicroVax]];

2. Sintaxe: sc <RETURN>.

1. Localizado no [Controle de Nível de Sinal];

2. O [Seletor Coarse do Controle de Nível de Potência] é um dos [Seletores de Controle de Nível de Potência].

1. Localizado no [Controle de Nível de Sinal];

2. O [Seletor Coarse do Controle de Nível de Recepção] é um dos [Seletores de Controle de Nível de Recepção].

1. Localizado no [Painel do [Amplificador de Gradientes]].
[Seletor DVM Channel]
1. Seleciona qual das [Bobinas de Gradiente] terá sua corrente indicada no [Visor DVM Channel].
1. Faz o ajuste grosso (passo de [Procedimento de [Controle de Nível de Sinal]]. 
Simbolo

Nocao

[Seletor Fine do Controle de Nível de Potência]

1. Faz o ajuste fino (passo de $1 \mathrm{~dB}$ ) do [Sinal de Transmissão] no [Procedimento de [Controle de Nível de Sinal]].

[Seletor Fine do Controle de Nível de Recepção]

1. Faz o ajuste fino (passo de $1 \mathrm{~dB}$ ) do [Sinal de Recepção] no [Procedimento de [Controle de Nível de Sinal]].

[Seletores de

1. Faz o ajuste do [Sinal de

Controle de Nível de Potência]

1. Localizado no [Controle de Nível de Sinal];

2. O [Seletor Fine do Controle de Nível de Potência] é um dos [Seletores de Controle de Nível de Potência].

1. Localizado no [Controle de Nível de Sinal];

2. O [Seletor Fine do Controle de Nível de Recepção] é um dos [Seletores de Controle de Nível de Recepção].

1. Localizado no [Controle de Nível de Sinal];

2. Os [Seletores de Controle de Nível de Potência] são o [Seletor Fine do Controle de Nível de Potência] e o [Seletor Coarse do Controle de Nível de Potência].

1. Localizado no [Controle de Nível de Sinal].

2. Os [Seletores de Controle de Nível de Recepção] são o [Seletor Fine do Controle de Nível de Recepção] e o [Seletor Coarse do Controle de Nível de Recepção].

[Seletores de

1. Determinam a frequência do [Sina

1. Localizado no [Sintetizador de RF];

Frequência] de Transmissão] no [Conector Output].

2. Os [Seletores de Frequência] são ajustados em $2.35 \mathrm{MHz}$.

[Sequência de 1. Consiste da finalização do [Rack Finalização Primária] de Equipamentos], do [Amplificador de Potência de RF], das [Bobinas

de Gradiente], do [Macintosh], do [MicroVax].

1. Pode ser feita imediatamente após da utilização do [Tomógrafo]; 2. A [Sequência de Finalização Primária] visa finalizar os subsistemas necessários para a operação do [Tomógrafo] que foram inicializados na [Sequência de Inicialização Secundária]. 
Simbolo

[Sequência de

Finalização

Secundária]
Nocao

1. A [Sequência de Finalização Secundária] consiste da finalização do [Sistema de Refrigeração de Ambiente], do [Circuito Externo de Refrigeração] e do [Magneto].
[Sequência de 1. A [Sequência de Inicialização Inicialização Primária]

Primária] deve ser feita com uma

[Sistema de Refrigeração de

Ambiente], do [Circuito Externo de Refrigeração] e do [Magneto].
Impacto

LAL - 29

1. A [Sequência de Finalização Secundária] pode ser feita logo após a utilização do [Tomógrafo];

2. A [Sequência de Finalização Secundária] não deve ser feita caso o [Tomógrafo] vá ser utilizado nas próximas horas, levando-se em conta os tempos envolvidos na [Sequência de Inicialização Primária].

1. A [Sequência de Inicialização Primária] consiste da inicialização do antecedência de pelo menos 8 horas para obter alta [Homogeneidade do Campo], ou 4 horas para obter [Campo Magnético Principal] estável com [Homogeneidade do Campo] variável.

1. Pode ser feita imediatamente antes da utilização do [Tomógrafo]; 2. A [Sequência de Inicialização Secundária] visa inicializar os subsistemas necessários para a operação do [Tomógrafo], com exceção daqueles que já o foram na [Sequência de Inicialização Primária].
[Sequência Spin Eco 1. É o protocolo de [Aquisição] Multislice] utilizado pelo [Tomógrafo] para obter [Imagens] utilizando a técnica de Spin Eco Multi Slice.

[set ver]
1. Comando que faz com que o comando [sc] mostre menssagens de aviso durante sua execução.
1. O comando [set ver] deve ser digitado na [Janela de Comando do [MicroVax]];

2. Sintaxe: set ver <RETURN>. 


\begin{tabular}{|c|c|c|}
\hline Simbolo & Nocao & LAL - 30 \\
\hline [setup] & $\begin{array}{l}\text { 1. Comando que faz o [MicroVax] } \\
\text { configurar o [Espectrômetro] de } \\
\text { acordo com o [Arquivo de } \\
\text { Parâmetros]. }\end{array}$ & $\begin{array}{l}\text { 1. O comando [setup] deve ser } \\
\text { digitado na [Janela de Comando do } \\
\text { [MicroVax]]; } \\
\text { 2. Sintaxe: setup arquivo <RETURN>. } \\
\text { Onde arquivo é o nome do [Arquivo } \\
\text { de Parâmentros]; } \\
\text { 3. O comando [setup] é executado } \\
\text { tanto no [Procedimento de [Controle } \\
\text { de Nível de Sinal]] quanto na } \\
\text { [Aquisição]. }\end{array}$ \\
\hline [Sinais de RMN] & $\begin{array}{l}\text { 1. Sinais de RF gerados pelo } \\
\text { [Paciente], [Voluntário] ou } \\
\text { [Amostra] submetidos ao [Campo } \\
\text { Magnético Principal] e ao [Sinal de } \\
\text { Transmissão]. }\end{array}$ & $\begin{array}{l}\text { 1. Sinônimo de [Sinal de Recepção] e } \\
\text { [FID]. }\end{array}$ \\
\hline [Sinal de Recepção] & $\begin{array}{l}\text { 1. Sinais de RF gerados pelo } \\
\text { [Paciente], [Voluntário] ou } \\
\text { [Amostra] submetidos ao [Campo } \\
\text { Magnético Principal] e ao [Sinal de } \\
\text { Transmissão]. }\end{array}$ & $\begin{array}{l}\text { 1. Sinônimo de [Sinais de RMN] e } \\
\text { [FID]. }\end{array}$ \\
\hline $\begin{array}{l}\text { [Sinal de } \\
\text { Transmissão] }\end{array}$ & $\begin{array}{l}\text { 1. Sinal de RF gerado pelo } \\
\text { [Espectrômetro] e amplificado pelo } \\
\text { [Amplificador de Potência de RF] } \\
\text { usado no [Procedimento de } \\
\text { Shimming] e na [Aquisição]; } \\
\text { 2. Sinal de RF gerado pelo } \\
\text { [Sintetizador de RF] usado no } \\
\text { [Procedimento de Sintonia]. }\end{array}$ & $\begin{array}{l}\text { 1. O [Sinal de Transmissão] - na } \\
\text { noção } 2 \text { - tem frequência de } 2.35 \\
\text { MHz. }\end{array}$ \\
\hline $\begin{array}{l}\text { [Sintetizador de RF } \\
\text { do [Espectômetro]] }\end{array}$ & $\begin{array}{l}\text { 1. Gera o sinal de RF de }(2.35+ \\
\text { 117.8) MHz e a [Base de Tempo do } \\
\text { [Espectrômetro]]. }\end{array}$ & $\begin{array}{l}\text { 1. Localizado no [Rack de } \\
\text { Equipamentos]; } \\
\text { 2. O sinal de RF é modulado em AM e } \\
\text { FM pelo [Espectrômetro], que gera } \\
\text { os pulsos de RF que compõe o [Sinal } \\
\text { de Transmissão]. }\end{array}$ \\
\hline
\end{tabular}


Simbolo

[Sintetizador de RF] 1. Gera o [Sinal de Transmissão] utilizado para fazer o [Procedimento de Sintonia].

1. Utilizado no [Procedimento de Sintonia].

[Sistema de Computadores]

[Sistema de Refrigeração de Ambiente]

[Tela de Visualisação]

\section{Impacto}

LAL - 31

1. Localizado na [Sala de Equipamentos].

2. O [Sintetizador de RF] pode operar em dois modos, indicados pelos

[Indicadores Remote/Local]: no modo Local, a frequência é controlada pelos [Seletores de Frequência] e a amplitude é controlada pelo [Ajuste Level]; no modo Remote, o controle de frequência e de atenuação do sinal são feitos remotamente por um controlador externo ligado ao [Sintetizador de RF];

3. O [Sintetizador de RF] opera em $2.35 \mathrm{MHz}$

1. Localizado no [Tomógrafo], abaixo e à esquerda da [Cama];

2. Durante o [Procedimento de Sintonia] o cabo da [Bobina de RF] é ligado ao [Sintonizador].
1. Conjunto de condicionadores de ar utilizado para manter a temperatura da [Sala de [Tomografia]] em condições de operação.

1. Tela preto e branco, com 256 níveis de cinza, ligada ao [Macintosh].

1. Processo de aquisição de [Imagens] por RMN;

2. Imagem resultante da [Aquisição].
1. Localizada na [Sala de Operação];

2. A [Tela de Visualisação] é utilizada na visualização de [Tomografia].

[Tomografia]

1. Constituído pelo [MicroVax], [Disco de Sistema do [MicroVax]], [Disco de Usuários do [MicroVax]],

[Macintosh] e [Tela de Visualisação].

1. Realiza o controle da operação do [Imagens] e visualização das [Imagens]. 
Simbolo

[Tomógrafo]

[torm]

Transformador do

[Magneto]]

[Ventilador]

[Visor de Posição]
1. É o sistema, localizado na [Sala de

[Tomografia]], que realiza

[Tomografia];

2. Parte do sistema, localizado na

[Sala do [Tomógrafo]], onde o

[Paciente], [Voluntário] ou

[Amostra] são colocados.

1. Comando do [Macintosh] que abre uma conexão com o [MicroVax].
1. O comando [torm] deve ser digitado em uma das [Janelas de Comando do [Macintosh]];

2. Sintaxe: torm <RETURN>; 3. A [Janelas de Comando do [Macintosh]] onde o comando [torm] é digitado torna-se uma [Janela de Comando do [MicroVax]].

1. Localizado na [Sala de Equipamentos]. da [Fonte de Alimentação do [Magneto]].

1. Utilizado para ventilação interna do [Tomógrafo], quando com [Paciente] ou [Voluntário].

1. Indica o deslocamento da [Cama], em cm, com relação à posição onde o [Botão Posicionador] foi pressionado pela última vez.
1. Localizado na [Sala do [Tomógrafo]].

1. Localizado no [Painel do [Tomógrafo]].

1. Localizado no [Painel do [Amplificador de Gradientes]].

1. Localizado no [Painel da [Fonte de Alimentação do [Magneto]]].

1. O [Voluntário] não pode ser portador de marca-passo e não pode possuir objetos magnetizáveis implantados ou próximo à região a ser examinada.

1. O comando [vt100] deve ser digitado na [Janela de Comando do [MicroVax]];

2. Sintaxe: vt100 <RETURN>. 
APÊNDICE VI - Modelo EER completo do DataTORM 


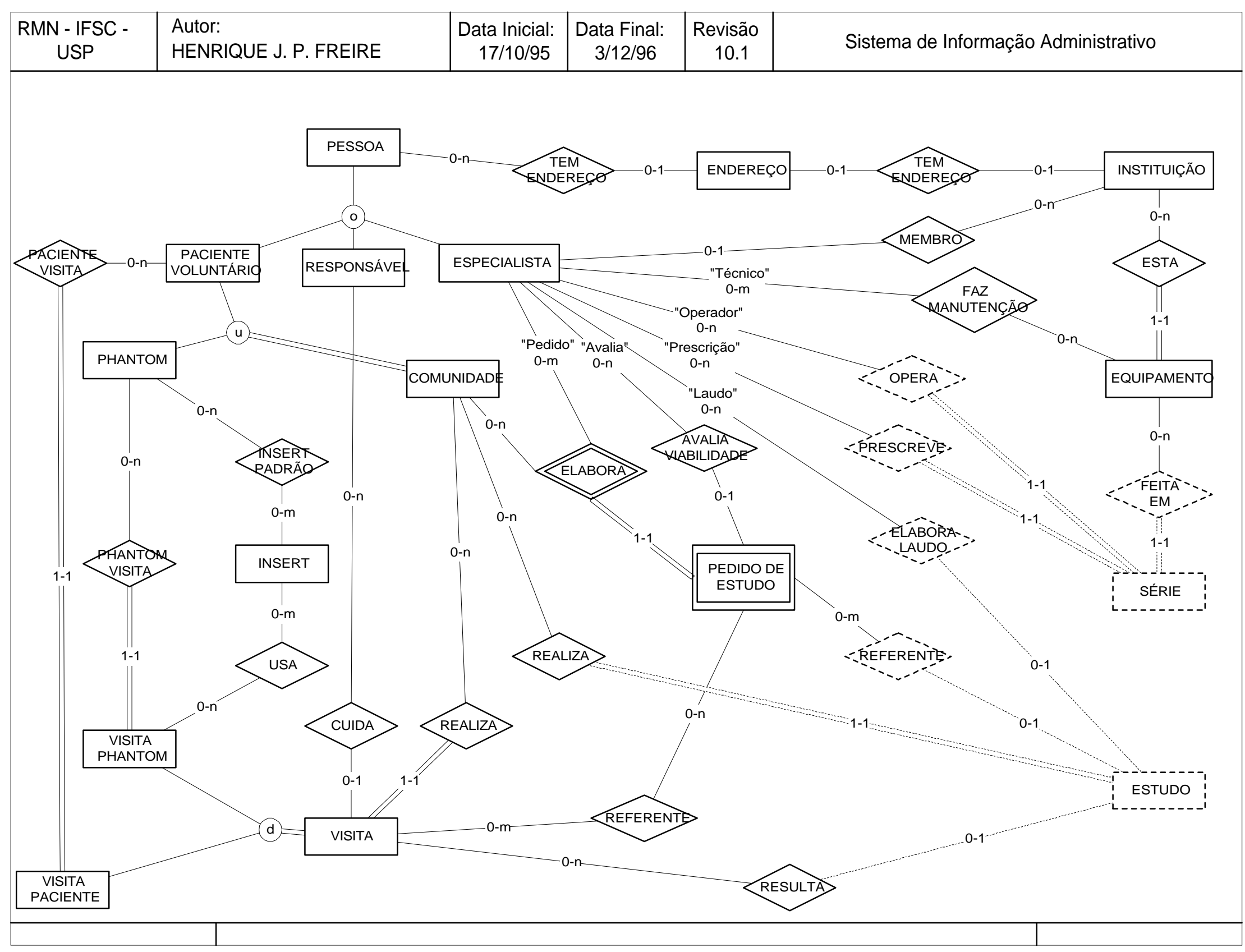




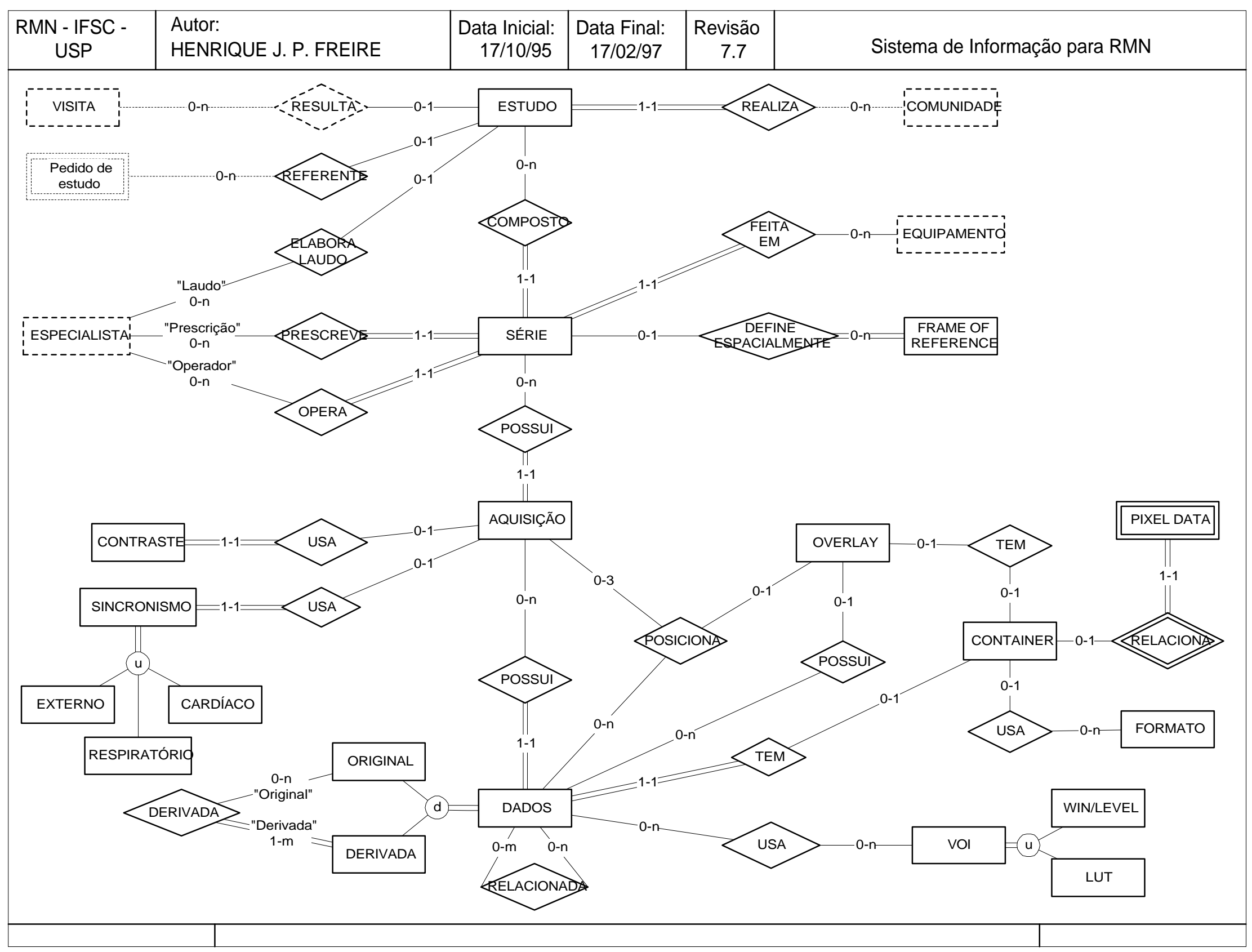




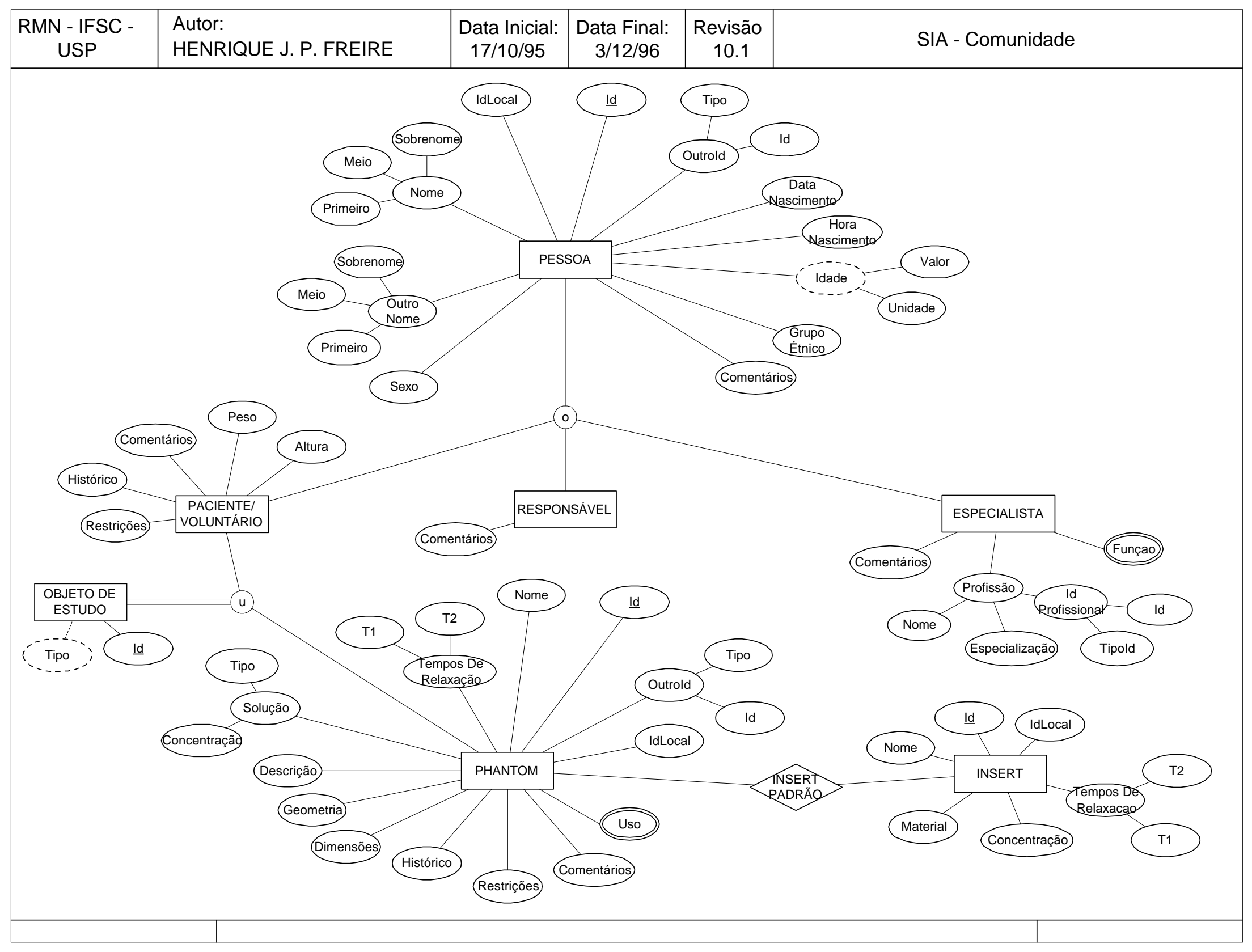




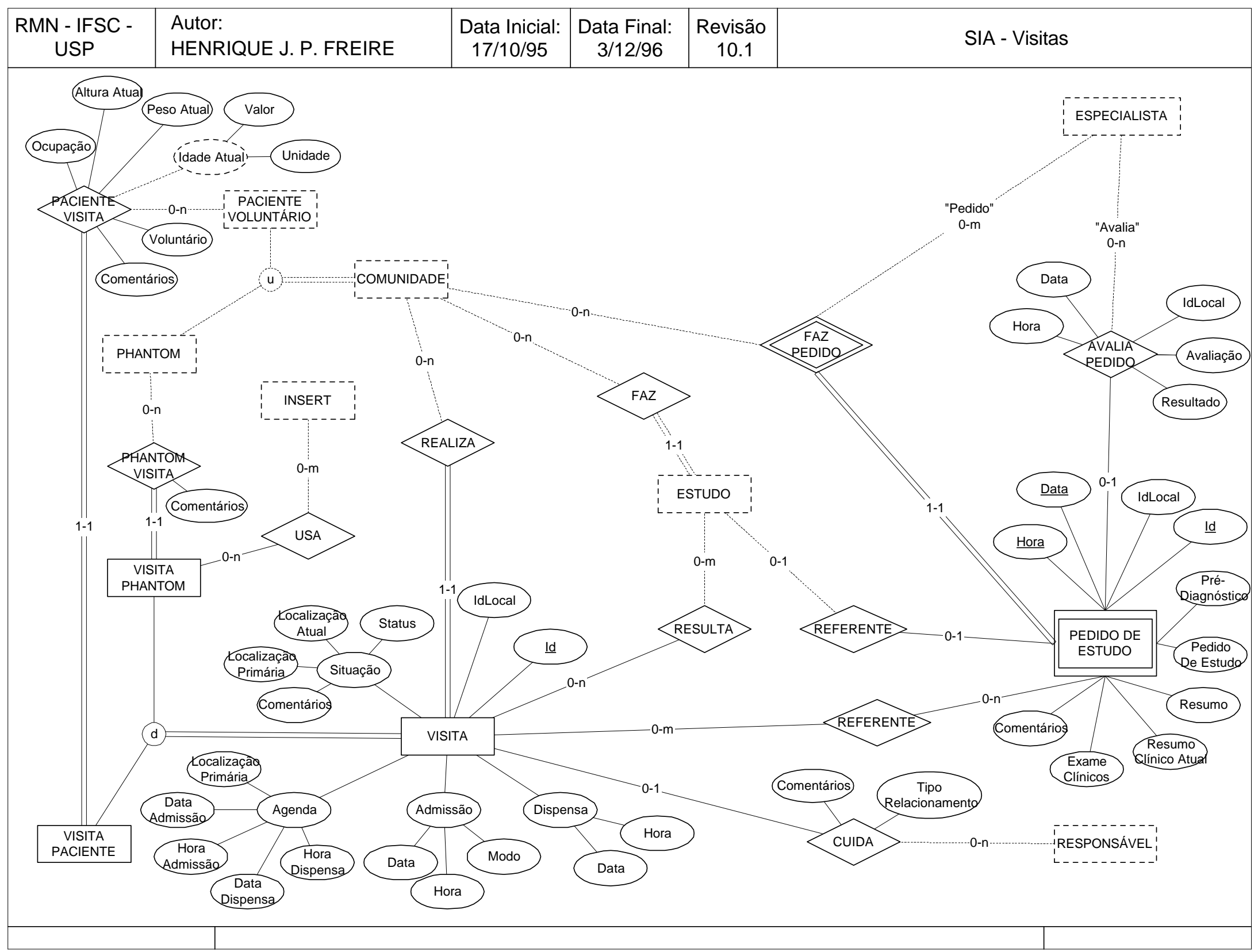




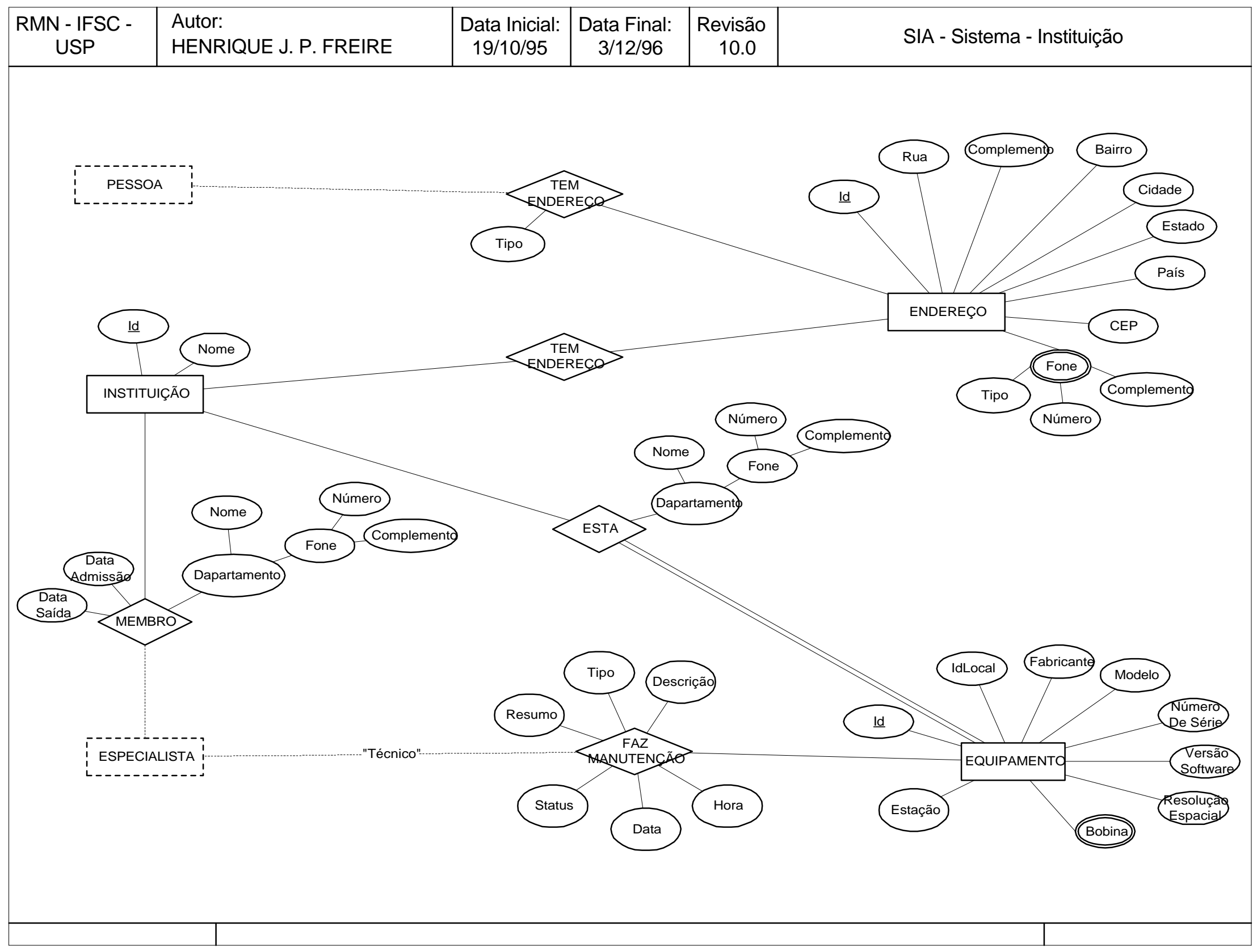




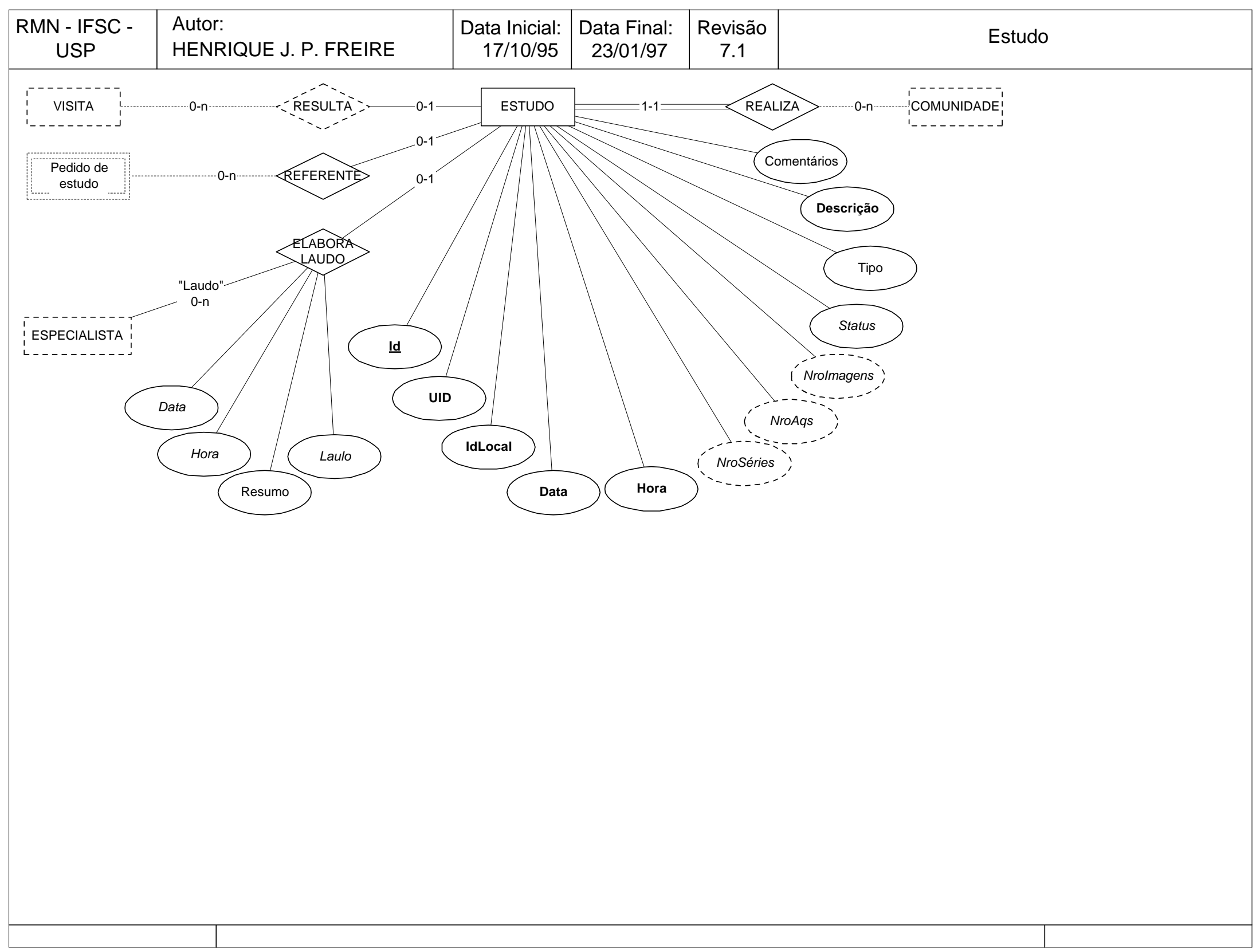




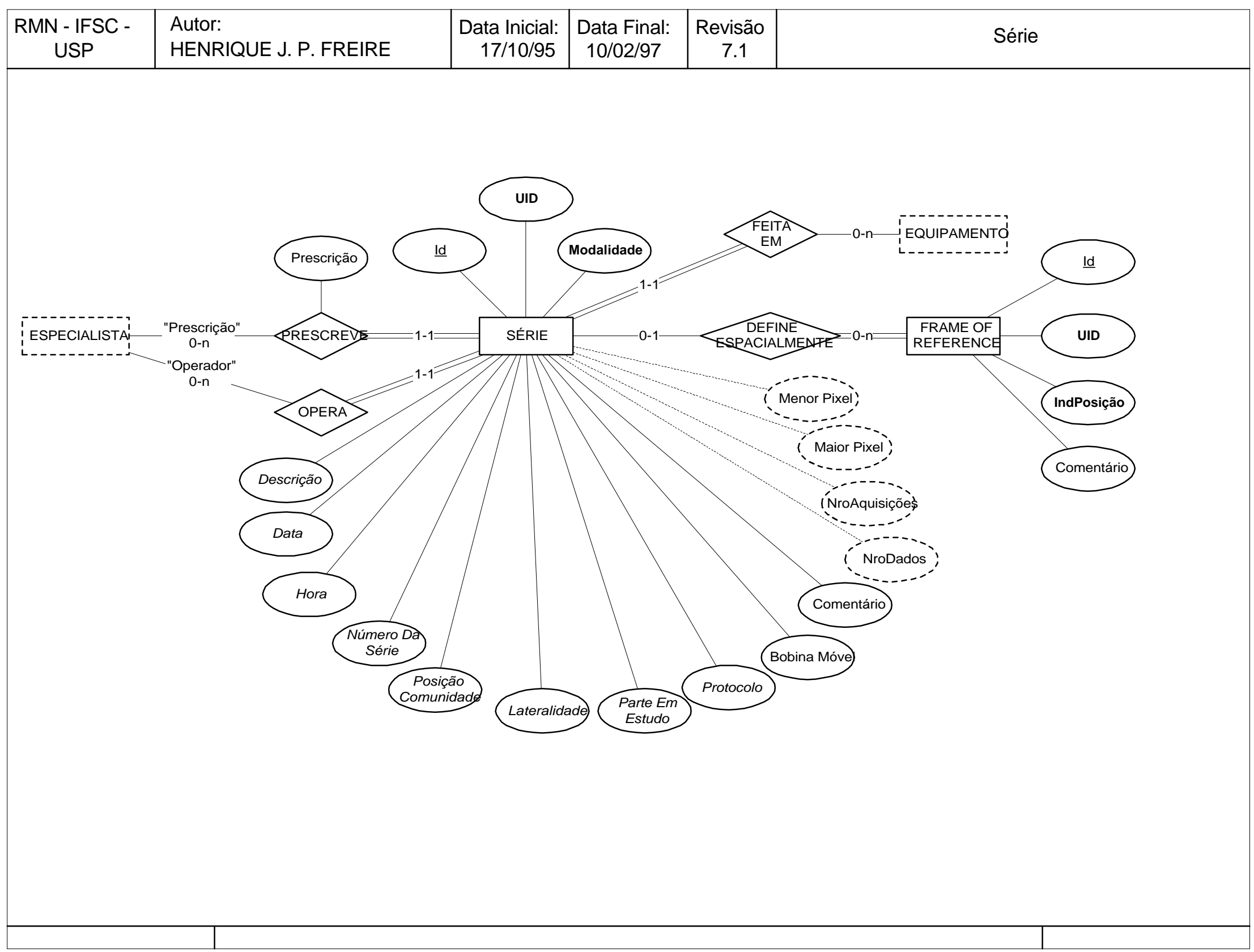




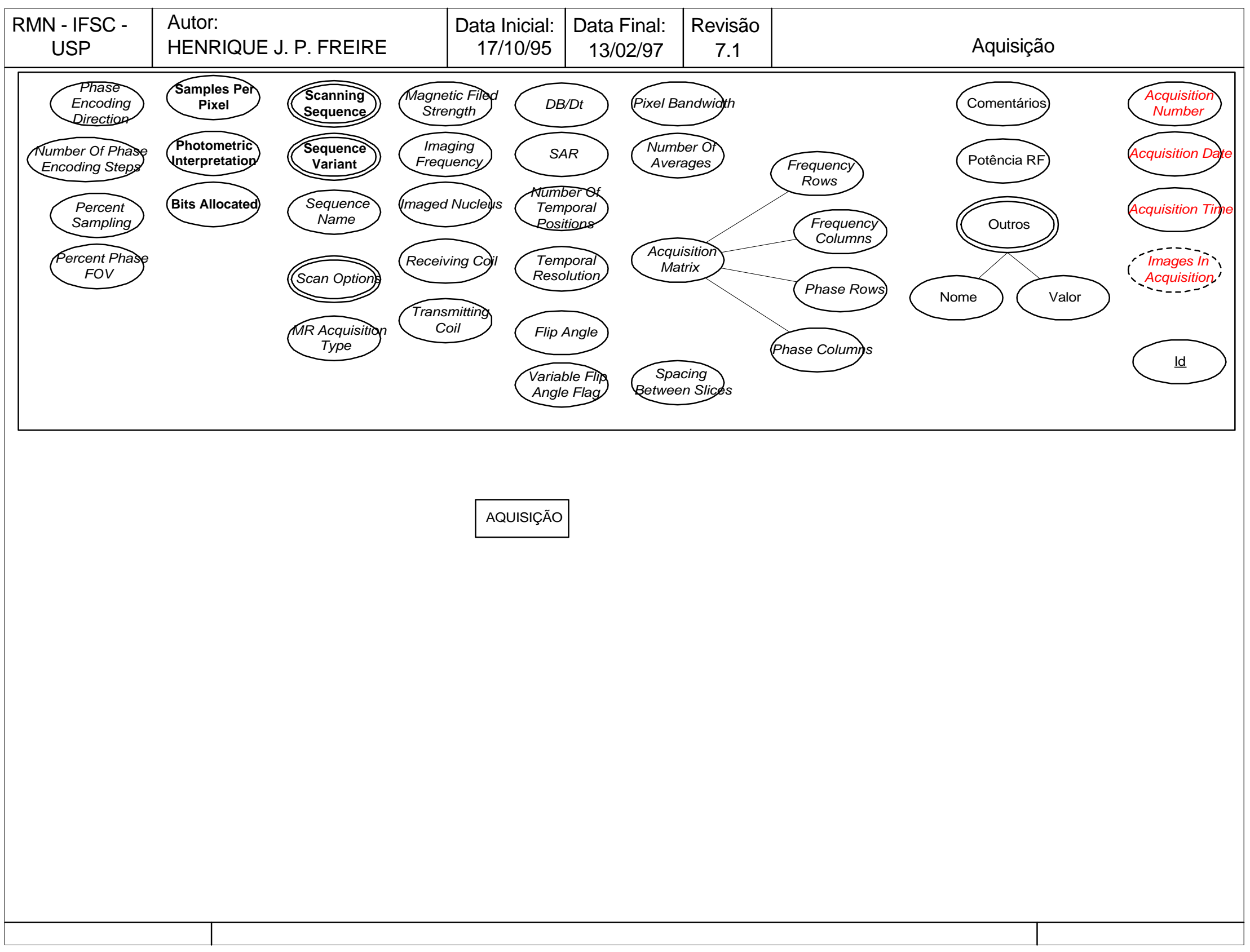




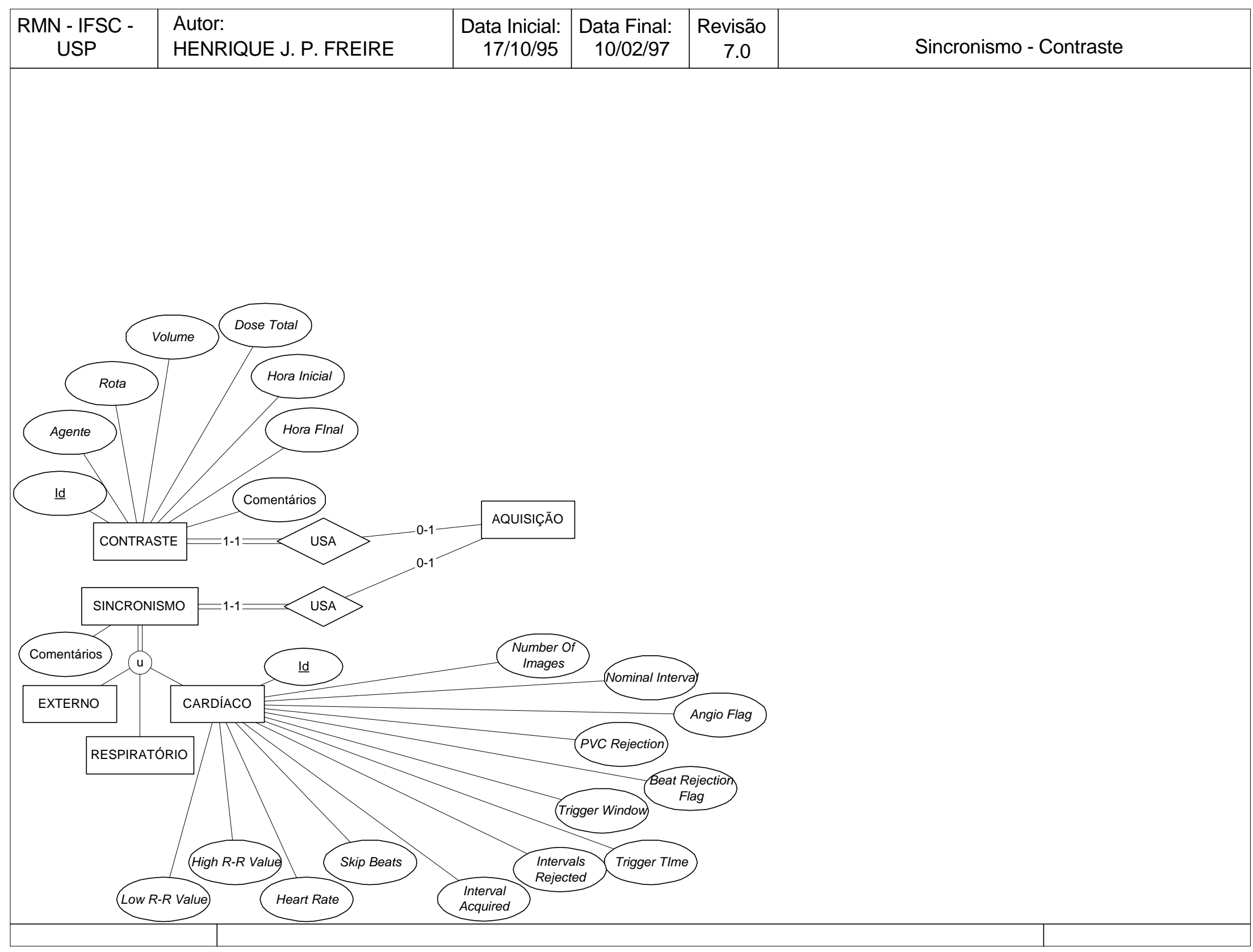




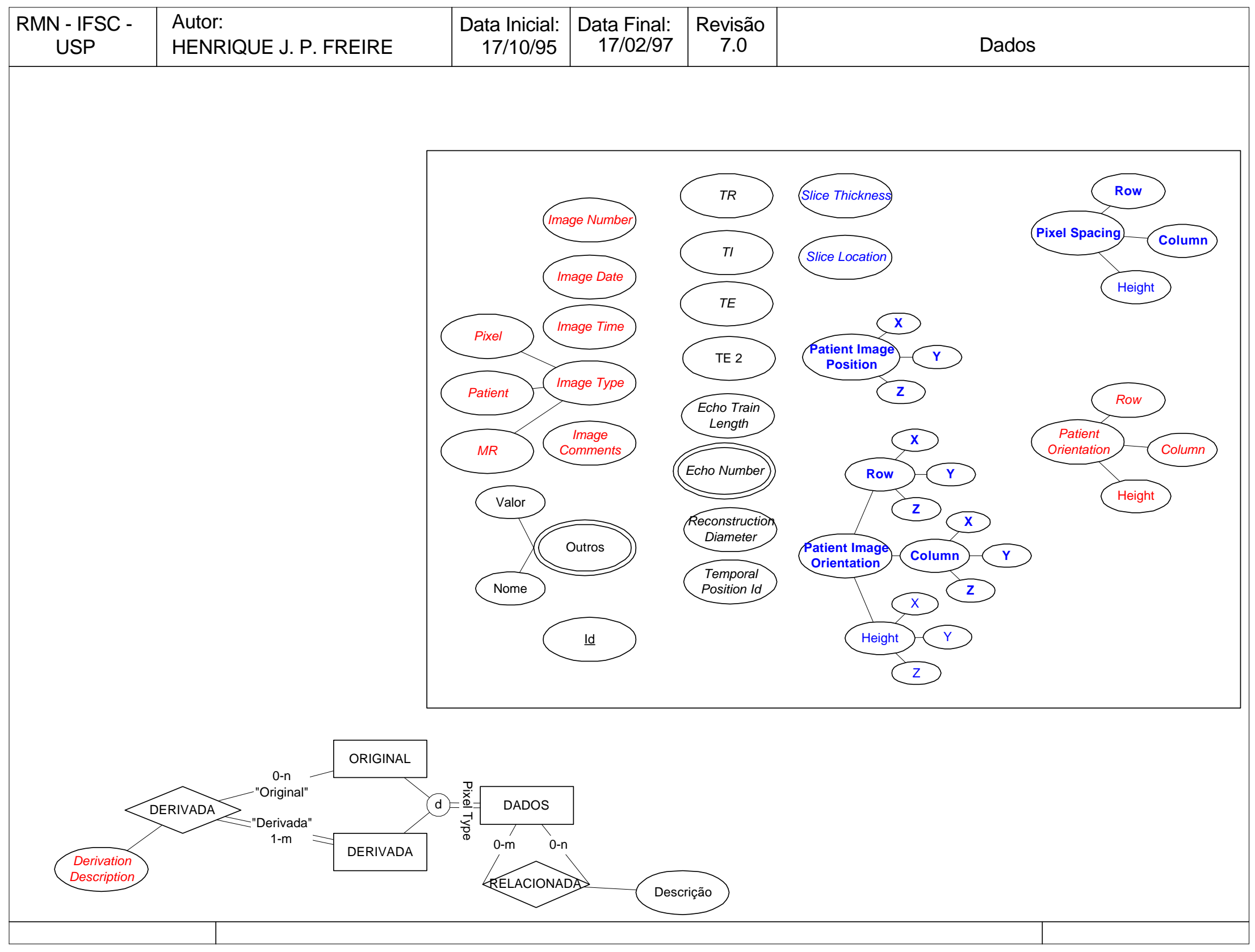




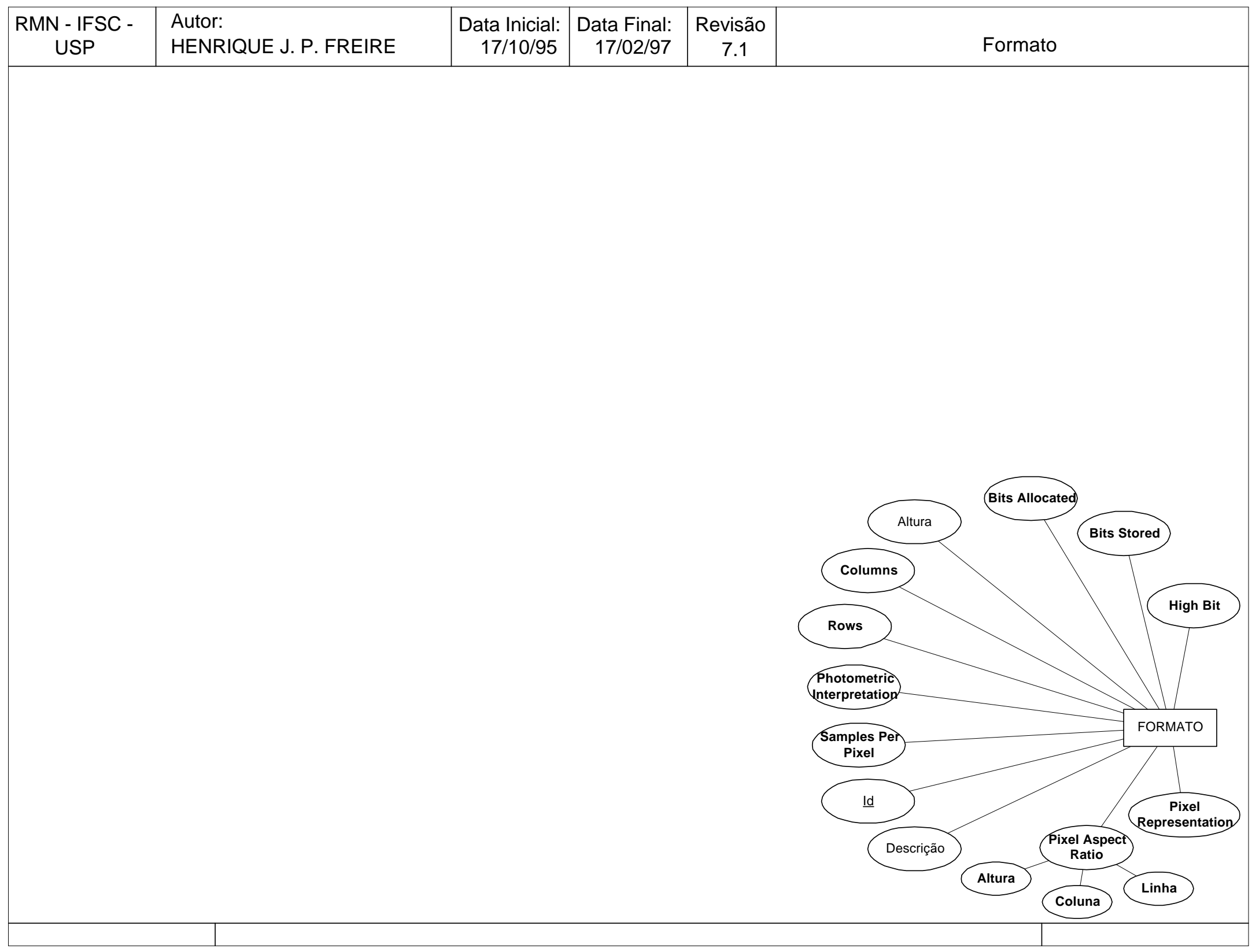




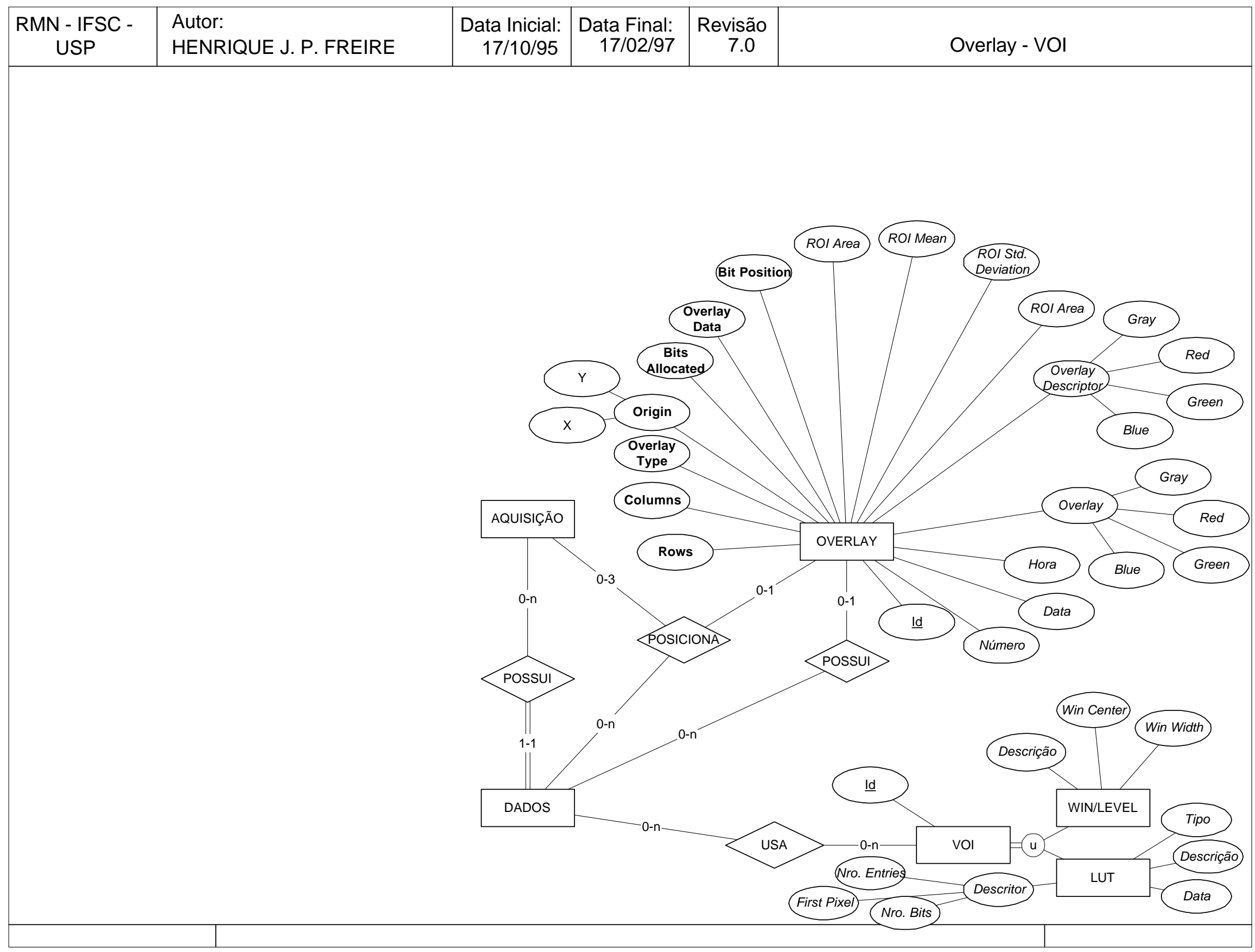




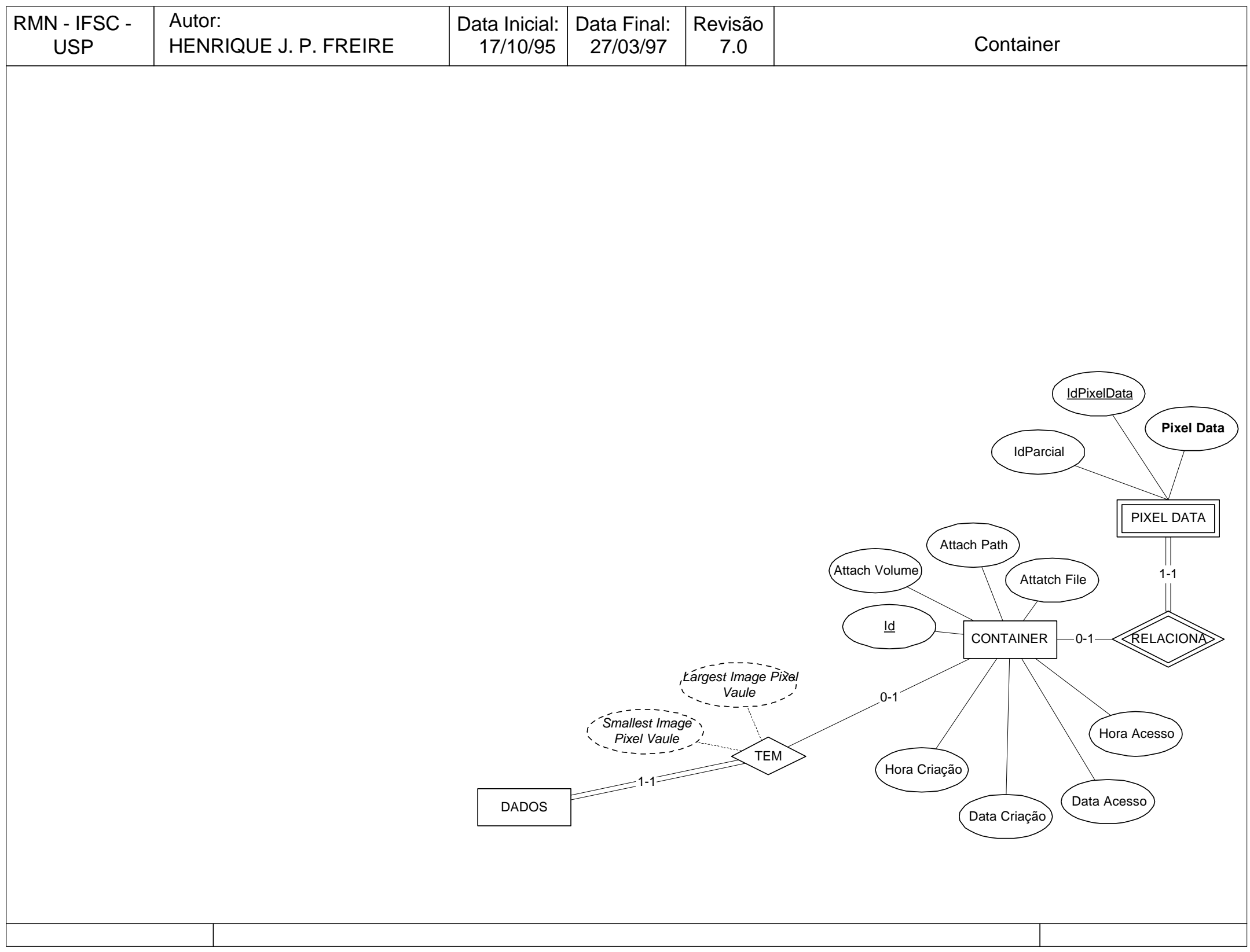




\section{APÊNDICE VII - Dicionário de dados}

Termos especiais usados no dicionário de dados:

PK: chave primária;

FK: chave estrangeira;

SK: chave surrogate;

Req: requerido, o valor do atributo deve possuir um valor válido. Esta caracterísitica é subentendida nos atributos que são PK;

Em PK: indica que o atributo é parte de um atributo composto que forma a chave primária da relação;

CK: chave candidata. 
DataTORM - Dicionário de Dados
Campo
Tipo de dado
Bytes Descrição
Dic. Dados - 1

\section{Bobina}

$\begin{array}{llll}\text { IdEquipamento } & \text { Number (Long) } & 4 & \begin{array}{l}\text { Em PK: FK para Equipamento; Identificador do } \\ \text { equipamento ao qual a bobina está associada. }\end{array} \\ \text { Bobina } & \text { Text } & 16 & \text { Em PK; Nome que identifica a bobina } .\end{array}$

\section{Comunidade}

IdComunidade

Tipo

$\begin{array}{ll}\text { Number (Long) } & 4 \\ \text { Text } & 16\end{array}$

PK da categoria Comunidade. Identificador de comunidade no SIA.

16 Req; Nome da categoria da comunidade: PacVol ou Phantom.

\section{Endereço}

IdEndereço

Rua

Number (Long)

4

PK: Identificador de endereço.

Complemento

Text

DICOM:Patient Address (0010,1040 LO) - Nome da rua, avenida, etc.

$\begin{array}{llr}\text { Bairro } & \text { Text } & 64 \\ \text { Cidade } & \text { Text } & 64 \\ \text { Estado } & \text { Text } & 2 \\ \text { País } & \text { Text } & 64 \\ \text { CEP } & \text { Text } & 64\end{array}$

DICOM:Patient Address (0010,1040 LO) - Número, apartamento, bloco, etc.

4 DICOM:Region of Residence (0010,2152 - LO) Bairro, vila, distrito.

DICOM:Patient Address (0010,1040 LO) - Nome da cidade.

DICOM:Patient Address (0010,1040 LO) - Sigla do estado.

64 DICOM:Country of Residence (0010,2150 - LO) Nome do país.

64 DICOM:Patient Address (0010,1040 LO) - Número do CEP ou código similar.

\section{EndPessoa}

IdPessoa

Number (Long)

Em PK; FK para Pessoa; Identificador de pessoa.

IdEndereço

Number (Long)

TipoEnd

Em PK; FK para Endereço; Identificador de endereço.

Tipo de endereço: Residencial; Comercial; Outro.

\section{Equipamento}

IdEquipamento

Estação

IdLocal

Fabricante

Modelo

NúmeroSérie
Number (Long)

\section{Text}

Text

Text

Text

Text
PK; Identificador de equipamento no SIA.

DICOM:Station Name (0008,1010 SH) - Nome da estação que gerou os dados de RMN.

Identificador usado pelo sistema de informação local.

DICOM:Manufacturer (0008,0070 LO) - Nome do fabricante do equipamento que produz as imagens digitais.

DICOM:Manufacture's Model Name (0008,1090 LO) Modelo do equipamento.

DICOM:Device Serial Number (0018,1000 LO) Número de série usado pelo fabricante. 


\begin{tabular}{|c|c|c|c|}
\hline Campo & Tipo de dados & Bytes & Dic. Dados - 2 \\
\hline VersãoSoftware & Text & 64 & $\begin{array}{l}\text { DICOM:Software Versions }(0018,1020 \text { LO) - } \\
\text { Designação do fabricante para a versão de software. }\end{array}$ \\
\hline ResoluçãoEspacial & Number (Single) & 4 & $\begin{array}{l}\text { DICOM:Spatial Resolution (0018,1050 DS) - Resolução } \\
\text { espacial limitante do equimamento, em mm, para } \\
\text { objetos de alto contraste. Se varia em uma série de } \\
\text { imagens, o valor é da resolução no centro da imagem. }\end{array}$ \\
\hline Idlnstituição & Number (Long) & 4 & FK Req para Instituição; Identificador de Instituição. \\
\hline NomeDepartamento & Text & 64 & $\begin{array}{l}\text { DICOM:Institutional Department Name (0008,1040 LO) - } \\
\text { Departamento da instituição aonde está o }\end{array}$ \\
\hline Fone & Text & 16 & Telefone do departamento aonde está o equipamento. \\
\hline ComplFone & Text & 16 & Complemento de telefone, por exemplo ramal. \\
\hline
\end{tabular}

\section{Especialista}

IdEspecialista

$\begin{array}{lll}\text { Profissão } & \text { Text } & 64\end{array}$

PK; FK para especialização Pessoa-Especialista; Identificador de especialista.

Especialização Text

TipoldProfissional Text

IdProfissional Text

Comentários Memo

Idlnstituição Number (Long)

NomeDepartamento Text

Text

FoneDepartamento Text

FoneDeptoCplnto Text

Nome da profissão.

Especialização profissional.

Datalngresso

Date/Time

Tipo de identificador profissional.

DataDesligamento

Date/Time

$-$

Identificador profissional.

Comentários específicos sobre o especialista.

FK para Instituição; Identificador de instituição.

$64 \quad$ Nome do departamento ao qual o especialista está associado.

Telefone do departamento.

Complemento do número do telefone, por exemplo

Data de ingresso na instituição.

8

Data de desligamento da instituição.

\section{FoneEnd}

IdEndereço

Tipo

Telefone

Complemento
Number (Long)

Text

Text

Text

\section{FunçãoEspecialista}

IdEspecialista

Number (Long)

Text

Função Text
Em PK; FK para Endereço; Identificador de endereço ao qual o telefone está associado.

Em PK; Tipo de telefone: residencial, comercial, fax, celular.

Em PK; DICOM:Patient's Telephone Numbers (0010,2154 SH) - Número de telefone.

Complemento, por exemplo: ramal.

Em PK; FK para Especialista; Identificador de especialista.

Em PK; Função ou papel desempenhado pelo especialista: Avaliação, Pedido, Prescrição, Operação, Manutenção.

\section{Insert}




\begin{tabular}{|c|c|c|c|}
\hline Campo & Tipo de dados & Bytes & Dic. Dados - 3 \\
\hline Idlnsert & Number (Long) & 4 & PK; Identificador do insert. \\
\hline Nome & Text & 64 & Nome do insert. \\
\hline IdLocal & Text & 64 & Identificador local. \\
\hline Material & Text & 64 & Nome do material predominante ou principal do insert. \\
\hline Concentração & Text & 16 & $\begin{array}{l}\text { Concentração do material no caso de ser usada uma } \\
\text { solução. }\end{array}$ \\
\hline T1 & Number (Single) & 4 & Tempo de relaxação T1, em ms. \\
\hline T2 & Number (Single) & 4 & Tempo de relaxação T2, em ms. \\
\hline
\end{tabular}

\section{InsertPadrão}

IdPhantom

Number (Long)

Em PK; FK para Phantom; Identificador de phantom.

Idlnsert

Number (Long)

Em PK; FK para Insert; Identificador de insert.

\section{Instituição}

Idlnstituição

Nome

Number (Long)

4

PK; Identificador da instituição.

IdEndereço

Text

DICOM:Institution Name (0008,0080 LO) - Nome da instituição.

Number (Long) 4

FK para Endereço; Identificador de endereço.

\section{Manutenção}

IdTécnico

IdEquipamento

Data

Hora

Tipo

Resumo

Status

Descrição

\section{PacVol}

IdPacVol

Altura

Peso

Histórico

Restrições
Number (Long) 4

Number (Long) $\quad 4$

Date/Time 8

Date/Time

Text

Text

Text

Memo

Number (Long)

Number (Single) 4

Number (Single) 4

Memo

Memo
Em PK; FK para Especialista; Identificador do especialista responsável pela manutenção.

Em PK; FK para Equipamento; Identificador do equipamento submetido à manutenção.

Em PK; DICOM:Date of Last Calibration $(0018,1200)$ Data da última manutenção.

8

Em PK; DICOM:Time of Last Calibration $(0018,1201)$ Hora da última manutenção.

16 Tipo de manutenção: corretiva, adaptativa ou

64 Breve resumo da manutenção.

16 Status da manutenção: OK, Em manutenção, Desativado.

Descrição da manutenção efetuada sobre o equipamento.

PK; FK da especialização Pessoa-PacVol; Identificador de PacVol.

DICOM:Patient's Size (0010,1020 DS) - Altura ou tamanho do paciente/voluntário, em metros.

DICOM:Patient's Weight (0010,1030 DS) - Peso do paciente/voluntário, em kilogramas.

DICOM:Additional Patient History (0010,21B0 LT) Histórico do paciente-voluntário.

Restrições conhecidas para realização de um estudo de ressonância. 


$\begin{array}{llll}\text { Campo } & \text { Tipo de dados } & \text { Bytes } & \begin{array}{l}\text { Descrição } \\ \text { ComentáriosPacVol }\end{array} \\ \text { Memo } & - & \begin{array}{l}\text { DICOMatient Comments (0010,4000 LT) - } \\ \text { Comentários específicos do paciente-voluntário. }\end{array} \\ \text { IdComunidade } & \text { Number (Long) } & 4 & \begin{array}{l}\text { SK Req para categoria Comunidade; Identificador de } \\ \text { comunidade. }\end{array}\end{array}$

\section{PedidoEstudo}

Id

IdComunidade

IdEspecialista

DataPedido

HoraPedido

IdLocal

Resumo

Pedido

Prediagnóstico

ResumoClínico

ExamesClínicos

Comentários

IdEspecialistaAvalia

ção

DataAvaliação

HoraAvaliação

IdLocalAvaliação

Resultado

Avaliação

\section{Pessoa}

IdPessoa

IdLocal

OutroldTipo

Outrold

NomePrimeiro

NomeMeio
Text

Number (Long)

Number (Long)

Number (Long)

Date/Time

Date/Time

Text

Text

Memo

Memo

Memo

Memo

Memo

Number (Long)

Date/Time

Date/Time

Text

Text

Memo

Number (Long)

Text

Text

Text

Text
PK; Identificador de Pedido de Estudo.

FK Req de definição para comunidade; Identidicador da comunidade correspondente ao estudo.

FK Req de definição para Especialista; Identificador de especialista que formula o pedido de estudo.

Req; Data da elaboração ou cadastro do pedido de estudo.

8

64

64 Hora da elaboração ou cadastro do pedido de estudo.

Identificador usado pelo sistema de informação local para identificar os pedidos de estudo.

Req; Resumo rápido para indicar o tipo de estudo que está sendo pedido.

Texto descrevendo o pedido de estudo.

DICOM:Admiting Diagnoses Description (0008,1080 LO 1-N) - Texto contendo o pré-diagnóstico.

Resumo clínico atual.

Resultados de outros exames.

Comentários.

FK Especialista_avaliação; Indentificador do especialista responsável pela avaliação.

8

Data em que a avaliação foi elaborada ou registrada.

8

Hora em que a avaliação foi elaborada ou registrada.

64 Identificador usado pelo sistema de informação local para identificar a avaliação.

16

Resultado da avaliação da viabilidade de realização do estudo: aprovado ou reprovado.

Texto com o resultado da avaliação, indicando a possibilidade de realizar o estudo requisitado.

PK; Identificador de pessoa no SIA.

DICOM:Patient's ID (0010,0020 LO) - Identificador de pessoa usado pelo sistema de informação local.

16 DICOM:Other Patient's ID (0010,1000 LO) - Tipo de outro identificador.

64 DICOM:Other Patient's ID (0010,1000 LO) - Outro identificador.

64

DICOM:Patient's Name $(0010,0010$ PN) - Primeiro nome.

64 DICOM:Patient's Name (0010,0010 PN) - Nome do meio. 


\begin{tabular}{|c|c|c|c|}
\hline Campo & Tipo de dados & Bytes & Dic. Dados - 5 \\
\hline NomeÚltimo & Text & 64 & DICOM:Patient's Name $(0010,0010$ PN) - Último nome. \\
\hline OutroNomePrimeiro & Text & 64 & $\begin{array}{l}\text { DICOM:Other Patient's Name }(0010,1001 \text { PN 1-N) - } \\
\text { Primeiro nome de outro nome alternativo. }\end{array}$ \\
\hline OutroNomeMeio & Text & 64 & $\begin{array}{l}\text { DICOM:Other Patient's Name }(0010,1001 \text { PN 1-N) - } \\
\text { Nome do meio de outro nome alternativo. }\end{array}$ \\
\hline OutroNomeÚltimo & Text & 64 & $\begin{array}{l}\text { DICOM:Other Patient's Name }(0010,1001 \text { PN 1-N) - } \\
\text { Último nome de outro nome alternativo. }\end{array}$ \\
\hline Sexo & Text & 1 & $\begin{array}{l}\text { DICOM: Patient's Sex (0010,0040 CS) - Sexo: } \\
\text { M(asculino), F(eminino), O(utro). }\end{array}$ \\
\hline DataNascimento & Date/Time & 8 & $\begin{array}{l}\text { DICOM: Patient's Birth Date }(0010,0030 \mathrm{DA}) \text { - Data de } \\
\text { nascimento (dd/mm/aa). }\end{array}$ \\
\hline HoraNascimento & Date/Time & 8 & $\begin{array}{l}\text { DICOM: Patient's Birth Time }(0010,0032 \text { TM) - Hora de } \\
\text { nascimento (hh:mm). }\end{array}$ \\
\hline IdadeValor & Number (Byte) & 1 & $\begin{array}{l}\text { Primeira parte de: DICOM:Patient's Age (0010,1010 } \\
\text { AS) - Idade da pessoa no momento do cadastro. Por } \\
\text { exemplo: } 36 \text { A(nos), } 8 \text { S(emanas), } 4 \text { M(eses) ou } \\
\text { 20D(ias). Indicada ou calculada a partir da data de }\end{array}$ \\
\hline IdadeUnidade & Text & 1 & $\begin{array}{l}\text { Segunda parte de: DICOM:Patient's Age (0010,1010 } \\
\text { AS) - Idade da pessoa no momento do cadastro. Por } \\
\text { exemplo: } 36 \text { A(nos), } 8 \text { S(emanas), } 4 \text { M(eses) ou } \\
\text { 20D(ias). Indicada ou calculada a partir da data de }\end{array}$ \\
\hline GrupoÉtnico & Text & 16 & $\begin{array}{l}\text { DICOM:Ethinic Group }(0010,2160 \mathrm{SH}) \text { - Grupo étnico } \\
\text { ou raça. }\end{array}$ \\
\hline Comentários & Memo & - & Comentários. \\
\hline
\end{tabular}

\section{Phantom}

\begin{tabular}{|c|c|c|c|}
\hline IdPhantom & Number (Long) & 4 & PK; Identificador de Phantom. \\
\hline Nome & Text & 64 & Nome do phantom. \\
\hline IdLocal & Text & 64 & Identificador usado no sistema de informação local. \\
\hline OutroldTipo & Text & 16 & Tipo de identificador. \\
\hline Outrold & Text & 64 & Outro identificador. \\
\hline Descrição & Memo & - & Descrição do phantom. \\
\hline Geometria & Text & 16 & Geometria do phantom: Cilindro, Esfera, Cubo, etc. \\
\hline Dimensões & Text & 16 & Dimensões do phantom: indicação aproximada. \\
\hline TipoSolução & Text & 16 & Tipo da solução. \\
\hline Concentração & Text & 16 & Concentração da solução. \\
\hline T1 & Number (Single) & 4 & Tempo de relaxação $T 1$. \\
\hline T2 & Number (Single) & 4 & Tempo de relaxação T2. \\
\hline Histórico & Memo & - & Histórico do phantom. \\
\hline Restrições & Memo & - & $\begin{array}{l}\text { Restrições de uso do phantom em estudos de } \\
\text { ressonância. }\end{array}$ \\
\hline Comentários & Memo & - & Comentários. \\
\hline IdComunidade & Number (Long) & 4 & $\begin{array}{l}\text { SK Req para categoria Comunidade; Identificador de } \\
\text { comunidade. }\end{array}$ \\
\hline
\end{tabular}


Campo

Responsável

IdResponsável

Comentários

Memo

SIA_Comentários

IdComentátio

Usuário

Data

Hora

Tipo

Status

Resumo

Comentário

\section{tblAquisição}

IdAquisição

NroAqs

Dat

Hora

SamplesPerPixel

Photometriclnterpret Text

ation

BitsAllocated

Number (Long)

4

$\begin{array}{ll}\text { NomeSeqüência } & \text { Text } \\ \text { TipoAquisição } & \text { Text }\end{array}$

B0

Number (Single) 4

Freqüência
64

8 Postergado, Executado..

Palavra chave ou pequeno resumo sobre o

Descrição detalhada do comentário.

Nome do usuário que registrou o comentário.

Data em que o comentário foi feito.

Hora em que o comentário foi feito.

Tipo de comentário: sugestão, identificação de erro, ...

Status do comentário: Anotado, Aceito, Rejeitado,
Dic. Dados - 6 Identificador de responsável.

Comentários específicos sobre o responsável.

PK; Identificador de comentário.

PK; Identificador de Aquisição.

DICOM: Acquisition Number (3 0020,0012 IS) - "A number identifying the single continuous gathering of data over a period of time which resulted in this

DICOM: Acquisition Date (3 0008,0022 DA) - "The date the acquisition of data that resulted in this image

DICOM: Acquisition Time (3 0008,0032 TM) - "The time the acquisition of data that resulted in this image

Req; DICOM: Samples per Pixel (1 0028,0002 US) -

"Number of samples (planes) in this image" $(=0001$ para MR, 0003, 0004)

Req; DICOM: Photometric Interpretation (1 0028,0004 CS) - "Specifies the intended interpretation of the pixel data" (MONOCHROME1 OU MONOCHROME2 para MR)

Req; DICOM: Bits Allocated (1 0028,0100 US)

"Number of bits allocatedfor each pixel sample. Each sample shall have the same number of bits allocated." (=16 para MR)

16 DICOM: Sequence Name (3 0018,0024 SH) - "User defined name for the Scanning Sequence and Sequence Variant combination"

16 Req; DICOM: MR Acquisition Type (2 0018,023 CS) "Identification of data encoding scheme. Enumerated values: $2 \mathrm{D}=$ frequency $x$ xphase, $3 \mathrm{D}=$ frequency $x$ phase $\mathrm{x}$ phase"

DICOM: Magnetic Field Strength (3 0018,0087 DS) "Nominal field strength of MR magnet, in Tesla"

DICOM: Imaging Frequency (3 0018,0084 DS) "Precession frequency in $\mathrm{MHz}$ of the nucleus being addressed" 


\begin{tabular}{|c|c|c|c|}
\hline Campo & Tipo de dados & Bytes & Dic. Dados - 7 \\
\hline Núcleo & Text & 16 & $\begin{array}{l}\text { DICOM: Imaged Nucleus ( } 30018,0085 \mathrm{SH})- \text { "Nucleus } \\
\text { that is resonant at the imaging frequency. Ex.: } 31 \mathrm{P} \text {, }\end{array}$ \\
\hline BobinaRecepção & Text & 16 & $\begin{array}{l}\text { DICOM: Receiving Coil (3 0018,1250 SH) - "Receiving } \\
\text { coil used" }\end{array}$ \\
\hline BobinaTransmissão & Text & 16 & $\begin{array}{l}\text { DICOM: Transmitting Coil (3 0018,1251 SH) - } \\
\text { "Transmitting Coil Used" }\end{array}$ \\
\hline $\mathrm{dB} / \mathrm{Dt}$ & Number (Single) & 4 & $\begin{array}{l}\text { DICOM: } \mathrm{dB} / \mathrm{dt} \text { ( } 30018,1318 \mathrm{DS}) \text { - "The rate of change } \\
\text { of the gradient coil magnetic flux density with time }\end{array}$ \\
\hline PotênciaRF & Number (Single) & 4 & Potência máxima de RF na aquisição. \\
\hline SAR & Number (Single) & 4 & $\begin{array}{l}\text { DICOM: SAR (3 0018,1316 DS) - "Calculated whole } \\
\text { body Specific Absorption Rate in watts/kilogram" }\end{array}$ \\
\hline NroPosTemporais & Number (Long) & 4 & $\begin{array}{l}\text { DICOM: Number of Temporal Positions ( } 30020,0105 \\
\text { IS) - "Total number of temporal positions prescribed" }\end{array}$ \\
\hline ResTemporal & Number (Single) & 4 & $\begin{array}{l}\text { DICOM: Temporal Resolution (3 0020,0110 DS) - "Time } \\
\text { delta between Images in a dynamic of functional set } \\
\text { of Images" }\end{array}$ \\
\hline ÂnguloFlip & Number (Single) & 4 & $\begin{array}{l}\text { DICOM: Flip Angle ( } 30018,1314 \text { DS) - "Steady state } \\
\text { angle in degrees to wich the magnetic vector is } \\
\text { flipped from the magnetic vector of the primary field" }\end{array}$ \\
\hline ÂnguloFlipVar & Text & 16 & $\begin{array}{l}\text { DICOM: Variable Flip Angle Flag (3 } 0018,1315 \mathrm{CS}) \text { - } \\
\text { "Flip angle variation applied during image acquisition. } \\
\text { Enumerated values: } Y=\text { yes, } N=\text { no" }\end{array}$ \\
\hline DirCodFase & Text & 16 & $\begin{array}{l}\text { DICOM: Phase Encoding Direction ( } 30018,1312 \text { CS }) \text { - } \\
\text { "The axis of phase encoding with respect to the } \\
\text { image. Enumerated values: ROW=phase encoded in } \\
\text { rows, COL=phase encoded in columns" }\end{array}$ \\
\hline NroCodFase & Number (Single) & 4 & $\begin{array}{l}\text { DICOM: Number of Phase Encoding Steps ( } 3 \\
\text { 0018,0089 IS) - "Total number of lines in k-space in } \\
\text { the 'y' direction collected during acquisition" }\end{array}$ \\
\hline PercentSampling & Number (Single) & 4 & $\begin{array}{l}\text { DICOM: Percent Sampling (3 0018,0093 DS) - "Fraction } \\
\text { of acquisition matrix lines acquired, expressed as a } \\
\text { percent" }\end{array}$ \\
\hline PercentPhaseFOV & Number (Single) & 4 & $\begin{array}{l}\text { DICOM: Percent Phase Field of View ( } 30018,0094 \\
\text { DS) - "Ratio of field of view dimension in phase } \\
\text { direction to field of view dimension in frequency } \\
\text { direction, expressed as a percent" }\end{array}$ \\
\hline PixelBandwidth & Number (Single) & 4 & $\begin{array}{l}\text { DICOM: Pixel Bandwidth ( } 30018,0095 \mathrm{DS}) \text { - } \\
\text { "Reciprocal of the total sampling period, in hertz per } \\
\text { pixel" }\end{array}$ \\
\hline NEX & Number (Single) & 4 & $\begin{array}{l}\text { DICOM: Number of Averages ( } 30018,0083 \mathrm{DS}) \text { - } \\
\text { "Number of times a given pulse sequence is repeated } \\
\text { before any parameter is changed" }\end{array}$ \\
\hline MatrizAqsFR & Number (Long) & 4 & $\begin{array}{l}\text { DICOM: Acquisition Matriz ( } 30018,1310 \text { US) - } \\
\text { "Dimensions of acquired frequency/phase data before } \\
\text { renconstruction. Multi-valued: frequency } \\
\text { rowslfrequency columnslphase rows/phase }\end{array}$ \\
\hline MatrizAqsFC & Number (Long) & 4 & $\begin{array}{l}\text { DICOM: Acquisition Matriz ( } 30018,1310 \text { US) - } \\
\text { "Dimensions of acquired frequency/phase data before } \\
\text { renconstruction. Multi-valued: frequency } \\
\text { rowslfrequency columnslphase rows/phase }\end{array}$ \\
\hline MatrizAqsPR & Number (Long) & 4 & $\begin{array}{l}\text { DICOM: Acquisition Matriz (3 } 0018,1310 \text { US) - } \\
\text { "Dimensions of acquired frequency/phase data before } \\
\text { renconstruction. Multi-valued: frequency } \\
\text { rowslfrequency columnslphase rows/phase }\end{array}$ \\
\hline
\end{tabular}




\begin{tabular}{|c|c|c|c|}
\hline Campo & Tipo de dados & Bytes & Dic. Dados - 8 \\
\hline MatrizAqsPC & Number (Long) & 4 & $\begin{array}{l}\text { DICOM: Acquisition Matriz (3 } 0018,1310 \text { US) - } \\
\text { "Dimensions of acquired frequency/phase data before } \\
\text { renconstruction. Multi-valued: frequency } \\
\text { rowslfrequency columns/phase rows lphase }\end{array}$ \\
\hline InterSlice & Number (Single) & 4 & $\begin{array}{l}\text { DICOM: Spacing Between Slices ( } 30018,0088 \text { DS) - } \\
\text { "Spacing between slices, in mm. The spacing is } \\
\text { measured from the center-to-center of each slice" }\end{array}$ \\
\hline Comentários & Memo & - & Comentários específicos de aquisição. \\
\hline IdSérie & Number (Long) & 4 & FK Req para Série; Identificador de Série. \\
\hline IdContraste & Number (Long) & 4 & FK para Contraste; Identificador de Contraste. \\
\hline IdSincronismo & Number (Long) & 4 & FK para Sincronismo; Identificador de Sincronismo. \\
\hline
\end{tabular}

\section{tblAquisiçãoOutros}

$\begin{array}{llll}\text { IdAquisição } & \text { Number (Long) } & 4 & \text { Em PK; FK para Aquisição; Identificador de Aquisição. } \\ \text { Nome } & \text { Text } & 16 & \text { Em PK; Nome do atributo. } \\ \text { Valor } & \text { Text } & 64 & \text { Em PK; Valor do atributo. }\end{array}$

\section{tblAquisiçãoScanOpt}

$\begin{array}{lll}\text { IdAquisição } & \text { Number (Long) } & 4 \\ \text { ScanOpt } & \text { Text } & 16\end{array}$

Em PK; FK para Aquisição; Identificador de Aquisição.

Em PK; DICOM: ScanOptions (2 0018,0022 CS 1-N) "Parameters of scanning sequence. Defined terms: PER, RG, CG, PPG, FC, PFF, PFP, SP, FS"

\section{tblAquisiçãoScanSeq}

$\begin{array}{ll}\text { IdAquisição } & \text { Number (Long) } \\ \text { ScanSeq } & \text { Text }\end{array}$

Em PK; FK para Aquisição; Identificador de Aquisição.

Em PK; DICOM: Scanning Sequence $(10018,0020$ CS 1-N) - "Description of the type of data taken.

Enumerated values: $\mathrm{SE}=$ Spin Echo, IR=Inversion Recovery, GR=Gradient Recalled, Echo Planar, RM=Research Mode"

\section{tblAquisiçãoSeqVar}

$\begin{array}{lll}\text { IdAquisição } & \text { Number (Long) } & 4 \\ \text { SeqVar } & \text { Text } & 16\end{array}$

Em PK; FK para Aquisição. Identificador de Aquisição.

Em PK; DICOM: Sequence Variant (1 0018,0021 CS 1-N) - "Variant of the Scanning Sequence. Defined terms: SK, MTC, SS, TRSS, SP, MP, OSP, NONE"

\section{tblContainer}

$\begin{array}{lll}\text { IdContainer } & \text { Number (Long) } & 4 \\ \text { DataCriação } & \text { Date/Time } & 8 \\ \text { HoraCriação } & \text { Date/Time } & 8 \\ \text { DataAcesso } & \text { Date/Time } & 8 \\ \text { HoraAcesso } & \text { Date/Time } & 8 \\ \text { AttachVolume } & \text { Text } & \end{array}$

PK; Identificador do Container de dados.

Req; Data de criação do Container.

Req; Hora de criação do Container.

Req; Data do último acesso ao Container.

AttachVolume 


\begin{tabular}{|c|c|c|c|}
\hline Campo & Tipo de dados & Bytes & Dic. Dados - 9 \\
\hline AttachPath & Text & 255 & Req; Path para o arquivo que contêm os dados. \\
\hline AttachFile & Text & 255 & Req; Nome do arquivo que contêm os dados. \\
\hline IdFormato & Number (Long) & 4 & FK para Formato; Identificador de Formato. \\
\hline \multicolumn{4}{|l|}{ tblContraste } \\
\hline IdContraste & Number (Long) & 4 & PK; Identificador de Contraste. \\
\hline Agente & Text & 64 & $\begin{array}{l}\text { Req; DICOM: Contrast/Bolus Agent (2 0018,0010 LO) - } \\
\text { "Contrast or bolus agent" }\end{array}$ \\
\hline Rota & Text & 64 & $\begin{array}{l}\text { DICOM: Contrast/Bolus Route (3 0018,1040 LO) - } \\
\text { "Administration route of contrast agent" }\end{array}$ \\
\hline Volume & Number (Single) & 4 & $\begin{array}{l}\text { DICOM: Contrast/Bolus Volume ( } 30018,1041 \text { DS) - } \\
\text { "Volume of contrast agent in cubic centimeters" }\end{array}$ \\
\hline DoseTotal & Number (Single) & 4 & $\begin{array}{l}\text { DICOM: Contrast/Bolus Total Dose ( } 30018,1044 \text { DS) - } \\
\text { "Total amount of the active ingredient in injection" }\end{array}$ \\
\hline Horalnicial & Date/Time & 8 & $\begin{array}{l}\text { DICOM: Contrast/Bolus Start Time (3 0018,1042 TM) - } \\
\text { "Time of start of injection" }\end{array}$ \\
\hline HoraFinal & Date/Time & 8 & $\begin{array}{l}\text { DICOM: Contrast/Bolus Stop Time (3 0018,1043 TM) - } \\
\text { "Time of end of contrast injection" }\end{array}$ \\
\hline Comentários & Memo & - & Comentários relativos à aplicação do contraste. \\
\hline \multicolumn{4}{|l|}{ tblDados } \\
\hline IdDados & Number (Long) & 4 & PK; Identificador de Dados. \\
\hline Nrolmg & Number (Long) & 4 & $\begin{array}{l}\text { Req; DICOM: Image Number (2 0020,0013 IS) - "A } \\
\text { number that identifies this image" }\end{array}$ \\
\hline Data & Date/Time & 8 & $\begin{array}{l}\text { Req; DICOM: Image Date (2C } 0008,0023 \mathrm{DA}) \text { - "The } \\
\text { date image pixel data creation started. Required if } \\
\text { image is part of a series in which the images are } \\
\text { temporally related" }\end{array}$ \\
\hline Hora & Date/Time & 8 & $\begin{array}{l}\text { DICOM: Image Time (2C } 0008,0033 \text { TM) - "The time } \\
\text { image pixel data creation started. Required if image is } \\
\text { part of a series in which the images are temporally } \\
\text { related" }\end{array}$ \\
\hline TipolmgPixel & Text & 16 & $\begin{array}{l}\text { Req; DICOM: Image Type (1 } 0008,0008 \text { CS I-n) - } \\
\text { "Image identification characteristics" - Valor 1: } \\
\text { (ORIGINAL, DERIVED) }\end{array}$ \\
\hline TipolmgPatient & Text & 16 & $\begin{array}{l}\text { Req; DICOM: Image Type ( } 10008,0008 \text { CS I-n) - } \\
\text { "Image identification characteristics" - Valor 2: } \\
\text { (PRIMARY, SECONDARY) }\end{array}$ \\
\hline TipoMR & Text & 16 & $\begin{array}{l}\text { DICOM: Image Type (3 0008,0008 CS 1-n) - "Image } \\
\text { identification characteristics" - Valor } 3: \text { (MPR, } \\
\text { PROJECTION IMAGE, T1 MAP, T2 MAP, DIFFUSION } \\
\text { MAP, DENSITY MAP, PHASE MAP, VELOCITY MAP, } \\
\text { IMAGE ADDITION, PHASE SUBTRACT, MODULUS } \\
\text { SUBTRACT, OTHER) }\end{array}$ \\
\hline TipoOutro & Text & 16 & $\begin{array}{l}\text { DICOM: Image Type ( } 30008,0008 \text { CS I-n) - "Image } \\
\text { identification characteristics" - Valor4: (AXIAL, } \\
\text { LOCALIZER, ...) }\end{array}$ \\
\hline Comentários & Memo & - & $\begin{array}{l}\text { DICOM: Image Comments ( } 30020,4000 \text { LT) - } \\
\text { "User-defined comments about the image" }\end{array}$ \\
\hline
\end{tabular}


Campo

TR

TE

TE2

TI

$\begin{array}{ll}\text { EchoTrainLength } & \text { Number (Long) } \\ \text { DiamRecon } & \text { Number (Single) }\end{array}$

Espessura

Localização

PoslmgX

PosImgY

PoslmgZ

OrientRX

OrientRY

OrientRZ

OrientCX

OrientCY

Number (Single)

Number (Single) 4

Number (Single) 4

Number (Single) 4
Tipo de dados Bytes Descrição

Dic. Dados - 10

DICOM: Repetition Time (2C 0018,0080 DS) - "The period of time in msec between the beginning of a pulse sequence and the beginning of the succiiding (essentially identical) pulse sequence. Required except when Scan Seq. is EP and Seq. Variant is not

DICOM: Echo Time (2 0018,0081 DS) - "Time in msec between the middle of the excitation pulse and the peak of the echo. In SK case, TE(eff) is the time between the middle of the excitation pulse to the peak of the echo that is used to cover center k-space"

Segundo tempo ao eco.

DICOM: Inversion Time (2C 0018,0082 DS) - "Time in msec after the middle of inverting RF pulse to middle of excitation pulse to detect the amount of longitudinal magnetization. Required if Scanning Sequence has value IR"

DICOM: Echo Train Length (2 0018,0091 IS) - "Number of lines in k-space acquired per excitation per image DICOM: Reconstruction Diamenter (3 0018,1100 DS) "Diameter in $\mathrm{mm}$ of the region from within which data were used in creating the reconstruction of the image. Data may exist outside this region and portions of the patient may exist outside this region"

DICOM: Temporal Position Identifier (3 0020,0100 IS) "Temporal order of a dynamic or functional set of DICOM: Slice Thickness (2 0018,0050 DS) - "Nominal slice thickness, in $\mathrm{mm} "$

DICOM: Slice Location (3 0020,1041 DS) - "Relative position of exposure expressed in $\mathrm{mm} "$

DICOM: Image Position (Patient) (1 0020,0032 DS) "The $x, y$, and $z$ coordinates of the upper left hand corner (first pixel transmitted) of the image" - X

DICOM: Image Position (Patient) (1 0020,0032 DS) "The $x, y$, and $z$ coordinates of the upper left hand corner (first pixel transmitted) of the image" - Y

Number (Single) 4 DICOM: Image Position (Patient) (1 0020,0032 DS) -

"The $x, y$, and $z$ coordinates of the upper left hand corner (first pixel transmitted) of the image" - Z

Number (Single) 4

DICOM: Image Orientation (Patient) (1 0020,0037 DS) -

"The direction cosines of the first row and the first column with respect to the patient" - Row X

DICOM: Image Orientation (Patient) (1 0020,0037 DS) -

"The direction cosines of the first row and the first column with respect to the patient" - Row $Y$

DICOM: Image Orientation (Patient) (1 0020,0037 DS) -

"The direction cosines of the first row and the first column with respect to the patient" - Row Z

DICOM: Image Orientation (Patient) (1 0020,0037 DS) -

"The direction cosines of the first row and the first column with respect to the patient" - Column X (Composto)

DICOM: Image Orientation (Patient) (1 0020,0037 DS) -

"The direction cosines of the first row and the first column with respect to the patient" - Column $\mathrm{Y}$ (Composto) 


\begin{tabular}{|c|c|c|c|}
\hline Campo & Tipo de dados & Bytes & Dic. Dados - 11 \\
\hline OrientCZ & Number (Single) & 4 & $\begin{array}{l}\text { DICOM: Image Orientation (Patient) }(10020,0037 \text { DS) - } \\
\text { "The direction cosines of the first row and the first } \\
\text { column with respect to the patient" - Column Z } \\
\text { (Composto) }\end{array}$ \\
\hline OrientHX & Number (Single) & 4 & $\begin{array}{l}\text { DICOM: Image Orientation (Patient) }(10020,0037 \text { DS) - } \\
\text { "The direction cosines of the first row and the first } \\
\text { column with respect to the patient" - Heigth X } \\
\text { (Composto) }\end{array}$ \\
\hline OrientHY & Number (Single) & 4 & $\begin{array}{l}\text { DICOM: Image Orientation (Patient) }(10020,0037 \text { DS) - } \\
\text { "The direction cosines of the first row and the first } \\
\text { column with respect to the patient" - Heigth Y } \\
\text { (Composto) }\end{array}$ \\
\hline OrientHZ & Number (Single) & 4 & $\begin{array}{l}\text { DICOM: Image Orientation (Patient) ( } 10020,0037 \text { DS) - } \\
\text { "The direction cosines of the first row and the first } \\
\text { column with respect to the patient" - Heigth Z }\end{array}$ \\
\hline PixellSpacingR & Number (Single) & 4 & $\begin{array}{l}\text { DICOM: Pixel Spacing (1 } 0028,0030 \mathrm{DS} \text { ) - "Physical } \\
\text { distance in tha patient between the center of each } \\
\text { pixel, specified by a numeric pair - row value } \\
\text { (delimiter) column value in mm" - R (Composto) }\end{array}$ \\
\hline PixellSpacingC & Number (Single) & 4 & $\begin{array}{l}\text { DICOM: Pixel Spacing (1 } 0028,0030 \mathrm{DS} \text { ) - "Physical } \\
\text { distance in tha patient between the center of each } \\
\text { pixel, specified by a numeric pair - row value } \\
\text { (delimiter) column value in mm" - C (Composto) }\end{array}$ \\
\hline PixellSpacingH & Number (Single) & 4 & $\begin{array}{l}\text { DICOM: Pixel Spacing (1 } 0028,0030 \text { DS) - "Physical } \\
\text { distance in tha patient between the center of each } \\
\text { pixel, specified by a numeric pair - row value } \\
\text { (delimiter) column value in } \mathrm{mm} \text { - H (Composto) }\end{array}$ \\
\hline OrintPacienteR & Text & 16 & $\begin{array}{l}\text { DICOM: Patient Orientation (2C } 0020,0020 \mathrm{CS}) \text { - } \\
\text { "Patient direction of the rows and columns of the } \\
\text { image. Required if image is part of a series which } \\
\text { does not require the Image Plane Module" - } \\
\{A, P, R, L, H, F\} \text { (Composto) }\end{array}$ \\
\hline OrintPacienteC & Text & 16 & $\begin{array}{l}\text { DICOM: Patient Orientation (2C } 0020,0020 \mathrm{CS}) \text { - } \\
\text { "Patient direction of the rows and columns of the } \\
\text { image. Required if image is part of a series which } \\
\text { does not require the Image Plane Module" - } \\
\{A, P, R, L, H, F\} \text { (Composto) }\end{array}$ \\
\hline OrintPacienteH & Text & 16 & $\begin{array}{l}\text { DICOM: Patient Orientation ( } 2 \mathrm{C} 0020,0020 \mathrm{CS}) \text { - } \\
\text { "Patient direction of the rows and columns of the } \\
\text { image. Required if image is part of a series which } \\
\text { does not require the Image Plane Module" - } \\
\{A, P, R, L, H, F\} \text { (Composto) }\end{array}$ \\
\hline IdAquisição & Number (Long) & 4 & FK Req para Aquisição; Identificador de Aquisição. \\
\hline IdContainer & Number (Long) & 4 & FK para Container; Identificador do Container. \\
\hline MenorPixel & Number (Long) & 4 & $\begin{array}{l}\text { DICOM: Smallest Image Pixel Value ( } 30028,0106 \text { US } \\
\text { ou SS) - "The minimum actual pixel value encountered } \\
\text { in this image" - Calculado }\end{array}$ \\
\hline MaiorPixel & Number (Long) & 4 & $\begin{array}{l}\text { DICOM: Largest Image Pixel Value ( } 30028,0107 \text { US ou } \\
\text { SS) - "The maximum actual pixel value encountered in } \\
\text { this image" - Calculado }\end{array}$ \\
\hline
\end{tabular}

\section{tblDadosDerivada}

$\begin{array}{lll}\text { IdDadosDerivado } & \text { Number (Long) } & 4 \\ \text { IdDadosOriginal } & \text { Number (Long) } & 4\end{array}$

Em PK; FK para Dados_Derivado. Identificador de Dados derivado.

Em PK; FK para Dados_Original. Identificador de Dados original. 


\begin{tabular}{|c|c|c|c|}
\hline Campo & Tipo de dados & Bytes & Dic. Dados - 12 \\
\hline Descrição & Memo & - & $\begin{array}{l}\text { DICOM: Derivation Description ( } 30008,2111 \text { ST) - "A } \\
\text { text description of how this image was derived" }\end{array}$ \\
\hline \multicolumn{4}{|l|}{ tbIDadosEco } \\
\hline IdDados & Number (Long) & 4 & Em PK; FK para Dados. Identificador de Dados. \\
\hline Echo & Number (Long) & 4 & $\begin{array}{l}\text { DICOM: Echo Number ( } 30018,0086 \text { IS } 1-n) \text { - "The } \\
\text { echo number is used in generating this image. In the } \\
\text { case of segmented k-space, it is the effective Echo }\end{array}$ \\
\hline \multicolumn{4}{|c|}{ tblDadosOutros } \\
\hline IdDados & Number (Long) & 4 & Em PK; FK para Dados. Identificador de Dados. \\
\hline Nome & Text & 16 & Em PK; Nome do atributo. \\
\hline Valor & Text & 64 & Em PK; Valor do atributo. \\
\hline \multicolumn{4}{|c|}{ tblDadosPosiciona } \\
\hline IdAquisição & Number (Long) & 4 & Em PK; FK para Aquisição. Identificador de Aquisição. \\
\hline IdDados & Number (Long) & 4 & Em PK; FK para Dados. Identificador de Dados. \\
\hline IdOverlay & Number (Long) & 4 & Em PK; FK para Overlay. Identificador de Overlay. \\
\hline \multicolumn{4}{|c|}{ tblDadosRelacionada } \\
\hline IdDadosOrigem & Number (Long) & 4 & $\begin{array}{l}\text { Em PK; FK para Dados que são referenciados a } \\
\text { DadosDestino. Identificador de Dados. }\end{array}$ \\
\hline IdDadosDestino & Number (Long) & 4 & $\begin{array}{l}\text { Em PK; FK para Dados que são referenciados por } \\
\text { DadosOrigem. Identificador de Dados referenciados. }\end{array}$ \\
\hline Descrição & Memo & - & Descrição da referência entre dados. \\
\hline \multicolumn{4}{|c|}{ tblDadosUsaVOI } \\
\hline IdDados & Number (Long) & 4 & Em PK; FK para Dados. Identificador de Dados. \\
\hline IdVOI & Number (Long) & 4 & Em PK; FK para VOI. Identificador de VOI. \\
\hline \multicolumn{4}{|l|}{ tblEstudo } \\
\hline IdEstudo & Number (Long) & 4 & PK; Identificador de Estudo. \\
\hline UID & Text & 64 & $\begin{array}{l}\text { CK Req; DICOM: Study Instance UID (1 0020,000D UI) - } \\
\text { "Unique identifier for the study" }\end{array}$ \\
\hline IdLocal & Text & 16 & $\begin{array}{l}\text { CK Req; DICOM: Accession Number (2 } 0008,0050 \mathrm{SH}) \\
\text { - "A RIS generated number which identifies the order } \\
\text { of the study" }\end{array}$ \\
\hline Data & Date/Time & 8 & $\begin{array}{l}\text { Req; DICOM: Study Date (2 0008,0020 DA) - "Date the } \\
\text { study started" }\end{array}$ \\
\hline Hora & Date/Time & 8 & $\begin{array}{l}\text { Req; DICOM: Study Time (2 0008,0030 TM) - "Time de } \\
\text { study started" }\end{array}$ \\
\hline Tipo & Text & 16 & Tipo do estudo: Diagnóstico ou Pesquisa \\
\hline Status & Text & 16 & $\begin{array}{l}\text { DICOM: Study Status ID (x } 0032,000 \text { A CS) - "Identifies } \\
\text { the state of the study. Enumerated Values:CREATED, } \\
\text { SCHEDULED, ARRIVED, STARTED, COMPLETED, } \\
\text { VERIFIED, READ" }\end{array}$ \\
\hline
\end{tabular}




$\begin{array}{llll}\begin{array}{l}\text { Campo } \\ \text { Descrição }\end{array} & \begin{array}{l}\text { Tipo de dados } \\ \text { Text }\end{array} & \begin{array}{l}\text { Bytes } \\ \text { Comentários }\end{array} & \begin{array}{l}\text { Descrição } \\ \text { DICOM: Study Description (3 0008,1030 LO) - }\end{array} \\ \begin{array}{llll}\text { "Institution-generated description or classification of } \\ \text { the study (component) performed }\end{array} \\ \begin{array}{llll}\text { Comentário relativo ao estudo. } \\ \text { IdComunidade }\end{array} & \text { Number (Long) } & 4 & \text { FK Req para Comunidade. Identificador de } \\ \text { IdPedidoEstudo } & \text { Number (Long) } & 4 & \begin{array}{l}\text { FK Chave estrangeira para Pedido de Estudo. } \\ \text { Identificador de Pedido de Estudo. }\end{array} \\ \text { IdVisita } & \text { Number (Long) } & 4 & \text { FK para Visita. Identificador de Visita. }\end{array}$

\section{tblEstudoRefPedido}

$\begin{array}{lll}\text { IdEstudo } & \text { Number (Long) } & 4 \\ \text { IdPedidoEstudo } & \text { Number (Long) } & 4\end{array}$

Em PK; FK para Estudo. Identificador de Estudo.

Em PK; FK para Pedido de Estudo. Identificador de Pedido de Estudo.

\section{tbIFormato}

$\begin{array}{lll}\text { IdFormato } & \text { Number (Long) } & 4 \\ \text { SamplesPerPixel } & \text { Number (Long) } & 4 \\ \begin{array}{lll}\text { Photometriclnterpret } \\ \text { ation }\end{array} & \text { Text } & 16 \\ \text { Rows } & \text { Number (Long) } & 4 \\ \text { Columns } & \text { Number (Long) } & 4 \\ \text { Altura } & \text { Number (Long) } & 4 \\ \text { BitsAllocated } & \text { Number (Long) } & 4 \\ & & \\ \text { BitsStored } & \text { Number (Long) } & 4 \\ \text { HighBit } & \text { Number (Long) } & 4 \\ & & 4 \\ \text { PixelRepresentation } & \text { Number (Long) } & 4\end{array}$

PixelAspectRatioR Number (Long)

PK; Identificador de Formato.

Req; DICOM: Samples per Pixel (1 0028,0002 US) "Number of samples (planes) in this image" - (=1 para $\mathrm{MR})$

6 Req; DICOM: Photometric Interpretation (1 0028,0004 CS) - "Specifies the intended interpretation of the pixel data" - (MONOCHROME1 ou MONOCHROME2 para MR)

Req; DICOM: Rows (1 0028,0010 US) - "Number of rows in the image"

Req; DICOM: Columns (1 0028,0011 US) - "Number of columns in the image"

Req; Número correspondente à altura da imagem.

Req; DICOM: Bits Allocated (1 0028,0100 US) -

"Number of bits allocated for each pixel sample. Each sample shall have the same number of bits allocated"

Req; DICOM: Bits Stored (1 0028,0101 US) - "Number of bits stored for each pixel sample. Each sample shall have the same number of bits stored"

Req; DICOM: High Bit (1 0028,0102 US) - "Most significant bit for pixel sample data. Each sample shall have the same high bit"

Req; DICOM: Pixel Representation (1 0028,0103 US) "Data representation of the pixel samples. Each sample shall have the same pixel representation. Enumerated values: $0000 \mathrm{H}=$ unsigned integer, $0001 \mathrm{H}=2$ 's complement"

Req: DICOM:Pixel Aspect Ratio(1C 0028,0034 IS)-"Ratio of the real world spacing of the pixels in the image, specified by a numeric pair: row value (delimiter) column value. Required if aspect ratio is not $1 / 1$ and the Image Plane Module is not applicable"R

PixelAspectRatioC Number (Long) IS)-"Ratio of the real world spacing of the pixels in the image, specified by a numeric pair: row value (delimiter) column value. Required if aspect ratio is not $1 / 1$ and the Image Plane Module is not applicable"C 


\section{Campo}

PixelAspectRatioH

Descrição

\section{tblFrmOfRef}

IdFrmOfRef

UID

IndPos

Descrição

\section{tblLaudo}

IdEstudo

IdEspLaudo

Data

Hora

Resumo

Laudo

\section{tblOverlay}

IdOverlay

Número

Data

Hora

Rows

Columns

Type

OriginX
Tipo de dados Bytes Descrição

Dic. Dados - 14

Req; DICOM:Pixel Aspect Ratio(1C 0028,0034

IS)-"Ratio of the real world spacing of the pixels in the image, specified by a numeric pair: row value (delimiter) column value. Required if aspect ratio is not $1 / 1$ and the Image Plane Module is not applicable"H

Text

CK Req; Descrição do formato.

Number (Long)

Text

Text

Text

Number (Long)

Number (Long)

Date/Time

Date/Time

Text

Memo

Number (Long)

4

Number (Long)

4

8

8

Date/Time

Number (Long)

Number (Long)

Text reference for a Series" external auditory meatus"

50 Descrição. $\mathrm{G}=$ graphics, $\mathrm{R}=\mathrm{ROI}$

PK; Identificador de Frame of Reference.

CK Req; DICOM: Frame of Reference UID (1 0020,0052 UI) - "Uniquely identifies the frame of

64 DICOM: Position Reference Indicator (2 0020,1040 LO) - "Part of the patient's anatomy used as a reference, such as the iliac crest, orbital-medial, sternal notch, symphysis pubis, xiphoid, lower coastal margin,

PK; Identificador de Overlay.

Req; Resumo do laudo.

DICOM: Interpretation Text (x 4008,010B ST) - "Text of the interpretation" - Laudo do estudo.

Número do Overlay.

Data de criação do Overlay.

Hora de criação do Overlay.

Req; DICOM: Rows (1 60xx,0010 US) - "Number of Rows in Overlay"

Req; DICOM: Columns (1 60xx,0011 US) - "Number of Columns in Overlay"

Req; DICOM: Overlay Type (1 60xx,0040 CS) "Indicates whether this overlay represents a region of interest or other graphics. Enumarated values:

Req; DICOM: Origin (1 60xx,0050 SS) - "Location of first overlay point with respect to pixels in the image, given as row and column" - Row (Composto) 


\begin{tabular}{|c|c|c|c|}
\hline Campo & Tipo de dados & Bytes & Dic. Dados - 15 \\
\hline OriginY & Number (Integer) & 2 & $\begin{array}{l}\text { Req; DICOM: Origin ( } 160 x x, 0050 \text { SS) - "Location of } \\
\text { first overlay point with respect to pixels in the image, } \\
\text { given as row and column" - Column (Composto) }\end{array}$ \\
\hline BitsAllocated & Number (Long) & 4 & $\begin{array}{l}\text { Req; DICOM: Bits Allocated ( } 160 x x, 0100 \text { US) - } \\
\text { "Number of bits allocated in the overlay" }\end{array}$ \\
\hline BitPosition & Number (Long) & 4 & $\begin{array}{l}\text { Req; DICOM: Bit Positon (1 60xx,0102 US) - "Bit in } \\
\text { wich overlay was stored" }\end{array}$ \\
\hline ROIArea & Number (Long) & 4 & $\begin{array}{l}\text { DICOM: ROI Area (3 60xx,1301 IS) - "Number of pixels } \\
\text { in ROI area" }\end{array}$ \\
\hline ROIMean & Number (Single) & 4 & DICOM: ROI Mean (3 60xx,1302 DS) - "ROI Mean" \\
\hline ROIStdDev & Number (Single) & 4 & $\begin{array}{l}\text { DICOM: ROI Standard Deviation (3 60xx,1303 DS) - } \\
\text { "ROI standard deviation" }\end{array}$ \\
\hline DescGray & Number (Long) & 4 & $\begin{array}{l}\text { DICOM: Overlay Descriptor - Gray ( } 360 x x, 1100 \text { US) - } \\
\text { "The number of bits in each entry of }(60 x x, 1200) "\end{array}$ \\
\hline DescRed & Number (Long) & 4 & $\begin{array}{l}\text { DICOM: Overlay Descriptor - Red (3 60xx,1101 US) - } \\
\text { "The number of bits in each entry of }(60 x x, 1201) "\end{array}$ \\
\hline DescGreen & Number (Long) & 4 & $\begin{array}{l}\text { DICOM: Overlay Descriptor - Green (3 60xx,1102 US) } \\
\text { - "The number of bits in each entry of }(60 x x, 1202) "\end{array}$ \\
\hline DescBlue & Number (Long) & 4 & $\begin{array}{l}\text { DICOM: Overlay Descriptor - Blue( } 360 \times x, 1103 \text { US) - } \\
\text { "The number of bits in each entry of }(60 \times x, 1203) "\end{array}$ \\
\hline Gray & Number (Long) & 4 & $\begin{array}{l}\text { DICOM: Overlays - Gray ( } 360 x x, 1200 \text { US) - "Overlay } \\
\text { bits. A value of } 1 \text { indicted that the pixel is part of the } \\
\text { overlay plane" }\end{array}$ \\
\hline Red & Number (Long) & 4 & $\begin{array}{l}\text { DICOM: Overlays - Red ( } 360 x x, 1201 \text { US) - "Overlay } \\
\text { bits. A value of } 1 \text { indicted that the pixel is part of the } \\
\text { overlay plane" }\end{array}$ \\
\hline Green & Number (Long) & 4 & $\begin{array}{l}\text { DICOM: Overlays - Green ( } 360 x x, 1202 \text { US) - "Overlay } \\
\text { bits. A value of } 1 \text { indicted that the pixel is part of the } \\
\text { overlay plane" }\end{array}$ \\
\hline Blue & Number (Long) & 4 & $\begin{array}{l}\text { DICOM: Overlays - Blue ( } 360 x x, 1203 \text { US) - "Overlay } \\
\text { bits. A value of } 1 \text { indicted that the pixel is part of the } \\
\text { overlay plane" }\end{array}$ \\
\hline IdDados & Number (Long) & 4 & FK para Dados. Identificador de Dados. \\
\hline IdContainer & Number (Long) & 4 & $\begin{array}{l}\text { DICOM: Overlay Data (1C 60xx,3000 OW) - "Overlay } \\
\text { data shall be contained in this attribute or imbedded } \\
\text { with the image pixel data in group 7FE0. Required if } \\
\text { overlay data are in this group" Chave estrangeira para } \\
\text { o Container de dados. }\end{array}$ \\
\hline
\end{tabular}

\section{tblPixelData}

IdPixelData

IdParcial

PixelData

\section{tblPosProc}

IdPosProc

Nome

Orient

EixoCod
Number (Long)

Number (Long) $\quad 4$

OLE Object

Number (Long)

Text

Text

Text
PK; FK de definição para Container. Identificador do Container que define os dados armazenados.

Chave parcial de PixelData. Identificador de PixelData.

Objeto OLE que contêm os dados.

PK; Identificador de um registro de dados no modelo PosProc.

$64 \quad$ Nome da aquisição

1 Orientação do plano: $\mathrm{C}$ (oronal), $\mathrm{S}$ (agital) e

1 Eixo de codificação de fase: $X, Y$ e Z 


\begin{tabular}{|c|c|c|c|}
\hline Campo & Tipo de dados & Bytes & Dic. Dados - 16 \\
\hline TE & Number (Single) & 4 & Tempo ao Eco [ms] \\
\hline TR & Number (Single) & 4 & Tempo de repetição [ms] \\
\hline DwellTime & Number (Single) & 4 & Intervalo entre medidas [ms] \\
\hline NroMed & Number (Integer) & 2 & Número de médias \\
\hline NroPts & Number (Integer) & 2 & Número de pontos do sinal \\
\hline FOVLeit & Number (Single) & 4 & Tamanho do Campo de Visão no Eixo de leitura [cm] \\
\hline FatorEco & Number (Single) & 4 & Porcentagem do eco que é aquisicionado [\%] \\
\hline FLarmor & Number (Single) & 4 & Frequência de Larmor central \\
\hline NroPlanos & Number (Integer) & 2 & Número de planos \\
\hline OffSet & Number (Single) & 4 & $\begin{array}{l}\text { Distância do centro das imagens ao isocentro do } \\
\text { magneto }[\mathrm{cm}]\end{array}$ \\
\hline DistPI & Number (Single) & 4 & Distância entre planos [cm] \\
\hline EspePI & Number (Single) & 4 & Espessura dos planos [cm] \\
\hline FOVFase & Number (Single) & 4 & $\begin{array}{l}\text { Tamanho do Campo de Visão no Eixo de codificação } \\
\text { [cm] }\end{array}$ \\
\hline NroCod & Number (Integer) & 2 & Número de codificações de fase \\
\hline NroPrePul & Number (Integer) & 2 & Número de pulsos pré-condicionantes \\
\hline Phi & Number (Single) & 4 & Ângulo cosseno diretor [graus] \\
\hline Teta & Number (Single) & 4 & Ângulo cosseno diretor [graus] \\
\hline Beta & Number (Single) & 4 & Ângulo cosseno diretor [graus] \\
\hline NomePaciente & Text & 64 & \\
\hline DataNascimento & Text & 16 & Texto no formato "dd/mm/aaaa" \\
\hline Sexo & Text & 1 & $\{\mathrm{M}, \mathrm{F}\}$ \\
\hline DataAquisicao & Text & 16 & Texto no formato "dd/mm/aaaa" \\
\hline Tecnica & Text & 64 & \\
\hline Contraste & Text & 64 & $\{\mathrm{~T} 1, \mathrm{~T} 2$, Densidade $\}$ \\
\hline Posicao & Text & 4 & $\{\mathrm{HS}, \mathrm{HP}, \mathrm{HDR}, \mathrm{HDL}, \mathrm{FS}, \mathrm{FP}, \mathrm{FDR}, \mathrm{FDL}\}$ \\
\hline Anatomia & Text & 64 & \\
\hline trmWinUP & Number (Integer) & 2 & \\
\hline trmWinDN & Number (Integer) & 2 & \\
\hline trmReverso & Number (Integer) & 2 & $\{0,1\}$ \\
\hline trmComm & Text & 255 & \\
\hline STop & Text & 2 & Valor da string do Topo da Tela \\
\hline
\end{tabular}




$\begin{array}{llll}\text { Campo } & \text { Tipo de dados } & \text { Bytes } & \text { Descrição } \\ \text { SBot } & \text { Text } & 2 & \text { Valor da string da parte de baixo da Tela } \\ \text { SLef } & \text { Text } & 2 & \text { Valor da string do lado esquerdo da Tela } \\ \text { SRig } & \text { Text } & 2 & \text { Valor da string do lado direito da Tela }\end{array}$

\section{tblPosProclmg}

IdPosproclmg

FDrive

Number (Long)

4

Text

Text

Text

Text

OLE Object

Number (Long)

IdPosProc

\section{tblSérie}

IdSérie

UID

Modalidade

Descrição

Data

Hora

Número

Posição

Lateralidade

Text

ParteEmEstudo

Text

Protocolo

Text

BobinaMóvel

Text

8
PK; Identificador de imagem importada de PosProc.

Unidade de disco onde de onde se importou a imagem.

255 Caminho na unidade de disco de onde se importou a imagem.

$255 \quad$ Nome do arquivo.

255 Extensão do arquivo.

Imagem.

FK Req para PosProc. Identificador de dados de PosProc.

PK; Identificador de Série.

64 CK Req; DICOM: Series Instance UID (1 0020,000E UI) - "Unique identifier for the series"

16 Req; DICOM: Modality (1 0008,0060 CS) - "Type of equipment that originally acquired the data used to create the images in this series" - CR, CT, DS, MR, NM, OT, US

64 DICOM: Series Description (3 0008,103E LO) - "Use provided description of the series"

DICOM: Series Date (3 0008,0021 DA) - "Date the Series started"

8 DICOM: Series Time (3 0008,0031 TM) - "Time the Series started"

Req; DICOM: Series Number (2 0020,0011 IS) - "A number that identifies this Series"

DICOM: Patient Position (2C 0018,5100 CS) - "Patient position descriptor relative to the equipment. Required for CT and MR images." - HFP, HFS, HFDR, HFDL, FFP, FFS, FFDR, FFDL

16 DICOM: Laterality (2C 0020,0060 CS) - "Laterality of (paired) body part exemined. Required if the body part examined is a paired structure. Enumerated values: $R=$ rigth, $L=l e f t "$

DICOM: Body Part Examined (3 0018,0015 CS) - "Text description of the part of the body exemined. Defined terms: SKULL, CSPINE, TSPENE, SSPINE, COCCYX, CHEST, CLAVICLE, BREAST, ABDOMEN, PELVIS, HIP, SHOULDER, ELBOW, KNEE, ANKLE, HAND, FOOT, EXTREMITY"

64 DICOM: Protocol Name (3 0018,1030 LO) -

"User-defined description of the conditions under which the Series was performed"

16 Bobina móvel utilizada. 


\begin{tabular}{|c|c|c|c|}
\hline Campo & Tipo de dados & Bytes & Dic. Dados - 18 \\
\hline Comentário & Memo & - & Comentários específicos da série. \\
\hline MaiorPixel & Number (Long) & 4 & $\begin{array}{l}\text { DICOM: Largest Pixel Value in Series ( } 30028,0109 \text { US } \\
\text { ou SS) - "The maximum value of all images in this }\end{array}$ \\
\hline MenorPixel & Number (Long) & 4 & $\begin{array}{l}\text { DICOM: Smallest Pixel Value in Series }(30028,0108 \\
\text { US ou SS) - "The minimum value of all images in this }\end{array}$ \\
\hline IdEstudo & Number (Long) & 4 & FK Req para Estudo. Identificador de Estudo. \\
\hline IdEspPrescrição & Number (Long) & 4 & $\begin{array}{l}\text { FK Req para Especialista_prescrição. Identificador de } \\
\text { Especialista responsável pela prescrição da série. }\end{array}$ \\
\hline Prescrição & Memo & - & Prescrição da série feita pelo especialista \\
\hline IdEspOperador & Number (Long) & 4 & $\begin{array}{l}\text { FK Req para Especialista_operador. Identificador do } \\
\text { Especialista que é o operador da série. }\end{array}$ \\
\hline IdEquipamento & Number (Long) & 4 & $\begin{array}{l}\text { FK Req para Equipamento. Identificador de } \\
\text { Equipamento. }\end{array}$ \\
\hline IdFrmOfRef & Number (Long) & 4 & Chave estrangeira para Frame of Reference. \\
\hline \multicolumn{4}{|l|}{ tb/Sincronismo } \\
\hline IdSincronismo & Number (Long) & 4 & PK; Identificador da categoria Sincronismo. \\
\hline Tipo & Text & 16 & $\begin{array}{l}\text { Req; Tipo da categoria: CARDÍACO, RESPIRATÓRIO, } \\
\text { EXTERNO }\end{array}$ \\
\hline Comentários & Memo & - & Comentários à respeito da utilização do sincronismo. \\
\hline \multicolumn{4}{|c|}{ tblSincronismoCardíaco } \\
\hline IdSincCar & Number (Long) & 4 & PK; SK para categoria Sincronismo. \\
\hline Nrolmagens & Number (Long) & 4 & $\begin{array}{l}\text { DICOM: Cardiac Number of Images (3 0018,1090 IS) - } \\
\text { "Number of Images per cardiac cycle" }\end{array}$ \\
\hline Nominallnterval & Number (Long) & 4 & $\begin{array}{l}\text { DICOM: Nominal Interval (3 0018,1062 IS) - "Average } \\
\text { R-R interval used for the scan, msec" }\end{array}$ \\
\hline AngioFlag & Text & 16 & $\begin{array}{l}\text { ??? Colocar em Dados??? DICOM: Angio Flag ( } 3 \\
0018,0025 \mathrm{CS} \text { - "Angio Image Indicator. Primary image } \\
\text { for angio processing. Enumerated values: } Y=\text { Image is } \\
\text { angio, } \mathrm{N}=\text { Image is not angio" }\end{array}$ \\
\hline PVCRejection & Text & 64 & $\begin{array}{l}\text { DICOM: PVC Rejection (3 0018,1085 LO) - "Description } \\
\text { of type of PVC rejection criteria used" }\end{array}$ \\
\hline BeatRejectionFlag & Text & 16 & $\begin{array}{l}\text { DICOM: Beat Rejection Flag ( } 30018,1080 \mathrm{CS}) \text { - "Beat } \\
\text { length sorting has been applied. Enumerated values: } \\
\mathrm{Y}=\mathrm{yes}, \mathrm{N}=\mathrm{no} \text { " }\end{array}$ \\
\hline TriggerWindow & Number (Long) & 4 & $\begin{array}{l}\text { DICOM: Trigger Window (3 0018,1094 IS) - "Percent of } \\
\text { R-R interval, based on heart rate, prescribed as a } \\
\text { window for a valid/usable trigger" }\end{array}$ \\
\hline TriggerTime & Number (Single) & 4 & $\begin{array}{l}\text { Req;DICOM: Trigger Time (2C } 0018,1060 \mathrm{DS}) \text { - "Time, } \\
\text { in msec, between peak of the R-R wave and the peak } \\
\text { of the echo produced. In the case of segmented } \\
\text { k-space, the TE(eff) is the time between the peak of } \\
\text { the echo that is used to cover the center of k-space" }\end{array}$ \\
\hline IntervalsRejected & Number (Long) & 4 & $\begin{array}{l}\text { DICOM: Intervals Rejected (3 0018,1084 IS) - "Number } \\
\text { of R-R intervals rejected" }\end{array}$ \\
\hline IntervalsAcquired & Number (Long) & 4 & $\begin{array}{l}\text { DICOM: Intervals Acquired (3 0018,1083 IS) - "Number } \\
\text { of R-R intervals acquired" }\end{array}$ \\
\hline SkipBeats & Number (Long) & 4 & $\begin{array}{l}\text { DICOM: Skip Beats ( } 30018,1086 \text { IS) - "Number of } \\
\text { beats skipped after a detected arrhythmia" }\end{array}$ \\
\hline
\end{tabular}




\begin{tabular}{|c|c|c|c|}
\hline Campo & Tipo de dados & Bytes & Dic. Dados - 19 \\
\hline HeartRate & Number (Long) & 4 & $\begin{array}{l}\text { DICOM: Heart Rate (3 0018,1088 IS) - "Beats per } \\
\text { minute" }\end{array}$ \\
\hline HighRR & Number (Long) & 4 & $\begin{array}{l}\text { DICOM: High R-R Value (3 0018,1082 IS) - "R-R } \\
\text { interval high limit for beat rejection, msec" }\end{array}$ \\
\hline LowRR & Number (Long) & 4 & $\begin{array}{l}\text { DICOM: Low R-R Value (3 0018,1081 IS) - "R-R } \\
\text { interval low limit for beat rejection limit" }\end{array}$ \\
\hline
\end{tabular}

\section{tbIVOI}

IdVOI

Tipo

$\begin{array}{ll}\text { Number (Long) } & 4 \\ \text { Text } & 16\end{array}$

PK; Identificador da categoria VOI.

16

Req; Tipo de categoria: WIN/LEVEL ou LUT.

\section{tbIVOI_LUT}

IdVOI

Tipo

Descrição

DescriptorEntries

Text

Number (Long)

64

DescriptorFirstPixel

Number (Long)

DescriptorNroBits

Number (Long)

4

Data

OLE Object

\section{tbIVOI_WinLevel}

IdVOI

Descrição

Number (Long)

4

64

WinCenter

Number (Single)

WinWidth

Number (Single) 4

\section{Usalnsert}

IdVisitaPhantom

Number (Long)

4

Idlnsert

Number (Long)
PK; SK para categoria VOI.

DICOM: Modality LUT Type (x 0028,3004 LO) "Specifies the output values of this Modality LUT" $\mathrm{OD}=$ optical density; US=unspecified

DICOM: LUT Explanation (3 0028,3003 LO) - "Free form text explanation of the meaning of the LUT"

DICOM: LUT Descriptor (1C 0028,3002 US ou SS) "Specifies the format of the LUT Data in this sequence. Required if the VOI LUT Sequence is sent" - Number of entries in the LUT

DICOM: LUT Descriptor (1C 0028,3002 US ou SS) "Specifies the format of the LUT Data in this sequence. Required if the VOI LUT Sequence is sent" - Primeiro pixel.

DICOM: LUT Descriptor (1C 0028,3002 US ou SS) "Specifies the format of the LUT Data in this sequence. Required if the VOI LUT Sequence is sent" - Número de bits em cada entry.

DICOM: LUT Data (1C 0028,3006 US ou SS 1-n) - "LUT

Data in this sequence. If padding is required to complete a full word, the padding value shall be 0 . Required if the VOI LUT Sequence is sent"

PK; SK para categoria VOI.

DICOM: Window Center \& Width Explanation (3 0028,1055 LO 1-n) - "Free form explanation of the meaning of the Window Center and Width. Multiple values correspond to multiple Window Center and Width values"

DICOM: Window Center (3 0028,1050 DS 1-n) "Window Center for display"

DICOM: Window Width (1C 0028,1051 DS 1-n) "Window Center for display. Required if Window Center is sent"

Em PK; FK para VisitaPhantom; Identificador de VisitaPhantom.

EM PK; FK para Insert; Identificador de Insert. 
Campo

\section{UsoPhantom}

\author{
IdPhantom
}

Uso

\section{Visita}

IdVisita

IdLocal

Status

LocalAtual

LocPrimária

Comentários

DataAdm

HoraAdm

ModoAdm

DataDis

HoraDis

DataMarAdm

HoraMarAdm

DataMarDis

HoraMarDis

LocPrimáriaMar

Text

IdComunidade

Number (Long)

IdResponsável

Number (Long)

TipoRelacionamento

Text

Memo

Number (Long) 4

Text

Number (Long)

4

64

64

64

Memo

Date/Time

Date/Time

Text

Date/Time

Date/Time

Date/Time

Date/Time

Date/Time

Date/Time

8

64

Comentário
Dic. Dados - 20

Descrição 


\begin{tabular}{|c|c|c|c|}
\hline Campo & Tipo de dados & Bytes & Dic. Dados - 21 \\
\hline IdVisPacVol & Number (Long) & 4 & $\begin{array}{l}\text { PK; FK para a especialização Visita-VisitaPacVol; } \\
\text { Identificador de VisPacVol. }\end{array}$ \\
\hline IdPacVol & Number (Long) & 4 & FK Req para PacVol; Identificador de \\
\hline AlturaAtual & Number (Single) & 4 & $\begin{array}{l}\text { DICOM:Patient's Size (0010,1020 DS) - Altura ou } \\
\text { tamanho do paciente/voluntário, em metros. }\end{array}$ \\
\hline PesoAtual & Number (Single) & 4 & $\begin{array}{l}\text { DICOM:Patient's Weight (0010,1030 DS) - Peso do } \\
\text { paciente/voluntário, em kilogramas. }\end{array}$ \\
\hline IdadeAtualValor & Number (Byte) & 1 & $\begin{array}{l}\text { Primeira parte de: DICOM:Patient's Age }(0010,1010 \\
\text { AS) - Idade da pessoa no momento do cadastro. Por } \\
\text { exemplo: } 36 \mathrm{~A} \text { (nos), } 8 \mathrm{~S} \text { (emanas), } 4 \mathrm{M} \text { (eses) ou } \\
20 \mathrm{D} \text { (ias). Indicada ou calculada a partir da data de }\end{array}$ \\
\hline IdadeAtualUnidade & Text & 1 & $\begin{array}{l}\text { Segunda parte de: DICOM:Patient's Age }(0010,1010 \\
\text { AS) - Idade da pessoa no momento do cadastro. Por } \\
\text { exemplo: } 36 \mathrm{~A} \text { (nos), } 8 \mathrm{~S} \text { (emanas), } 4 \mathrm{M} \text { (eses) ou } \\
20 \mathrm{D} \text { (ias). Indicada ou calculada a partir da data de }\end{array}$ \\
\hline Ocupação & Text & 16 & $\begin{array}{l}\text { DICOM:Occupation (0010,2180 SH) - Ocupação da } \\
\text { pessoa. }\end{array}$ \\
\hline Voluntário & Yes/No & 1 & $\begin{array}{l}\text { Indica se a pessoa é voluntária para os estudos feitos } \\
\text { na visita correspondente. }\end{array}$ \\
\hline Comentários & Memo & - & Comentários sobre a visita de paciente ou voluntário. \\
\hline
\end{tabular}

\section{VisitaPhantom}

IdVisitaPhantom

IdPhantom

Comentários

\section{VisRefPedido}

IdPedidoEstudo

IdVisita

\section{Number (Long)}

4

Number (Long)

Memo

Number (Long)

4

Number (Long)
PK; FK para a especialização Visita-VisitaPhantom; Identificador de VisitaPhantom.

FK Req para Phantom; Identificador de Phantom.

Comentário sobre a visita de phantom.

Em PK; FK para Pedido de Estudo. Identificador de Pedido de Estudo.

Em PK; FK para Visita. Identificador de Visita. 
APÊNDICE VIII - Formulários do SGBD DataTORM 


\section{DataTORM}

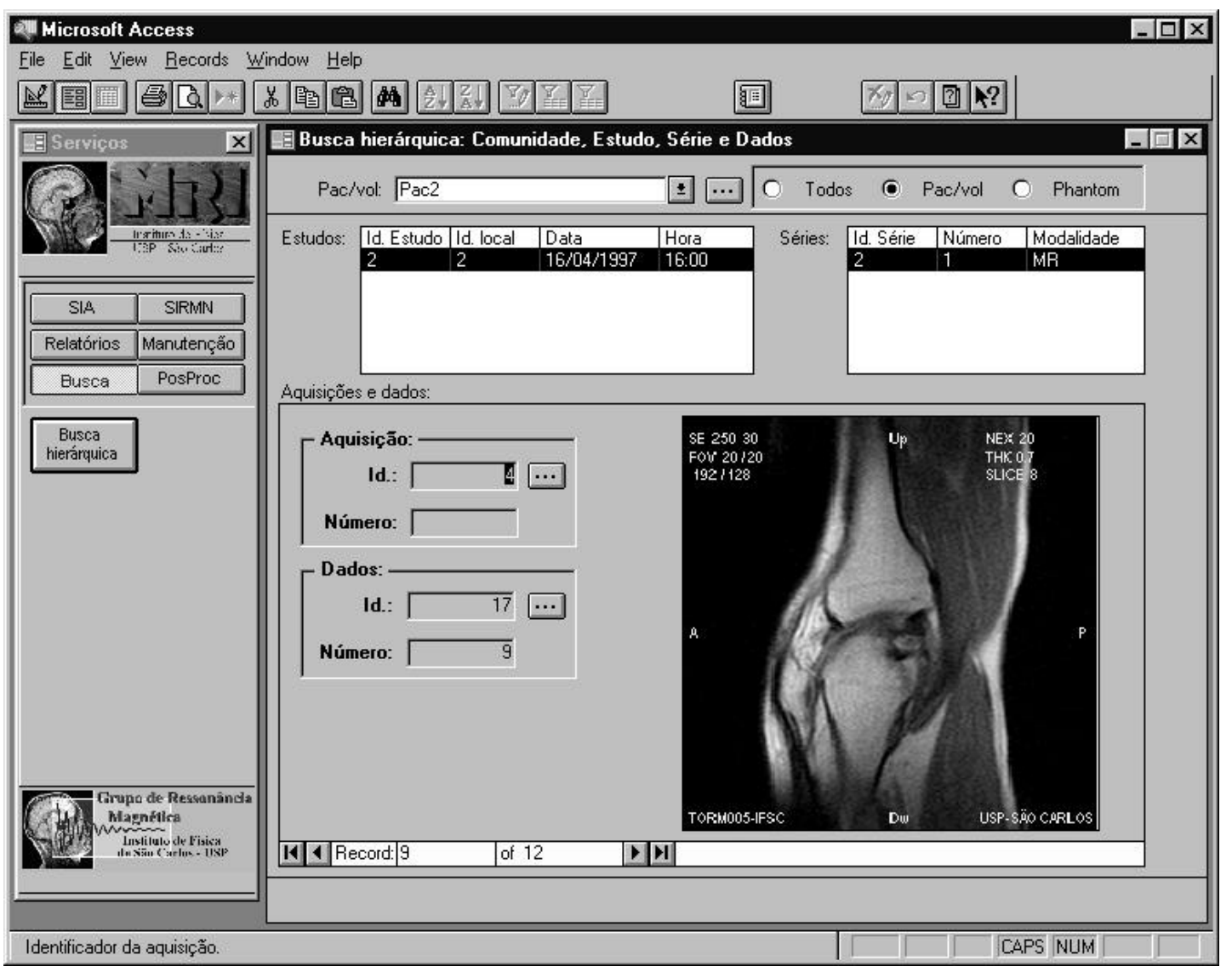

Figura 1 - Visão geral do aplicativo DataTORM com a barra de grupos de serviços e um formulário de busca. 
APÊNDICE VIII - 3

\section{Grupo de serviço SIA}

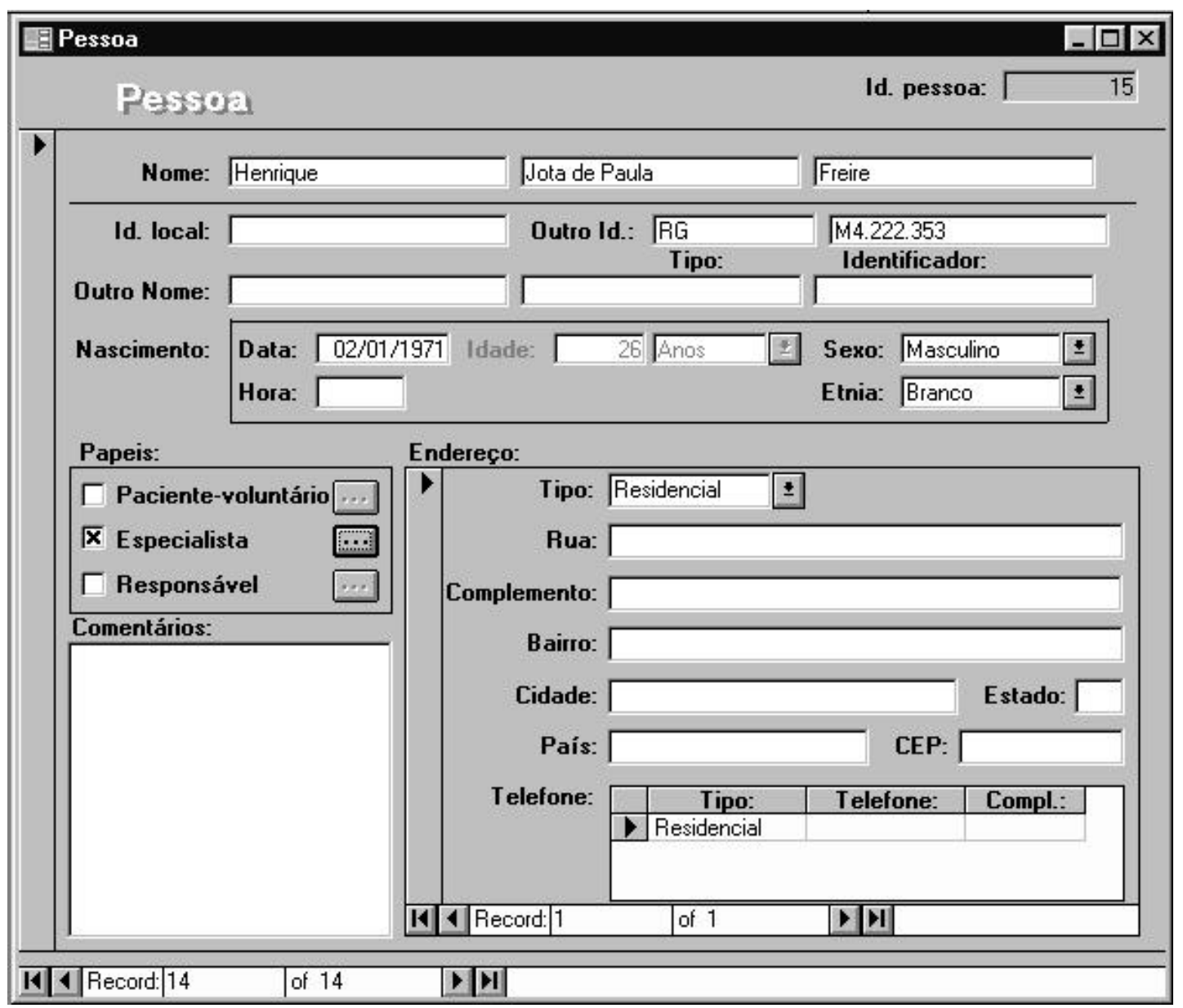

Figura 2 - Formulário Pessoa. 


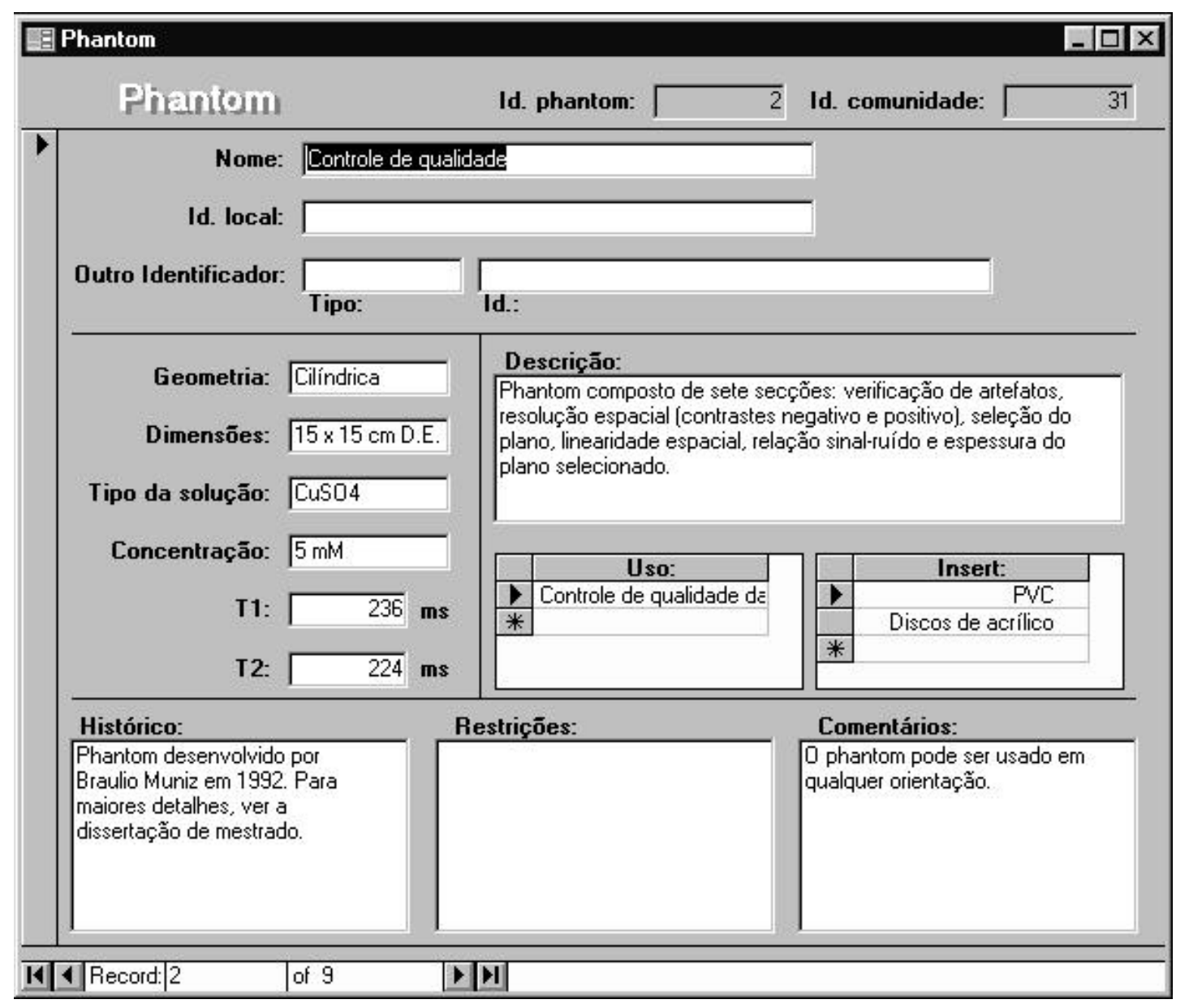

Figura 3 - Formulário Phantom. 


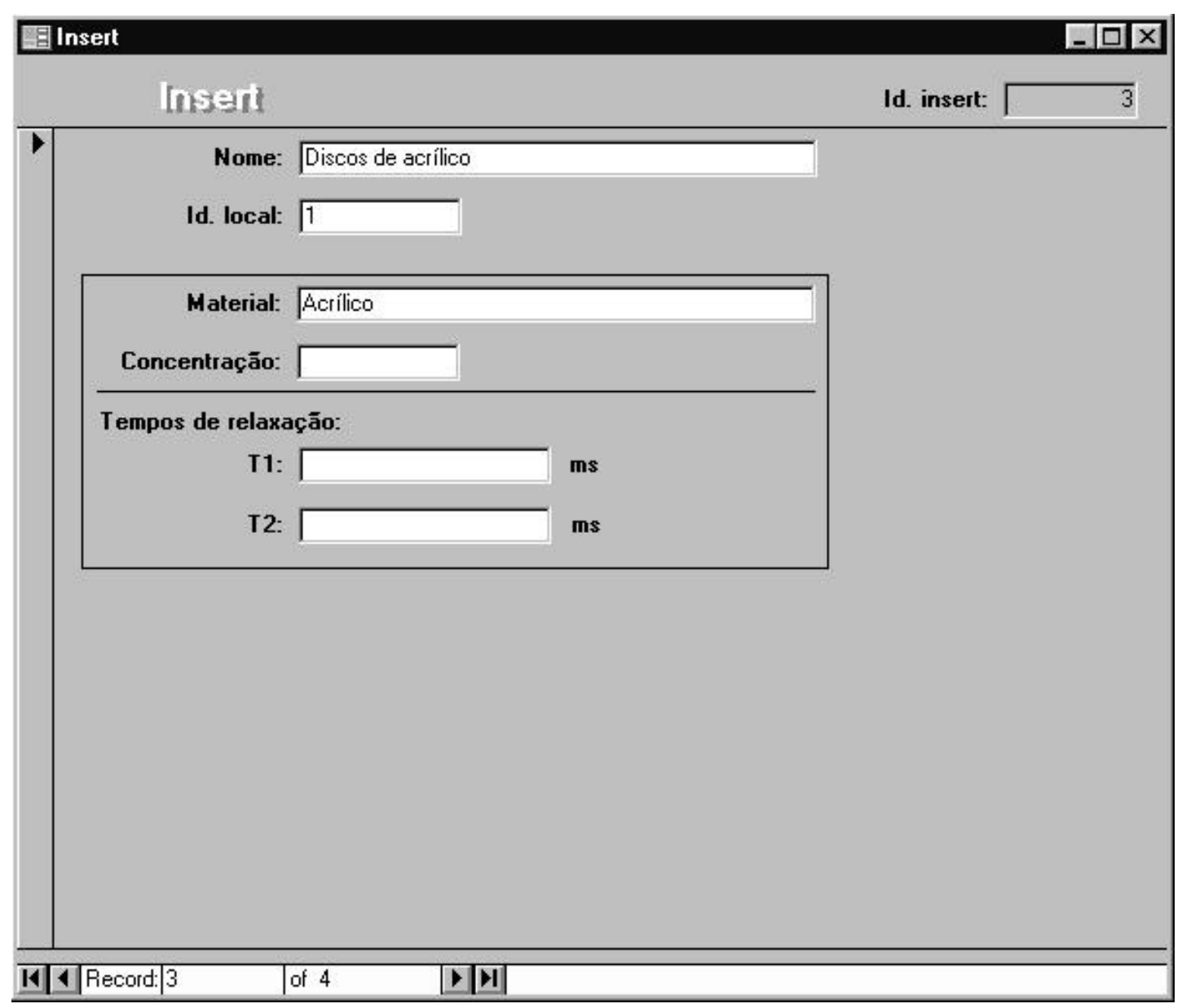

Figura 4 - Formulário Insert. 


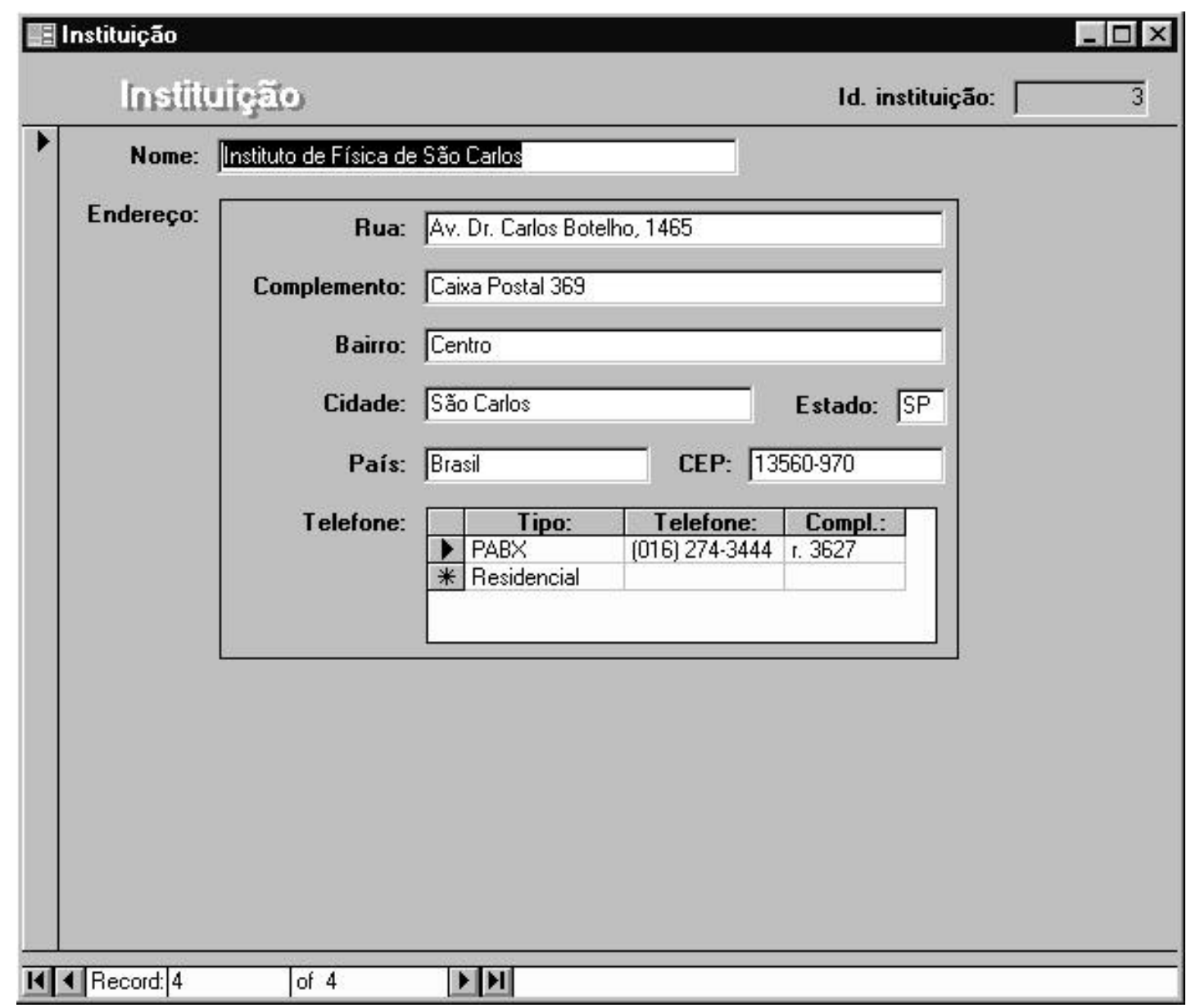

Figura 5 - Formulário Instituição. 


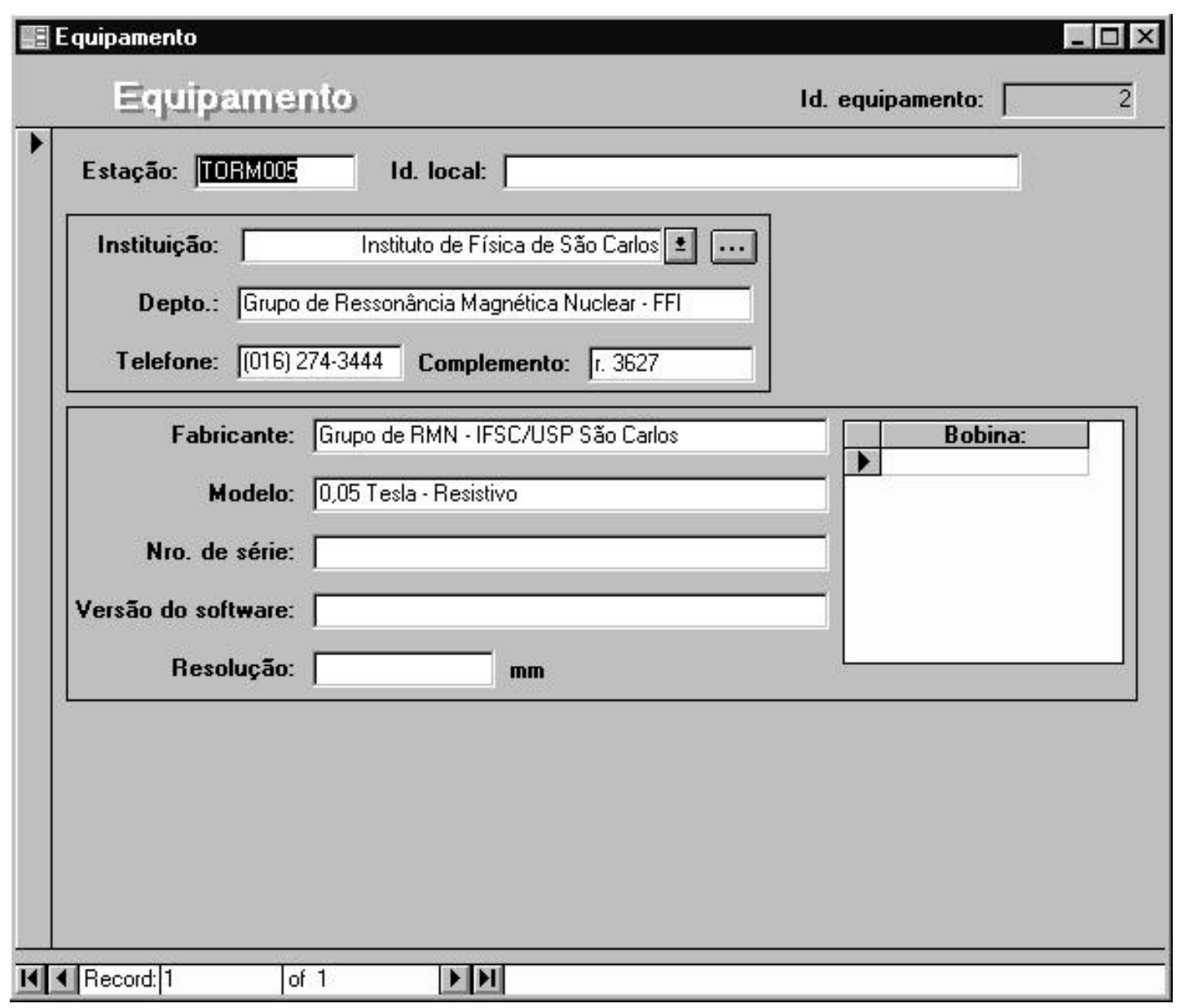

Figura 6 - Formulário Equipamento. 


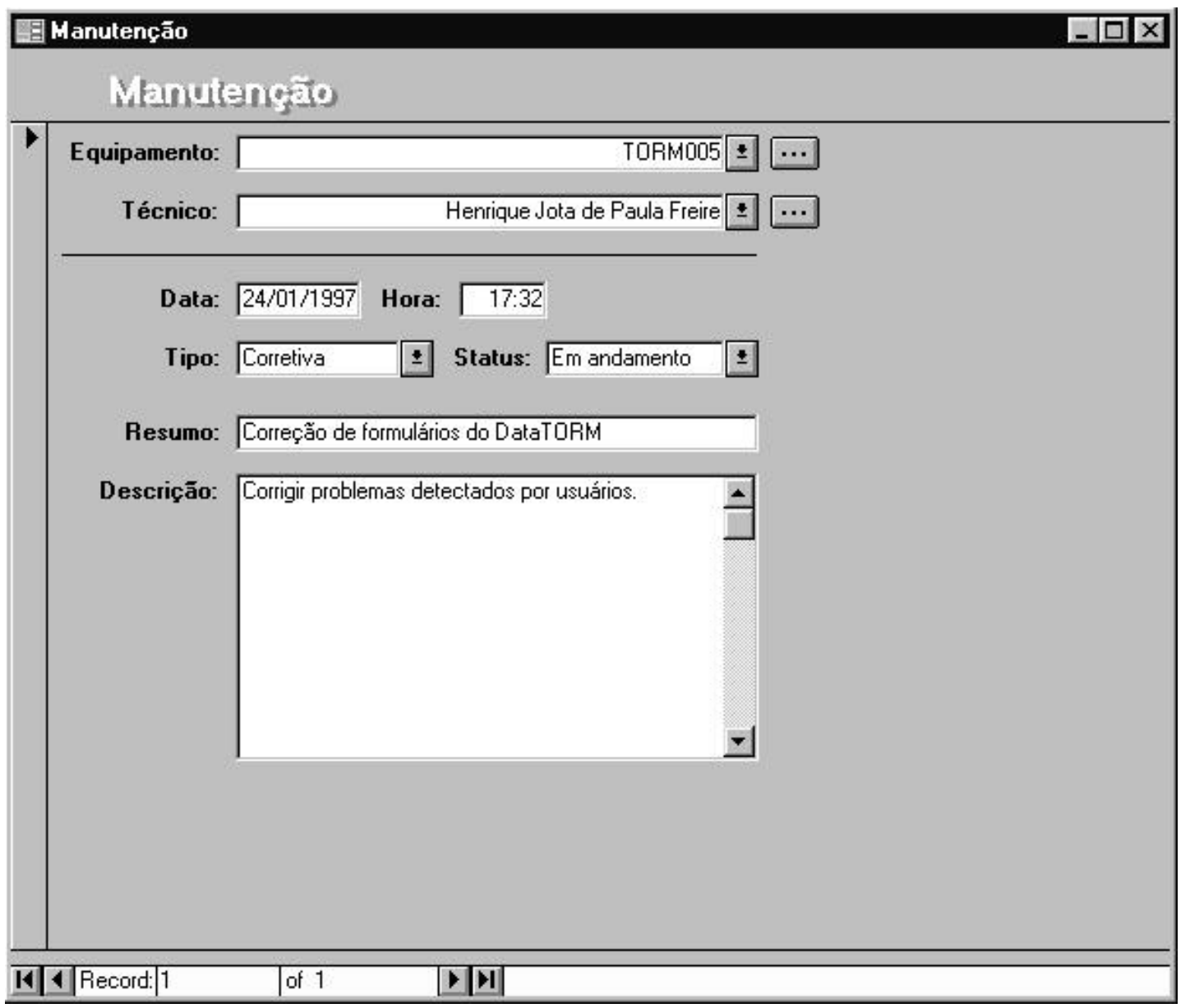

Figura 7 - Formulário Manutenção. 


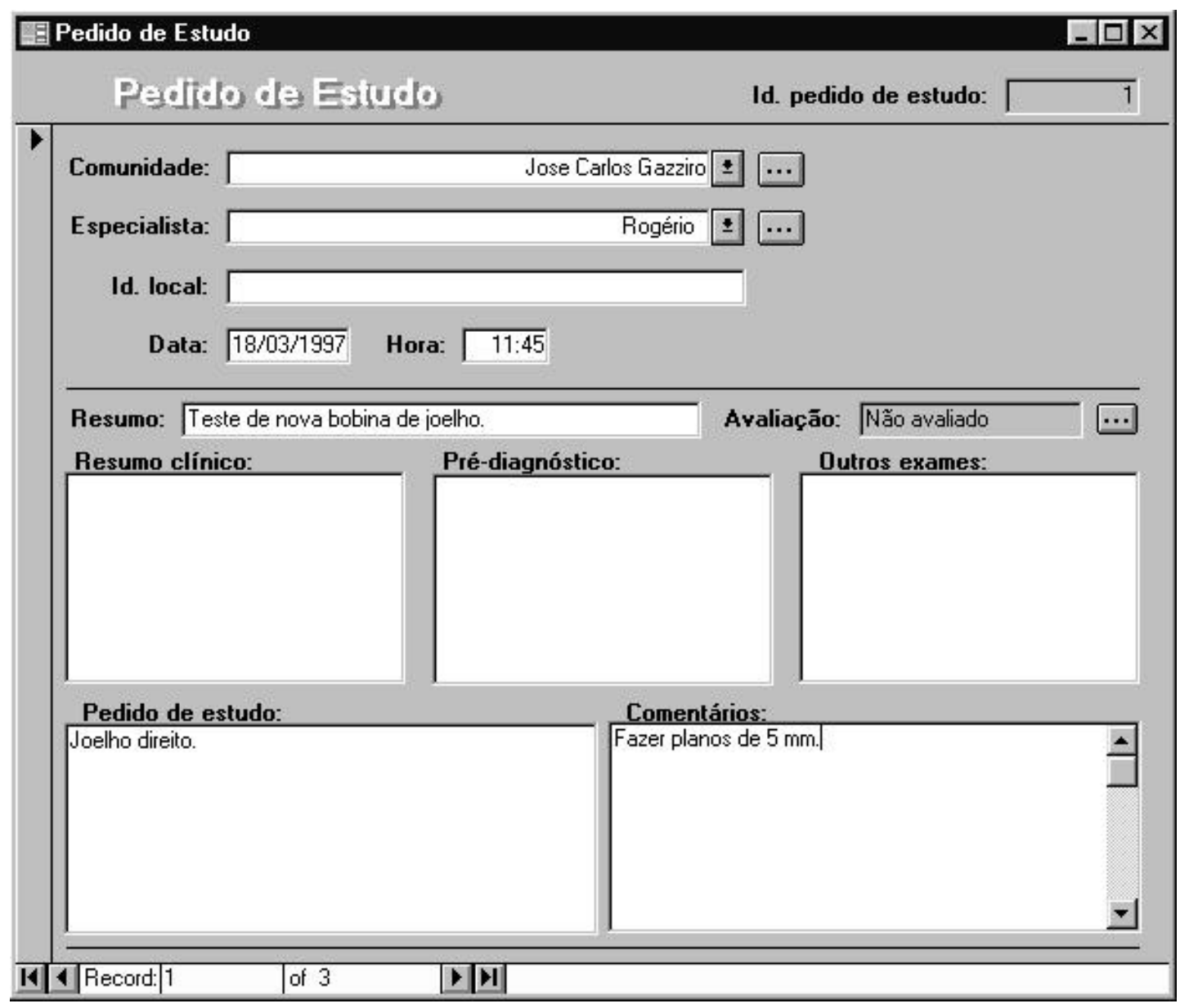

Figura 8 - Formulário Pedido de Estudo. 


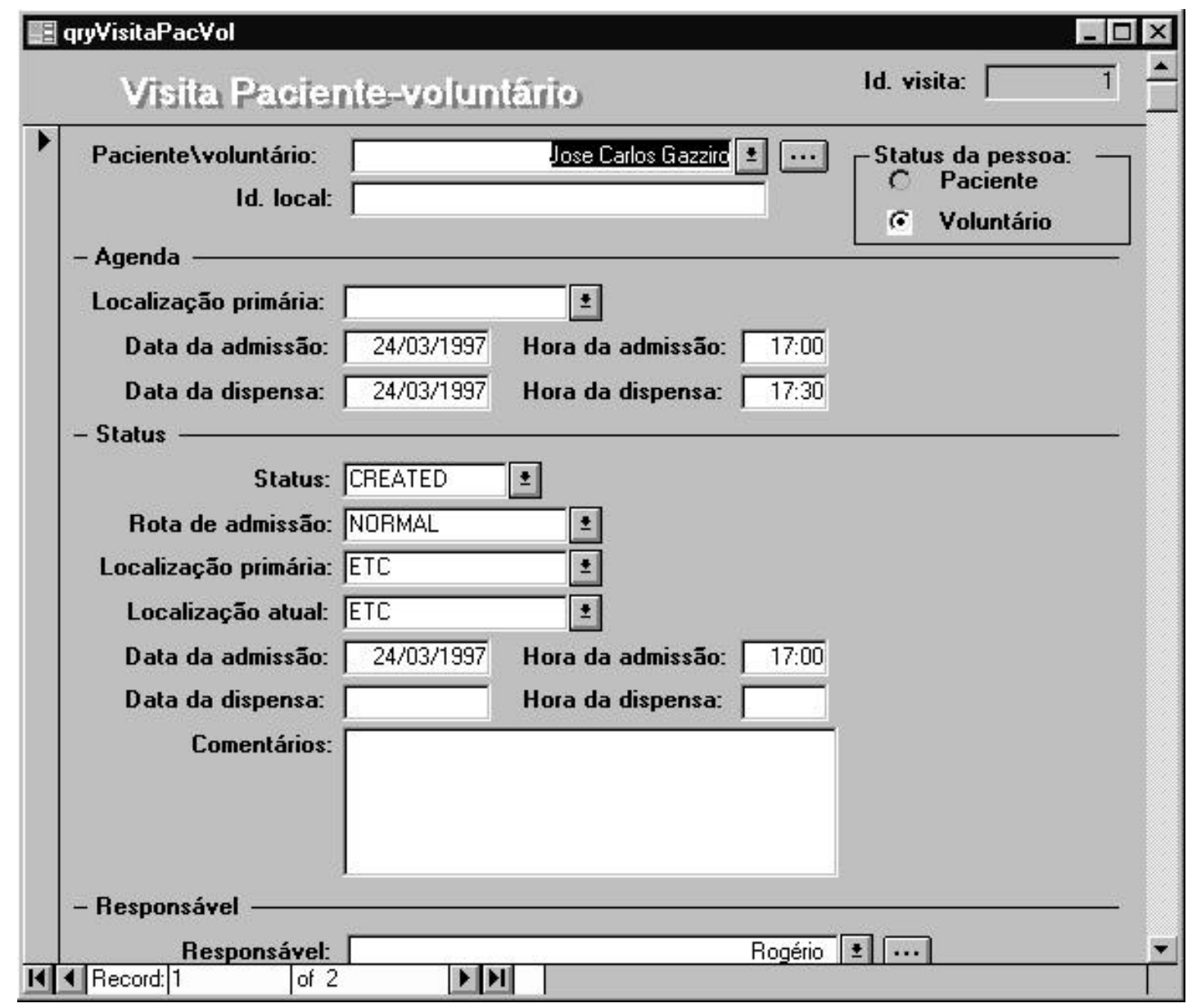

Figura 9 - Formulário Visita Paciente/Voluntário. 


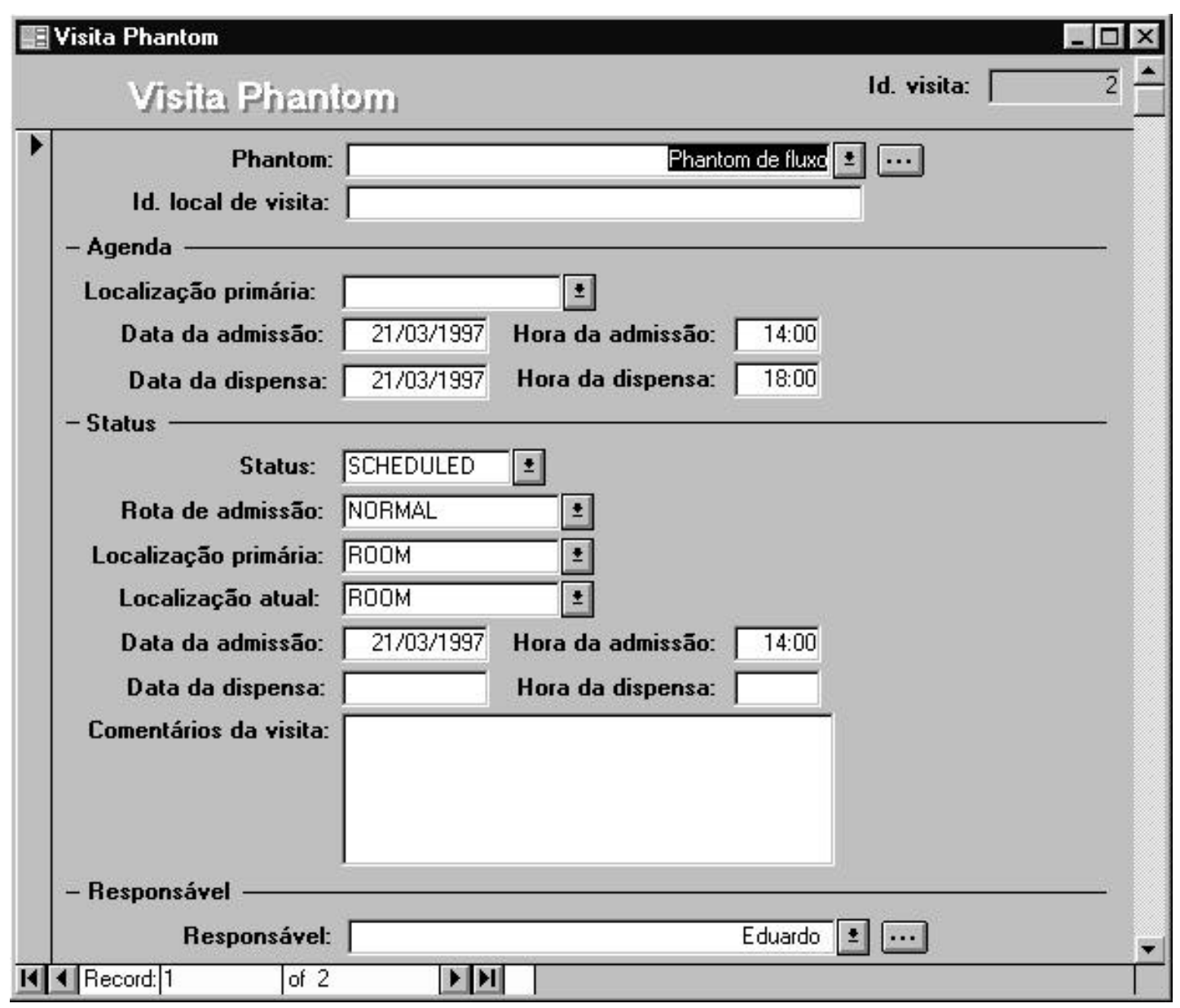

Figura 10 - Formulário Visita Phantom. 


\section{Grupo de serviço SIRMN}

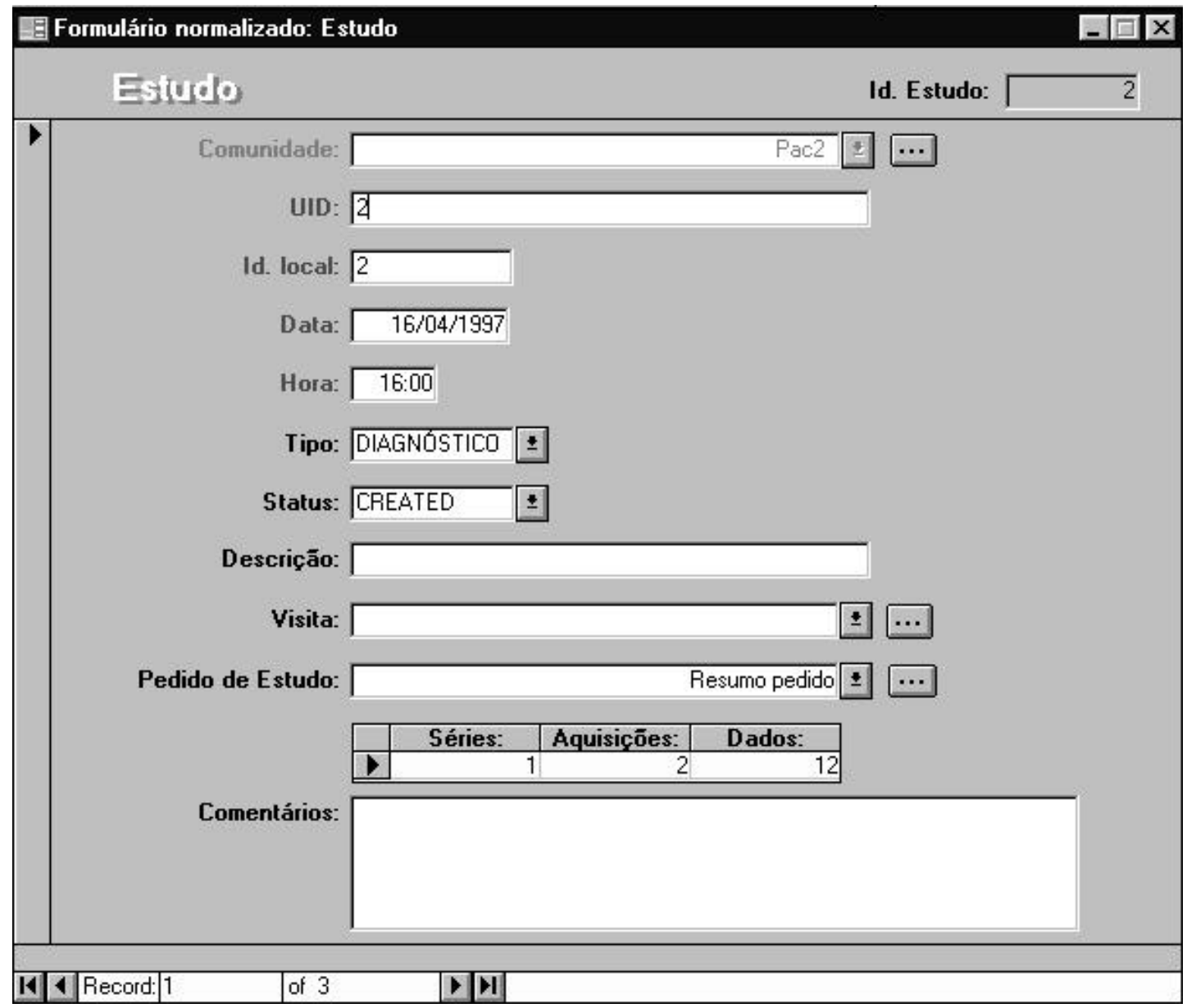

Figura 11 -Formulário Estudo. 
APÊNDICE VIII - 13

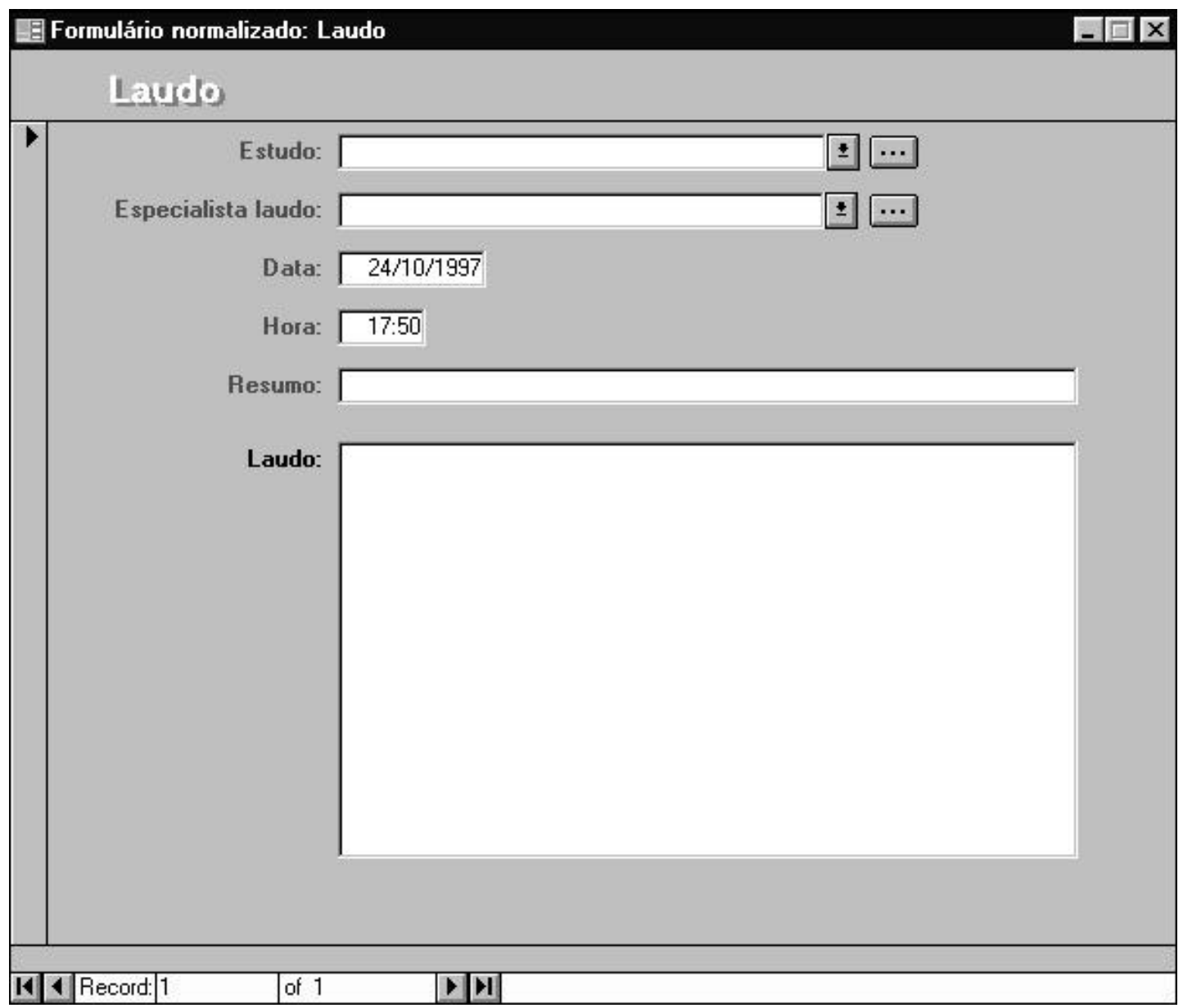

Figura 12 - Formulário Laudo. 


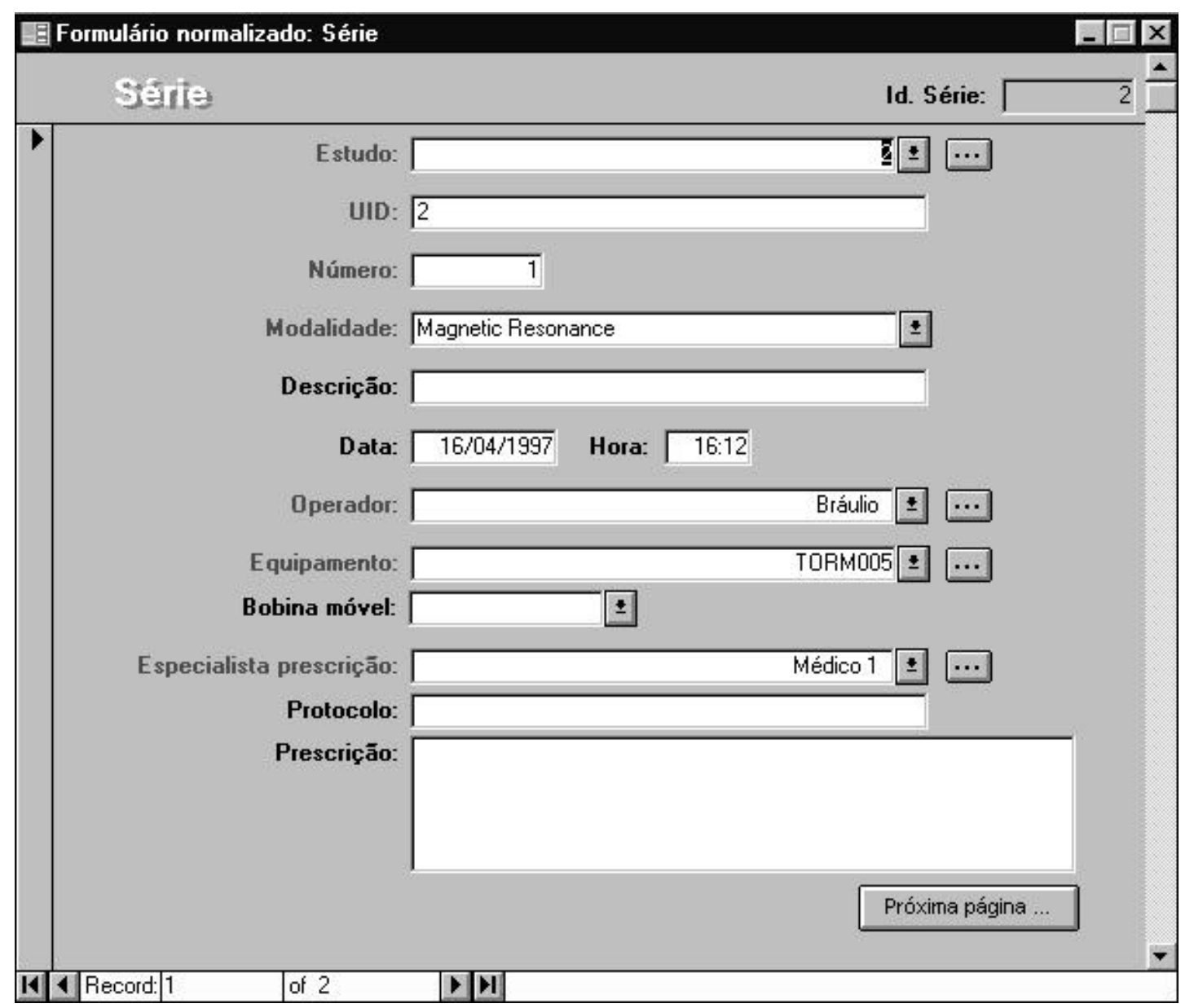

Figura 13 - Formulário Série (primeira página). 


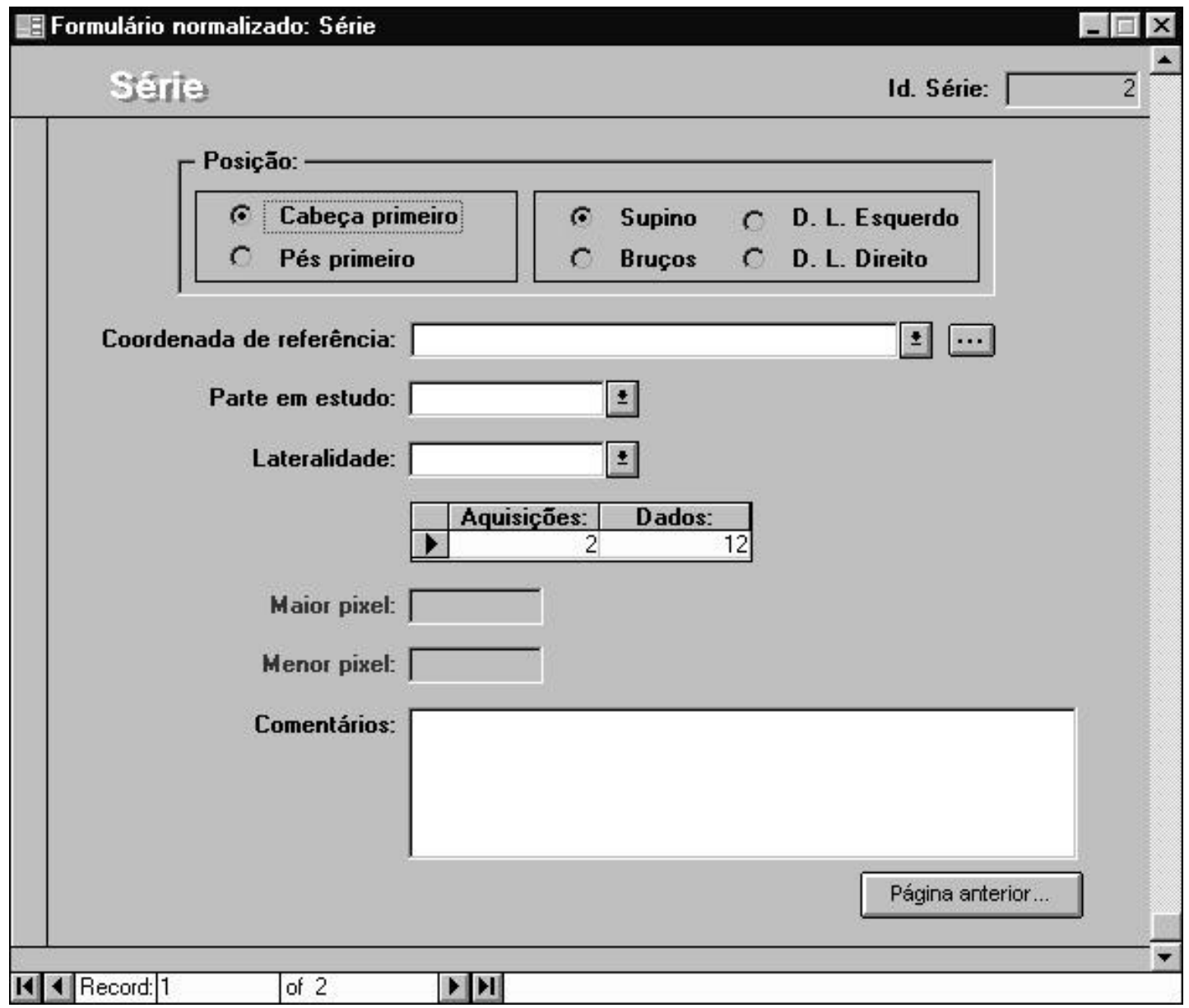

Figura 14 - Formulário Série (segunda página). 


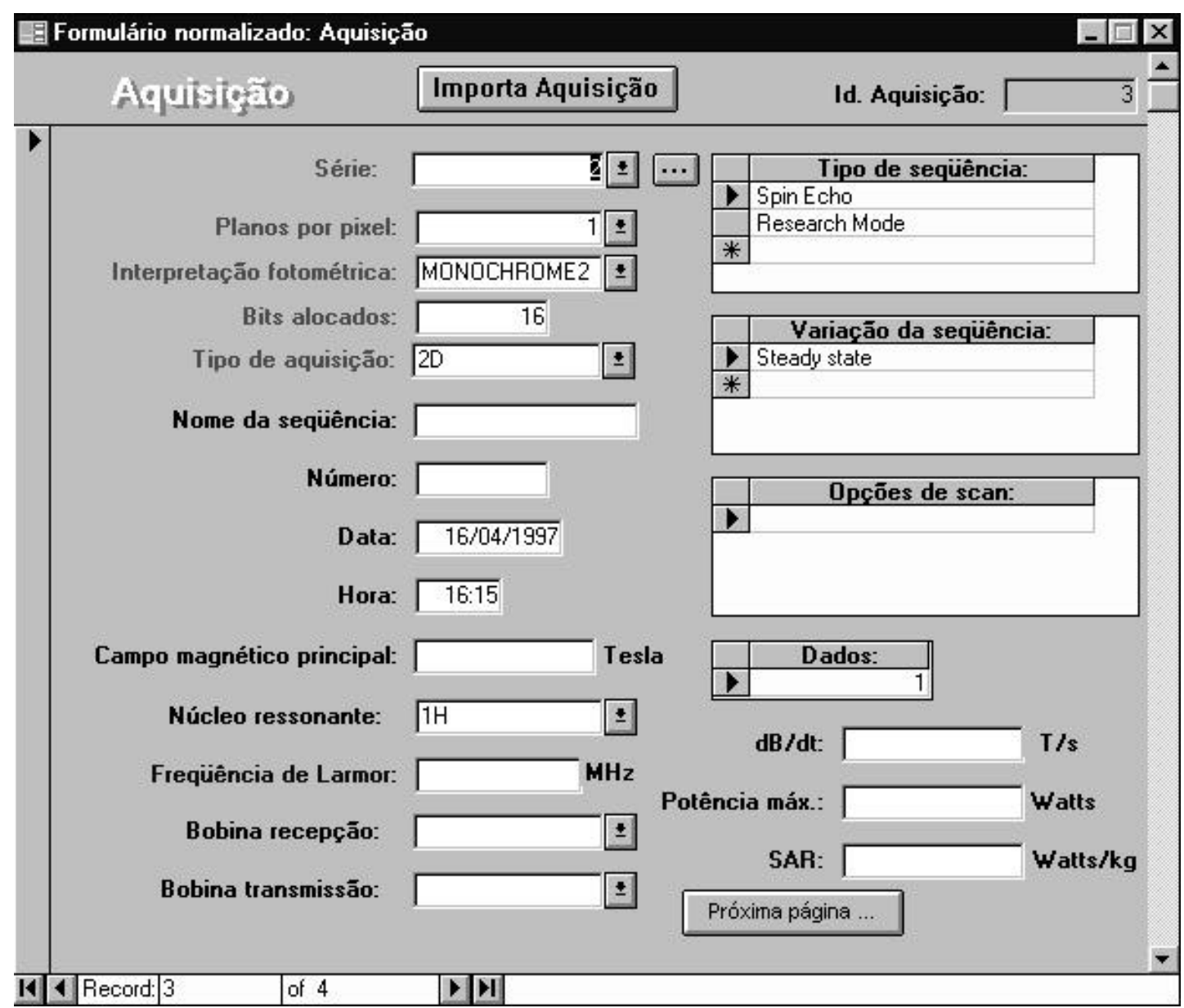

Figura 15 - Formulário aquisição (primeira página). 


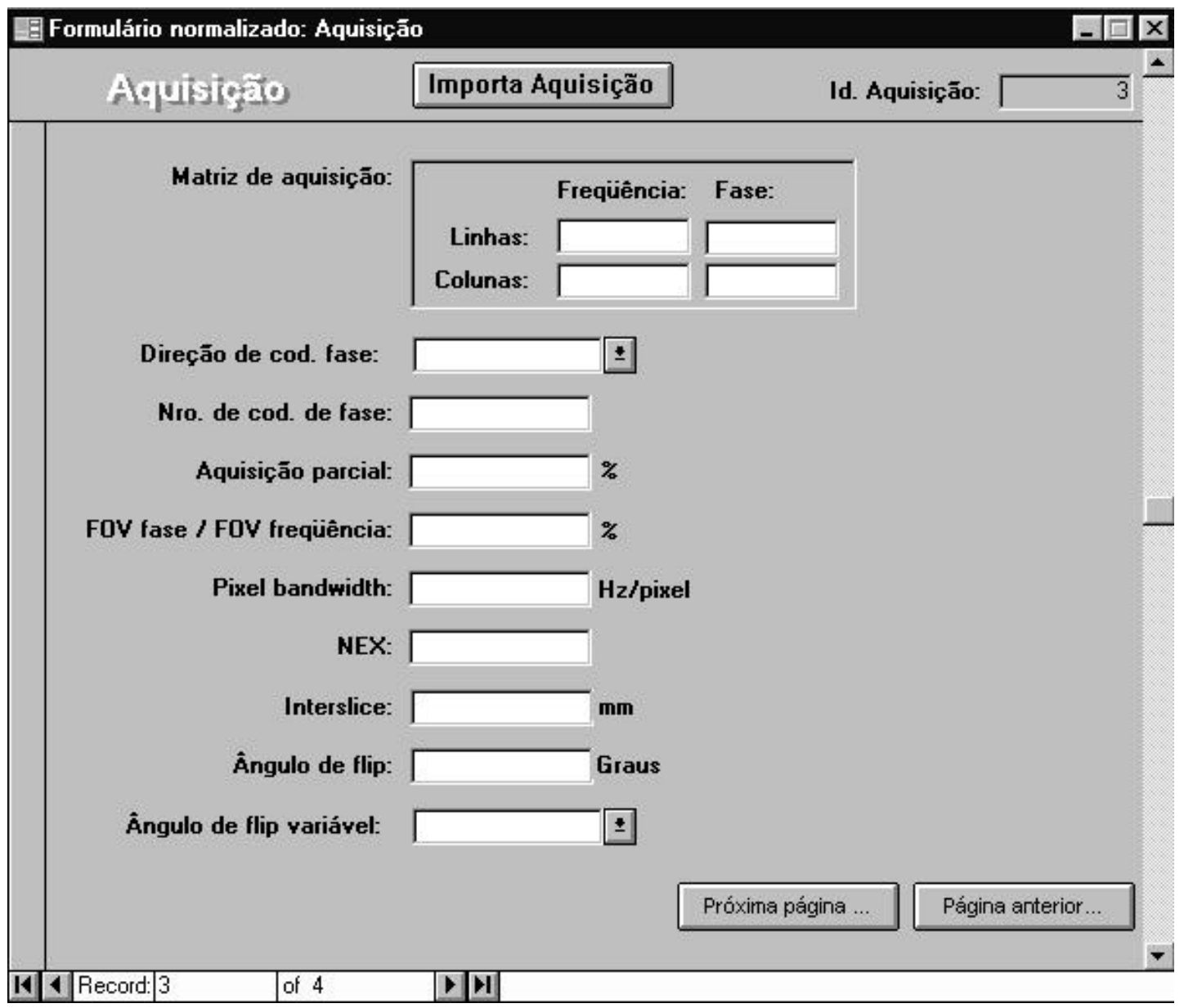

Figura 16 - Formulário aquisição (segunda página). 


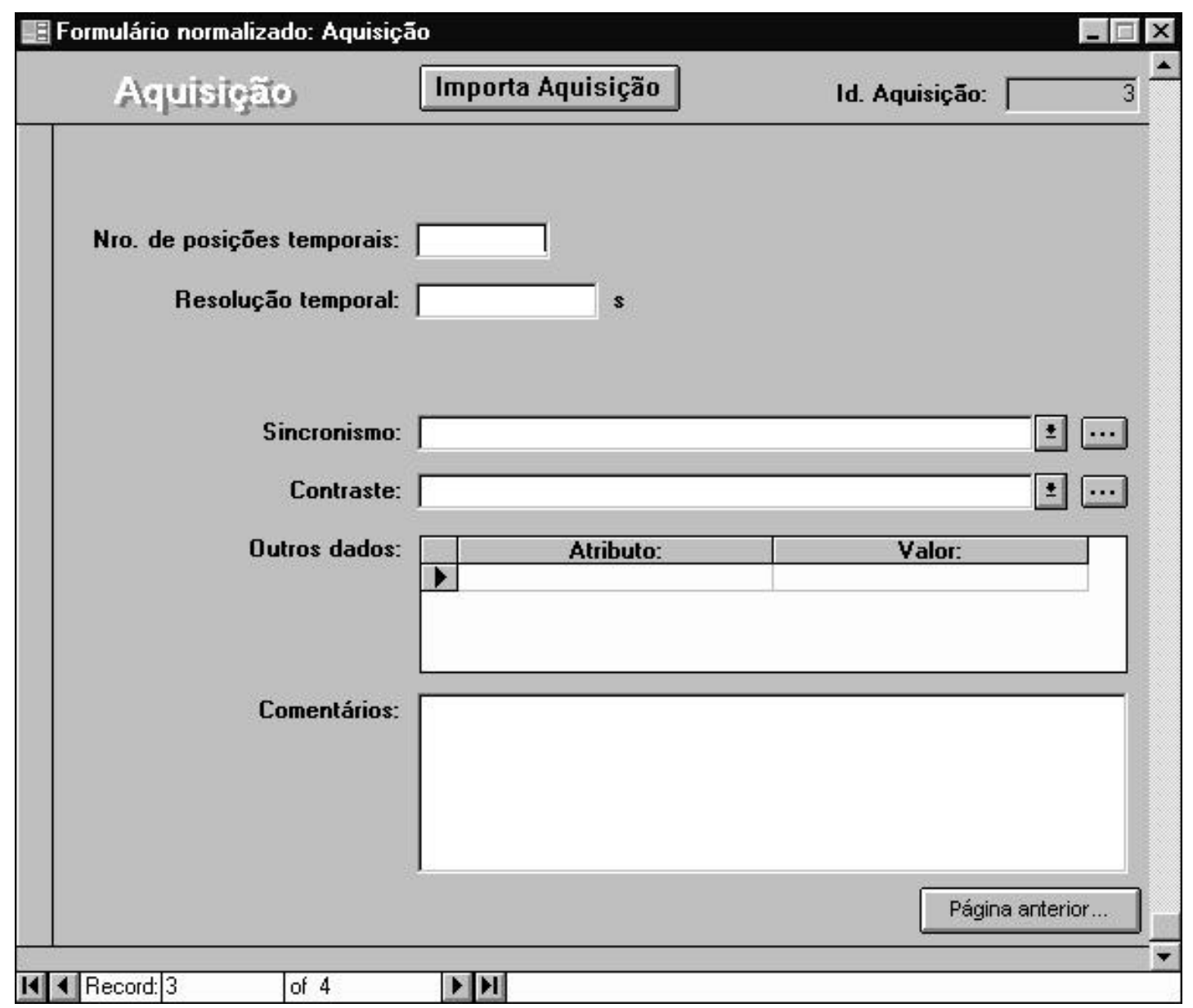

Figura 17 - Formulário aquisição (terceira página). 


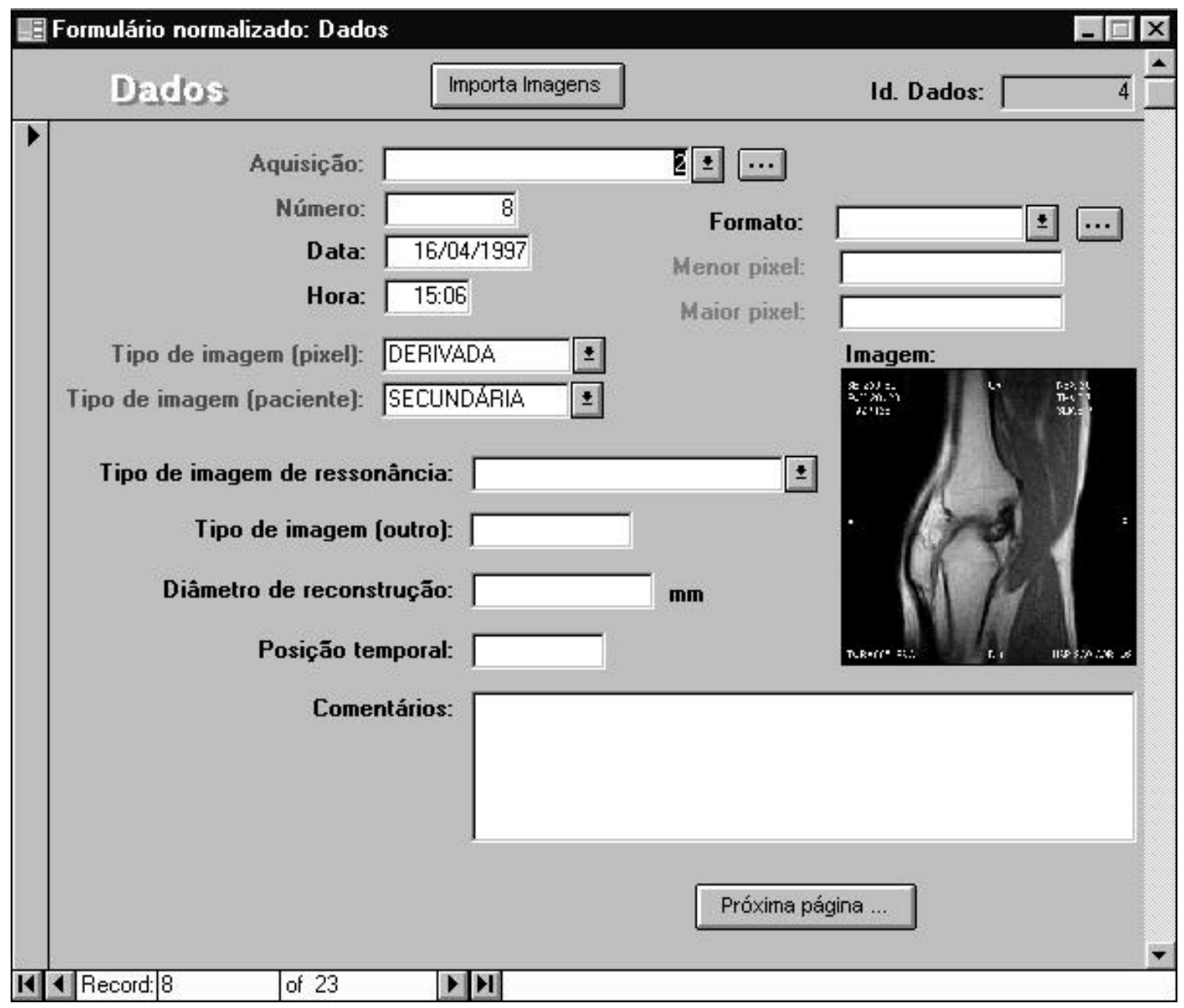

Figura 18 - Formulário Dados (primeira página). 


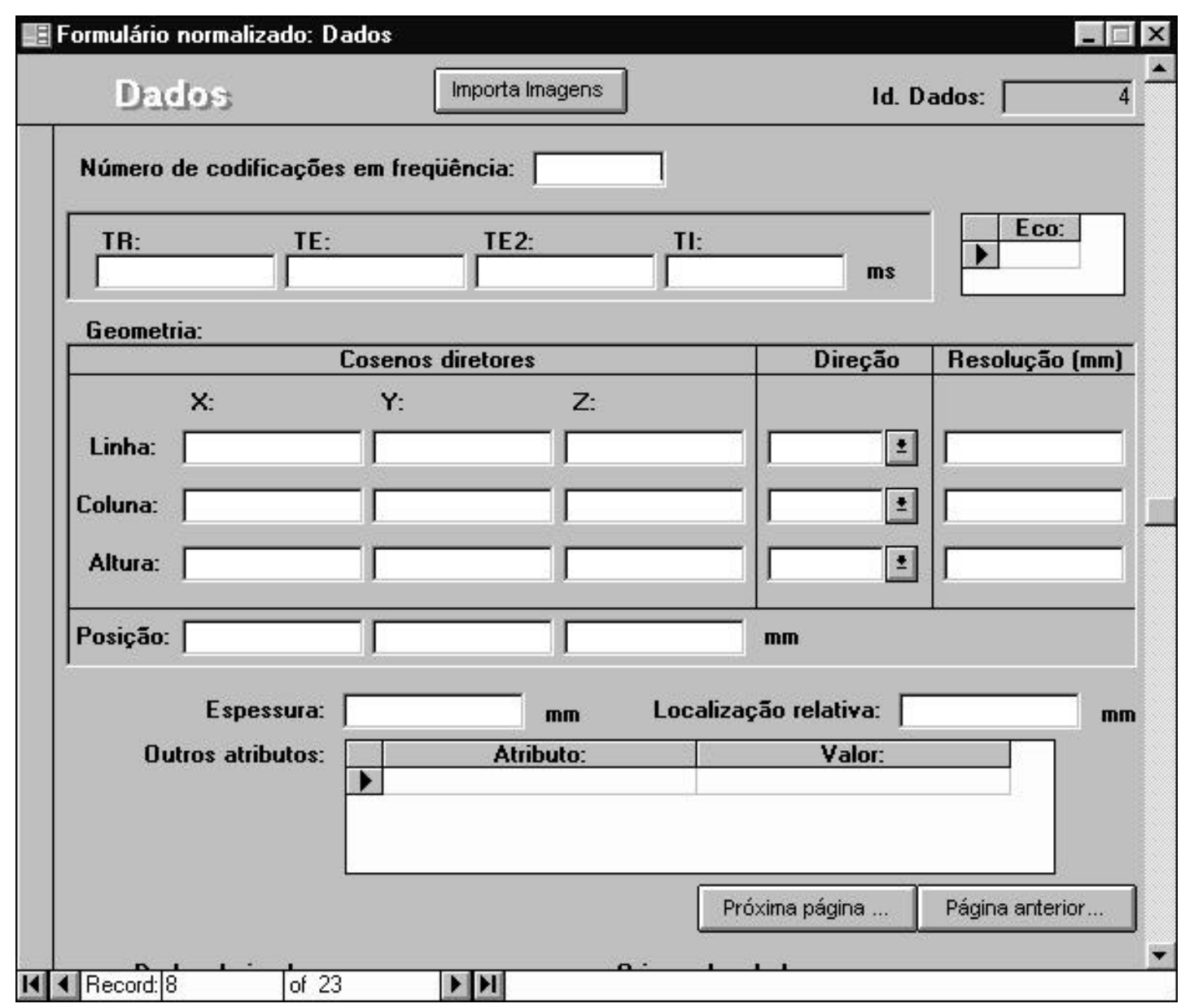

Figura 19 - Formulário Dados (segunda página). 
APÊNDICE VIII - 21

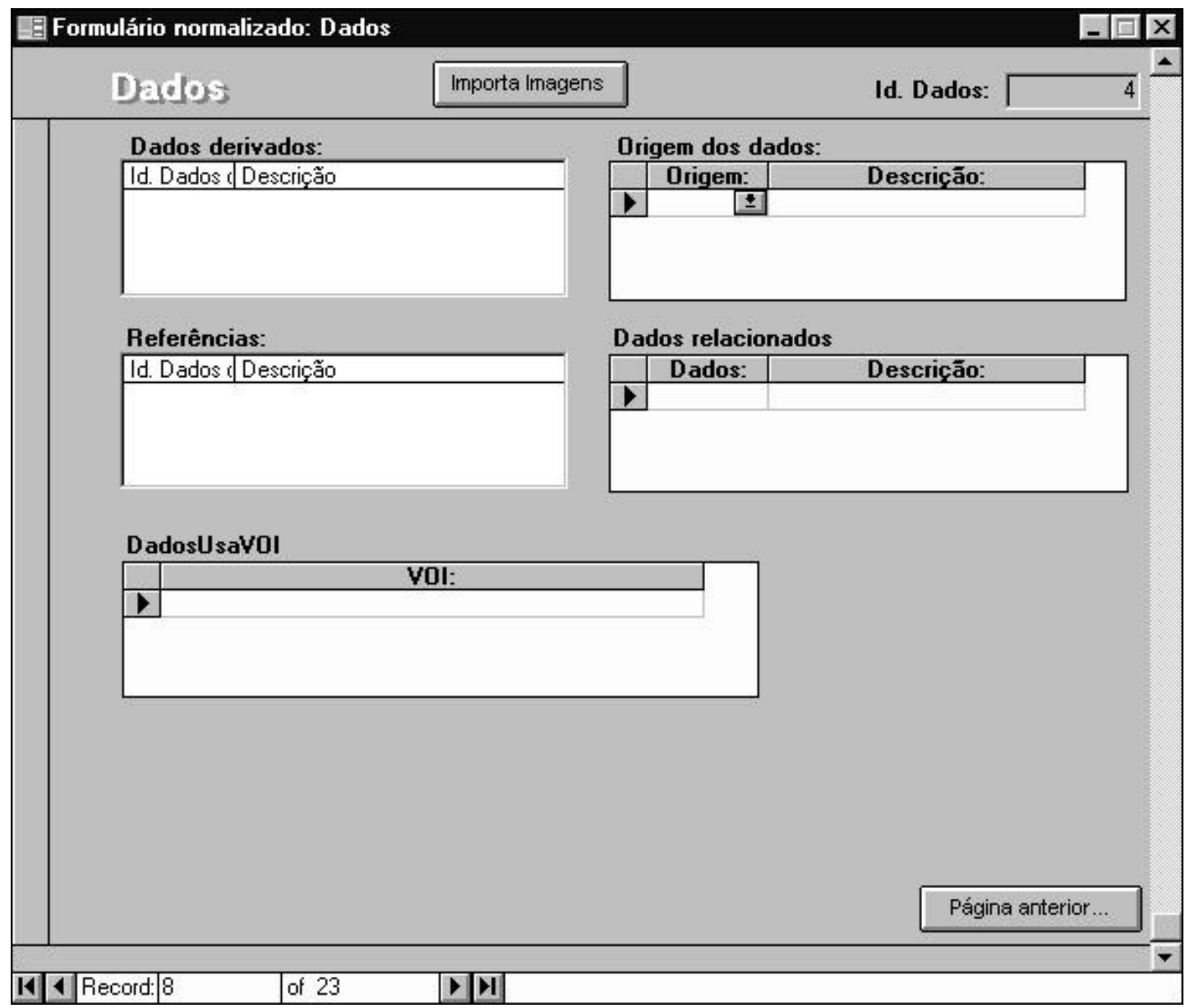

Figura 20 - Formulário Dados (terceira página). 


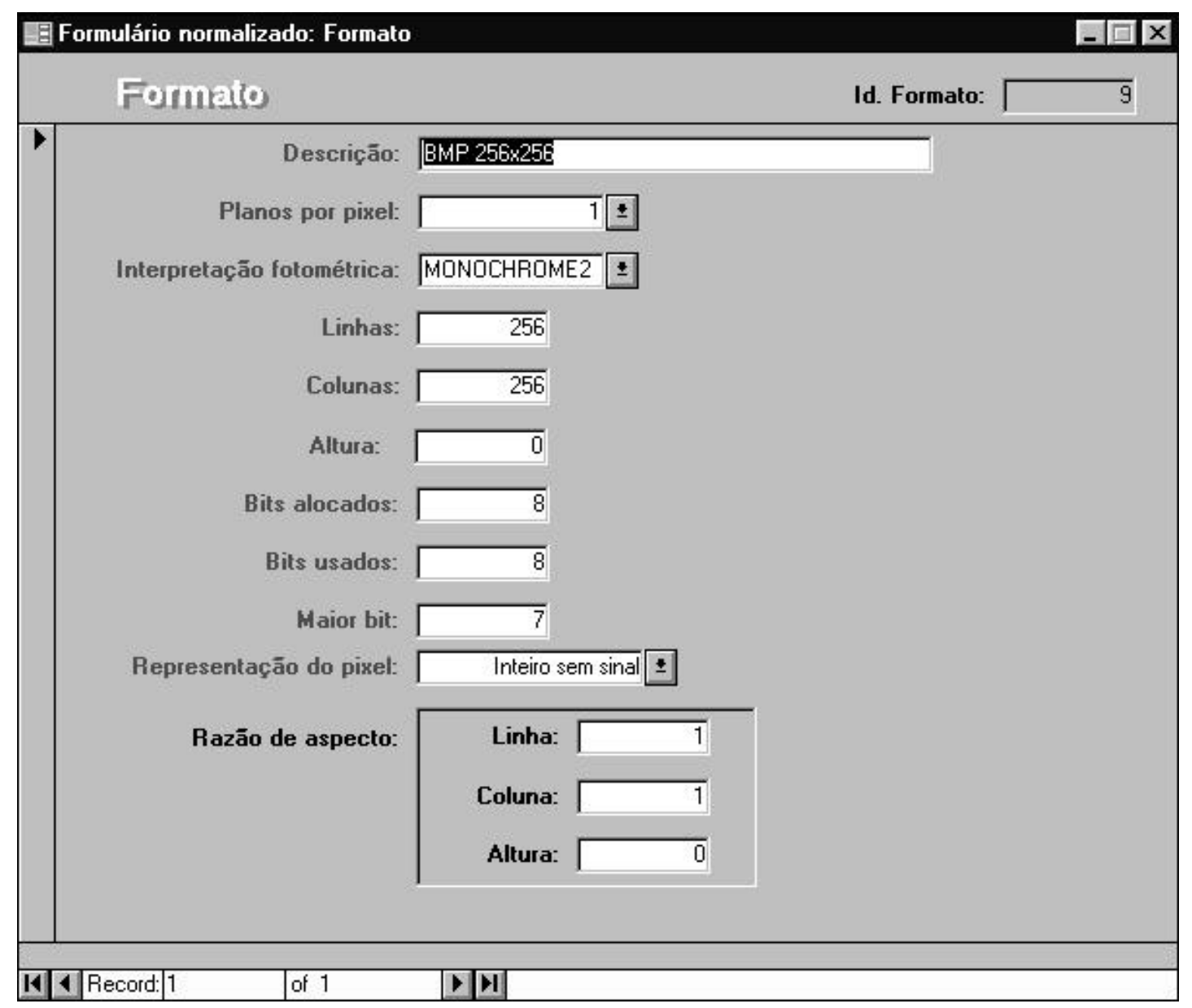

Figura 21 - Formulário Formato. 


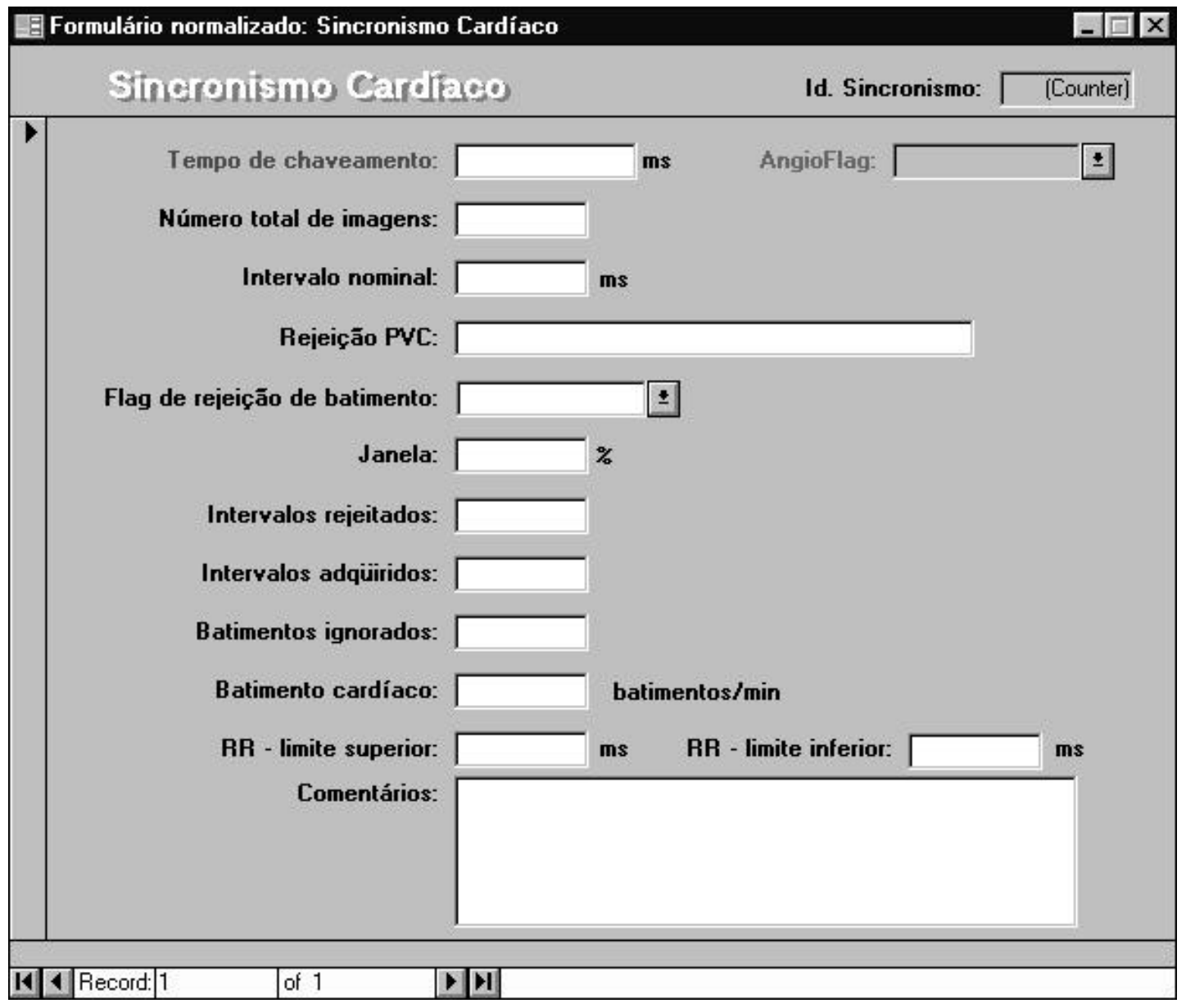

Figura 22 - Formulário Sincronismo Cardíaco. 
APÊNDICE VIII - 24

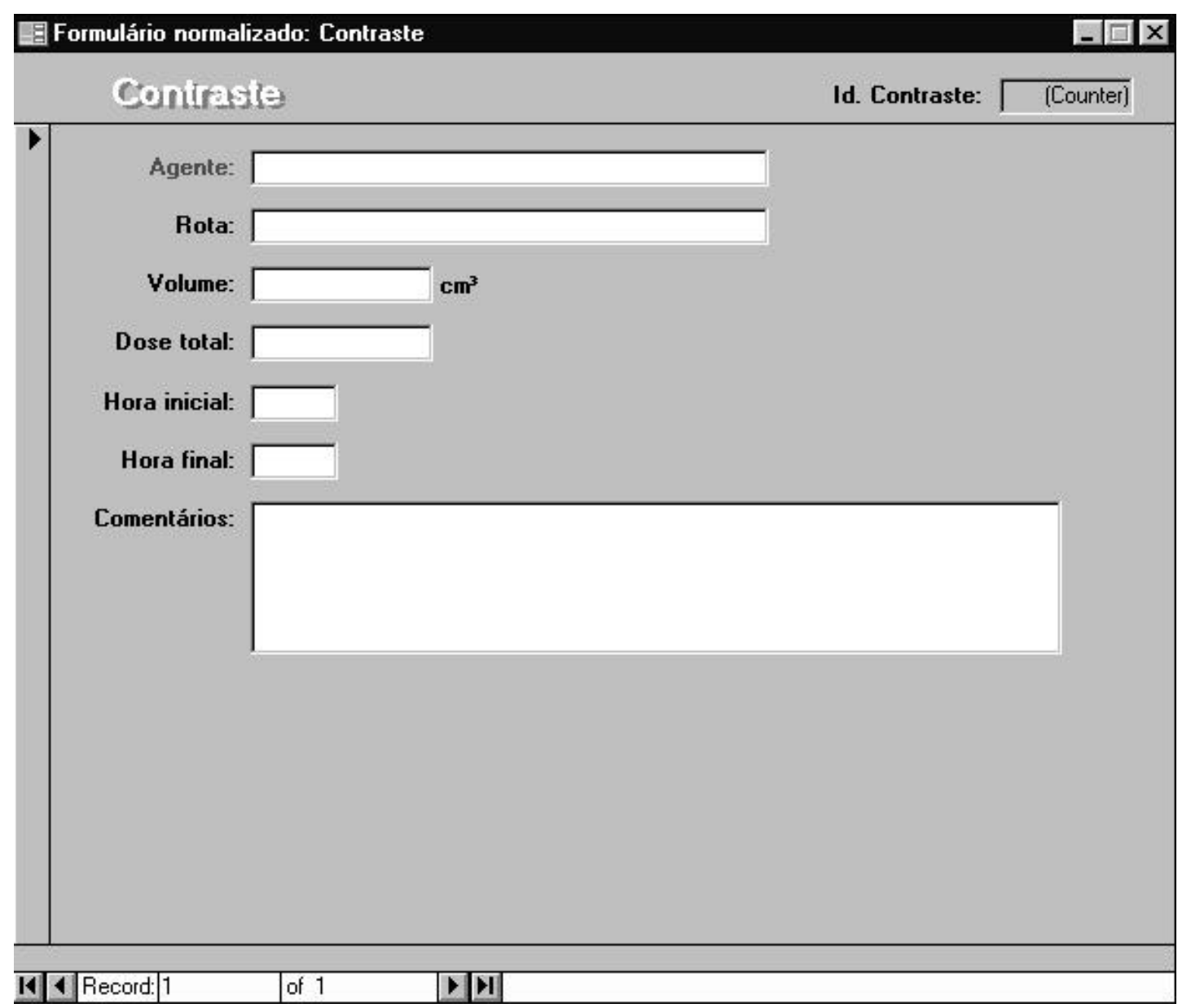

Figura 23 - Formulário Contraste. 
APÊNDICE VIII - 25

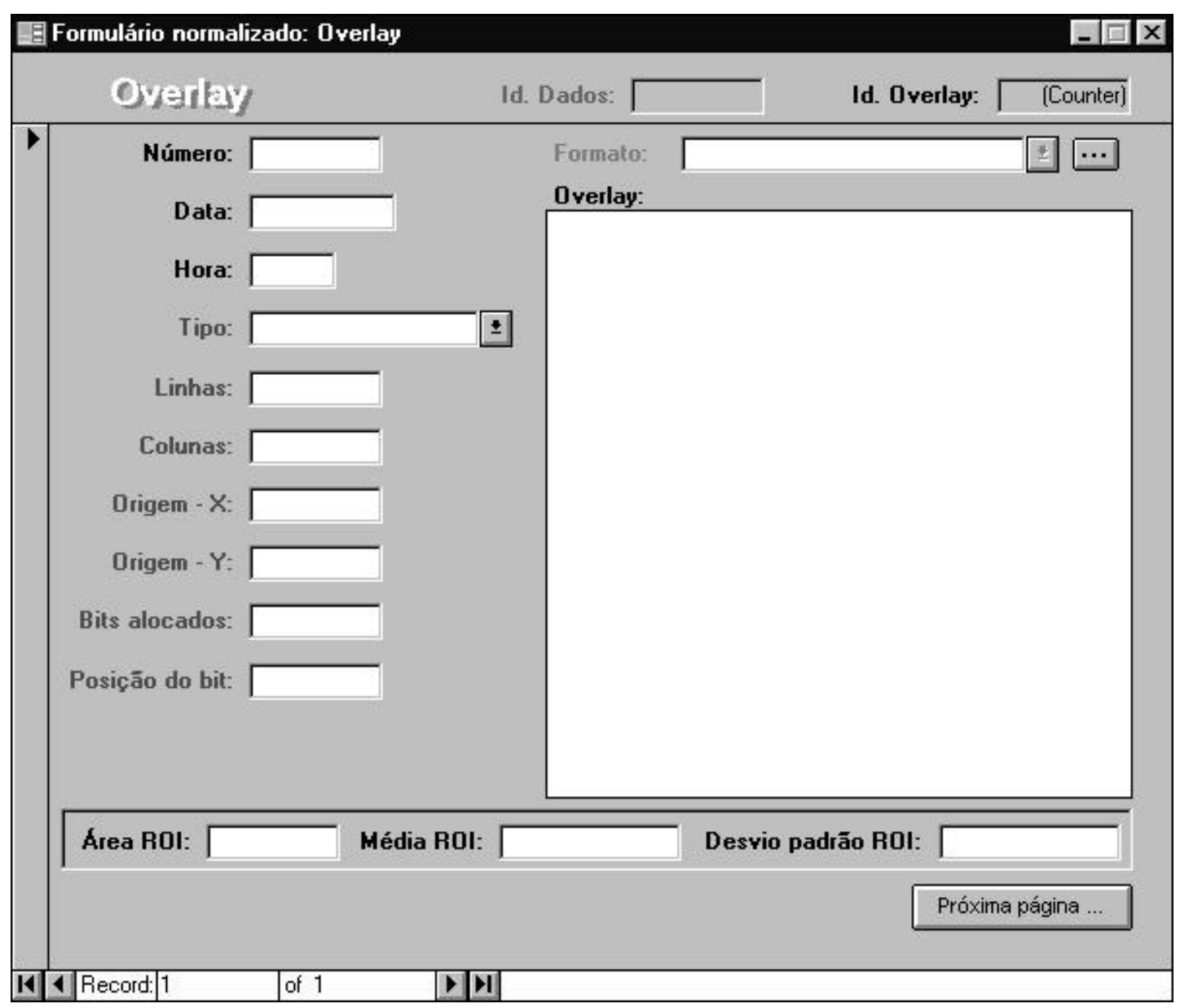

Figura 24 - Formulário Overlay. 


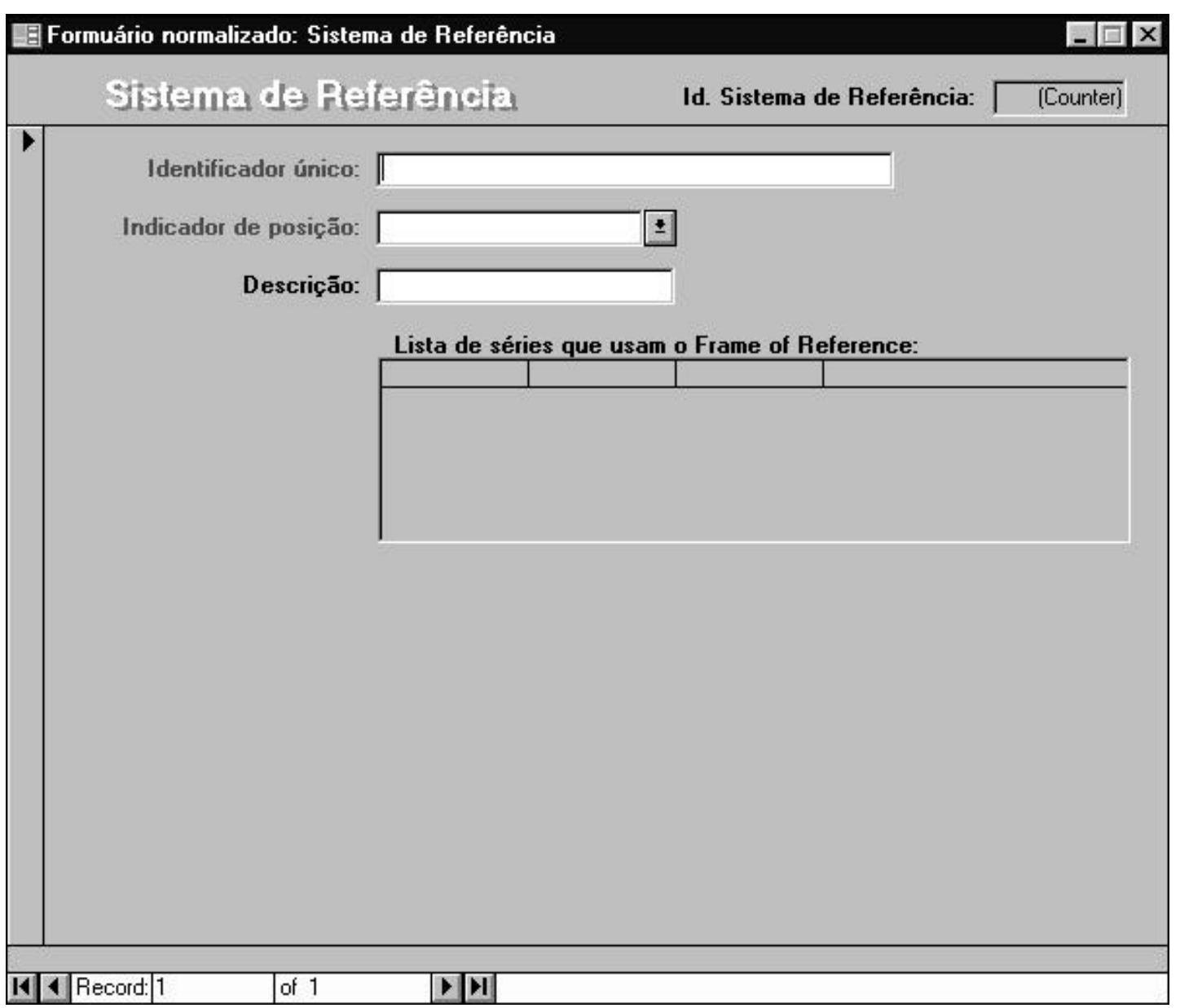

Figura 25 - Formulário Sistema de Referência. 
APÊNDICE VIII - 27

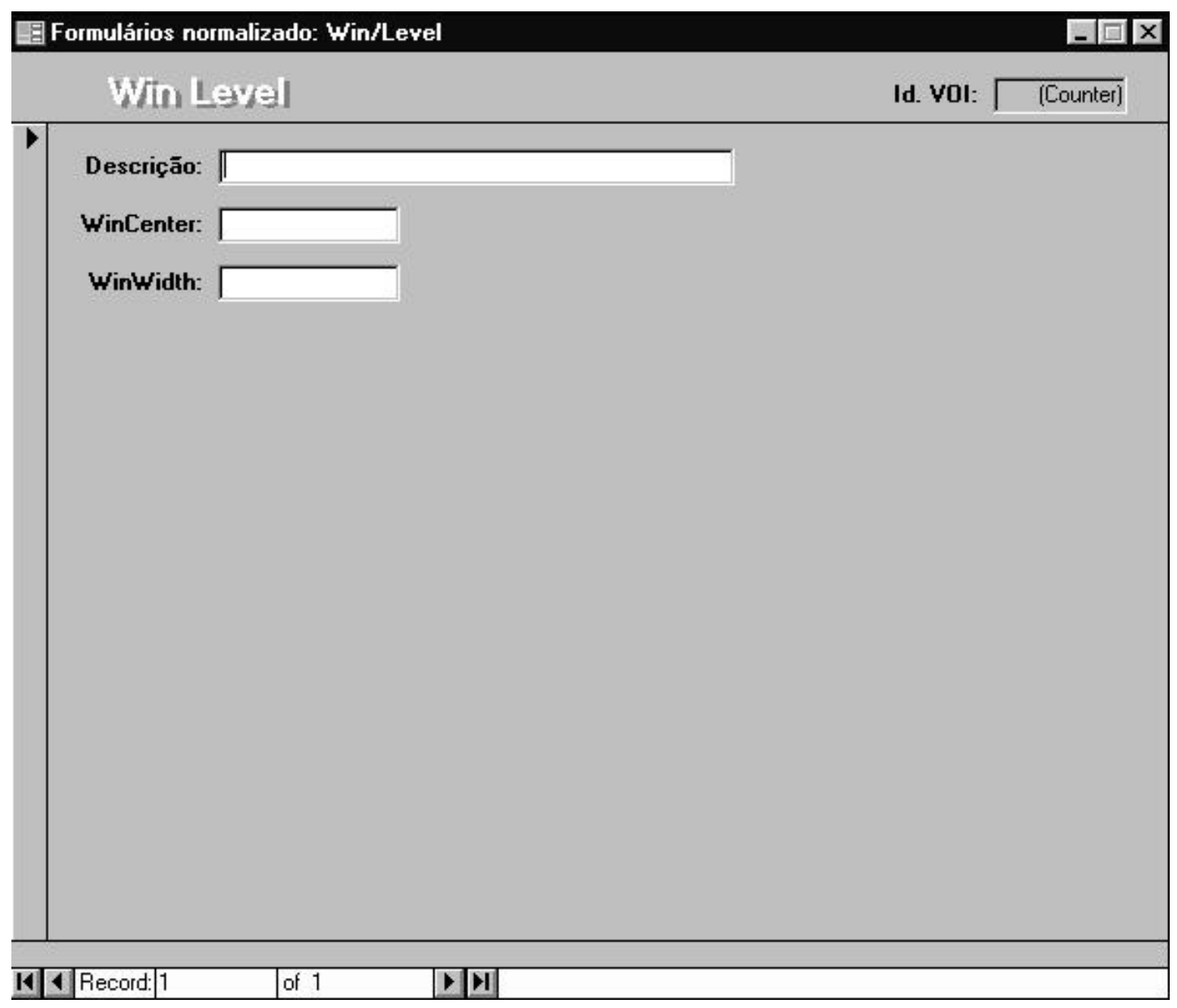

Figura 26 - Formulário Win/Level. 
APÊNDICE VIII - 28

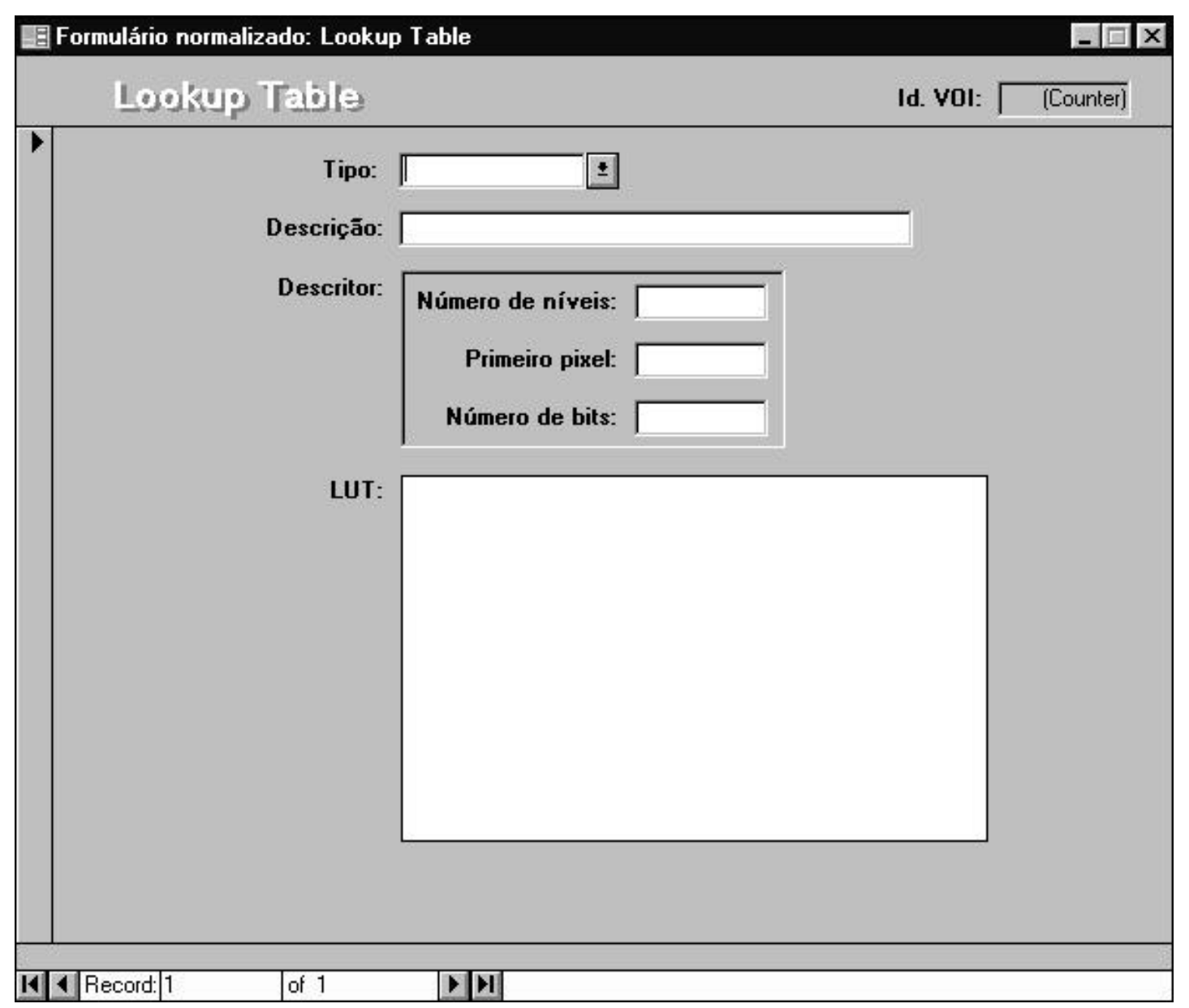

Figura 27 - Formulário Lookup Table. 


\section{Grupo de serviço MANUTENÇÃO}

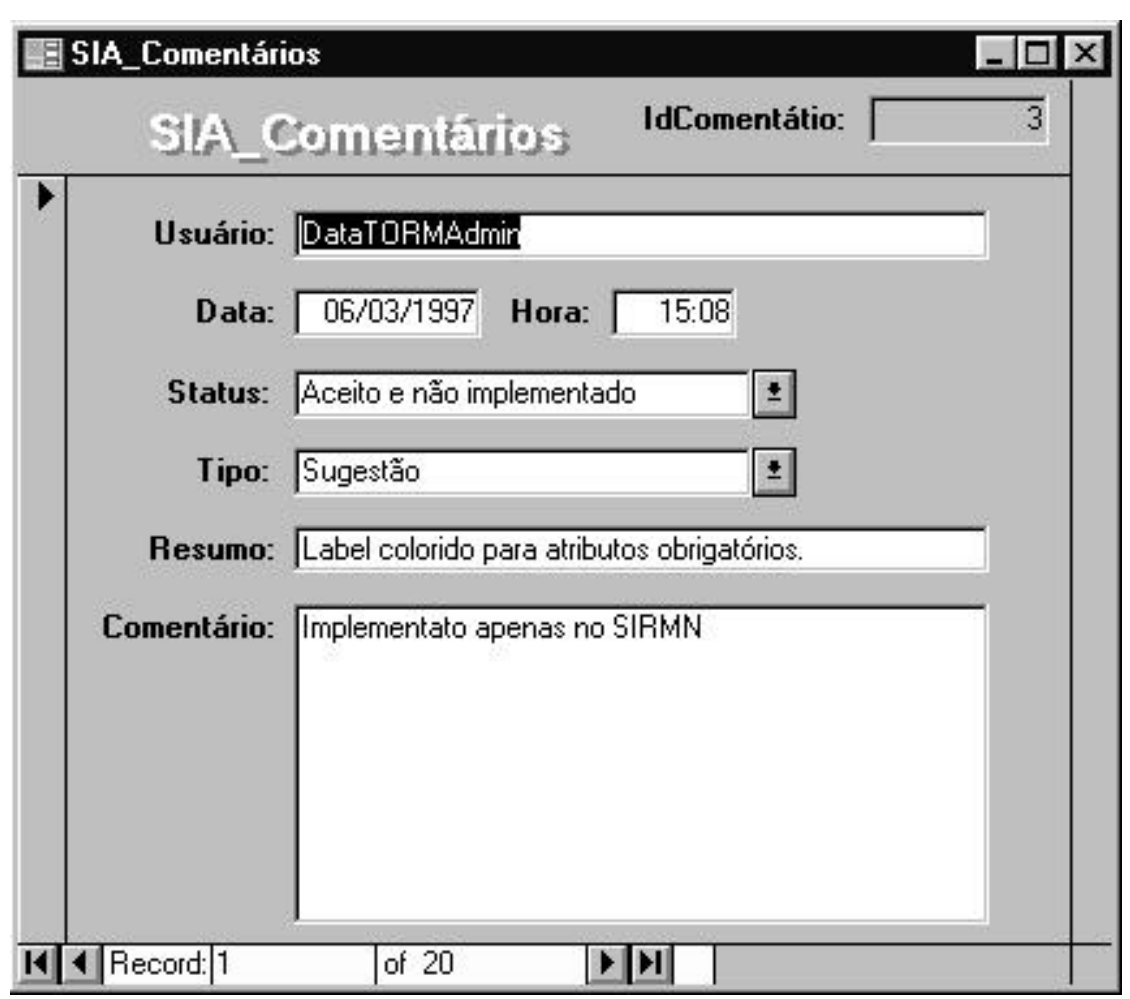

Figura 28 - Formulário Comentários. 


\section{Grupo de serviço BUSCA}

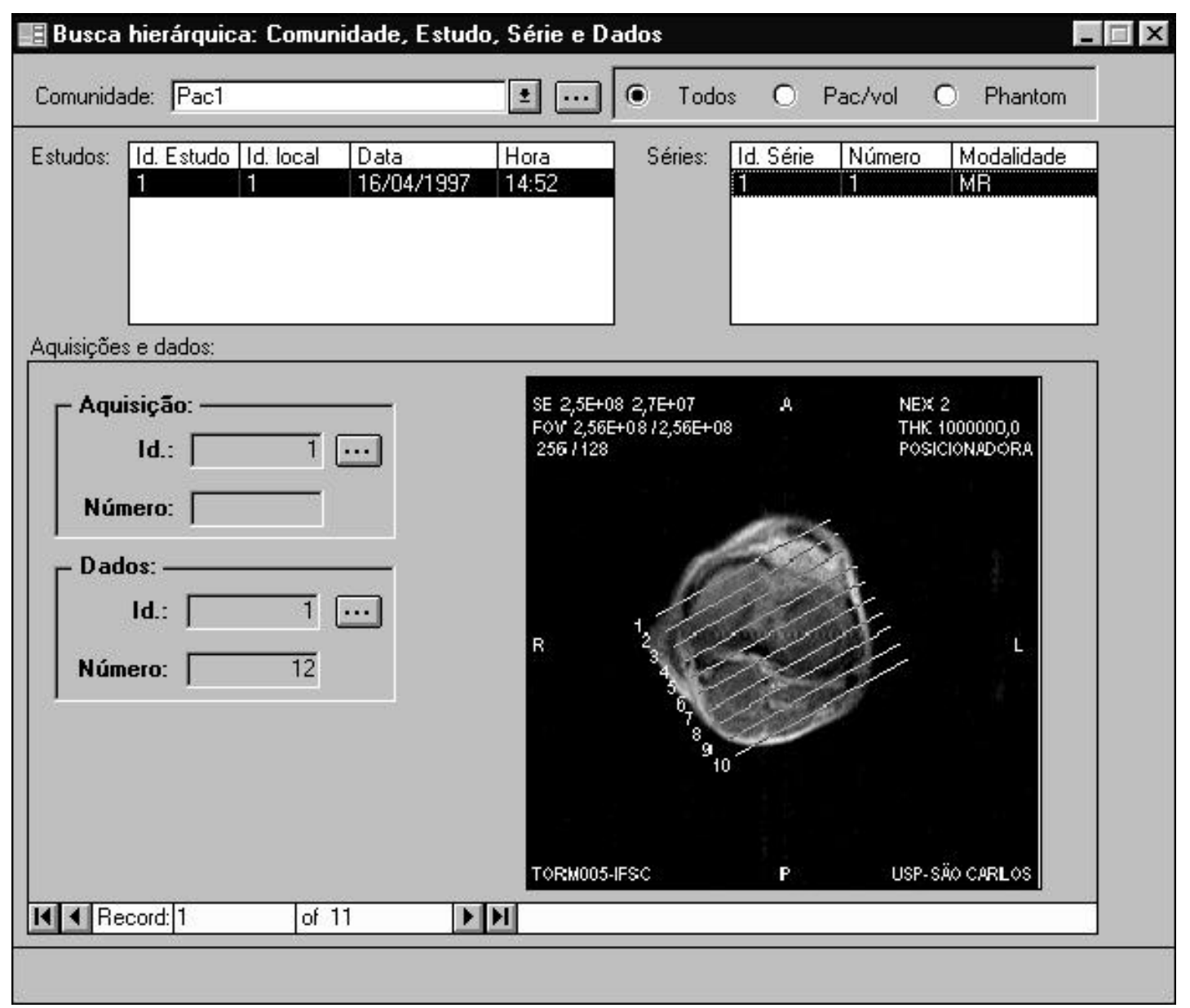

Figura 29 - Formulário Busca. 


\section{Grupo de serviço POSPROC}

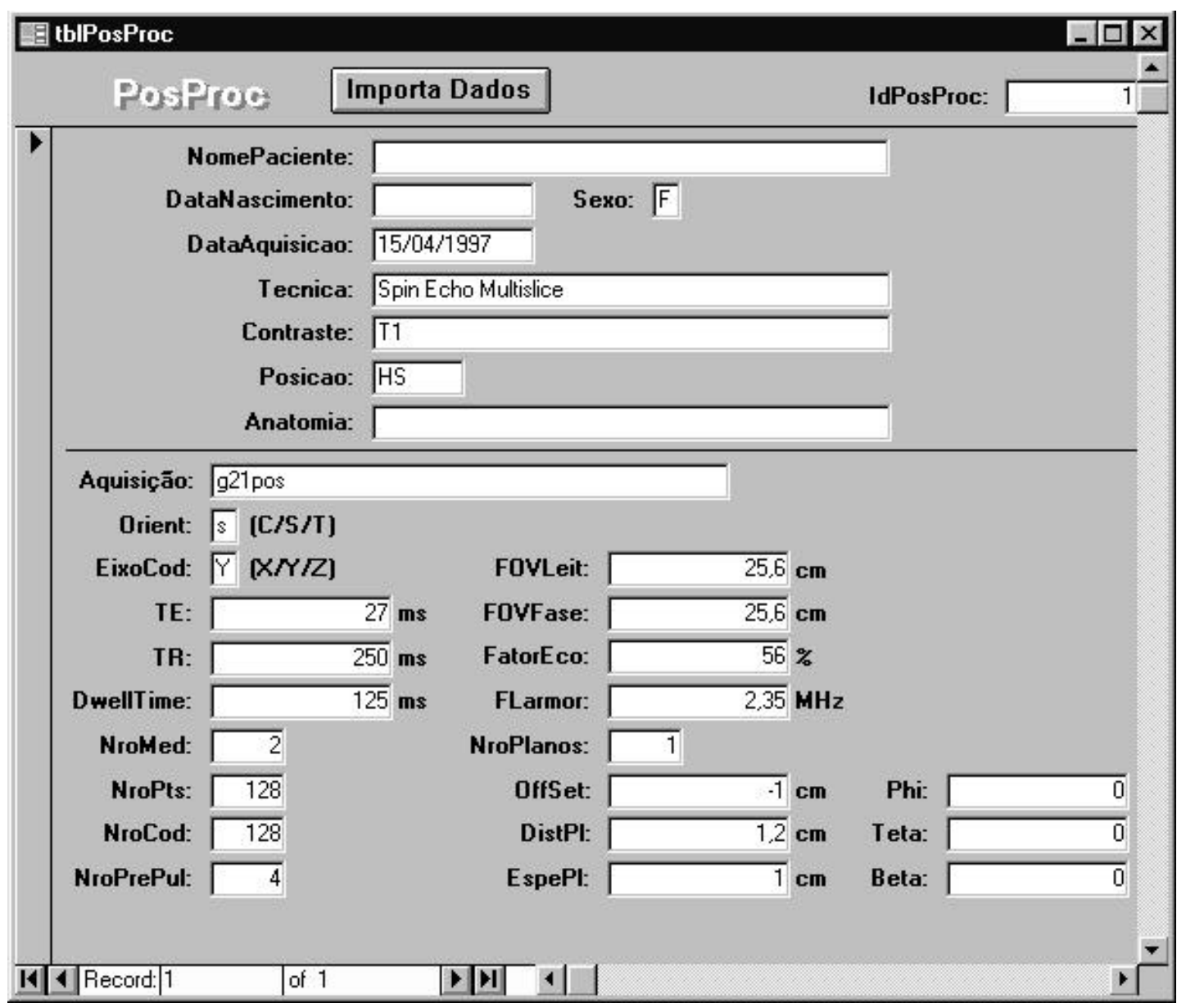

Figura 30 - Formulário PosProc (primeira página). 


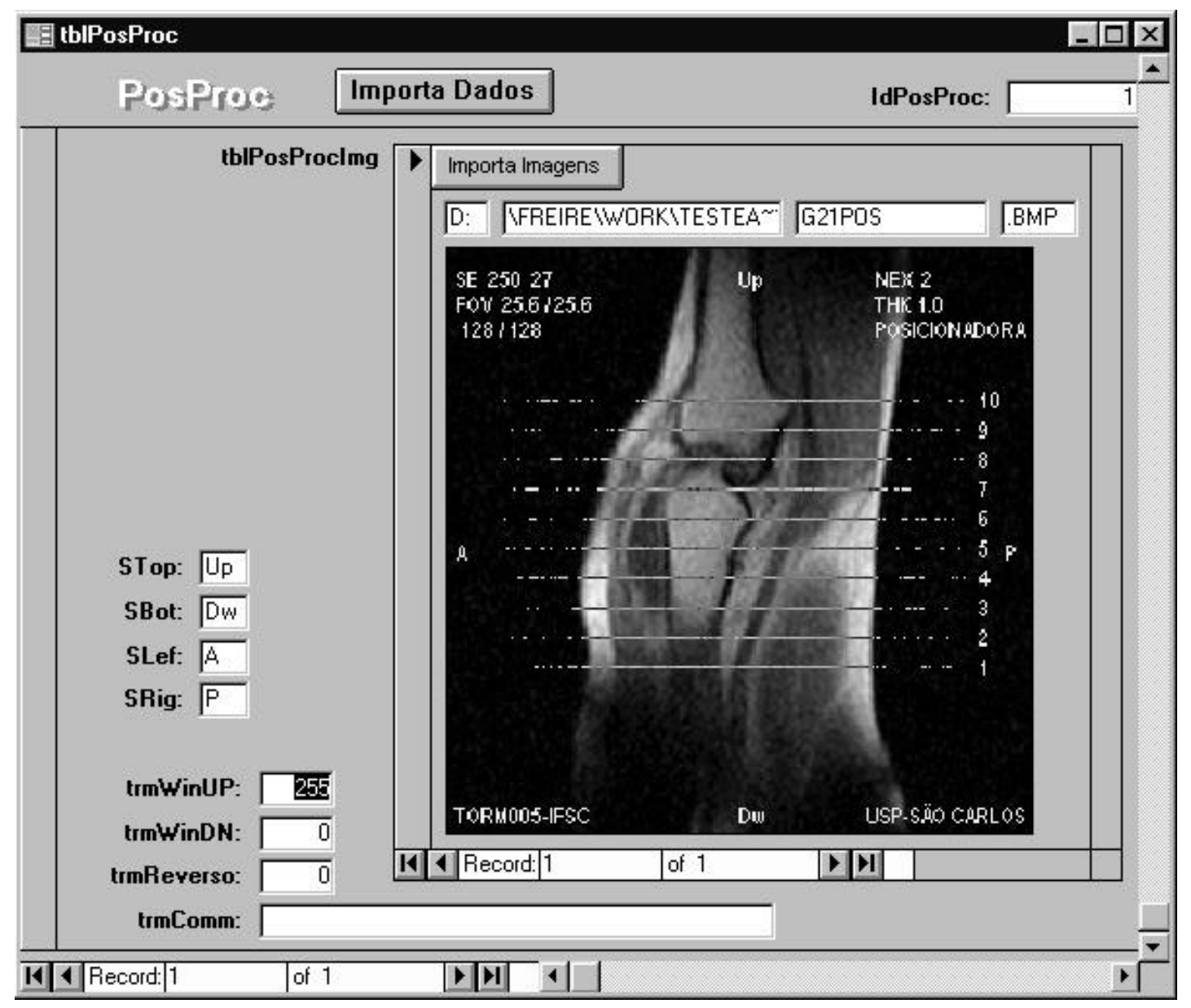

Figura 31 - Formulário PosProc (segunda página). 